UNIVERSIDAD POLITÉCNICA DE VALENCIA

FACULTAD DE BELLAS ARTES DE SAN CARLOS

\title{
DE LA AUTOFORMACIÓN COMO PRÁCTICA INSTITUYENTE \\ EN LAS METRÓPOLIS POSTFORDISTAS
}

Tesis doctoral presentada por:

Dña. Majosé Miquel Bartual aka Mijo Miquel

Dirigida por:

Dña. Marina Pastor Aguilar

D. Vicente Ponce Ferrer

Julio, 2013 


\section{RESUMEN}

A través de un recorrido teórico- práctico, nos proponemos investigar cómo, en el contexto de las metrópolis postfordistas, determinados procesos de autoformación pueden llevar a transformaciones sociales en el ámbito político. En esta premisa, analizaremos previamente si la autoformación constituye en sí un cuestionamiento de los lugares asignados en la redistribución de los saberes, vinculada a procesos de cooperación social y resistencia, así como a la generación de instituciones del común.

\section{RESUM}

A través d'un recorregut teòric- pràctic, ens proposem investigar com, en el context de les metròpolis postfordistes, determinats processos d'autoformació poden dur a transformacions socials en l'àmbit polític. En aquesta premissa, analitzarem prèviament si l'autoformació constituix en si un qüestionament dels llocs assignats en la redistribució dels sabers, vinculada a processos de cooperació social i resistència, així com a la generació d'institucions del comú.

\section{ABSTRACT}

Through a theoretical and practical approach, our proposal is to investigate how, in the context of post-fordist metropolis, certain self-education processes can lead to social transformations in the political sphere. On this premise, we analyze first whether self-education constitutes a challenge to their assigned locations in the redistribution of knowledge, linked to processes of social cooperation and resistance, as well as the generation of common institutions. 


\section{Agradecimientos}

En primer lugar, me gustaría agradecer en esta tesis a Dña. Marina Pastor y a D. Vicente Ponce su acompañamiento paciente y generoso ejerciendo de tutores, porque han sabido mostrarme caminos e indicarme pistas así como hacerme evitar trampas dialécticas varias.

Igualmente, me gustaría dar las gracias a todos mis compañeros de colectivos, por realizar conmigo este viaje de descubrimiento, contrastando constantemente su visión del mundo con la mía, alimentando el camino con su ilusión, sus conocimientos y sus ganas.

En tercer lugar, a mis amigos más cercanos, porque me han sostenido, aguantado, permitido, respaldado y un sinfín de pequeños apoyos circunstanciales que me han permitido robarle tiempo al tiempo.

Por último, a mi familia que no ha perdido la esperanza en todo este proceso de que, verdaderamente, un día, acabara lo iniciado, empezando por mis padres que han hecho todo lo que estaba en sus manos por facilitarme la tarea. Para terminar, quisiera dedicársela, especialmente, a mi hijo Diego que ha sido el primero en sufrir mis tardes y noches delante de la pantalla, y a Emmanuel que ha insistido en las virtudes del rigor teutón, almohadillando las pausas para compensar. A todos ellos, a todas ellas, gracias. 


\section{Índice de contenidos}

1. Introducción

2. Érase una vez... la Universidad 12

2.1 Criterios y carencias 13

2.2 De la universidad de élite a la universidad de masas 17

2.3 La consolidación del paradigma universidad-empresa 20

2.4 Conclusiones, posiciones, proyecciones 30

3. Crisis, ¿qué crisis? 36

3.1 Presentación de la representación 37

3.2 Sujeto y democracia o sujeción a la democracia __ 44

3.3 De lo público a lo común: vías de transformación ___ 49

3.4 La libertad a recuperar 56

4. Algunas preguntas y algunas respuestas, quizás 62

4.1 El afecto y la ley, reconstitución de la ciudadanía 63

4.2 Metrópolis postfordistas 69

4.3 La inclusión diferencial__ 74

4.4 (Pequeño paréntesis autobiográfico y por tanto carente de todo rigor) 80 4.5 Del precariado a la intermitencia 95 4.6 ¿Y cómo la llamaremos? 107 
5.1 Poder constituyente y poder constituido ___ 113

5.2 Introito autónomo y combatiente __ 118

$5.3 \mathrm{El} 25 \mathrm{~S}$ como proceso destituyente _ 125

5.4 Relectura de la llustración, la ignorancia compartida___ 132

5.5 Centros sociales autogestionados y otras instituciones anómalas 137

5.6 La autoformación, por fin _ 143

5.7 Edu-factory y las universidades del común___ 153

5.8 Barra Diagonal también disfruta trabajando___ 156

6. Tres, dos, uno... ¡A Acción!__ 168

6.1 Reversibilidades pragmáticas ___ 169

6.2 Autoformación productiva __ 171

6.3 Producción autoformativa___ 185

6.4 Autoformato__ 190

6.5 Comboi a la fresca _ 221

6.6 El Solar Corona 50

6.7 La Coordinadora de Iniciativas Vecinales (LaCIV) __ 255

6.8 La Calderería__ 260

7. Finales y principios

8. Bibliografía __ 282

Anexol - Informe PQDT__ 298

Anexo II - El Ferrocarril Clandestino piensa con Rancière __ 328

Anexo III - Dossier La Calderería___ 336

Anexo IV - DVD Material audiovisual__ 390 


\section{Introducción}

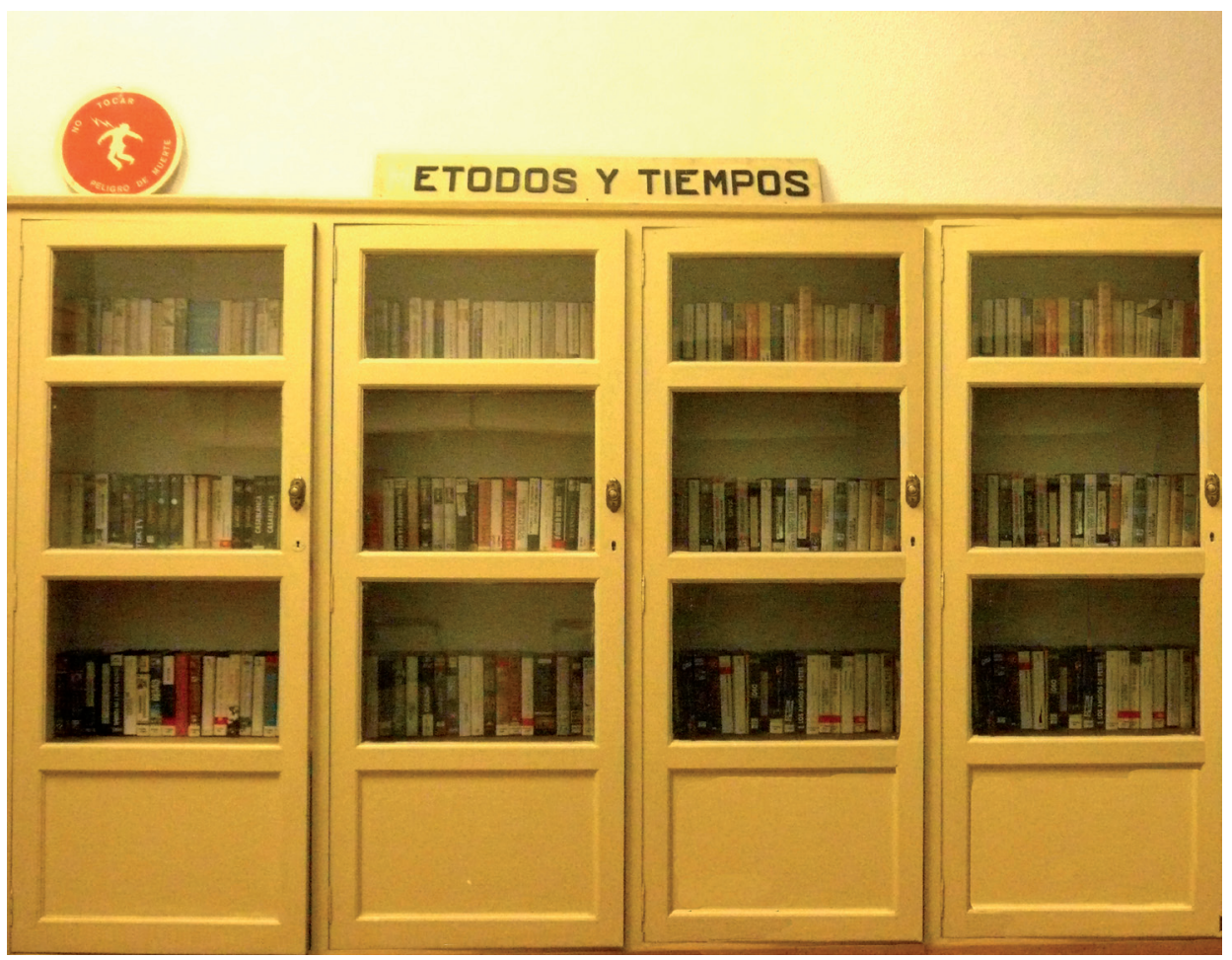

Fig. 1 
Puesto que por algún lado hay que empezar y, del mismo modo, por algún lado hay que terminar, aunque no se sepa muy bien lo que significa terminar en este contexto, como si se pudiera obtener algún rédito fijo, alguna posesión inalterable que elimine para siempre fisuras, suturando el pliegue al otorgar el tan codiciado título de doctora, podríamos decir que la motivación principal de esta tesis es el espejismo de un cierre. Aún a sabiendas de lo que sabemos, que no hay clausura posible, ni siquiera deseable, somos conscientes de lo positivo que resulta para la salud mental, cuando menos, producir un objeto tridimensional transportable que represente el símbolo de un acabamiento.

No obstante, esta tesis se plantea abiertamente como un devenir en sí misma, como la prolongación en papel de un proceso de pensamiento y de una experiencia vital, por lo que esperamos que no termine con este acto, ya que da cuenta de algo mucho más integrado en nuestra existencia que un ritual académico. Bien es verdad que en el proceso, hemos reforzado el aprendizaje al sistematizarlo, aunque nos obligue a concluir en falso, e igualmente, no nos cabe ninguna duda de que hemos mejorado la capacidad de comunicar eso que andamos transitando. Porque discurrir y transitar son dos términos afines, esperamos que estas páginas sean capaces de provocar un desplazamiento leve de la mirada que empezó a recorrerlas y que, en ese amago de comunicación, se construyan puentes, porque buena falta nos hacen los sentidos compartidos. Por ello, consideramos necesaria realizar una puntualización respecto a los diferentes registros de lengua empleados, esperando que se entiendan desde el profundo sentimiento de frustración que la situación actual nos provoca, quebrando la teórica neutralidad académica con la que se disfrazan los impostores de lo público. En verdad, queremos provocar incomodidad lingüística, cuando menos, mediante incorrecciones programadas, pero no es más que una manifestación nimia de la rabia, que nunca ha sido académica.

Hoy en día, con unas instituciones del conocimiento alejadas de las realidades que estamos viviendo, enfrentadas como estamos a la crisis profunda de nuestro sistema político y de creencias, donde lo público es simultáneamente asaltado y cuestionado como insatisfactorio, y se dibuja aún con trazos inseguros un posible horizonte del procomún; parece bastante sensato plantearse alternativas posibles, intentando generar mecanismos de acción colectiva que estén a la altura del reto de innovación política ante el que nos encontramos. Por ello, a raíz de nuestras experiencias desde un grupo activista, todavía más estético que político, redactamos un primer trabajo que hablaba de la disolución del arte en las prácticas culturales. La experiencia vital nos ha ido llevando cada vez más lejos de nuestro punto de partida, o cada vez más cerca de nuestro propósito inicial, progresivamente refinado por el aprendizaje y la experimentación. 
Tanto en nuestra actividad como docentes universitarias, como en nuestra actividad dentro de colectivos de autoformación e intervención, hemos continuado avanzando en terrenos que nos eran desconocidos, por lo que no hemos dejado de plantear hipótesis y buscar constataciones usando nuestro día a día como campo de pruebas. De ese sustrato, hemos hecho una tesis. Si tuviéramos que enunciar una hipótesis clara, diríamos que nuestro cuestionamiento esencial gira en torno a cómo, en el contexto de las metrópolis postfordistas, determinados procesos de autoformación pueden llevar a transformaciones sociales en el ámbito político. En esta premisa, partimos de la presuposición de que la autoformación constituye en sí un cuestionamiento de los lugares asignados en la redistribución de los saberes, ya que se plantea desde la autonomía del conocimiento, con la intención de vincularse a procesos de cooperación social y resistencia, así como a la generación de instituciones del común.

El segundo objetivo es comprobar que las prácticas de autoformación combinadas con movimientos sociales pueden provocar la emergencia de un carácter institucional. Este convertirse en institución en el buen sentido de la palabra, es decir, en una entidad capaz de instituirse a sí misma, tiene a su vez como objetivo obtener una posición de interlocución legitimada desde la que dialogar con los poderes constituidos, ya que dicho diálogo resulta necesario para poder provocar cambios de orden político. Y para terminar, nos gustaría evaluar si, mediante este proceso de autoformación instituyente, aprovechando los intersticios tanto físicos como conceptuales para generar espacios del común, se puede o no hablar de constitución de una comunidad y si así lo fuera, de qué tipo.

Por tanto, el objetivo general es suficientemente claro: establecer un diagnóstico, mediante prácticas metropolitanas de activación, que demuestre que las premisas teóricas enunciadas sobre el potencial de la autoformación se cumplen efectivamente, produciendo tanto cambios políticos como sociales, a través de un mínimo común dinamizador que permita catalizar la suficiente energía y la suficiente ignorancia como para provocar dichos cambios. Para ello, contamos con poner en práctica dichos procesos de autoformación vinculados a prácticas de los movimientos sociales orientadas a la ocupación y transformación del territorio, analizando si, efectivamente, ello permite constituirnos como entidad empoderante y si este desplazamiento facilita el diálogo con los poderes constituidos de manera que se pueda generar un espacio consolidado de autogestión.

Teniendo estos objetivo claros, nos planteamos la metodología adecuada que requiere, por sus mismas premisas de base, llevar a cabo un proceso de investigación que, alejándose de la lógica académica tradicional, pueda generar un dispositivo de aprendizaje colectivo donde no exista la figura del investigador que goza de legitimidad institucional. A su vez, emanando de sus propias consideraciones en torno a la autoformación, se plantea la pregunta de cómo ese ejercicio 
de exploración y acumulación de conocimiento puede formar parte de prácticas de intervención directa encarnadas en conflictos concretos que se dan en la metrópolis.

Esta doble articulación, de materia a estudiar y de metodología aplicada, nos devuelve en un bucle a nuestra posición inicial. Si bien, en ese contexto, la investigadora funciona como la bisagra que permite sistematizar prácticas antagónicas, también es simultáneamente la que está implicada en la generación de herramientas de cambio y su aplicación a territorios concretos, intentando evitar además que esta captura de conocimientos suponga una estructuralización de los mismos y su conversión en la materia muerta que nunca quisimos tener entre manos.

Por ello nos gustaría incidir en que esta investigación será, ante todo, una investigación "situada": es decir, una investigación que se separa conscientemente de la tradicional investigación académica y de su relación instrumental y objetualizadora con el objeto de estudio y, que, por el contrario, se sitúa claramente en la posición de intentar pensar con, a partir de las exigencias propias de las dinámicas investigadas. Con ello, esta investigación se inserta en la amplia tradición epistemológica que liga objetividad y parcialidad, procedente tanto del punto de vista de las encuestas obreras como de los trabajos de investigación feminista. Esta visión concede la primacía a las prácticas que atañen a los procesos de transformación social y considera el proceso de producción de conocimiento como parte del proceso de producción de subjetividad, es decir, se encarna en lo que viene a llamarse investigación militante.

La definición más común de este tipo de investigación es "aquella que desarrolla tanto una teoría como una praxis de producción de saberes y sociabilidad alternativa a partir de su "no saber" ${ }^{1}$ y que se sitúa en un territorio de nadie. No es una investigación académica porque trabaja con colectivos autónomos, usa una metodología en la que la experiencia no es una conformación de hipótesis sino que son las hipótesis las que activan una experiencia, mediante la inducción, y se ocupa de producir saberes útiles a las luchas sociales más que de acumular conocimientos. No obstante, tampoco se puede identificar con una militancia política porque no parte de un corpus ideológico preciso ni trata de asesorar a ningún movimiento social ni intelectualizar las experiencias, sino que busca pistas para una nueva socialidad en las prácticas emergentes. Supone el uso de metodologías de investigación por parte de los movimientos sociales, importante para quebrar la reclusión identitaria de los mismos así como las inercias antagonistas.

Este modelo de investigación lo hemos combinado en las aplicaciones prácticas con las metodologías propiamente participativas. Como especificaremos

1. COLECTIVO SITUACIONES. "La investigación militante". En MALO de MOLINA, Marta (Editora), Nociones Comunes. Experiencias y ensayos entre investigación y militancia. Madrid: Ed. Traficantes de sueños ,2004. 
en el análisis de los modelos prácticos, las metodologías participativas se han usado a menudo para facilitar la gobernabilidad en sociedades en las que hay un gran desprestigio de la democracia representativa como, desgraciadamente, es nuestro caso hoy día, y, con este motivo, han sido parcialmente institucionalizadas. Por ello, resulta importante subrayar que la militancia investigadora no se limita al uso de una metodología determinada de investigación, sino que, para hacerlo con propiedad, debe ir vinculada a una organización colectiva transformadora, tejer vínculos entre sujetos y saberes heterogéneos que han de aliarse o crear proyectos políticos para activar procesos de empoderamiento.

Esta doble pertenencia implica superar la relación investigadora-objeto de estudio y transformarla en una relación sujeto-sujeto, que pase del individuo a las redes de relaciones, que escuche los diferentes puntos de vista y haga devoluciones creativas que faciliten la construcción colectiva de soluciones. Las metodologías participativas suponen sistematizar los procesos sociales de democracia contributiva que emanan siempre de procesos colectivos de autoorganización, es decir, de las prácticas mismas en las que estamos implicadas. Por tanto, nuestro punto de partida es la concepción de la participación social como una forma de organización horizontal, diferente al modelo imperante, que intenta poner en pie mecanismos de empoderamiento para la transformación social.

Nos gustaría igualmente introducir una matización respecto a la contraposición o la coincidencia entre la figura de la investigadora y su objeto de investigación en el análisis de problemas comunes. Cuando se trata de analizar, proponer y compartir cuestiones en las que estamos implicados y que, por tanto, nos afectan directamente en su doble sentido de afección y de afecto, no se puede producir una diferenciación entre investigadora y objeto de estudio, porque se impone la urgencia de los verdaderos problemas con sus afiladas dimensiones. Igualmente pensamos que la horizontalidad en sí misma no supone una garantía de mejora alguna, como desarrollaremos más adelante en el bloque dedicado a metodologías participativas. Pensamos y aquí dejamos constancia, que la horizontalidad supone una condición diferencial no sólo porque presupone las capacidades igualitarias de todos sus integrantes, sino también y fundamentalmente, porque los expone a todos a aquello que desconocen, porque les une en la ignorancia compartida.

Para terminar con esta breve e impaciente introducción tal y como mandan los cánones, pasamos a describir la estructura interna de este trabajo que, en sí, es bastante sencilla. Como estructura general, podemos decir que contamos con unos primeros capítulos en los que se establece el marco conceptual para después abordar las prácticas empíricas que sustentarán las fundamentaciones teóricas desarrolladas. Tras la introducción, en el segundo capítulo, se analiza la cuestión del conocimiento y sus instituciones a lo largo del tiempo y se intenta ofrecer un diagnóstico desde la actualidad, atendiendo a sus carencias referentes a 
la conexión con la sociedad y su posición ante la crisis generalizada que tenemos que afrontar. Esta crisis tanto económica como política que abordamos en el tercer capítulo, en donde analizamos las bases de nuestra democracia escorada, lo que nos obliga a cuestionar conceptos como el de libertad o independencia así como a abordar otros como la autonomía o el afecto, y a realizar un pronóstico de futuro que evidencie la urgente necesidad de reacción que caracteriza al presente.

El cuarto capítulo entra en la descripción de la unidad de análisis operativo, la metrópolis postfordista, identificando el sujeto de cambio en el precariado y proponiendo su transformación positiva en la figura del intermitente. A continuación, enunciamos con claridad la necesidad de un proceso destituyente que abra las puertas a determinados cambios y citamos dos casos de estudio, referentes tanto a la Universidad como a la producción cultural, en los que se plantean y desarrollan herramientas de transformación que permitan por lo menos iniciar dicho cambio. Para terminar, el sexto capítulo, bastante extenso en sí, agrupa todos los casos empíricos en los que hemos desarrollado las premisas teóricas enunciadas en primera persona del plural. Por último, como es de rigor, ofrecemos un capítulo con finales y principios que intenta ofrecer la continuidad en lo real de este cierre en falso. Y sin más, damos paso al torrente de palabras. 
2.Érase una vez... la universidad

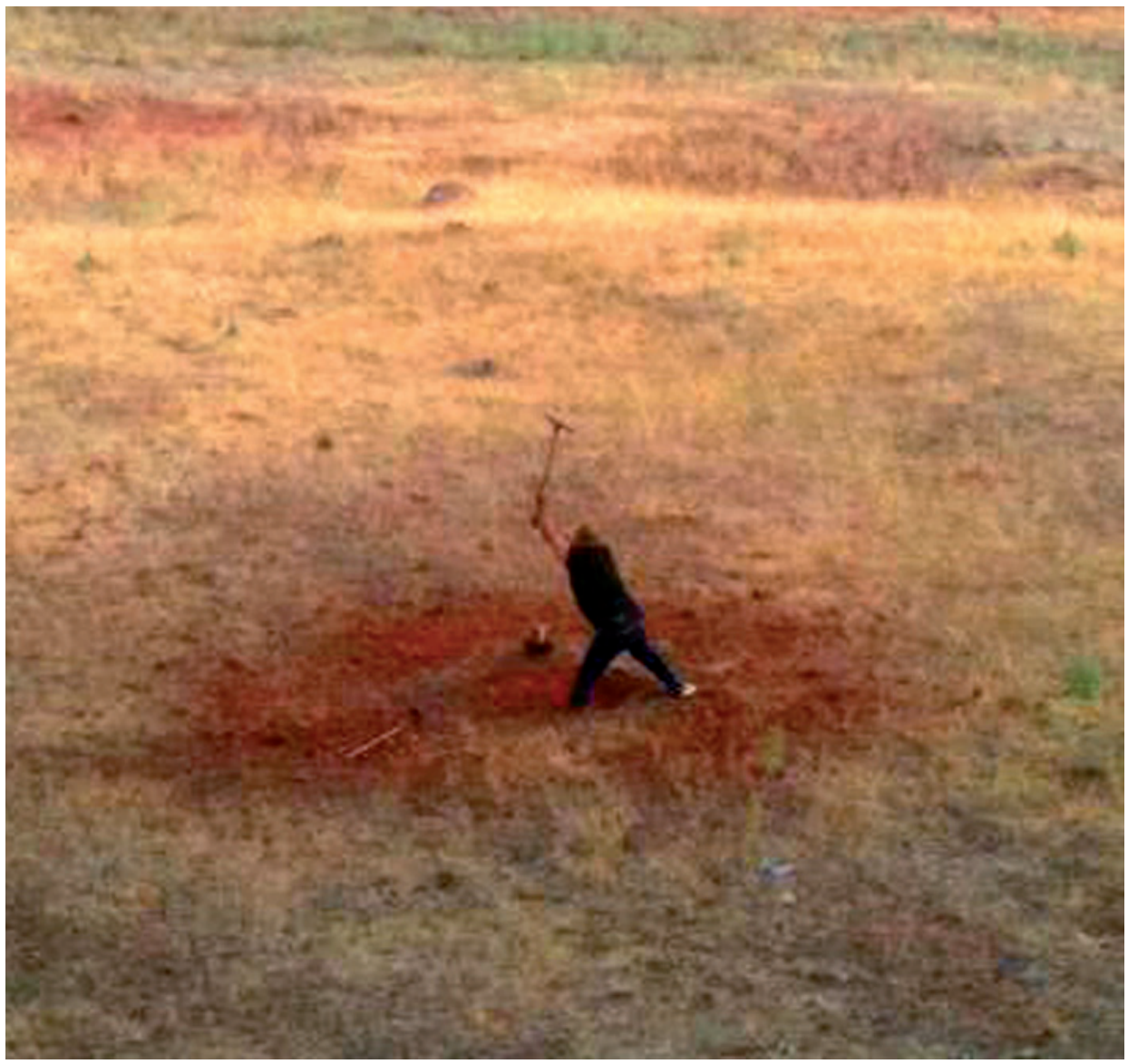

Fig.2 


\subsection{Criterios y carencias}

El punto de partida de esta tesis es un rumor. Una voz que circula sotto voce e incluso a menudo se obvia, de tan patente, una opinión que se tiene los primeros años de universidad, antes de naturalizar la situación asumiendo en su totalidad el statu quo establecido, los silencios instalados. Empezamos mal, lo sabemos, proponiéndonos una tesis a partir de un rumor, pero es que es un rumor insistente, diseminado, prolongado en el tiempo, es un rumor respaldado por revueltas, huelgas, alternativas y dudas. Es una duda inmensa que se ha instalado en el centro de nuestro lugar de trabajo, peluda y molesta, incluso a veces maloliente cuando se persiste en no sacarla del armario para airearla un poco y que coja color. Así que no nos queda más remedio de vez en cuando que sacarla utilizando cierto grado de violencia, políticamente incorrecta, y hacer que se desnude ante nosotros para mirarla bien y decirnos si legitimamos su existencia, si le hacemos los papeles, la acomodamos en un banco y empezamos a pensar en cómo transformarla en algo menos molesto o por lo menos, de menor volumen, o si nos planteamos seriamente enviarla a su casa, hacer como si nunca hubiera existido y seguir dejándonos acunar por el rumor, ese sí, imposible de eliminar por su finura, por su persistente levedad. Y es que la universidad, perdonen, la Universidad, anda hecha unos zorros con tanto cambio de identidad y no sabe muy bien a qué perfil ajustarse, si al de Facebook, al del EEES o al de la ilustración emancipada.

Por todo ello, nos parece importante hacer la limpieza en casa y ver si, efectivamente, toca hacer reforma en la cocina y en los bajos fondos. No hablamos de nada nuevo, por el momento hablamos de opiniones y sentimientos. A lo largo de esta investigación hemos escuchado mil veces la frase "La universidad está muerta", "En la universidad no pasa nada", como si fuera algo tan inamovible como decir "La hiperespeculación financiera está en el origen de la crisis", o "Este año la sequía nos ha dado una tregua". Hemos escuchado también "La carrera me ha decepcionado", "Estoy desilusionada con lo que me he encontrado", y otras tantas maneras de enunciar el desencanto. Si bien es verdad que no hemos llevado a cabo ninguna investigación sistemática basada en encuestas sobre el nivel de 
satisfacción de los usuarios, ni siquiera sobre el nivel de satisfacción de los docentes, hemos observado, hemos escuchado, hemos preguntado, y hemos estado dando clases en la universidad desde hace bastantes años. Hablamos de la anécdota, de la charla de café, de la pausa entre horas, pero también de la reunión seria. Y notamos que en las reuniones se habla fundamentalmente de presupuestos, subvenciones y adjudicaciones, se habla de los sexenios retribuidos y de la distribución de la docencia, también de los planes de estudios aunque la decisión final acabe dependiendo a menudo de la redistribución de cuotas de poder, o de metodologías docentes que pocas veces provocan cambios en los modos y maneras, por no hablar de otras cuestiones que, por más dolorosas, no nos atrevemos a enunciar, como la crisis.

Decimos que los grupos de investigación funcionan con la moneda del prestigio reconocido y de la financiación obtenida, de los acuerdos con empresas o de la ocupación de espacios y bastante menos con la satisfacción por lo investigado. Decimos también que echamos de menos las apasionantes discusiones que teníamos en la cantina cuando éramos estudiantes y que pocas veces más se produjeron. Y todo esto sin ánimo de crítica, puesto que todo ello es comprensible, necesario, adecuado. Pero no basta, como saben los compañeros que intentan hacerlo de otra manera que, por supuesto, los hay. Docentes que optan personalmente por salirse de las casillas en su mejor sentido, por combinar su trabajo con el de otros, por preocuparse por cuestiones inanes que nunca nadie subvencionaría. Que no se ofendan todos ellos, ni siquiera los otros porque no es una opción personal únicamente. Porque no estamos hablando de los casos particulares, hablamos de las estructuras que modelan comportamientos. Hablamos de lo que sucede en la universidad pública y reglada de forma tan habitual que ya no le prestamos atención, que no le damos importancia. Y estamos tan acostumbrados a no pensar en términos de cambio o de mejora sino de menor mal posible, que aún nos contentamos de las hierbas que cogemos. Y eso incluso antes de Bolonia.

Así que nos hemos metido en el desagradable proceso de remitirnos a las fuentes, a los documentos constitucionales y brutocráticos, a los análisis paralelos de la institución académica, a la crítica a diferentes niveles no vaya a ser que se nos acabe acusando de ser banales, de hacer periodismo de bajo rango, de carecer de todo rigor científico y no alcanzar el nivel mínimo requerido para redactar una tesis. Por tanto, procuraremos hacer una especie de diagnóstico utópico-crítico de nuestra institución, utópico porque nos damos cuenta de la distancia que nos separa de nuestros deseos y porque no dejamos de ser conscientes de que los cambios internos que se están produciendo en la institución están tomando la dirección exactamente inversa, crítico porque intentaremos llevarlo a cabo basándonos en intuiciones que podrían conformar los siguientes criterios de carencia, intuiciones que iremos desgranando a lo largo de la tesis: 
1. Carencia de lo público: mercantilización generalizada de la institución, con lo que ello implica también de privatización oculta.

2. Carencia de lo social: desconexión de los movimientos sociales y de la vida en general.

3. Carencia de lo crítico: elisión de las aspiraciones de conocimiento y del desarrollo de pensamiento crítico.

4. Carencia de lo común: perfeccionamiento de los modelos de expropiación de los saberes según la lógica de los cercamientos de los comunes aplicada a la educación.

A cambio, tenemos presente la pervivencia de las dialécticas amo-esclavo y la perpetuación de un modelo de enseñanza instaurado desde los niveles más tempranos que implica la ausencia de autonomía conceptual y operativa. En el análisis que hizo Hegel de las relaciones de poder en su tratado sobre La fenomenología del espíritu ${ }^{2}$, especialmente en el capítulo sobre la dialéctica del amo-esclavo, se detalla este tipo de relación que supone que el esclavo es necesario al amo en la medida en que es el sujeto que le ratifica en su posición de poder. De ahí surge una relación de codependencia basada en supuestos de reconocimiento que fluyen únicamente en un sentido unidireccional, operación que se multiplica y perpetúa en muchos ámbitos de vida. La relectura que haría Alexander Kojève ${ }^{3}$ en términos de deseo de reconocimiento actualizará esta visión de la distribución del poder, posteriormente tratada tanto por Michel Foucault, que quebrará definitivamente la dicotomía complejizándola, como por Jacques Rancière en sus teorías sobre el reparto de lo sensible. Para intentar paliar lo apresurado de este recorrido, a lo largo de la tesis, iremos analizando con mayor detenimiento los conceptos desarrollados por estos dos últimos.

2. HEGEL, G.W.F., Fenomenología del espíritu. México: Fondo de Cultura Económica, 1966. So mos conscientes de que Hegel plantea una inversión final de la dialéctica en la que el esclavo acaba convirtiéndose en amo del amo pero, como indicamos a continuación, queremos hacer referencia al deseo de reconocimiento en sí y a su frustración.

3. La relación entre Amo y Esclavo no es pues un reconocimiento propiamente dicho. Para verlo, analicemos la relación desde el punto de vista del Amo. El Amo no es el único en considerarse Amo. El Esclavo lo considera también como tal. Es pues reconocido en su realidad y en su dignidad humanas. Pero ese reconocimiento es unilateral, ya que no reconoce a su vez la realidad y la dignidad humanas del Esclavo. Es entonces reconocido por alguien a quien él no reconoce. Y allí está la insuficiencia -y lo trágico- de su situación. El Amo ha luchado y arriesgado su vida por el reconocimiento, pero sólo ha obtenido un reconocimiento sin valor para él. Porque él no puede ser satisfecho sino por el reconocimiento de aquel a quien acepta como digno de reconocerlo. La actitud del Amo es, en consecuencia, un obstáculo existencial. En La dialéctica del amo y del esclavo, por Hegel, comentada por Alexander Kojève, consultada el 11 de julio de 2012 y disponible on line en http://www.sindominio.net/etcetera/PUBLICACIONES/minimas/62_Kojeve.pdf. 
Si extrapolamos esta relación al ámbito educativo, posición en la que primaría el deseo de reconocimiento como agente capaz de evaluar y legitimar a otro individuo, frente a una imagen de transferencia bidireccional de conocimiento, veremos cómo supone un bloqueo doble. Por una parte, el amo, que correspondería en este caso al profesor, nunca puede ser reconocido por alguien que considere su igual, por lo tanto, el valor de su consideración siempre estará disminuido; por otro, el deseo constante de reconocimiento como superior impide que el alumno acabe estando en disposición de independizarse culminando en cierta manera su aprendizaje con una trayectoria autónoma y un reconocimiento de lo que de por sí aporta al docente. Frente a este modelo, se dibujaría uno que partiera de la autonomía, el diseño propio de itinerarios y la socialización constante de los materiales generados de manera que la educación no se planteara a través de una relación de poder tan cerrada y estanca.

Durante las décadas de los 60-70, se llevaron a cabo numerosos intentos de quebrar esta dialéctica especialmente acusada en todos los entornos que Foucault definiría como propios del disciplinamiento: el movimiento de antipsiquiatría, las diferentes corrientes pedagógicas de educación alternativa (desde la versión anglosajona de A.S.Neill hasta las teorías de Paulo Freire), etc. de las que nos ocuparemos someramente más adelante. No obstante, como si el conocimiento acumulado durante estas décadas con sus errores y sus aciertos no pudiera servirnos de base, la universidad sigue manteniéndose impermeable a todo ello a pesar de que el desarrollo de la tecnología no hace más que facilitar el cambio de modelo. En plena generación transmedia ${ }^{4}$, no hacer uso de las posibilidades de socialización del conocimiento, seguir pensando con la lógica de la escasez y de la propiedad exclusiva, muestra una estrechez de miras apabullante en un ámbito en el que la curiosidad por nuevos horizontes debiera constituir una presencia evidente. Sin embargo, ¿cómo operar un cambio de modelo si ya no nos quedan casi palabras para nombrar lo que también ellos nombran? Esa larga ristra de objetivos, capacitaciones y competencias políticamente correctas que, por poco que nos paremos a pensar lo que nombran, empiezan a resultar sospechosas, proponen teóricamente una adaptación práctica a un modelo de aprendizaje activo en el que se intenta suavizar el viejo modelo de la clase magistral para dar pie a relaciones autónomas.

Eso dicen que hacemos pero pocos revisamos nuestros modos de hacer para producir un verdadero cambio renunciando a esta posición que heredamos, sino que adaptamos nuestro programa a lo que nos dicen que se tiene

4. JENKINS, Henri. Convergence Culture, Where Old and New Media Collide. Nueva York: New York University Press, 2006. Término acuñado por este autor y utilizado para referirse a las nuevas generaciones que producen y consumen narraciones transmediáticas. Esta noción aplicada al uso en educación de las nuevas tecnologías se tratara en el capítulo dedicado a la autoformación. 
que hacer, o mejor dicho, a cómo nos dicen que se tiene que llamar ahora eso que hacíamos. No lo hacemos porque seguimos la inercia pedagógica de toda una vida pero, sobre todo, porque la aplicación de esta nueva metodología recae únicamente sobre nosotros sin que haya un correlato en términos de reducción del número de alumnos, incremento de horas de atención personalizada, etc. Y así operamos un doble vaciamiento, de lo que ya teníamos y de lo que nos impedimos percibir como diferente porque utilizamos su nombre para nombrar lo idéntico. Estamos en un momento de crisis generalizada, no únicamente económica sino fundamentalmente una crisis de palabras, estamos sometidos a una expropiación de los espacios pero también de los conceptos, ¿desde dónde pensar si hasta las palabras nos llevan a su terreno y nos imposibilitan nombrar ese deseo?

En nuestro intento de encontrar otras maneras de hacer que no son, al fin y al cabo, más que otras maneras de vivir, empezaremos por dibujar un marco de análisis previo sobre el proceso de transformación de la institución universitaria, un somero recorrido descendente desde su constitución hasta las últimas transformaciones producidas a raíz de la instauración del Espacio Europeo de Educación Superior con la intención de abordar este recorrido contrastándolo con lo anteriormente dicho y siendo conscientes de que la universidad es simultáneamente centro de producción de los comunes, de circulación de conocimiento y objeto de la restructuración neoliberal.

\subsection{De la universidad de élite a la universidad de masas}

Ya desde sus inicios, la Universidad europea nace como una institución orientada a la formación de sus capas dirigentes a través de la transmisión del saber acumulado y socialmente legitimado. Este es un hecho que nadie que se haya parado a pensar un momento en el asunto puede obviar. La universidad, tal y como se concibe en su origen desde el Renacimiento, ha sido una institución concebida y mantenida como herramienta de perpetuación conservadora, humanista y meritocrática (conservadora porque pretende mantener un estado social de cosas, humanista porque pretende transmitir conocimientos orientados a la formación de la persona en las diferentes artes y ciencias, y meritocrática, porque los resultados obtenidos y el posicionamiento dentro de la jerarquía no es hereditario sino que se somete al criterio del mérito propio), entre cuyos objetivos se han conjugado dos tareas principales:

1. Educar a las futuras capas dirigentes.

2. Transmitir un saber socialmente acumulado que predispone a la valoración prestigiosa de disciplinas en la base de la alta cultura: el derecho romano, la historia de Occidente, la filosofía griega, etc. generando un proceso de autolegitimación evidente. 
En este sentido, durante mucho tiempo, la Universidad ha cumplido a la perfección su papel de guardiana de un saber antiguo, socialmente útil para el gobierno consolidado. No obstante, a partir del siglo XVIII-XIX, se introducen otros objetivos que ya no tienen tanto que ver con la reproducción de una cultura del poder como con la capacitación profesional de capas más amplias de la población. El siglo XVIII es aquel caracterizado por la llustración que, con su "sapere aude" (enseña actual de muchas universidades), intenta emancipar al hombre de tutelas forzosas y/o voluntarias mediante el conocimiento, y que se plantea como un mecanismo regulador de los sujetos ya que los iguala a todos. Si bien en el siglo XIX, la Universidad aún es minoritaria y sigue vinculada al poder político, debe ocuparse no sólo de legitimar a las capas dirigentes sino también de extender su vinculación con el ejercicio de las profesiones intelectuales cada vez más predominantes. A pesar de estar subvencionada por fondos públicos, su asistencia sigue procediendo de capas altas de la población ya que supone una inversión en dinero y en tiempo de vida que pocos estratos sociales pueden permitirse. La universidad burguesa tiene pocos alumnos y aún menos profesores, todos ellos disfrutando de un prestigio social consolidado y se dedica fundamentalmente a la docencia y a la investigación, es decir, a la generación y transmisión de saberes. En esta fase, como hemos dicho, se desarrollan las enseñanzas orientadas al ejercicio profesional (medicina, derecho, etc.) y empieza a delimitarse una cierta autonomía respecto a los poderes políticos si bien es cierto que en su mayoría coinciden en intereses y orientaciones.

A lo largo del siglo XX, se produce una aceleración en la transformación de la sociedad en la que cada vez tiene mayor importancia la adquisición y producción de conocimientos entendidos también en términos de información. Se empieza a generar una sociedad tecnocrática que requiere de otros saberes para poder responder a nuevas necesidades de profesionalización: la sociología, la antropología, la psicología y otras disciplinas afines ocupan el puesto de la filosofía, las ciencias de la información se superponen a la política y a la historia, etc. En el ámbito universitario, tanto el número de alumnos como el de estudios y profesiones, aumenta exponencialmente. Empieza a dibujarse un cambio en la percepción de la educación superior que, de un derecho, empieza a ser considerada un servicio, y un servicio puede fácilmente considerarse en una sociedad mayoritariamente terciaria la posibilidad de un negocio.

Aparecen por tanto las universidades privadas (en España, las primeras creadas a finales del siglo XIX corresponden a universidades de carácter religioso: Deusto, la Pontificia de Comillas y la de Salamanca, aunque la gran mayoría fueron creadas a partir de la década de los noventa del siglo pasado, en donde hubo una gran efervescencia que se mantiene hasta la actualidad) que funcionan como instituciones que imitan a la pública pero también adoptan la noción de que la 
educación es una mercancía sujeta a los mecanismos del mercado ${ }^{5}$. Este cambio perceptivo es el que afectará a modo de boomerang a la educación pública ya que sitúa definitivamente la educación en el ámbito de la competencia. Competir por un sector de mercado implica por una parte, considerar a los alumnos no como personas en vías de formación sino como clientes potenciales. Por otra parte, implica también la búsqueda de fórmulas varias para adecuar los estudios a las demandas de ese mismo mercado, independientemente de su importancia formativa. Más adelante, desarrollaremos de manera detallada lo que supone en sí este proceso de mercantilización y de financiarización ${ }^{6}$ de la enseñanza superior.

Siguiendo en líneas generales el análisis que del asunto lleva a cabo Monserrat Galcerán ${ }^{7}$ en "El discurso oficial de la Universidad", el paso de la universidad de élite a la universidad de masas, tanto la privada como la pública, supone pues, tal y como hemos dicho, la inclusión de alumnos procedentes de las capas no dominantes y de los que no se espera que automáticamente inicien una trayectoria ascendente social a pesar de la realización de estudios superiores. Implica igualmente la proliferación de nuevas titulaciones y la vinculación a una sociedad rápidamente cambiante. Este proceso sucede sin el aumento correlativo de la capacidad de los centros (tanto físicamente como en el número de docentes) pero, lo que es peor, tampoco se produce una democratización real de los organismos de decisión a pesar de que a nivel interno, se elijan los cargos mediante votaciones. El hecho de que esta democratización no sea real se demuestra por el hecho evidente de que la universidad tiene poco o nulo peso a la hora de influir sobre las dotaciones presupuestarias, la adaptación a normativas europeas y otros tantos ámbitos fundamentales de decisión.

5. A principios de 2008 , las cinco universidades valencianas realizaron con ayuda del IVIE (Instituto Valenciano de Investigaciones económicas) un estudio sobre el impacto socioeconómico de sus actividades para valorar sus efectos sobre la economía valenciana, aunque en el título y en los propósitos iniciales apareciera también la dimensión social, esta era obviada: PASTOR, José Manuel y PÉREZ, Francisco. La contribución socioeconómica de las Universidades públicas valencianas. Valencia: Ed. UV, 2009.

6. Patrón de acumulación en el cual la realización de beneficios tiene lugar fundamentalmente a través de los canales financieros, en lugar de a través del comercio y la producción de mercancías. Las reformas estructurales llevadas a cabo a partir de la década de los setenta, así como el final de Bretton Woods, dieron inicio a un nuevo contexto internacional donde el ámbito financiero comenzó a dominar y determinar el funcionamiento del ámbito productivo. Esta nueva configuración de las relaciones entre el sistema productivo y el sistema financiero es el pilar de lo que muchos autores han llamado la financiarización, GARZÓN ESPINOSA, Alberto, Economía Crítica y Crítica de la Economía, Número 5, Mayo-Junio 2009.

7. GALCERÁN, Montserrat, "El discurso oficial sobre la Universidad". En Logos Anales del Seminario de Metafísican³6, p.11-32. Madrid: Universidad Complutense de Madrid, Madrid, 2003. 
Durante los años 70, se consolida la transformación del sistema capitalista en sociedad de la información, siguiendo el modelo de Silicon Valley, según la describe en muchas de sus facetas Manuel Castells ${ }^{8}$ y en la que resulta fundamental el siguiente concepto: la información de cualquier ámbito, tras ser registrada y analizada, posee en sí un valor económico derivado de su venta directa o de su uso como base de datos para otras actividades lucrativas. Así, en el capitalismo informacional o cognitivo, se da una interacción productiva entre el perfeccionamiento de las tecnologías que procesan la información y los mecanismos de rentabilización económica de esa misma información (patentes, innovaciones industriales, producciones visuales, etc.). De hecho, la transformación de la información en conocimiento es la que constituye la palanca de la innovación sobre la que se desarrolla la estrategia competitiva actual de la empresa y eso presupone la existencia de una cadena de elementos que trabajen en una misma dirección:

1. La universidad o centros de investigación de alto nivel

2. Un entorno empresarial dinámico

3. Instituciones de capital riesgo que puedan actuar como inversoras.

La vinculación y combinación de estos tres elementos constituye la base sobre la que se asienta la promoción a nivel europeo de la universidad-empresa de forma simultánea al enraizamiento y desarrollo pleno del llamado capitalismo cognitivo. Al respecto, como orientación básica, podemos citar la definición de Andrea Fumagalli ${ }^{9}$, que reza así:

En el capitalismo cognitivo, el conocimiento es el motor de la acumulación. La producción de valor ya no se basa sólo y exclusivamente en la producción material sino que se basa cada vez más en los elementos inmateriales, vale decir en las "materias primas" intangibles, difícilmente mesurables y cuantificables, que descienden directamente del uso de las facultades relacionales, sentimentales y cerebrales de los seres humanos.

\subsection{La consolidación del paradigma universidad-empresa}

Volviendo a las transformaciones de la universidad, podemos decir que, en sí, esta combinación público-privado no supone ningún inconveniente ya que, en teoría, su convergencia beneficiaría a la sociedad en general si hubiera un mecanismo de reconocimiento y "devolución" correcta a los diferentes sectores

8. CASTELLS, Manuel. La era de la información: (vol. 1 La sociedad red; vol. 2 El poder de la identidad; vol. 3 Fin de milenio). Madrid: Alianza Editorial, 2006.

9. FUMAGALLI, Andrea. Doce tesis sobre el capitalismo cognitivo. [En línea]. Disponible en: <http://www.grupomartesweb.com.ar/index.php?view=article\&catid=45> [Consulta: 12 de Febrero 2.012]. Para más información sobre este asunto, remitirse a Capitalismo cognitivo, propiedad intelectualy creación colectiva. Madrid:Traficantes de Sueños, 2004. 
implicados. No obstante, una de las marcas de la universidad actual es la inexistencia de devolución al grueso de la sociedad y el engrosamiento de los vínculos y dependencias con las empresas, que forman efectivamente también parte de la sociedad pero que no se han caracterizado nunca por socializar sus beneficios. Todas las últimas reformas universitarias inciden en la necesidad de que la Universidad se adecúe a las demandas de la sociedad pero, cuando observamos de cerca la interpretación que se hace de este excelente propósito, a menudo se confunde sociedad con empresa y beneficio con rentabilidad. Simplemente en términos cuantitativos, el hecho de que se haya producido un aumento progresivo y continuado del número de estudiantes universitarios, ha transformado a la universidad en un potente agente económico, no sólo por la cantidad de dinero que puede llegar a movilizar como productora de servicios sino en la medida en que puede dinamizar posteriormente el conocimiento generado tanto por sus trabajadores como por el ambiguo estatuto de la mayoría de sus becarios.

De hecho, lo que resulta fundamental pensar es que, si bien la estrategia de la reforma universitaria plantea este proyecto político-económico como "natural", responde únicamente al criterio de adaptación de las instituciones universitarias a los requerimientos del capitalismo cognitivo, es decir, a la conquista de la ideología neoliberal de un nuevo espacio en el que implantar su lógica de mercado, tal y como detalla Ferreiro Baamonde ${ }^{10}$. Para este autor, resulta claro que desde los inicios, esta reforma ha estado orientada a convertir en rentable la universidad que se sitúa desde hace tiempo en el centro del capitalismo cognitivo basado en la valorización del conocimiento, sobre todo cuando este puede hacerse rentable a corto o medio plazo mediante la apropiación por el sector productivo. No es el único en pensarlo. La plena asunción de un modelo neoliberal de desarrollo posible supone admitir como única alternativa a la reducción de fondos estatal y al desmantelamiento generalizado del estado del bienestar, la mercantilización de la universidad. En este análisis, a menudo se ha optado por resumir las tensiones que se producen en su seno a un dilema básico: la búsqueda y transmisión de conocimiento planteada en tanto derecho público versus la formación adecuada de futuros empleados en el marco del capitalismo cognitivo, obviando el hecho de que no se trata únicamente de una sumisión al sistema neoliberal por parte de la universidad sino de un solapamiento generalizado de la vida misma y del capitalismo, tal y como explica Tomás Herreros ${ }^{11}$ :

\footnotetext{
10. FERRERIRO BAAMONDE, Xulio. "Mercantilización y precarización del conocimiento: el proceso de Bolonia". En La universidad en conflicto: capturas y fugas en el mercado global del saber. Madrid:Traficantes de sueños, 2010, p. 113-144

11. HERREROS, Tomás. "Laboratorios de autoformación, universidades anómalas, nuevas universidades". En: La universidad en conflicto: capturas y fugas en el mercado global del saber. Madrid:Traficantes de sueños, 2010, p.145-170.
} 
Lo más llamativo del capitalismo actual es la transición de la subsunción formal a la subsunción real de la sociedad en el capital. Dicho en otras palabras, el capital ya no tiene por único objeto el trabajo, sino que toma la vida en todas sus dimensiones. El capital pretende explotar la vida, mercantilizarla por completo. El ocio, los afectos, los saberes, la cultura, la metrópolis, y no sólo la fábrica o la oficina, son subsumidos en el capital, convertidos en materia de la que el capital pretende extraer beneficio, plusvalor.

La descripción que Foucault hizo de la biopolítica ${ }^{12}$ cuadra perfectamente con esta visión del proceso ya que el análisis que realiza del neoliberalismo le permite decir que, en el régimen de la biopolítica, todo lo que conforma al sujeto constituye una inversión que puede convertirse en futura ganancia. Para el homo oeconomicus ${ }^{13}$, tal y como lo dibuja Foucault en su seminario para el Collège de France, el hombre se convierte en un empresario de sí mismo, haciendo recaer toda la responsabilidad de sus éxitos y fracasos sobre sí mismo. Si transponemos esta noción al análisis del entorno académico, el estudiante es un inversor de sí mismo que debe tomar las decisiones adecuadas para poder ser considerado como un trabajador cualificado en el futuro. Su formación la concibe como un capital cultural que podrá rentabilizar más adelante y como tal, se considera que es él en tanto beneficiario el que debería asumir los costes, siguiendo la lógica del cálculo económico. Esta nueva noción de "hacer pagar" se está imponiendo cada vez más desde todos los ámbitos sin tener en cuenta que la educación pública garantizada surge como mecanismo igualador de diferencias y no como proceso de selección de los más pudientes o de los más "arriesgados inversores".

En ese sentido, la mecánica de los másters se convierte en la zanahoria de la cualificación mínima necesaria por la que se pagan tasas mucho mayores que en el tramo anterior y a cambio, el estudiante consigue despegarse del grupo perdedor, aquel que sólo ha conseguido realizar el tramo económicamente menos oneroso. De esta manera, se niega simultáneamente el principio democratizador y nivelador que emana de la noción de educación pública y se naturaliza el hecho de invertir personalmente o fracasar en el propio futuro, derivando la responsabilidad formativa sobre el individuo y financiarizando el proceso. Esta naturalización implica un acercamiento global al siguiente paso: el modelo anglosajón en el que absolutamente todos los tramos universitarios están financiados por el alumno mediante la obtención de créditos blandos en los que el Estado se limita a pagar los intereses durante un tiempo limitado. Resultaba insoportable pensar que quedaban aún por rentabilizar espacios formativos y no haber hecho nada para ocuparlos. Como dijo

12. Biopolítica: conjunto de saberes, técnicas y tecnologías que operan sobre las poblaciones haciendo de la vida misma un objeto de gobierno, poder y también de resistencia. Para una profundización del concepto de biopolítica foucaultiano, se puede consultar: FOUCAULT, Michel, El nacimiento de la biopolítica, Curso en el Collège de France 1978-1979, Buenos Aires: Fondo de Cultura Económica, 2007.

13. FOUCAULT, Michel, Ibídem, clase del 4 de abril de 1979, p. 331-350. 
el subdirector general de la UNESCO hasta 2004, John Daniel, "Si el sistema de comercialización de la commodity funcionó con los bocadillos de McDonalds, no hay razón para que no funcione con la educación" ${ }^{14}$. Por todo ello, los análisis críticos sobre las transformaciones en las que se está viendo implicada la universidad pública como centro generador de conocimiento no pueden quedarse únicamente en los análisis del proceso de Bolonia sino que, para quebrar la autosuficiencia académica más allá de los retos laborales, deben remitirse obligatoriamente al conjunto de la sociedad e intentar poner en marcha procesos que devuelvan cierta autonomía y empoderamiento a la sociedad que desea explorar nuevas vías de aprendizaje y autogobierno.

Volviendo a las investigaciones de Ferreiros, este autor hace un recorrido de la reorientación universitaria desde las primeras reuniones en 1989 de la European Round Table of Industrialistst ${ }^{15}$, en las que se abordó la definición del funcionamiento universitario desde el punto de vista del empleador y se redactaron los textos que posteriormente fueron recogidos por el Libro Blanco de la Comisión Europea sobre Enseñary Aprender: hacia una sociedad cognitiva ${ }^{16}$, en donde se incidía en la necesidad de flexibilizar contenidos y premiar la excelencia en el ámbito universitario. En la declaración de Bolonia de 1999, y en otras posteriores (Praga 2001, Berlín 2003, Bergen 2005), 45 países europeos deciden la creación de un Espacio Europeo de Educación Superior (EEES) adecuado a las necesidades de la Europa del Capital.

El EEES, entendido como proyecto para la armonización de la formación superior en los países europeos, debe jugar un papel esencial en la consecución del objetivo marcado en Lisboa, convertir a Europa en la "economía basada en el conocimiento más competitiva y dinámica del mundo" y esta enunciación bienpensante se concretaba en dos propósitos: que la Universidad formara a personal cualificado para operar en el marco de la economía cognitiva (tecnológicamente preparado, flexible, adaptativo) y que potenciara el crecimiento y la productividad a través de sinergias con la sociedad (entendida esta como mercado).

La reforma de la educación superior en Europa se enmarca dentro de las políticas y acuerdos neoliberales impulsadas por la OMC. Desde la OMC y a través del Acuerdo General para la Comercialización de los Servicios (AGCS) ${ }^{17}$,

\footnotetext{
14. Boletín del Sector Educación de la UNESCO, Educación HOY, n³, octubre de 2002, http:// unesdoc.unesco.org/images/0012/001299/129980s.pdf

15. Véase: www.ert.be. En este foro empresarial participan representantes de empresas europeas como Inditex, Nokia, Nestlé, Telefónica, E.On,Total, Vodafone, etc.

16. SANZ FERNÁNDEZ, Fernando. "La mercantilización de la educación como escenario mundial del espacio europeo de educación superior". En: Educación XX1, 2.006, núm. 9., pp. 57-76.

17. Disponible on line en http://www.wto.org/spanish/thewto_s/whatis_s/tif_s/agrm6_s. htm y consultado el 12 de junio de 2012.
} 
se pretende alcanzar el objetivo de la "completa liberalización del mercado de servicios". Los servicios incluidos en el AGCS son todos aquellos cuya prestación no sea totalmente gratuita y tengan, de un modo u otro, circunstancias competitivas o comerciales (art. 1.3.b y c del AGCS). A efectos prácticos, esta limitación no existe para ninguno de los servicios públicos, puesto que ya existe en todos la iniciativa privada. La educación fue incluida dentro del AGCS a propuesta de EE.UU., Australia, Nueva Zelanda y Japón, todos ellos países que han instaurado el modelo anglosajón de universidad privada y países exportadores de servicios de educación ${ }^{18}$. Por otro lado, el AGCS (art.15) pretende acabar directamente con la idea de financiación pública de la enseñanza, al calificarla como "efecto distorsionador en el comercio de servicio"' y afirmar que "cualquier miembro que considere que una subvención acordada por un Estado miembro le perjudica, podrá poner en marcha el proceso de examen y solicitar una consulta en el órgano de resolución de diferencias" tribunal de la OMC que aplicará sanciones a los países que establezcan obstáculos a la libre competencia. Así la normativa acordada, de obligado cumplimiento para los Estados miembros, exige a éstos que no interpongan 'obstáculos innecesarios' a la libre circulación de mercancías (art.6). En resumen, los objetivos del AGCS suponen considerar que la enseñanza pública es tratada como competidora desleal en el mercado de la educación.

No obstante este proteccionismo, resulta obvio pensar que las universidades privadas son mucho más rentables desde cualquier punto de vista, pudiendo mantener simultáneamente la lógica de las universidades de élite y la nueva lógica de universidad-empresa ya que tienen un número reducido de alumnos, mayor financiación tanto directa mediante el pago de mensualidades como indirecta por sus relaciones con empresas o grupos ideológicamente potentes vinculados con la iglesia, por ejemplo, u otros grupos deseosos de influir en la formación de las futuras clases dirigentes, selección que se opera desde el principio por la vía económica. Ante esta situación, las universidades públicas con un presupuesto cada vez menor deben hacer frente a un número cada vez mayor de alumnos y ajustarse sin posibilidad de negociación a normativas que limitan paralelamente su autonomía bajo el manto de la equiparación.

En esta transformación, según Montserrat Galcerán ${ }^{19}$ cabrían dos derivas radicalmente diferentes: por una parte, la que ya hemos descrito y que se está produciendo de forma cada vez más acentuada, deriva que responde a los requerimientos de las capas dominantes de la sociedad, es decir, centros privados subvencionados con fondos públicos que ofrezcan una enseñanza de calidad de forma paralela a los centros de masas, destinados estos a cualificar adecuadamente

18. ROSS, Andrew. "La emergencia de la Universidad Global", en La universidad en conflicto: capturas y fugas en el mercado global del saber, Madrid: Traficantes de sueños, 2010, p. 51-70. 19. GALCERÁN, Montserrat, op.cit., p. 24. 
la fuerza de trabajo general al producirse una integración cada vez mayor entre la universidad y la empresa. Por otra, aparecería la demanda de deriva que parte de la universidad pública que exigiría una mejora de la financiación de los centros públicos, pudiendo ofrecer una enseñanza de calidad sin criterios económicos de selección, que considerara por tanto la educación como bien público y no únicamente como capacitación profesional y que, ya que no establecería vinculaciones de dependencia económica, pudiera implementar medidas de control sobre el sometimiento de la universidad a la empresa. En la misma medida en que la universidad pública aplica criterios económicos para pensarse, hace imposible la reivindicación de la segunda deriva porque está dejándose modelar por criterios que deberían serle secundarios.

El hecho de que los centros educativos se piensen con la lógica de la empresa, es decir, como entidades que ofrecen un producto o servicio en competencia con otros en un entorno de mercado, subordina la generación y transmisión de conocimiento a la ley general del sistema capitalista: producir con el menor coste y la máxima oportunidad de ganancia. Sobre todo, porque si analizamos lo que supone producir con el menor coste y la máxima oportunidad de ganancia en el entorno universitario, vemos que no significa únicamente controlar el despilfarro del dinero público o la endogamia bajo el manto de la solidaridad sino que supone la precarización del trabajo académico, como no podía ser menos cuando el sujeto histórico del siglo XXI será el precario. Bajo ese paraguas encontramos no sólo al inmigrante o a la mujer que opera en la esfera de la reproducción sino también al productor cultural y al universitario. Los diferentes modelos de inclusión precaria dentro del ámbito académico incluyen contratos laborales intermitentes, sobrecualificación de los trabajadores, extralimitación de tareas asignadas bajo la promesa de un cambio futuro de status laboral, diferencias salariales desproporcionales al trabajo ejecutado, y muchas otras características similares al funcionamiento de cualquier otra gran corporación.

Desgraciadamente, y como para el resto de situaciones en las que la crisis no ha servido más que para acentuar la dirección que se estaba tomando, en el caso de la universidad, la oculta privatización parcial que supone la aplicación que los gobiernos han hecho del texto presente en el plan de Bolonia sigue su curso, privatización del espacio educativo en la que se han reproducido las mismas añagazas con las que sucedió la privatización de la sanidad, de los transportes o de las comunicaciones; la mercantilización subyacente a toda la vida - el cercamiento conceptual a un estado social y a una manera de pensar el mundo. El análisis de su privatización oculta se podría llevar a cabo de forma paralela a las producidas en los otros ámbitos: externalización parcial y progresiva de servicios, multiplicación de contratos a raíz de la creación de una clase de trabajadores permanentes con contratos de breve duración y la preservación de un núcleo de trabajadores a tiempo completo, falsa competencia ya que se da en condiciones diferentes de 
obligación social (contratos de autónomos, etc.), estimulación de la rivalidad interna, aparición de marcadores de productividad que diferenciaran los ingresos percibidos, participación de empresas privadas en segmentos institucionales, etc. culminando la indiferenciación entre lo público y lo privado. Hoy en día, el Estado es el garante de la empresarialización de la universidad, como otro más de los síntomas de la crisis del Estado del bienestar que permite capturar la producción del común y extender la precariedad laboral a todos los ámbitos.

Esta indiferenciación aún se hace más evidente cuando tratamos otra de las características de la universidad post Bolonia: la inclusión diferencial aplicada a los centros de educación superior, es decir, la jerarquización de los centros según niveles de excelencia establecidos atendiendo a criterios de productividad. En estos procesos de inclusión diferencial, el nivel de cualificación de la fuerza de trabajo depende de en qué institución se haya estudiado y de la posición de esta institución en la jerarquía del mercado. En este caso, podríamos aventurar la similitud entre el funcionamiento de las agencias de calificación de riesgo que ocultan sus intereses políticos, como se está evidenciando en los últimos tiempos, y las agencias de calidad universitarias que priorizan intereses económicos a la hora de calificar las universidades-empresa. Por ello, atendemos indignadas a las invitaciones por parte de la OMC a los países en vías de desarrollo de dedicarse exclusivamente a los tramos educativos preuniversitarios, dejando para los centros de excelencia ya consolidados del extranjero (principalmente de la órbita anglosajona) la tarea de cualificar a sus jóvenes, como si fuera una franquicia cualquiera, consecuencia lógica de su establecimiento y expansión como negocio similar al de cualquier otra marca comercial ${ }^{20}$.

En cualquier caso, resulta evidente la apuesta por centros de dos niveles, independientemente de su condición privada o pública, aquellos que cualifican al proletariado cognitivo y aquellos que designan a sus estudiantes como pertenecientes a una élite, retomando la vieja función universitaria de separar la paja del grano, tan útil socialmente. La promoción de centros de excelencia en todo el mundo ha mostrado el declive europeo, que ha intentado recuperar su primacía universitaria activando el proceso Bolonia para restablecer la competitividad respecto a otros países en esta universidad globalizada en donde cada centro o agrupación de centros se convierte en una especie de transnacional público-privada de la educación superior. En resumen, la inclusión diferencial supone que, cuando

20. El Banco Mundial entendió que las universidades africanas no generaban suficientes retornos. Consecuentemente les impuso que dejaran de invertir en la universidad, concentrando sus pocos recursos en la educación primaria y secundaria y permitiendo que el mercado global de educación superior les resolviera el problema de la universidad. Esta decisión tuvo un efecto devastador en las universidades de los países africanos. DE SOUZA SANTOS, Boaventura. La universidad popular en el siglo XXI, Lima: Fondo Editorial de la Facultad de Ciencias Sociales, 2006 p. 25. 
se está hablando de equiparación de los estudios a nivel europeo, se estén provocando unas desigualdades de partida como son la segmentación entre los que sólo acceden a estudios de grado y los que puedan permitirse un postgrado, entre los que estudian en universidades calificadas dentro del rango de los campus de excelencia y las que no.

A esto tenemos que sumarle el reverso de la empresarialización en lo referente al alumnado que sufre una doble privatización mediante la sustitución de las becas (que no desaparecen sino que se van reduciendo progresivamente al limitar su concesión a importes cada vez menores a medida que bajan los sueldos) por créditos, como ya hemos comentado anteriormente en referencia al segundo tramo de educación superior. Esta progresiva sustitución tiene consecuencias a diferentes niveles. Por una parte, implica una relación viciada con las entidades bancarias que acaban beneficiándose de la concesión de créditos a un público cautivo, imponiendo su presencia desde el detalle más pequeño como puede ser la creación de un carnet universitario combinado con una tarjeta de débito para cualquier alumno, hasta el cobro de matrículas de inscripción y tasas universitarias y otros tantos privilegios. Por otra, la implantación de la deuda - créditos blandos para compensar la reducción de las becas, proceso de endeudamiento del trabajador -estudiante según el modelo anglosajón - culmina la financiarización del sistema. Citando a Monserrat Galcerán ${ }^{21}$, la financiarización se define del siguiente modo:

Se entiende por tal el fenómeno, tan extendido en las sociedades capitalistas, que hace que los compradores tengan que acudir a la deuda para financiar sus compras, lo que supone un notable negocio financiero para las entidades bancarias pero a la vez está en la raíz del empobrecimiento actual: personas con fuertes deudas y con trabajos precarios que no pueden sufragar sus gastos. La deuda de las poblaciones alimenta a su vez las burbujas especulativas y es uno de los elementos de la actual crisis sistémica. (...) Si las condiciones económicas siguen mal, el volumen de deuda llega a ser impagable y la consiguiente restricción del crédito provoca un empeoramiento de la situación de los deudores, los cuales tienen que renegociar la deuda con más gravámenes todavía, que seguirán alimentando el negocio financiero.

¿Acaso no resulta similar a las operaciones que se están desarrollando en los últimos tiempos con ciertos países europeos? Como para ellos, optar por refinanciar deudas de la población ocupada sometida a un empobrecimiento progresivo así como de la creciente población desocupada en un marco de precariedad generalizada como solución a la reducción presupuestaria en servicios que anteriormente se consideraban prioritarios, resulta poco menos que suicida. Simultáneamente, no sabemos si con intención irónica, se impone un modelo de

21. GALCERÁN, Montserrat. "La educación universitaria en el centro del conflicto", en La universidad en conflicto: capturas y fugas en el mercado global del saber. Madrid: Traficantes de sueños, 2010, p.18. 
medición del conocimiento por número de créditos, correspondiendo cada crédito a un número determinado de horas - atribuir una medida de tiempo al conocimiento como se ha venido midiendo desde los tiempos del fordismo la fuerza laboral, sería otra de las medidas más en las que la universidad se equipara a la empresa.

El nuevo sistema de créditos (ECTS; European Credit Transfer System) propone medir no ya los resultados académicos sino el tiempo dedicado al estudio. Se estima que la "jornada media" del estudiantees de 40 horas semanales, excluyendo así a todo aquel que necesita simultanear la carrera con el trabajo. El estudiante se convierte en un trabajador de sí mismo, en su propia inversión. El empleo de su tiempo de trabajo medido en horas se contrapone a su valor monetario: los créditos de aprendizaje tiene efectivamente un coste claro, sobre todo si exigen la solicitud de créditos bancarios.

Otra de las características secundarias del proceso Bolonia sería la descualificación de los saberes: el devenir instituto de la universidad, tal y como lo define la red de universitarios llamada Edu-factory ${ }^{22}$ surgida entre otras, de las diferentes movilizaciones estudiantiles que han recorrido en los últimos años Europa: la Onda Anómala italiana, las diferentes manifestaciones de París del 2003, 2004-2006, 2009, las movilizaciones y ocupaciones griegas e inglesas así como las españolas. El devenir instituto supone elevar las barreras del reconocimiento de las competencias, requiriéndose un tramo más para ser reconocido en su totalidad. La reducción de horas de docencia presencial, además de justificar reducciones de plantilla, reduce también el nivel de conocimientos, no porque el profesor dé menos clases magistrales sino porque se reduce el tiempo de desarrollo conjunto por parte de los alumnos, abocados inevitablemente a la formación individual. Se asimila menos en menos tiempo, la compresión de cinco a cuatro años del itinerario de grado se está haciendo con una sensación de pérdida inevitable de calidad que se pretende recuperar durante el postgrado, sin caer en la cuenta de la gran diferencia que supone pasar de ser alumno a ser cliente y a un cliente se le trata siempre bien, el nivel exigido es menory el aprobado es casi un must, visto el coste de los estudios de máster.

De esta manera, la reducción de años de estudio a cuatro basada en la afirmación de que las metodologías activas de enseñanza, teóricamente implementadas a través de la reforma de Bolonia, transforman al alumno en un agente autónomo con capacidad de completar paralelamente su formación, se convierte en una declaración de buenas intenciones en la medida en que el cambio metodológico no viene respaldado por medidas administrativas y económicas que

22. www.edu-factory.org. Edu-factory es un colectivo transnacional centrado en las transformaciones de la Universidad global, la producción de saberes y las formas de conflicto. La página web de esta red global recoge y conecta investigaciones teóricas con los movimientos universitarios. La red ha organizado encuentros en todo el mundo, entre otros, el llamado Commoniversities en Barcelona en noviembre del 2010, encuentro en el que participamos y que reseñaremos más adelante. 
permitan activarlo de forma efectiva. El alumno obtiene finalmente en 5 años una titulación superior, rebajándose la calificación mínima del contenido financiado, siendo el diploma de 4 ó 3 años (dependiendo de la carrera y el país) una escala inferior que convierte al egresado en un trabajador de segundo nivel. Por tanto, la discriminación por criterios económicos acaba siendo una realidad así como la financiarización propuesta como alternativa.

A este hecho ya suficientemente comentado le podríamos sumar toda una serie de medidas que contribuyen a convertir los estudios de grado en una prolongación de la escuela. Todo ello infantiliza el modelo, un modelo que se supone quiere formar a trabajadores flexibles, innovadores etc. y que sin embargo, paternaliza su recorrido impidiendo cualquier opción fuera de norma como simultanear trabajo y estudios (segregación económica añadida) que se convierte en una opción casi imposible, matricularse de más asignaturas de las programadas o retomar dos cursos en uno. Esta infantilización de la educación superior tiene su correlato en el trabajo requerido al profesorado que, sin que ello suponga un incremento salarial, debe aumentar las actividades de seguimiento, cayendo en la burocratización no sólo de la relación con alumnos sino también la propia con las materias, porcentajes de evaluación, mediciones permanentes, pequeños trabajos de cuantificación que reducen la operación docente a un intercambio de pruebas de que se está siendo sumiso a los planes, directrices y procedimientos de calidad varios, limitando el tiempo dedicado verdaderamente a la preparación de la materia.

Somos conscientes de que no hemos abordado detalladamente la cuestión de la investigación que sufre un proceso paralelo de empresarialización mediante la instauración del Espacio Europeo de Investigación, similar al EEES. Su objetivo es generar una red de centros de excelencia científica en donde excelencia científica no significa relevancia académica sino literalmente "capacidad para producir conocimientos explotables con fines industriales" ${ }^{23}$. La cooptación de la investigación a través de la constitución de cátedras mixtas en donde las empresas marcan las líneas de investigación sería otra de las estrategias de apropiación del común, así como la ayuda que la universidad presta a las empresas spin-off, empresas nuevas en el seno de otras empresas u organizaciones, ya sean públicas o privadas, que en España adquieren el nombre de Empresas de Base Tecnológica y trasladan las innovaciones científicas a la producción y comercialización de productos. Sin olvidar que la financiación de estas investigaciones supone la retirada de fondos a otras líneas de investigación como las de las ciencias sociales o las artísticas que difícilmente podrían demostrar su rentabilidad a corto plazo y menos aún con fines industriales.

23. Comunicación de la Comisión al Consejo, al Parlamento europeo, al comité económico y social y al Comité de las Regiones. Hacia un espacio europeo de Investigación, 2000. COM (2000) 06 final, p. 10. 
En este sentido, Castells ${ }^{24}$ hace una diferenciación necesaria entre las líneas de investigación básica, realizadas con financiación pública, y la investigación aplicada, fomentada y parcialmente subvencionada por las empresas que se benefician posteriormente de sus avances. Si bien la investigación básica no promueve directamente el rendimiento competitivo, que se produce en el nexo entre la investigación básica y la aplicada, resulta necesaria para poder desarrollar la aplicada y es la que puede permitirse cambios radicales de paradigma o investigaciones cuyo rendimiento no sea directamente eficaz, o como en el caso de las investigaciones sobre la malaria, económicamente rentable (ya que los países afectados por ella son fundamentalmente pobres por lo que no aportarían un beneficio como el que el último avance en cosmética estética podría aportar). Por ello, ahora que los fondos públicos destinados a la investigación de base son cada vez menores, ha llegado el momento de reivindicar este tramo de investigación frente a las argumentaciones relacionadas con beneficios económicos o empleabilidad que están en la raíz de este tipo de orientaciones.

Para terminar, quisiéramos señalar el estatuto esencialmente precario de los investigadores españoles en donde muchas veces se establecen contratos por proyecto y donde se produce un reconocimiento parcial de sus derechos laborales, se asumen períodos de trabajo no remunerado así como la exigencia de actualizar permanentemente los conocimientos de forma autónoma, acrecentando una vez más la inclusión diferencial postfordista en todas las modalidades laborales, ya sean de docencia como de investigación.

\subsection{Conclusiones, posiciones, proyecciones}

Tras este breve análisis del estado de la cuestión, sería quizás el momento de aventurar posibles alternativas de funcionamiento que pudieran hacer frente $\mathrm{o}$, por lo menos, paliar algunas de estas carencias y conflictos. No se trataría, como otras veces se ha pretendido, de una vuelta atrás a un estadio previo en el que se pudiera mantener la idea de una universidad de élite con un estatuto de autonomía que le permitiera gobernarse de forma independiente. Esto sería pretender volver a una lógica de clase dirigente que puede permitirse generar y transmitir conocimientos alejada de la sociedad que la financia, sin implicarse en ella y pudiendo exigir esa independencia que tan necesaria ha sido en momentos de opresión política. Se trata efectivamente, tal y como se explicita en el EEES, de hacer que la universidad establezca vínculos y devuelva a la sociedad lo que la sociedad le aporta en primer lugar, pero no desde un punto exclusivamente económico sino fundamentalmente crítico. Tal y como especifica Paul Lauter ${ }^{25}$, la autonomía

24. CASTELLS, Manuel, op. cit., pp. 160-166.

25. LAUTER Paul. Contenido, cultura, carácter. [En línea]. Disponible en http://www.worksanddays.net/2003/File05.Lauter_File05.Lauter.pdf. [Consulta: 24 de Febrero de 2011]. 
de la universidad, como la autonomía del arte, tuvieron su lógica y sus ventajas en determinado momento pero seguir manteniendo hoy ese supuesto resulta progresivamente complicado:

Las universidades enseñan a través de lo que son. Cuando una gran universidad con un presupuesto de 11.000 millones de dólares contribuye a empobrecer una ciudad que ya está en niveles de indigencia utilizando la deslocalización para forzar a la baja los salarios de los que trabajan en sus comedores, está enseñando quién cuenta y quién no, quién decide en el mundo urbano actual. Cuando la ciudad estadounidense en la que la gran universidad lleva a cabo una investigación médica tiene una tasa de mortalidad infantil superior a la de Costa Rica, se está dando una lección sobre prioridades. Cuando entre el 60 y el 70 \% de las horas lectivas de la gran universidad -y de muchas universidades que no son para nada grandes ni prestigiosas - son impartidas por personal temporal, muchos de los cuales cobran por debajo del nivel de la pobreza y no cuentan con ninguna cobertura social, ni despachos, ni seguridad laboral, lo que se está imponiendo es una redefinición de la función docente como una industria de servicios.

La universidad puede ser un punto central desde donde articular diferentes propuestas y protestas en relación al precariado y su consolidación como clase social con autoconciencia, como ha venido sucediendo últimamente cuando en numerosos países europeos se han producido revueltas con reivindicaciones que iban mucho más allá del ámbito universitario. En 2006 en Francia, se produjeron numerosas revueltas a raíz de la aprobación del CPE (contrato de primer empleo) que agudizaba las condiciones de desregulación de las garantías sociales establecidas en el CNE (Contrato de Nuevo Empleo). El CNE entró en vigor en agosto de 2005 y es aplicable a todos los trabajadores de empresas con menos de 25 personas. En cambio, el CPE afecta exclusivamente a los jóvenes con menos de 26 años y a las empresas con más de 25 trabajadores. En ambos casos, no se requería una causa específica de despido después de un período de prueba de 2 años. A raíz de los tumultos estudiantiles que protestaban contra un futuro precario, se anuló la aprobación del CPE. En España, en agosto de 2011, aprovechando el estío, se han aprobado medidas para poder realizar contratos de formación durante dos años a jóvenes de hasta 30 años y nadie ha parecido cuestionarlo ni desde las universidades ni desde otros ámbitos, quizás por encontrarnos en período vacacional.

Para terminar con este capítulo introductorio, nos gustaría citar un par de los muchos ejemplos de presión a las universidades públicas en el mundo, ejemplos en sí anecdóticos pero sumamente esclarecedores respecto a las mejores previsiones que se puedan hacer sobre la evolución de la enseñanza pública en el territorio español. El caso del Departamento de Filosofía de la Universidad de Middlesex en Gran Bretaña puede resultar esclarecedor en cuanto a la consideración de los criterios de eficacia aplicados a las universidades que, aún siendo de por sí cuestionables, ni siquiera su cumplimiento protege de un ataque frontal contra 
disciplinas y especializaciones que, claramente, no resultan rentables. Podríamos reflexionar sobre el cierre en $\mathbf{2 0 1 0}$ del departamento de Filosofía de dicha Universidad que corresponde a la aplicación directa de la lógica de beneficios del work based learning, es decir, de la formación laboral pagada por el "futuro" trabajador. Su cierre nos podría inducir a pensar que este departamento estaba perdiendo estudiantes $u$ obteniendo resultados de investigación mediocres así como un número reducido de subvenciones para proyectos de investigación, hechos que sumados, justificarían en cierto modo su cierre, visto el recorte económico que se había impuesto ese mismo año a las universidades.

Sin embargo, Filosofía era el departamento que estaba obteniendo mejores resultados investigadores año tras año en toda la Universidad de Middlesex; en los últimos resultados baremables antes de su cierre, el departamento estaba situado en la posición 13 de 41 instituciones de Gran Bretaña y primera dentro de todas las universidades creadas a partir de 1992. El número de estudiantes matriculados seguía siendo creciente y su programa de MA era considerado como el mejor del país. Aún así, el decano de la facultad de Humanidades explicó la decisión declarando que Filosofía no estaba realizando una contribución "mensurable" a la Universidad, lo que implica que la investigación, a pesar de lo que se viene repitiendo desde Bolonia, no es un factor prioritario a la hora de tomar estas decisiones ${ }^{26}$. A raíz de su cierre, se produjeron numerosas manifestaciones así como escritos de apoyo por parte de universidades y departamentos de toda Europa, entre los que se contó el nuestro, pero a pesar de el respaldo del entorno académico y las garantías de "eficacia bolonina", no hubo ni siquiera posibilidades de negociación.

De la misma manera, un ejemplo claro de la evolución globalizante por la que nos hemos decantado en España es el que se ha producido al respecto en Chile. En este país, de 1981 a 2000, la enseñanza básica y secundaria en manos de la educación pública ha pasado del $78 \%$ a menos del $50 \%$, siendo subvencionada por el Estado chileno con dinero público, es decir, subcontratando parcialmente tramos educativos de base y ejerciendo un control muy débil sobre las subvenciones concedidas a los establecimientos privados que modifican tasas y acaban lucrándose a costa de la ciudadanía que funciona como un público cautivo. Durante este período, se crearon igualmente gran cantidad de universidades privadas, de alto coste y baja calidad, endeudando de forma directa a las familias que optaban por esa vía. Por su parte, las antiguas universidades estatales y aquellas de grandes

26. Para más información sobre este asunto, remitirse a las siguientes direcciones: http:// savemdxphil.wordpress.com/,

http://www.guardian.co.uk/commentisfree/2010/apr/29/philosophy-minorities-middleqsex-university-logic, http://boonery.blogspot.com/2010/04/on-to-middlesex.html, entre muchas otras páginas que tratan este caso en profundidad. 
corporaciones privadas, comenzaron a cobrar tarifas de mercado y endeudaron al resto con créditos facilitados por el Estado que fomentó abiertamente este modelo de negocio. La élite política chilena ha justificado en su mayoría este modelo de financiarización de la enseñanza universitaria que, además de hacer repercutir el $45 \%$ de la educación sobre los propios ciudadanos, ha reducido sensiblemente la calidad de la misma, según revelan los baremos de calidad internacionales. Chile ha ampliado su cobertura educativa tanto en número como en extensión de rango social pero las consecuencias que está teniendo respecto a la economía general del país no se pueden desdeñar. Chile permitió que las universidades privadas compitieran libremente con las universidades estatales sin controlar la calidad de los resultados ni las implicaciones económicas. Respecto a este proceso podemos citar el análisis de Andrés Oppenheim ${ }^{27}$ :

Como la mayoría de los estudiantes de clase trabajadora que accedieron a las universidades no podían afrontar el pago de sus cursos, Chile adoptó un sistema usado en Australia, que permite que los estudiantes empiecen a pagar por su educación una vez que se gradúen y consigan un empleo. Con la explosión de estudiantes de los últimos años, muchos nuevos graduados se vieron incapaces de pagar sus préstamos. Y como sus padres eran garantes de los créditos, toda la familia se encontró con deudas enormes, lo que ayuda a explicar el respaldo de muchos adultos al movimiento estudiantil. Lo que es peor, a diferencia de lo que ocurre en Australia, donde a los graduados se les exige pagar un cierto porcentaje de sus salarios cuando consiguen un empleo, en Chile tienen que pagar una suma fija, independientemente de los ingresos. Los universitarios de hoy saben que estarán estrangulados financieramente en cuanto se gradúen.

Ante esta situación insostenible, desde agosto de 2011 en Chile se han venido produciendo numerosas revueltas, ocupaciones y manifestaciones tanto de estudiantes como de otros sectores de la sociedad exigiendo la reinstauración del derecho a la educación gratuita por lo menos en un $60 \%$ mientras que las negociaciones con el presidente y con el Parlamento no han llegado a comprometerse más que hasta cubrir el $40 \%$. Este ejemplo de transformación de la educación superior sirve para poner sobre el tapete la discusión en torno a si es deber del Estado garantizar el acceso a una educación de óptima calidad a todos los ciudadanos o si, verdaderamente, a estas alturas del caos, esto tiene una importancia relativa frente asuntos considerados prioritarios como la crisis económica que acaba justificando la financiarización extensiva de la vida como única dimensión posible. Las protestas estudiantiles que paralizaron Chile han sido vistas en gran parte del mundo como un síntoma del fracaso del sistema universitario abierto a la iniciativa privada que rige en el país, nosotros podemos verlo como nuestro posible futuro, anunciado ya por diferentes políticos, tanto a nivel de gobierno central como por parte de algunos de los representantes de las diferentes comunidades autónomas.

27. OPPENHEIMER, Andrés, EL PAÍS - Internacional, 29-08-2011. 
En cuanto a la legitimación de estas operaciones a nivel internacional, Kyung-wha Kang, alta comisionada adjunta de las Naciones Unidas para los Derechos Humanos, en respuesta a este enfrentamiento directo entre parte de la sociedad chilena y su gobierno, instó recientemente a la implementación de una educación universitaria gratuita en Chile. Nos preguntamos si esta intervención responde a un giro en la política educativa internacional que hasta el momento, como hemos visto, se había lanzado abiertamente hacia formas graduales de neoliberalización del sector, o si defenderá esta tesis en todo el espectro global, lo que incluye desde las universidades tradicionalmente elitistas del ámbito anglosajón hasta las paupérrimas universidades del Tercer Mundo y si, al fin y al cabo, la comisionada adjunta de las Naciones Unidas para los Derechos Humanos puede llegar a tener algún tipo de influencia real en ello.

Finalmente, nos gustaría citar la repolitización del ámbito universitario español que ha implicado, entre otras acciones como la creación de numerosas universidades libres, las extensas movilizaciones contra la imposición del proceso de Bolonia que llevaron a la ocupación de la Universidad Autónoma de Barcelona (UAB) en 2008, a su reocupación puntual y la de algunas otras como Madrid o Sevilla tanto en 2009 como en 2011, etc. La reconversión del ámbito universitario en un entorno politizado permite augurar ciertas esperanzas de cambio aunque sea interno y no oficial. Ni siquiera en sus relaciones con el exterior más allá del conflicto por el conocimiento, la universidad puede mantener una posición neutra, posición que no corresponde a su estar en el mundo. Se trataría pues de hablar inicialmente de procesos como la denuncia de las reformas, el cuestionamiento de la supeditación de la universidad a los intereses empresariales, la defensa de su capacidad niveladora y democrática, la reacción ante la descualificación de los saberes; todo ello supeditado al reconocimiento de su posición central en el conflicto del capitalismo cognitivo. Eso no significa que tenga que renunciar a su papel como formadora de trabajadores, a su necesaria vinculación con la empleabilidad de sus egresados, ya que seguimos considerando necesario su papel de preparación para una realidad laboral (aunque hoy en día sea caso inexistente con un país con 6 millones de parados y un éxodo constante de todos aquellos que destaquen mínimamente como para hacerse un hueco en el extranjero). No obstante, no consideramos que estas dos facetas de la universidad sean incompatibles entre sí o que haya algo censurable en una búsqueda de consecución laboral, siempre que no sea el único criterio de medición.

Intentando, pues, encontrar un punto intermedio, nos damos cuenta de que resulta fácil encontrar protestas comunes a todos los diferentes grupos que están apoyando un cambio dentro de la Universidad, resulta sin embargo más complicado encontrar una alternativa común. No obstante, las exigencias de cambio en la universidad deberían apuntar a un objetivo más amplio: luchar contra los procesos de desclasamiento y precarización del trabajo cognitivo en general y por la reapropiación de la producción de saberes. ¿Acaso es el conocimiento un bien 
social que debe circular sin dejarse cooptar por nadie ya que su propia condición le garantiza la reproducción ad infinitum sin merma de su calidad? ¿O debe priorizarse su valor como mercancía sometida a la lógica de la propiedad exclusiva frente a la lógica libre de los comunes?

En resumen, deberíamos iniciar una reflexión interna seria sobre todas estas cuestiones, con la ingenuidad de los que piensan que se puede cambiar algo, con la fuerza de los que saben que no van a poder cambiar únicamente su ámbito sin operar un cuestionamiento generalizado de nuestro funcionamiento como sistema de valores y como sociedad. En estos momentos en los que no tenemos tanto que perder porque lo hemos echado a perder casi todo, por lo menos tengamos la valentía de los desesperados, los que llaman las cosas por su nombre. De esta manera, reconocer el punto en el que nos encontramos quizás nos permita pensar nuestra universidad de otra manera, intentar conectar con movimientos sociales, refrescar nuestras enciclopédicas opiniones con necesidades del presente, ser críticos con nuestras benevolentes valoraciones, comunicar nuestras dudas, preguntar a nuestros compañeros y alumnos sin miedo a las respuestas, no esperar al último recorte para tirarnos de los pelos. Recordemos que el problema no es únicamente una crisis de la universidad sino una crisis generalizada por lo que, independientemente de que se piensen alternativas y soluciones a la mercantilización de la producción y transmisión de conocimientos, dentro y fuera de la Universidad, es necesario abrir la búsqueda de alternativas de autogobierno y empoderamiento.

La necesidad de nuevas maneras de pensar y de actuar resulta especialmente acuciante hoy ya que sería ingenuo pretender que la quiebra del modelo político y del modelo económico, por no hablar del ecosistema, no sean realidades que exijan un punto y aparte, una reflexión seria y colaborativa sobre nuevas maneras de gobernarse. Pero la crisis generalizada surge también como la oportunidad para repensar el espacio europeo no sólo desde el punto de vista educativo, sino también utópico; en el mejor de los casos, si fuéramos conscientes del momento histórico en el que nos encontramos, podríamos transformar la defensa de la universidad pública en la construcción de las instituciones del procomún. ${ }^{28}$

28. Huelga decir que, en el transcurso de esta investigación, han ido pasando muchas cosas en este país, que los rectores, los profesores y los estudiantes se baten en vano contra la destrucción acelerada de la Universidad pública, que se atrincheran en la defensa de pequeñas migajas, sabedores todos de que vamos a tener que hacer frente a una derrota humillante y generalizada si no hay un movimiento masivo de repulsa a las medidas que desguazan el Estado del Bienestar. 


\section{Crisis, ¿qué crisis?}

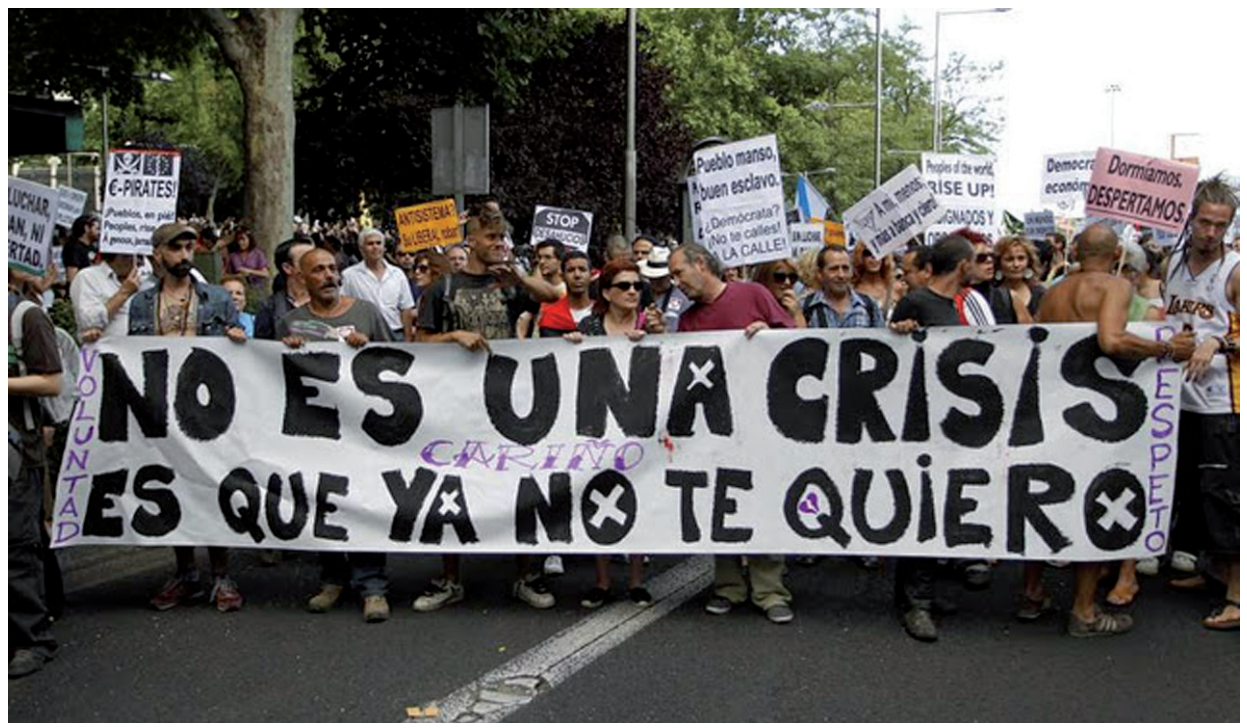

Fig. 3 
Aquella sociedad cuya paz depende de la inercia de unos súbditos que se comportan como ganado, porque sólo saben actuar como esclavos, merece más bien el nombre de soledad que de sociedad

Baruch Spinoza ${ }^{29}$

\subsection{Presentación de la representación}

La crisis esta que nos deletrean como si fuera el miedo, puritito miedo porque, según dicen, esto se nos ha ido de las manos, nos hemos metido demasiadas rayas y hecho demasiadas casas, hemos sido irresponsables con nuestras cosas y que ahora toca apretarse el cinturón y estrujarse la cabeza, manteniendo perfil bajo no vaya a ser que se fijen en nosotros y al que levante la cabeza duro con él. Pero no. Esto no es así. Sólo nos cuentan el lado de la crisis que se lee con la gafas del miedo, nos meten el miedo dentro, nos dicen "Cuidado, que el lobo ya ha llegado". Teníamos antes un largo preformateo del imperio del mal, que no era el capital, sino el terror que nunca supimos a ciencia cierta si acabó sucediendo de forma imprevista o si fue un montaje, a esos niveles hemos llegado de literaturidad de nuestras vidas en las que resulta imposible saber hasta dónde llegan las ficciones, divergencias y derivas de lo real en lo más obvio, tanto dudamos que reconocemos no haber superado el estadio de la leyenda. Porque la cuna del hombre la mecen con cuentos, como decía León Felipe, nos sabemos arropados en el mismo lecho en el que dormimos con el monstruo de la escasez, el ogro de la recesión, el dragón de la deuda.

Con esas palabras nos tapan los ojos, no nos dicen que crisis quiere decir cambio, quiere decir hasta aquí hemos llegado y ahora pensemos qué vamos a hacer. Eso no, sobre todo eso no, no vaya a ser que nos dé por pensar qué otras maneras tenemos de reestructurar los pactos de realidad, no vaya a ser que nosotras, que no sabemos de nada, vayamos a meter la mano en la manteca con los dedos sucios. Y así vemos cómo se reproduce desde el nacimiento hasta la crisis más palmaria el mismo modelo de conocimiento donde prima la diferenciación entre el experto y el ignorante, mediante la que únicamente se legitima al primero que es el que puede opinar a pesar de haber demostrado su inoperancia, mientras que el resto no puede cuestionar siquiera, hasta dónde íbamos a llegar, las razones de la crisis, la respuesta que se le está dando, el rescate bancario y no el rescate de la vida en aras de un común perverso y viciado en el que se salva a los bancos que arriesgaron y se endeudaron ellos también por encima de sus posibilidades; que

29. SPINOZA, Baruch, Tratado político. Madrid: Alianza, 1986. 
sean ellos los que apechuguen con sus primas y jubilaciones y trapicheos varios, dicen las voces de la calle, indignadas, sin ni siquiera la esperanza de ser escuchadas. Pues todos asumimos como verdad inapelable que no hay nada que hacer, ni siquiera algo que decir, al respecto. Eso creemos temblando. $Y$ votamos como quien va a la iglesia, cruzando los dedos.

Porque aquí no pasa nada, estamos hasta las cejas metidos en una crisis económica, que es una crisis política, que acaba siendo una crisis de civilización, si nos acabamos remitiendo a la construcción articulada de la tríada individuo-mercado-técnica, sin la que no hubiera podido consolidarse con la misma compacidad este sistema de gobierno que abarca la vida misma y aquí sigue sin pasar nada. Nada más allá del deterioro de toda una serie de garantías sociales que van debilitando vínculos y erosionando barreras para acabar definiendo un capitalismo más que neoliberal, más que avanzado, más que postfordista, sólo nos falta ponerle nombre para darle ya plenos derechos consolidados y empezar a tragar las ruedas de molino que nos toquen: el nivel máximo de sometimiento al ejercicio neoliberal, el último ajuste realizado en esta crisis que no hace más que confirmar que no hay otros mundos posibles, la limitación conceptual impuesta por el miedo generalizado.

Y ahora, como esto es una tesis, vamos a hablar con la palabra del experto. $Y$ digamos que el miedo fue sembrado desde tantos frentes, que no fue una catástrofe inútil para tantos, que el mundo de nuevo intenta cerrar las puertas al deseo con otro nombre, porque un deseo que no se base en el miedo a la carencia, puede andar quebrándole la espalda al cuento. Nos remitimos aquí al análisis realizado por Javier Toret ${ }^{30}$ en el que intenta dilucidar las razones por las cuales seguimos sin responder de forma colectiva a la imposición de esta nueva fase de ajustes. El autor se plantea qué hacer ante la unívoca enunciación mediática de la crisis cuya consecuencia más directa es este bloqueo introyectado, no sólo porque el análisis de los mecanismos de semiotización nos puede permitir generar cierta distancia sino porque lo que de verdad está en juego es el rechazo a esta nueva fase y la puesta en marcha de respuestas que puedan ser eficaces en la actualidad. No sólo tenemos que entender lo que está sucediendo y cómo nos lo están contando, sino que tenemos que inventar nuevos mecanismos de acción colectiva que permitan defenderse, entre otras cosas, de la implacable maquinaria mediática puesta en contra de cualquier acción de este tipo, ya que, huelga decirlo, los medios de comunicación son el vehículo por excelencia de esta forma de control y producción de una subjetividad sometida ${ }^{31}$.

30. TORET, Javier. Producción de subjetividad en tiempos de la crisis. [En línea]. Disponible en:<https://n-1.cc/pg/file/read/2535/produccin-de-subjetividad-en-tiempos-de-la-crisisnotas-para-el-encuentro-crisis-sistmica-nuevos-derechos-mquinas-creativas-de-lucha-ycontrapoder> . [Consulta 9 enero de 2010]

31. No entraremos aquí a justificar esta afirmación porque excede con creces el contenido de la tesis. 
Este autor hace un análisis de los diferentes factores que en España siembran la pasividad ante esta crisis y que afectan de diversa manera a las diferentes generaciones: aquella ya mayor que ronda los 70-80 años y que vivió en carne propia la construcción en clave de sacrificio que supuso el Estado del bienestar, lo vive con una sensación de fracaso al ver la desaparición de todo aquello que surgió como una condición permanente en la construcción de un Estado de derecho pero que ve deshacerse con la fragilidad de una burbuja. Entre medias, tendríamos a la generación apolítica posterior (entre los 40 y los 50 años) para la que el posicionamiento político era casi una cuestión de mal gusto, con una cultura de participación pública prácticamente inexistente por lo que sus mecanismos de respuesta colectiva son nulos; y una tercera generación paradójicamente aislada por los dispositivos de comunicación y sobreinformación que, sin embargo, está aprendiendo a utilizarlos como vía de comunicación y construcción de una realidad paralela a la de los medios de comunicación mayoritarios. Todos ellos, o mejor dicho, todas nosotras hemos visto cómo esta crisis con carácter sistémico y global ha pasado de ser enunciada como una guerra total y permanente a partir del 11-S, a ser construida a partir de la imagen del derrumbe que supone la constatación de la incertidumbre también total y permanente.

Más adelante hablaremos del incardinamiento esencial de esta incertidumbre en la sociedad postfordista y de cómo la estructura social y laboral se ha modificado hasta crear una clase metropolitana precarizada, una clase con una conciencia en gestación que está buscando a la desesperada sus líneas de fuerza para operar una subjetivización diferente. Por el momento, tan sólo constatamos cómo gran parte de la población de nuestro país se ve sometida a una precarización generalizada de sus vidas, a una flexibilidad y movilidad permanentes y percibidas casi como deseables ya que la alternativa es peor, la exclusión de la sociedad, el fantasma de la penuria. La soledad y el miedo que producen tienen efectos diluyentes sobre la creación de cualquier tejido social consistente y nos sitúan en el ámbito de la resistencia, sino directamente en la idea de supervivencia que implica una confrontación con los otros que son iguales pero que deben caer porque cuando el asunto se pone bravo, se instala la ley del más fuerte. Precarias contra precarias a la deriva, el miedo al otro sumado al miedo a la catástrofe propia, para doblegar dos veces.

Al fin y al cabo, no hay nada mejor para reforzar la pasividad que la pérdida de alternativas pues otro de los factores fundamentales que provocan este bloqueo es, sin lugar a dudas, la deslegitimación generalizada de la clase política sin excepciones. Nos limitaremos aquí a consignar esta desconfianza para pasar a analizar más adelante el proceso de divergencia entre las bases teóricas del sistema democrático y su actualización en el presente. Por el momento, citaremos únicamente la opinión de Toret cuando habla del peso que tiene la complicidad y/o desfase de la izquierda parlamentaria así como del sindicalismo oficial que llevan a un 
bloqueo generalizado de la participación social. Si a esto le sumamos un espacio de comunicación saturado y la psicologización de los problemas sociales, tenemos una visión más o menos ajustada de la pasividad imperante. El autor concluye diciendo que nos encontramos ante la necesidad vital de resemiotizar la crisis desde una perspectiva de clase, iniciando una subjetivización colectiva autónoma desde lo positivo porque no se podrá dar el común precario sin una producción de subjetividad propia mutualista. Y eso supone, nada más y nada menos, que la necesidad de generar un nuevo sindicalismo social que construya un nosotros colectivo, un imaginario de lucha contra la gestión de la crisis. No obstante, este artículo lo escribe en 2009, cuando la crisis apenas está asomando las orejas, y ya anuncia algunos de los movimientos que hemos visto hechos realidad en el último año:

Si nos bloquean el futuro, nosotros bloqueamos la ciudad" dicen los y las estudiantes $e$ investigadores precarios que están dando vida a esta increíble onda anómala que viene de las universidades italianas. Esta bella consigna que nos habla de prácticas de bloqueo por parte de los estudiantes, no sólo de la didáctica, sino del metro, o los trenes y de la normalidad de la ciudad, nos habla de cómo organizar un cortocircuito social de la ciudad. Este bloqueo nos evoca una huelga metropolitana basada en la organización vírica y molecular de un movimiento masivo de indignación colectiva contra la crisis, la situación de la universidad y el propio mercado de trabajo-formación ${ }^{32}$

Desgraciadamente, incluso cuando esta especie de huelga metropolitana se ha hecho realidad, ni siquiera entonces acaba pasando algo. Más bien parece que la sociedad española se haya polarizado cuando una parte de la población se ha desmarcado de la pasividad hacia formas de expresión colectiva, intentando transformar la gestión individualizada del malestar en una colectivización del rechazo, como ha sido el caso durante las ocupaciones sucesivas de plazas y la constitución de asambleas 15-M; mientras que la otra parte de la población ha votado abiertamente en las elecciones por una radicalización del credo neoliberal.

Tal y como analiza Alain Badiou ${ }^{33}$, en España se ha producido en los últimos tiempos y de forma progresivamente acusada a medida que se han ido acumulando estos episodios de rechazo, una disyunción radical entre la presentación y la representación de lo que podría considerarse una verdad política. Esta noción de verdad según la entiende Badiou no emana de una visión totalitarizante del gobierno en la que dicha verdad se impondría como principio inapelable, pero tampoco se reduce al campo de las opiniones como lo plantearía Hannah Arendt en su búsqueda de una armonía social dialogante o, desde otro

32. TORET, Javier, Ibid, p. 14.

33. BADIOU, Alain. "Que signifie changer le monde?: séminaire 2010-2011". Entretemps. Disponible en: http://www.entretemps.asso.fr/Badiou/10-11.htm\#_ftnref21. [Consulta: 10 de enero de 2012]. 
punto de partida, toda la crítica posterior a la postmodernidad relativista. En este caso, Badiou hace referencia a una verdad que se evidencia a través de un acontecimiento, de su irrupción como realidad presentada y no como constructo representativo, requiriendo por su misma presencia la necesidad de renegociar los términos de lo posible y de lo imposible, relegando al ámbito de la representación lo que debería haberse legitimado desde la presentación:

En el referido caso español, ha habido una simultaneidad pasmosa entre la aparición de una presentación real (la reunión de la juventud en una plaza madrileña) y un fenómeno representativo (una victoria electoral aplastante de la derecha española). El movimiento ha tenido que declarar la vacuidad total del fenómeno electoral ("no nos representan") en nombre de la presentación. Es una lección: la posibilidad de una verdad política por un lado y la perpetuación del régimen representativo por otro, se produce en una suerte de teatralidad de una manera a la vez simultánea y separada. Es una síntesis disyuntiva de dos escenas teatrales. Disyuntiva, porque a través de un acontecimiento popular masivo lo que se produce es una separación de la representación; lo que se sostiene es que no hay que tener por realmente dado lo que es simplemente visible, que hay que saber ser ciego a la representación. La representación es el régimen del resultado. No quedarse atrapado ahí significa que el proceso, en el terreno de la verdad política, cuenta más que el resultado.

Pero contrariamente a esta opinión, los resultados electorales en el campo de la representación están valiendo para justificar todo tipo de medidas incluso contrarias a las prometidas previamente a las elecciones, como si los votos fueran una carta blanca durante cuatro años más que un compromiso a unos planteamientos registrados en un programa electoral. En cuanto al ámbito de la presentación y sus consecuencias políticas, nada más lejos que una consideración real por la vía de la reflexión de los motivos que han generado la emergencia de estos movimientos de lucha contra la gestión de la crisis. Parece ser que cerrar los ojos o acusar a la oposición, que tampoco ha tenido parte en este movimiento espontáneo, es la única respuesta posible desde el poder político representativo. En cualquier caso, este movimiento hacia la expresión del malestar no nos ha servido para generar una imagen pública de cambio, ya que las reseñas mediáticas han incidido sistemáticamente en sus características menos favorables, sino en su folclorismo, por no hablar de la campaña en contra que se desató a raíz de la provocación de determinados incidentes violentos ajenos a las propias asambleas ${ }^{34}$.

Cuando todas las asambleas se pronunciaban de forma inequívoca como pacíficas ${ }^{35}$, cuando se desmarcaban una y otra vez de cualquier episodio

34. Véase http://jmgoig.wordpress.com/2011/06/15/estrategias-del-poder-para-desprestigiar-movimientos-sociales-el-caso-parlamentcamp/ y http://www.youtube.com/ watch? $\mathrm{v}=28 \mathrm{sf} \times 5 \mathrm{NkTBg}$

35. Véase http://www.acampadavalencia.net/2011/06/15/comunicado-de-la-comisionjuridica/\#more-1166 
violento que, provocado o surgido espontáneamente (preferimos no entrar ahora en esa discusión), pudiera producirse a raíz de desalojos y manifestaciones varias; no obstante, los medios de comunicación y los políticos siguieron identificando a sus participantes como violentos hasta considerar violenta la propia presencia en sus plazas. Independientemente de ello, habría que dedicarle todo un capítulo a la violencia como gran tabú, uno de los elementos que contribuye a incrementar el bloqueo, ya que cualquier acción que pueda ser percibida como tal cae inmediatamente en el terreno de lo autocensurado. No es este el lugar para hacer una apología de la violencia, evidentemente, pero también resulta obvio pensar que el mutuo acuerdo no suele ser moneda de cambio en estos casos, pretenderlo entraría dentro del territorio Bambi en el que sabemos que no nos encontramos así que, si pretendemos un cambio estructural, deberíamos pensar con qué armas contamos para hacer presión porque estamos viendo la enorme desproporción de poderes y privilegios que rigen esta teórica democracia representativa. Por no alegar lo obvio, como si la hiperexplotación del territorio, o los desahucios forzados a pesar de los pagos no fueran actos violentos, por no seguir enumerando los diferentes grados de violencia estructural a la que nos vemos sometidos desde tantos frentes, psicológicos, económicos, ecológicos... En resumen, a pesar de las numerosas y constantes presencias colectivas en nuestras calles y plazas, se ha hecho todo por neutralizar cualquier posibilidad de transformación subjetiva en el imaginario social que pudieran haber motivado estos empoderamientos colectivos en la dirección de considerar la crisis como una oportunidad de cambio. Sin embargo, desde todos los ámbitos, se sigue incidiendo y remachando el imaginario del miedo a carecer como organizador del deseo social, volviendo al texto de Toret.

Por todo ello, en vez de ponernos en manos de otros para encontrar las soluciones a esta crisis, en vez de cargar sobre nuestras espaldas las incertidumbres y los miedos y asumir a título privado los fracasos y las precarizaciones, la pérdida de futuro más allá del resistir, necesitamos recuperar nuestra propia autonomía de pensamiento, empezar enfrentándonos a la ausencia de alternativas de todo tipo a la que nos hemos acostumbrado, desnaturalizándola. Frente a la lógica expropiadora que nos conmina a consultar al experto, a temblar esperando el oráculo, podemos reunirnos en nuestra ignorancia, sumando desconciertos para buscar apoyos en donde reposar una realidad que se nos desmonta y a la que nos aferramos y para ello, ¿qué mejor que volver a plantearnos cómo sembramos esa visión única del universo, qué sucedió en el camino para que todos encontráramos el mismo tipo de respuestas, o peor dicho, el mismo tipo de preguntas? ¿y dónde se hacen las preguntas sino en las instituciones del conocimiento?

Ya hemos visto lo que ha pasado con estas instituciones inmersas en procesos de privatización y mercantilización en los que las materias impartidas y la misma investigación están determinadas por criterios bien ajenos a las necesida- 
des del conocer y hoy en día, ¿qué más necesitamos conocer de lo que sabemos que no nos ha servido? Así que quizás nos fuera de provecho dedicar todo este capital creativo que desarrollamos en las épocas de bonanza orientándolo hacia la posibilidad de pensar/proponer/experimentar nuevos modelos en educación, pero también en gobierno, recuperar en cierta manera la realidad de un sujeto razonado y pensante, capaz, en efecto, de establecer acuerdos, pactos y contratos a los que llega por medio del conflicto/diálogo, pero también la realidad de un sujeto afectado y afectante que es capaz de generar lazos de autonomía y dependencia y, si nos ponemos utópicas, simplemente recuperar la posibilidad de pensar conjuntamente pasando de un sujeto privado a un nosotros que piensa.

En este análisis previo de la situación en la que se encuentra la Universidad pública en la actualidad, no hemos abordado más que lo referente al enfoque institucional y los efectos de la aplicación del proceso de Bolonia en cuanto a la mercantilización generalizada de la enseñanza universitaria, pero no hemos analizado dos elementos fundamentales en lo que respecta a los procesos de aprendizaje: ni el contenido de los mismos ni la metodología de aprendizaje empleada. En cuanto al contenido, nos resulta obvia la crítica implícita en esta investigación, en lo que respecta a la metodología, la comentamos brevemente cuando hacemos referencia a la autoformación, al analizar los modelos de investigación-acción participativa o de investigación militante. Nos gustaría simplemente indicar que, en ambos casos, el modelo universitario actual no es fruto directo de la aplicación de las nuevas normativas establecidas en Bolonia, aunque tal y como hemos analizado en el capítulo anterior, ellas afecten o acentúen los efectos que ambos elementos puedan tener a la hora de determinar el tutelazgo generalizado, y la distancia que se quiere imponer entre un "conocimiento neutro", cuya sujeción a necesidades concretas se aplica únicamente en el ámbito del beneficio empresarial, y el mundo en el que se encuentra inmerso, del que emana y al que vuelve, en vez de intentar satisfacer o por lo menos, suscitar, desafíos del orden de lo político y lo social que se están presentando como acuciantes en nuestra realidad más inmediata.

Necesitaríamos plantearnos previamente qué formas de gobierno estamos considerando como las únicas válidas y por qué en estos momentos deberíamos dedicarnos a analizar nuestra realidad para gobernarnos de forma conjunta que no significa ni masificada ni unánime. ¿Qué ha pasado para que las políticas públicas que afectan a grandes capas de la población, como es el caso de la reforma de la enseñanza superior europea, se tomen en reuniones compuestas por delegados políticos y tecnócratas de la administración europea sin que se produzca debate alguno en la sociedad más allá del acallamiento de las protestas surgidas del ámbito universitario y no sólo de los docentes "beneficiarios" afectados por los recortes y privatizaciones sino por los propios alumnos? ¿En qué momento se ha producido una dejación o cooptación de la capacidad de decisión sobre cuestiones 
centrales de nuestro gobierno? Y lo que es peor, ¿qué ha pasado para que las fuerzas políticas no se sientan ni siquiera inclinadas a iniciar un debate abierto con la sociedad en casos como estos en que hay una oposición de considerables dimensiones que intenta hacerse oír de múltiples maneras? ¿Acaso no disponemos de los medios tecnológicos para hacerlo? ¿O simplemente se trata de mantener un tratamiento de minoría de edad al conjunto de la población?

Podríamos pues revisar en cierto modo las condiciones del pacto que realizamos en Europa en general y en España en particular, sobre nuestros modos de gobierno que parecen estar cada día más blindados a cualquier cambio, bajo la excusa a veces de los fundamentalismos acechantes, otras, bajo la amenaza de la pérdida de identidades o bajo cualquier otro techo que resulte conveniente para la campaña de opinión pública del momento. Nombraremos las falsas transiciones y los acuerdos a medio gas, la desarticulación generalizada de una sociedad que se había puesto en pie con esperanza y que ha acabado siendo una con el mercado. Frente a ello, cómo no retomar la inabarcable derrota que supuso para los movimientos autónomos en España la simulación de una democracia postfranquista basada en pactos entre los antiguos mandos y los nuevos partidos, a espaldas de lo que había sido la oposición hasta el momento, evidenciando la imposibilidad física del cambio. Una derrota que estableció un punto de partida en el que, para empezar, se había de negar esa misma derrota, se necesitaba dibujar una realidad posible en la que el sujeto histórico relacionado con el trabajo se vio desmantelado para pasar a ser un "sujeto libre", un aspirante a la libertad de su propia precarización. Retomaremos este marco en el apartado dedicado a las luchas obreras de los 70, como antecedente de cierta idea de autonomía prefiguradora de las bases que nos llevan en la actualidad a los procesos de autogestión y autoformación colectiva. Pero por el momento, nos va a servir para iniciar una breve reflexión sobre la consolidación de un determinado modo de gobierno que está mostrando su evidente fracaso en la actualidad. Para hacerlo, nos remitiremos a las tesis de Monserrat Galcerán que de nuevo contribuye a aclarar estos procesos, esta vez en su libro"Deseo y libertad" ${ }^{36}$.

\subsection{Sujeto y democracia o sujeción a la democracia}

Estamos viendo cómo la visión del sujeto moderno se encuentra en la base de nuestro sistema de gobierno, directamente relacionada con un proceso previo de construcción del individuo como aquel cuya vida depende de él mismo, es decir, caracterizado por su condición de libre en tanto independiente de los otros. Galcerán considera que en la actualidad esta noción de libertad se

36. GALCERÁN, Monserrat, Deseo (y) libertad, una investigación sobre los presupuestos de la acción colectiva. Madrid: Traficantes de sueños, 2009. 
sitúa bajo el signo liberal de la competencia: la libertad del individuo sería aquella que le permite actuar sin constricciones en el ámbito de su esfera de acción, una libertad exclusiva que se resume en la tan manida frase: "La libertad de cada uno empieza donde termina la del otro". Esta idea de un sujeto con autonomía de medios de vida, y que defiende su derecho a no ser coaccionado actúa como bisagra con el Estado de un mercado basado en normas de intercambio que funcionan como normas de respeto a los límites de la apropiación individual. Pero según Galcerán, esta definición de libertad considera la necesidad de regular la competitividad entre unos y otros como único elemento común en la sociedad, frente a una noción de libertad más amplia en la que la relación entre los individuos no sea antagonista ni de independencia recíproca sino que incluya las dependencias reales y necesarias que sustentan nuestra sociedad sin convertirlas únicamente en leyes.

De hecho, Galcerán hace un análisis detallado del uso y abuso que se hace de la palabra libertad en relación con el concepto de individuo moderno, independiente y autónomo, autonomía que en este caso respondería a un sesgo triple de clase, de género y de raza. En resumen, podríamos decir que el concepto liberal de libertad es restrictivo, aplicable únicamente a varones de raza blanca y cierto estatus social, lo que supone una interpretación de la libertad con carácter ideológico, casi reducida a los hombres como propietarios consumidores y a su capacidad de elegir, si queremos llevar esta suposición hasta el extremo. Partiendo de esta lógica individualista, ¿cómo encontrar justificaciones teóricas para la acción colectiva que garanticen la supervivencia social? Los teóricos modernos como Habermas intentan combinar la libertad personal con la necesaria cooperación en el marco de sociedades políticas basadas en el intercambio entre iguales, mediante acuerdos políticos que respondan a esta idea de sujeto independiente y racional. El mercado y los Estados modernos surgirían de estas luchas para limitar los viejos poderes aristocráticos y monárquicos. Bajo este supuesto se realiza la legitimación de las instituciones comunes, ya no bajo pretensiones de derecho natural (como sería el caso de las religiones o las monarquías) sino artificiales, justificadas en el ámbito jurídico y/o político. Según la doctrina liberal, los individuos autónomos y libres que compiten entre sí o cooperan, logran alcanzar acuerdos de no intromisión que cristalizan en normas de acción colectiva, tanto más legitimas cuanto más universales, que legitiman a su vez a las instituciones que permiten vivir en comunidad.

Como hemos indicado, la concepción liberal dominante de la libertad combinada con la construcción del sujeto desde el Renacimiento se extrapola para constituir la idea de un Estado nacional como sujeto histórico capaz de dotarse de una legislación que incardine la acción colectiva de los particulares con el bien común. Por tanto, la teoría del sujeto político que subyace a la constitución de los Estados nacionales europeos lo seguiría considerando como un sujeto con la capacidad de ejercer la reflexión que nos permite concebirnos como seres 
racionales que creamos leyes. En ese sentido, el yo colectivo funciona como una transposición del yo individual mediante el que "se habla en nombre del otro", tal y como sucede en los sistemas de representación típicos de delegación de poderes en las democracias occidentales. Aquí entraríamos en la cuestión de la soberanía, el Estado moderno se constituye como único sujeto político legítimo, siendo el único que tiene un poder constituyente, es decir, aquel poder con capacidad para crear un ordenamiento jurídico y para redefinir el ámbito político. El Estado se considera pues como una transposición de los diferentes sujetos aislados que tendrían en teoría el derecho a cuestionar el principio del Estado en caso de que este no se atuviera a "principios racionales", mediante el ejercicio en pleno derecho de esa misma razón que les guió en su constitución inicial. No obstante, ese mismo Estado acaba siendo un ejercicio de despotismo ilustrado ya que su poder es trascendente en el sentido de que no puede ponerse en cuestión, como si derivara automáticamente de una voluntad común que lo ratifica, aunque no se sepa muy bien en qué momento se manifestó y aprobó a perpetuidad dicho pacto político. De esta manera, la suposición de un sujeto libre y consciente se articula en una teoría política del racionalismo jurídico que le presupone falsamente como un agente libre de su propia obediencia.

Como todos nosotros sabemos, en las modernas democracias representativas, la única acción permitida es un voto propio deliberado en la soledad de la conciencia de cada uno, pero ese presupuesto exigiría que se siguiera manteniendo un concepto abstracto y ahistórico de la razón encarnada en un sujeto. Implicaría igualmente su capacidad de cuestionamiento que le es denegada, por una parte; y por otra, que esa separación de conciencias fuera real, como si la construcción de la subjetividad no fuera un proceso social tal y como la consideró Foucault en sus textos ${ }^{37}$. Para este autor, el sujeto no es lo más interno, como se pretendería, sino exactamente lo contrario, lo más externo, producto de todo un sistema de enunciación que le es ajeno. Las dos acepciones de sujeto inciden en el mismo hecho: sujeto como sometido a otro mediante algún sistema de control o bien sujeto como sometido a una identidad propia mediante un determinado gobierno de sí. De hecho, si el sujeto es construido desde el exterior, no podemos hablar de seres libres más que como producto de un discurso que interioriza los parámetros de disciplina y castigo, mientras que nuestro sistema legislativo presupone la libertad y, por tanto, la plena responsabilidad de los sujetos. Frente a esa visión, el sujeto según Foucault se definiría como el punto de anclaje de un discurso de control que subjetiva mediante prácticas de sí, por tanto, ni sujeto libre, ni trascendente y ni siquiera independiente en su propia subjetivación.

37. FOUCAULT, Michel. Vigilar y castigar,. México: Siglo XXI, 1976.; "El sujeto y el poder". En: Más allá del estructuralismo y la hermenéutica. Buenos Aires: Nueva Visión, 2001, pp. 241-259. 
El poder en este sistema se ejercería mediante una economía calculada del daño que acaba sustituyendo al suplicio en las sociedades libres. Foucault define esta implantación de tecnologías de control y disciplina de las multitudes como las artes de gobernar y castigar que actúan fundamentalmente mediante la interiorización del control, interiorización que el catolicismo supo desarrollar mediante dispositivos refinados como los exámenes de conciencia y las confesiones. Este dispositivo de subjetivación denominado poder pastoral es un poder que actúa simultáneamente de forma totalizadora e individualizadora, a través de esta estructura sofisticada que integra a los individuos disciplinándolos mediante una matriz de individualización Bien es sabido que el ejercicio de ese poder se ha extendido desde la institución religiosa hacia una panoplia de ellas que, mediante dichas tácticas de individuación, modelan a la persona según los criterios de normalidad impuestos desde la familia, la educación, la medicina, la psiquiatría, etc., sin necesidad de ejercer violencia expresa alguna o cuando menos, limitada a "situaciones de excepción".

Este proceso de subjetivización que se construye a través de los diferentes disciplinamientos (la escuela, el ejército, el hospital...) se manifestaría físicamente en los múltiples dispositivos espaciales de control (de plena actualidad como veremos en el análisis posterior de la metrópolis) así como en el refinamiento de los mecanismos de control del tiempo propios del fordismo, también actualizados por una extensión del tiempo de trabajo a todos los tiempo de vida que se pondrían a "trabajar" mediante el consumo reiterado, modulando los registros posibles de cualquier "sujeto", tal y como sucede en el postfordismo. Desde diferentes puntos, se ha actualizado el estudio de esa normativización del sujeto cuando se denomina la sociedad en la que vivimos como "sociedad terapéutica" en la que la prevención de la desviación y la deriva de cualquier irregularidad a la responsabilidad personal son elementos clave de su funcionamiento:

Pero para que la movilización funcione, este malestar social tiene que encauzarse, y ese encauzamiento debe comportar, en última instancia, su inutilización política. Para ello toda dimensión colectiva del malestar tiene que ser borrada: el malestar social será reconducido a una cuestión personal. Así cada vida se adapta e integra en la propia movilización. El querer vivir del hombre anónimo funciona entonces dentro de la movilización, y como su principal impulsor. De esta manera, vivir acaba siendo sinónimo de movilización. Es por eso que el poder tiene que ser fundamentalmente un poder terapéutico dirigido a mantener funcionando una sociedad enferma. El poder terapéutico no pasa tanto por el internamiento como por la intervención sobre toda la sociedad. Su intervención no perseguirá curar, sino prevenir, evaluar riesgos, chequear aptitudes, y sobre todo, tratar cada caso como particular. Este es el secreto del modo terapéutico de ejercicio del poder ${ }^{38}$

38. ESPAI EN BLANC. Prólogo a La sociedad terapéutica. Materiales para la subversión de la vida, Barcelona: Ed. Bellaterra, 2008. 
Por otra parte, volviendo al análisis de esas mismas instituciones sociales que surgen como el resultado de la acción política colectiva, podríamos decir que todas ellas revisten un carácter autoconstituyente como resultado de su propio ejercicio del poder que refuerza su legitimidad política. De esta manera, adquieren una especial consistencia sistémica que las hace casi invulnerables mediante la creación de "subsistemas específicos, en ocasiones extraordinariamente codificados y sujetos a un reglamento interno propio, lejos de cualquier intervención a no ser por los cauces previamente establecidos. Las sociedades actuales se presentan mayoritariamente bajo este perfil, razón por la cual cualquier acción política de transformación parece llamada al fracaso" 39. En nuestra sociedad no hay posibilidades de llevar a cabo un cambio político en caso de que sus ciudadanos así lo deseen ya que las estructuras y constricciones básicas del sistema son normas incuestionables y sancionadas por un extenso aparato judicial y de castigo que actúan como blindaje integral del sistema con una gran compacidad. Como ejemplos candentes en la actualidad, podemos citar el intento de Yorgos Papandreu el 2 de noviembre de 2011 de llevar a cabo un referéndum en Grecia en torno a las medidas económicas que se estaban tomando como respuesta al rescate de la UE para mantener el país dentro del sistema de la Unión Europea. Más allá de las razones del propio presidente de Grecia o de las instituciones europeas, lo que resultó evidente fue la inmediata respuesta del resto de mandatarios condenando la medida y acusándolo poco más o menos de traidor a los magnos principios de la democracia.

La evidente antidemocracia y separación del sensus communis más básico, no han supuesto sin embargo merma alguna en la credibilidad política de aquellos que, en un boomerang conceptual digno de mención, han tachado de antidemocrática la intención de convocar un referéndum y que no han tenido mayor problema en intentar cambiar las constituciones nacionales que se suponían intocables en el momento en el que ha sido económicamente necesario, sin consulta previa. Pero si hasta ahora hemos analizado la relación que mantiene la construcción de un sujeto adjetivado como libre y su transposición al Estado como sujeto histórico igualmente basado en la noción de libertad (liberal), y cómo esa relación está basada en premisas erróneas, retomaremos brevemente el marco de creación de los Estados nacionales tal y como los hemos conocido en Europa desde principios de su emergencia en el siglo XVIII para analizar la creación de la esfera pública y su evolución en relación con estos mismos conceptos de sujeto, libertad y Estado.

39. GALCERÁN, Monserrat, op. cit., p.63. 


\subsection{De lo público a lo común: vías de transformación}

Tal y como coinciden en decir Galcerán y Carlos Prieto del Campo ${ }^{40}$, la revolución democrática está asociada desde sus inicios a la revolución socialista en el sentido que supone una democratización del poder público así como una socialización de la economía mediante la introducción del sufragio universal (sólo para hombres), la separación de la Iglesia y el Estado (sólo en algunos países), la libertad de prensa, de reunión y de asociación (sólo bajo circunstancias "normales"), la creación de partidos obreros y sindicatos asociada a la obtención de determinadas prestaciones sociales, así como la mecánica de formas representativas de poder, ya fuere bajo la implantación mediante un proceso de unificación nacional, ya como confederación de poderes locales, desplazando en cualquier caso el antagonismo entre capital y trabajo desde el terreno de la fábrica al del Estado nacional. De esta manera, hacen referencia ambos autores al proceso clásico de subjetivación del movimiento obrero que, partiendo de la noción de clase, se extiende a la de sujeto político, identificando dicho sujeto con la forma de Estado. Así pues, el Estado quedaría constituido como rastro de los enfrentamientos de las luchas de clases que llevaron a la consolidación del derecho y la política, la condensación inicial de una relación de fuerzas entre clases cuya reproducción aseguró el equilibrio mediante una distribución asimétrica del poder político implícita en el reparto desigual de los recursos económicos, culturales y sociales.

Según Prieto, la construcción histórica de lo público se produciría pues a consecuencia de la oposición a la unilateralidad de las formas del capitalismo histórico, oposición que permitió negociar las condiciones del pacto social pero que no logró definir una alternativa sistémica. Aún así, a finales del siglo XIX, las clases sociales empezaban a contar con instrumentos teóricos inéditos y fueron capaces de generar un análisis socioeconómico y de integrarlo posteriormente en un proyecto revolucionario racional, siendo esta teorización del capitalismo fundamental en la práctica política antisistémica. De esta manera, la introducción de lo público en la estructura social supuso un cuestionamiento de los procesos mismos de legitimación política y de organización social, e introdujo la crítica a los criterios de maximización de los niveles de explotación y beneficio así como de socialización de las pérdidas a favor únicamente de determinados grupos privilegiados. En el inacabable proceso de conflicto y negociación entre los diferentes intereses, el Estado y lo público constituyen los ejes del enfrentamiento político en torno a la socialización de la producción y el enriquecimiento general de la fuerza de trabajo colectiva (mediante políticas de socialización de la sanidad, la educación, el

40. PRIETO del CAMPO, Carlos. “Lo público y lo común: Estado, derecho, Administración pública/poder constituyente,capitalismo, movimientos antisistémicos". En: Revista Trasversales, 2009, número 14.. 
transporte, la comunicación, etc.) - todo ello acaba conformando lo que definimos como esfera pública dentro del Estado del bienestar.

El Estado del bienestar implementado a mediados del siglo XX sería la forma de organización política de base nacional impuesta en las sociedades capitalistas altamente industrializadas y gestionadas con métodos democráticoparlamentarios, producto de la mezcla entre el discurso neoliberal y el reconocimiento de derechos sociales. Si bien la mediación entre el Estado y la sociedad produce la existencia de un sistema de seguridad social que disminuye el riesgo social y garantiza un mínimo nivel de vida, así como la regulación de la producción económica en busca de una igualdad de oportunidades, no llega a cuestionar las formas políticas de democracia parlamentaria. Este capitalismo organizado introduce una regulación de base de los sistemas de protección social mediante el establecimiento de prestaciones y garantías sociales (seguro de desempleo, pensiones, sanidad y educación públicas, etc.) así como mecanismos de regulación social y laboral en lo que respecta a los salarios y horarios de trabajo, derechos laborales, retribuciones extraordinarias etc. No obstante, Prieto del Campo cuestiona este Estado del bienestar obteniendo un diagnóstico de las mismas características que encontraba Galcerán en la definición de sujeto libre en las democracias occidentales. Para él, la dinámica del Estado del bienestar concede lo mínimo al antagonismo proletario puesto que lo nacionaliza, lo vincula a la raza blanca, lo patriarcaliza, y lo asocia a la lógica del trabajo asalariado.

En la segunda mitad del siglo XX, se produce pues la consolidación a nivel estatal de lo que se ha llamado inclusión diferencial ${ }^{41}$, a la que hemos aludido ya en el capítulo anterior aplicándola a los diferentes centros de enseñanza universitaria y que aquí se presenta en su condición central: asociada a los derechos sociales. Posteriormente, analizaremos en detalle el papel que la inclusión diferencial puede tener en la metrópolis postfordista, marcando toda una serie de fronteras internas que determinan las diferentes maneras de poder vivir en la metrópolis extendida en la que nos encontramos. Al respecto de la inclusión diferencial aplicada al trabajo y a la ciudadanía, dirá Prieto: "Sólo el ciudadano nacional - con estratificaciones de género y territoriales diferenciadas - será sujeto de derechos y perceptor del salario indirecto que se desprende de la actividad pública" ${ }^{42}$. Galcerán hará también referencia a dicha inclusión como un dispositivo interno de control social más que de compensación, poniendo como ejemplo numerosos casos en los que se dan

41. Forma de gestión de la población que ha tomado la diferencia como un elemento de gobierno basado en formas de inclusión diferencial a partir de etiquetajes previos, acuñado por MALO, Marta y ÁVILA, Débora. "El gobierno de la diferencia: gestión y gradaciones de derechos sociales". En: Repensando la metrópolis. Prácticas experimentales en torno a la construcción de nuevos derechos urbanos. Málaga: Centro de Estudios Andaluces, 2010.

42. PRIETO del CAMPO, Carlos, op. cit., p. 18. 
situaciones de inclusión/exclusión contradictorias atendiendo a los diferentes criterios posibles. Las progresivas medidas de inclusión/exclusión con su cuota de invisibilización de determinados sectores funcionarían por tanto como otro dispositivo de disciplinamiento interno similar a la extensión de los demás dispositivos asociados a la constitución del Estado.

Pero para seguir con este análisis de las formas de gobierno formal en las que nos encontramos, abordaremos la crisis de ese Estado de bienestar percibido inicialmente como progreso social aunque en su misma concepción contuviera un desequilibrio que lo fragilizara hasta llegar al punto en el que nos encontramos. Galcerán plantea que ya desde su constitución, se produjo una desproporción entre los recursos del sistema debido a las necesidades de pacto social que obligaron por una parte, a atender a las exigencias de toda la serie de garantías y prestaciones sociales que enumeramos anteriormente, pero que simultáneamente, al no cuestionar el sistema capitalista y plantearse desde la ausencia de mecanismos de control económico, supusieron una descapitalización del Estado. Este modelo ha sido cuestionado tanto desde la izquierda más radical que criticaba la necesidad de someterse al círculo fordista del empleo asalariado cuyos ingresos debían dedicarse al consumo para poder mantener la maquinaria en marcha, como desde la derecha que aludía a la insostenibilidad del modelo por considerar excesivas las garantías y prestaciones sociales pactadas.

De esta manera, tal y como se había anunciado, se produjo la previsible crisis del modelo: el Estado se descapitalizó, entre otras cosas, porque se desarrollaron toda una serie de herramientas financieras que posibilitaron la huida de los sectores pudientes de las cargas impositivas, mientras que los trabajadores asalariados tributaban según la ley empobreciéndose; las Administraciones públicas se fueron endeudando progresivamente con las instituciones financieras y estas últimas acabaron determinando con sus préstamos las opciones posibles dentro de los presupuestos generales. Todo ello sin nombrar los atributos específicos que revistió en España: la corrupción presente en todos los ámbitos de la sociedad, la financiarización generalizada por la burbuja inmobiliaria producida por la concesión de créditos fáciles y su posterior estallido, y otros tantos factores externos que no han hecho más que agudizar al máximo un desequilibrio de partida. Prieto del Campo ${ }^{43}$ resume esta deriva diciendo:

En el ámbito estrictamente tributario, este ciclo ha tenido lugar en España y en Europa en un entorno caracterizado, por un lado, por una tasa tenue de innovación fiscal ante las nuevas formas de poder económico y concentración de la riqueza, por una presión fiscal por debajo de la de los países de nuestro entorno, incrementada en España desde

43. PRIETO del CAMPO, Carlos. Apuntes preliminares sobre la economía política de lo común en la era del poder constituyente de la intelectualidad de masas antagonista. [En línea]. Disponible en: <www.universidadnomada.net> [Consulta: 05 de diciembre de 2010]. 
2008 por la abolición del Impuesto sobre el Patrimonio y el debilitamiento estructural del Impuesto sobre Sucesiones y por la persistencia sistémica del fraude, la evasión y la elusión fiscales; $y$, por otro, por la persistencia de políticas continuistas de gasto público marcadas por un crecimiento lento de las políticas de bienestar y cohesión social, por la dificultad de converger con los niveles de gasto social predominante en los países de nuestro entorno.

En resumen, nos encontramos en un momento en que la victoria de las posiciones privatizadoras neoliberales está imponiendo sus criterios económicos para terminar de desmantelar lo ya había sido progresivamente privatizado: medidas severas de contención del gasto público, mayor precarización laboral y mercantilización acentuada de los servicios públicos, entre otras medidas de pauperización generalizada. Si esto sucede en el ámbito público, podemos imaginarnos cuáles están siendo las medidas desde el ámbito empresarial: deslocalización de la producción, flexibilización absoluta de las condiciones de trabajo, discontinuidad laboral, etc.

Contrastando con esta visión, para Prieto del Campo resulta fundamental incidir en estos momentos en que lo público no es caridad ni solidaridad, sino que implica el reconocimiento del valor de cooperación social del trabajo vivo del que el capital se apropia gratuitamente y de las cargas y los costes que deriva inequitativamente sobre los sujetos productivos. En ese caso, el Estado puede funcionar como campo de experimentación para deconstruir relaciones de dominación, lo público convierte a lo jurídico en un elemento clave de esta lucha en busca del equilibrio social. La contrapartida es que seguimos creyendo en una democracia nominal que, estancada en sus formas, no admite posibles negociaciones que impliquen una modificación constituyente. ¿Qué hacer cuando los mecanismos de acción colectiva se ven tan limitados por los procesos de legitimación establecidos que no se permite ninguna desviación? Cuando la democracia liberal representativa se ha transformado en una democracia de partidos gubernamentales de masas y el parlamento, que sirvió inicialmente de control del poder, se convierte en un espacio de escenificación espectacular de la política, el panorama se estructura de manera diversa a la enunciada idealmente:

1. La libertad deja de ser garantía de cambio para serlo de sujeción a las normas y de interiorización de la subordinación.

2. El mercado funciona como esfera de circulación de la acumulación capitalista y no como sistema de intercambio entre pares.

3. El Estado se estructura como una democracia de élites.

4. El sujeto, según se entiende en la constitución de la democracia, no existe como tal, entre otras cosas porque no puede ejercer su derecho a razonar.

Esta combinación de factores lleva a la compactación de las élites dominantes compuestas por grandes corporaciones, burocracias ejecutivas y 
burocracias de los partidos, lo que Inmanuel Wallerstein ${ }^{44}$ llama agentes de la acumulación, los nuevos gestores del capitalismo mundial. Famosa es la discusión entre Wallerstein y Étienne Balibar sobre la constitución o no de una nueva clase dominante mundial en base a su capacidad decisoria organizada que equivaldría a la que tuvo en su momento la vieja burguesía decimonónica. Independientemente de que Balibar se retractara posteriormente de su posicionamiento en contra de la consideración de dichos agentes como nueva clase dominante mundial, no podemos dejar de sospechar quien está decidiendo en estos momentos de crisis y no parece que sean únicamente los partidos. Parece bastante evidente que la división de poderes es ilusoria pero además, ni siquiera se visibiliza de forma honesta que el poder económico en forma de entidades financieras y grandes compañías transnacionales es uno de los elementos clave con capacidad de decisión en la actualidad. Balibar escribiría posteriormente lo siguiente:

Cuando más se amplía e intensifica la construcción europea, en mayor medida localiza el poder real, no en el "centro" ni en la "periferia", sino en el punto mismo de articulación entre las instancias comunitarias y las instituciones nacionales. Es en este punto (ampliamente invisible e inaccesible para los ciudadanos) donde se instala la clase política de la Unión, cuya existencia sigue dependiendo estrechamente de su "enraizamiento" nacional, aunque al mismo tiempo se presenta como una clase de intermediarios indispensables entre los dos niveles de "competencia" política. Evidentemente, esta clase mantiene una relación mucho más estrecha con el "lobbying" de los poderes económicos que con la representación popular. 45

Sin embargo, la única forma de acción política reconocida es el partido a pesar de que se da un bajísimo nivel de participación ciudadana, un alto nivel de desmotivación política y unos índices elevados de abstención, todos ellos síntomas de la crisis profunda de legitimidad de la política. En un momento en que se tendría que hacer frente a retos de primer orden que implicaran la aplicación de otra lógica de prioridades, la inercia de funcionamiento de la política se muestra especialmente fallida en su prolongación del modelo de márketing político. Que la política se ha estetizado, convertida en producto de marketing en el que se vende una imagen y sus batallas se libran en el campo de la opinión pública, es algo que resume con acierto Gilles Achache ${ }^{46}$ cuando habla del tercer modelo comunicativo de la política: el de la investigación de mercados, que sucederá en el tiempo a un primer modelo dialógico basado en la argumentación entre iguales, y a un segundo propagandístico. Este modelo importa del campo comercial la representación de lo social bajo la apariencia de la diversidad que no se basa en antagonismos sino en

\footnotetext{
44. WALLERSTEIN, Inmanuel, BALIBAR, Etienne. Raza, nación y clase. Madrid: lepala, 1991. 45. BALIBAR, Etienne. Europe, Constitution, Frontière. París: Les Éditions du passant, 2004. 46. ACHACHE, Gilles. "El marketing político". En: El nuevo espacio público. Buenos Aires: Gedisa, 1992. .
} 
la acumulación de rasgos que le permitan dirigirse al mayor número de nichos del mercado. Por tanto, no busca ni una implicación especial por parte de su votante ni valor sustancial cualquiera. Más bien, preferiría prescindir de ambos y jugar de forma aséptica el juego de la participación democrática con la misma frialdad con la que el cliente (que de eso se trata) votaría a un concursante de la televisión o a un vídeo de youtube.

En cuanto a la relación con los medios de comunicación, son los que le otorgan la legitimidad activa que no obtiene de otras maneras, teniendo en ellos un papel privilegiado la publicidad que, como hace con cualquier otro producto, se adapta para poder llegar al corazón de diferentes públicos mediante la emotividad. Y como sabemos, las estrategias publicitarias poco tienen que ver con la argumentación racional o con la posibilidad de verificar sus promesas ya que inconscientemente, el receptor las interpreta en ese registro y asume su funcionalidad persuasiva que se impone sin duda a la informativa. Como dice Achache, el tercer modelo sólo se puede situar en un tipo de sociedad fragmentada que tenga asumida su posición de consumidor costumizado:

De este modo plantearemos la siguiente hipótesis: la comercialización política sólo podía desarrollarse y estar en posición dominante en sociedades que se caracterizan por un vínculo discontinuo. Allí donde el espacio público se ha fragmentado en diversos espacios particulares, en sistemas de valor e intereses varios, las categorías de la comercialización pueden envolver a la comunicación política: en esas sociedades que ya no proporcionan ningún término, ningún punto fijo arquimediano a partir del cual fuera posible pensar su unidad: las nuestras. ${ }^{47}$

No es de extrañar que, como una empresa más, la casta política se alíe con las demás empresas gestoras de las riquezas y privilegios, manteniendo la ilusión democrática mediante la simulación de alternancias bipartidistas y un adecuado bombardeo mediático en todos los frentes. Recordemos que la política sigue definiéndose como el ámbito de negociación posible entre clases en el centro mismo de los mecanismos económicos y administrativos, para nada la aplicación neutra de una lógica económica y tecnocrática, como posteriormente se ha intentado naturalizar. Resulta fundamental cuestionar hoy en día más que nunca la veracidad de estas características que se presuponen de manera similar en el capitalismo global actual.

El Estado como tal sigue siendo la forma de gobierno constituyente naturalizado en el que las soluciones a la crisis deben emanar de los tecnócratas mismos que contribuyeron a crearla, como está siendo el caso de los diferentes gobiernos recientemente constituidos. Bastaría nombrar el caso de Grecia cuyo primer ministro Papademos fue vicepresidente del Banco Central Europeo (BCE)

47 ACHACHE, Gilles, op. cit., p. 87. 
hasta 2010, el caso de Italia con Mario Monti, primer ministro y ministro de economía italiano, ex comisario europeo de Mercado Interior y de Competencia, por no hablar de nuestro propio país en el que el actual ministro de economía fue presidente de Lehman Brothers en España y Portugal, escapando a su quiebra. Y con esa apelación fiduciaria a la condición científica, racional y neutra de sus soluciones pretenden tranquilizarnos mientras asistimos al proceso inverso, es decir, al desmantelamiento de la esfera pública apelando a razones de fuerza mayor.

Tenemos pues ante nosotros un reto de innovación política que implica la invención de dispositivos políticos para romper con la hegemonización de los partidos y de los agentes de la acumulación de manera que se incluya al conjunto de trabajadores visibles e invisibles (tanto del ámbito de la producción como de la reproducción). Como dice Galcerán, la incapacidad para crear nuevas formas de acción política ante las condiciones de absoluta impunidad de los poderes públicos nos hace rehenes y cómplices de decisiones catastróficas que se están tomando de forma global. Para empezar, deberíamos admitir que todos los procesos se han globalizado y que, si se opera únicamente a escala local, resulta imposible responder a una realidad de precariado globalizado al desvincularlo de los procesos mundiales de explotación global.

Esta desconexión con el verdadero nivel en el que se están tomando las decisiones, una política articulada en torno al Estado nación, convierte el empeño político en un agente menor ya que los procesos de reajuste político operan a una escala que jamás fue nacional. No sólo el sistema de estados nacionales con legislación universalista ha quedado obsoleto, sino que el poder político se ha supeditado al dictado de agencias internacionales $y$, alegando situaciones de "excepción", ha vulnerado los principios mismos del derecho internacional en numerosas situaciones. Pongamos como ejemplo el caso de la ejecución de Osama Bin Landen cuya muerte, sin proceso de extradición ni juicio alguno, pasó por la esfera mediática acallando cualquier voz que pudiera insinuar la vulneración de las bases de justicia a nivel internacional, de hecho ni siquiera hubo imagen alguna; por no hablar de las modificaciones por parte de Francia e Italia del Tratado de Schengen, seguidas de Dinamarca, en donde hipócritamente se silenciaba la denegación de auxilio a inmigrantes que podrían acogerse al derecho de asilo por las situaciones, esas sí, de excepción que estaban viviendo en sus países.

La crisis profunda de la política y de la administración pública, incapaces de amortiguar sensiblemente la desigualdad generalizada que no hace más que incrementarse, requiere un posicionamiento mucho más arriesgado y de mayor alcance: la constitución diferencial de lo común como forma colectiva de bienestar y justicia social, forma que implica una crítica a lo público en tanto: 
a) Conceptualización errónea de la nación, la soberanía nacional y la ciudadanía étnica;

b) De las políticas públicas y su interrelación con estrategias de capital privado;

c) De la creación de una casta política que se blinda en sus privilegios bajo la capa de la función pública.

Lo común no niega todos los procesos que llevaron a la creación de lo público y menos aún sosteniendo las críticas realizadas en su contra desde finales de la década de los 70 y que han llevado bajo diferentes coartadas y gobiernos tanto de izquierdas como de derechas a los sucesivos procesos de privatización, sino que los amplía conceptualmente a la necesidad de reproducción global de justicia social. No estamos desterrando lo público sino asumiendo la necesidad de una mejora de la idea de lo público. Como resumirá Prieto del Campo ${ }^{48}$ :

La crítica de lo público desde lo común implica precisamente criticar, deconstruir, desmontar y revertir el carácter limitado, etnonacionalista, euroanglocéntrico y colonial de las políticas que organizaron la esfera democrática durante el último siglo: lo común es lo público despojado de las dinámicas y las limitaciones sistémicas que lo hacían susceptible de reproducir el carácter no igualitario de la sociedad capitalista y dotado de un principio de soberanía rigurosamente posnacional.

Hoy en día, es tal el impulso de destrucción de todas las bases que sustentan el estado social como mecanismo igualitario que valdría la pena reclamar aún más de lo que se tenía para evidenciar en toda su amplitud la gran desigualdad que estamos sembrando. Empieza a convertirse en una necesidad urgente el cuestionamiento legitimado de todas estas irregularidades y la exploración de nuevas prácticas políticas activadas desde los movimientos sociales, pero resulta también fundamental que empecemos a hacerlo desde otra construcción conceptual del sujeto y de su teórica libertad que parta de ese territorio a mitad construido a mitad por construir como es lo común. Por el momento, retomaremos las nociones de libertad de nuevo de la mano de Galcerán para intentar encontrar un punto de partida diferente.

\subsection{La libertad a recuperar}

Como hemos visto, la concepción liberal dominante de la libertad nos convierte en seres independientes y competidores los unos de los otros, bloqueando nuestra acción común ya que lo común se interpreta únicamente en clave de respeto a la autoridad, guiado por el miedo al otro. Monserrat Galcerán realiza un rastreo del concepto de libertad que escapa a esta noción liberal recurriendo a Marx, Spinoza o las feministas contemporáneas como son Rosi Braidotti y Vandana Shiva 48. PRIETO del CAMPO, Carlos, op. cit., p. 14. 
para redefinir el término "libertad" que, a su vez, nos remite igualmente a la historia de los movimientos sociales para redefinir la acción colectiva. Si nos remitimos a la ética de Spinoza ${ }^{49}$, la noción de individuo que plantea este autor es radicalmente diferente de la propuesta por otros filósofos de su época ya que entiende que somos tan sólo cuerpos con afecciones y que poseemos la capacidad de aliarnos con otros formando cuerpos más extensos e inteligentes. Nuestras pasiones y afectos nos llevarían a incrementar o reducir la potencia del ser que sería el fin último, un movimiento permanente hacia la conservación o la mejora de la existencia, lo que Spinoza llama conatus y que otros autores han puesto en relación con la "voluntad de vivir" nietzschiana.

Ante todo, la lectura que hace Spinoza de la libertad hace hincapié en el concepto de autonomía que viene a remplazar al de independencia, ya que la autonomía no es sólo la capacidad de defenderse a uno mismo, como sería más bien el caso en la acepción liberal de libertad, sino también la capacidad de unirse a otros para aumentar la potencia común constituyendo un cuerpo conjunto. De esta manera, podríamos hacer una relectura de la libertad como la pasión alegre que nos lleva a mejorar la existencia mediante la construcción de un mundo común y en común y convertirla en una de las salidas a la lógica vigente de la dominación que se perpetúa naturalizándose: superar la reducción a la independencia y competencia de individuos para aludir a la capacidad creativa de los seres humanos de construir un mundo común y compartido. Se trataría por tanto de fomentar y generar formas de sociabilidad que van más allá del do ut des a pesar de estar inmersos en una mercantilización y precarización inauditas: considerarnos cuerpos que se conectan entre sí en un conjunto de lazos sociales, culturales y económicos ya que nuestras capacidades nunca son individuales sino resultado de la vida que se construye colectivamente, de la cultura compartida y del lenguaje heredado. Puesto que todos los seres humanos somos más dependientes que independientes, más valdría no partir de una supuesta libertad que pretende que todas las dependencias son voluntarias, sino del análisis de las múltiples dependencias para intentar trazar estrategias que generen vínculos equitativos de interacción. Sería una muestra de gran ingenuidad creernos libres en un mundo de dominación, por lo que nos sirven los autores que intentan desenmascarar la falacia de que en las llamadas sociedades libres no hay dominación y las dependencias entre nosotros son voluntariamente adquiridas. Resultaría en todo caso más sensato anteponer al individuo el conjunto de vínculos en los que nacemos y nos socializamos, reconociendo que lo primero no es el individuo sino el común. Citando a Shiva, diremos que:

La concepción de la libertad como independencia tiene sus orígenes en el patriarcado capitalista y atribuye una autosuficiencia ficticia a aquellos hombres poderosos que son dueños de capital y propiedades - aún siendo de hecho dependientes de las mujeres, de

49. SPINOZA, Baruch, Ética demostrada según el orden geométrico. Madrid: Ed. Trotta, 2009. 
los agricultores, de los trabajadores y de otras culturas y especies. Más aún:estos hombres pueden llegar a vivir el espejismo de que aquellos y aquellas a quienes explotan y sobre quienes se sustentan, dependen de ellos en realidad ${ }^{50}$

Por ello, volviendo al argumento de las relaciones autónomas frente a la independencia de individuos, ¿qué posibilidades de acción colectiva existen desde ese punto de vista? Podemos recuperar la noción de economía viva utilizada por el ecofeminismo, que, a diferencia de los análisis clásicos, incluye en su concepción las infinitas tareas de producción y reproducción considerando que, si bien no entran dentro del análisis de las economías mercantiles, son justamente todas las tareas que permiten la continuidad de la vida en una cadena continua de interdependencia y afecto. Podríamos implementar sistemas diferenciales de medición de la riqueza, como hacen en Bután ${ }^{51}$ en donde se mide anualmente el nivel de felicidad de sus ciudadanos, o poner en marcha las propuestas que desde diferentes teóricos como Christian Felber ${ }^{52}$ o Florence Jany-Catrice ${ }^{53}$ apelan a una Economía del Bien Común, admitiendo ya desde la base que podemos ser autónomos pero nunca independientes.

Podemos plantear modelos alternativos de gobierno de todo tipo que intenten paralizar el soterramiento de lo colectivo, pero cualquiera de estas opciones pasa por el surgimiento de una fuerza alternativa que permita quebrar la consistencia sistémica en un entorno político que ha erigido todo tipo de defensas incluso contra sí mismo, reconociendo en su urgencia la necesidad de constituirnos en interlocutoras legitimadas de los poderes públicos. El problema sigue siendo el mismo de siempre, conseguir la fuerza presentativa suficiente como para que el sistema representativo se vea obligado a tenerla en cuenta y por tanto, a legitimarla otorgándole la fuerza de representación. Si el poder, según Foucault, es una red que atraviesa todo lo social, no hay un afuera donde situar movimientos alternativos, pero quizás la introducción de prácticas disruptivas en este entramado codificado de pactos subyacentes pueda generar fisuras o intersticios que permitan renegociar determinados aspectos dentro de la distribución de la representación. Si la política

50. SHIVA, Vandana. Manifiesto para una democracia de la Tierra. Barcelona: Ed. Paidós, 2005, p. 111.

51. En Bután, se realiza la medición del FIB (Felicidad Interna Bruta) Es una alternativa a la medición de Producto Interno Bruto (PIB) de la mayoría de los países del mundo. La medición se basa en bienestar psicológico, uso del tiempo, salud, educación, estándar de vida, cultura, ambiente, vitalidad de la comunidad y gobiernos locales. El gobierno realiza cada dos años una encuesta como método de medición de estos aspectos y de otras 72 variables. 52. FELBER, Christian. L'EConomie citoyenne - ou quand l'intérêt général s'invite dans le bilan des entreprises París: Actes Sud, 2011.

53. JANY-CATRICE, Florence, GADREY, Jean. Les nouveaux indicateurs de richesse. París: Ed.Ladecouverte, 2007. 
es la demarcación de un campo posible de acción para una serie de agentes ampliando o reduciendo sus posibilidades, su potencia del ser, si nos queremos poner spinozianas, estas cuñas, fisuras o incoherencias internas pueden hacer posible lo imposible, si nos remitimos de nuevo a la definición de acontecimiento realizada por Alain Badiou:

En el orden de la política, es el Estado el que declara lo que entra dentro de lo posibley lo que no (y esto lo hace también mediante mecanismos como el objeto identitario). Esta función le es arrebatada al Estado por el acontecimiento popular masivo; es la gente reunida la que prescribe una nueva posibilidad, comprometiéndose con la idea de que son ellos los que tienen la potestad de definir un posible. Esto es lo que crea las condiciones de una extensión. $\mathrm{O}$, dicho de otra forma, esto es lo que ocurre cuando todo el mundo comprende que ya no seestá en el mismo régimen de delimitación de lo quees posible y de lo quees imposible. ${ }^{54}$

Se ha aplicado esta definición de acontecimiento, o de "momento político", si queremos utilizar el término empleado por Rancière, para las ocupaciones de plazas y la generación de asambleas con intención instituyente o cuando menos, pensante. Como ya hemos comentado, el movimiento $15-\mathrm{M}$ y posteriormente la "primavera valenciana", han puesto claramente de manifiesto la distancia entre un poder real del pueblo y unas instituciones llamadas democráticas pero, de hecho, completamente entregadas a las imposiciones financieras internacionales, la enorme distancia entre el régimen de la presentación y el de la representación. Ya se ha producido pues la condición primera para que se dé ese momento político, el escenario de manifestación del pueblo frente a los aparatos de dominación. Quedaría ver cómo cumplir con la segunda condición necesaria para el cambio: la capacidad de transformar un movimiento de protesta en una fuerza autónoma no sólo independiente del sistema estatal y representativo, sino asimismo capaz de arrancar a ese sistema la dirección de la vida pública modificando la relación de fuerzas.

Esta sería la tarea esencial de los nuevos sujetos políticos y de las nuevas instituciones políticas, afrontar el reto de hacer posible lo imposible, pensar nuevas maneras de gobernarse que, si bien exigen un nivel global, podrín empezar a operar en un espacio político mínimo de referencia. Todas estas reflexiones sobre la relación entre política y vida ponen de manifiesto la necesidad de que los movimientos sociales vuelvan a pensar la cuestión de las instituciones mediante sus propias prácticas, sobre la necesidad de instituirse y modificar con ello la trayectoria de otras instituciones, favoreciendo la implantación de nuevas condiciones de producción de lo público o bien de lo común, si decidimos renunciar al uso de la palabra "público" por los motivos anteriormente alegados, de manera que se abran los siguientes posibles:

54. BADIOU, Alain. "Que signifie changer le monde?: séminaire 2010-2011". Entretemps. Disponible en: http://www.entretemps.asso.fr/Badiou/10-11.htm\#_ftnref21. [Consulta: 10 de enero de 2012]. 
a) Extensión de las dinámicas de resistencia colectiva, transformándolas en dinámicas de institución colectiva;

b) Enriquecimiento objetivo de las posibilidades de acción política más allá del sistema de partidos y sindicatos;

c) Posibilidad de constitucionalizar y democratizar el antagonismo y juridificar las luchas mediante dispositivos de producción administrativa, gasto público y sistema tributario.

En resumen, necesitamos ante todo, desarrollar estrategias válidas para convertirnos en interlocutoras de los poderes públicos con la capacidad de generar debates para paliar la crisis de funcionamiento de la política, es decir, la pérdida de capacidad del poder político de interactuar con la sociedad, incluidos los movimientos sociales. Por otra parte, la experimentación de formas inéditas de soberanía y de invención de proyectos políticos que contrarresten las dinámicas sistémicas de reproducción del capital y las formas de gobernanza de las élites que se benefician de tales dinámicas, tendría que afrontar la necesidad urgente de realizar un proceso de democratización radical de las instituciones europeas, aunque tampoco podemos limitarnos a hacer un análisis excesivamente optimista de las posibilidades de salirnos de unas dinámicas viciadas tan complejas e instauradas hasta lo más profundo de nuestra propia subjetivación. 



\section{Algunas preguntas y algunas respuestas, quizas}

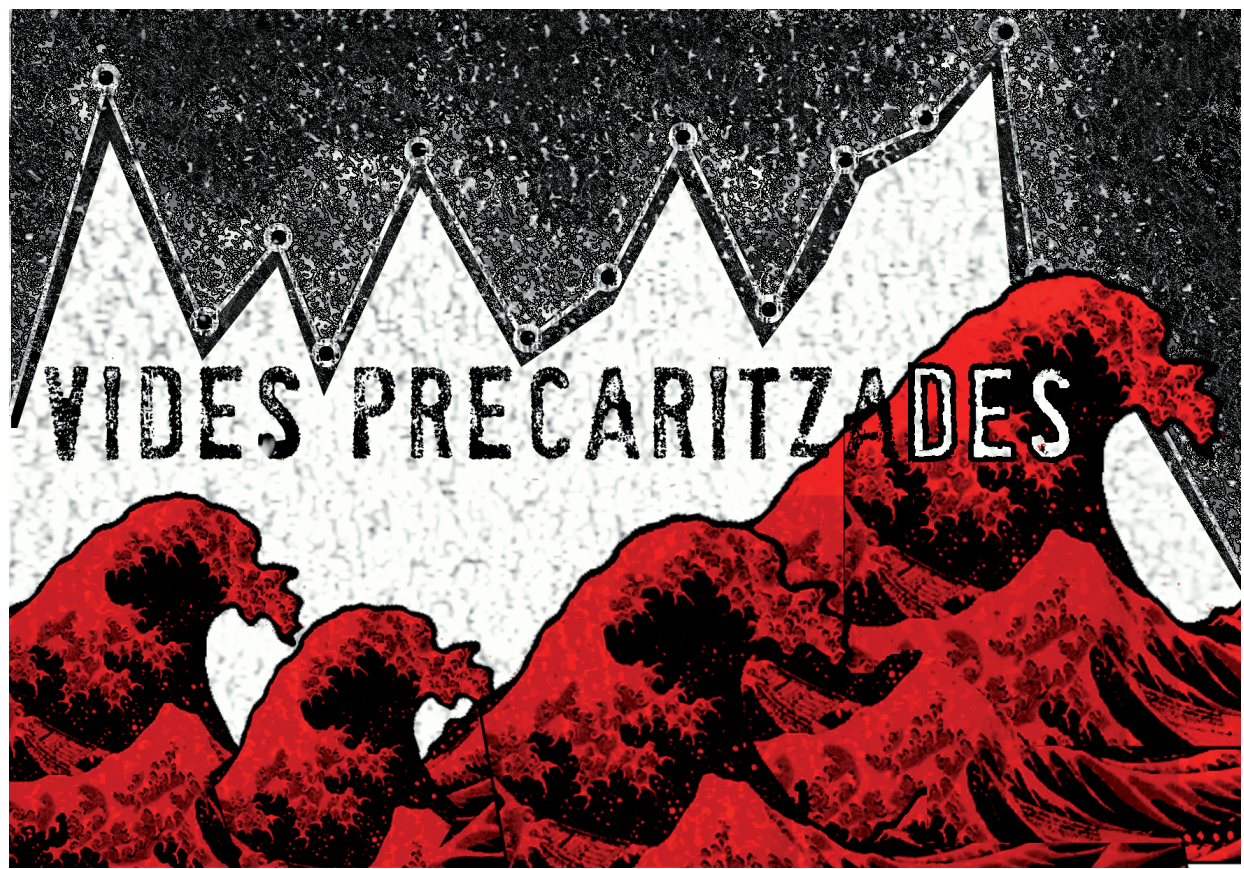

Fig. 4 
Los ciudadanos, cuando se rebelan contra el Estado, representan a la multitud contra el Pueblo.

Thomas Hobbes ${ }^{55}$

Un hombre que dice «no» es un hombre que rechaza pero que no renuncia. Albert Camus ${ }^{56}$

\subsection{El afecto y la ley, reconstitución de la ciudadanía}

Aristóteles, al final de su Política, tras haber analizado los diferentes sistemas de gobierno posibles y haber considerado que el mejor de ellos es la democracia, añade que si, bajo cualquiera de estos gobiernos posibles, un ciudadano va caminando y cae al suelo en la plaza pública, ante los ojos de los otros, sin ser asistido por ninguno de sus conciudadanos, esto es un signo claro de que, independientemente de la forma política que haya adoptado, dicho sistema es incorrecto. Con este ejemplo, habla el autor de la inadecuación de los sistemas políticos cuando no son capaces de crear una empatía entre ciudadanos, una empatía para con el conciudadano que cae. Si esa ley encarnada en un sistema político no tiene relación con una moral, se instala en el vacío y será tergiversada para beneficio propio y se transgredirá públicamente sin vergüenza para escarnio público, como es el caso hoy en día ante juicios en el que las pruebas del delito resultan clamorosas, aún inhabilitadas por torticeras interpretaciones de leyes y prescripciones.

Aunque en Aristóteles aún queden rastros de platonismo, ya que sigue realizando un tipo de pensamiento mágico en donde las formas de pensamiento se están empezando a abrir a un cierto racionalismo, impone la idea encarnada, dejando claro que no hay un ideal de política si ese ideal, en su realización-actualización, no responde a premisas morales básicas como puede ser la filia, o su reverso la empatía, el ser capaz de sufrir por el otro, de cambiarse el habitus con el otro y eso es una valoración que todos seguimos entendiendo con claridad y que pocos contradirían.

Por lo tanto, en lo que respecta a la política, podríamos decir que mantiene la misma relación respecto a la ética que la moral respecto a la ley. Si nos remontamos de nuevo al planteamiento de gobierno propuesto por Spinoza ${ }^{57}$,

55. HOBBES, Thomas. Leviatán o la materia, forma y poder de un estado eclesiástico y civil. Madrid: Alianza Editorial, 2006. Citado en VIRNO, Paolo, Multitud y principio de individuación, disponible en http://www.sindominio.net/arkitzean/multitudes/virno_multitud.html> [Consulta: el 14 de julio de 2012] .

56. CAMUS, Albert. L'homme révolté. París: Gallimard, 1951, p. 38.

57. SPINOZA, Baruch. Tratado político. Madrid: Ed.Alianza, 1986, vol. 4. 
que podríamos decir que comparte en cierta manera con Rousseau y su contrato social, la ley es un formidable instrumento pedagógico. Si la ley es simplemente una norma abstracta que hay que cumplir, no podemos pensar en el funcionamiento de un estado de derecho. Es una norma que se mantiene mientras haya una fuerza detrás que imponga su cumplimiento y en el momento en que esta fuerza se debilite, los ciudadanos la transgredirán porque no la habrán hecho suya, no la habrán incorporado a su moral. Es decir, una ley es correcta cuando sigue una lógica pedagógica, de acompañamiento. Cuando la ley es verdaderamente eficaz es cuando construye una moral, cuando construye al ciudadano. En el caso de Aristóteles, la filia aristotélica considera la moral como la construcción de un ser que atiende asimismo a su faceta afectiva, guiado por afectos. Desde ese punto de vista, la filia aristotélica cobra una sentido para nosotros porque Aristóteles, el pensador de las categorías de análisis de lo real, de lo concreto, también es el que demuestra que la mejor ley del mundo no lo es, no es perfecta, si no crea o no sabe crear algo que entra dentro del orden de lo cualitativo y no del orden normativo.

Sin embargo, tal y como hasta ahora hemos construido nuestra subjetividad basada en la noción de individuo, la separación entre Estado e individuo y por lo tanto, la vinculación inexistente con la aprobación de la ley no permiten que se perciba esa ley como proceso participativo, como indicación, sino como imposición. El establecimiento de la ley es un proceso, no es un estado, habría que salir de la noción del estado de derecho, y entrar en una lógica de la jurisdicción, de la palabra de derecho, recuperando un espíritu de la ley que tiene que unirse con la moral porque si no, nos encontramos donde estamos, un momento en el que la transgresión de la ley no afecta a la valoración moral sino únicamente al ámbito penal. En teoría, en nuestro gobierno hay una cierta inmanencia política, como hay una inmanencia metafísica, pero la manera de entender esto no es considerar que es algo inmediato, una especie de don divino, sino entender que la relación fundamental con la ley se debería producir a un nivel pedagógico, estableciendo una tautología que genere una equivalencia entre ciudadanía y ley; es la ley la que crea, a través de su condición pedagógica, un determinado ciudadano pero también se puede afirmar el proceso inverso, es el ciudadano el que interviene en la creación de la ley. Por ello, la ley no puede mantenerse en un estado de trascendencia que separa al ciudadano de las normas, tiene que poder producirse algún tipo de porosidad, lo que implica, como mínimo, que habría que mantenerse a la escucha y seguir permitiendo la evolución de la ley no por imposiciones políticas de uno u otro cariz, sino respondiendo a debates que emanen de la sociedad y a los que no hay que acallar, distraer y olvidar, sino fomentar y no tener miedo de poner sobre la mesa. Una sociedad que tiene miedo de generar debate, de abrir el campo de la discusión a su ciudadanía, es una sociedad esclerosada.

No obstante, cuando la vara de la justicia es esencialmente diversa dependiendo de sobre quién se aplique, se produce un desapego aún mayor entre 
ley y moral. Cuando se reproducen y airean públicamente situaciones de injusticia cotidiana insultantes para cualquiera que mantenga un mínimo de buen sentido, ¿qué posibilidad hay de creer en una ley justa asumida como moral? Esos son los procesos que acaban corrompiendo el entramado legal y sembrando el desconcierto y la desesperanza entre la ciudadanía. Esta es nuestra situación actual, vivimos instalados en la sociedad del malestar y no sólo económico, aunque no debemos olvidar que esta circunstancia se produce a dos bandas puesto que, si bien el estatuto de la ley es el que la hace inamovible, también el ciudadano se amolda y permanece en esta situación de pasividad asumida porque en su cabeza, la distancia entre la política y la acción es infinita y no le implica en ningún caso. No cree poder y no puede creer que el cambio sea posible.

Así que, ante la necesidad de introducir nociones que nos abran caminos, nos vemos desempolvando de nuevo viejos conceptos como el de isonomía, que es la variante autónoma de la anarquía. Henos aquí de nuevo inmersos en la literatura: dicen que dicen que la isonomía es la ausencia de poder y que deriva de la constitución de las ciudades-estado griegas en las que los ciudadanos convivían al margen de todo poder, sin una división entre gobernantes y gobernados. Este concepto de ausencia de poder resulta casi chistoso después del análisis realizado por Foucault sobre las múltiples estrategias y centros de poder pero sospechamos que supone una realidad diferente de la que le atribuimos ya que suscitó críticas por parte de los defensores de la democracia frente a la isonomía tales como que la pretendida ausencia de poder es, en realidad, otra clase del mismo: es la peor forma de gobierno, el gobierno por el demos. Sin entrar a comentar la valoración negativa sobre el posible gobierno del pueblo, podríamos criticar este supuesto gobierno diciendo que se basa en una noción de pueblo vacía de significado.

De hecho, aunque el dogma compartido por los hombres de las dos revoluciones del XVIII fue la convicción de que la fuente y el origen del poder político residían en el pueblo, esta noción se transformó pronto en voluntad general, en un pueblo vacío de contenido, sometido a la opinión pública que ya no es creada por el público sino impuesta a ese mismo, como ya hemos visto. Sospechamos que, en parte y sumado a lo anteriormente dicho referente a la construcción del sujeto y a su cuestionable libertad, se debe simultáneamente a un olvido clave en la interpretación de la igualdad. En la democracia, mediante la asunción de los derechos humanos, todo hombre sólo por su nacimiento es considerado libre e igual a los demás hombres. Esta extensión de los derechos a todos los sujetos acaba volviéndose contra esos mismos sujetos que se ven privados de una teórica igualdad inexistente y llevados a ejercer un solo ámbito de esa libertad que tanto anhelan. Citando a Hannah Arendt, diremos que: 
La diferencia entre el concepto antiguo de igualdad y nuestra idea de que los hombres han nacido o han sido creados iguales y que la desigualdad es consecuencia de las instituciones sociales y políticas, o sea de instituciones de origen humano, apenas necesita ser subrayada. La igualdad de la polis griega, su isonomía, era un atributo de la polis y no de los hombres, los cuales accedían a su igualdad en virtud de la ciudadanía, no en virtud del nacimiento. Ni igualdad ni libertad eran concebidas como una cualidad inherente a la naturaleza humana, sino convencionales y artificiales, productos del esfuerzo humano y cualidades de un mundo hecho por el hombre. ${ }^{58}$

De esta manera, el ciudadano sólo puede ser igual a los demás en el espacio compartido con éstos, sobre la base de un pacto previo de reconocimiento. De igual manera, la libertad es una condición pública y requiere de su ejercicio para actualizarse. Si el individuo no ejerce el gobierno de sí mismo y por tanto, de su estado, mal podrá ser considerado ciudadano libre o igual a los demás. La capacidad igualitaria de todos los ciudadanos que reivindica constantemente Rancière ${ }^{59}$ adquiere aquí un atributo claro de acción; sin la aplicación real de ese igualitarismo, no hay atributo, lo que implica simultáneamente un derecho de participación pero también la exigencia del ejercicio de ese derecho: que se den simultáneamente las condiciones de posibilidad y de voluntad (poder y querer ejercer la actualización concreta de esa igualdad). Por otra parte, si el espacio público se caracteriza por la participación, es decir, por el ejercicio de la libertad en cuanto gobierno, se distancia entonces radicalmente de la noción de mercado y se convierte en un foro de deliberación colectiva productor tanto de bienestar común como de conocimientos, como ha sido el caso en las últimas experiencias ciudadanas del 15M.

Por tanto, según la interpretación que hace Hannah Arend de la isonomía como poder horizontal a la Rancière así como de la noción de ciudadano que exige la puesta en acto de la isonomía, no habría ciudadano sin ejercicio de la ciudadanía, puesto que no se trata de un derecho pasivo sino de una exigencia activa. En la medida en la que el ciudadano lleva a cabo una implicación activa en el gobierno de lo que es suyo, puede ser llamado como tal. Pero en unos sistemas en los que la implicación del ciudadano se reduce al voto o a la imposición de ejecución de tareas a la Botella ${ }^{60}$, es decir, a cubrir con el trabajo personal voluntario puestos de trabajo que deberían estar cubiertos por trabajadores remunerados, sin que ello

58. ARENDT, Hannah. Sobre la revolución. Madrid: Revista de Occidente, 1967, p. 37.

59. RANCIÊRE, Jacques . El desacuerdo. Política y filosofía. Bueno Aires: Nueva Visión, 1996.

60. La alcaldesa de Madrid, Ana Botella, propuso en enero de 2012 que se cubrieran con voluntarios parte de los servicios públicos de la ciudad para, según ella que los madrileños se impliquen para hacer rentables esos espacios públicos, centros culturales, polideportivos, que hemos construido y por la crisis no podemos atender a todas las necesidades que requieren, consultado el 12 del 4 de 2012 y disponible on line en http://www.elmundo.es/elmundo/2012/01/26/madrid/1327601221.html. 
suponga ninguna contrapartida de autogestión a ningún nivel, las posibilidades reales que hay de tomar una posición activa en el gobierno se limitan al gobierno de sí, más mediatizado que nunca por este modelo pasivo de "estar en el mundo". Es verdad que hoy en día, desde múltiples plataformas de ciudadanos, estamos tentados de adoptar la manera en la que Rancière ve las cosas, es decir, asumiendo que la anarquía no es interpretada como ausencia de gobierno sino como otro gobierno posible. El anarquismo no es el caos, no es la ausencia de orden sino otro orden posible. Estamos tanteando la posibilidad de que haya otro elemento de unión comunitario posible más allá del Estado, reconociendo que no es el Estado o nada, no es el Estado o la sociedad civil librada a sí misma, sino que pueden haber otras posibilidades diferentes de organizar la sociedad civil.

Se puede sentir que estamos en el principio de algo, intentando crear otra comunidad posible. Pero esta posible comunidad de la que hablamos no es la community a la americana, cuyo ejemplo más excesivo sería la gated community ${ }^{61}$, en el sentido de un Estado en pequeño que replica sus formas de gobierno. El Estado en su acepción violenta de hoy en día, el Estado liberal que funciona como un avatar extremadamente eficaz de la sociedad de control se ajusta como un guante a esta noción de community, se acomoda a la perfección, pero obviamente, no en el sentido usado por Fourier. A diferencia de esta, la comunidad de la que nos gustaría hablar funcionando bajo el manto de la filia politikón, es aquella capaz de generar asambleas desparejas, de las que podríamos encontrar difícilmente puntos en común, mayores, jóvenes, blancos negros, mujeres, hombres, agricultores, obreros, intelectuales, etc., que hablan desde sus diferencias en la igualdad de capacidades, en la no categorización, en la ausencia de control. En nuestro cuestionamiento del statu quo, del estado del Estado, no se trataría de que, como en las antiguas revoluciones, estemos deseosos únicamente de liberarnos de un estado de sometimiento, lo que deseamos es practicar el ejercicio de nuestra libertad en un movimiento revolucionario en donde revolucionario también adquiriría el siguiente significado acuñado de nuevo por Arendt:

61. Las gated communities son urbanizaciones cerradas, cuyo ordenamiento y vialidad pueden ser orden privado, con un perímetro definido por muros o rejas, y que poseen una única entrada controlada por un servicio de seguridad. Estos barrios segregados se han popularizado en los Estados Unidos bajo la modalidad de la inclusión diferencial explícita: urbanizaciones de mayor o menor entidad que se caracterizan por imponer una serie de normas ajenas al Estado general y que limitan la posibilidad de pertenecer a ellas a miembros que cumplen con determinadas condiciones como ser negros, carecer de hijos, tener perros y un largo sinfín de posibles parámetros de exclusión. J. Rifkin en su libro "La era del acceso" (Paidós, 2000) habla de cómo en estas comunidades se produce una sustitución de la lógica de la propiedad por la lógica del acceso que, como en la inclusión diferencial, es una de las claves que nos permiten entender el mundo actual. 
Pero ni la violencia ni el cambio pueden servir para describir el fenómeno de la revolución; sólo cuando el cambio se produce en el sentido de un nuevo origen, cuando la violencia es utilizada para constituir una forma completamente diferente de gobierno, para dar lugar a la formación de un cuerpo político nuevo, cuando la liberación de la opresión conduce, al menos, a la constitución de la libertad, sólo entonces podemos hablar de revolución. ${ }^{62}$

Resulta obvio que lo que proponemos es el inicio de un proceso que lleva implícito el aprendizaje de su objetivo: mediante la participación, queremos aprender a participar, mediante la autogestión, a gobernarnos. Este aprendizaje no pretende un estallido y recambio del poder, no queremos oponer una globalización a otra globalización, lo que proponemos es la paulatina incorporación de actores sociales al ejercicio del poder, léase, la administración de los recursos, la toma de decisiones y el establecimiento de leyes mediante redes horizontales de cooperación entre colectivos e individuos. Partiendo de estas premisas, el objetivo que debiera plantearse el discurso crítico es pensar cómo se puede desarrollar una materialización de la idea de Rancière ${ }^{63}$ de política en tanto estallido de una insurgencia puntual que genere una extensión de la igualdad, y que no derive a medio plazo en policía (aludiendo con ello a la división del cuerpo social en segmentos y a la organización de las relaciones entre dichos segmentos siguiendo una estructura de sumisión y dominio, de jerarquización social); el reto real pues seguiría estando en cómo mantener el equilibrio entre la política y el momento en que lo político se constituye en poder consolidado, si es que ese momento se llega a producir. Consecuentemente, se trata de un problema tanto teórico como práctico, aplicable a experiencias y situaciones concretas. Por ello, se trataría de pensar fórmulas que permitan que, de un momento de insurgencia puntual, se derive un proceso a medio y largo plazo que propicie una transformación profunda de la estructura de dominación pre-existente.

Eso nos obliga a cambiar de registro, y evaluar el proceso en su temporalidad: hay un tiempo para el acontecimiento, otro de maduración política, otro de reflexión, del compromiso y por último, un intento de hacer duradero eso que se ha construido, una voluntad de permanencia. Ese paso a una voluntad de eternización, ese cambio de temporalidad es el momento en el que hay que estar atento, quizás este ideal de querer perpetuar un sistema no sea un ideal aplicable o ni siquiera deseable. Cuando Maurice Blanchot en La comunidad inconfesable, retoma la cuestión de Mayo del 68 entendiéndola como un momento en el que se produce la emergencia de la política, del acontecimiento, habla de su condición de fiesta de la comunicación, de la posibilidad de estar juntos sin la necesidad de hacerlo en torno a un proyecto o a una

62. ARENDT, Hannah, op. cit., p. 42.

63. RANCIÈRE, Jacques, op. cit.. 
voluntad política determinada, sino simplemente una igualdad común ante lo imposible hecho realidad puntual. Pero añade:

Creo que se dio entonces una forma de comunidad, diferente de aquella cuyo carácter hemos definido, uno de esos momentos en que comunismo y comunidad se encuentran y aceptan ignorar que se han realizado perdiéndose inmediatamente. No hay que durar, no hay que tomar parte en ningún tipo de duración.... ${ }^{64}$

Por ejemplo, en pedagogía no se plantea la cuestión del final del saber, de su término, se entiende que es un proceso que no termina nunca, que no está guiado por un deseo de llegar a algo y aferrarse a ello, se incluye el rechazo y el cuestionamiento como elementos fundamentales de este proceso. La cuestión clave, por tanto, sería la de la temporalidad, la del deseo de permanencia, la ilusión de la eternidad, que también es un avatar de la sociedad de control. Esa ilusión de que vamos a conservar el estado de cosas hasta el final de los tiempos porque consideramos que estamos aplicando el mejor sistema posible, como llevamos haciendo desde siempre, es una ilusión a desterrar si somos conscientes de hasta qué punto el patrimonio está reñido con la revolución, entendida esta como cambio, como movimiento. No nos queda otra opción aunque siempre podemos hacer de la revolución un patrimonio e intentar conservar el modelo de formación continua aplicado a nuestro gobierno.

\subsection{Metrópolis postfordistas}

Pero abordemos brevemente el marco en el que sucede esta confluencia de tensiones y fuerzas convergentes, de conflictos y de retos, el contexto en el que se está produciendo la crisis (la que después acabaremos llamando la crisis de las ilusiones, el gran engaño), es decir, la metrópolis. Para abordar hoy en día las dinámicas que confluyen en los epicentros del cambio, no basta con atender a criterios urbanísticos o ecológicos, siendo necesaria la aplicación simultánea de un análisis político y social que pueda ir más allá de la propia disposición espacial. Sería de rigor empezar diciendo que hay una diferencia entre los conceptos de ciudad y de metrópolis que poco tiene que ver con la dimensión de la acumulación de recursos y personas, ni tampoco con su emplazamiento en el primer o en el tercer mundo, sino con un cambio general en las relaciones de producción y de captación del trabajo. Por resumir, diremos, citando a Negri ${ }^{65}$, que hoy en día la metrópolis es a la clase metropolitana lo que el obrero era a la fábrica. ¿Qué significa esta frase tan sugerente? Ni más ni menos que en los procesos de transformación que acompañan al paso del fordismo

64. BLANCHOT, Maurice,. La comunidad inconfesable. Madrid: Arena Libros, 2007, p. 56. 65. NEGRI, Antonio. La metrópolis y la multitud. DDOOSS [en línea] disponible en <http:// ddooss.org/articulos/otros/Antonio_Negri.htm > [Consulta 12 de Febrero 2.012] 
al postfordismo, la metrópolis se convierte en el lugar central de producción y explotación pero también de creatividad y rebelión, características que antes servían para describir la centralidad de la fábrica.

Este paso de la fábrica a la metrópolis no significa que se tenga en cuenta la realidad urbana como única dimensión a relatar, ni como escenario de una modernidad triunfante a la Baudelaire, ni siquiera como un decorado de decadencia post-ciencia ficción, sino más bien como imagen de un determinado entrelazamiento de las relaciones de poder. Cuando anteriormente se decía que la industrialización era el modo hegemónico de trabajo, no se hacía referencia a la cantidad de trabajadores que se dedicaban a ocupar un puesto dentro de las cadenas de producción sino que se hacía referencia a la imposición del modelo de trabajo industrial a todos los ámbitos de la vida. Su forma se impuso desde la agricultura a la educación pasando por los parámetros de gobierno. Sus ritmos, sus máquinas, la manera de habitar el tiempo, se convirtieron en la forma natural de concebir una vida en la que la jornada laboral y las horas de ocio estaban determinadas por el horario de producción. De la misma manera, en la actualidad, el modo de producción inmaterial de la clase metropolitana, a la que también podría llamarse precariado, es el que ocupa un lugar hegemónico, siempre en términos de modelo y no de cantidad dentro del sistema en el que nos encontramos, el capitalismo cognitivo. De hecho, algunas de las críticas que se han realizado al uso del término "capitalismo cognitivo" vienen en parte de esta confusión. Por ejemplo, Cristina Morini ${ }^{66}$ prefiere utilizar el término biocapitalismo por esas razones:

Con el término "biocapitalismo", nos referimos a un proceso de acumulación que se basa en la explotación no sólo del conocimiento sino de todas las facultades humanas, desde las relacionales-lingüisticas hasta las afectivas-sensoriales. Se nos pone a trabajar en nuestros tiempos de ocio, porque el consumo es una cadena más, aún fordista pero unida a una cadena de deuda fomentada por entidades bancarias que, mediante la concesión de créditos fáciles, incitaron a un consumo y financiarización generalizados mientras que, a la hora de asumir impagos, echan mano de grandes instituciones modificando el interés, siendo casi nulo el interés al que le rescata el estado y siendo enorme el interés al que presta el banco. Se trata de una acepción más amplia respeto al concepto más utilizado de "capitalismo cognitivo", que también nos parece adecuado a las actuales transformaciones productivas y sociales, que pero tiene el riesgo de ser malentendido por una supuesta relevancia del papel exclusivo jugado por el conocimiento.

Por supuesto que sigue habiendo una mayoría de trabajadores que no se ocupan, o por lo menos no mayoritariamente, de la denominada producción de bienes inmateriales por lo que no formarían parte de esta clase, encumbrada

66. MORINI, Cristina. “El trabajo de cuidado como arquetipo del biocapitalismo”. Webjournal. [En línea].Disponible en web: <http://swarm-webjournal.info/articulo/el-trabajo-de-cuidado-como-arquetipo-del-biocapitalismo >. [Consultado el 20 de enero de 21012]. 
como modelo de análisis. Pero, como hemos dicho, la exportación del modelo de producción inmaterial a otras formas de trabajo hace que las características propias de los productores culturales, por elegir un ejemplo cercano de trabajador inmaterial, como sector paradigmático de la autoexplotación neoliberal, se estén extendiendo a todo el ámbito laboral. La indiferenciación entre tiempos de trabajo y tiempos de vida, con su consecuente autoexplotación, la cesión de los beneficios de las externalidades positivas generadas a otros agentes económicos, la libertad precaria paradójicamente paralela a la incapacidad de gestionar tiempos y horarios, el aislamiento de los trabajadores y por tanto, la imposibilidad de sindicación, son todas características reconocibles en los productores-gestores culturales pero igualmente aplicables a los empleados de las grandes cadenas o a cualquier otro trabajador del ámbito de los servicios, por poner otros ejemplos.

Por ello, consideramos que el paso del fordismo al postfordismo, aunque haya sido llamado capitalismo cognitivo, corresponde a una transformación generalizada de los modos de producción y captación de la plusvalía, simultánea a la creciente importancia de la producción inmaterial, pero aplicable a todos sus ámbitos. Por tanto, antes de seguir avanzando en la experiencia de la metrópolis tal cual la experimentamos en la actualidad, detengámonos un momento para detallar esta transformación esencial para la comprensión de nuestras circunstancias, aunque sea con la superficialidad de la descripción sintética que siempre engaña con su sencillez aparente.

Si tuviéramos que definir en pocas líneas el fordismo en su aspecto más técnico diríamos que es una forma de organización de la producción industrial caracterizada por una gran especialización del trabajo, estructurada a través de cadenas de montaje, llevada a la práctica por Henry Ford a partir de 1908 en sus fábricas de automóviles. Este planteamiento de la producción basado en la optimización de los procesos mediante su separación y estandarización permitió abaratar costes de manera que el precio de venta fuera menor y pudiera resultar accesible a un mayor número de gente. Si a esto le sumamos el hecho de que se mantuvieran salarios altos de manera que, como decía Ford, "cada uno de mis obreros pueda comprarse un coche de los que fabrica", entramos de lleno en la sociedad del consumo, generando un ciclo en teoría impecable de producción masiva asociada a consumo masivo.

Tenemos pues por una parte, la atomización de los procesos de producción sumada a la estructuración mediante cadenas móviles de montaje que posibilitan el establecimiento de un ritmo fijo de producción, así como la estandarización de los productos que permite abaratar costes e incrementar exponencialmente el volumen de ventas. Por otra parte, al mantener elevados salarios, los trabajadores se convierten en consumidores, generando lo que se consolidará como "clase media" situada un escalón por encima del proletariado. 
Este incremento de la producción-venta permite la expansión de un mercado nacional alimentado por los trabajadores que, al recibir un salario fijo por horas, pueden optar a diferentes herramientas de financiación para ampliar su consumo. Finalmente, la homogeneización y centralización de los centros de producción tiene como consecuencia no prevista el fortalecimiento del sindicalismo de clase que se encuentra entre las manos una herramienta poderosa de negociación: la huelga que implica la quiebra de los ritmos fijos de producción fordista.

Se pasa de una negociación individual a una colectiva, necesaria para garantizar una capacidad adquisitiva a los trabajadores en su conjunto, pero como efecto de rebote, esa fuerza sindical permite, tal y como hemos detallado en el capítulo anterior, la negociación de una serie de prestaciones sociales que conformarían lo que conocemos como estado del bienestar. Volver a la base descriptiva de manual a veces sirve para resaltar la necesidad de disponer de armas para la negociación y de armas colectivas, en esta crisis como en las otras, no lo olvidemos. El modelo fordista entra en crisis en la década de los 70 debido a la confluencia de factores económicos y sociales que convierten a este modelo en insostenible al desequilibrarlo. Safón ${ }^{67}$ especifica entre otros motivos los siguientes:

1. El final del sistema de cambio fijo de moneda (el patrón oro) al de paridad variable, lo que introduce un factor de variabilidad en el precio de materias primas y por tanto, del producto final.

2. La crisis del petróleo, y su escalada de precio, que también condiciona un aumento en los costes de producción rompiendo los márgenes de beneficio.

3. La internacionalización en dos sentidos: el incremento del coste del trabajo en relación con el aumento de la conflictividad laboral trae como consecuencia la búsqueda por parte de las grandes empresas de mercados laborales más baratos, lo que lleva a la deslocalización y la subcontratación. Si esto se combina con la saturación del mercado nacional y la pérdida de capacidad adquisitiva de los trabajadores, se produce una corriente de empresas que producen para exportar hacia mercados no fordistas.

Estos factores fuerzan un cambio del modelo productivo que pasa del producto estandarizado y asequible, a una segmentación del mercado que enfatiza la especificidad, la calidad o el precio del producto concebido para un determinado nicho de mercado. Para poder adaptarse a esa demanda de flexibilidad, las empresas fordistas empiezan a abandonar su modelo vertical y generalizan los procesos de externalización y descentralización, recurriendo a las pequeñas y medianas empresas,

67. SAFÓN CANO, Vicente. “¿Del fordismo al postfordismo?: El advenimiento de los nuevos modelos de organización industrial". En: Actas del I Congreso de Ciencia Regional de Andalucía: Andalucía en el umbral del s.XXI. [En línea]. Disponible en< http://www.uca.es/escuela/ emp_je/investigacion/congreso/mbc011.pdf> [Consulta: 23 de Agosto de 2.011] 
con mayor capacidad de cambio y menor capacidad de sindicación. Las soluciones a la crisis fordista pasan por la flexibilización de todo el sistema productivo, lo que incluye tanto los procesos de fabricación como la mano de obra empleada.

La introducción de nuevas tecnologías permite producir productos diferenciados según los mercados gracias a la automatización programable de gran parte de la fabricación que se puede llevar a cabo en emplazamientos alejados entre sí. El trabajador medio de baja cualificación prácticamente desaparece sustituido por la cadena de fabricación. Como hemos dicho, se generaliza la subcontratación por parte de las grandes empresas a otras empresas especializadas, y la deslocalización que traslada la producción a países donde la mano de obra es más barata y en donde los beneficios fiscales son mejores. La introducción del concepto de red, tanto el de "empresa red" (introducido por Manuel Castells ${ }^{68}$ y posteriormente retomado por Recio ${ }^{69}$ ), como el de "redes de empresas", como forma organizativa más eficaz para afrontar y gestionar las nuevas demandas y las nuevas formas de producción se establece y transnacionaliza asociado a la forma de producción just-in-time, es decir, la producción únicamente de aquello para lo que hay demanda, manteniendo los stocks al mínimo tanto en términos de materia prima como de trabajadores contratados. El postfordismo industrial es un modelo que prioriza la gestión del excedente, optimizando la relación entre lo que se necesita (materias primas, fuerza de trabajo, energía, etc.) y lo que se produce.

En términos de trabajo, la flexibilización del mercado laboral se convierte en una realidad impuesta que sustituye los ciclos de vida laboral largos y seguros por la precarización generalizada. Como dice Recio, la temporalidad es el recurso de las empresas para afrontar ajustes de la actividad productiva y esta es una temporalidad que la empresa hace pesar sobre el sistema mediante los mecanismos de protección social, como después veremos al analizar el estatuto del intermitente. Los salarios bajan, al deslocalizar o subcontratar en mercados laborales más baratos y al producir para la exportación. La fragmentación de la negociación laboral, a consecuencia de la diversidad de estructuras productivas y la configuración en red, se convierte en una característica extendida del pacto laboral, las empresas negocian con una gran diversidad de situaciones laborales y tipos de empleados, lo que reduce la capacidad de negociación de cada uno de esos grupos e incluso permite a la empresa situarlos fuera de convenio, etc. Si a este panorama general, le sumamos todos los rasgos asociados a la producción inmaterial, la desregulación y deslocalización se vuelven aún más acusadas.

68. CASTELLS, Manuel, op. cit..

69. RECIO, A. "Empresa red, distribución de la renta y relaciones laborales". En VII Jornadas Economía Crítica. Albacete: Universidad Castilla la Mancha, (2000). 


\subsection{La inclusión diferencial}

Como comentamos, la imposición de este modelo de trabajador a toda la sociedad produce un efecto claro de inclusión diferencial ${ }^{70}$, definida como forma de gestión de la población que ha tomado la diferencia como elemento central de gobierno. Como han analizado Marta Malo y Débora Ávila, nos encontramos inmersos en un panorama de individualización radical. A diferencia de los años 80 en los que se produjeron diferentes luchas vecinales a través de las cuales se mantuvo articulada parte de la sociedad y resultaba más fácil vivir un sujeto colectivo generando un común, en la actualidad resulta imposible organizarse de la misma manera a causa de la aplicación sistemática en diferentes ámbitos de dicha inclusión diferencial que se instaura fundamentalmente mediante tres acciones claras:

1. Producción de un sujeto: se genera la construcción social de un sujeto como empresario de sí mismo, de manera que todo lo que le suceda sea a causa de sus acciones (lo bueno y lo malo), culminando el proceso de individuación ya analizado por Foucault al duplicar el modelo de individuación psicológico con el laboral, generando un sentimiento de culpa. Según Santiago López Petit ${ }^{71}$, el nosotros que había protagonizado el gran ciclo de luchas autónomas de los años 70 y que, gracias a su autonomía de clase, había impuesto una crisis política de dominación al capital, fue desarticulado finalmente en el paso del fordismo al postfordismo. La socialidad obrera articulada en sindicatos dejó de ser un peso importante en el modelado de los pactos sociales para instituir al individuo como interlocutor único que, de su imagen heroica de self-made man triunfante, pasa a adquirir el aspecto inequívoco del cobarde superviviente, es decir, ni siquiera en el caso de escapar a la caída, se puede eludir la pérdida e incluso la sensación de traición, de ganar contra el otro.

La famosa cuestión del sujeto debe contemplarse en el horizonte del paso de la sociedad-fábrica a la metrópolis, en el interior de esta narración que habla de derrota. Si eso lo enmarcamos en la noción de sociedad terapéutica esbozada por Espai en Blanc ${ }^{72}$ en donde es el sujeto el que está "enfermo" o "inadaptado", esta tendencia psicologízante y responsabilizadora se incrementa. Pongamos un ejemplo para comprobar cómo funciona. Durante los años 70/80, el análisis institucional de la enorme tasa de paro se centraba en procesos

70. MALO, Marta y ÁVILA, Débora, en "El gobierno de la diferencia: gestión y gradaciones de derechos sociales", en Repensando la metrópolis. Prácticas experimentales en torno a la construcción de nuevos derechos urbanos. Málaga: Centro de Estudios Andaluces, 2010.

71. LÓPEZ PETIT, Santiago. “QQué es hoy una vida política?", En: Impasse:dilemas políticos del presente. Buenos Aires: Tinta Limón, 2009.

72. ESPAI EN BLANC (coord.), La sociedad terapéutica. Materiales para la subversión de la vida. Barcelona: Bellaterra, 2008. 
socioeconómicos y políticos, haciendo referencia obligatoria a las políticas del Estado y a sistemas estructurales mientras que ahora se considera y se trata el paro como un problema individual. Se implantan programas de formación y de dinamización,como si fuera el trabajador el que no ha sido capaz de adaptarse a los requerimientos del mercado y no el mercado el que ningunea la mano de obra e introduce mecanismos de desviación al Estado de los costes de la precarización laboral, forzándole a asumir el estatuto del intermitente como rango laboral generalizado.

2. Etiquetaje de grupos: En términos sociales, esta producción diferencial del sujeto (frente a la necesidad de subjetivación militante que proponía Carlos Prieto del Campo) se concreta en la generación sistemática de grupos en torno a los que se van a gestionar la población. Para poder hacerlo, no se eliminan las diferencias sino que se estandarizan, clasificando a la población en grupos claramente definidos que convierten esas diferencias en categorías: autóctono, con/sin papeles, niño, en formación, ciudadano comunitario o no comunitario etc. y se afronta la gestión desde esa atomización generalizada. Por tanto, se trata de un gobierno de y por la diferencia, que en sí no conlleva desigualdad alguna, más bien se ha instalado siguiendo el proceso contrario, es decir, intentando mantener un principio de equidad según el cual "a necesidades distintas, soluciones diferentes".

No obstante, este razonamiento acaba por situar a cada uno en una posición diferente que, a causa de la gradación de derechos sociales que implica, produce el efecto contrario: la oposición y consecuente división de los individuos, como veremos en el siguiente punto. La diferencia no sólo se acepta como tal sino que se promueve; en cualquier espacio en donde se gestiona la población, hay una filosofía subyacente que convierte esta diferencia en el punto de gestión de manera que, por las razones que hemos comentado, resulta muy complicado generar una empatía social, más aún cuando una de las armas más potentes que se ponen una y otra vez en acto es el miedo a convertirse en un fracasado por cuenta propia.

3. Hiperestratificación social: mediante el etiquetaje de grupos, se establece una escalera en donde cada uno ocupa una posición inclusiva pero muy diferente en términos de garantías sociales. Para hacerlo, se ponen en marcha toda una serie de mecanismos legales para graduar esos derechos según el etiquetaje social previo, que conlleva diferentes derechos o carencias. Las posiciones no son fijas sino que son muy precarias de manera que nuestra posición social está siempre bajo la amenaza de desintegrarse. En estos momentos de escasez, nuestras posiciones no se leen en términos de mejora posible sino en clave clara de amenaza. La población, tan inestable, tan fraccionada, etiquetada, autoculpabilizada y precarizada se pone lógicamente a competir entre sí, en educación, en trabajo, de manera que se produce a menudo una negociación de condiciones laborales a la baja y una desviación de la negatividad hacia los grupos teóricamente más favorecidos en vez de hacia los gestores no equitativos. 
A nivel laboral, los derechos que se garantizan no son los mismos dependiendo del estatuto de trabajo que se aplique, del funcionario a la empleada del hogar, del fijo discontinuo al eterno becario, del contratado en prácticas al profesional autónomo o al parado de larga duración, sus correspondientes prestaciones sanitarias, de formación, de baja por enfermedad, etc. responden a todo un abanico declinable de posibilidades, con lo que su valoración en términos de población "útil" no será la misma, por no hablar de la enorme distancia de todos ellos para con el estatuto privilegiado asociado a cargos políticos que tanto se está cuestionando en la actualidad. La sociedad no se divide en incluidos y excluidos, entre la mayor parte de la población y los marginales o marginalizados, sino en este continuo hipersegmentado con distintas franjas de trabajadores que se benefician de diversos grados de protección social. Esta gradación de la protección es la que transforma la diferenciación en segmentación jerárquica y por tanto en desigualdad. Los efectos directos de este abanico de posiciones inestables se concretan en lo que las mismas autoras denominan miedo-ambiente, fruto de la rivalidad y la competencia entre diferentes grupos sociales que se exacerba cuando la política de la escasez se aplica a todos los ámbitos

En teoría, seguimos viviendo en un Estado garantista, es decir, que asegura de forma universal la protección social, pero podemos constatar que se ha producido la sustitución de la lógica de derechos sociales universales por una lógica de ayudas particulares sometidas a un triple proceso de filtrado similar en todos los ámbitos. El primero de ellos, generalizado, consiste en la segmentación jerárquica institucionalizada como sistema de gestión legal. Por ejemplo, cuando se lanzan ayudas a la formación, no son para el conjunto de la población sino únicamente para determinados grupos. Cuando se llevan a cabo recortes y subidas de tasas universitarias, estos incrementos de tasas se gestionan aplicando criterios de segmentación, primera o segunda matrícula, primer tramo de la educación superior, máster, o bien para ciudadanos no comunitarios que aunque lleven veinte años viviendo en nuestro país, por el hecho de ser hijos de padres no comunitarios, no han accedido a la nacionalidad española y por tanto, se ven penados con el incremento máximo de pago de tasas.

Si tratamos el caso de la sanidad, vemos que se reproduce el mismo esquema, puesto que su acceso se ve modulado a través de la ley y de toda una serie de normativas oficiales y legislativas desconocidas en su mayor parte por la sociedad y sometidas a constante matización. Hay un gran número de casos en los que se acuerda una tarjeta especial con condiciones de atención desiguales para las personas sin recursos, o sin papeles, que les exige tramitar, antes de recibir la tarjeta, un reconocimiento previo del derecho a la salud mediante instancias diferentes de las sanitarias como por ejemplo, en el caso de los sin papeles, en el que deben recurrir a un informe de trabajo social, etc. 
Posteriormente, tienen que hacer frente a un segundo nivel interno, que responde a directrices y normativas que sólo conocen los profesionales que trabajan en ese sector. De esta manera, a través de la ignorancia, se produce la exclusión, y como este, muchos otros mecanismos sutiles de filtrado que practican los servicios sociales. Requisitos nuevos para conseguir las mismas ayudas como estar empadronados, condición que se opone a aquella que imposibilita hacerlo en casos en los que se considera, por ejemplo, que hay demasiadas personas empadronadas por unidad de residencia, hecho que suele ser habitual en el caso de los migrantes en donde el hacinamiento responde a las condiciones de precariedad en las que sobreviven. Por no hablar de algo tan simple como la posibilidad de recibir atención sanitaria en una comunidad autónoma diferente de aquella en la que se está domiciliado que condiciona el hecho de poder ser beneficiarios o no de recetas. Miles de maneras de etiquetar e introducir una gradación descendente de derechos que acaba resolviéndose en un tercer nivel: el humano. Cuando hay escasez, cuando los derechos no están garantizados, a menudo acaban siendo decisivas las entrevistas realizadas por funcionarios que deciden si mereces o no una entrevista con la asistencia social, por ejemplo, requisito básico para que las personas sin recursos puedan obtener la tarjeta sanitaria que "les corresponde".

Siguiendo esta lógica, se producen a menudo incrementos del presupuesto destinado a control de las ayudas y seguimiento de los casos mientras que se reducen los presupuestos destinados a las ayudas en sí. La gestión de la crisis se produce siguiendo este esquema, culpabilizando a quien ha caído, fomentando la competencia, léase, rivalidad, entre aquellos que se encuentran en posiciones inestables, interviniendo mediante sistemas de ayuda parciales sin cuestionar que es el propio sistema el que está generando esa desigualdad, instalando la sociedad en una distancia social cada vez mayor. ¿Qué hacer? Asumir lo que tenemos, un contexto de clara fractura social. Pero ¿cómo recuperar lazos de solidaridad, emprender la construcción de comunes, encontrar enunciados que sean colectivos, llevar a cabo un trabajo reticular?

No sabemos cómo ponerlo en la práctica y menos aún cómo llegar a la gente que le afecta realmente, que a día de hoy acaba siendo la mayoría de la sociedad. Además de enunciar, necesitamos articular y más aún, reticular acciones y conocimientos, pero en ningún caso se nos puede exigir que sepamos cuál es el camino como única posibilidad para empezar a enunciar. Como dice Judith Butler ${ }^{73}$, al comentar el movimiento Occupy, cuando se le exige a este una lista de reivindicaciones y un plan de acción posible para cada una de ellas, se le está pidiendo que entre en una lógica fraccionada en donde cada uno de los puntos abordados podría resolverse separadamente:

73. BUTLER, Judith, Pero ¿qué reivindican? Y ¿adónde van ahora?, en http://es.scribd.com/ epidermicus/d/86333441-Butler-Judith-So-What-Are-the-Demands-Occupy-Wall-Street 
Claro que podemos elaborar una lista, y también ampliarla e incluso concretarla, pero ninguno de los elementos que la componen puede ayudarnos a explicar qué es lo que aglutina a todos esos elementos que figuran en la lista. Sin embargo, si decimos que cada una de estas cuestiones son un ejemplo de las crecientes desigualdades y diferencias de renta que se derivan directamente de las formas contemporáneas del capitalismo y que todas juntas son la demostración de que el capitalismo se basa en ese tipo de desigualdad económica y social y la reproduce, entonces estamos exponiendo cómo funciona un sistema y, concretamente, cómo funciona el capitalismo en la actualidad.

Pero volviendo a la inclusión diferencial, este modelo tan evidente hoy en día tiene un correlato inmediato en el espacio físico de la metrópolis, en donde el término inclusión oculta la exclusión parcial de franjas poblacionales de determinados espacios, ya sea de forma abierta, legal, como en el caso de las comunidades cerradas o los centros comerciales donde la ley y la fuerza, encarnadas en el guardia de seguridad de turno, se aseguran de que no haya filtraciones; hasta las exclusiones raciales, económicas o comportamentales propias de la dialéctica entre el centro y las periferias que se acaba reproduciendo en cualquier lugar. La multiplicación asimétrica de controles interiores frente a una permanente exaltación de los flujos y las redes, la profusa creación de zonas exclusivas comerciales, residenciales, etc. paralela a la de espacios de exclusión (guetos, centros de internamiento de extranjeros,) serían algunos de los síntomas paradójicos de esta inclusión diferencial.

Si hacemos una breve revisión de lo que supone este proceso de transformación metropolitana asociada al modelo de producción postfordista, podemos nombrar numerosas maneras de "poner a trabajar la ciudad" del mismo modo en que se pone a trabajar a la vida. La reducción del espacio considerado como público a través de las privatizaciones fragmentarias (publicidad, terrazas, cercamientos, desaparición de elementos comunes gratuitos como fuentes o bancos), la estandarización del mismo (plazas duras, mobiliario urbano hostil) anulando la posibilidad de espacios comunes de encuentro, la multiplicación de dispositivos de control tanto tecnológico como normativo para reducir la ocupación del espacio público a actos de consumo bajo la coartada de la ciudad convertida en espectáculo, ya sea turístico, ya sea de ocio programado, la multiplicación de ordenanzas cívicas que escapan a cualquier capacidad de decisión por parte de los ciudadanos, y todo un sinfín de expropiaciones similares, hacen que lo común metropolitano sea un espacio cada vez más escaso, de manera que resulta casi obligatoria la puesta en marcha de dinámicas de recuperación del mismo, mediante procesos de análisis y participación comunitarios que permitan incidir de forma eficaz y positiva en esta anulación progresiva con la intención de revertirla.

Siguiendo en el marco de la metrópolis, observamos cómo se encuentra en un permanente vaivén entre ser el lugar de creación de lo común, de 
ese procomún que va más allá del espacio físico y que incluye la propiedad pública pero también los códigos, los afectos, las imágenes; y ser el espacio de captación de ese procomún por determinadas instancias privadas que "ponen a trabajar" su capacidad creativa. Tal y como especifica Yann Moulier Boutang ${ }^{74}$, el problema central del intercambio mercantil en la economía del capitalismo cognitivo estriba en el peso creciente de las externalidades positivas, es decir, de los efectos productivos positivos y gratuitos de las múltiples interacciones, en una sociedad basada en el conocimiento, así como de las externalidades negativas, fundamentalmente del ámbito de la ecología. En ninguno de los dos casos, el sistema económico puede establecer un mecanismo de devolución/compensación que responda a ese esquema. Pongamos de nuevo el caso de los artistas a los que se recurre ya de una forma casi canónica cuando se trata de hablar de los fenómenos de gentrificación ${ }^{75}$ en las ciudades. Si nos remitimos a la tríada marxista de la renta, el beneficio y el salario, observamos que durante toda la época de la industrialización había una centralidad de los beneficios como forma de captación de plusvalía. En la actualidad, durante el postfordismo, podemos decir que la renta se ha convertido en uno de los pilares de la producción de ganancias a través de la progresiva complejidad de las herramientas financieras y sus procesos de virtualización. Como bien indica Vincent Navarro ${ }^{76}$ cuando habla de la enorme concentración de las rentas durante los últimos años:

¿Y de dónde procede tanta riqueza? La respuesta es fácil. Viene sobre todo de las rentas del capital, y muy en especial de las rentas del capital financiero. En 1997, antes de que se iniciara la crisis de 1999 (en Asia, América Latina y Rusia) el valor de las transacciones financieras era 15 veces el valor del producto interno bruto mundial. En 2008 pasó a ser ya 70 veces. Las cincuenta empresas mayores del mercado (excepto una) son financieras. Así, mientras que las rentas del capital financiero subían, las rentas del trabajo disminuyeron. El $40 \%$ de renta inferior vio el porcentaje de la renta total poseída descender a sólo un $12 \%$. Actualmente, el sector financiero está dominando el capital.

Cifras demoledoras. Ya hemos analizado en diferentes momentos los procesos de financiarización de las familias y de los Estados que suceden a gran escala pero queremos sumarle un análisis "a ras de tierra" de esta transformación económica. Por poner un ejemplo de gran sencillez y literalidad que atañe al "poner a trabajar la ciudad", en el caso de las rentas producto de los bienes inmobiliarios,

74. MOULIER BOUTANG, Yann. "Riqueza, propiedad, libertad y renta en el capitalismo cognitivo". En: Capitalismo cognitivo, propiedad intelectual y creación colectiva. Madrid: Traficantes de sueños, 2004.

75. La gentrificación es un proceso de transformación urbana en el que la población original de un sector o barrio deteriorado y pauperizado es progresivamente desplazada por otra de mayor nivel adquisitivo como consecuencia de programas de recalificación de espacios urbanos estratégicos.

76. NAVARRO, Vicent. Los súper ricos y la Banca, artículo publicado el 5 de junio de 2012 disponible on line en http://www.vnavarro.org/?p=7354. 
como bien sabemos, su valor no depende únicamente de las calidades inherentes de los inmuebles sino de la dinámica cultural de los barrios en los que se sitúan que tiende a reflejarse en la tasación de los mismos. Nos encontramos ante el caso repetido tantas veces de barrios "en fase de desguace" que inician un ciclo de recuperación mediante la generación de un entorno cultural creativo (véase Richard Florida ${ }^{77}$ y sus tan cacareadas ciudades creativas) por parte de artistas que aprovechan las rentas bajas para sobrevivir a su precariedad y que, de esta manera, paradójicamente, provocan el rápido crecimiento de esas mismas rentas por el valor añadido que suponen.

Independientemente de que el deterioro original sea fruto de una operación especulativa previa, lo que únicamente empeora el diagnóstico pero no modifica el ciclo, en este caso, se sabe que ese beneficio no revierte en los generadores sino que acaba rebotando contra ellos, obligados a trasladarse de nuevo a zonas en donde las rentas y todo lo que las rodea (comercios, espacios de ocio, etc.) sigan siendo bajas ya que su condición precaria no se ha visto modificada un ápice. La renta se convierte pues en una forma de captación de las externalidades positivas generadas a través de la expropiación de las dinámicas culturales que revalorizan la propiedad en determinados barrios. Este fenómeno no es más que uno más dentro de muchos otros destinados a esta modalidad de captación y sirve de ejemplo a la progresiva complejidad de los movimientos económicos metropolitanos.

\section{4 (Pequeño paréntesis autobiográfico y por tanto carente de todo rigor)}

Hace diez años que vivo en Russafa, un barrio cercano al centro histórico de mi ciudad, Valencia. Forma parte de la primera ampliación programada que se hace en las ciudades en torno a finales del siglo XIX y principios de XX, lo que se denomina generalmente como Ensanche, Eixample si queremos mantener el parentesco con las intervenciones urbanísticas realizadas en Barcelona. Esta ciudad surge tras París y Viena como el tercer centro de planificación urbanística que, bajo las órdenes de lldefonso Cerdá, proyectará la ampliación de la ciudad, el Eixample, realizando un ordenamiento por manzanas con arcadas en cuyo interior habría jardines en principio planificados como públicos. No obstante, su plan fue llevado a cabo de forma diferente a la proyectada ya que el acceso a las zonas internas se convirtió inmediatamente en privado, reduciéndose además sus dimensiones. La idea de lo público cuaja pero rápidamente se convierte en público sólo para unos pocos.

77. FLORIDA, Richard. La clase creativa. La transformación de la cultura del trabajo y el ocio en el siglo XXI. Barcelona: Paidós, 2010. 
Estos tres casos aislados prefiguran el auge de lo urbano que se manifestaría con el cambio de siglo motivado igualmente por los cambios socioeconómicos producidos por la revolución industrial. Una de las consecuencias de esta revolución fue la necesidad de construir grandes bloques de viviendas, fábricas y edificios públicos con la misma rapidez con la que se extendió ese modo de producción. En el caso de mi barrio, la burguesía floreciente se instala en estas nuevas zonas rodeadas de jardines, especialmente en la demarcada por la antigua Avenida de José Antonio, actualmente denominada Reino de Valencia, y el río Turia, convertido en una amplia zona ajardinada tras realizarse su desviación definitiva. La definición de sus orígenes y límites, tomada de fuentes institucionales ${ }^{78}$, sería la siguiente:

L'Eixample" es el nombre con el que el Ayuntamiento de Valencia denomina al segundo de los diecinueve distritos que forman todo el término municipal de la ciudad de Valencia. En el distrito de "L'Eixample" encontramos tres barrios claramente definidos: Russafa, el Plá del Remei, y la Gran Vía. Cabe destacar que pertenecen todos ellos al histórico distrito del primer ensanche de la ciudad de Valencia, que en 1865 hizo derribar la muralla medieval que rodeaba el centro histórico para poder disfrutar de grandes vías, arboledas y espacios donde edificar nuevas y señoriales viviendas. Tras varios proyectos, en $1884 \mathrm{se}$ presentó el proyecto definitivo de ensanche de la ciudad y fue aprobado por el Gobierno central en 1887.

Los límites del distrito vinieron determinados por cuatro importantes elementos: el trazado de la muralla en el norte, el cauce del río Turia por el este, el viejo Camino de Tránsitos por el sur (actual avenida Peris y Valero), y la barrera que suponían las vías del ferrocarril por el oeste. Las grandes vías de las Germanías y del Marqués del Turia formaron el eje principal del distrito junto con la diagonal avenida del Reino de Valencia. Desde 1877 pasó a formar parte de la ciudad de Valencia, y en la actualidad forma el mayor barrio en extensión de todo el distrito. En su extremo norte encontramos la Plaza de Toros de Valencia que recae a la calle Játiva, y su ligera forma triangular la forman los límites de la calle Ruzafa y la avenida Reino de Valencia por el norte, la avenida Peris y Valero por el sudeste, y las calles Gibraltar y Alicante -además de las vías del ferrocarril-por el oeste hasta llegar de nuevo a la calle Játiva. Incluye además la mitad oriental del futuro Parque Central de Valencia.

Prestemos atención a la última frase de esta descripción ya que es la que nos dará la clave de la transformación que ha sufrido el barrio en los últimos 20 años, la enésima enunciación de la gran promesa que provoca sonrisas con sólo nombrarla: el Parque Central, el proyecto de zona verde (y grandes torres) en el centro de la ciudad fruto de la liberación de suelo tras el soterramiento de las vías de tren. En torno a su espejismo, se han producido numerosas operaciones especulativas e intentos de cooptación por parte de las promotoras del enriquecimiento que supondría su realización tanto en términos de valor catastral como de

78. http://www.valencia.es/, consultada on line el 20 de julio de 2011. 
valor inmobiliario. Resumiremos brevemente el proceso que, por ser un clásico, no deja mucho campo a la duda. Russafa fue durante muchos años un barrio popular, en donde abundaba el pequeño comercio local que abastecía a sus habitantes, un barrio con sus centros de reunión y desarrollo de la vida social, dos iglesias, un mercado, un parque, dos colegios públicos y una tradición fallera muy arraigada que articulaba su vida social en torno a los "casales".

A pesar de ser colindante con el centro histórico de la ciudad, se consideró que el distrito de Russafa era periférico en su composición ya que, como todos los barrios cercanos a las vías del tren, la mezcla de clases populares, hostales de baja estofa y prostíbulos, lo hacía irrecuperable para una burguesía moderada que optó por ocupar el espacio entre la Gran Vía, los jardines del Río y la avenida diagonal del Reino de Valencia. Las naves de garajes, carpinterías, la grúa municipal, talleres mecánicos o almacenes ocupaban en esta zona esos patios centrales de las manzanas que hubieran debido destinarse a espacios comunes ajardinados. El destino natural de un proletariado con aspiraciones. Atendiendo a la evolución del barrio constatada por Francisco Torres ${ }^{79}$, sociólogo especializado en el estudio de las dinámicas de convivencia en barrios multiculturales, veremos cómo:

A partir de los años 70, el barrio había perdido población, buena parte del pequeño comercio había cerrado y la intensidad y centralidad de las relaciones vecinales se había debilitado. Sin embargo, desde primeros de la década de los 90 el proce so de pérdida de población se detuvo y algunas de sus características tradicionales, como la animada vida de calle y la intensa actividad económica, han revivido aunque modificadas. A los vecinos de "toda la vida", se han sumado los nuevos vecinos autóctonos de la década de los 90, jóvenes estudiantes y profesionales en su mayoría, y los vecinos extranjeros queen enero de 2005 constituían el 15,9\% del total del vecindario.

En esta primera fase, la población extranjera que se integra en el barrio es fundamentalmente magrebí y lo hace tanto instalándose a vivir en él como abriendo simultáneamente comercios halal, teterías y otras tiendas que abastecen a la población magrebí no sólo del barrio sino de otras zonas. De esta manera, Russafa se convierte en un espacio de sociabilidad y no solo de alojamiento para dichos inmigrantes. Este esquema se reproduce en menor grado en lo que respecta a la población subsahariana, son transformaciones lentas en las que las familias integran a los niños mediante los establecimientos educativos y ellas mismas lo hacen a través de los comercios de proximidad que abren en sus mismas calles. De la misma manera, se formalizan las primeras asociaciones de inmigrantes que fomentan una integración a todos los niveles mediante asesoramiento jurídico, clases de español, clases de árabe,

79. TORRES, F."Las dinámicas de la convivencia en un barrio multicultural. El caso de Russafa en Valencia". En Papeles del CEIC, 2006, vol. 2006/1, n²3. 
etc. Esta primera ola migrante, asumida sin gran problema por un barrio, contrasta con la manera en que se produce la segunda ola.

Inicialmente podríamos hablar de una situación de co-presencia residencial, distinta de la experiencia anglosajona del barrio étnico y de la inserción residencial segregada, es decir, se comparten los espacios públicos a causa de las residencias mixtas pero se separan los espacios íntimos, produciéndose lo que viene a llamarse inserción urbana, no hay integración plena pero tampoco hay oposición abierta si atendemos a la clasificación sociológica que diferencia 3 tipologías de multiculturalidad: la hostilidad, la co-presencia y la convivencia. La convivencia implicaría una deseable interacción y relación positiva entre vecinos autóctonos e inmigrantes, objetivo que sería deseable alcanzar en todo barrio. Tal y como especifica Torres ${ }^{80}$, se entiende la inserción urbana como el proceso de paulatina incorporación de los inmigrantes a la ciudad como vecinos, trabajadores, consumidores y usuarios de los servicios públicos. Pero esta incorporación puede hacerse de formas muy diferentes que impliquen grados diversos de respeto y aceptación entre los diferentes habitantes. Por tanto, no se puede igualar automáticamente inserción e integración, caracterizándose la última por tres variables: la igualdad de condiciones, derechos y obligaciones, el respeto y el derecho a la diferencia y una dinámica social que fomente la interrelación entre grupos. En el caso de Russafa, podemos hablar de un primer momento de co-presencia residencial previo al paulatino proceso de inserción integrada, quebrado a su vez por las dinámicas propias de la gentrificación que demonizan al migrante para expulsarlo en una segunda fase. Intentaremos analizar este proceso con más detalle.

El hecho de que inicialmente se elija este barrio como destino de migrantes y artistas, responde al mismo esquema que se ha reproducido en muchas otras ciudades europeas de determinado tamaño, en las que un cierto cosmopolitismo unido a la degradación de zonas del centro histórico o adyacentes, como es el caso aquí, permite la concentración en ellas de esta mezcla de componentes poblacionales. Según el análisis realizado por Albert Moncusí ${ }^{81}$, el parque de viviendas es considerablemente antiguo puesto que la mayor parte de ellas (68,88\%) fueron construidas entre 1900 y 1961 y casi la mitad del conjunto de edificios (46,83\%) antes de 1941. Dichos datos contrastan con el hecho de que para el conjunto de la ciudad la media de antigüedad en la construcción de edificios se sitúa entre los años 1960 y 1980. Los edificios de mayor antigüedad en el barrio están ubicados en la zona delimitada por las vías del ferrocarril hasta la calle Cuba, incluyendo, además de ésta última, las

80.TORRES, F., Ibid.

81. MONCUSÍ FERRÉ, Albert, Nuevos y viejos vecinos en dos barrios de Valencia (Orriols y Russafa), Valencia: Ayuntamiento. Regidoria de Benestar Social i Integració, 2009. 
calles Gibraltar, Denia, Filipinas, Buenos Aires, es decir, allí donde se produce posteriormente la mayor concentración de viviendas de inmigrantes.

La mayoría de la población original censada a principios de los 90 compró sus viviendas en el momento de su construcción por lo que la población respondía en ese momento a dos características diferenciales respecto a otros barrios: su origen era fundamentalmente valenciano, con poca migración nacional, y su media de edad era bastante elevada. Se trata de una población envejecida tanto en lo que respecta a sus habitantes como a las personas que regentaban los comercios de proximidad. Esto significa que en el momento en que empieza a realizarse el relevo generacional, a partir de la década de los 90, la existencia de este parque inmobiliario envejecido va a favorecer la entrada de inquilinos de bajo poder adquisitivo. Por una parte, las grandes naves destinadas a garajes, carpinterías etc., se convierten por sus dimensiones y precio en estudios ideales para los artistas. Por otra, las casas más viejas con condiciones de habitabilidad bastante precarias, son destinadas a los alquileres dudosos, es decir, a gente cuyos avales son también cuestionables: los inmigrantes. Igualmente, los comercios de proximidad en que sus dueños se jubilan son ocupados inicialmente por la primera ola de inmigración marroquí y posteriormente, en áreas localizadas, por inmigrantes subsaharianos (calle Denia) y chinos (calle Cuba).

Esto hace que, en pleno boom inmobiliario generalizado, en la zona se produzca un fenómeno de doble nivel que ya Torres achaca a procesos de especulación y que se ve recalcado por Moncusí en estudios posteriores. Por un lado, se realiza la promoción de edificios de nueva planta. Por otro, se produce un deterioro de las zonas en las que se alojan inmigrantes cuyas casas son ya de menor calidad. Algunas de esas casas, abandonadas, sufren fenómenos de ocupación simultáneos a la introducción de la compra-venta de drogas en esos sectores, situación ante la que, voluntaria o inadvertidamente, la policía hace reiteradamente la vista gorda. En resumen, tras una primera década de transformación progresiva de la población, a partir del 2000, determinadas zonas (curiosamente, las limítrofes al proyecto del Parque Central se cuentan entre ellas) empiezan a degradarse sensiblemente por la dejación de control policial, el deterioro de casas y su ocupación ilegal, la aparición y multiplicación de solares en las zonas en las que ya sólo se puede contemplar el derribo.

Paralelamente, se lanza la idea de que el barrio está invadido de inmigrantes, que su proporción es mucho mayor que en otras zonas, a pesar de que las estadísticas demuestran lo contrario, ya que se ha producido un estancamiento e incluso decrecimiento de la población extranjera a lo largo del 2000, pasando Russafa de ser el cuarto barrio en población migrante a ser el veinteavo. A pesar de ello, se generaliza la visión contraria e incluso empiezan a lanzarse rumores sobre la vinculación con Al-Qaeda de la población árabe que cuenta ya con una mezquita propia en la calle Buenos Aires, edificio que se convierte en el símbolo de la teórica"colonización"musulmana. 
Como a estas alturas sabemos y más si los medios de comunicación intervienen en ello, la concentración étnica es un fenómeno construido también de forma subjetiva. No importa tanto la presencia real de población de determinado origen étnico como la creencia en la misma, ya que en aplicación del famoso teorema de Thomas, "cuando una situación es definida por las personas como real, es real en sus consecuencias" ${ }^{82}$. La primera visión de riqueza multicultural que se tuvo al principio se ve sustituida por una de "invasión", fomentada por grupos de ultraderecha (España2000) que realizan manifestaciones y agresiones varias, así como por determinados medios de comunicación y otros agentes de identidades e intereses no declarados. Moncusí ${ }^{83}$ dirá al respecto:

La idea de la "invasión mal enfocada" hace referencia a una teoría extendida en casos como los que nos ocupan en los que se atribuye la huída de las personas autóctonas a la llegada de inmigrantes extranjeros y a una degradación que sería consecuencia de ella. Como ha propuesto Aramburu (2001), para el caso de Ciutat Vella en Barcelona, la relación de causa-efecto entre abandono de población autóctona y llegada de inmigrantes es más una profecía que se cumple a si misma que una realidad constatable de forma contundente. El autor sugiere que la degradación se produce vinculada a un proceso de especulación urbanística y como la antesala a la rehabilitación y construcción de inmuebles para su comercialización. Entonces, la concentración de personas de bajo estatus socioeconómico -entre la que se encontrarían personas extranjeras- sería una manifestación más de esa especulación, a la que seguirían formas de gentrificación.

En Russafa, encontramos una situación parecida tanto en la dinámica del mercado de vivienda como en la percepción de los vecinos. Se producen los primeros enfrentamientos entre asociaciones de vecinos, ya que una de ellas opta por apoyar los argumentos racistas de la ultraderecha atendiendo a la atmósfera de inseguridad. Hay que pensar que el ambiente que, hasta entonces, se había vivido en el barrio era casi pueblerino en el sentido de que la mayoría de las personas que vivían allí se conocían entre sí desde largo tiempo, y ese conocimiento mutuo les ofrecía una sensación de seguridad y confianza a personas que iban envejeciendo, con lo que ello conlleva de incremento de la sensación de vulnerabilidad. Por tanto, resultaban blancos perfectos para la campaña mediática que ofrecía una imagen de peligrosidad del barrio asociada a la población extranjera, realizada especialmente entre los medios de comunicación que la gente mayor de extracción popular del barrio leía y miraba, por lo que no es de extrañar que parte de esta población original se sumara a propuestas de incremento de control policial y de rechazo de la población extranjera.

En resumen, en términos asociativos, se produjeron disensos de importancia dentro de las asociaciones por lo que algunos de sus miembros así

82. THOMAS, W. I. The child in America: Behavior problems and programs. New York: Ed. Knopf, 1932.

83. MONCUSÍ FERRÉ, Albert, op. cit. p. 56. 
como parte de la población española renovada, en su mayoría profesionales liberales, artistas, etc., entienden que hay que iniciar una nueva plataforma en la que también se integre a la población extranjera y que sirva para convertirse en interlocutora válida cara a las Administraciones: de esta manera se funda en octubre de 2002 la Plataforma per Russafa ${ }^{84}$, que jugará un papel importante en la definición del barrio durante la última década, agrupando a diferentes entidades vecinales con la excepción de la asociación de Vecinos inicial.

Tras esta construcción de la imagen de deterioro barrial con su consecuente reducción asociada de precios de venta y aprobación de derribos de edificios en mal estado, posterior a su ocupación ilegal pero consentida que ha terminado por dar la puntilla a construcciones que bien hubieran podido rehabilitarse manteniendo una estética propia de barrio con casas de techos altos y suelos de azulejo hidráulico, se sucede la promoción y construcción de nuevas viviendas de cierta calidad, para sentar las bases de un proceso de gentrificación. Se lanza el rumor de la inminencia del Parque Central, hasta ese momento acallado y, amparándose en él, se lanza un proyecto de construcción de un parking en el mismo espacio en el que se encuentra el único parque del barrio. Esta amenaza surge paralela a las primeras solicitudes (que datan de 2002) de un equipamiento escolar más que necesario en la zona. Afortunadamente, el barrio cuenta con un denso tejido asociativo que inicia, desde la mencionada Plataforma de Ruzafa, a la que se suman otras asociaciones, el largo período aún no concluido de manifestaciones vecinales, actos reivindicativos, recogida de firmas y participaciones en los Plenos de la Junta Municipal con acciones legales orientadas fundamentalmente a dos cuestiones: bloquear la construcción del parking en la única zona verde existente y activar la construcción de un nuevo colegio en la calle Puerto Rico para paliar la carencia de plazas escolares (más de cien niños por año desplazados a otros centros escolares o a colegios religiosos concertados).

Para el Ayuntamiento ha llegado pues, la hora de actuar con contundencia que, con los dineros, y sus promesas, no se juega. En 2004, se pone en marcha el programa policial MAS con la intención de higienizar el barrio que había ya llegado a un punto en el que se habían sucedido dos violaciones y los coches con "farloperos" al volante que pasaban haciendo vibrar las calles para comprar desde sus vehículos lo que hiciera falta para acabar la noche se habían hecho ya presencia habitual, mucho más amenazadora que cualquier discusión subida de tono entre magrebís o cualquier llanto borracho ecuatoriano. A su favor hay que decir que cuando se ponen a limpiar algo, lo hacen a fondo, pues a partir de entonces y hasta que dan por terminada la tarea, no hay momento del día en el que no haya presencia policial en las calles, control de sin papeles, derribo deseado de casas tomadas,

84. www.russafa.org, consultado on line el 12 de julio de 2011. 
limpieza de cara a toda prisa y con toda violencia. Desde las altas instancias, se ha percibido la oportunidad económica que supone el barrio, se ha sembrado miseria y se quiere recoger dinero: se inicia en la zona el espejismo inmobiliario declarado que ya se había propagado como una plaga por diferentes barrios y ciudades, parece que la población entera desayuna cocaína de la euforia que nos recorre. En mi barrio, de la multiplicación de locutorios, se pasa a la profusión de inmobiliarias, los bancos de la esquina conceden créditos como si fueran bizcochos, las tiendas de barrio suspiran y sueñan un destino burgués, los primeros carteles de lofts de lujo aparecen en el horizonte.

Paralelamente, se siguen reivindicando equipamientos básicos como una mejor biblioteca, un centro para mayores o un polideportivo, instalaciones que no se ejecutan ya que, según nos aseguran, cuando la promesa del Parque Central se convierta en una realidad en un futuro luminoso, todas nuestras necesidades serán cubiertas con creces. En el 2004, el Ayuntamiento ya había hecho públicos los primeros proyectos de Parque Central en los que la superficie destinada a zona verde había quedado sensiblemente reducida, hecho que provocó una respuesta de oposición por parte de las asociaciones vecinales de ambos lados ya que veían cómo se frustraban sus aspiraciones de obtener un verdadero "pulmón verde" en el centro de la ciudad así como equipamientos básicos largamente pospuestos. Las edificaciones proyectadas eran necesarias, según el Ayuntamiento, para poder financiar fundamentalmente el soterramiento de las vías de tren que constituye la operación más costosa asociada a la construcción de la nueva estación del AVE. La estación Valencia Joaquín Sorolla, construida en la urgencia de dar servicio a los trenes de alta velocidad, se concibe desde el principio como una estación provisional, aunque todos sabemos que tardaremos mucho tiempo, si es que llegamos a verlo, en conseguir la unión de dos barrios mediante el soterramiento de las vías y por tanto, el posible traslado de dicha estación junto a la original.

El folletín del Parque Central, con sus intensas negociaciones de todo tipo, culmina en la convocatoria del concurso organizado en diciembre de 2009 por la Sociedad Valencia Parque Central, al que se presentaron 36 despachos de arquitectura de ocho países distintos, entre los que se encontraban algunas de las principales firmas de arquitectura nacional e internacional, en la línea con los delirios de grandeza de un ayuntamiento endeudado hasta las cejas. Este concurso lo gana la paisajista americana Kathryn Gustafson con una propuesta folclórica que dice querer seguir el diseño de platos cerámicos valencianos e inspirada igualmente en un poema de Ausiàs March Ilamado "Aigua plena de seny", por si cabía algún a duda sobre el valencianismo inane este que practicamos y que nos ha llevado a la quiebra técnica en la Comunidad. El espectáculo ante todo. Espectáculo de humo pues no hay dineros ni para realizar la primera fase del Parque adyacente al barrio y menos aún para el Polideportivo y Centro cultural que los vecinos vienen reclamando desde hace siglos en las Naves de Ribes situadas esa zona. 
Las primeras inversiones del Plan Riva, puesto en marcha en Russafa para rehabilitar la zona tras su deterioro programado, se han destinado a la línea de metro, precisamente lo contrario de lo que requerían los vecinos. Nadie discute los beneficios de la línea 2 del metro, con estaciones en General Urrutia y Reino de Valencia, el día en que finalmente se acabe, pero cualquiera ve la urgencia de las reivindicaciones vecinales en lo que respecta a prestaciones que se consideran básicas. A continuación incluimos un ejemplo de la extensiva campaña de protección y concienciación del barrio realizada por parte de la Plataforma que ha abarcado desde la redacción de propuestas de emplazamiento del parking en espacios que no repercutieran negativamente sobre el mismo (se llegaron a presentar tres propuestas diferentes totalmente desarrolladas a nivel técnico), pasando por la campaña de recogida de firmas o la edición de trípticos que explicitaban la voluntad expresa de convertir el barrio de Russafa en un barrio de diseño participativo. ¡Hubiera podido ser un proceso tan ejemplar, innovador y lindo que hasta al Ayuntamiento le hubiera beneficiado! Por no hablar de la posibilidad remota de generar un barrio cooperativo como se ha hecho en algunas poblaciones catalanas como, por ejemplo, Sants ${ }^{85}$. Pero sabemos que la noción que tienen en este Ayuntamiento del urbanismo participativo es bastante relativa y atañe más bien a la participación privada de los beneficios públicos como, a estas alturas, cualquiera mínimamente enterado de la política valenciana, bien sabe.

Más allá de las reivindicaciones concretas, la Plataforma ha permitido establecer acuerdos sobre cómo abordar los problemas del barrio así como erigirse en interlocutora reconocida por todas las partes implicadas, excepto por el propio Ayuntamiento. Estos años de dinámicas antagonistas concretas, basadas no obstante en la concertación, en colaboraciones y desacuerdos, han tenido consecuencias no menospreciables para el tejido asociativo: se ha consolidado una red de relaciones y contactos de personas activas de los diferentes sectores de vecinos del barrio. En la propia web de la Plataforma, encontramos esta información sobre su posicionamiento y sus logros:

El nacimiento de la Plataforma per Russafa (junio 2001) supuso unir voluntades que, desde diversas asociaciones, se habían planteado mejorar el barrio. Desde la nueva identidad plural, nos manifestamos en enero del 2002 "Por la convivencia, contra el abandono y olvido del barrio". Comoresultado de ello lanzamos la campaña "Mejoremosnuestro barrio" en marzo del 2002, a través de más de 50 buzones repartidos por el mismo, pidiendo:

- la reforma del colegio Balmes

- Ia tramitación de la Escuela de la calle Puerto Rico

- la ampliación de la zona de juegos infantiles

- la creación de un local social multicultural e intergeneracional

85. Para más información al respecto, véase http://sants.coop/que-es-el-projecte-barri-cooperatiu 
- ayudas a la rehabilitación de edificios

- remodelación PGOU en c/Platerías.

$Y$ estos son algunos de los logros obtenidos

1. Apoyando las iniciativas del A.M.P.A. del Colegio Público Balmes, se ha logrado que para el curso 2005/2006 se abriera reformado.

2. Mejora de la zona de juegos del único parque que tenemos en el barrio (parque Manuel Granero).

3. La escuela de la calle Puerto Rico, que puede empezar a construirse en medio año.

4. En contra de cualquier provocación violenta y por la convivencia y respeto a la diversidad que conforma el barrio, denunciamos la actitud de "España 2000" en la marcha de 2002, siendo la primera vez que una denuncia de este tipo es tramitada a querella.

5. Colaborando con otras asociaciones y presionando a la administración: en 2005 se abrieron el Centro de Jubilados y el Centro Municipal de Juventud, y el Plan RIVA-Russafa está en proyecto gracias a la presión vecinal.

Como vemos, resulta fundamental para la "salud" de la ciudad, que se fomente activamente la existencia de un tejido asociativo en todos los barrios que permita mediar entre lo que la Administración considera beneficioso y la realidad de la población que lo vive y que, por tanto, está en una posición inmejorable para captar las necesidades, adaptaciones y proyectos viables en cada zona. Desde la posición institucional, no sólo no se debería entrar en una lógica antagonista con los propios ciudadanos y sus asociaciones, como viene siendo reiteradamente el caso en esta ciudad, cuestión que posteriormente veremos en el desarrollo detallado del proyecto Comboi a la fresca, sino que se debería fomentar la creación y funcionamiento de plataformas de mediación Ayuntamiento-sociedad civil de manera que la co-gestión participativa fuera una realidad y no este remedo de participación que dicho Ayuntamiento proclama realizar a los cuatro vientos, cuando se ha demostrado reiteradas veces que un buzón de participación unidireccional y no vinculante es un modelo ineficaz y obsoleto, sobre todo si se ningunea de forma reiterada a las organizaciones que, desde la sociedad civil, elevan sus peticiones, comentarios y sugerencias a las instituciones.

De los logros enumerados por la Plataforma, la construcción del colegio de la calle Puerto Rico sigue sin ser realidad 10 años después, aunque lleve tres años con el suelo expropiado y sin poner en marcha la licitación, habiendo el Ayuntamiento amenazado un par de veces ya con cederlo a capital privado y convertirlo en una escuela concertada, obteniendo sistemáticamente una respuesta de rechazo por parte de las asociaciones del barrio. La ausencia de voluntad y de fondos mantiene bloqueado este proyecto esencial para asegurar una mínima calidad de vida en un barrio, asegurar las necesidades educativas en los tramos obligatorios de formación. Por otra parte, el Plan Riva-Russafa se implementó, efectivamente, abriendo una oficina de información en el mismo barrio con gran presencia de los políticos que se hicieron las correspondientes fotos. Lamentablemente, el Plan lleva sin fondos para 
respaldar las rehabilitaciones que promueve desde su creación en 2007, con lo cual ha resultado una operación de lavado de cara interesante. La única actuación perceptible, que corresponde a fondos del Plan Confianza, se inició en abril de 2009 y terminó dos años después, con las obras de reurbanización y adecuación del Eje de la calle Puerto Rico y adyacentes.

El Conseller de Infraestructuras y Transportes, Mario Flores, y la alcaldesa de Valencia, Rita Barberá, acudieron a la calle Puerto Rico para presentar el inicio de estas obras. Flores subrayó que "la reurbanización del barrio dará un protagonismo especial a los peatones, a través del arbolado, el mobiliario urbano y los carriles bici. También se emplearán materiales para tratar de insonorizar los vehículos, de manera que, los vecinos notarán que habrá mucho menos ruido", destacó. Por su parte, la alcaldesa aseguró que a través de estas iniciativas se va a "mejorar la estética del barrio de Ruzafa, pero respetando su singularidad y sensibilidad". Añadió que con las obras "comienza el despegue de Ruzafa, que culminará cuando llegue el Parque Central". ${ }^{86}$ Para confirmar todo este análisis, el 17 de agosto de 2012 se publica en los periódicos la noticia del cierre de la oficina del plan de Rehabilitación Integral (RIVA) de Russafa, dejando la mayor parte del plan de regeneración del barrio pendiente, cinco años después de su triunfante inauguración por parte de las autoridades.

Resulta un tanto sospechoso que de las actuaciones necesarias, se haya llevado a cabo únicamente aquella para la que el Gobierno central ha aportado dinero. Será que aquí no tenemos dinero porque Calatrava se lo ha llevado todo montado en un coche de Formula 1. Pero más sospechoso todavía resulta que su intervención haya consistido en reurbanizar las calles que actualmente albergan numerosas terrazas de ocio, mediante aceras más espaciosas y asfalto fonorreductor para que los vecinos sólo escuchemos el ruido de la juerga que se monta debajo de nuestras ventanas, que siempre es más agradable que el de los vehículos a motor. Porque la verdadera transformación del barrio se ha producido siguiendo el mismo modelo de la Goutte d'Or o del Belleville parisinos y de tantos otros.

Fracasada (parcialmente, abortando su pleno desarrollo delirante de lofts esnifables) la operación inmobiliaria a causa de la crisis, a pesar de mantener aún precios de lujo para construcciones que no lo son, justificadas por ese valor simbólico de barrio de moda; el barrio se convierte en carnaza de la noche, en destino fashion que reúne el fantasma de la multiculturalidad, la homosexualidad y el arte. A lo largo de la última década, y especialmente durante los últimos cuatro años, he visto cómo iban desapareciendo los negocios de proximidad, las carpinterías, las droguerías, las panaderías, las tiendas de electrodomésticos, para verse progresivamente sustituidas por restaurantes en un primer tiempo, y por

86.www.diariocriticocv.com/ciudadanos/flores/barbera/plan-confianza/barrio-de-ruzafa/351444, 4 de febrero de 2011. 
bares y discotecas en un segundo tiempo que consolidan la consagración como barrio de moda sacrificado en aras del esparcimiento general de la población valenciana, zona de ocio asaltada de jueves a domingo por las hordas de ciudadanos que desean olvidar el resto de su semana.

Pero aquí, ¿quiénes son los malos si es que tiene que haberlos? ¿Los matrimonios envejecidos que cierran el horno de toda la vida porque sus hijos no quieren hacerse cargo y aprovechan la jugosa oferta que les hace el tirillas de turno que ha tenido la buena idea de poner la enésima bocatería de nombre "La virada" y aire marino? ¿O los primeros homosexuales que intentaron sentirse a gusto en un barrio instalándose en sus fincas y abriendo los primeros negocios LGTB aprovechando que su asociación tenía la sede aquí desde tiempos inmemoriales? ¿O quizás fueron los promotores de eventos que aprovecharon del éxito del barrio con una imagen identitaria diferencial para lanzar la campaña "Russafa entiende", no de sensibilización o de normalización de la homosexualidad, sino de circuito nocturno de ocio combinado? Por no hablar de que dos semanas después, disfrutamos del circuito de tapas eróticas promocionado por una conocida marca de vinos y un mes antes, del festival Rússafart ${ }^{87}$, evento artístico que detallaremos a continuación como emblema teórico de la gentrificación urbana...

De hecho, todo este paréntesis, más allá de la introspección autobiográfica, pretendía analizar un caso concreto de polinización cultural, de externalidad positiva recuperada por agentes terceros, siguiendo el modelo de barrio creativo. En este ejemplo, el papel realizado por los artistas sigue al milímetro los ejemplos clásicos de comercialización barrial asociada a un valor simbólico añadido. Del barrio, de los mismos artistas, surge una iniciativa de encuentro en 2008 basada en abrir los estudios a los visitantes intentando ofrecer una visión no comercial de la actividad creativa. A continuación, incluimos el texto realizado por la artista Hélène Crécent, promotora junto con otros artistas de la primera convocatoria autogestionada:

Por primera vez, los artistas profesionales del barrio valenciano de Russafa celebran un fin de semana de Portes obertes dels tallers artístics. Una manifestación colectiva que hemos denominado RUSSAFART y que quiere descubrir lo que acontece tras las paredes del barrio y mostrar que existe un colectivo latente de individuos que expresan lo que piensan a través de su creación. De viernes a domingo, 23, 24 y 25 de mayo, más de medio centenar de artistas, entre pintores, escultores, fotógrafos y videoartistas de Russafa, os invitan a descubrir sus lugares de reflexión y de acción. Participan 22 talleres y 8 espacios (que acogen las exposiciones colectivas de aquellos que no disponen de taller propio y las proyecciones de videoarte).En total, son 70 artistas del mundo de las artes plásticas que ofrecen al público un imaginario íntimo y personalísimo al que habitualmente pocos tienen acceso y que es reflejo de su trabajo y, a veces, de su mundo interior. Talleres, en ocasiones, pequeños con capacidad para transformarse en todo un universo. Se trata de

87. www.russafart.com, consultado on line el 17 de abril de 2012. 
una ocasión pionera en Valencia y similar a la que acontece en otras ciudades europeas. Un recorrido, diseñado a modo de libre circuito, que permite practicar la sana costumbre del paseo por las calles del barrio y visitar cada uno de los talleres abiertos ex profeso para ello, con ágape incluido. La iniciativa se plantea como una forma de practicar la comunicación con el otro. El encuentro para el re-conocimiento. Una ocasión para la activación de la vida del barrio en su vertiente cultural y creativa donde se ofrece la oportunidad de disponer de lugares de reflexión común, de disfrute y de aprecio.

Este primer evento tenía el valor de que respondía a una situación auténtica y que lo hacía siguiendo un modelo de bottom-up, desde abajo y de forma horizontal, un montón de artistas que desde sus casas-estudios, llevaban trabajando en el barrio, desarrollando su actividad, deciden abrir a sus vecinos dichos espacios y compartir sus procesos creativos. En ese momento, ya había algunas galerías de arte funcionando, el Sporting Club de Russafa o Color Elefante, así como un par de talleres de enmarcación pero, en general, la mayoría de artistas desarrollaban su labor sin conocimiento de sus vecinos, de manera que fue un momento mágico en el que verdaderamente, la calle se llenó de gente curiosa que se introducía en casas y talleres, y de artistas contentos de poder compartir su obra mostrando el proceso artístico que hay detrás, los bocetos, las maquetas, las dudas. Esta primera iniciativa autogestionada que salió adelante gracias al entusiasmo de sus promotores y a su trabajo generoso de coordinación sin remunerar, tuvo un eco enorme en los medios de comunicación. Casualmente, la sociedad valenciana recibió esta oleada de frescura como si llevara años esperándola, celebrando su inventiva y su condición diferencial. Todos nos frotamos las manos. Unos por sus suculentas previsiones, otros por sus magros beneficios creativos. El barrio, por tener la excusa de recorrer sus calles.

Hubo muchos problemas antes de relanzar la segunda convocatoria. Podríamos decir, si queremos ser solemnes, que la primera convocatoria fue la última y murió de éxito, porque lo que vino después poco tuvo que ver con esa primera experiencia. Aquellos que, en la primera, voluntariamente y sin retribución consiguieron a duras penas editar un folleto desplegable en el que se incluía un pequeño plano con la situación de los diferentes estudios y galerías, se echaron atrás ante el éxito de la convocatoria que hacía que, de repente, muchos otros artistas, ya no necesariamente pertenecientes al barrio, quisieran formar parte de él y que se concibiera como un posible gran evento patrocinado por marcas comerciales, y no como una iniciativa de mutuo conocimiento y convivencia entre vecinos. Los ojos nos brillaban a todos. No sabíamos que éramos inocentes, no sabíamos que habíamos perdido ya la virginidad. Estábamos orgullosos de nuestro barrio autogestionario, de nuestra multiculturalidad, de nuestra polisexualidad. Y no éramos los únicos. Las siguientes convocatorias (2010 y 2012) sucedieron siguiendo el guión establecido: "Restaurantes, Bares y Comercios colaboradores-anunciantes de la 
guía Russafart abren sus puertas durante todo el día para el disfrute de sus visitantes". Aún no entendemos qué les llevó a poner tres mayúsculas seguidas, quizás para marcar que lo importante no eran las obras sino los lugares donde se exponían.

De esta manera, tras muchas discusiones y la desaparición de la primera infancia, Russafart se proyectó como una posibilidad común de negocio: para los artistas que se daban a conocer y para el barrio, que veía crecer su fama como lugar de ocio diferente, con librerías-café, con estudios de artista, con discotecas de moda. Surgió de entre todos un gestor que se ofreció a coordinar por un módico precio las siguientes convocatorias y de repente, estábamos pagándole un catálogo conjunto en el que no teníamos ni arte ni parte, una camiseta patrocinada por Mahou (que abasteció igualmente a estudios y talleres de su dorado producto a cambio de la publicidad asociada) y un sinfín de otras pequeñas reverencias a la sociedad de consumo. A la iniciativa se habían sumado todos los bares, restaurantes y demás establecimientos de ocio del barrio, previo pago de otra "módica" cantidad al mismo gestor. Es decir, lo peor de la autogestión y lo peor de la sumisión. Nos habíamos convertido en carne de espectador, en aura ya no fría, sino congelada y vendida en porciones, en salchichón low cost de la cultura.

Sólo que lo que simbolizábamos ya no era verdad. Ya no éramos ese barrio de convivencia y proximidad con negocios cercanos de gente conocida. Ese barrio cálido que abría sus puertas para que sus conciudadanos miraran sus enaguas creativas. Ese barrio de poca monta y mucha vida, diferente de las gated communities situadas junto al Complejo Espectacular del señor Calatrava, con sus piscinas internas y sus salas de gimnasio con horario combinado de Pilates, con sus calles bien asfaltadas y su correcta proporción de zonas verdes, con sus farolas de barrio residencial. No, nosotros teníamos que representar nuestro papel de vida que arrambla, de vida no mediatizada por expectativas burguesas, de Mimí tísica en plena Bohème. Pero nos habíamos convertido únicamente en una zona de ocio. Y esta transformación ha arrojado cierta luz sobre las diferentes actuaciones urbanísticas del barrio, sobre la intención de hacer el parking en el parque, sobre la aprobación del plan de ensanche de las aceras, sobre la generosa oferta del Ayuntamiento a los negocios chinos mayoristas de habilitarles una zona en un polígono industrial de la periferia porque repentinamente molestaban con las furgonetas de carga la vida del barrio, de manera que se liberaran de una sola vez un gran número de bajos disponibles...

¿Qué se hubiera podido hacer para evitarlo? ¿Qué está aún en nuestras manos? Si observamos el proceso que se ha llevado a cabo en otras zonas como Belleville en París, el Ayuntamiento fomentó que se pudiera llevar a cabo un contraplan urbanístico llamado la Bellevilloise, mediado por Anne Querrien y realizado por diferentes grupos de trabajo de habitantes del barrio. Eso significa poner en práctica con todas sus implicaciones la democracia contributiva, tal y como se ha venido definiendo en Francia, contrapuesta a la democracia participativa que está 
tímidamente introduciéndose en nuestro país. La segunda supondría llevar a cabo encuestas de opinión sobre diferentes posibilidades diseñadas por expertos: decidir si se prefiere la opción $\mathrm{A}$, la B o la C, y como mucho, poder incluir en algún buzón material o digital alguna sugerencia complementaria que permitiera matizar levemente lo que ya han pensado los expertos que, como todos sabemos, son los que saben, mientras que los que están viviendo cotidianamente los problemas y conocen las posibilidades de desarrollo que implican sus propias realidades, no.

Madeleine Hersent ${ }^{88}$, especialista en planes de desarrollo de economía social en barrios desfavorecidos y en grupos de mujeres, comentaba en el seminario de economía crítica de La Calderería ${ }^{89}$ cómo los programas de economía social que intentan dinamizar barrios con problemas de integración y de precariedad laboral, aplican generalmente recetas que no tienen en cuenta las capacidades de las personas que, en concreto, tienen necesidad de desarrollar una actividad económica determinada, que debe ajustarse a sus posibilidades reales, por ejemplo: mujeres, cabeza de familia, que pueden desarrollar actividades en un determinado horario laboral porque deben hacer frente a todas las demás responsabilidades familiares simultáneamente. Mujeres que pueden dar de comer a 50 personas pero no pueden perder un año en un proceso de formación para un trabajo al que nunca podrán ni siquiera optar a la entrevista. Sin embargo, un planteamiento de democracia contributiva, como hemos venido diciendo hasta la saciedad, supone poner en las manos de los directamente afectados las propuestas y negociaciones internas que lleven a planes basados en sus propias necesidades y condiciones: creer realmente en sus capacidades igualitarias a la Rancière. En resumen, este planteamiento supondría un posicionamiento político claro a favor de la población, cosa que dista mucho de ser realidad en el caso de Valencia. En referencia a la situación concreta de Russafa, Torres ${ }^{90}$ detalla hasta qué punto la deriva de un barrio es fruto de una voluntad política:

Subrayar la importancia del contexto local que constituye el barrio, no supone olvidar los factores y actores que más allá de Russafa inciden en el proceso. Por citar sólo algunos ejemplos, el proceso de renovación urbana está condicionado por la normativa municipal, de construcción y de comercio. Igualmente, la dinámica de substitución del vecindario modesto por otro de rentas superiores es favorecida por la ausencia de una política de vivienda social. Más allá de la ciudad, los procesos de convivencia en los barrios multiculturales están marcados por la gestión de la inmigración que se realiza y las políticas sociales que se aplican. Así, la convivencia y los procesos que se dan en los barrios multiculturales como Russafa constituyen una cuestión política, entendida como gobierno de la polis, de los asuntos comunes a todos los ciudadanos y ciudadanas.

Más claro, agua.

88. http://www.lelabo-ess.org/?Madeleine-Hersent

89. http://www.lacaldereria.org/?page_id=65.

90. TORRES, F., op. cit., p. 36. 


\subsection{Del precariado a la intermitencia}

En la línea de lo anteriormente dicho (previo al paréntesis que sirve exactamente para lo que sirve), la misma violencia con la que se programa la expropiación de la metrópolis y sus sistemas de gobierno en donde se entrelaza la lógica de la soberanía, la disciplinaria y el nuevo modelo de gobernanza, hace que cualquier movimiento de resistencia se vea obligado a producir nuevos modelos de vida y no sólo nuevos modelos de gobierno; del mismo modo que el biopoder se infiltra en todas las capas de la existencia, la biopolítica ha de dar cuenta de un planteamiento holístico tal y como especifica Maurizio Lazzarato ${ }^{91}$ cuando habla de la transformación del concepto de biopolítica en el itinerario conceptual propuesto por Foucault ${ }^{92}$ hasta el uso más reciente acuñado por Michael Hardt y Toni Negri ${ }^{93}$ que implica también una creación en positivo. Las últimas entrevistas realizadas a Foucault en 1984 permiten pensar la transformación del biopoder en una biopolítica, el paso de un "arte de gobernar" a la producción y gobierno de nuevas formas de vida. Hardt y Negri desglosaron posteriormente las posibilidades de los conceptos biopodery biopolítica para conectarlos con las potencias productivas de lo que dentro de la tradición marxista se denomina "la multitud". El biopoder no designaría entonces sólo una forma de dominación sino también una potencia productiva que podría desvirtuar las regularizaciones propias del capitalismo. En consecuencia, Hardt y Negri recondujeron la discusión sobre la biopolítica hacia las posibilidades de conexión con la teoría crítica de la sociedad y, más en concreto, con una cierta resistencia en positivo.

Esta noción de biopolítica englobaría la proliferación de movimientos de gran diversidad al que asistimos en la actualidad, movimientos como los de cuidadanía ${ }^{94}$, los que se oponen a la destrucción que supone la construcción 91. LAZZARATO, Maurizio. . "Del biopoder a la biopolítica". Multitudes, Marzo de 2.000 [en línea]. Disponible en <http://www.sindominio.net/arkitzean/otrascosas/lazzarato.htm> y consultado el 17 de junio de 2011.

92. FOUCAULT, Michel. El nacimiento de la biopolítica, Curso en el Collège de France 1978-1979. Buenos Aires: Fondo de Cultura Económica, 2007 y FOUCAULT,Michel. Dits et Écrits, IV, París: Ed. Gallimard, 1984, p. 741.

93. HARDT, Michael y NEGRI, Antonio. Imperio. Buenos Aires: Ed. Paidós,2002.

94. Ese término procedente del ecofeminismo y de las teorías del decrecimeinto permite entender los trabajos de cuidados enraizados en las prácticas que generan una vida sostenible. Es reconocer que "la vida vivible está por construir en la interacción con otros, que la vida se dirime en la vida misma y que no puede procurarse fuera de la vida (en los mercados)".'La Cuidadanía implica un derecho a cuidar, a no cuidar por obligación y ser cuidada/o, sin que esto signifique subordinación para las mujeres. El Decrecimiento y la Cuidadanía reclaman el derecho y las posibilidades de reorganizar nuestra sociedad de forma colectiva y de crear colectivamente nuestra propia vida de forma sostenible". Julia Weingärtner y Marta Monasterio. En “Poner la vida en el centro: respuestas del ecofeminismo y del decrecimiento a la UE", En Menos para vivir mejor, Número 64, primavera 2010. 
metastásica en el territorio, los que afirman el derecho a la vivienda o los que demandan la libre movilidad de las personas, por no hablar de los movimientos que desean poder definir su propio movimiento, como por ejemplo, las asambleas $15 \mathrm{M}$ de toda España, como un amplio espectro de procesos de empoderamiento insertados en el paisaje político. Estos movimientos, todos ellos, ponen en el centro la necesidad de preguntarse por los nuevos modos de operar en el entorno metropolitano, sobre cuáles pueden ser las estrategias eficaces en este contexto. Por ejemplo, en las últimas huelgas generales ${ }^{95}$, se hizo evidente la falta de contemporaneidad de esta herramienta de lucha ya que, volviendo al ejemplo de los productores culturales o los trabajadores de cuidados, el ámbito de precarización extendido a gran parte de la población hace totalmente testimonial la teórica presión económica provocada por su paro ya que este sólo revierte en perjuicio propio.

Por la misma razón precaria, la ocupación del espacio metropolitano acaba siendo la opción más contemporánea, como se puede comprobar en las últimas revueltas a nivel mundial. En 2000, cuando los piqueteros en Argentina quería manifestarse, se dijeron: "No tenemos fábricas, han cerrado, se han deslocalizado, tomemos pues la ciudad" evidenciando el paso de la fábrica a la metrópolis como espacio de lucha. En 2005, las revueltas en la periferia de París (en donde se produjo la intersección de exclusión racial y educación, la base de acceso al trabajo), mostraron la destrucción del tejido social en un proceso de confluencia de precarización migrante-étnica mediante el ataque a la propia ciudad, a sus instalaciones y a su símbolo por antonomasia, el coche. Por último, el ejemplo de todas las plazas tanto en los países árabes como en Europa, va más allá de la ocupación puntual del espacio, transformándose en una apropiación vital del mismo, convertido en residencia frente a los mismos ayuntamientos. Estas prácticas de "habitar la ciudad" exponiendo el cuerpo hubieran sido impensables hace tan sólo dos años y hoy día los tenemos integrados totalmente en nuestro corpus de acciones en la ciudad pero también contra la forma de la ciudad.

Por el momento, ante el blindaje de las condiciones políticas de participación, todo ello acaba concretándose en una lucha política a pie de calle, exponiendo los cuerpos, parando los desalojos por impago de hipotecas, respondiendo ante la detención de inmigrantes, encerrándose en las facultades, ocupando las plazas, las calles, manifestándose una y otra vez bajo la lluvia de epítetos como violentos, bárbaros, sufriendo el endurecimiento de las medidas de represión contra la expresión pública del desacuerdo y del malestar. Podríamos

95. La huelga general del 29 de marzo de 2012 contra la reforma laboral aprobada el 19 de febrero del mismo año, o la huelga general del 14 de noviembre de 2012, contra las políticas de ajuste del gobierno, esta última fue simultanea a las convocadas el mismo día en Portugal, Italia, Grecia, Chipre y Malta. Se considera la primera huelga internacional del siglo XXI y la primera huelga general europea. 
recuperar de forma íntegra la definición de las formas de resistencia contra los diferentes poderes que desarrolla Foucault en "El sujeto y el poder" 96 :

1. Son luchas transversales, transnacionales.

2. La meta de estas luchas son los efectos de poder en cuanto tales.

3. Son luchas inmediatas, es una crítica a lo más cercano, sin enemigo principal a gran escala ni metarrelato de emancipación, en ese sentido, son luchas anarquistas. 4. Son luchas que cuestionan el rango del individuo, afirman la diferencia pero atacan los procesos de aislamiento, son luchas en contra del "gobierno de la individualización".

5. Se oponen a los efectos del poder ligados al saber, a la competencia y a la capacitación: luchan contra los privilegios del saber, ponen en cuestión el "régimen del saber".

En el proyecto de investigación "Globalización desde abajo" llevado a cabo por Marta Malo ${ }^{97}$, dicha autora lleva a cabo un diagnóstico general del momento actual resumido en características como la densificación de procesos de descontento, también llamado malestar, la apertura de diferentes líneas de auto-organización y creatividad social inaugurando un frágil nosotros que intenta construir un nuevo principio de realidad y que correspondería igualmente a la definición realizada por Foucault de las formas de resistencia. Estas luchas comparten claramente con los movimientos de liberación de los 60-70 tanto el rechazo del trabajo rutinario y de los aparatos estatales como la vindicación de la singularidad, así como el hecho de carecer de un metarrelato de emancipación. De igual modo, no actúan únicamente como reacción a la globalización y a la crisis sino que aplican un principio transversal de relectura del internacionalismo (analizando el caso de hackers, migrantes y todo tipo de trabajadores inmateriales). Marta Malo establece cuatro líneas principales de definición de las nuevas formas de resistencia propias de la globalización desde abajo:

1. Plantean una nueva geometría variable de amigo-enemigo: se salen de la lógica de un enfrentamiento determinado contra un enemigo demarcado y no hacen de ese enfrentamiento el punto máximo del movimiento revolucionario, oponiendo una globalidad a otra globalidad. Organizan el conflicto sin dirigirlo hacia la toma de poder sino a la sustracción, al punto de fuga donde operar un desplazamiento, con la idea de abrir un agujero para que algo escape. Para hacerlo, el movimiento global adopta herramientas diferentes. La figura de la sustracción como herramienta puede ejemplificarse por la desobediencia social.

96. FOUCAULT, Michel. "El sujeto y el poder". En: Más allá del estructuralismo y la hermenéutica. Buenos Aires: Nueva Visión, 2001.

97. MALO de MOLINA, Marta. Globalización desde abajo. Esquema del proyecto de investigación [en línea].Disponible en: <http://marceloexposito.net/pdf/1969_martamalo_globalizaciondesdeabajo.pdf>[Consulta: 7 de Julio de 2.012] 
Salir a las plazas el día de reflexión antes de las elecciones vaciando de sentido la prohibición y las elecciones mismas sería un ejemplo de dicho proceder. En este momento, hay numerosas posturas desde los colectivos de resistencia que invitan a una insumisión civil mucho más extensa pero trabajando siempre desde lo concreto, desde la táctica.

2. Generan formas de socialidad que se dan como inmediatamente políticas: con una nueva politicidad"situacional"ya que no responden a una estructura común de organización de sentido como sucedía en el movimiento obrero, sino a una emanación del sentido desde prácticas a menudo intuitivas que consiguen, mediante el uso de herramientas de autoformación e investigación-acción militantes, reapropiarse no sólo de espacios sino de palabras dotándolas de nuevo de contenido. Como ejemplo de ello, podemos poner a los numerosos centros sociales diseminados por la geografía española, las redes vecinales de nueva composición, las comunidades hackers y tantos otros casos de socialidad política.

3. Derivada en cierto modo de esta, la comunicación funciona como materia prima de la política, haciendo de la capacidad de comunicar y de las herramientas que lo permiten (internet, tecnologías de vídeo y de audio, tácticas de guerrilla de la comunicación en plataforma digitales o en espacios públicos, etc.), un modo de acción política y un mecanismo de generación de imaginario y de nuevas subjetividades diferenciales. Ya en otros capítulos hablábamos de la necesidad urgente de modificar tanto el imaginario de la crisis como el del sujeto promotor de cambios. Ante una crisis de palabras causada por la expropiación de conceptos, no nos queda más remedio que inventar las palabras que necesitamos entendiendo que a través de ellas y de su difusión, estamos operando también una transformación política de resubjetivación.

4. Por último, como el lado positivo de la economía postfordista que supone una sumisión del trabajo inmaterial a la flexibilidad, deslocalizada y en red, surge la figura del virtuoso cuya tarea consiste en favorecer y gestionar el flujo de informaciones y de relaciones así como en producir las ideas innovadoras que permitan reapropiarse y dinamizar situaciones y estructuras. Esta figura, enunciada por Virno ${ }^{98}$, desafía las tradicionales divisiones entre el pensamiento, la acción y la enunciación y dota de pleno sentido a las prácticas de investigación-acción participativa o investigación militante. De esta característica, emana nuestro propio proyecto de autoformación como veremos en la parte práctica, entroncando con el cuestionamiento de la universidad realizado en el primer capítulo, evidenciando que sus modos de hacer no fomentan nuevos comportamientos "contributivos" que concedan la misma importancia a la teoría y a la praxis encarnada, que practiquen una devolución intrínseca a la sociedad ni que se permitan aprender con ella.

98. VIRNO, Paolo. Gramática de la multitud. Para un análisis de las formas de vida contemporáneas. Madrid:Traficantes de Sueños, 2003. 
Pero ¿quién está practicando esta lucha? ¿Qué sujeto revolucionario podemos nombrar en la actualidad? ¿Podemos identificar algún sustrato de la población que permita plantear, desde las diferencias y en la ausencia de metarrelatos, un nosotros posible? Desgraciadamente, tal como hemos visto en el análisis del postfordismo, si hay hoy en día una identidad que cubre lo social, se trata de la que confiere la precarización generalizada, el "ser precario" como nuestro único modo de ser. El sujeto político que correspondía a la identidad concedida por el trabajo se ha quebrado y esa desarticulación que coincide, a su vez, con la reconstrucción del sometimiento al trabajo que la práctica del rechazo del trabajo planteada ya desde los 70 había debilitado, supone el abandono de las luchas contra la identidad salarial, más aún en un momento en donde el índice de paro vuelve de nuevo real la célebre frase de "El trabajo os hará libres". Se entra en la democracia desde una derrota oculta y se produce la fragmentación yoíca postfordista, glamurosa victoria del biopoder que todo lo impregna. En esa situación, la silueta del precariado emerge de la niebla general, definida desde su condición negativa únicamente, unida por la precariedad que le da vida.

El precariado recorre pues en la actualidad toda la esfera social, no sólo los trabajadores del espectáculo y de la cultura que son aquellos que identificamos como intermitentes con mayor facilidad, sino también profesores interinos, investigadores, temporeros, las víctimas de procesos de restructuración (lo que viene a llamarse paro tecnológico) así como todos aquellos trabajadores de sectores económicos a los que se les impone ya una reforma laboral en la que han perdido la mayoría de los derechos sociales duramente negociados durante décadas, por no decir siglos. Las medidas de austeridad están justificando actualmente cualquier recorte tanto privado como institucional aún a sabiendas de que ese tipo de medidas no han hecho más que precarizar aún más el tejido social e impedir una recuperación económica basada en los mismos principios que, desde las instituciones, se esgrimen como válidos. De esta manera, se dan aberraciones como las siguientes: por decreto ley, a todos los interinos en el ámbito docente (ya sea en estudios de primaria, secundaria, bachiller o cualquier otro cursado en escuelas oficiales) con contratos firmados hasta septiembre de 2012, se les rescinde automáticamente dicho contrato que pasa a ser válido hasta junio del mismo año, porque se considera que, durante los meses de julio y septiembre, dichos trabajadores realizan tareas que otros pueden asumir (sin que ello suponga, por supuesto, incremento alguno de retribución para estos segundos) y que las vacaciones pagadas son un lujo que la Administración no puede permitirse. Repito, las vacaciones pagadas son un lujo que la Administración no puede permitirse, eso dicen. Y si la Administración, que debiera ser la primera defensora de los derechos sociales, lo considera un lujo, ¿qué pensará la empresa privada? No insultaremos porque esto es una tesis. 
Además de todos los sectores anteriormente enunciados, la definición completa de precariado tiene obligatoriamente que incluir al sector más sumergido de la economía, a pesar de situarse en la base misma de la sociedad: el sector de los cuidados o de la reproducción social. De hecho, si gracias a él se sostiene toda la estructura social en tiempos de bonanza, cuanto más no lo hará en tiempos de crisis como los actuales. El término "economía de los cuidados" o de reproducción social, siendo este último el término generalmente utilizado por los economistas políticos feministas del ámbito anglosajón, hace referencia a todos los trabajos no remunerados que se producen en el ámbito doméstico y que contribuyen a generar y mantener los vínculos sociales.

Sistemáticamente, es un sector que ha quedado fuera de toda consideración económica porque excede al ámbito de la acumulación producida por el trabajo productivo, involucrado en la distribución de la plusvalía generada por medio de los factores productivos que estaba a la base del capitalismo. Sin embargo, corresponde a las tareas que, en realidad, permiten que se produzca ese mismo trabajo productivo porque aseguran que exista la estructura de cuidados necesaria para que este siga funcionando: la alimentación, la limpieza, la reproducción y los cuidados de gestión y de servicios asociados a cualquier sociedad humana, sin los que se perdería cualquier calidad mínima necesaria para mantener un espejismo de civilización, como la asistencia a los niños, a los mayores, a los enfermos, a los discapacitados, etc. Resulta obvio, por poco se piense en ello, que el concepto capitalista de producción no puede entenderse adecuadamente sin el aporte de la reproducción social, por lo que debieran revisarse las dicotomías inadecuadas entre trabajo productivo e improductivo así como los mecanismos de creación de valor.

Sin necesidad de añadir más, damos por supuesto que ha quedado claro el concepto así como el hecho de que, en la mayoría de los casos, que no en todos, estos trabajos de reproducción social son realizados por mujeres, duplicando a menudo su jornada de producción retribuida con este doblete de gratuidad. El hecho de que, en países como Francia, por cada hijo correspondan dos años de cotización en la Seguridad Social a la persona que se ha hecho cargo de su crianza como reconocimiento a esta tarea de reproducción social, muestra hasta qué punto todo este trabajo resulta, no sólo no directamente retribuido, sino totalmente invisible a la sociedad española, estando en su misma base y siendo la mejor expresión de "afecto" spinoziano que pueda encontrarse. No obstante, si nos retrotraemos al pacto entre familia y trabajo productivo en el que se basa la teoría política del patriarcado, vemos que todo ese capital aportado de afectos, emociones y conocimientos transmitidos es impagable y se justifica por amor ya que en su nombre se realizan todas esas tareas no retribuidas. 
Al respecto, podría decirse que el trabajo de cuidados encarna la crisis de la medida del valor en el sistema de trabajo actual, lo que permite extrapolar su modelo al de la producción cultural. En ambos casos, existe una falta de definición de esas actividades como trabajo, una ausencia de diferenciación entre el tiempo de trabajo y el tiempo de vida, más una ausencia de retribución o bien, como mucho, una retribución simbólica justificada por amor: el mismo que ha condicionado a las mujeres a asumir las tareas de cuidado es el que hace que los trabajadores del conocimiento lleven a cabo sus actividades sin retribuir. Desde las prácticas para asociaciones privadas o públicas hasta la escritura de artículos, pasando por clases magistrales puntuales, conferencias o publicaciones de investigaciones personales, son todas ellas actividades que se realizan en base a la relación afectiva que el trabajador establece con su oficio y que sirve de coartada a la indefinición y precariedad que se ve obligado a asumir.

En el caso de los productores culturales, su autonomía respecto a estructuras laborales más rígidas se ha teñido de cierto sentimiento de liberación, de superación de un sistema de salarios y de una flexibilidad móvil casi imperativa. Esta imagen positiva de las transformaciones de su status no ha hecho más que encubrir una realidad en la que la autoexplotación, bajo la coartada del arte por el arte, del amor al arte, acaba siendo una constante. Entre otras características, la indiferenciación entre el tiempo de trabajo y el de vida, la desindicalización y precarización generalizada, la discontinuidad laboral, la obligación de formación continua que aumenta la presión sobre la responsabilidad individual del éxito o el fracaso y un distanciamiento obvio de toda una serie de garantías sociales, hacen que el productor cultural se mantenga en un ámbito desprofesionalizado y vulnerable, siempre al borde del estrellato en su sentido literal, contra un muro de carencias. Por lo que podemos decir, retornando a la teoría establecida por Cristina Morini ${ }^{99}$, en la que compara ambas economías en base al amor que exigen, que:

Es la intromisión del elemento afectivo lo que ha permitido al biocapitalismo la conducción del trabajo cognitivo, del trabajo del conocimiento hacia el camino de la gratuidad. (...) En la época de las prácticas generalizadas, del consumo y del lenguaje como trabajo, de la construcción de imaginarios hechos para compensar la miseria de la medida mediante la cual el trabajo es remunerado, del índice de crecimiento basado en el conocimiento, la asistencia, la mano de obra migrante invisible, la inseguridad generalizada, la cuestión histórica de la mano de obra gratuita asume nueva importancia y centralidad. Se convierte, como hemos dicho, en un patrón general de la producción contemporánea.

Si pensamos en el tanto por cien de la población que se dedica a trabajos de reproducción, y le sumamos aquellos que realizan trabajos inherentemente intermitentes, tendremos un porcentaje elevadísimo de precarios y en muchos casos,

99. MORINI, Cristina, op. cit., p.8. 
de precarias al cuadrado e incluso al cubo. Por poner el ejemplo que me resulta más cercano, mi propia biografía para la que espero no necesitar citas, podría decir que acumulo precariedad sobre precariedad: como madre, ama de casa, ejecuto todas las tareas no remuneradas propias de la reproducción. Como profesora asociada de la universidad, cumplo con tareas que otros realizan recibiendo un salario triplicado, para ahorrarle cargos a la función pública que decide bloquear el desarrollo de la carrera docente, precarizando para poder mantener la demanda que realmente necesita a un coste menor. Por último, como productora cultural, llevo a cabo gestiones de congresos, encuentros, debates, traducciones y todo tipo de actividades similares (que pueden ir desde el diseño de un flyer hasta el seguimiento de una página web pasando por las llamadas telefónicas pertinentes, el estudio de los temas tratados y una miríada de tareas de gestión anexas a la producción cultural central) con la benevolencia propia del que se considera rico.

En muchos de esos casos, las instituciones que participan en ello se ven directamente beneficiadas de la gratuidad de mi "trabajo" a cambio de un capital simbólico del que me estaría teóricamente beneficiando (en otra vida quizás). Me podría considerar triplemente idiota pero por amor, no lo hago. Por no hablar de que, para poder llevar a cabo cada una de esas tres actividades, me veo obligada o elijo implicar a terceras personas en tareas no retribuidas que van desde cuidar a mi hijo mientras yo presento a un filósofo en una institución, hasta pedir que den gratis esa conferencia que he organizado. Reproduzco la autoexplotación por amor ad infinitum. Cometo los mismos errores e injusticias que serían considerados como trueques entre iguales si no hubiera terceros beneficiarios de todas estas externalidades positivas que no retribuyen a nadie. No se trata de estar en contra de la economía del don, nadie menos apropiado que yo para hacerlo. Se trata de valorar ese trabajo que hacemos y sobre todo, de analizar a quién beneficia realmente, si se trata de un ejercicio del don o de idiocia, si es una opción personal o una generalización estructural. Pasemos de una vez del paradigma de la retribución al de la redistribución, por favor, estoy cansada de explotar a mis amigos y de hacerme amiga de quienes me explotan.

Para hacer frente a situaciones similares e intentando operar cuando menos una transformación en lo que respecta al punto de vista de las instituciones, Pascal Nicolas Le Strat ${ }^{100}$ sugirió en su momento intercambiar la noción de precariado por la de intermitencia como manera de reconocer un sujeto social diferencial que no responde ya a la pauta del sujeto obrero, modificando la visión del precariado basada en su condición negativa por una visión empoderante.

100. NICOLAS-LE STRAT, Pascal. "La constitution intermittente de l'activité". En: Multitudes no 17, París, verano 2004. 
Según este autor, la intermitencia no es sinónimo de precariedad, ni política ni socialmente, sino que se considera como una característica propia de muchas actividades que puede reinterpretarse en clave positiva, como una de las vías para superar la imposición totalizadora de la identidad-trabajo que impide dedicar tiempos al desarrollo de otras actividades en torno a lo común igualmente beneficiosas para la sociedad que las entiende y fomenta. En Francia, en respuesta a esta reivindicación y amparada por las reflexiones teóricas que analizan su situación, surge la Coordinadora de Precarios e Intermitentes que elabora inmediatamente una propuesta de pagos compensatorios basados en un régimen de intermitencia que quiere ser a la vez un instrumento de lucha contra la precarización del máximo de personas y un medio que permita, en la discontinuidad de los empleos, aumentar su potencia de acción.

Se empieza por considerar que la actividad de los intermitentes es la de agenciamiento de temporalidades heterogéneas, es decir, el reconocimiento de que, en el capitalismo cognitivo, no se produce una diferenciación clara entre tiempo de vida, tiempo de formación/creación y tiempo de trabajo sino una sucesión de temporalidades consecutivas o simultáneas: lo que ellos llaman tiempos «llenos» y tiempos «vacíos», tiempos de relación con los públicos y tiempo de trabajo. Este punto de vista implica reconocer que la intermitencia es fructífera y necesaria en muchos casos y forzada como recurso para evitar todo tipo de costes empresariales, en muchos otros. Por ello, Lazzarato y Antonella Corsani ${ }^{101}$ que han trabajado sobre este punto junto a Le Strat, dicen que esa precarización a la que se intenta responder desde la apelación a la asistencia social, no es una asistencia, es una precarización implícita en los nuevos modos de trabajo que además produce una riqueza común en sus tiempos muertos. Esas intermitencias no las asume la empresa cuando es ella la que las provoca (sino es el mismo Estado, como ya hemos visto en el ejemplo de los interinos), ¿cómo se podría hacer derivar esa inclusión de tiempos muertos reivindicaciones salariales a aquellos que las provocan? Y en el caso de trabajos en sí intermitentes, ¿cómo incluir a esos trabajadores dentro de un sistema? En el número monográfico sobre la intermitencia de la revista Multitudes ${ }^{102}$, Corsani dice así:

El sistema de bienestar no es un simple dispositivo de redistribución de los ingresos, un seguro contra los riesgos sociales o de la vida, y menos aún un sistema asistencial. La mayor parte de los presupuestos sociales, considerados como gastos en las cuentas de las administraciones públicas y en la contabilidad nacional, son inversiones que conciernen a la producción de bienes comunes: la formación, la investigación, la cultura, la sanidad, la financiación de los individuos en general, etc. Las huelgas de profesores, los intermitentes y los investigadores lanzan interrogantes sobre la producción, la difusión

101. CORSANI, Antonella y LAZZARATO, Maurizio. "Intermitencia: reapropiación de la movilidad, producción de lo común". En: Contrapoder: 2005, n 9.

102. Multitudes n 17, París, verano 2004. 
y la apropiación de los bienes comunes que juegan en la producción capitalista contemporánea el mismo papel central que el que desempeñaba la producción industrial en el capitalismo de Smith y de Marx.

Por ello, debemos considerar que el paro no es lo opuesto al empleo, sino uno de los momentos de la movilidad de la fuerza de trabajo. En las condiciones de producción actuales, el INEM ya no es un seguro contra la pérdida de empleo, sino antes bien una fuente de financiación de la flexibilidad. Esto se hace evidente en el caso de los intermitentes pero también para el régimen general. La externalización no se produce sólo en el campo de la producción: las empresas externalizan también los costes de la flexibilidad, transfiriéndolos a la Administración.

Pero intentemos darle la vuelta a la ecuación, salir del punto de vista de las víctimas y pensar cuáles pueden ser los puntos positivos de estas intermitencias. Como todos estos autores nos permiten observar, los intermitentes atacan el proyecto capitalista en el punto en el que se articula su arma más eficaz: la flexibilidad. Efectivamente, como ya habían hecho los productores culturales, la defensa del puesto de trabajo, del trabajo para todos, puede ir más allá de la disyuntiva «empleo de por vida» $\mathrm{y}$ «flexibilidad padecida», al reivindicar abiertamente la reapropiación de la movilidad, siempre que ello lleve asociado el cuestionamiento profundo del concepto mismo de producción y de trabajo.

Podíamos remontarnos para ello al famoso capítulo XXIV de "EI Capital" 103 en el que se cuenta el secreto que, según Karl Marx, se encuentra en el origen de la acumulación capitalista: el proceso de cercamiento de las tierras comunales (commons) que no sólo supone la injusticia de una expropiación forzosa sino la implantación de leyes contra el nomadismo y la exigencia de que todo hombre justifique un salario, el principio de la identidad-trabajo. La disolución de las mesnadas feudales a finales del siglo XV y principios del XVI no hace más que iniciar un largo proceso de expropiación progresiva mediante sucesivas leyes, de expulsión de monjes convirtiéndolos en hombres en busca de sustento mediante la Reforma religiosa y finalmente, la desaparición forzada de los yeomen independientes y la expulsión de las grandes fincas de gran cantidad de campesinos que se vieron obligados a convertirse en mano de obra que alimentará las calderas de la revolución industrial.

Frente a esta violencia histórica que ha marcado profundamente la sociedad, surge en el siglo pasado la corriente del autonomismo, correspondiente a la experiencia, tanto teórica como práctica, de los movimientos sociales europeos desde los años setenta hasta la actualidad. Dicha corriente pretendía romper con el marxismo en tanto desechaba la noción del proletariado y de proletarización y se orientaba hacia las posibilidades liberadoras que suponía el distanciamiento para

103. MARX, Karl. El Capital. Madrid: Ed. Alianza, 2010. 
con las relaciones salariales vigentes en el fordismo. Como hemos visto en la segunda parte de este capítulo, el mismo fordismo se fue transformando hasta cooptar estas formas de obtención de la subsistencia en condiciones más flexibles, aunque esta deriva se iniciara como "movimiento de rechazo del trabajo", así denominado por los trabajos sociológicos de la época. El punto de partida del autonomismo era la crítica al sujeto representado por el obrero industrial privilegiado por el marxismo y el anarcosindicalismo, ya que éste había sido totalmente absorbido por la lógica domesticadora de la sociedad de consumo y la negociación con el capital intermediada por el Estado. Es decir, esta corriente, saliendo del camino marcado por el marxismo, intenta plantearse otros sujetos posibles que no sean dependientes de la dimensión laboral fija, poniendo el dedo en la problemática a la que nos vamos a tener que encarar en el futuro próximo: la redistribución laboral y la compensación salarial.

A esto se añade la consideración muy pertinente sobre la relación directa entre capacidad de consumo y exigencia laboral: durante los últimos treinta años, el mecanismo reforzador de la sociedad se ha basado mucho más en la "necesidad" de consumo que en cualquier ideología política, en la invasión constante y omnipresente de la publicidad que ocupa todos los ámbitos de la vida y exige de nosotros, como ciudadanos que trabajan por su pueblo, que consumamos, que sigamos consumiendo patrióticamente si hace falta, hasta relanzar el país. Desgraciadamente, en plena crisis, seguimos aplicando a fondo este punto de vista que, en vez de optar por introducir la noción de decrecimiento y todo lo que ello llevaría aparejado (cuestiones morales, ecológicas, sociales y políticas), introduce a golpe de martillo medidas de austeridad que poco tienen que ver con esa noción de ir a menos. Continuar el análisis de nuestra sociedad en esa dirección nos llevaría muy lejos de nuestro propósito inicial, aún así nos gustaría dejar constancia de la condición esencial que para nosotras supone la urgente reversión del sistema: salir de una vez de esta idea de la expansión y el progreso constantes para adoptar el modelo de la contención, sino directamente del decrecimiento.

Volviendo a nuestras consideraciones sobre el estatuto laboral en el biocapitalismo, Yann Moulier-Boutang ha trabajado en profundidad sobre este tema, siendo capaz de proponer alternativas que aprovechen la desestructuración generalizada que está suponiendo la crisis. Para él, no cabe ninguna duda de que hay que salir de la condición dicotómica trabajo/paro del capitalismo cognitivo. Puesto que el endurecimiento de las condiciones de exclusión y explotación abre la posibilidad de encontrar una salida al capitalismo tout court, se puede hacer palanca sobre la condición positiva de la precarización en el sentido de la superación de la imposición del sistema salarial como único posible así como sobre la aplicación de un sistema de redistribución de rentas y de liberación de tiempos para la construcción del procomún. 
La gran conquista del salario, que debilitó profundamente el carácter esclavista del trabajo, fue el acceso a la protección social y la extensión de esta protección a la familia de los titulares del empleo en la economía manufacturera. Sólo un nuevo debilitamiento del salario mediante la atribución incondicional de una renta de existencia a todas aquellas personas que, de principio a fin de todo el proceso de la producción material garantizan su beneficio permitirá: derrotar a la exclusión; desarrollar una presión suficiente sobre el mercado para conducirlo a un régimen no de pleno empleo, sino de otro tipo de empleo; garantizar la renta de los para-asalariados de la sociedad de la información. La verdadera respuesta al nuevo movimiento de los cercamientos consiste en operar sobre el salario, el mismo tipo de innovación que la licencia de copyleft ha operado sobre el derecho de autor y sobre el derecho de reproducción del software. Una hermosa tarea para el siglo XXI. ${ }^{104}$

En esta propuesta de atribución incondicional de una renta de existencia, en España denominada"renta básica", Boutang coincide con numerosos movimientos ciudadanos que, desde múltiples centros, reclaman cuando menos una reflexión pública al respecto. Pero como nuestros hombres políticos no son muy dados a permitir debates, sobre todo en temas tan controvertidos, sino más bien a acallarlos, la ignoran con la misma tranquilidad con la que ignoran cuestiones como la democracia participativa que, en su nivel más básico, podría ponerse en marcha de forma inmediata. Bien es verdad que resulta grotesco pensar que una propuesta similar pueda salir adelante para escapar de un sistema salarial que ya no es operativo, y no por su eficacia o por su justeza sino porque ataca directamente a las nociones de progreso y propiedad a las que nos hemos aferrado hasta ahora. Tras tantos siglos de andar jugando con el sudor de la frente y la libertad, nos vemos en la necesidad no de llevar a cabo un cambio de sistema sino casi un cambio de civilización que nos permita pasar de la sumisión al trabajo a la redistribución de los recursos.

Podríamos ponernos metafóricos y hablar de cómo la imposición del modelo "un hombre, un salario" ha supuesto un cercamiento similar en la multiplicidad de posibilidades de organización que podríamos haber contemplado, como si reduciendo los pastos comunes y la libertad de movimiento y profesión, redujéramos también la lógica común y hubiéramos por tanto seguido operando cercamiento tras cercamiento, de los campos, del gobierno, de la educación, del espacio, intentando desterrar las parcelas de humanidad compartida. Retomar esta discusión parece quizás extraño pero ¿cómo fomentar de forma más abierta el trabajo común, el debate ciudadano, las prácticas emancipatorias del consumo sino mediante la constitución de una renta básica? ¿Cómo fomentar verdaderamente la creación y el mantenimiento de espacios de convergencia más allá de los centros comerciales? Nuestra miseria como sociedad está a la altura de nuestros deseos.

104. MOULIER BOUTANG, Yann, op. cit., p. 128. 
Veremos si ahora que los procomunes de base peligran, nuestros mares y cielos, nuestros alimentos, somos capaces de reaccionar de alguna manera y darnos espacio para pensarnos de otras maneras.

A pesar de todos estos razonamientos acumulados, a pesar de que verdaderamente no tenemos mucho que seguir defendiendo, excepto los que nos contemplan con la insultante distancia de aquellos que no son conscientes de estar inmersos en la crisis (aquellos que se creen a salvo por motivos inciertos), resulta también evidente que la tendencia general de la humanidad es resistirse al cambio. Por mucho que su necesidad sea tan palpable como una piedra en el pecho. Por ello, como ya hemos comentado, va a haber que ir pensando en los cómos, en los de qué manera se introduce el cambio, porque si esperamos que el sistema democrático de partidos tal y como está planteado, en plena derrota clamorosa, nos ofrezca las posibilidades de transformación, vamos aviados. Si bien la transformación de la consideración del precariado en intermitencia ya le concede un agenciamiento positivo, siempre que haya un correlato por parte de la Administración que contemple esta nueva realidad laboral cada vez más extendida y las soluciones que se proponen para adecuarse a ella (por supuesto, de poco sirve generar una visión positiva de la intermitencia sin cobertura asociada a dicha aprobación), esto sigue sin contestar a la pregunta anteriormente realizada sobre el verdadero sujeto actual de las luchas.

\section{6 ¿Y cómo la llamaremos?}

Entre tanto desconcierto, surge en la línea con el discurso spinoziano que hemos ido fragmentando y deglutiendo a lo largo de estos capítulos, la figura de la multitud que se opondría a la noción de pueblo hobbesiana. Para Hobbes, la multitud correspondería al estadio natural del hombre y por principio, sería refractaria a la idea de Estado así como a la de obediencia, no accediendo nunca al status de "persona jurídica" porque no se sometería a las leyes establecidas por un soberano. La recuperación de esta oposición viene de la mano de Paolo Virno en su Gramática de la multitud ${ }^{105}$. En ella, nos recuerda el debate que se planteó en la constitución de los Estados modernos en el siglo XVII entre la noción de pueblo precursora del Estado ${ }^{106}$, que simboliza el conjunto de ciudadanos con una voluntad única, y el concepto de multitud spinoziana ${ }^{107}$ que se opone a esa unidad conservando su naturaleza múltiple. Hay que entender que esta discusión gira en torno a las mejores formas de gobierno posible, siendo la monarquía y la democracia las dos formas preferenciales a debate. Advierte Virno que, en esta

105. VIRNO, Paolo. Gramática de la multitud. Madrid: Traficantes de sueños, 2003.

106. Establecida por Thomas Hobbes en op. cit.

107. SPINOZA, Baruch, op. cit. 
lucha, el concepto de multitud resultó perdedor frente al de pueblo, como podemos imaginar visto el presente.

En la serie de parejas que nos hemos obstinado en construir, la doctrina liberal intentaría plantear la cuestión en términos público/privado, siendo lo privado aquello que excede a la normativización estatal, pero también aquello que está privado de presencia pública y que, por tanto, se puede ignorar. De igual modo, la lectura socialdemócrata reposaría sobre la distinción entre colectivo e individual, siendo la multitud el elemento singular que no se considera en la balanza. Pero, para Virno, resulta importante recuperar la idea de multitud en la medida en que mantiene la diferencia sin perder la alianza. En una entrevista que Maurizio Lazzarato ${ }^{108}$ hace a Paolo Virno en torno a este tema, Virno comenta cómo el concepto de multitud corresponde a la identidad de los ciudadanos de las repúblicas libres comunales anteriores a los grandes Estados nacionales e incide en el concepto de jus resistentiae como eje de la diferencia, concepto que no se limita a la defensa propia sino que extiende a la defensa de lo propio:

Usar el «derecho de resistencia», es hacer valer, contra el poder central, las prerrogativas de una singularidad, de una comunidad local, de una asociación de artesanos, es salvaguardar las formas de vida ya plenamente afirmadas, es proteger las costumbres ya enraizadas. Se trata por tanto de defender algo positivo: es una violencia conservadora (en el buen sentido, en el sentido noble del término). Es quizás el jus resistentiae, el derecho de proteger algo que ya existe y que parece digno de durar, lo que acerca más la multitud del siglo XVII y la multitud posfordista. Para esta no hay ya (no se trata de "tomar el poder») que construir un Estado nuevo, un nuevo monopolio de la decisión política, sino que defender las experiencias plurales, los embriones de la esfera pública no estatal, las formas de vida innovadoras. No la guerra civil, sino el jus resistentiae.

Retomamos aquí pues todas las características de las luchas de resistencia activa hasta ahora planteadas, desde la multiplicidad, desde la ausencia de metarrelato, desde la existencia paralela y no desde la oposición antagónica. Como dice Virno, la firme oposición de Hobbes contra la idea de multitud se basaba también en que su unión reposaba en alianzas efímeras, en una simple reunión de personas que no están comprometidas entre sí y esa ligereza imposibilita toda forma de control. Virno se resiste a separar la idea de multitud de la de clase obrera aún reconociendo que la forma de trabajo instaurada en el postfordismo supone una relectura diferencial, sobre todo por la ausencia de unidad, pero intenta justificar esta continuidad desde la definición misma de clase obrera como sujeto que produce plusvalor y en ese sentido, la multitud podría considerarse incluida en la definición. Sin embargo, admite que son otras tanto la organización de las formas de conflicto como la noción de que el trabajo asalariado puede considerarse como un

108. LAZZARATO, Maurizio.."Multitud y clase obrera". En: Revista Contrapoder no 7, Madrid, 2003. 
elemento transitorio, acercándose pues la multitud a las posturas del autonomismo y por tanto, a su oposición a la lectura marxista, y de hecho, que es este cúmulo de diferencias el que le lleva a enunciar con detalle su gramática de la multitud.

La relectura que de ella hacen tanto Virno como Hardt y Negri ${ }^{109}$, (a pesar de que estos últimos se oponen a la idea de asimilar multitud y clase obrera), implica que, si se le considera como el sujeto múltiple alternativo a un gobierno central, se puede pensar la posibilidad de la irrupción de una democracia no-representativa, de una ampliación del espacio de gobierno público más allá del marco del Estado. Sus motores para vencer las desigualdades de este sistema son la cooperación y la hibridación, todo ello en un marco de intercambio lingüístico facilitado por las nuevas redes de conexión de grupos sociales. La desobediencia civil representaría una de las formas básicas de acción política de la multitud y eso nos permite vincularla a las características anteriormente enunciadas propias de la presente crisis así como a una posible puerta de salida a esta farsa partidista. Para Negri, el ejercicio de un poder constituyente contrapuesto al poder constituido tampoco tendría que pasar necesariamente por una revolución sino por la generalización de experiencias autogestionarias que permitan articular una sociedad paralela. Transforma así en inmediatamente político y antagónico al sistema, cualquier tipo de movimiento cooperativo y de resistencia, por más parcial y local que sea, independientemente de su importancia, su extensión o nivel de oposición real al capital.

Esta amplitud de miras resulta sumamente optimista a la vez que un tanto contradictoria con la pretensión de singularidad en la multitud ya que equipara sin matizar propuestas de cariz diverso. Se trataría, en cualquier caso, de integrar la multiplicidad de sujetos dentro de un nuevo concepto de democracia que los convierta en actores políticos de una nueva esfera pública no estatal y para hacerlo, para que los ciudadanos puedan liberar esos tiempos dedicados a lo común, habría que volver a la disociación de la remuneración del trabajo a través de una renta básica, por establecer un vínculo directo entre los propósitos de Boutang et alii y la noción de multitud, acercándola a una propuesta concreta.

De hecho, la crítica más generalizada que se le hace a la idea de multitud es que sigue resultando excesivamente ambigua para poder encarnar un sujeto político convincente, o así lo ven numerosos intelectuales entre los que se encuentra Santiago López Petit ${ }^{110}$, cuya objeción principal se centra en la ausencia de consideración de la vida misma, en el sentido que él le da de vida totalmente movilizada por el capital. Una vida que ha perdido su carácter problemático para

109. HARDT, Michael y NEGRI, Antonio. Multitud. Guerra y democracia en la era del Imperio. Madrid: Editorial debate, 2004.

110. LÓPEZ PETIT, Santiago. El infinito y la nada. El querer vivir como desafío. Barcelona: Ed. Bellaterra, 2003. 
convertirse en una pura y simple solución al problema político y que nos enfrenta a un doble callejón sin salida: por un lado, a la imposibilidad de hacer una política radical; y por otro, a la imposibilidad de escapar de las metodologías y estrategias políticas tradicionales, pues, a su parecer, el nuevo sujeto político que se propone no es más que una actualización del sujeto político del marxismo (el proletariado).

En cualquier caso, el problema con la noción de multitud, si bien responde en sus características a los movimientos que están surgiendo en el planeta especialmente en los últimos dos años, no es el de su definición sino el de su posible eficacia. Ante los acontecimientos mundiales a los que asistimos o que se silencian cotidianamente en la actualidad, revueltas, tumultos, asambleas, críticas desde las instancias más legitimadas y otro sinfín de antagonismos emergentes, no podemos por menos que evidenciar la extensión y multiplicación de las multitudes difusas y el despliegue de su capacidad antagónica e instituyente pero también su incapacidad aparente para imponerse a los decretos aprobados desde las altas instancias financieras, la mal llamada Troika y la alargada sombra del mercado financiero que especula con las deudas nacionales hundiendo y reflotando países enteros. Nos encontramos en un punto clave en el que estamos midiendo nuestras fuerzas, el mainstream de la información y la ola de canales alternativos, las instancias políticas y los mercados financieros, los instituidos y los destituyentes. Intentemos estar a la altura de nuestros deseos bajo cualquiera de los nombres que se nos quieran adjudicar.

Entre todos ellos, me permitiré destacar el de comunidad tal y como lo declina Marina Garcés en su excelente prólogo a "Escritos políticos" de Blanchot 111, donde traza una línea vinculante entre diferentes visiones de esa comunidad posible basada en la fuerza del rechazo. Como ya hemos repetido hasta la saciedad, quizás no tengamos un proyecto alternativo declinado en todas sus fases, ni siquiera las respuestas a algunas de las preguntas esenciales sobre sujetos y predicados, pero sabemos lo que rechazamos y sabemos lo que deseamos. Somos fuertes en nuestro No, siendo esa negación un No certero como el que Blanchot invoca para hablar de la ruptura con un principio de realidad que hace posible que determinadas opciones se entiendan como normales y otras no, y que esa anormalidad instalada nos obligue a enunciar la ruptura. Una ruptura conjunta cuya única fuerza de unión sería el rechazo, llevado a cabo por hombres y mujeres que no están juntos pero que comparten "Ia amistad de ese No certero, inquebrantable, riguroso, que les mantiene unidos y solidarios" 112 .

111. BLANCHOT, Maurice. Escritos políticos. Madrid: Acuarela libros, 2010.

112. BLANCHOT, M., Ibid. 
Y de esa manera nos hace sentir la autora cuando dibuja con trazo seguro la unión con el hombre rebelde de Albert Camus que permite la emergencia de un sujeto conjunto ("Yo me rebelo, luego nosotros existimos") a través del movimiento de rechazo mismo. Cuando en España, novecientos médicos se declaran objetores de conciencia de la medida que deja sin asistencia sanitaria a los inmigrantes sin papeles, no necesitan constituir otra comunidad mas que la que su rechazo genera mediante ese No rebelde. De la misma manera que Blanchot decía No a la guerra de Argelia, legitimando moralmente una desobediencia civil. De la misma manera que la población vienen manifestándose con cada vez mayor frecuencia en este nuestro país digno del mayor esperpento con o sin permiso de las autoridades, confirmando el valor absoluto del rechazo y la condición anónima de lo común, lo que Banchot denomina la"comunidad anónima de nombres" que no requiere de sustantivo alguno.

Pero Marina Garcés aún va más lejos en su propuesta de filiación entre diferentes comunidades ya que retoma la teoría de Maurice Merleau-Ponty ${ }^{113}$ para hablar de los límites, puesto que la comunidad supone también la conciencia del límite, de un límite que no se entiende como barrera de separación. MerleauPonty, al hablar del límite que supone el cuerpo, lo plantea en términos positivos, es decir, un límite imposible porque un cuerpo no puede existir sin intercambiar permanentemente con el mundo que le rodea, no es una piel que limita sino un cuerpo que interactúa, que respira, come, desgasta, roza, agrede o lame. Un cuerpo que se constituye en nosotros, un cuerpo que se abre a los vínculos y que es capaz de darse cuenta de que dos cuerpos, dos individuos, no se definen por la línea de fricción que se establece entre ellos sino por su imposibilidad de no intercambiar, por la obligatoriedad del lazo.

Pero ¿cómo retomar el fantasma de la comunidad después del comunismo? ¿Quizás inventando términos como el de multitud o admitiendo la inane dignidad de la compañía inoperante? En esta comunidad ausente, hecha de cuerpos que se exponen de forma conjunta, que niegan el límite establecido en base a una teórica libertad falsamente respetuosa del otro, podríamos intentar recuperar la dignidad de los actos, actualizando con ello esta noción de comunidad en el rechazo, de comunidad rebelde y encarnada. Como diría Blanchot, "El poder de rechazar no se realiza a partir de nosotros mismos, ni en nuestro solo nombre, sino a partir de un comienzo muy pobre que pertenece en primer lugar a quienes no pueden hablar" ${ }^{114}$ y por el momento, ese está siendo nuestro punto de partida.

113. MERLEAU-PONTY, Maurice. Las aventuras de la dialéctica. Buenos Aires: Ed. Leviatán, 1957. Somos conscientes de lo problemático que puede resultar mezclar la fenomenología, el existencialismo y las teorías del sujeto foucaultianas pero aún somos más conscientes de la necesidad imperante de inventar vínculos, de amalgamar conceptos, para salir de una onanidad (palabra inventada también, sí, señora, pero suficientemente justa) individualista que no nos basta. 114. BLANCHOT, M. op. cit., p. 11. 


\section{La autoformación como práctica instituyente}

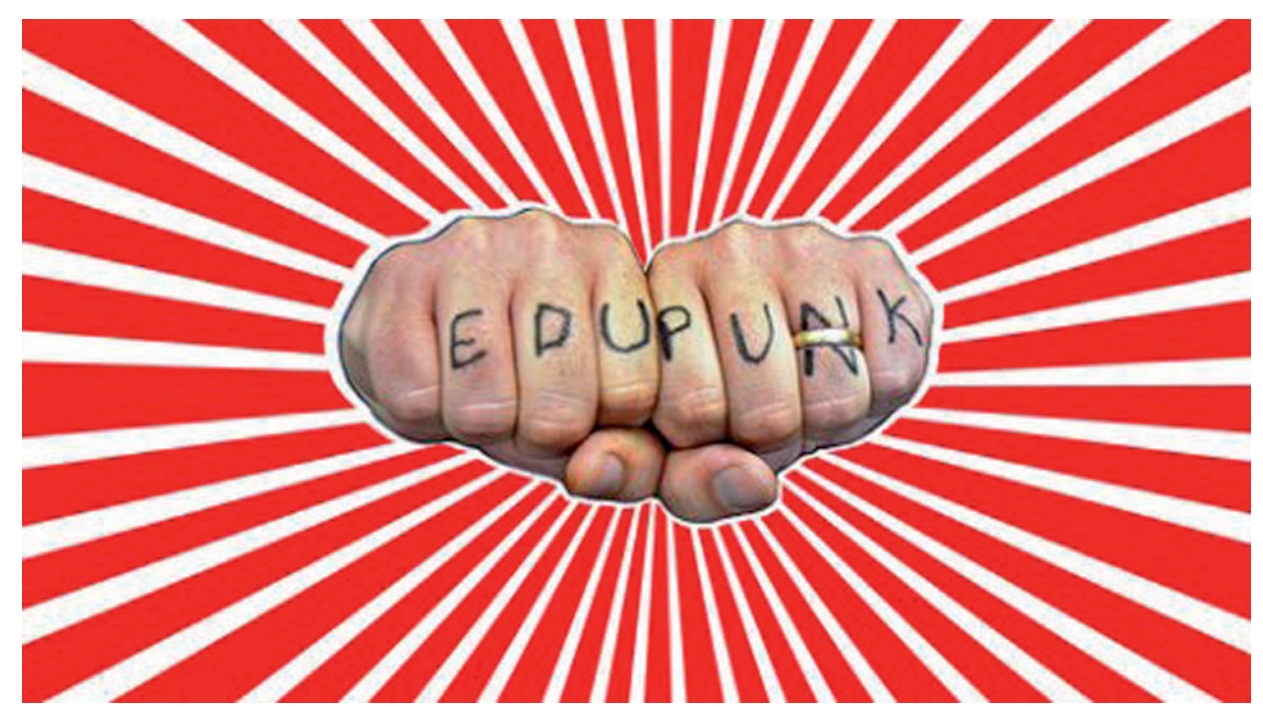

Fig. 5 
El hombre no posee instintos, hace instituciones

Gilles Deleuze $1^{115}$

\subsection{Poder constituyente y poder constituido}

En los capítulos anteriores, hemos intentado abordar las cuestiones referentes al marco de análisis general en el que se contextualizan las experiencias que corresponden a nuestras prácticas de transformación, que detallaremos en los últimos capítulos. Por una parte, hemos llevado a cabo un análisis inicial de las carencias fundamentales de la universidad pública, carencias que le impiden conectarse con la sociedad e intentar dar respuesta a todos los interrogantes que nos asaltan en este presente tan acuciante. Por otra, las bases de esta democracia que hace aguas nos obligan a poner entre comillas conceptos como el de libertad o independencia así como a abordar otros como la autonomía o el afecto.

Todo ello nos enfrenta a la necesidad de una reflexión interna sobre la noción de crisis, así como sobre la urgencia a la hora de inventar nuevos mecanismos de acción colectiva que nos permitan reaccionar ante la enésima carga del capital y sus inamovibles pretensiones de flexibilidad. Nos encontramos ante un reto de innovación política que tenga en cuenta ya no lo público, sino lo común, que suponga un cambio de escala y de apreciación general sobre la deriva que podría ir asociada a estos cambios a todos los efectos. Para ello, como ya hemos planteado, necesitamos identificar el sujeto de transformación posible ante la crisis en la metrópolis postfordista, la comunidad ausente que podría aportar mecanismos de activación y articulación de la misma. En este capítulo, intentaremos responder a la cuestión de cómo y de dónde podría emanar el conocimiento necesario para provocar un cambio en los modos de conceptualización y de gobierno, así como la metodología de transformación empleada para ello en diferentes experiencias prácticas.

Recordamos de nuevo los propósitos enunciados al final del segundo capítulo respecto a la necesidad de transformar la resistencia en una dinámica de institución colectiva, yendo más allá del sistema de partidos, aunque para ello 115. DELEUZE, Gilles. Instincts et institutions, Lîle déserte et d'autres textes. París: Minuit, p. 25. 
necesitemos constituirnos previamente en interlocutoras legitimadas de esos mismos poderes públicos con la capacidad de generar debates y proponer acciones autónomas. No obstante, hacemos de nuevo hincapié en que se trataría más bien de instituirse que de convertirse en inamovible institución y por ello, resulta tan importante recordar cuantas veces sea necesario el debate entre emergencia y perdurabilidad, entre revolución y esclerotización. Enlazando con el principio del tercer capítulo, ese debate constituye un punto de inflexión decisivo en la posibilidad de instituir procesos y generar instituciones diferentes, denominadas por ciertos autores como instituciones autónomas o "monstruosas", para acompañar e impulsar nuevas prácticas sociales transformadoras sin caer por ello en el autismo de lo estable.

Es cierto que la referencia a esa concepción de la "institución" es bastante escasa aunque la podemos encontrar en un texto de Gilles Deleuze llamado "Instintos e instituciones" ${ }^{116}$, en el que aborda directamente la diferencia entre instinto, institución y ley de forma muy somera pero extremadamente precisa. Deleuze parte de la base que tanto instinto como institución son dos maneras de buscar la obtención de una satisfacción; la primera actuando de forma directa sobre el objeto de deseo, la segunda estableciendo un sistema secundario de medios para garantizar su consecución, liberando al organismo de su tendencia y sometiéndolo a otras pautas de satisfacción. Esta distinción es importante en la medida en que permite interpretar la institución como un modelo positivo de satisfacción de tendencias frente a la ley que actuaría mediante la limitación de las acciones:

Contrariamente a las teorías de la ley que ponen lo positivo fuera de lo social (derechos naturales) y lo social en lo negativo (limitación contractual), la teoría de la institución pone lo negativo fuera de lo social (necesidades), para preservar la sociedad como esencialmente positiva, inventiva (medios originales de satisfacción).

Siguiendo esta lógica, Deleuze habla de que se puede medir el grado de democratización de un país según el equilibrio existente entre leyes e instituciones: un país bajo la tiranía tendría muchas leyes y pocas instituciones que medien con los ciudadanos, mientras que un país más democrático produciría mayor número de instituciones y un sistema legislativo reducido. Por supuesto, esto siempre depende de la relación que se establece entre la ley, la moral y la ciudadanía, tal y como comentamos en el capítulo precedente, así como del tipo de instituciones mediadoras que pueden ir desde la transparencia y participación hasta el impedimento burocrático, como nuestra experiencia cotidiana nos enseña. Esta interpretación positiva de la institución constituye una bocanada de aire fresco frente a los aires anti-institucionales que, a partir de los 60, imposibilitan cualquier articulación consistente de un discurso antagonista y más aún cuando, desde un sector de la intelligentsia, se ha vinculado en el imaginario social la lectura que

116. DELEUZE, Gilles, Ibid. 
hace Foucault de las instituciones y sus técnicas disciplinarias. Tenemos que ser conscientes de la contribución que un proceso de institucionalización puede suponer a la hora de desbloquear un espacio político neutralizado durante los últimos 30 años. Frente a las posiciones antagónicas y dicotómicas de parte de la izquierda más o menos radical, reapropiarse y tergiversar elementos fundamentales en la distribución de poderes, como la noción de institución, resulta un proceso clave a la hora de plantear un régimen diferente de saber y de poder. Para ello, quizás podamos remitirnos a la última época de Foucault en la que, yendo más allá del estudio de las instituciones disciplinarias en nuestra sociedad, realiza una interpretación positiva de la capacidad instituyente de la sociedad americana:

Desde el siglo XIX, las grandes instituciones políticas y los grandes partidos políticos han confiscado el proceso de la creación política; quiero decir con ello que intentaron dar a la creación política la forma de un programa político para hacerse con el poder. Pienso que hay que preservar cuanto fue producido en la década de 1960 y a principios de la de 1970. Una de las cosas que hay que preservar, a mi modo de ver, es la existencia, fuera de los partidos políticos, y fuera del programa normal y ordinario, de una cierta forma de innovación política, de creación política y de experimentación política. [...] Aquellos movimientos sociales han transformado verdaderamente nuestras vidas, nuestra mentalidad y nuestras actitudes, así como las actitudes y la mentalidad de otras personas -personas que no pertenecían a esos movimientos. ${ }^{117}$

Por otra parte, volviendo al texto de Deleuze, vemos cómo el instinto marca la carencia y el deseo de satisfacción pero no justifica la institución resultante que responde a dicha búsqueda de satisfacción. El instinto podría haber encontrado su satisfacción o una manera sublimada de procesarla de muchas formas diferentes, pero se cristaliza en una concreta, consideración de nuevo fundamental para zanjar las polémicas vanas entre naturaleza y cultura. La institución no es la forma "natural" de canalizar pulsiones e instintos sino que es una de las formas posibles que puede adoptar por lo que, en sí, desarrolla una actividad social constitutiva de modelos. Ser capaz de institucionalizarse supone ser capaz de generar modelos de relación determinados, pero si queremos llevar aún más lejos estas consideraciones sobre instintos e instituciones, nos podemos remitir a la frase que encabeza el capítulo. La distancia entre un instinto natural propio de los animales y la pulsión cultural e instituida de los humanos es mayor de la que podíamos suponer.

Pongamos como ejemplo, en relación al deseo sexual, la creación de la institución del matrimonio que sería aquella que proveería de una satisfacción

117. "Michel Foucault, an Interview: Sex, Power and the Politics of Identity», entrevista con B. Gallagher y A. Wilson, Toronto, junio de 1982, recogida en Dits et écrits II, 1976-1988, París:Gallimard, 2001, pp. 15-65, citado en SANCHEZ CEDILLO, Raúl, Hacia nuevas creaciones políticas. Movimientos, instituciones, nueva militancia, Revista Transversal, julio 2007, disponible on line en http://eipcp.net/transversal/0707/sanchez/es/ 
determinada a esa tendencia. No obstante, los estudios que, desde los años 80 , se han dedicado a profundizar sobre la relación entre cuerpo, mirada y placer en la representación pornográfica, llegan a otra conclusión. La mayoría de estos análisis de la pornografía parten de la Historia de la Sexualidad de Foucault, según la cual la sexualidad moderna y sus placeres son el resultado no tanto de la represión de un deseo originario como de configuraciones específicas de saber-poder que construyen ese mismo modelo y al respecto, Beatriz Preciado dice lo siguiente:

La modernidad desplaza el ars erótica tradicional según la cual el placer surge de la experiencia y del autocontrol, en beneficio de una scientia sexualis, un conjunto de técnicas científicas (visuales, jurídicas, médicas...) destinadas a producir lo que Foucault denomina «la verdad del sexo». Así se pondrán de manifiesto la complicidad entre las técnicas pornográficas de representación y normalización del cuerpo y los dispositivos médicos y jurídicos, la complejidad y la evolución histórica de la narración pornográfica, así como la construcción política de la mirada y del placer pornográficos y su relación con las disciplinas de gestión del espacio urbano. ${ }^{118}$

Son pues las instituciones las que modelan el deseo equivalente a un instinto de una determinada manera, aplicando de forma conjunta un proceso de interiorización que lo permita percibir como natural. Uniendo estos dos elementos, tendríamos la posibilidad de concebir unas instituciones que pueden servir para introducir modelos diferentes de gobierno, fruto de la experiencia política de la contemporaneidad, para la que intentan generar alternativas a partir de un deseo modelado por ellas mismas y temperado por el contexto. De ahí la necesidad de instituirse como manera de salir de la lógica del capitalismo pero también como forma de legitimación en tanto institución de un nosotros propia y válida de manera que pueda operar en forma de mediación política ${ }^{119}$. El problema radicaría en cómo constituirse en institución legitimada que se permita introducir cambios sin que medie una emergencia violenta, una oposición frontal, entrando con ello en la dialéctica de dependencia respecto al sistema político estatuido.

En relación a todo ello, resulta más que pertinente remitirse a la diferenciación entre poder constituyente y poder constituido que analiza Arendt ${ }^{120}$ cuando describe el proceso legislativo llevado a cabo tanto en la Revolución Francesa como en la Revolución Americana. Ya en 1789, en la preparación de la Constitución

\footnotetext{
118. PRECIADO, Beatriz. Museo, basura urbana y pornografía. [En línea]. Disponible en: $<$ http://lasdisidentes.wordpress.com/2012/08/12/museo-basura-urbana-y-pornografiapor-beatriz-preciado/> [Consulta: 4 de Mayo 2.112]

119. Mediación política significa traducir la movilidad constitutiva del sujeto de clase en movilidad política, en capacidad continua de apreciación de los espacios políticos y de recalibrar constantemente el tiro con arreglo a los mismos., en NEGRI, Antonio. Politica di classe. Milán: Macchina Libri Edizioni, 1980, p. 39.

120. ARENDT, Hannah. Sobre la revolución. MAdrid: Revista de Occidente, 1967
} 
Francesa de 1791, se establece la diferencia entre el poder constituido equivalente a la Constitución puesta por escrito como ley fundamental, y el poder constituyente emanado de la Asamblea en la que se debatirán los términos de la Constitución a aprobar. La incógnita que se plantea siempre es quién o qué legitima el nuevo poder constituido, cuya autoridad es otorgada por una Asamblea autoconstituida, es decir, no legitimada ella misma por ninguna instancia reconocida y menos aún por una Constitución, ya que es su tarea redactarla. Este "instituirse", un constituirse antes de constituirse según lo define Gerald Rauing ${ }^{121}$, se puede realizar de muchas maneras y resulta interesante recordar cómo en Francia fue la Asamblea Nacional la que desarrolló la primera constitución para la nación, asamblea conformada atendiendo a criterios de representación basados en el trabajo; mientras que en Estados Unidos se produjo una discusión sobre la Constitución, apartado por apartado, en las asambleas de municipio así como en los parlamentos de cada Estado, de manera que implicó de forma abierta a un número mucho mayor de ciudadanos (obviamente, ni las mujeres ni los esclavos, ni los indígenas tuvieron nada que decir en este asunto).

Aunque el nivel de participación y de representatividad es más o menos extenso dependiendo de cada caso, hay que decir que, en ambos, funcionó siguiendo el principio de representación y la lógica de la institución en el sentido de auto-constitución. Estas condiciones que nos pueden parecer fundacionales y por tanto, lejanas, se repiten en la actualidad no sólo en los procesos constituyentes de países sudamericanos como Bolivia o Ecuador, sino también en la propia Europa cuando se plantea la posibilidad de implantar una Constitución europea. Podemos decir con orgullo que Europa se está volviendo progresivamente más impositiva y menos participativa, superando incluso el umbral dicotómico de la votación sí/no, prescindiendo con total convicción de los preceptos democráticos al uso en aras de la eficacia contra el miedo. Porque la crisis lo vale, vaya que sí.

Pero lo que nos interesa aquí es cómo generar un proceso que en sí mismo tenga capacidad instituyente y por tanto, transformadora, que nos permita modificar la propia estructura política que podría legitimar el cambio pero que se ha blindado, lógicamente, en su deseo de permanencia, aferrándose al poder. Simultáneamente, habría que atender a la tendencia de toda estructura a perpetuarse y blindarse en sus condiciones de manera que, de nuevo, evite su renovación. Félix Guattari ${ }^{122}$ también analiza la tendencia a la "estructuralización" que es como dicho autor denomina el procedimiento de clausura en la institución en base

121. RAUNIG, Gerald. "Prácticas instituyentes, n².La crítica institucional, el poder constituyente y el largo aliento del proceso instituyente". Eipcp. [En línea]. Disponible en web: $<$ http://transform.eipcp.net/transversal/0507/raunig/es>. [Consulta: 12 de Junio 2.012] 122. GUATTARI, Félix. "Máquina y estructura". En Psicoanálisis y transversalidad. Buenos Aires: Siglo XXI, 1976. 
a las experiencias de las luchas autónomas contra las variantes estalinistas de la izquierda así como la esclerotización de los movimientos sociales surgidos en la ola de Mayo del 68. Para él, la dificultad radica obviamente en el establecimiento de máquinas institucionales que no se consoliden en estructuras sociales, especialmente en las estatales. Este trabajo continuo de apertura exige, por tanto, una implicación innovadora que pruebe nuevas formas de organización insurrecta que se opongan de forma consciente a la estructuralización: dicen que dicen que fue el caso de la Comuna de París, de los soviets y demás formas consejistas así como de la revolución española del 36 y de mayo del 68 . Siempre hace falta mucha literatura para acabar creyendo que algo es posible aunque nadie sepa muy bien si pasó realmente o si tan sólo se hizo relato.

\subsection{Introito autónomo y combatiente}

Tenemos tanto miedo a ser estigmatizados, hoy en día resulta tan ridículo estéticamente posicionarse en una izquierda utopista, que necesitamos situarnos a mil kilómetros del término comunista a pesar de hablar de los comunes, y ello nos impide siquiera pensar el pasado con una visión de continuidad. Por ello, quizás nos sirva para nuestro presente recordar cierta genealogía de las luchas autónomas, puesto que, en el fondo, de ello se trata, de transformar nuestro malestar en un combate del pensamiento para generar crisis, pero crisis en el sentido de cambio, mediante procesos de autoformación que nos preparen para las previsibles derivas políticas de nuestras instituciones.

Podríamos trazar una línea de lucha que vaya desde las trade unions (unicamente orientadas a las luchas laborales) inicialmente surgidas en Inglaterra, a la Comuna francesa y el desarrollo del anarquismo, declinándose en la consolidación del consejismo de los años 20-30 en Alemania, en la extensión y puesta en práctica de los principios del comunismo libertario, el colectivismo agrario en Levante, Cataluña y Aragón, (ya que en zonas más industrializadas es el sindicalismo el que se hace mayoritario), y termine en mayo del 68, las protestas anti-Bolonia y las estrategias de antagonismo actuales. Pero desgraciadamente, también podemos trazar una línea de cooptación y neutralización de todos estos movimientos autónomos por parte de aquellos que optan por su estructuralización, por su conversión en máquinas estatales, aunque inicialmente partan de posiciones tan insurgentes como los primeros, intentando encontrar similitudes literarias entre la ilegalización y proscripción del anarquismo por parte de los comunistas en la U.R.S.S. (Bakunin/ Kropotkin versus Marx y la constitución e inmediata ilegalidad de la AIT), el golpe que los comunistas dan a la CNT y al POUM en los sucesos del 37 en España, la toma de poder de los comunistas y UGT en la transición española mediante la neutralización por imposición de modelos anticonsejistas en las luchas autónomas de los 
70, la canalización de las protestas antiBolonia o las dificultades en la creación de nuevos modelos de autogestión en diferentes realidades contemporáneas como los centros autogestionados, las asambleas 15M, la plataforma $25 \mathrm{~S}$ y demás instancias constituyentes de la actualidad.

¿Por qué remontarnos a un asunto cuyas coordenadas ideológicas y contexto parecen estar vinculados de forma bastante lateral con nuestra investigación? ¿Cómo hacer ese salto sin banalizar lo sucedido y sin enfangarse en matices impropios que lleven la discusión a territorios que nunca debió atravesar? Con irreverencia, obligatoriamente. A pesar de todo, intentaremos abordar brevemente este asunto tan explosivo como son las luchas autónomas porque nos ha hecho imaginar un patrón de funcionamiento común a varios de los ejemplos analizados y sobre todo, porque reconocemos ese patrón en las luchas actuales, en las asambleas del $25 \mathrm{~S}$, en los comités de barrio. Si bien es verdad que trazaremos un vínculo en el apartado de autoformación con los procesos de generación de conocimiento autónomo que supusieron las encuestas obreras, situadas en paralelo a los debates suscitados por las cartografías militantes de los Iconoclasistas ${ }^{123}$, en el sentido de que tanto las encuestas como las cartografías eran fundamentalmente herramientas para desencadenar la discusión y el reconocimiento de la situación en que se encontraban sus protagonistas, es decir, desarrollar la conciencia de clase y su potencia como grupo en un caso, y en el otro, la conciencia de la explotación más allá de la clase, ya disuelta su condición de sujeto histórico, pero también de su capacidad de reacción, aquí nos conformaremos con esbozar una posible línea de investigación sobre procesos de neutralización.

En este caso, no se trata únicamente de la autoformación como práctica instituyente sino de los paralelismos que hemos detectado entre los procesos de autogobierno y su disolución, en el caso de las asambleas obreras, y los producidos durante las huelgas universitarias más recientes provocadas por la aplicación del plan Bolonia (2008) o bien, en el propio proceso de constitución de centros culturales autogestionados, al ver repetidos determinados ciclos. Esta revisión genealógica de las luchas autónomas, al observar el presente comparándolo con lo que se barajaba en un momento de radicalización de la sociedad española, ofrece una visión bien diferente de lo que proponemos hoy, rebajando su radicalidad y a la vez, mostrando la gran distancia a la que se halla de los planteamientos estratégicos de esos momentos, despolitizada la sociedad, instalada en la precarización y el miedo, sumida en el temblor de lo privado. Simultáneamente, nos puede servir de advertencia para procurar que, de nuevo, la emergencia de nuevos modelos políticos autogestionados no termine en la esclerotización de rigor.

123. http://iconoclasistas.com.ar. 
Nos remitiremos, como un ejemplo extrapolable a otros momentos políticos de conflicto abierto, a las luchas autónomas de los 70 en territorio español, aprovechando que se ha realizado un trabajo exhaustivo de recopilación y visibilización por parte de diferentes colectivos que ha dado lugar a un archivo multimedia ${ }^{124}$. Se trataría de hablar del propio contenido del archivo puesto en relación con lo que hoy podrían llamarse nuevas luchas autónomas que buscan una repolitización de la vida cotidiana y desde esa posición, una reconfiguración de las herramientas de modificación del mundo que ya no pasan por los partidos o sindicatos tradicionales, ni siquiera por las ONG desactivadas mediante los mecanismos de la financiación estatal, sino por la posibilidad de generar espacios de encuentro, difusión y modificación, como dicen respecto a este archivo de las luchas autónomas.

Resulta importante esta cuestión del archivo porque intenta recuperar contenidos invisibilizados por requerimientos del guión, para que todo sucediera tan suavemente como fuera posible, ya que nuestra transición supuso el cierre en falso de las luchas obreras, y no obstante, se vendió como modélica. De esta manera, se ignoró el propio cuestionamiento del capitalismo, ya que las luchas del momento no sólo estaban haciendo presión por la libertad sino también por un cambio de modelo político y económico. Sin embargo, se canalizó la lucha obrera dentro de los límites de la democracia capitalista y se silenciaron las luchas autónomas que se apartaban de esta lógica del pacto puesto que, en su anticapitalismo, estaba incluido el cuestionamiento de los sindicatos y del sistema de partidos. Por ello, actualizar mediante este archivo la noción de olvido hecho de memoria (cómo las otras memorias cubren e invisibilizan modelos diferentes de construcción comunitaria), la imposibilidad de salirse de las estructuras y seguir ocupando un lugar en la historia, puede ser una actitud cuando menos preventiva ante los sucesos que están acaeciendo a ese nivel en el presente.

Santiago López Petit, en este archivo, piensa que las luchas autónomas tienen tres características fundamentales: una interpretación de la historia articulada en torno a la noción de interrupción (la revolución se concibe como una ruptura del continuum histórico que posibilita la emergencia de experiencias colectivas de autoorganización, tal y como planteaba Arendt); una visión transversal y existencial de lo político, es decir, para nada una actividad reservada a una élite de expertos y llevada a cabo en unos espacios y tiempos establecidos, sino una actividad extendida a todas las facetas de la vida que deviene una vida politizada o bien una política encarnada, como se prefiera; y la búsqueda de un modelo organizativo que prescinda de cualquier atisbo de orden jerárquico y no delegue en una vanguardia la dirección política de la lucha. Todas estas características, que son comunes a los

124. Un libro, http://www.autonomiaobrera.net/pages/y-un-libro.php (editado por Traficantes de Sueños, Madrid, 2008), y una película, http://www.autonomiaobrera.net/pages/ la-pelicula.php, (Orsini Zegrí, Falconetti Peña / Espai en Blanc / 2008 / 75 minutos). 
ejemplos dados, suponen su fuerza pero también su debilidad ya que, mediante estrategias más bien banales en su mayoría, pueden acabar siendo ocultadas por las opciones que, coexistiendo con ellas, se consolidan en modelos estables, jerárquicos y profesionalizados de la política, volviendo a separarla de esa vida de la que surge.

Cuando se le planteó a Rancière ${ }^{125}$ directamente la pregunta sobre el problema de la organización cuando, tras un acontecimiento en el que la política se hace vida, hay que empezar a establecer modos de funcionamiento, respondió que resulta obvio que cualquier gobierno implica una distribución de tareas; pero que esa distribución no implica de por sí una transformación automática de la política en policía, en distribución disimétrica de poderes y consolidación de la atribución de roles asociados a regímenes diferentes de saber y de poder. Cuando vemos los documentos relativos a los conflictos políticos de los 70 o bien, a las más recientes luchas antibolonia o las inmediatas emergencias constituyentes de la sociedad española, vemos cómo en estas cuestiones se juega el gobierno y la persistencia de la autonomía. En la entrevista que se le hace a Galcerán en la Revista Cubana de Filosofía ${ }^{126}$, la autora habla de su experiencia en lo que fue la desactivación de cierta corriente dentro del Partido Comunista provocada por estas derivas de representación:

En cambio lo que hubo fue una desmovilización general calmada y tranquila. La Dirección volvió. Carrillo se instaló en España. Volvieron los viejos exiliados. Retomaron el control del Partido y lo transformaron. Cambiaron incluso, la organización interna; éste me parece un tema importante porque nosotros estábamos organizados por células sectoriales: movimiento estudiantil, movimiento obrero, movimiento de barrios, movimiento de mujeres. Las células eran como núcleos de activistas en el seno de los movimientos sociales. Carrillo impulsó una reorganización de tal manera que las células fueran territoriales, o sea por barrios. ¿Qué ocurrió? Muchos de nosotros aunque viviéramos en un determinado barrio, no conocíamos a los vecinos. Perdimos esa inserción en los movimientos sociales que eran tan potentes y no ganamos una inserción en el vecindario aunque en algunas zonas éste tuviera mucho movimiento. La prueba es que el único movimiento que siguió funcionando durante años fue el movimiento vecinal. Pero para el resto de los militantes fue un desastre.

Podríamos hablar de cómo se van filtrando procesos equivalentes de neutralización cuando las asambleas se ven forzadas a elegir delegados, a mantenerlos como interlocutores, a definirse mediante membretes y nombres, a alcanzar pactos estériles o quizás no tanto. Nos gustaría remitirnos a los testimonios

\footnotetext{
125. I Congreso Internacional de Estética y Política. En torno al pensamiento de Jacques Rancière, Instituto Francés de Valencia, del 23 al 25 de marzo de 2011.

126. GALCERÁN, Monserrat, en Revista Cubana de Filosofía n²7, entrevistada por Félix Valdés García el 26 de abril de 2010.
} 
contenidos en los documentales asociados así como en los textos correlativos, no sólo de las luchas autónomas sino también de los sucesos del 37 y los muy posteriores del 2000, porque nos permite analizar la realidad a dos niveles: por una parte, respecto a la voluntad o rechazo de consolidación de unas estructuras políticas, similar a la actualidad; y por otra, respecto a la diferencia de posicionamiento respecto al uso de la violencia frente a las luchas en las que nos encontramos inmersos.

En estas luchas autónomas, por lo que respecta al tipo de gobierno, se concedió inicialmente el máximo poder a la asamblea, por lo que se produjeron numerosas discusiones sobre quién debía estar en la comisión representativa. Cada uno de los movimientos que se realizaban, generaba un debate y votaciones a mano alzada, lo que implicaba un compromiso con el resto de compañeros al implicar un posicionamiento abierto. A los miembros de los partidos y a los sindicatos no se les dejaba subir como representantes de su organización sino como elegidos por la asamblea. Eso no impidió que a menudo se produjera una atribución falsa de las huelgas a estas mismas estructuras, invisibilizando de forma consciente un trabajo de la multitud. De hecho, con frecuencia los partidos y sindicatos de izquierda quisieron instrumentalizar sus luchas más "exitosas", como la huelga de los trabajadores de la fábrica Roca de la localidad barcelonesa de Gavà diluyendo su trasfondo revolucionario y transformándolo en reivindicaciones concretas.

No obstante, eran luchas profundamente anticapitalistas pues, aunque se basaban en reivindicaciones laborales de orden coyuntural (y no en objetivos políticos o abstracciones ideológicas de contenido anticapitalista explícito), apuntaban más allá de la democracia representativa y se rebelaban contra la lógica del pacto social que impuso la transición postfranquista. A continuación, incluimos una transcripción del testimonio de un dirigente de las luchas obreras a partir del minuto 32.00 del documental "Autonomía obrera" ${ }^{127}$ que resulta especialmente clarificador respecto al proceso de normalización de estas luchas autónomas:

Nosotros éramos una organización de lucha, nosotros no éramos un sindicato sino una organización de lucha que sirve para lo que sirve, para luchar por nuestros intereses, por esta idea obrera igualitaria, pero claro, llega el momento en que hay que legalizarse porque sino no podemos ir a las mesas de negociación, porque no nos reconocen, y venga va, a legalizarse (...) Hombre, no podemos estar cambiando todo el tiempo de representantes porque la patronal quiere tener un interlocutor que esté un tiempo porque no puede estar hablando cada día con uno; cuando para nosotros, lo verdaderamente provechoso era eso, que cada día iba una diciéndole la misma cosa quizás con matices diferentes y sin posibilidad de consensuar ni de decidir, tenía que venir a explicarnos y preguntar qué

127. Documental "Autonomía obrera", de $31: 03$ a 32:51 mn, en http://es.wikipedia.org/wiki/ Anarquismo_en_España. 
hago y nos decían, eso no puede ser, venga, se perpetúan los delegados (...) No podemos seguir así, escribiendo estos papeles en blanco que luego se pierden y no se sabe ni de dónde salen, hay que poner un membrete aquíy hay que hacer un anagrama, un anagrama pero si yo no lucho con un anagrama, pero es que para enviar un escrito a otras organizaciones, tendría que poner un anagrama (...) En la puerta de nuestro local tendría que haber una pancarta, venga, luego llega un congreso, pues como viene la prensa, vale la pena poner nuestro anagrama y nuestra consigna, nuestros líderes y venga de nuevo a ponerlo todo (...) todo esto va convirtiéndonos en una organización o una estructura que tenía un objetivo muy claro, que valía para acaba quedándose paralítica en unas cosas y potenciándose en otras en la medida en que se introduce en la lógica del sistema y hoy, ya no la reconoce ni su padre.

Este proceso lo encontramos repetido en las luchas antibolonia del 2008 en las que las autoridades exigen interlocutores fijos, procedentes preferiblemente de los sindicatos, más que estudiantes salidos de las asambleas, que tienen que volver a negociar cada uno de los puntos con todos los demás compañeros y que se resisten a encuadrarse en marcos fijos de identificación. De nuevo, podemos observar el mismo fenómeno en las asambleas $15 \mathrm{M}$ a las que se desestima utilizando los mismos argumentos: ¿Quiénes son? No nos representan (ellos, dicen también), si quieren algo que conformen un partido y se presenten a las elecciones, que sigan las normas del juego, que especifiquen sus reivindicaciones, que presenten su programa, su logo, su lista de miembros. Las formas en teoría inocentes por las que el régimen de poder vuelve a instaurarse dándole voz a quien tiene que dársela para que no se pueda colar la insurgencia constituyente de sí misma. Eso y la demonización de cualquier violencia (que no sea la propia) cuando en los 70, la noción de que se trataba de un pulso a muerte era muy evidente y cuestiones como la legalidad eran el marco en el que los movimientos de oposición se dotaban de armas.

Esta oposición radical suponía la extensión de una lógica de la lucha, no del conflicto sino de la lucha abierta que, poco a poco, por la inclusión a partir del 76 en las mesas de negociación con las instancias políticas del momento y con la patronal, se fue convirtiendo en una negociación controlada. Se llegó allí partiendo de unas luchas autónomas que bebían tanto del marxismo como del anarquismo, teniendo como referentes tanto la comuna como los soviets, pero también una construcción de la oposición clandestina sometida a represión permanente, con ejecuciones en el 74 como la de Salvador Antich y sus compañeros y sucesos como los de Vitora en el 76, en donde se encontró una fuerte justificación de la violencia resistente. Según está históricamente documentado, durante el mes de enero de 1976, unos seis mil trabajadores iniciaban una huelga en contra del decreto de topes salariales y en defensa de mejores condiciones de trabajo. Dos meses después convocaban por tercera vez una huelga general que fue masivamente seguida el día 3 de 
marzo. Ese mismo día, la policía armada entró en la Iglesia San Francisco de Vitoria, en la que estaba previsto realizar una asamblea de trabajadores $y$, haciendo caso omiso de la decisión del párroco y del contenido del Concordato, conminó al desalojo y atacó tanto con gases lacrimógenos como con disparos a los manifestantes que salían del recinto religioso, saldándose la operación con varios muertos y numerosos heridos.

Hechos como este hacen que hasta el 78-79, todavía existiera la idea que estábamos en una época pre-insurreccional con un planteamiento claro de clase contra clase en la que una emplea toda su violencia y la otra debe dotarse de todo lo que pueda para defenderse y para atacar, por lo que la violencia de ambas partes se refuerza y se legítima. En esos momentos, las luchas eran luchas y la violencia ejercida, ya fuera sobre los esquiroles en las huelgas ya fuera sobre las mismas fuerzas del orden, estaba justificada como respuesta a un nivel similar de violencia estatal. Esta valoración de la lucha armada hizo que los movimientos autónomos se separaran de la base social en la que reposaban y se acabaran ubicando en una posición suicida.

De hecho, por esta radicalización que pierde fuerza cuando el estado de derecho se impone, hay una tregua impuesta también que establece que todas las luchas se resuelvan dentro de los límites de lo consensuado, eliminando la visión del conflicto, la agresividad del tira y afloja, la polémica inherente a toda sociedad, produciendo en cierta manera una neutralización social e individual. Hoy, instalados en la derrota, ni siquiera apostamos por la oposición fuerte, la idea de una insurrección es completamente ajena al entorno, los que pretenden una mínima agitación son condenados sin ni siquiera pruebas como fue el caso de Tiquun ${ }^{128}$, el grupo francés que anunció mediante la edición de su libro "L'insurrection qui vient" ${ }^{129}$ sucesos que podemos reconocer en el presente. Para lo bueno y para lo malo, nos encontramos obligados a enunciar constantemente nuestra voluntad pacifista aunque sea destituyente.

Respecto a la solidaridad de la protesta, valga decir que es un término obsoleto en la actualidad, es verdad que el capitalismo se ha hecho uno con la vida y que las armas que consistían en aguantar conjuntamente el tirón del enfrentamiento se han perdido en el camino porque no hay "nosotros" en el que ampararnos. Las cajas sociales, la socialización de las ganancias que suponía considerar que la lucha era colectiva porque implicaba un reparto de salarios equitativo aunque acabara siendo una cantidad mínima, evidenciaba la condición horizontal del enfrentamiento y su condición antagonista. La huelga hoy día es un simulacro de oposición porque nadie va a mantener una huelga indefinida, ni siquiera a planteársela, con la mitad de la población teniendo que hacer frente a deudas que no le permiten

128. http://es.wikipedia.org/wiki/Tiqqun.

129. zinelibrary.info/files/pdf_Insurrection.pdf 
soñar con dejar el trabajo, con las tasas de desempleo más altas de la democracia, con el miedo instalado. El precariado tiene otra perspectiva por su propia situación.

Como dicen las malas lenguas, la derrota de la clase obrera fue la sociedad de consumo, que obligó a negociar convenios a la baja por el nivel de endeudamiento particular, la financiarización de las vidas, porque ¿quién puede mantener un mes de huelga cuando se ha metido con la hipoteca de una casa que ha pagado a precios estratosféricos y cuando aún si se la embarga el banco, ni siquiera con esto puede rescindir su deuda? Habría que encontrar las vías de enfrentamiento cuando la situación se vuelve así de insostenible, sólo que nos faltan armas ya que no contamos ni con el colchón de la solidaridad social ni con el recurso a la violencia, y sin armas válidas, ¿qué posibilidades reales tenemos de cambiar las normas? Como dice Sánchez Cedillo:

Esta revolución institucional es inseparable de la capacidad de expresar contrapoderes, de la capacidad de imponer la huelga metropolitana contra la movilización total productiva de las poblaciones. ¿Cabe acaso pensar en una derrota del régimen de guerra/excepción fuera de esta capacidad de ejercer una fuerza colectiva y éticamente regulada contra la violencia de la movilización total metropolitana? ${ }^{130}$

\subsection{El 25S como proceso destituyente}

De esta manera, salta la alarma sobre si los nuevos procedimientos de empoderamiento serán canalizados a las formas ya conocidas y fracasadas de gestión comunitaria. ¿Sucederá de la misma manera con los movimientos asamblearios $15 \mathrm{M}$ de la actualidad, sujetos a la presión de constituirse como partido para legitimarse en un estado supuestamente democrático? ¿Qué otros procesos podrían considerarse instituyentes en este caso? ¿Cómo superar la paradoja de intentar hablar en nombre de una colectividad a la que no representan si nos atenemos a los resultados electorales? Pero ¿cómo creer en la legitimidad de un sistema en el que casi un tercio de la población se abstiene reiteradamente? Porque el silencio nunca se ha considerado un mecanismo de alarma respecto a la carencia de representatividad de nuestros representantes, ese dato no ha tenido consecuencias en la modificación de la opinión pública; sin embargo si queremos ser medianamente rigurosas respecto al estado de nuestra democracia, debemos reconocer que las tasas de participación descendentes no son un síntoma de mucha salud como tampoco lo es el hecho de que, reiteradamente, todos los medios de comunicación opten por mostrar la visión propuesta por los partidos en la que se ignora, en vez de dar la voz de alarma, esta participación reducida.

130. SANCHEZ CEDILLO, Raul. "Hacia nuevas creaciones políticas. Movimientos, instituciones, nueva militancia "Eipcp [en línea]. Disponible en web:

<http://transform.eipcp.net/transversal/0707/sanchez/es>. [Consulta: 12 Junio de 2.012] 
La importancia de las estrategias de visibilización, naturalizadas por su difusión reiterada, es una evidencia que tendemos a olvidar por su omnipresencia en todos los aspectos de la vida y la duda que siembra sobre la realidad de la realidad. Como ejemplo, podemos ver a continuación dos gráficos que responden a esta diversidad de visiones, correspondiendo el primero de ellos a los índices de participación en las elecciones generales de 2011 y el segundo, aquel que han difundido todos los medios, a la subsiguiente repartición de escaños.

$\%$ censo
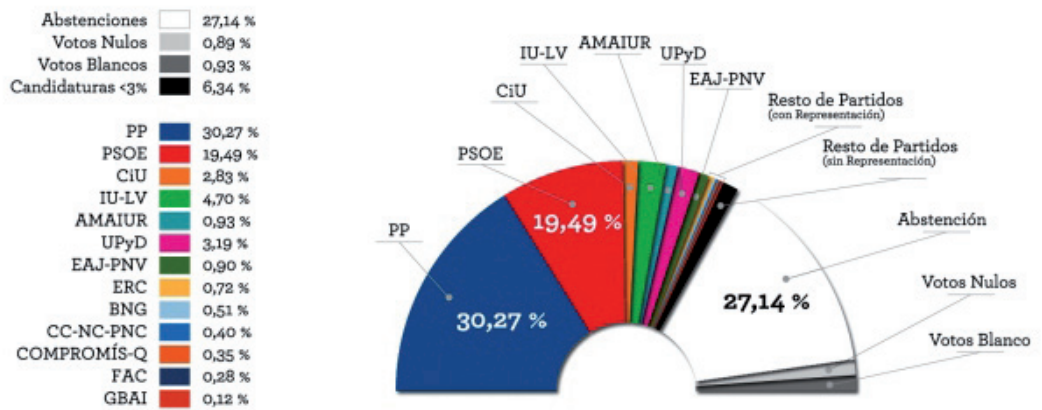

$\%$ de escaños
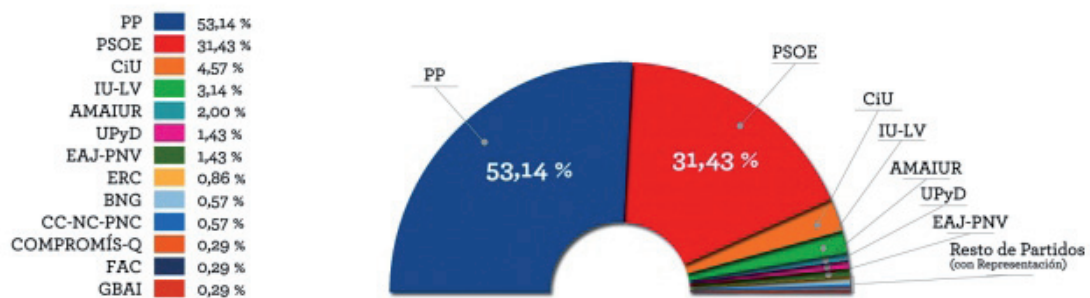

Fig. 6

Una visión sensiblemente diferente de la realidad de un país que quizás explique eso que no se explica nadie porque, en la versión más extendida de la realidad, más de la mitad de la población española apoya una opción de derechas y un tercio, su alternativa bipartidista, con lo que automáticamente, cualquier opción política ajena a esos dos partidos (y no hablamos únicamente del 
sistema de partidos) queda cuantitativamente menospreciada. Esta no es una tesis que encuentre soluciones, ni siquiera mejores opciones, es una tesis que parte de la derrota generalizada de la emancipación, de la crisis del discurso y de la quiebra de un statu quo que permitía determinada ocultación del simulacro representativo, únicamente, pero que intenta obtener cierta lucidez a partir de los análisis a pie de pista de este país a la deriva, y a veces, algo tan sencillo como una imagen, contribuye a clarificar el horizonte.

Cuando observamos el proceso que se está produciendo en España en referencia a lo que denominamos la enorme distancia entre la presentación y la representación en la política española, veremos cómo por parte de los grupos que intentan generar una alternativa no partidista al gobierno, se están produciendo debates interesantísimos sobre las formas democráticas, el funcionamiento de las asambleas y la articulación de multiplicidades frente a la crisis. Respecto a ello, podemos percibir que antes que instituyente, este movimiento heterogéneo se quiere destituyente, se necesita inicialmente destituyente, para poderse así reorganizar en torno a un debate que, tal y como habíamos comentado en referencia a las dos revoluciones, sea capaz de constituirse ex novo en las premisas estructurales de gobierno, es decir, respecto a las reglas democráticas en sí.

Como muestra de ello, podemos citar hechos recientes que sirven de ejemplo para analizar cuáles son los términos que hoy en día se están manejando desde los movimientos revolucionarios (usando revolucionario en el sentido acotado por Harendt y ya citado). Por parte de la Plataforma ¡En Pie! 131, se convocó el 30 de julio de 2012 una propuesta de "ocupación del Congreso" que incluimos aquí en el calor del enfrentamiento porque nos resulta totalmente representativo de esta voluntad destituyente-constituyente así como del proceso de articulación con otras plataformas convocantes y la distribución de poder dentro de las asambleas ya que en este tipo de juegos democráticos nos va el futuro. Como dijo un amigo anónimo, "No hay nada más fácil que manipular una asamblea", sólo que en el conocimiento está nuestra emancipación y por las redes van circulando diferentes documentos sobre cómo analizar e impedir el excesivo control de las asambleas por parte de grupos de presión así como reflexiones e indicaciones sobre cómo mejorar la accesibilidad de las asambleas a todo tipo de ciudadanos y la transparencia y adecuada difusión de las actas resultantes. Volvemos pues al ágora primigenia y al aprendizaje de base de los procedimientos democráticos. Quisiéramos esperar que las nuevas generaciones que aprenden a debatir en estos foros exijan de sus gobernantes que lleven a cabo discusiones reales y no únicamente simulacros democráticos. A continuación, incluimos el texto de la convocatoria así como el primer manifiesto que surgió de la anónima Plataforma ¡EnPie!:

131. http://plataformaenpie.wordpress.com/25s/ 
Bajo el nombre "Ocupa el Congreso", entendiéndolo como la ocupación simbólica del espacio de decisión sobre nuestro presente y nuestro futuro, convocamos a la ciudadanía de toda España el día 25 de Septiembre de 2012 a manifestarse rodeando el Congreso de forma indefinida hasta conseguir la dimisión del gobierno actual, la disolución de las Cortes y de la Jefatura del Estado y la apertura de un proceso de transición hacia un nuevo modelo de organización política, social y económica, haciendo de éste, el llamamiento de unión de todas las luchas por una sociedad más justa y democrática. Instamos a todas las personas que residan fuera de Madrid a organizar medios de transporte para facilitar su traslado al centro neurálgico del estado actual con el fin de apoyar esta acción. En el caso de que les sea imposible acudir a Madrid, proponemos que posibiliten, coordinen y participen en acciones similares en su localidad, bien en sus parlamentos autonómicos o ante las delegaciones de gobierno.

A esta proposición se le adjuntó un manifiesto que pretendía establecer una serie de puntos para resumir el grueso de sus reivindicaciones a partir de las que se podría empezar a negociar.

\section{Manifiesto 25S (del 30 de julio de 2012)}

Nosotras, personas comunes hartas de sufrir las consecuencias de vivir en un sistema condicionado y coaccionado por los mercados, que es a todas luces insostenible, y nos ha llevado a ser víctimas de una estafa a gran escala a la que han llamado crisis, nos unimos para redactar este manifiesto e invitamos a toda la ciudadanía a unirse a las reivindicaciones que reclamamos en él.

Consideramos que la situación ha traspasado todos los límites tolerables y que somos víctimas de un ataque sin precedentes por parte del poder económico, que utilizando la crisis como pretexto, está arruinando nuestras vidas, y cuyos culpables son quienes se han configurado como una oligarquía intocable, con la complicidad de todas las fuerzas políticas representadas en el parlamento, manipulando todos los poderes del Estado para mantener sus privilegios y enriquecimiento desmedido e ilícito.

Ya no hay manera de ocultar que vivimos un gigantesco fraude social, con gobiernos que sistemáticamente nos traicionan haciendo exactamente lo contrario a sus compromisos electorales, y que no hay justicia alguna en los tribunales para los banqueros, políticos y empresarios culpables de la situación. Solo vemos cómo esta estructura de poder viciada e inmoral implanta políticas que acaba con nuestros derechos y destruye nuestras vidas, y cómo somos víctimas de una represión injustificable cuando demandamos un cambio en la situación.

Creemos que el problema es de tal envergaduray sus raíces tan profundas que su solución no pasa por efectuar reformas basadas en los mecanismos del sistema político actual, en consecuencia exigimos: 
1 - La dimisión del gobierno en pleno, así como la disolución de las Cortes y de la Jefatura del Estado, por traicionar al país y al conjunto de la ciudadanía de forma premeditada, llevándonos al desastre.

2 - La apertura de un proceso constituyente transparente y democrático, a fin de redactar una nueva Constitución, con la participación de toda la ciudadanía, de manera que le sea propia, pues no reconocemos carácter democrático alguno al actual texto constitucional, redactado por una camarilla a espaldas del pueblo, y que consagró la dominación de los herederos del franquismo y quienes pactaron con ellos. Ha de ser el pueblo quien determine el modelo de organización social en el que quiere vivir, y no al contrario.

3 - La auditoría de la deuda pública de España, con moratoria del pago de la deuda hasta haber delimitado claramente las partidas que no han de ser pagadas por la nación, pues han servido a intereses privados que utilizaron al país para sus propios fines y no los del conjunto de la ciudadanía española. Igualmente, exigimos el procesamiento de todas aquellas personas que se demuestren sospechosas de tales maniobras, y que respondan con sus bienes en caso de resultar condenados.

4-La reforma de la ley electoral con el diseño de un nuevo proceso electoral, a fin de que represente verdaderamente la voluntad del pueblo ante cualquier elección que sea necesaria para facilitar el desarrollo de un proceso constituyente democrático.

5 - La derogación inmediata de los recortes y de todas las reformas en contra del estado de bienestar tomadas con la excusa de la crisis, y que suponen restricciones de derechos y libertades de la ciudadanía, pues no sólo son un desastre para el país, sino que han sido impuestos traicionando la voluntad del pueblo.

6-Unaprofunda reforma fiscal, que hagapagarmás a quienes más beneficio obtienen de la sociedad. Igualmente, exigimos la derogación de la amnistía fiscal decretada por el gobierno, cuya injusticia es una verdadera burla a los contribuyentes honrados.

7 - La supresión de todos los privilegios de quienes ostenten cargos políticos o públicos, y la implantación de mecanismos eficaces de control en el desempeño de sus funciones.

8 - La paralización inmediata de todos los desahucios, y la puesta a disposición de la población a precio de alquiler social de las viviendas en propiedad de los bancos y cajas que hayan sido ayudados con fondos públicos.

9-Lacreación de nuevos empleos, cuya primera premisa sea la sostenibilidad, y cuyo fin sea el desarrollo de la humanidad, así como la gestión coherente de los empleos disponibles de tal modo que toda la población pueda trabajar para vivir pero no se vea obligada a vivir para trabajar. Es un enorme engaño que haya que trabajar cada vez más, falacia sustentada en la avaricia de los grandes intereses y contraria a los intereses de la gente común. 
Por todo lo expuesto convocamos a la ciudadanía el día 25 de Septiembre de 2012 a manifestarse de forma indefinida en las puertas del Congreso hasta conseguir la dimisión del Gobierno y la apertura de un Proceso Constituyente, haciendo de éste, el llamamiento de unión de todas las luchas por una Sociedad más justa. Somos la inmensa mayoría, somos el pueblo, tenemos razón, y no vamos a dejaros pasar.

A raíz de esta convocatoria que tuvo un éxito insospechado en las redes, hubo muchas voces que se alzaron cuestionando la pertinencia de "ocupar"el Congreso así como el peligro de hacer una apuesta tan fuerte sin tener alternativas claras de articulación de un escenario "post" si se consiguiera hacer tambalear al Gobierno en el mejor de los casos. De la plataforma y de la convocatoria, se criticó la falta de transparencia, horizontalidad e inclusividad, pecados capitales viniendo de una plataforma que exige comportamiento democrático. Resulta bastante plausible pensar que se trataba más bien de una pataleta sobre quién encabeza el movimiento de resistencia y por qué no se ha contando con su insustituible presencia, en primer lugar. Al fin y al cabo, todos somos humanos y difícilmente salimos de las reglas del juego que hasta ahora se han utilizado: protagonistas épicos de la salvación de la sociedad y no multitudes anónimas que establecen pactos consensuados que requieren de ratificación permanente, de una actualización constante del ejercicio de la democracia.

Tras el cuestionamiento de esta convocatoria y de la polémica de la"ocupación", el 25 y 26 de agosto de 2012 se abrió la propuesta a las plazas, asambleas $y$ todos aquellos que quisieran iniciar un proceso deliberativo sobre
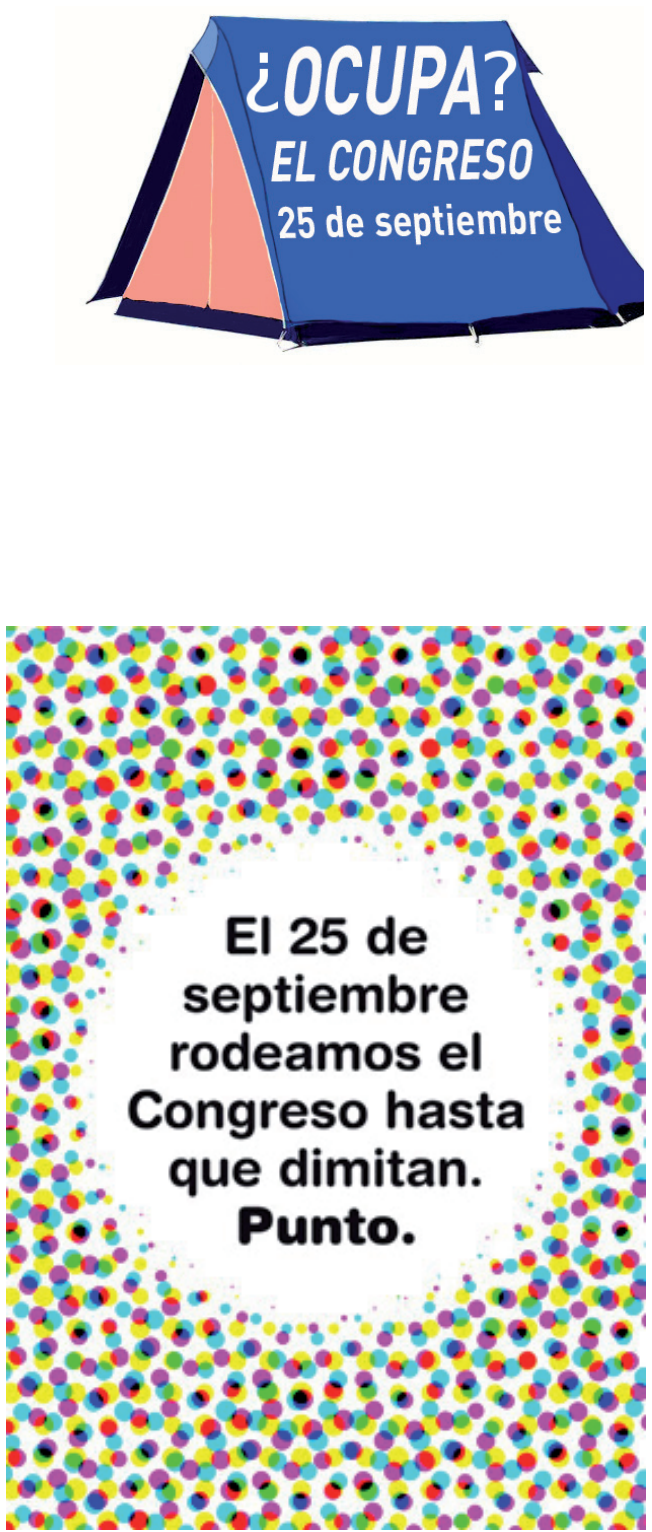
la actitud a adoptar cara al 25S y se creó entonces la Coordinadora 25-S ${ }^{132}$, integrada por organizaciones, plataformas, asambleas y colectivos en busca de"un nuevo modelo social basado en la soberanía popular participativa". La Plataforma ¡En Pie! se diluyó en esta coordinadora en términos de igualdad con el resto de participantes y se abordó la discusión creando tres grupos de trabajo: comunicación, acción y contenidos, difundiendo a través de las redes sociales los acuerdos y conclusiones surgidas a raíz de la celebración de asambleas periódicas abiertas. Se publicó igualmente un nuevo manifiesto en el que se hablaba, ya no de ocupar el Congreso, sino de rodearlo, matizando igualmente toda una serie de términos que, sin ceder en las exigencias, daban una impresión de menor ideologización revolucionaria, para intentar evitar la etiqueta de "radicales", como si se pudiera conseguir con tan sólo cambiar unas palabras, como si, de antemano, no estuvieran ya jugadas todas las cartas.

En cualquier caso, independientemente de que estas iniciativas contribuyan a visibilizar la voluntad destituyente de parte de la sociedad española, lo verdaderamente interesante de estos movimientos es la reapropiación y actualización de los procesos democráticos desde la base de la sociedad, en un despliegue de nombres y posibilidades que se oponen frontalmente al: "No hay nada que hacer sino sobrevivir a la crisis". Necesitamos ya no reaprender, sino partir desde el $A B C$ de la política para poner en acto ese pensamiento nuevo que intentamos desarrollar. Por una parte, asumir que nos queda una tarea destituyente que cumplir en primer lugar, aprovechando esta energía social que circula a causa del estado crítico de nuestro país y de unos cuantos que nos precedieron en este desmantelamiento de la realidad. Posteriormente, nos tendremos que enfrentar a otro problema bien distinto: la fase constituyente. ¿Qué pasará después si cae el gobierno? ¿Cómo conseguir una democracia real, el fin del sistema de partidos tal y como lo conocemos, nuevas formas de decisión directa y organización de la vida en común? Tendríamos que pensar desde ya en las posibilidades de formalizar una democracia construida desde abajo no sólo en la serie de puntos establecidos en el manifiesto del 25S, que serían ni más ni menos que el mínimo común denominador, sino con un planteamiento claramente propositivo y que pudiera extenderse a escala europea. Llevar a cabo un proceso deliberativo y vinculante, activar la inteligencia colectiva que lleva fructificando desde hace tiempo, de forma más concreta y articulada desde el estallido del $11 \mathrm{M}$. Porque si no lo hacemos, como dicen desde las plataformas 15M, quedaremos a merced de los gestores profesionales de la protesta o atrapados en un rechazo impotente.

132. http://coordinadora25s.wordpress.com. 


\subsection{Relectura de la ilustración, la ignorancia compartida}

En esta línea entramos en el debate nodal de esta tesis, el proyecto de autoformación como dispositivo de dinamización político que, en cierto modo, podría considerarse parcialmente un delirio post-ilustrado, si no fuera porque nos conocemos el derecho y el revés de esa tela que ya hemos tejido tantas veces, lo que significa que, por lo menos, tenemos escritas todas las coartadas para justificar nuestro pseudo-elitismo democratizante. En cualquier caso, con similar afán enciclopedista, abordamos la necesidad de dotarnos de armas formativas ya que en el activismo rara vez se produce la acumulación de saber sino, en la mayoría de los casos, un relevo generacional que desaprovecha los conocimientos adquiridos mediante las prácticas antagonistas.

Desde los movimientos sociales, pocas veces hemos sido capaces de poner en marcha instituciones colectivas estables que nos sirvan para generar debates en torno a estos saberes no académicos así como para agruparlos, contrastarlos y transmitirlos apropiadamente. Resulta importante reflexionar sobre cómo institucionalizar determinados saberes-activismos cuando resulta obvio el corte existente en relación a la edad, que se extiende en una horquilla entre los 25 y los 35 años de personas que se dedican mayoritariamente a estas actividades, abandonadas posteriormente por necesidades materiales o desarrollos familiares que dificultan su continuidad.

Nos encontramos ante la absoluta necesidad de empresas políticas como Traficantes de Sueños ${ }^{133}$, que funcionen en red como la Universidad Nómada ${ }^{134}$, y que trabajen para articular una plataforma desde la que trabar sinergias cara a los urgentes cambios a los que nos aboca esta triple crisis que estamos mascando. $\mathrm{Si}$ a eso le sumamos el desarrollo de las capacidades igualitarias a lo Rancière mediante una toma de poder, un empoderamiento de los medios de conocimiento, los contenidos y los lugares, tenemos dispositivos conjuntos de producción de teorías y prácticas orientados a la transformación política que también es la vida.

Tenemos que asumir que la política tan sólo puede denominarse política cuando provoca cambio y este cambio tan sólo es posible en grupos que tengan la potencia de transformación política, personas con poder fáctico capaces de cambiar la estructura con su emergencia organizada. En la actualidad, en España por lo menos, todos somos sujetos desde los que puede emanar el cambio, vista la crisis profunda que nos agita, pero resulta mucho más probable que los sujetos transformadores provengan de los siguientes cuatro grupos: trabajadores inmigrantes ilegales, trabajadores cognitivos de clase media con empleos precarios,

133. http://www.traficantes.net.

134. http://www.universidadnomada.net. 
jóvenes de los suburbios, y estudiantes de instituto o de universidad. A estos grupos se suman aquellos que, por la gravedad de la crisis, se encuentran en una posición desesperada, en la que todos los privilegios o por lo menos, los equilibrios precarios obtenidos a lo largo de décadas, desaparecen de manera abrupta, dejándoles la sensación de que ya no tienen nada que perder y que, por tanto, pueden salirse de sus casillas, léase, de sus marcos de pensamiento, y pasar a la acción.

Para fomentar la activación de estos grupos transformadores, resulta necesaria la generación de estructuras que favorezcan un proceso similar al planteado por el maestro ignorante y hacerlas visibles, léase atractivas, a estos cuatro grupos: a través de la creación de escenarios de formación alternativos, consolidar estructuras de manera que se pueda producir el empoderamiento intelectual de los potencialmente capaces de cambio y la aplicación fáctica de dicho empoderamiento en la creación de plataformas de acción a nivel económico y social. En resumen, como ya hemos dicho, se trataría de consolidar formas de socialidad que se den como inmediatamente políticas: con una nueva politicidad encarnada o específica cuyo sentido proceda del ejercicio intuitivo de sus prácticas, reapropiándose de espacios y palabras para transformarse así mediante una operación conjunta que combine la praxis como herramienta teórica y el pensamiento como herramienta de transformación.

Como ejemplo de su puesta en acto, tras un análisis como el que hemos realizado de la economía metropolitana, nos gustaría recorrer someramente determinadas prácticas políticas que anteceden y coexisten con el 15M, para mostrar hasta qué punto pueden enmarcarse dentro de lo que Boutang llama externalidades positivas o polinización social y que la teoría feminista lleva décadas intentando visibilizar, como ya hemos mostrado al hablar del trabajo de los cuidados o reproducción social así como de la producción cultural. En muchos de estos casos, para hacer referencia a la creación de valor mediante un trabajo conjunto, se suele hablar de cuencas de cooperación, definidas por Negri, Lazzarato y la misma Corsani como "áreas, redes o circuitos compuestos por una vasta pluralidad de agentes heterogéneos, cualificaciones y saberes que producen a través de formas de interacción e intercambio cooperativo siguiendo una lógica y una espacialidad que desborda los perímetros de la forma-empresa y de la forma-estado" ${ }^{135}$. Recordamos simplemente que las cuencas de cooperación, no obstante, por la peculiaridad de su funcionamiento, suelen sufrir la captura del valor producido por dicha cooperación social a través de dispositivos de explotación complejos, tales como los definidos en el análisis de los procesos de gentrificación de las ciudades.

Estas formas dispersas de cooperación entre múltiples sujetos, sea mediante redes sociales, sea mediante la constitución de entornos creativos, 135. SGUIGLIA, Nicolás. Libertad, autonomía y procomún. Movimientos urbanos en la era de la precariedad. Málaga: Universidad Libre Experimental, 2010, p. 23. 
constituye una aportación difusa a la ciudad y no puede considerarse ni economía privada ni pública sino economía de lo común. Esta noción del común o de procomún que venimos utilizando a lo largo de la tesis y de la que ya hemos descrito los orígenes (traducción al castellano del concepto jurídico-filosófico anglosajón de commons) se aplica inicialmente a aquello que siendo de todos no pertenece a nadie, como el aire, el agua, los bosques, el acervo cultural, la secuencia del genoma humano y otros conceptos generales sin los cuales la vida resultaría imposible. Pero a esta acepción inicial se le ha sumado otra complementaria incluida ya en la RAE ${ }^{136}$ bajo el sucinto epíteto de utilidad pública. No obstante, si nos sentimos semánticamente generosas y queremos abarcar una realidad que de otra manera permanecería innominable, podremos decir que el procomún corresponde a determinados bienes y recursos de utilidad pública, utilizados, gestionados y producidos de forma compartida. Esta noción es la que resulta clave para diferenciar el régimen del procomún del régimen de lo privado y/o lo público, tal y como lo hace Nicolás Sguiglia ${ }^{137}$ cuando especifica lo siguiente:

Estos bienes y recursos comunales pueden ser naturales o artificiales, materiales o inmateriales e incluyen los llamados bienes y recursos públicos bajo la responsabilidad y gestión estatal. El régimen de lo privado permite la apropiación y uso exclusivo de determinados bienes y recursos. El régimen de lo público otorga la titularidad y la reglamentación de su uso y provecho al Estado. El régimen del común o procomún establece que la producción, cuidado, acceso y uso de determinados bienes y recursos recaiga en la comunidad en su conjunto, sea cosas de todos e inalienable, sea asunto público aunque no necesariamente estatal.

Por tanto, el procomún se caracterizaría por esta diferencia clave respecto a sus principios de gestión:

1. Propiedad y gestión colectivas

2. Plena igualdad en el acceso

3. Distribución equitativa

4. Cooperación de sus integrantes

5. Descentralización en su gestión

Y para aquellos que nos están esperando con las armas alzadas o con la mano presta, insistimos en que la crítica de lo público no es una renuncia a la gestión pública de determinados servicios de clara utilidad general, sino la protección frente a su progresivo sometimiento a cuestiones bastante ajenas al bien común y con ello, no estamos dando muestras de radicalidad ninguna sino que plasmamos el parecer de gran parte de la población que considera que las administraciones públicas, del signo que sean, se están caracterizando por su corrupción, ineficacia y perpetuación blindada. Por todo ello, necesitamos volver la mirada a los

136. Disponible en http://lema.rae.es/drae/

137. SGUIGLIA, Nicolás, op. cit., p.30. 
cuestionamientos y respuestas que proceden de innumerables experimentos de producción del común para intentar aislar sus rasgos diferenciadores y su capacidad de innovación política.

Separado del Estado y del mercado, lo común, heredero de la tradición libertaria y colectivista que ha mantenido un frente abierto de tensión con la tendencia a la estructuralización, se construye a través de los movimientos sociales, articulados mediante procesos de autoorganización. Estos procesos, descritos desde la biología, la física y la teoría de sistemas, funcionan incrementando la complejidad de su propio sistema sin ser guiados por agentes externos. No obstante, hay una serie de elementos definidos como atractores por la ciencia que pueden catalizar los diferentes impulsos necesarios para que se desencadene el movimiento hacia la autoorganización, sin por ello predeterminar su forma, únicamente precipitando energías e impulsos de manera que encuentren una forma concreta de existir. ${ }^{138}$

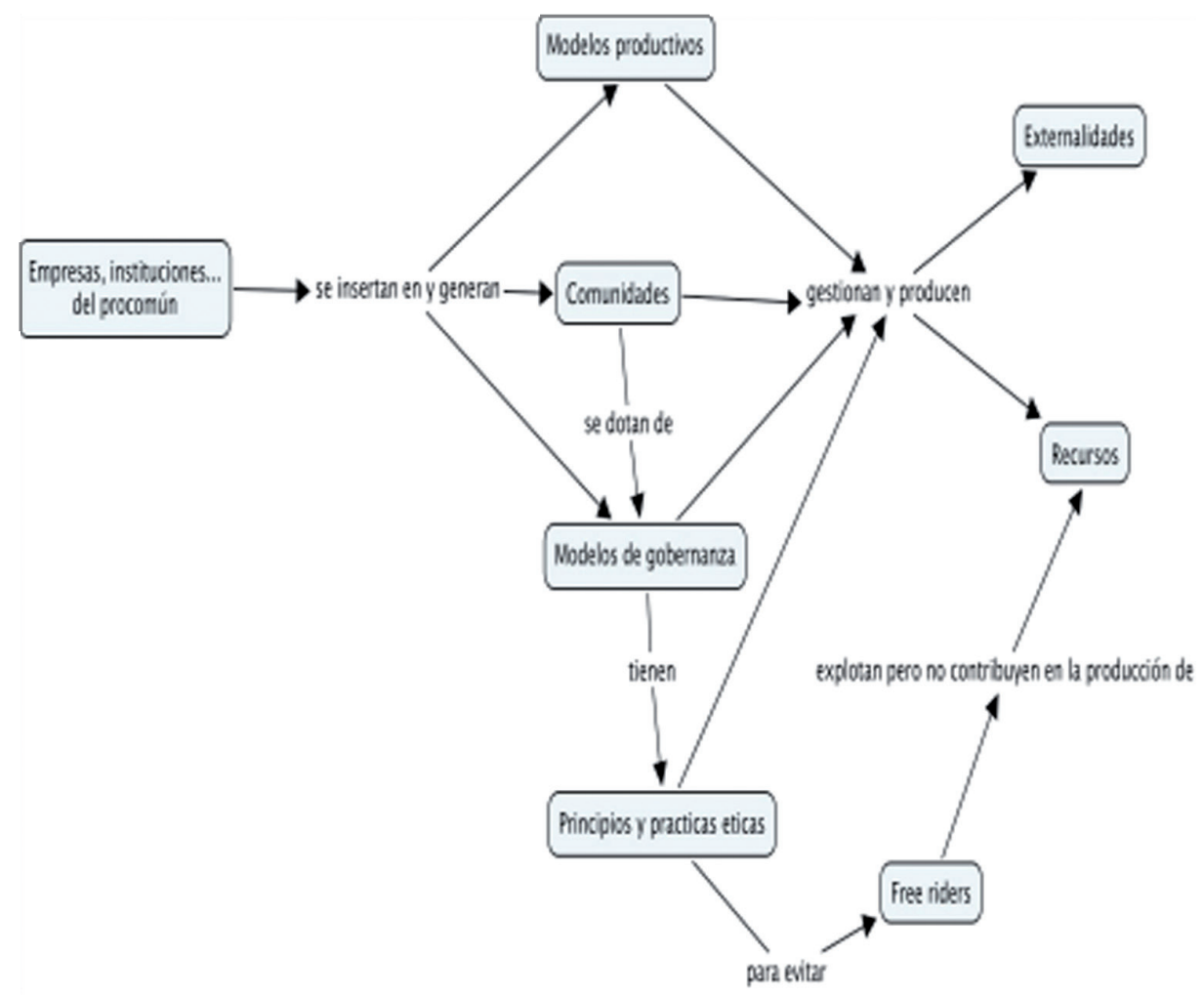

138. Esquema fruto de la investigación colectiva realizada en Eutokia el 20 y 21 de junio de 2012, cuyo informe está disponible on line en http://www.slideshare.net/ColaBoraBora/edp-infomesesioneseutokiafinal. 
Si extrapolamos esta noción científica a la ciudad, tal y como hace Sguiglia en el artículo citado, podemos identificar determinadas entidades, redes o movimientos colectivos en tanto atractores de reestructuración social, a través de la creación de comunidades biopolíticas dirigidas a la producción, cuidado y gestión de instancias colectivas del común. En muchos casos, estos atractores corresponden a la forma denominada "institución del común". Resulta casi redundante incidir en la cuestión de la institución del común a través de la conformación y diseminación de instituciones del común. Este objetivo se introduce en la sociedad mediante diferentes procesos de transformación en marcha que ya hemos enunciado parcialmente y que completamos a continuación.

Por una parte, recordamos que la consolidación de la deriva universitaria hacia la mercantilización y utilitarismo que supone el plan de Bolonia, la aleja de forma casi definitiva de la posibilidad de producción de pensamiento crítico desde las instituciones del conocimiento, la posibilidad de que se gasten recursos y tiempos en generar estructuras reflexivas y autorreflexivas así como mecanismos de flexibilización que permitan algún tipo de modulación por parte de los usuarios - que en vez de convertirse en clientes que exigen sus derechos por el pago realizado, puedan constituirse en verdaderos agentes de transformación tecnológica pero también crítica. Por otra parte, como veremos detalladamente a continuación, tenemos cuatro líneas convergentes que funcionan como atractores:

1. Las diferentes plataformas colectivas de socialización política pasan de ser bunkers del movimiento okupa a centros sociales de segunda generación desde los que surgen y conviven diferentes movimientos autónomos, desde la insumisión original hasta las oficinas de derechos sociales y las campañas a nivel nacional, intentando cubrir el espacio que han dejado los sindicatos que, al contar con el empleo, no intervienen en el ámbito de los trabajadores invisibles.

2. A este campo se suman los autónomos creativos o colectivos que llevan a cabo producción cultural, inicialmente transformados en asociaciones sin ánimo de lucro, y que, posteriormente, deciden poner fin a esta política de "clientelismo" y pasan a verse obligados a conformarse como empresas que entran en un sistema de créditos. No obstante, siguen buscando maneras de articularse que puedan servir de modelo a otros sectores de la sociedad, precarizados y vaciados de su valor por instancias productivas que los cooptan, como veremos en el informe del encuentro Paraquienesdifrutamostrabajando.

3. De forma paralela, surgen las universidades libres que van creciendo amparadas en los centros sociales y que, de forma simultánea, empiezan a generar redes para lanzar programas de autoformación que funcionen a nivel nacional y que estén directamente vinculados con los movimientos sociales de base, como veremos en la descripción del encuentro Commoniversity. 
4. A ello, finalmente se suma la progresiva porosidad de las instituciones de la cultura y fundamentalmente, del arte, que empiezan a respaldar todas estas actividades antagonistas y llevan a cabo un proceso de transferencia, por una parte de dinero y legitimación y por otra de renovación y consecuencia con todos aquellos principios generados entre otras, desde las prácticas de arte público y la consolidación de modos de relación colaborativos y/o antagonistas.

Por último, no olvidemos que esto sucede en un contexto en el que la metrópolis se dibuja como espacio de producción en sí misma y en el marco de la crisis que termina de teñirlo todo de inevitable. A continuación, analizaremos pues cómo se produce la transferencia de conocimiento de estos ámbitos a la sociedad en general desde el capital de conocimiento antagonista o subalterno, los modos de hacer autónomos y los procesos de empoderamiento, en torno a un eje que articula las siguientes dos líneas: el aprendizaje y la transformación social. Resumiendo, atendiendo a estas dos líneas, podemos hablar de diferentes experimentaciones en este sentido con rasgos diferenciadores respecto a otras formas de politización de la vida:

1. Plataformas de intervención política metropolitanas como pueden ser los centros sociales autogestionados que adoptan la forma de instituciones en movimiento y que trataremos a continuación.

2. Redes de autoformación a raíz de la crisis profunda de la universidad sobre la que ya nos hemos extendido sobradamente, que adoptan la forma de proyectos editoriales, revistas transnacionales, dispositivos nómadas de formación a través de seminarios, debates y proyectos conjuntos de investigación, laboratorios hacker, etc.

\subsection{Centros sociales autogestionados y otras instituciones anómalas}

En el territorio yermo de los 90 , surgieron alternativas a la catástrofe imaginativa, modelos diferentes, aunque discontinuos y desarticulados, ya desde los centros sociales ocupados, ya desde la estructuración de redes digitales orientadas a la movilización global o desde el desarrollo jurídico de formas alternativas a la propiedad intelectual como las licencias copyleft o las cooperativas de hackers, todos ellos necesarios para ir sembrando un sustrato propicio al cambio, con las herramientas necesarias para llevarlo adelante. Para conseguirlo, muchas de ellas llevaron a cabo diferentes procedimientos de ocupación de espacios como plataforma necesaria para desarrollar su actividad y constituirse como instituciones del común en activo.

Bajo esta fórmula de las instituciones monstruo o en movimiento, nos encontramos ante una gran variedad de formas de negociación de los espacios. 
Desde los que se plantean y extienden bajo la forma de la okupación o reapropiación directa de la riqueza a través del capital fijo de edificios, como ha sido el caso de la mayoría de centros sociales ocupados (CSO) del territorio español a lo largo de la década de los 90; hasta aquellos más recientes basados en una cesión del espacio por parte de instituciones legitimadas, como es el caso de los CSA (centros sociales autogestionados), entre otros el Ateneu Candela ${ }^{139}$ en Terrassa o Tabacalera ${ }^{140}$ de Madrid. Digamos que los primeros forman parte de una ola inicial que, a partir de los 80 hasta la actualidad, basaba su existencia en una identidad diferencial, en lo que Deleuze llamaba devenir minoritario. Los segundos corresponderían a centros de segunda generación que intentan estabilizar los proyectos de ocupación mediante diferentes estrategias de cesión, y vincularlos a los nuevos sujetos metropolitanos, con el propósito de expandirse y difundir teorías y prácticas más que bunkerizarse en una posición antagonista sin fisuras. ${ }^{141}$ De esta manera, conciliando la dialéctica entre el conflicto y la negociación, han encontrado fórmulas híbridas de existencia que permiten el diálogo tanto con los propietarios de los espacios como con la Administración. Desde el Ateneu Candela que paga un alquiler al propietario mediante una subvención municipal hasta la Tabacalera que ha negociado con el Ministerio de Cultura, pasando por el Patio Maravillas ${ }^{142}$ que continúa ocupando espacios en desuso mediante reapropiación directa, tenemos modelos muy diferentes de dotación de espacios.

Los 90 fueron años de transformación tanto del sistema productivo como de la política institucional y por tanto, lógicamente, también de los movimientos sociales encarnados fundamentalmente en este modelo de centros sociales autogestionados. Como hemos dicho, estos emplazamientos pasan de ser lugares de exclusión diferenciadora a centros de producción, en un largo proceso de transformación interna y ajuste a una realidad cambiante. Desde los primeros años de la década en los que la resistencia es la protagonista, junto con la defensa del territorio conquistado y la relación difícil con el entorno, pasando por un momento intermedio en el que los centros sociales empiezan a salir de su aislamiento y a integrar diferentes formas de socialidad no mercantilizada que empieza a reconocerse desde el exterior, hasta el final de la década en el que se produce una verdadera explosión asociada a la introducción de nuevas tecnologías.

Se realizan los primeros hackmeetings, de los que nacerán los hacklabs, laboratorios cuyas herramientas fundamentales son la combinación de la autofor-

\footnotetext{
139. http://ateneucandela.info/

140. http://latabacalera.net/

141. Para más información sobre este proceso, véase "AUTONOMIA y Metrópolis". En: Del Movimiento okupa a los Centros Sociales de Segunda Generación. Málaga : La Invisible, 2008.

142. http://patiomaravillas.net/
} 
mación con los nuevos canales de difusión. La explosión de la autogestión de la comunicación redefine claramente el alcance y la composición social de los centros que disponen de canales de radio, que retransmiten mediante streaming ciclos de autoformación, que convocan y difunden campañas a través de sus páginas web y otro sinfín de posibilidades de articulación política abiertas gracias a estas nuevas tecnologías. Los usuarios de dichos centros empiezan a pertenecer a la generación transmedia, acostumbrada a la apropiación, remezcla y difusión de todo tipo de contenidos, por lo que la integración de estas herramientas se realiza paulatinamente de forma casi natural si no fuera porque, para hacerlo, ha de vencer toda una serie de prejuicios propios de la primera época de los centros sociales en la que el conocimiento formalizado de determinadas maneras se considera propio de las academias y por tanto, intolerable. Dificultando la superación de este prejuicio, se suma la experiencia de la cooptación de saberes antagónicos por parte de las instituciones del saber, hecho que podría ejemplificarse mediante esta misma tesis si no fuera porque emana de una experiencia real en el territorio realizada en primera persona del plural.

Paralelamente, en la última década, los centros sociales han pasado por una fase activa de oposición a la globalización, inaugurada desde Estados Unidos con las grandes manifestaciones de Seattle (1999) que propagan la noción de anticumbre y que tienen un punto claro de inflexión tras la muerte de un activista en Génova (2001). Desde ese punto, los centros pasan por momentos de depresión y momentos de euforia, intentando encontrar un lugar adecuado dentro de sus posibilidades de acción, entre la dialéctica de la guerra y la proposición de alternativas, complejizando una vez más un modelo que escapaba ya de antemano a las clasificaciones. Intentando esclarecer su papel, lanzan diferentes procesos de auto-encuesta con los que poder llevar a cabo un diagnóstico de su situación, y que pasan a ser simultáneamente herramientas de articulación de centros, como es el caso del primer encuentro europeo de centros sociales celebrado en Ljubljana, en 2008. En plena resaca de los movimientos antiglobalización, se decide plantear un nuevo modelo de centro que incluya abiertamente dispositivos de autoformación, con colaboraciones incluso con instituciones para constituir una alternativa de transformación potente y para ello, se propone un programa conjunto de investigación militante a nivel europeo del que saldrán, entre otras, plataformas digitales de discusión como puede ser la red Edu-factory, de la que hablaremos en breve a propósito de la autoformación.

Este modelo híbrido no se limita a los espacios y a las redes de difusión sino que se hace extensivo a muchas otras áreas, porque, desde el principio, pone en red recursos e iniciativas diferentes e incluso contradictorios, mezclando recursos públicos y privados, relaciones institucionales y de oposición, modelos de acción no convencionales con formas de representación clásicas, contenidos 
que puedan parecer apolíticos con campañas de opinión claramente estratégicas. Es un modelo que a menudo se autodenomina monstruoso ${ }^{143}$, porque su forma parece apolítica, pero que busca no obstante generar unas posibilidades de creación colectiva que reinventen dispositivos de acción política; otra forma de traducir la potencia de los sujetos en paradigmas originales de organización de la vida social. Muchas veces, los centros sociales han constituido la posibilidad de asentar formas de democracia en un espacio urbano marcado por la precariedad de los vínculos sociales, mediante una gestión ciudadana que fomenta los valores del procomún y la cultura libre. Son experiencias basadas en el empoderamiento y la autoorganización que articulan lo que se ha venido a llamar commonfare, un estatuto del común que se contrapone a la noción de welfare, y que se caracterizan por:

1. La constitución de una comunidad biopolítica basada en la cooperación social.

2. La implementación de infraestructuras para lo común en cuanto a la disponibilidad de instalaciones y su autogestión.

3. La asunción del papel estratégico de los centros sociales en la emergencia y consolidación de los movimientos sociales, en un claro proceso de retroalimentación.

4. El diseño de una programación cultural estable y de referencia en territorio urbano que permite activar dispositivos de creación como acto de resistencia y de afirmación.

5. La implementación de dispositivos de organización del trabajo a través de Oficinas de Derechos Sociales así como de cooperativas y emprendimientos varios de carga social. Resulta innovador el desarrollo de formas de empresarialidad política, denominada empresas del procomún. ${ }^{144}$

6. La creación de circuitos de autoformación e investigación militante que atiendan a las necesidades de discurso crítico a las que nos enfrentamos en la actualidad.

Vamos a extendernos, por su especial importancia, en los dos últimos puntos característicos de estas instituciones anómalas. En el caso de las Oficinas de Derechos Sociales (ODS), surgen como nuevas modalidades sindicales necesarias para la inclusión de los invisibles, precarizados, becarios, trabajadores reproductivos de los cuidados, mujeres dedicadas al trabajo doméstico, migrantes sin papeles, llevando adelante procesos de autoformación, desde asesorías jurídicas a campañas de concienciación-sabotaje como los scratching en la campaña Ciudad

143. Para más referencia a las instituciones monstruo, véase el número monográfico de la revista Transversal, http://eipcp.net/transversal/0508, y en concreto, el artículo de la Universidad Nómada, Prototipos mentales e instituciones monstruo. Algunas notas a modo de introducción. 144. http://ypsite.net/procomun/ 
sin fronteras ${ }^{145}$, por todo el territorio español, con una posición activa de lucha por la defensa de los derechos laborales de los invisibilizados.

Las ODS han constituido otro sindicalismo posible y necesario, el de los invisibles y precarizados, que sitúan en primer plano las relaciones de producción invisibles. En concreto, las ODS han trabajado abiertamente tres cuestiones fundamentales: la cuestión de los cuidados como crítica feminista radical a una sociedad organizada en función de los intereses de los mercados, el problema de la vivienda que ha movilizado a miles de personas y la organización entre migrantes y autóctonos, aunque en la actualidad, se hayan centralizado en torno al problema de la crisis y el rechazo a la gestión que de ella se está haciendo desde las instancias políticas del país.

El análisis del que suelen partir estas Oficinas es el de lo social individualizado sin contractualidad clásica, considerando que lo que se produce es, como en la intermitencia, un contrato dentro de los sistemas de gestión de la propia metrópolis, fuera de la fábrica, sustituida por la metrópolis como la ecología fundamental de la producción. Las ODS se enfrentan a precariedades laborales de todo tipo, fundamentalmente de los trabajadores invisibles, constituyendo una red de dispositivos en todo el Estado, practicando un sindicalismo de corte social, ofreciendo clases de castellano a los inmigrantes, asesorías jurídicas, etc. Para ello, es necesaria una primera fase de acercamiento entre los diferentes colectivos que, como ya indicamos, pueden ser promotores de cambio (cognitariado precario, inmigrantes ilegales, jóvenes de los suburbios y estudiantes universitarios), generando dispositivos de encuentro que cubran esta primera fase. Se trataría de servir de punto de encuentro sin privilegiar ninguna de estas presencias, activando los mecanismos que sirven de cobertura en el tema migratorio o del trabajo doméstico, entre otros, como puerta de entrada para diagnosticar y actuar frente a estas realidades invisibles.

En lo que respecta a estas oficinas, Madrid y Barcelona centralizan las luchas emergentes del precariado en las propuestas de lanzamiento de este nuevo sindicalismo biopolítico. Más adelante, reseñaremos algunos intentos de organización similar y en el mismo marco espacial, de los trabajadores de la cultura, en concreto sobre el encuentro celebrado en Madrid Paraquienesdisfrutamostrabajando ${ }^{146}$, como un ejemplo de puesta en práctica de estos principios metodológicos en un ámbito que nos atañe directamente y en el que jugamos un papel activo. El 15M también supone una forma de socialidad política que incluye la participación de sectores intergeneracionales aunque la presencia de jóvenes sigue siendo mucho mayor por cuestiones obvias de tiempos de vida que ya hemos explicitado. Organizaciones como el Movimiento de Resistencia Global (MRG), el Movimiento

145. http://ateneucandela.info/node/191

146. http://paraquienesdisfrutamostrabajando.net/ 
por una Vivienda Digna, los MayDay o los HackLabs, convocatorias de personas de condiciones sociales y políticas bien diferentes pero agrupadas bajo estas reivindicaciones, han obtenido bastante visibilidad y han servido de caldo para los movimientos contrahegemónicos.

Reuniendo gran parte de todas estas reivindicaciones en los centros sociales de segunda generación, se ha lanzado de forma conjunta una Carta de Derechos Comunes Urbanos ${ }^{147}$ que contempla, entre otras, las siguientes exigencias y que aquí reproducimos parcialmente para volcar con claridad sus reivindicaciones en la línea de toda la teoría expuesta hasta ahora en esta tesis:

1) Derecho universal e incondicionado a una Renta Básica. Digámoslo sin ambages: la mayor parte del trabajo de cuidado, de la actividad creativa, de la formación, no es remunerada en forma alguna. En la medida en que la ciudad deviene actividad productiva, el trabajo asalariado no puede ser ya la condición del trabajo en general, sino sólo una de sus situaciones particulares. La jurisprudencia y la política fundamentan, no obstante, toda posibilidad de derecho en el trabajo asalariado. No extrañe así que los derechos queden rebajados a la condición, en última instancia, de derechos laborales. La debilidad y la estrechez de semejantes cimientos degeneran siempre en menor protección social y menos derechos para una parte creciente de la población. Es por ello que la Renta Básica, o un salario universal incondicionado (pongamos 800 euros, el salario medio del precariado en España), no sólo paliaría los sufrimientos y penurias de millones de personas que se encuentran en el paro o que sencillamente sufren a diario la hiperexplotación y la infrarremuneración, sino que sería también un justo pago del trabajo actualmente no remunerado. En este campo, los gobiernos territoriales pueden hacer importantes avances: tasando las actividades especulativas sobre el suelo y la vivienda, gravando las rentas financieras, revertiendo las desigualdades con toda clase de prestaciones (transporte, vivienda, renta), preparando en definitiva el terreno para hacer efectiva la distribución equitativa de un excedente de riqueza que es mayor que en cualquier época pasada.

2) Reconocimiento de los comunes. No hay vida, ni sociedad, ni existencia colectiva digna de tal nombre sin el reconocimiento de los medios y recursos comunes que la sustentan. La ciudad aparece como tal en su dimensión pública y común, en su constitución como espacio público. Pero también en el conjunto de garantías necesarias para la reproducción de la vida: desde la salud y el cuidado, hasta el medio ambiente y los bienes naturales (como el agua y el aire); desde la educación hasta las pensiones. Sin el reconocimiento de la condición común de estos bienes y recursos, la vida urbana no sólo se marchita en una cadena de obligaciones sometidas a distintos dispositivos de explotación (como la hipoteca, el trabajo precarizado, las formas privadas de aseguración social, etc.), sino que propiamente se desvanece en una colección de vidas privadas y enfrentadas al reto de la supervivencia. Los poderes económicos han encontrado aquí el lugar privilegiado para la expansión de nuevas formas de beneficio: privatizando los servicios públicos de salud, atacando las pensiones en favor de los fondos

147. http://www.swarm-webjournal.info/beta/page/manifiesto-de-los-comunes-por-unanueva-carta-de-derechos-sociales/ 
privados, encareciendo abusivamente la educación pública al tiempo que promocionaban la formación concertada y privada. Es por ello que lo que aquí se juega es el futuro de la sociedad en tanto tal: el reconocimiento de formas de propiedad y gestión comunales, y no sólo como bienes patrimoniales en manos de las instituciones públicas, es la mejor defensa y argumento frente a la privatización generalizada de la existencia.

3) Derecho a la información y a la libre producción y reproducción de conocimiento. El conocimiento es ya uno de los más importantes bienes comunes de nuestro tiempo: generado por medios cada vez más colectivos, producto de una ingente inversión social (además de grandes cantidades de dinero público), compartido en redes y espacios de intercambio. Es así que toda apuesta política consecuente debe proponer primero la quiebra de toda traba institucional a la producción, modificación y multiplicación de los conocimientos. La actual ofensiva por la privatización del conocimiento, lejos de mostrarse como una solución viable para la producción de un acervo creciente de obras intelectuales, es hoy el principal obstáculo a las formas de cooperación e intercambio que efectivamente lo garantizan. Los gobiernos locales deberán trabajar en este terreno a través del estímulo de la inversión pública y la experimentación colectiva con formas innovadoras de producción y distribución del conocimiento y la cultura. Sólo así se reconocerá y se defenderá el valor social (y también económico) de una de las mayores producciones colectivas de nuestro tiempo.

4) Derecho a la movilidad. La declaración de un estatuto de ciudadanía universal es la única contraparte justa a la financiarización del ciclo económico, la hipermovilidad del capitaly la aceleración vertiginosa de las tasas de explotación del Sur Global. Este derecho sólo obtendrá cumplida realización con la abolición de las fronteras interestatales, pero también de aquellas más sutiles que fragmentan los espacios urbanos en zonas de exclusión, guetos migrantes y espacios de control. Las fronteras internas reproducen efectivamente la gradación de las libertades dentro de un mismo espacio urbano y al mismo tiempo hacen efectiva la negación de los derechos más elementales: a la residencia, al voto, de asociación, a una renta mínima, etc. Las instituciones locales y los gobiernos de las ciudades pueden y deben intervenir en la abolición de tales mecanismos de exclusión, restableciendo en la práctica (por medio del acceso a los servicios y derechos sociales) un estatuto generalizado de ciudadanía en igualdad de condiciones. En caso de no hacerlo, los espacios urbanos degenerarán en las realidades monocolor de la segregación, la inclusión diferencial, mayor desigualdad y en definitiva una creciente ingobernabilidad.

\subsection{La autoformación, por fin}

Resulta evidente que para trabajar con esta serie de objetivos como horizonte utópico, se van a necesitar muchos cambios de mentalidad y muchos procesos de formación que nos lleven a instaurar unas bases similares o, por lo menos, a investigar en lo que supondría una aproximación práctica a las mismas. Dentro de las mismas instituciones monstruo, se contemplaba ya desde el encuentro de Ljubljana la necesidad de generar circuitos de autoformación y difusión como condición fundamental para ello. 
Para empezar, contra la interpretación dominante de la autoformación en la misma línea que la autoayuda, como una actividad aislada de compactación del individuo que, por sí mismo, se blinda en esta carrera por la supervivencia mediante la acumulación de útiles cognitivos, la autoformación sería un cuestionamiento de los lugares asignados, de la redistribución de los saberes, en la que aquellos que ignoran quieren saber y cuestionan, desde su ignorancia, lo que se les presenta como contenido del conocimiento. A mil kilómetros de la formación permanente que responde a criterios de capacitación especializada orientada a su explotación mediante el trabajo, en los procesos de autoformación se produciría la conexión de las luchas contra el desclasamiento del trabajador cognitivo, los ciclos de resistencia y las experimentaciones organizativas destinadas a la generación de instituciones-monstruo. En ella, frente al ámbito totalmente individual de la salvación propia en la espiral competitiva, el espacio global se ha afirmado definitivamente como el lugar de la investigación y de la acción política.

Resulta pues necesario analizar el surgimiento de estos nuevos modelos de formación y generación de conocimiento que parten muchas veces de la ignorancia, de estar inmersos en la confusión, realizando co-investigaciones a tientas, tejiendo propuestas fragmentadas que tienen la imposibilidad utópica como horizonte. Pasaremos por tanto a rastrear procesos de autoformación que han ido derivando en estas prácticas de metodología híbrida y que Garcés ${ }^{148}$ localiza con gran agudeza siguiendo tres modelos complementarios entre sí y diferenciales respecto a la enseñanza académica, suponiendo cada uno de ellos el desarrollo de posibilidades inherentes a los procesos formativos, pero que dotan de nuevo sentido al tándem educación-emancipación, enmarcándolo en la línea directa de la autoformación:

1. La educación como colaboración horizontal en red.

2. La educación como participación comunitaria.

3. La educación como auto-organización de la clase trabajadora.

En el primer punto, la colaboración horizontal en red, resulta insoslayable el hecho de que las nuevas tecnologías han propiciado el cuestionamiento de las formas de producción, transmisión y legitimación del saber, favoreciendo la producción horizontal de conocimientos frente a su consumo. Estamos en un momento en que hemos pasado de la cultura textual a la contextual y de ahí a la transmediática, en la que el consumo y remezcla de las narraciones desarrolladas en diferentes medios es la forma más generalizada de re-producción cultural. Como dicen los teóricos de la misma, la narración transmedia representa un proceso donde los elementos integrantes de una ficción se dispersan sistemáticamente a través de

148. GARCÉS, Marina. "Dar que pensar. Sobre la necesidad política de nuevos espacios de aprendizaje", en El combate del pensamiento, Barcelona: Ed. Bellaterra, 2010. 
múltiples canales de distribución, con el objetivo de crear una experiencia de entretenimiento unificada y coordinada; lo que no añaden estos ases del marketing es que los prosumidores ${ }^{149}$ cortan, remezclan y pegan con la misma rapidez que sus publicistas, para gran provecho de la empresa misma que inicia este círculo, pero en el camino, aprenden con naturalidad los vericuetos transfronterizos tecnológicos y los aplican a sus propios contenidos. Comparada con ello, la educación académica es de una linealidad pasiva insoportable. Por otra parte, citando a los Zemos $98{ }^{150}$ y su encuentro sobre la "Educación expandida", la educación es algo que sucede en cualquier lugar, pero si encuentra plataformas de intercambio abiertas y polivalentes, es bastante más probable que suceda de forma colaborativa y horizontal. Como ejemplo claro de ello, podemos nombrar la escuela de las Wikis ${ }^{151}$, la plataforma de intercambio de conocimiento de Platoniq ${ }^{152}$, con su experiencia en los diferentes Bancos Comunes de Conocimiento (BCC), etc. Como dice Garcés:

Esto implica, principalmente, tres desplazamientos: la disolución de fronteras institucionales y disciplinares; el acceso universal a la información y a los recursos culturales y, finalmente, la organización del trabajo colectivo en red. Educación expandida es por tanto, educación abierta y educación colaborativa. Como escriben los Zemos98 en la misma convocatoria, se trata de recuperar la idea de reciprocidad en las formas de distribución del conocimiento.

Todos somos conscientes de hasta qué punto la proliferación de programas de tratamiento de imagen, imagen en movimiento y textos asociados a las redes de intercambio de información ha supuesto una transformación de los modos de adquisición, apropiación y circulación de conocimientos tras la explosión de las redes sociales en cuanto a número de usuarios. Las relaciones personales y profesionales que tienen lugar en estas redes las convierten en lugares privilegiados para el aprendizaje informal y para la extensión del aula más allá de sus espacios y tiempos. Todos nosotros hemos poblado las redes y las utilizamos de manera natural, sin embargo desde la academia se están entendiendo e integrando con gran lentitud estas dinámicas mientras que desde los movimientos sociales, resulta impensable pasarse sin ellas ya que constituyen una herramienta fundamental a la hora de producir conocimiento de forma colaborativa y recíproca así como a la hora de su difusión.

149. La palabra prosumidor, o también conocida como prosumer, es un acrónimo formado por la fusión original de las palabras en inglés producer (productor) y consumer (consumidor). Igualmente, se le asocia a la fusión de las palabras en inglés professional (profesional) y consumer (consumidor). En http://es.wikipedia.org/wiki/Prosumidor

150. http://zemos98.org/

151. http://recursostic.educacion.es/observatorio/apls/wikiseneducacion/web/index.php/ P\%C3\%A1gina_Principal

152. http://www.youcoop.org/ y http://www.youcoop.org/es/bcc/p/2/que-es-banco-comun-de-conocimientos/ 
Igualmente, resulta de nuevo interesante nombrar la aspiración a liberar tanto los programas en sí mediante el software libre, como los contenidos mediante las diferentes licencias copyleft y los creative commons, de un sistema de mercantilización generalizada del conocimiento, para lo que se deben abordar seriamente y revisar todos los criterios hasta ahora utilizados para remunerar a los creadores de ambos elementos sin que, por ello, se limite la reproducción de plataformas y contenidos según una lógica de la escasez obsoleta para estas cuestiones. Esta es una de las batallas centrales en las transformaciones a las que nos va a llevar la crisis generalizada en la que nos hallamos, siendo necesaria una reflexión que parta de las condiciones reales de producción, distribución y retribución de contenidos que las nuevas tecnologías permiten (independientemente de las legislaciones creadas al respecto), frente a la política de negación que se lleva adelante por parte de las autoridades.

Por otra parte, resulta esencial entender el papel que las nuevas tecnologías están jugando a nivel político como armas de contra-información ante la progresiva censura de los medios de comunicación más convencionales. Desde el surgimiento de las Indymedia ${ }^{153}$ hace más de una década, hasta la extensión de las redes sociales con su vocación democratizante, hasta el punto que las mismas autoridades españolas, en concreto, el ministro del Interior Jorge Fernández Díaz, anunció el 11 de abril de 2012 en el Congreso de los Diputados que la convocatoria de manifestaciones violentas por Internet o por cualquier otro medio de comunicación será "delito de integración en organización criminal por alterar gravemente el orden público" ${ }^{154}$. Lo que no especifican es que si se convoca una manifestación pacífica y esta se convierte, por arte de birlibirloque y algunas cositas más, en sorprendentemente violenta, aquellos convocantes de la primera quedan automáticamente convertidos en convocantes de la segunda... una capa más de esta cebolla que nos va cubriendo, detalles, bagatelas.

En segundo lugar, respecto a la educación como participación comunitaria, tenemos la noción clara de que la autoformación no es una formación

153. Indymedia surge de la cooperación entre activistas tecnológicos - hackers y activistas mediáticos tradicionales, que empiezan a trabajar conjuntamente a finales de la década de los 90. De esta colaboración surge el primer Centro de Medios Independientes (IMC por sus siglas en inglés) para cubrir las protestas de Seattle creando un espacio de publicación abierta y coordinación de distintos medios independientes y alternativos con el objetivo de romper el cerco informativo de los medios corporativos. Hoy son más de 190 nodos que conforman la mayor red de medios de comunicación independientes con presencia en los cinco continentes. Más información en http://estrecho.indymedia.org/general/noticia/ historia-indymedia

154.http://www.europapress.es/nacional/noticia-alterar-orden-publico-hacer-convocatorias-ello-internet-sera-delito-integracion-organizacion-criminal-20120411103059.html 
autista sino una construcción compartida de comunidad. Aprender con es la única manera de vivir que conocemos, como bien sabía Merleau-Ponty. Intercambiar conocimientos, construir nociones, proponer soluciones y hacerlo sobre el terreno compartido, es lo que dota de sentido al proceso de aprendizaje, lo que constituye su origen y su deseable destino. Todo lo demás son sistemas de unificación, de tasación, de socialización indolora. Cualquier investigación parte de todo lo antes descubierto y prepara todo lo que sobre ella se construirá, pero no sólo, sino que en sí, es una experiencia obligatoriamente común, hasta en la más solitaria de las prácticas. Cuánto más cuando hablamos de buscar nombres a lo que no los tiene, de inventar caminos donde nadie antes los había vislumbrando, para abrir vías de transformación en la propia carne, en la misma calle. Los medios de comunicación de masas no son el modelo de la educación compartida por mucho que sean los más generalizados, no constituyen lo que se sigue banalizando bajo la etiqueta de cultura popular porque la cultura popular no es la que se consume, sino la que se produce de forma compartida.

Por todo ello, podemos decir que las nuevas tecnologías pueden servir para compartir pero que no bastan, que deben constituir sujetos y territorios compartidos también para que se construya comunidad mediante la formación, para que se puedan abrir espacios autónomos de crítica y reconstrucción de tejido social bajo las premisas de reciprocidad y colaboración. Esto implica también una modificación esencial del propio régimen del saber que establece una separación entre los agentes proyectada en los espacios, los tiempos y las formas de actividad, tal y como especifica Rancière ${ }^{155}$ frente a la que se incide en la generación de comunidad horizontal y por tanto, en la quiebra de los roles establecidos. Ahondando en ese sentido, debemos decir que la autoformación no busca la universalidad sino la construcción de lo común y en tanto común, está orientada a la producción de subjetividad, por lo que aquí encontramos otra diferencia fundamental respecto a la orientación de la investigación clásica, ese saberse encarnado y proponerse armado conceptualmente en aras de un posicionamiento activo.

Por último, la más clara de todas dentro de las líneas de la autoformación, aparece la formación como auto-organización de la clase trabajadora, que ya participa de las otras dos características enunciadas. Tanto la organización en red como la construcción de comunidad son dos elementos esenciales para poder erigir hoy en día procesos de transformación de la sociedad mediante el uso de la formación como arma, eso que tan claramente se ha ejemplificado durante las revueltas de los indignados que enarbolaban libros ante las fuerzas de seguridad a la voz de "Estas son nuestras armas". No hay imagen más bella para los ojos ilustrados.

155. RANCIÈRE, Jacques. La división de lo sensible. Salamanca: Centro de Arte de Salamanca, 2000. 


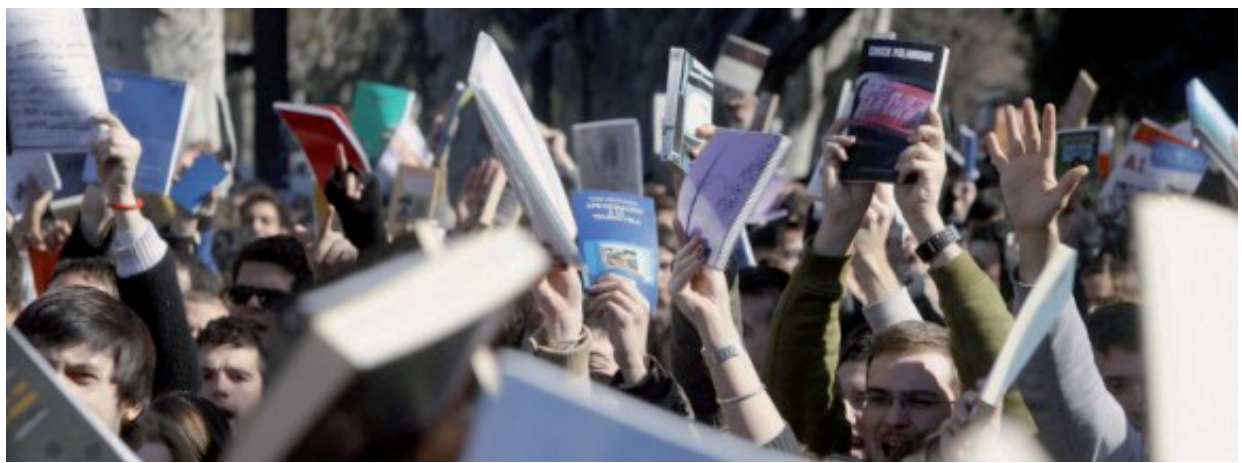

Dentro de este apartado, podemos incluir todos los procesos de evaluación y diagnóstico realizados tanto por el ámbito universitario autónomo como por la producción cultural, que son muchos y muy variados. Hablaremos especialmente de dos casos: el de Edu-factory y el de Paraquienesdisfrutamostrabajando, como dos modelos posibles de auto-organización basados en el debate, la encuesta y los grupos de trabajo; uno de ellos internacional, centrado en los procesos de formación y articulado en una plataforma digital, y el otro nacional, orientado a la producción cultural y limitado en el tiempo y en el espacio, ya que se trató de un encuentro "encarnado", que contó con nuestra presencia e interacción en tiempo real.

No obstante, antes de detallar estos dos ejemplos, podemos trazar una línea genealógica que una emancipación y autoformación a diferentes niveles. En este asunto, nos hemos dejado guiar por el libro Nociones Comunes. Experiencias y ensayos entre investigación y militancia ${ }^{156}$, cuya introducción redactada por Marta Malo, ofrece una visión general del territorio novedoso que surge de la confluencia entre encuesta e investigación militante, desarrollando posteriormente en sus diferentes capítulos un debate sobre la utilidad de la encuesta y de la co-investigación como herramientas políticas, contrastando la teoría con experiencias actuales de investigación militante. Tendríamos en este apartado fundamentalmente tres líneas de confluencia:

1. Metodologías de formación alternativas que parten de la experiencia inicial de Jacotot en Francia, sobre la que Rancière escribe su "El maestro ignorante" ${ }^{157}$. Jacques Rancière se interesa por el método de enseñanza natural de Jacotot porque se articula en torno a la emancipación más que a la subversión. Para el autor, la emancipación es la capacidad de los ciudadanos de instituir formas de ver, de pensary de relacionarse con el mundo que rompan con las que les imponen desde el poder. Es la institución pedagógica, como forma de poder, la que establece que, para aprender o comprender una cosa hace falta un maestro, partiendo de la

156. MALO de MOLINA, Marta (Editora), Nociones Comunes. Experiencias y ensayos entre investigación y militancia. Madrid: Ed. Traficantes de sueños, 2004.

157. RANCIÈRE, Jacques. El maestro ignorante. Barcelona: Ed. Laertes, 2003. 
premisa de que el alumno no puede hacerlo por sí mismo. De este modo crea una división jerárquica, una desigualdad, y bloquea la capacidad natural que tiene todo ser humano para instruirse por su propia cuenta. A juicio de Jacotot, la función del maestro no es enseñar lo que sabe sino poner a funcionar la igualdad de inteligencias. Este visión de la enseñanza o, más bien, del aprendizaje como el motor de una experiencia emancipadora, se propaga allende los mares, hasta encarnarse en experimentos como el Colectivo Situaciones o la UNILCO en Argentina y de vuelta a Europa. En ellas, podemos enmarcar la profusión de experiencias pedagógicas en nuestro propio país en tramos educativos de formación básica que siguen experiencias anglosajonas de los años 60 (el modelo Summerhill) hasta la Edupunk universitaria y las diferentes universidades libres.

\section{La co-investigación o la investigación-acción participante (IAP)} procedente de la sociología anglosajona en torno a 1950, como una investigación social que rompe con la división entre sujeto investigador y objeto investigado; o su vertiente más comprometida, la investigación militante, como la trasposición política que los italianos hacen de la primera. Como IAP, surge de la confluencia de los presupuestos de la coinvestigación con la pedagogía crítica social sudamericana, entre otras, la pedagogía del oprimido de Paulo Freire, hibridándose con el primer punto. La IAP articula investigación e intervención social, priorizando la acción colectiva y los saberes prácticos como lugares de validación de la teoría. Si bien la IAP se utilizó durante los 80 como herramienta de producción de consenso y reducción de la conflictividad, justo el efecto inverso que se pretendía inicialmente, la recuperación de sus presupuestos por parte de la investigación militante la ha vuelto a dotar de la fuerza de transformación que pretendía y se ha instalado como teoría encarnada, como praxis interpretativa que se define caminando.

3. La encuesta obrera procedente del marxismo (Engels realiza la primera sobre "La situación de la clase obrera en Inglaterra" en 1845, posteriormente Marx realizará una encuesta similar entre la clase obrera francesa en 1881) que encuentra su continuación en Italia en los años sesenta del siglo XX. En 1964, la revista de reflexión y debate Quaderni Rossi, considerada en sí como un instrumento de intervención, pone en marcha el proyecto de realizar una encuesta obrera en toda Italia con el doble objetivo de usarla como instrumento para analizar la transformación de la realidad obrera y como herramienta de organización de la conflictividad obrera y de autovalorización de la misma. A esta visión, se suma la experiencia de los grupos de autoconciencia feminista, también de origen anglosajón, de finales de 1960, que buscan igualmente una transformación de su situación a través de un análisis de las formas de opresión que se aplican sobre sus propias vidas, generando la teoría a partir de su experiencia personal. En el proceso,, aplican una metodología que, partiendo de ellas mismas, se orienta a la organización y a la acción transformadora. 
Marta Malo, en su libro, no deja de ser consciente de que estas tres metodologías y especialmente la tercera, no bastan para asegurar un cambio fundamental en el trabajo realizado y pone como ejemplo las similitudes aparentes con el toyotismo ${ }^{158}$ pero también marca las diferencias claramente:

Con cierto grado de provocación teórica, cabe sostener que el toyotismo no es más que la encuesta obrera cambiada de signo político, es decir, la adopción estratégica de la constitución de relaciones ético/afectivas dentro del momento productivo en sentido apologético, como valor añadido a la empresa, yno crítico. A este respecto, la actualidad de la encuesta no se plantea como fácil escamotaje político, sino en el máximo nivel de problematicidad. En efecto, si bien el trabajo de encuesta se coloca sobre el mismo terreno que el trabajo abstracto de la gestión de recursos humanos, para abordar la cuestión del trabajo vivo, precario e inmaterial, no basta con introducir en este un simple cambio de signo, una inversión especular, so pena del achatamiento de lo existente. Es preciso buscar la separación y la superación, la diferencia irreductible y antagonista.

Estas diferencias resultan fundamentales ya que tanto las conclusiones como las medidas relacionadas con estas resultan otras si se busca un consenso y la resolución, véase acallamiento de conflictos que si, por el contrario, de lo que se trata es, de forma conjunta y colaborativa e (idealmente) desjerarquizada, se puede ejercer sin miedo a controversias o represalias una visión crítica y utópica del estado de la cuestión, sea esta cual sea. En cualquier caso, en la convergencia de todas ellas que es el ámbito en el que operan los programas de autoformación, se trataría de no fomentar eventos sino procesos de coinvestigación, generando otras formas de gestión que supongan una crítica real, pasar a procesos lentos de configuración, análisis y transformación, manteniendo en todo momento la orientación teórico-práctica y siendo consciente de los tres peligros que acechan a este tipo de prácticas según Garcés: el confinamiento, la marginalización y la neutralización. De los dos primeros, producto de ese situarse en los confines, en los márgenes, ya hemos hablado cuando comentábamos la transformación de los centros sociales en sí, ya que supone pasar de ese devenir minoritario deleuziano a la aspiración de socializar para provocar una transformación a mayor escala.

El último tiene que ver más con los procesos de "proyectualización"en los que la investigación pasa casi a convertirse en un ritual que justifica determinada financiación, determinada línea curricular o medalla de la pertenencia alternativa. La neutralización por parte de las instituciones pero también la neutralización propia, casi como un proceso autoinmune en el que se replican las enfermedades de la

158. El toyotismo corresponde a una relación en el entorno de la producción industrial que fue pilar importante en el sistema de procedimiento industrial japonés y coreano, y que después de la crisis del petróleo de 1973 comenzó a desplazar al fordismo como modelo referencial en la producción en cadena. Se destaca de su antecesor básicamente en su idea de trabajo flexible, aumento de la productividad a través de la gestión y organización (just in time) y el trabajo combinado. (Wikipedia) 
academia pero sin dinero y bajo una coartada teóricamente participativa o social. Como dicen en Exit-Raval 159, "la autoformación no debe ser entendida como un sistema marginal a los circuitos reglados de la formación universitaria sino directamente como una práctica organizativa y de creación institucional". Por todo ello, lo que definiría a la autoformación serían las siguientes características:

1. la capacidad de organizar la autonomía del conocimiento vivo;

2. la capacidad de determinar la dirección colectiva y global de procesos de cooperación social;

3. la capacidad de generar instituciones del común a través de la disolución de la dialéctica público-privado.

Las dos primeras características ya las hemos tratado en el apartado de la autoformación como práctica instituyente orientada a la autonomía de pensamiento y a la transformación social. Respecto al último punto, el colectivo Exit-Raval define la autoformación de forma específica como la línea de fuga de la dialéctica público-privado. Para ellos, es fundamentalmente la construcción de lo común así como la forma de organización de los trabajadores cognitivos, un pensar conjuntamente y con acceso libre gratuito, con difusión libre también, buscando nuevos canales mediante las tecnologías, a través de conferencias, vídeos, comentarios, la planificación y organización a distancia mediante redes articuladas con propósitos comunes, sacando del ámbito mercantil el producto de sus investigaciones. Por tanto, supone en sí una reconstitución del ágora, la creación de mínimo común dinamizador.

Más allá de todas estas cuestiones, resumiríamos diciendo que la autoformación se opone a la mercantilización y desconexión social en la producción de saberes académicos mediante la creación de instituciones de lo común basadas en la producción de un conocimiento capaz de generar una subjetividad transformadora orientada a la producción de derechos sociales. De esta manera, se busca desarrollar la potencia subversiva del trabajo cognitivo conectando de forma transversal el saber académico y el saber antagonista. Al respecto, podemos citar como estructura modélica de autoformación los cuatro circuitos elementales planteados por la Universidad Nómada ${ }^{160}$ :

"(a) La elaboración de un circuito de proyectos de formación que ponga en circulación los paradigmas teóricos y los instrumentos intelectuales que consideremos más apropiados para producir esos mapas cognitivos aptos para (1)

159. www.exit-raval.net. EXIT es un espacio de autoformación investigación militante e intervención social ubicado en el barrio del Raval de Barcelona.

160. UNIVERSIDAD NÓMADA. Prototipos mentales e instituciones monstruo. Algunas notas a modo de introducción. Eipcp [en línea].Disponible en web: < http://eipcp.net/transversal/0508. >: [Consulta: 2 de Mayo 2.012] 
intervenir en la esfera pública creando swarming points de referencia y produciendo discursos contrahegemónicos; y, por añadidura, para (2) analizar las estructuras y dinámicas de poder —así como las potencias — realmente existentes;

(b) La gestación de un circuito de proyectos de coinvestigación que permita estudiar de modo sistemático las áreas de la vida social, económica, política y cultural a fin de producir cartografías dinámicas de la estructura social y de sus dinámicas útiles para orientar las prácticas antagonistas, para redefinir los conflictos y luchas existentes, y para producir nuevas formas de expresión dotadas de un nuevo principio de inteligibilidad social y epistemológica;

(c) El diseño de un circuito editorial y mediático que permita incidir transnacionalmente en la esfera pública y en los ámbitos de la producción intelectual así como en el de la enseñanza universitaria, con el objetivo de crear laboratorios analítico-intelectuales y, por ende, nuevos segmentos de referencia y de crítica de las formas hegemónicas de saber y de conceptualización de la realidad social; esta difusión se realiza a través de licencias de cultura abierta, de creative commons o de copyleft para oponerse a la creciente mercantilización del conocimiento y permitir su acceso a capas económicamente desfavorecidas;

(d) La trama de un circuito de fundaciones, institutos y centros de investigación que se convierta en la infraestructura autónoma de producción de conocimiento, que constituya un embrión de las formas de organización política por mor de la acumulación de análisis y propuestas concretas. Su actividad debería vincular el análisis de las condiciones regionales y europeas con las dinámicas estructurales de la acumulación de capital y de recreación de las opciones geoestratégicas globales que sean adecuadas para los movimientos."

Como hemos dicho, la vehiculación de estos circuitos se produciría a través de la confluencia de cuatro entidades: centros sociales, productores culturales autónomos, universidades libres e instituciones de la cultura, fundamentalmente relacionadas con el arte. En España, estas actividades las han llevado a cabo centros sociales autogestionados como El Seco ${ }^{161}$, el Patio Maravillas, el Ateneu Candela, Exit-Raval, la Casa Invisible, etc., diferentes universidades libres como la misma Universidad Nómada, la Rimaia ${ }^{162}$, o la ULEX, instancias dentro del ámbito de la producción cultural como YProductions o Zemos98 y finalmente, instituciones como el Centro de Arte Reina Sofía (MNCARS) o el Medialab ${ }^{163}$ que han colaborado de forma abierta con estas instituciones anómalas. Todos ellos se podrían considerar

161. http://www.cs-seco.org/, http://patiomaravillas.net/, http://www.lainvisible.net/

162. http://unilliurelarimaia.org/, http://www.ulexmalaga.org , http://www.slideshare.net/ yproductions

163.http://www.museoreinasofia.es/redes/presentacion/nueva-institucionalidad/2011. html, http://medialab-prado.es/laboratorio_del_procomun 
paradigmas de una actuación autoformante y vinculada a movimientos sociales, por lo que hemos incluido como material anexo a la tesis 15 entrevistas realizadas a representantes de todas ellas en las que se aborda la cuestión de la autoformación y la crisis, además de los diversos enfoques específicos de cada una de ellas.

\subsection{Edu-factory y las universidades del común}

Pero antes de remitirnos a estos casos concretos, nos gustaría retomar los dos ejemplos de autoformación transformadora propuestos como modelos de primer análisis. A nivel europeo, Edu-factory ${ }^{164}$, es un colectivo transnacional comprometido con las transformaciones de la universidad global y los conflictos en la producción de conocimiento, que ha actuado como centro de recogida de información y de articulación de procesos de auto-encuesta en el ámbito universitario, pero cuyas intenciones exceden con mucho el entorno académico. La página web de esta red global recoge y conecta las investigaciones teóricas y la información relativa a las luchas universitarias. Dicha red ha organizado encuentros en todo el mundo, prestando particular atención a las luchas de los estudiantes aunque Edu-Factory no es sólo eso.

Su origen procede de una lista de correo transnacional centrada en las transformaciones de la universidad, la producción de saberes y las formas de conflicto (edufactory@listculture.org), en la que desde su inicio, en 2007, han participado cerca de 500 militantes, estudiantes e investigadores de todo el mundo. Según el colectivo Edu-factory, coincidiendo con la visión que de ella tienen desde Exit-Raval y muchas otras de las entidades que hemos ido nombrando, la autoformación se definiría principalmente como la forma de lucha del trabajo cognitivo en el capitalismo avanzado, evidenciando el conflicto sobre la producción de saberes y la construcción del común, la lucha del precariado y la organización de instituciones autónomas.

Pero Edu-Factory constituye, ante todo, un punto de vista parcial en la crisis de la universidad, que se podría denominar como el fin de la universidad moderna y de su declinación estatal. Al contrario, ésta emerge como la forma de la lucha del trabajo cognitivo en el capitalismo contemporáneo: $y$, al mismo tiempo, como conflicto sobre la producción de los saberes y construcción de lo común, lucha del precariado y organización de instituciones autónomas. Edu-Factory es, por lo tanto, un lugar de conexión de las luchas, de las formas de resistencia y de experimentación organizativa. ${ }^{165}$

Por ello, esta red constituye un ejemplo claro de cómo pueden generarse circuitos de autoformación políticos que aporten armas para enfrentarse a la situación

164. http://www.edu-factory.org/wp/about/

165. Colectivo Edu-factory. "Nosotros no pagaremos vuestra crisis ¡Todo el poder a la autoformación!". En La universidad en conflicto: capturas y fugas en el mercado global del saber. Madrid:Traficantes de sueños, 2010, p. 47. 
actual. El primer capítulo de esta tesis parte de la presentación del libro editado por la misma Edu-factory como fruto de su proceso de co-investigación al respecto, y traducido al español por la editorial y empresa política Traficantes de Sueños, llamado La Universidad en conflicto: capturas y fugas en el mercado global del saber. Este libro aporta una cartografía de las formas de nueva institucionalidad, nacidas en y desde las luchas críticas a la privatización de la universidad, que a nivel global han contribuido a la constitución de planes de organización que tienen en todos los contextos un lugar común: la autoformación transformadora.

Las jornadas europeas Commoniversity ${ }^{166}$, convocadas por la red Edu-factory, coordinadas por la Universidad Nómada y Traficantes de Sueños y celebradas en Barcelona del 25 al 27 de noviembre de 2010 en colaboración con el MNCARS, Ilevan el subtítulo explícito de Hacer política con el saber en las transformaciones de la universidad global. Se trató de un encuentro de universidades anómalas cuyo objetivo explícito era repensar la acción política en el ámbito de las luchas del saber tras del cierre del ciclo de movilizaciones conocido como "movimiento antibolonia" y, en el resto de Europa, como "onda anómala". En él, participaron diferentes centros de las luchas estudiantiles de alrededor de Europa y fue el último encuentro europeo de un ciclo de encuentros (Bologna) y contracumbres (Viena y Madrid) que ha dejado como resultado una red de trabajo que continúa articulándose para responder a los nuevos parámetros de la crisis.

El propósito inmediato de Commoniversity era el de acercar, por un lado, diferentes experiencias de autoformación internacionales a un público estudiante interesado en conocerlas e incluso, en participar en sus posibles desarrollos futuros $y$, por otro lado pero en el mismo nivel de importancia, en aportar varias cartografías de la universidad global que permitieran radiografiar analíticamente los discursos que se están produciendo en las experiencias vinculadas a la red Edu-Factory. Por tanto, un encuentro de análisis y difusión con aspiraciones transformadoras ya que se plantea como una "carnalización" necesaria dentro de un proceso a largo plazo, no únicamente un acontecimiento cultural, sino un encuentro integrado en una continuidad y con un seguimiento proyectado que busca la constitución de una red europea de autoformación.

Para empezar, resultaba diferencial en su planteamiento ya que se nos propuso una serie de textos escritos al respecto para poder iniciar las discusiones vía digital en torno a determinados conceptos en común, especialmente un texto redactado con motivo del encuentro ${ }^{167}$ que aborda el conjunto de los diferentes debates de la red trasnacional Edu-Factory sobre la transformación de la universidad

166. http://commoniversity.wordpress.com/

167. CURCIO, Anna y ROMERO, Gigi. Hacia una gramática del conocimiento vivo.[En línea]. Disponible en <http://commoniversity.wordpress.com/>. [Consulta: 7 de febrero de 2011] 
global en el marco de la crisis financiera. La misma estructura del encuentro resulta ejemplificadora de las hibridaciones y participaciones de las que hemos venido hablando en este capítulo, ya que el encuentro se realizó tanto en espacios institucionales como el Palau de la Virreina o el Pati Manning, como en espacios okupados como la sede, ya desalojada, de la Universitat Lliure La Rimaia. De la misma manera, contó con participantes de todos estos ámbitos e intentó vincular centros culturales institucionales, universidades y centros sociales así como colectivos dedicados a estos menesteres político-formativos, como fue nuestro caso (en ese momento formábamos parte del colectivo de producción cultural Barra Diagonal ${ }^{168}$, que detallaremos en breve).

El encuentro se inició con una sesión de apertura centrada en el papel de las cartografías como formas organizativas concretas y como crítica de la Universidad Global, atendiendo a criterios como los de la inclusión diferencial aplicada a las universidades. A continuación, dieron inicio las diferentes mesas de debate con un primer bloque en el que representantes institucionales (Jesús Carrillo, Carles Guerra y Yaiza Hernández, todos ellos pertenecientes a instituciones del arte) introdujeron la mesa de debate Centros, institutos, museos de arte contemporáneo y capitalismo cognitivo en la enseñanza superior: ambivalencias, desafíos, alianzas, fracasos. En ella, se pudo debatir el modo en que los centros y museos han asumido funciones de educación superior a través de masters, seminarios, conferencias, publicaciones, pero también de colaboraciones e incluso alianzas con movimientos urbanos radicales $y$ anti/alterinstitucionales.

A continuación, dio comienzo la mesa dedicada a las Universidades anómalas. La autoformación como fuga de y conflicto con la universidad global. En ella, diferentes invitados de estas instituciones de Italia, Portugal y España lanzaron un debate sobre las posibilidades de acercarnos a la constitución de una Universidad Autónoma Global y su posible incidencia en la transformación generalizada hacia el modelo de universidad empresa. En la misma línea, representantes de la red Edu-factory así como de otros colectivos europeos similares (Creating Worlds y Radical Education Collective), se plantearon El network y la producción de conocimiento como práctica instituyente. En esta mesa de trabajo, se debatió la adecuación de la encuesta obrera marxista a otra forma de investigación apropiada para el actual régimen productivo, en la misma medida en que se ha cuestionado la educación en sí, haciéndose las preguntas sobre su posible acción política así como sobre la posibilidad de retroalimentar la práctica de la autoformación con la de la co-investigación.

Para terminar, el encuentro se cerró con una Asamblea de Universidades Anómalas Europeas que intentó seguir el modelo de encuesta y autoevaluación

168. http://barradiagonal.wordpress.com/ 
para poder operativizar los siguientes movimientos de la red en torno a dos puntos centrales: la autoformación y la investigación. Este encuentro resulta interesante como modelo de hibridación espacial y cognoscitiva, así como por abordar estas cuestiones desde una perspectiva teórica anclada en unas prácticas generales. A lo largo de estos dos años, podemos decir que la red Edu-factory ha seguido publicando sus cuestionamientos y debates, que se han producido 2 encuentros europeos que han intentado consolidar la red europea de autoformación en un momento en el que la deriva universitaria sigue de forma creciente el modelo empresarial, financiarizado y firmemente anclado en la inclusión diferencial. jLarga vida pues a las universidades anómalas y a sus aspiraciones de transformación!

\subsection{Barra Diagonal también disfruta trabajando}

Previamente al encuentro Communiversity, se produjo en Madrid en julio de 2010 el otro encuentro directamente relacionado con las prácticas de las que venimos hablando Para quienes disfrutamos trabajando y que ha sido un punto de inflexión para un cuestionamiento generalizado por parte de los productores culturales, si bien fue precedido por acciones destinadas al mismo propósito como Kultur-o-meter ${ }^{169}$ o las encuestas previas de YProductions. Consideramos necesario hacer un poco de

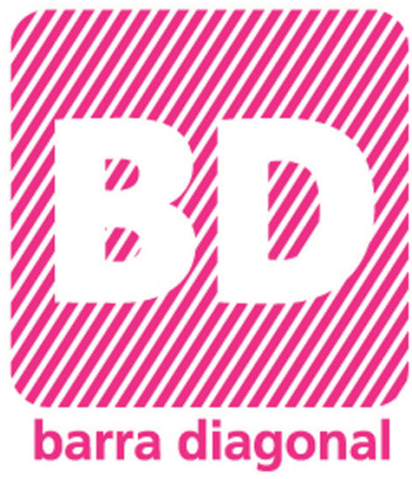

Fig. 9 memoria y encuadrar estas actividades dentro de nuestro propio recorrido, ya que también para nosotras fue un momento decisivo a la hora de orientarnos a determinadas prácticas autoformativas y de evaluación. Resulta inevitable pues hacer aquí referencia a una biografía personal y personalizada en la que teorías y prácticas han convivido sin ningún rubor, buscando la promiscuidad, favoreciendo los equívocos, borrando los caminos claros y privilegiando la autoformación en los campos en que la academia se ha mantenido en silencio.

Además de participar, a lo largo de los años, en numerosos encuentros de la geografía nacional que nos permitieron aprender modos y maneras de la autogestión, hemos acabado constituyendo colectivos que han buscado actuar tanto desde las prácticas (véase el trabajo realizado desde Guerra Mítica ${ }^{170}$ ) como desde una teoría emanada del cuestionamiento y de la auto-encuesta. Como ejemplo de ello, en 2008 fuimos cofundadoras de Barra Diagonal, colectivo centrado en la

169. http://kulturometer.org/

170.http://bookcamping.cc/referencia/1428-alistate-ya, http://vimeo.com/33555817, http://vimeo.com/33585721 son algunos de los vídeos de acciones del grupo activista del que formamos parte del 2002 al 2004. 
producción cultural, del que formamos parte hasta su disolución por exilio (del 80\% de sus componentes, que se encuentran actualmente repartidos entre Nueva York, Buenos Aires, Porto, Berlín y Valencia, situación que habla claramente del estado de cosas en la España de la pandereta). Este colectivo organizó junto con La Tejedora un primer encuentro llamado Infraestructuras Emergentes, basado en el cuestionamiento del propio papel del arte y la cultura en relación con las instituciones y la sociedad.

En 2007, el panorama cultural valenciano estaba en un punto muerto en el que llevaba ya demasiado tiempo instalado, fruto de las políticas que al respecto se habían venido aplicando desde las instancias gubernamentales, más bien orientadas a la producción de espectáculo. Dicha actitud había ido arrasando con gran parte de lo que en su momento hizo de nuestra ciudad un núcleo de producción y transmisión cultural digno de recibir tal nombre. Resulta evidente que cuando se parte de tan bajo, no se puede perder nada por intentarlo y ese año, fueron emergiendo diferentes propuestas que permitieron pensar en una reactivación de la producción cultural. Aunque muchas de ellas llevaban tiempo desarrollándose de forma más o menos subterránea o aislada, fue necesaria una mínima confluencia de agentes culturales y de visibilidad para que pudiéramos plantearnos la posibilidad de generar redes e incluso, soñar con la creación de una plataforma conjunta para intentar contrarrestar la atonía generalizada que parece dominar la zona.

De hecho, fueron ejemplos como los de LaTejedoraCCEC, Otro Espacio, la Sala Naranja; o hechos paralelos como la consolidación definitiva del Octubre Centre de Cultura Contemporània como un nodo activo de dinamización cultural o, en otro orden de cosas, la reactivación de iniciativas como el Festival de videocreación Mínima, la primera convocatoria de Perifèries o de La Impropia, los que han permitido seguir diciendo que, sí, más allá de la Copa de l'America o la Fórmula Uno, hay vida inteligente en esta tierra. La creación de la Asociación de Artistas Visuales de Valencia, Alicante y Castellón (AVVAC) no hizo sino confirmar el resurgimiento de una voluntad de colaboración también a ese nivel. Esta asociación, presente ya en la mayoría de las comunidades, intenta paliar una de las muchas carencias que llevamos arrastrando, carencias que puesto en marcha proyectos de análisis del territorio con nombres tan explícitos como "Tomándole el pulso a un cadáver".

En este contexto, surge la primera propuesta de proyecto cultural Infraestructuras emergentes que, partiendo de Juanli Carrión y Lorenzo Sandoval miembros del colectivo LaTejedoraCCEC, sirvió como punto de encuentro para la posterior formación de nuestra asociación, Barra Diagonal, constituida por ellos mismos más Juan Luis Toboso, Gisela Ahumada y Mijo Miquel. De forma conjunta, organizamos del 5 al 15 de marzo de 2008 este encuentro sobre gestión, producción y difusión artística cuyo propósito era analizar y discutir acerca de las estructuras artísticas en el territorio español. Para ello, se programaron jornadas de debate, talleres y exposiciones a realizar en diferentes espacios de la ciudad, desde museos 
a universidades pasando por centros de cultura y salas alternativas. Un gran número de actividades que pretendían generar un debate crítico con el que abrir nuevas vías para la gestión cultural independiente, la creación artística y la generación de redes a diversos niveles.

Las jornadas de debate tuvieron lugar en el MuViM y se articularon en cuatro líneas de fuerza. Su estructura combinó las ponencias de antropólogos, filósofos, artistas, profesores y críticos que participaron en las distintas sesiones a lo largo del día, con los foros de la tarde, en los que intervinieron representantes de diversos colectivos de creación, gestión artística y activismo cultural. Estas líneas de fuerza giraron en torno a planteamientos como los modelos de educación del arte, las prácticas artísticas independientes, o los nuevos espacios que suponen las comunidades en red. Entre los colaboradores, se contó con la presencia de especialistas como Félix Duque, Manuel Delgado, Marina Garcés, Santiago Eraso o Jorge Luis Marzo entre otros, así como con la presencia de los siguientes colectivos Basurama, Democracia, o Zemos98, con los que posteriormente hemos seguido colaborando.

Los tres talleres tuvieron una duración de tres días cada uno y se celebraron en diversos espacios del Octubre Centre de Cultura Contemporània-OCCC. El artista Rafael Tormo coordinó el taller 'Implosiones impugnadas' con el que pretendía provocar una crisis sobre la noción de espacio público dentro del espacio de la representación. El colectivo YP condujo el taller 'Así lo hicimos' sobre gestión de eventos artísticos a partir de sus propias experiencias y con una voluntad crítica en las bases de la generación de proyectos. Por último, se llevó a cabo el taller "ZINK! Encuentro furtivo de publicaciones independientes", conformado por 3 charlas en torno a los sistemas de gestión y distribución de publicaciones, una exposiciónmercadillo que recogió las distintas formas de autoedición existentes en el momento y la producción de ZINK 1.0, guía de publicaciones independientes.

En cuanto a las trece exposiciones, se ubicaron tanto en espacios independientes como en centros institucionales, intentando de esta manera generar una red de eventos articulados. De esta manera, desde la Sala Josep Renau de la Facultad de Bellas Artes de la UPV hasta la explanada del MUVIM ocupada por una furgoneta como espacio expositivo en tránsito, pasando por distintas salas de referencia del circuito artístico alternativo, se generó un entramado en el que tuvieron cabida obras tan distantes como los libros de artista, los documentales o las apropiaciones indebidas. De todo este conjunto, conferencias, talleres y exposiciones, conseguimos publicar un libro al que se puede acceder en la red ${ }^{171}$ ya que se realizó bajo la licencia de Creative Commons.

A raíz de estos encuentros, surgió la necesidad de constituirse como asociación que trabajara específicamente diseminando estos modelos de producción

171. http://es.scribd.com/doc/23942714/Infraestructuras-emergentes 
cultural en diferentes ámbitos y a través de varios soportes, con la intención de multiplicar los focos de creación y difusión por el territorio. Igualmente, la necesidad de articularse en redes con todos los demás nodos de emergencia resultó más fácil ya que las jornadas propiciaron el mutuo conocimiento de los diferentes participantes así como la motivación para trabajar en sinergia.

Barra Diagonal, en tanto asociación orientada hacia la producción de conocimientos, continuó realizando una serie de jornadas, seminarios y talleres a lo largo de dos años siguiendo la misma línea conceptual de cultura de base. Partiendo de una noción básica de educación expandida en la que, desde una posición externa, colaboramos con instituciones, centros de producción o espacios culturales así como con plataformas autogestionadas de producción cultural, llevando a cabo una diseminación de acciones comunicativas y de intercambio de conocimientos por el territorio. Encontramos sumamente importante el desarrollo de nodos de producción y difusión cultural que propicien las nuevas tecnologías, con un acercamiento de carácter crítico a estas, como forma de generar un tejido real que no dependa de las políticas institucionales para seguir vivo.

Posteriormente a los encuentros, realizamos una programación de carácter didáctico que se desarrolló en la prótesis del EACC ${ }^{172}$ a lo largo del 2009 y 2010. Para llevarlo a cabo, se invitó a tres colectivos, Hangar, centro de producción cultural, Liquidación Total y D-Forma, a impartir unos talleres que abordaran la cultura de proyectos. Esta estructura en diferentes bloques pretendía recoger un muestrario suficientemente amplio de prácticas proyectuales, muchas de ellas situadas en espacios liminares en los que se combinan la producción, la transmisión y la difusión.

Para continuar con la consolidación de nodos de producción y difusión, participamos en el encuentro MODIFI \#0 ${ }^{173}$ (Modelos, diferencias y ficciones en la producción independiente de cultura contemporánea) en octubre de 2009, un proyecto iniciado por Liquidación Total en colaboración con el Goethe-Institut de Madrid, el Foro Cultural de Austria y los Agentes Artísticos Independientes de Madrid (AAIM), plataforma que aglutina espacios e iniciativas independientes de productores de cultura contemporánea de Madrid. El eje central de trabajo de MODIFI \#0 fue articular el debate alrededor del estado de la producción cultural independiente desde el punto de vista del espacio cultural como lugar de producción de espacio social. En paralelo, a través de MODIFI \#0 se pretendió facilitar y acelerar el intercambio de información y conocimiento entre la escena local de Madrid y otros agentes culturales de dentro y fuera de las fronteras del Estado español, con las miras puestas en una revisión y replanteamiento de

172. http://www.eacc.es/

173. http://www.modifi.es/ 
las tácticas y estrategias de producción cultural independiente frente al nuevo paradigma de "industrias culturales".

Desde este colectivo, organizamos varios cursos sobre aplicación de la creatividad ("Y ahora, iqué?", EASD, mayo 2009) y unas jornadas sobre cultura abierta con la presencia de Richard Stallman y Simona Levi de Conservas ${ }^{174}$ ("Telescopy", Octubre CCC, febrero 2010), en las que quisimos abrir un espacio para discutir, difundir y compartir no sólo los planteamientos científicos y conceptuales en los que se basa el actual estadio de la evolución tecnológica, sino también los dilemas éticos y estéticos que están configurando lo que se ha dado en llamar la actitud 2.0. Por otra parte, también quisimos promover la difusión de estas propuestas en nuestro entorno más inmediato con el objetivo declarado de promover la participación crítica en las nuevas redes sociales, especialmente en las que se están gestando en el contexto específico de Valencia.

La estructura formal del evento contó con una serie de exposiciones teórico-prácticas de profesionales y colectivos que están centrando su trabajo en la investigación de estos ámbitos desde diversas disciplinas. Junto a estas actividades, una serie de conferencias y mesas redondas de expertos en la materia desembocaron en la formación de grupos de trabajo temáticos, abiertos a la participación de los asistentes. Siguiendo en esta línea de compaginar la reflexión crítica con los ejemplos prácticos, se organizaron una serie de conciertos de bandas que están trabajando con licencias Creative Commons y diferentes actividades de índole participativa (como talleres, jornadas de intercambio, etc.) en consonancia con la temática de las jornadas.

En la misma línea de autoevaluación como parte del colectivo Barra Diagonal, asistimos en julio de 2010 a las ya anunciadas jornadas llamadas Paraquienesdisfrutamostrabajando (PQDT), durante las que filmamos parte de las entrevistas adjuntadas como documentación junto con Adrián Rodríguezy Chinowski Garachana, miembros de Exit-Raval y la ULEX respectivamente. En ellas, se produjo un magnífico ejemplo de lo que venimos llamando autoformación y que participa plenamente de la metodología de trabajo basada en la auto-encuesta y la investigación-acción.

En cuanto a esta experiencia PQDT, pensamos que vale la pena adjuntar el informe completo sobre la condición de los productores culturales, un diagnóstico de la cultura, como excelente dispositivo de articulación de un sector precario, fruto del trabajo conjunto de esos días más un esfuerzo posterior de profundización y síntesis de todo lo dicho ${ }^{175}$. En cualquier caso, como resumen del mismo, para cerrar este bloque teórico y seguir con las prácticas propias, comentaremos a continuación brevemente la metodología seguida y los resultados obtenidos, remitiéndonos al informe completo para mayor profundidad.

174. http://conservas.tk/

175. Véase Anexo I. 


\section{PARA QUIENES DISFRUTAMOS TRABAJANDO Jornadas de precariedad y autoorganización del trabajo creativo}

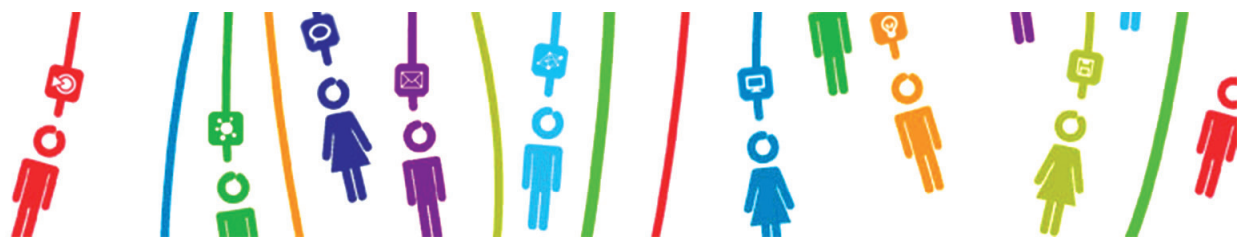

Fig. 10

El punto de partida fue la organización de unas jornadas/talleres con la intención de detectar y definir las áreas problemáticas relacionadas con la práctica del trabajador cultural, así como trazar unas posibles líneas de trabajo en aras de la creación de una especie de biosindicato que posibilitara un empoderamiento en este sector. Las jornadas se organizaron en la librería asociativa Traficantes de Sueños, que actuó como espacio-bisagra como ya ha hecho otras tantas veces, con la intención de reunir y dirigirse a públicos distintos, desde gestores culturales y artistas independientes hasta empresarios culturales y un público general de autónomos y precarios. Se trató de una iniciativa conjunta de la Universidad Nómada, Traficantes de sueños e YProductions, con la participación de la Casa Invisible y una financiación reducida por parte del Museo Reina Sofía (MNCARS). Esta diversidad de participantes supuso contar con una riqueza de puntos de vista pero también implicó la dificultad que plantea no partir de objetivos comunes sino únicamente de medios ya que, evidentemente, el activista social, el gestor cultural independiente y el empresario cultural no están buscando lo mismo en un encuentro así.

Por otra parte, el Reina Sofía participó en estas jornadas siguiendo una línea de trabajo voluntarista pero complicada, la que se abre en la pestaña "Otra institucionalidad" ${ }^{176}$. Como en el caso de la inclusión de las nuevas tecnologías y los programas de autoformación en los centros sociales, el rechazo es doble: el público y los agentes vinculados a la alta cultura siguen considerando negativo que determinadas instituciones se relacionen con movimientos "marginales" $y$ "politizados"; de igual modo, el éxito de intentos de colaboración productiva entre una entidad que no deja de ser una institución pública, vertical y jerárquica, y una difusa red de agentes culturales de gestión horizontal resulta bastante relativo, si entendemos "colaboración" como algo más que financiación y legitimación cara al ámbito institucional (como podemos suponer, en otros ámbitos, la colaboración de un museo se considera más bien un factor de deslegitimación).

176. http://www.museoreinasofia.es/redes/presentacion/nueva-institucionalidad.html 
Por ello, las iniciativas respaldadas por el museo y agrupadas bajo la ambigua etiqueta de "Redes" se plantean siempre desde está relación de "doble vínculo" que hace difícil gestionarlas a nivel simbólico más allá del apoyo económico. De hecho, la interacción del Museo se redujo en este caso a la financiación (cubría los costes de desplazamiento de las personas que participaron en el encuentro, el alojamiento de algunos de ellos, la publicidad y la web del evento) aún cuando sabemos que los actos que se limitan a la financiación tienden a convertir en inoperante la porosidad buscada. Con un poco más de interacción, en Commoniversity, la presencia de 3 representantes de instituciones en el bloque Centros, institutos, museos de arte contemporáneo y capitalismo cognitivo en la enseñanza superior: ambivalencias, desafíos, alianzas, fracasos, se planteó separada tanto en términos de programación como de espacio (otro horario, otro lugar) sin que se produjera posterior interacción en los demás bloques.

En cuanto a la metodología de trabajo de las jornadas en sí, tras una presentación más teórica el primer día a cargo de representantes de YProductions y de Serpica Naro (Milán), el segundo día abrió los talleres propiamente dichos, denominados «Para los que disfrutan trabajando (¿o no tanto?). Del malestar a la autoorganización.». En el primero de ellos, dirigido a la autoevaluación de las condiciones laborales, se constituyeron los primeros grupos de trabajo para llevar a cabo un señalamiento de los principales problemas de la producción cultural de hoy en día. Estos problemas se intentaron agrupar bajo tres rúbricas diferentes: personal, coyuntural y estructural, para intentar discernir la parte de responsabilidad, culpabilización y percepción subjetiva, la parte coyuntural que puede estar jugando la crisis entre otros factores, y por último, identificar los problemas verdaderamente estructurales del sector.

Aparecieron los problemas clásicos (precariedad, clientelismo, morosidad, etc.), pero también alguno insólito (las redes afectivas como fuente privilegiada de contratación, por ejemplo). El continuum vida-trabajo, la precariedad emocional y laboral o el incumplimiento de expectativas, por no hablar de los déficits institucionales, la falta de espacios de politización asociativa o la improbable rentabilidad de proyectos, fueron todos ellos problemas detectados por la mayoría de los asistentes. Para terminar la sesión, se hizo una puesta en común en la que los grupos fueron contando los diferentes obstáculos y factores de problematización detectados y se fueron anotando en unas pizarras para poder identificar los principales problemas del sector.

Las sesiones de trabajo fueron breves, procurando que siguieran un orden y no entraran en divagaciones que impidieran avanzar. Durante todo el encuentro, se intentó seguir esta pauta para hacerlo más fluido ya que éramos gran número de personas tratando temas muy complejos. Por otra parte, en vez de seguir el modelo de un programa de investigación con su secuencia 
de hipótesis-entrevistas-análisis, se trató más bien de la elaboración de un diagnóstico compartido sin pretensiones de objetividad. Tal y como se dice en el informe, este encuentro puede ser considerado como un auto-análisis, un ejercicio crítico acerca de lo que consideramos nuestras potencialidades, pero sobre todo nuestras debilidades. Puede que no tenga valor sociológico pero sirve para construir un mínimo común dinamizador en torno al que activar las posibilidades políticas de auto-organización del sector.

Tras una comida conjunta en un espacio asociativo como es "Esto es una plaza" (uno de los modelos de recuperación de espacios en desuso que seguiremos posteriormente en nuestras acciones colectivas), en la que se continuó informalmente la discusión de problemas comunes en torno a una serie de cuestiones que difícilmente aparecerían en los debates generales, volvimos al sistema de división por grupos de trabajo para iniciar el taller Puesta en común de herramientas para hacer frente a lo que hay. En él, se intentaron trazar líneas de acción destinadas a reducir los problemas que asolan este ámbito profesional. Roto el hielo tras la comida, y más familiarizados con el proceso de trabajo, esta sesión resultó más fructífera todavía a la hora de proponer posibles líneas de acción/solución a los problemas detectados en la primera sesión. Tras ella, se hizo otra puesta en común asamblearia en la que se intentó de nuevo mantener el orden de presentación de los grupos de trabajo y los temas que a debatir de manera que no nos alargáramos excesivamente ni perdiéramos la fuerza en vericuetos paralelos y trampas dialógicas varias.

Esto también permitió pensar y trabajar tanto a nivel más abstracto/ teórico (los mecanismos y "modos" de producción cultural postfordista, la noción de acción sindical para el ámbito de producción simbólica, etc.) como a nivel pragmático (cuestiones concretas de financiación - cooperativas, banca ética, crowdfunding - y de defensa ante los tan habituales retrasos en los pagos). Curiosamente, el análisis de problemas y la propuesta de soluciones oscilaban entre un análisis político y una crítica ética, a los que se superpuso el discurso de racionalización empresarial. Si bien las fronteras entre los dos primeros no estuvieron totalmente claras ya que la reivindicación del asociacionismo se mezclaba con el llamamiento a la solidaridad, el tercer enfoque implicaba la transformación de las políticas de organización y conflicto en una reivindicación de soluciones más bien técnicas: asesorías, estrategias de negocio, diversificación de clientes, etc. Podríamos decir que seguimos adoleciendo de una ausencia de visión general del sector que requiere de un diagnóstico más amplio centrado sobre las formas de contratación, los modelos de explotación del trabajo y la problemática remuneración de la producción cultural.

Para terminar, la última sesión de trabajo que realizamos al día siguiente se centró en la constitución de grupos de trabajo orientados a profundizar en la elaboración de herramientas útiles para la organización del sector como pueden 
ser las cartografías (mapas de trabajadores, empresas y recursos en el sector), la reedición del encuentro, los instrumentos asociativos orientados a estrategias de organización y conflicto, las herramientas web o la realización de talleres y dinámicas de grupo. La conclusión general fue que debemos repensar la posible acción sindical en el mundo de la producción postfordista que no puede llevarse a cabo bajo formatos como la huelga. La actualidad pide otras tácticas de acción y en ese sentido, el tema que más interés y ganas despertó fue el de las posibilidades de organización colectiva que elegimos llamar BioSindicato aunque con ello, tan sólo pretendíamos indicar la necesidad de pensar en términos concretos y políticos, en el más puro estilo de la investigación-acción participativa.

Para ello, detectamos la necesidad previa de identificar experiencias similares (locales o internacionales, pasadas o presentes, de un ámbito u otro) que nos ayuden a definirnos, como por ejemplo, la reivindicación de un estatuto laboral intermitente como condición estructural de nuestro trabajo, observando los procesos llevado a cabo para obtenerlo en países como Bélgica o Francia. Estas jornadas sirven, pues, como ejemplo de una manera de hacer que supone por una parte el deseo de autoformación, la aplicación de una metodología de investigaciónacción, el intento de creación de un biosindicato que si bien no ha llegado a consolidarse, esperemos que sea el germen de una articulación mayor del sector. Ha supuesto el lanzamiento de una serie de encuestas y articulaciones en red por parte de diferentes plataformas de producción cultural como es el caso de Zemos98 o de YProductions que detallamos a continuación.

En septiembre de 2010, YProductions desde el espacio CAMON, lanza el proyecto Redada Madrid: sobre metodologías de investigación en cultura ${ }^{177}$ con el objetivo de cartografiar y comprender las dinámicas que sigue la vida cultural de la capital. En febrero del 2011, en la misma sede de Traficantes de Sueños, se reúnen Atravesadas por la cultura ${ }^{178}$, Kultur-o-Meter y las coordinadoras de las jornadas Paraquienesdisfrutamostrabajando con objeto de pulsar las ganas y posibilidades de seguir creando dispositivos, investigaciones, redes y conflictos en y en torno a la producción cultural.

A raíz de este debate, se decide prolongar estas jornadas varios días y en ellas, comentar los talleres realizados por Atravesadas: "Lugares de las industrias culturales y creativas", ¿Quién teme a los trabajadores culturales" $\mathrm{e}$ "Instituciones de lo común", aprovechando para exponer la propuesta de encuesta al sector, destinada a conocer mejor nuestras percepciones y situaciones laborales. Igualmente, se expone la última investigación de Kultur-o-Meter, que buscaba analizar los presupuestos de cultura de una serie de instituciones públicas y privadas de Madrid aunque el

177. http://http//www.ypsite.net/redada.madrid/

178. http://atravesadasporlacultura.wordpress.com/ 
trabajo se centró finalmente en el Ayuntamiento de Madrid. Se presentaron los grupos de trabajo surgidos de las jornadas Paraquienesdisfrutamostrabajando así como la propuesta de biosindicato que ya hemos comentado. En cuanto a procesos abiertos de encuesta, se presentó la encuesta realizada por un grupo en el Reina Sofía basada en los trabajos de la Radical Education, y la nueva "Asociación de Gestión Cultural" que había conseguido el reconocimiento de "gestor cultural" como una profesión. Para terminar, se expusieron los resultados de la encuesta realizada por los compañeros sevillanos de la REU084 ${ }^{179}$.

Todas estas acciones se han ido combinando con proyectos varios dentro de la investigación de la cultura, proyectos necesarios y vertebradores cara a esta larga crisis. No obstante, nosotras ya no participamos en esta segunda fase de articulación. Nos disolvimos como Barra Diagonal tras el exilio de casi todos sus miembros y seguimos avanzando en nuestras propuestas locales desarrolladas fundamentalmente en la ciudad de Valencia, intentando trabajar en un entorno local con un planteamiento global, ampliando nuestro campo de acción para exceder el ámbito de la cultura. El contenido de esta deriva está recogido en la segunda parte de la tesis en la que intentaremos dar cuenta de nuestras acciones como co-fundadoras de los colectivos Autoformato y la Coordinadora de Iniciativas Vecinales (LaCIV).

Para terminar con esta primera parte, nos gustaría aportar material videográfico compuesto por 15 entrevistas grabadas a lo largo de 2010-2011 en diferentes ciudades, aprovechando los desplazamientos que realizamos con motivo de los seminarios de autoformación en los que participamos así como las diferentes actividades vinculadas a la investigación de esta tesis. En el primer bloque que hace referencia a toda una serie de lo que hemos venido denominando instituciones anómalas como pueden ser los centros sociales y las ODS, nos remitimos a las entrevistas grabadas a personas implicadas directamente en su gestión, procedentes de Madrid, Barcelona, Terrassa y Málaga.

Con esta selección que abarca propuestas tan diferentes como universidades libres, proyectos de pedagogías colectivas o centros sociales autogestionados, quisimos hacer un muestreo de proyectos en el que los entrevistados expusieran las líneas estratégicas básicas de cada proyecto explicitando su origen, trayectoria y situación actual. En casi todos ellos, vimos cómo esta descripción incluía de forma natural un análisis de las modalidades posibles de articulación de cada proyecto con las formas de organización política de los movimientos sociales en los que estaban inmersas, así como del posible impacto sobre la esfera pública local, estatal y europea mediante la constitución de redes. En algunos casos, en la entrevista se explicita la estrategia de reapropiación de

179. www.reu08.org 
recursos y la relación concreta con las Administraciones públicas, ilustrando la enorme variedad existente. Incluimos en todas ellas una pregunta que abriera la reflexión sobre la autoformación y la crisis, lo que nos permitió seguir profundizando en la relación que, desde dichos centros, se tiene con el marco actual y las necesidades de conocimiento que implica.

El segundo bloque de entrevistas sirve de referencia para los capítulos en los que, a partir del análisis del postfordismo, surge la figura del precario ejemplificado especialmente en el trabajador cultural. A lo largo de las entrevistas, podemos ver diferentes maneras de abordar esta precarización que muchas veces, como ya decíamos, admitimos por amor. Las conclusiones obtenidas a raíz de la auto-encuesta que se llevó a cabo en Para quienes que disfrutamos trabajando casan perfectamente con esta imagen del precario cultural que se mueve en un territorio de nadie, dividido entre la satisfacción por evitar el status de asalariado y la enorme dificultad que implica sobrevivir como autónomo, con unas armas de reivindicación obsoletas como podría ser la huelga, y deseando poder acceder al estatuto de intermitente, es decir, que desde el Estado se reconozca su condición laboral específica y diferencial no como un elemento coyuntural sino como una condición estructural.

Este bloque, además de para ratificar nuestra exposición teórica, sirve para ofrecer una visión encarnada de todas estas problemáticas, en la que personas que forman parte de estructuras legales, reconocidas tanto en el ámbito académico como en el alternativo, abordan cuestiones en su mayor parte emergentes como pueden ser los procesos de arquitectura que se alejan del concepto de autoría, los cuestionamientos a la propiedad intelectual, las editoriales entendidas como empresas políticas o los grupos de investigación vinculados a estructuras artísticas convencionales pero que abordan temáticas de autoformación claramente posicionadas a nivel político. Si bien en el próximo capítulo veremos hasta qué punto pueden llegar a difuminarse las disciplinas y fronteras, en este podemos ver que ya dentro de lo que se viene entendiendo como producción de conocimiento, las sucesivas alianzas y proyectos conjuntos han creado un territorio compartido desde el que quizás será posible trabajar en torno a una noción polifacética del común. 

6. Tres, dos, uno... ¡Acción!

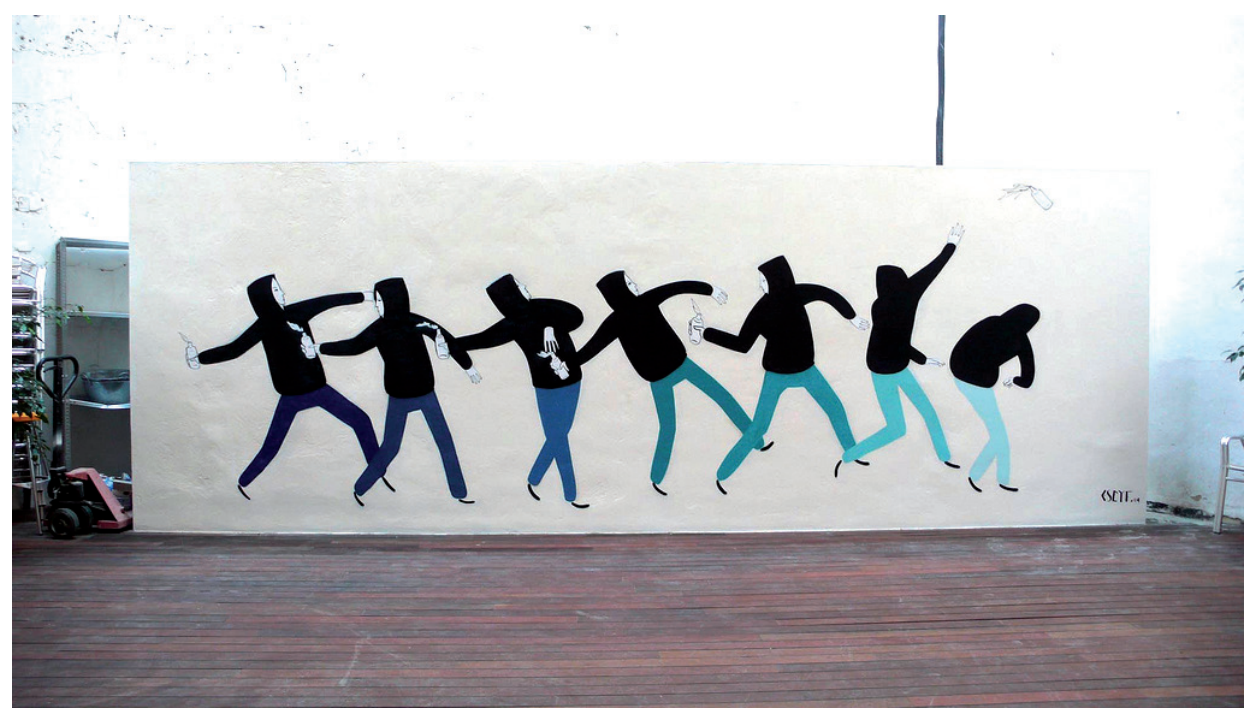

Fig. 11 
Ypor fin, hemos aprendido que el poder no es - para nadael lugar político por excelencia. Como decía Spinoza, el poder es el lugar de la tristeza y de la impotencia más absoluta Colectivo Situaciones ${ }^{180}$

\subsection{Reversibilidades pragmáticas}

Partiendo de todos estos presupuestos teóricos, hemos considerado la necesidad de llevar a la práctica en nuestro propio territorio estas premisas que no se limitan a su enunciación teórica sino que exigen, por su propia condición, una experimentación sobre el terreno, sobre todo, teniendo en cuenta el momento que nos ha tocado vivir. Habida cuenta de la crisis generalizada en la que nos encontramos, crisis de la democracia parlamentaria, crisis del sistema de gobierno capitalista, crisis de la universidad, no podemos encontrar mejor marco para proponer procesos de investigación militante que intenten dilucidar posibles caminos de recuperación de la gobernanza, entre otras necesidades perentorias que nos van acuciando.

Por tanto, hemos puesto en marcha diferentes dispositivos de introducción de determinados conceptos a nivel de ciudad, siendo la metrópolis la unidad de análisis y de aplicación, porque puede funcionar como microcosmos de procesos que se desarrollan a un nivel mucho mayor y fundamentalmente, porque es un ámbito en el que aún nos queda cierta esperanza de empoderamiento cuando nos hemos visto expropiadas de toda decisión. Este apartado de la tesis estará pues centrado en el trabajo personal que hemos realizado partir de las investigaciones sobre autoformación en las que nos hemos vistos inmersas desde los últimos años, de forma más intensiva a partir del 2008.

Tras una deriva artística iniciada con instalaciones, intervenciones y acciones, que fue transformándose en práctica activista interdisciplinar, nuestra actividad personal acabó adquiriendo un perfil de producción cultural bastante ambiguo ya que podría identificarse como investigación extradisciplinar situada en una especie de territorio en el que el ámbito artístico había quedado sino abandonado, por lo menos subsumido en otro tipo de producción menos acotable bajo este adjetivo. Debido a la vinculación directa con la teoría desarrollada y como ejemplo de esta deriva, nos parece importante hacer una revisión somera de las

180. Colectivo SITUACIONES, Sobre el Militante Investigador, www.situaciones.org 
actividades que pudieran agruparse bajo el epígrafe de autoformación llevadas a cabo en los últimos tres años, período en que la tesis ha terminado de conformarse. Posteriormente, analizaremos de forma más detallada el proyecto de autoformación que está poniendo en práctica en la actualidad y al que considera dotado de una cierta dimensión transformadora que justifique lo que se ha venido llamando práctica instituyente.

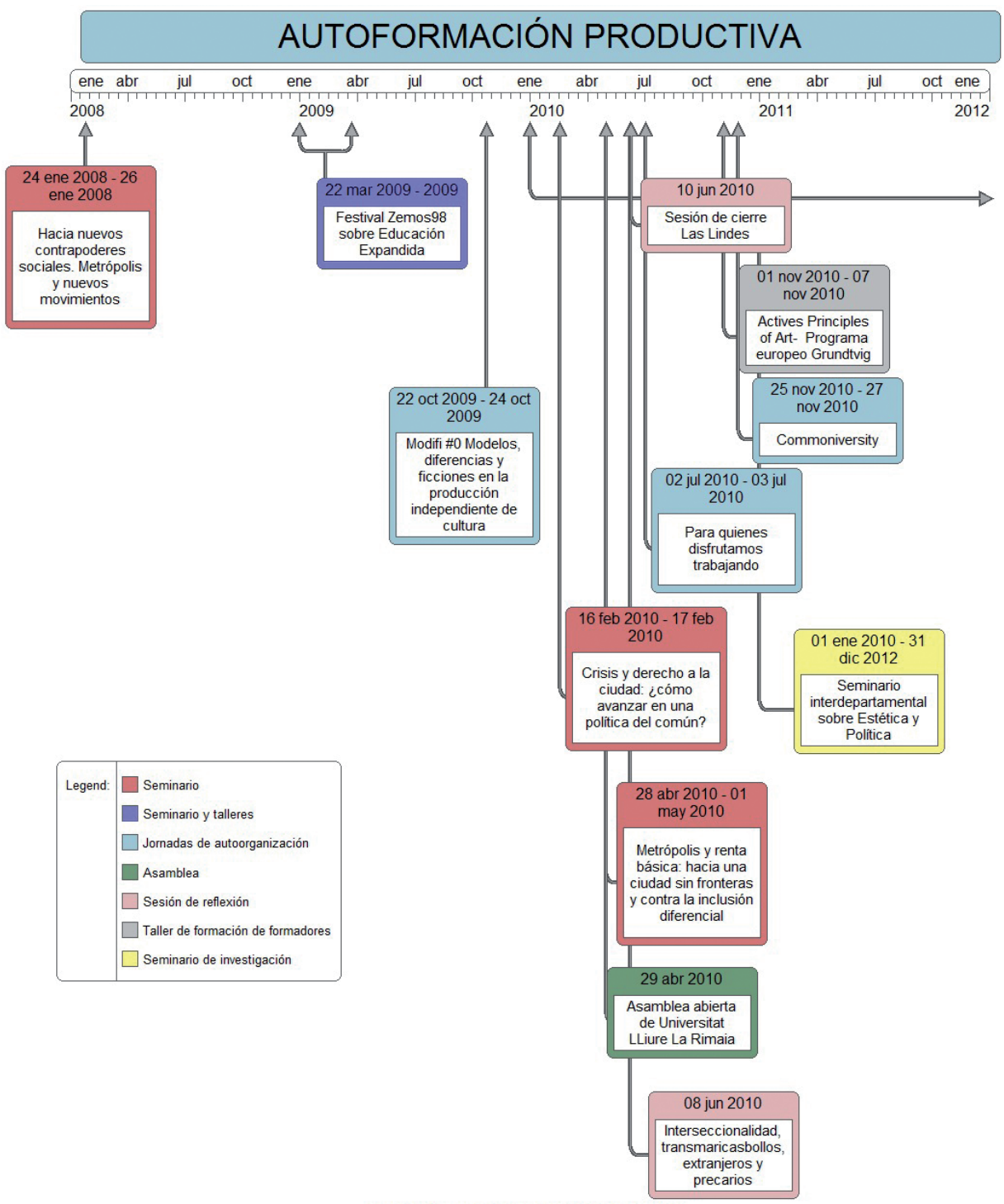


Por necesidades de claridad en la exposición y no necesariamente por una diferencia conceptual, esta etiqueta de autoformación se despliega en dos vertientes que se separan en formación y producción, siendo en este marco, prácticamente sinónimos pues ¿cómo diferenciar las actividades en las que se participa con la función de autoformarse y las que organiza con la misma intención? En estos procesos, a menudo se puede observar que los participantes pasan rápidamente a organizadores en la misma convocatoria o en las siguientes, puesto que resulta fundamental obtener ese tipo de implicación en la co-investigación ya que en caso contrario, no se habría conseguido cumplir uno de sus objetivos centrales.

Ambas líneas se desarrollan paralelamente en el tiempo abarcando en total los últimos cinco años, desde enero de 2008 hasta diciembre de 2012, fundamentalmente en el territorio español.

\subsection{Autoformación productiva}

Conscientes de que ni la Universidad ni otras instancias formativas más convencionales podían colmar determinados huecos de conocimiento sobre materias necesarias para llevar a cabo nuestro plan de reactivación de una determinada energía social asociada a procesos de autoformación, hemos asistido a diferentes seminarios impartidos por el territorio, principalmente organizados por la Universidad Nómada en sus sedes del Ateneu Candela, ExitRaval, La Casa Invisible y Traficantes de Sueños, pero no únicamente. Como veremos a continuación, ha habido un abanico mayor de interacciones que el que luego se ha recogido en la tesis, ya sea en la teoría, ya sea en las propias prácticas.

Muchas de las entidades implicadas en ellas están reflejadas en las entrevistas citadas en el capítulo anterior y entregadas como material anexo a la investigación, pero hay otras tantas en las que el material videográfico ha quedado sin editar ya que el modelo utilizado como reflexión o el tipo de contenido estaba relacionado con mis investigaciones y prácticas de una forma más tangencial. Se nos han quedado en el tintero análisis sobre grupos de funcionamiento ejemplar como es el caso de Las Lindes que intenta renovar el panorama pedagógico en la enseñanza secundaria o propuestas más artísticas como el Aula de Propulsión Escópica del colectivo RAMPA o el Laboratorio del Procomún de Medialab, estás dos últimas no aparecen recogidas ni en las entrevistas ni en la parte escrita. Nos hubiera gustado ofrecer todo el material pero por limitación de espacio y para evitar la saturación, hemos seleccionado las que considerábamos más pertinentes. Por ello, a continuación, vamos a enumerar y comentar brevemente esta selección de acciones formativas realizadas. 
Empezaremos detallando algunos de los seminarios de la Nómada que, por su cercanía política, han resultado fundamentales en nuestras prácticas posteriores. Para enmarcar estos seminarios, debemos citar la definición que la propia Nómada hace de sí misma porque nos parece que ejemplifica y detalla con gran precisión los propósitos que mueven a la autoformación y la consideración que de esta acción tenemos. Creemos igualmente que sus propósitos de comprender mediante la reflexión conjunta una situación y desarrollar también de forma conjunta las herramientas de transformación de dicha situación es un objetivo común a los diferentes modelos de autoformación propuestos.

La Universidad Nómada es un dispositivo híbrido de intervención política transnacional en las coordenadas definidas por la sociedad del conocimiento y el capitalismo cognitivo y por la nueva composición de clase inserta en el capitalismo global constituida por los nuevos sujetos proletarios inmersos en el paradigma de la intelectualidad de masas y del general intellect. Nuestras tareas inmediatas pretenden ser:

(1) pensar la producción y difusión de las herramientas intelectuales, teóricas y culturales necesarias para comprender cuáles son las formas de dominación, explotación y constitución de estos nuevos sujetos productivos que han surgido en la fábrica social como consecuencia de los mencionados procesos de reestructuración desencadenados para desactivar la potencia de las luchas de los movimientos antagonistas de las últimas décadas, así como para conceptualizar el circuito global de acumulación de capital y las nuevas formas de legitimidad política de acuerdo con las actuales modalidades de governance ideadas por las formas-Estado nacionales y supranacionales;

(2) inducir un proceso de clarificación de los paradigmas, herramientas, e instrumentos teóricos que manejan en la actualidad los sujetos y movimientos sociales que están apostando por llevar a la práctica un proyecto de carácter antisistémico y constituyente, mediante la explicitación rigurosa de los modos a través de los cuales es posible enjuiciar la actual coyuntura social, política e intelectual y su articulación geoestratégica, y con la indicación precisa de cuales son las líneas de trabajo intelectual y por ende político que queremos poner a prueba en los próximos años;

(3) constituir las líneas y estrategias de emergencia política que permitan la visibilidad social de un proyecto antisistémico definido por los mencionados sujetos sociales como un campo de fuerzas de geometría variable en el que puedan integrarse un número elevado de movimientos y sujetos diversos susceptibles de participar de acuerdo con la materialidad de nuestras propuestas y la consistencia de sus intereses con la intención de crear nuevas formas de hegemonía política y nuevas modalidades de transformación radical de nuestras sociedades. ${ }^{181}$

A pesar de la densidad discursiva que se anuncia ya desde la presentación, podemos decir que la Nómada está vinculada de forma satisfactoria a todo tipo de movimientos sociales que adelantan la praxis a la discusión teórica pero que salen reforzados mutuamente de este anclaje e intercambio. La Universidad Nómada,

181. http://www.universidadnomada.net/spip.php?article139 
de forma explícita, quiere ser el motor de arranque de un proyecto político que intervenga transversalmente en la realidad política actual, ante la crisis de determinadas formas de representación política institucional en el espacio nacional.

Los cursos y seminarios organizados por la Universidad Nómada son acciones formativas programadas junto con departamentos universitarios, en particular con la Universidad Complutense de Madrid, en la que la Universidad Nómada ha contribuido a la creación del Grupo de investigación Globalización y Movimientos sociales (GMS). Los cursos aspiran a una renovación radical de las prácticas formativas, lo que se traduce en un formato abierto y transversal y en una desaparición de las posiciones institucionales de poder a priori. Desde el principio, la Nómada se ha planteado dichos cursos siguiendo un formato híbrido ya que, por una parte, generan créditos reconocidos por la universidad y al mismo tiempo están abiertos a cualquier persona interesada, y en especial a las personas activas en los movimientos sociales y en las redes alternativas metropolitanas.

Esta hibridación por el momento resulta impensable en otras universidades del ámbito español, hecho que pone en evidencia la importancia de las personas que forman parte de ella ya que son las que propician los intersticios puntuales en grandes estructuras poco permeables al cambio. En este caso, la co-pertenencia de varios de sus promotores tanto a la Universidad Complutense como a la Nómada, es el elemento que ha permitido que se produjera esta porosidad e interacción no contemplada en las normativas vigentes. Esta actividad de la Universidad Nómada se enmarca en la voluntaria relación del saber de los movimientos sociales con las formas canónicas de enseñanza, de los circuitos universitarios existentes que no siempre son capaces de captar las necesidades o la riqueza de las necesidades sociales y políticas de los nuevos sujetos sociales. Como ya dijimos en páginas anteriores, estos ciclos de autoformación tienen una vocación transnacional con la intención manifiesta de generar una red internacional de centros de formación y análisis ligada a los movimientos sociales y a su tarea de diagnóstico social, intelectual y teórico.

\subsubsection{Hacia nuevos contrapoderes sociales. Metrópolis y nuevos movimientos - La Casa Invisible, Málaga, enero de 2008 http://www.universidadnomada.net/spip.php?rubrique48}

Asistimos en el centro social La Casa Invisible de Málaga, el 25-26 de enero de 2008 a este seminario multidisciplinar sobre la dimensión metropolitana, la forma del poder en los espacios metropolitanos, las transformaciones del capital y de las relaciones laborales, los nuevos movimientos y las conjeturas sobre una nueva capacidad de expresar potencia contra el poder a partir de las emergencias urbanas de cooperación social, como la experiencia de los centros sociales. 
Fig. 12

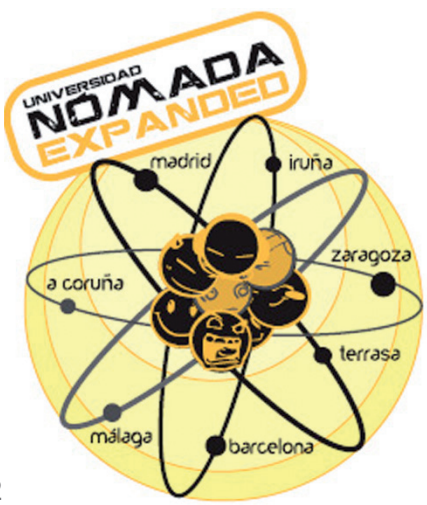

En este seminario observamos con sorpresa cómo, en lo que teníamos identificado como un centro ocupado sin más, al no haber tenido aún contacto con los nuevos centros autogestionados de segunda generación, se desarrollaba un programa de autoformación e investigación con un nivel de profundidad e implicación mucho mayor que los que en ese momento estaban organizándose desde la Universidad en mi propia Comunidad Autónoma. En él, hubo varios elementos diferenciales como puede ser la asistencia de un público heterogéneo interesado tanto en las discusiones sobre el paso de la sociedad fábrica a la metrópolis, la presentación de un libro del Observatorio Metropolitano sobre los modelos erróneos de ciudad practicados en Madrid, Sevilla y Málaga, como en los talleres de hip-hop militante con los que se cerraban las jornadas; o bien la continuidad de seminarios, comidas y fiesta en un mismo espacio multidisciplinar que aumenta considerablemente las interacciones informales entre los diferentes asistentes, lo que permite mezclar de forma natural saberes y proyectos.

Por otra parte, su realización en un espacio vivo abierto a cualquier interesado en el centro de la ciudad también implica una mayor oportunidad de impregnación que las altas torres de la academia, que celebran este tipo de seminarios en sus salones de actos que difícilmente se adecúan a procesos de co-investigación, a mesas redondas en igualdad de condiciones, etc. simplemente porque su propia disposición espacial y connotación de distribución de saberes se impone inevitablemente: en el estrado los que saben, abajo, los que reciben el maná. Por no hablar de su gratuidad y autogestión a pesar de conceder créditos computables por la competente Complutense para desmarcarse de forma clara de la mercantilización de los saberes (con lo que ello tiene de pros y de contras, claro, la benevolencia, la falta de reconocimiento o de consideración simplemente por el hecho de ser un seminario gratuito, la necesidad de financiación autogestionada, es decir, de autoexplotación encubierta). Para terminar, el hecho de grabar y poner en red el contenido de los seminarios también incide aún más en esta economía del don en donde no se aplica una lógica de la escasez obsoleta y perversa.

Estas características se repetirán en los diferentes seminarios a los que hemos asistido: el enraizamiento con los movimientos sociales locales, la ocupación de un espacio central en la metrópolis, la participación de un público joven, la profundidad de los análisis críticos, la generación de redes de trabajo y confianza, la inclusión de los propios dispositivos (centros sociales, ciudades-laboratorio, etc.) puestos en acto en la reflexión militante, la gratuidad de los seminarios, todos ellos elementos que rara vez se dan en los dispositivos de aprendizaje formalizados. 


\subsubsection{Festival Zemos98 sobre Educación Expandida - CACS, Sevilla, mar- zo de 2009 - http://www.zemos98.org/simposio/}

La 11 edición del Festival Internacional ZEMOS98, que se celebró en Sevilla entre los días 22 y 28 de marzo de 2009 , se centró en la búsqueda de nuevas formas de educación que incorporen y se adapten a los procesos sociales y comunicacionales que ha provocado Internet. La nueva cultura digital se caracteriza por la organización en red, el trabajo colectivo, la convergencia de medios, el copyleft etc. La mayor parte de estos procesos no se incorporan en los sistemas educativos convencionales, y así la nueva educación no está sucediendo ya sólo, ni principalmente, en los espacios formales, ni es liderada por las instituciones educativas. Son innumerables proyectos artísticos, científicos, comunicacionales y educativos con rasgos culturales, sociales, digitales y audiovisuales los que constituyen ahora la vanguardia de la educación en el siglo XXI.

Como dicen los Zemos, en este festival se intentó reflexionar en torno a la idea de resignificar la educación de manera que no esté solamente circunscrita al ámbito institucional, partiendo de la base de que la nueva coyuntura digital supone una nueva oportunidad para recuperar la idea de reciprocidad en las formas de distribución del conocimiento. La educomunicación -como concepto que va más allá del de educación, partiendo de una refundación a partir de la comunicación social- se funde con la ciencia y la creatividad generando una tercera cultura en red donde adquieren especial importancia el pensamiento de diseño, el concepto de laboratorio como espacio de trabajo, el proceso, la disolución de los límites entre lo profesional y lo amateur, la innovación como motor del conocimiento y el procomún como herramienta de investigación e interrelación.

Este festival consta de sesiones teóricas de exposición de trabajos o modelos innovadores de aprendizaje, así como de talleres prácticos en los que los asistentes se dividen por pequeños grupos para trabajar adoptando una postura activa y propositiva, como prolongación del análisis conjunto. Fruto de la reflexión realizada en el grupo de trabajo en el que participamos dentro del taller, surge la noción de la oficina de deseos que recoge dispositivos de participación ciudadana ya puestos en práctica de forma

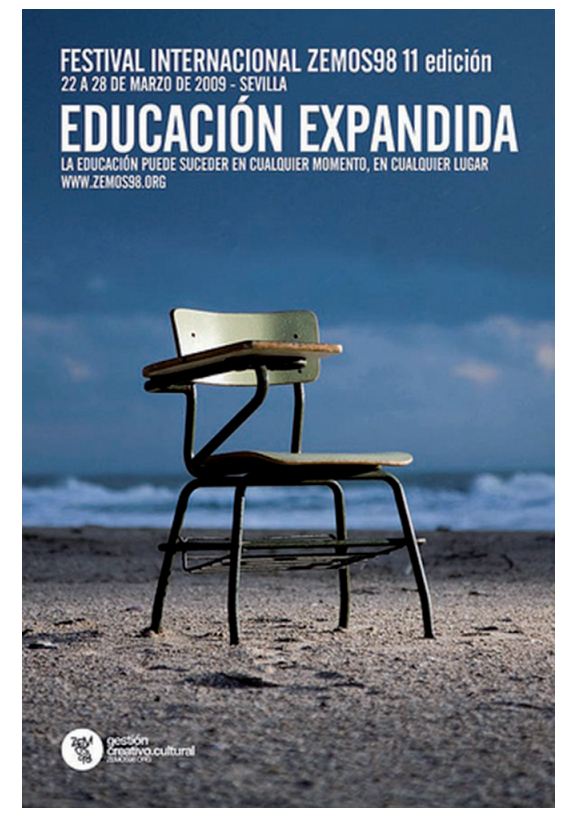

Fig. 13 
similar por La Fundición y por otras experiencias transductoras, y que se formaliza durante las sesiones de debate entre los que necesitamos poner en práctica este tipo de dispositivos en nuestras experiencias locales.

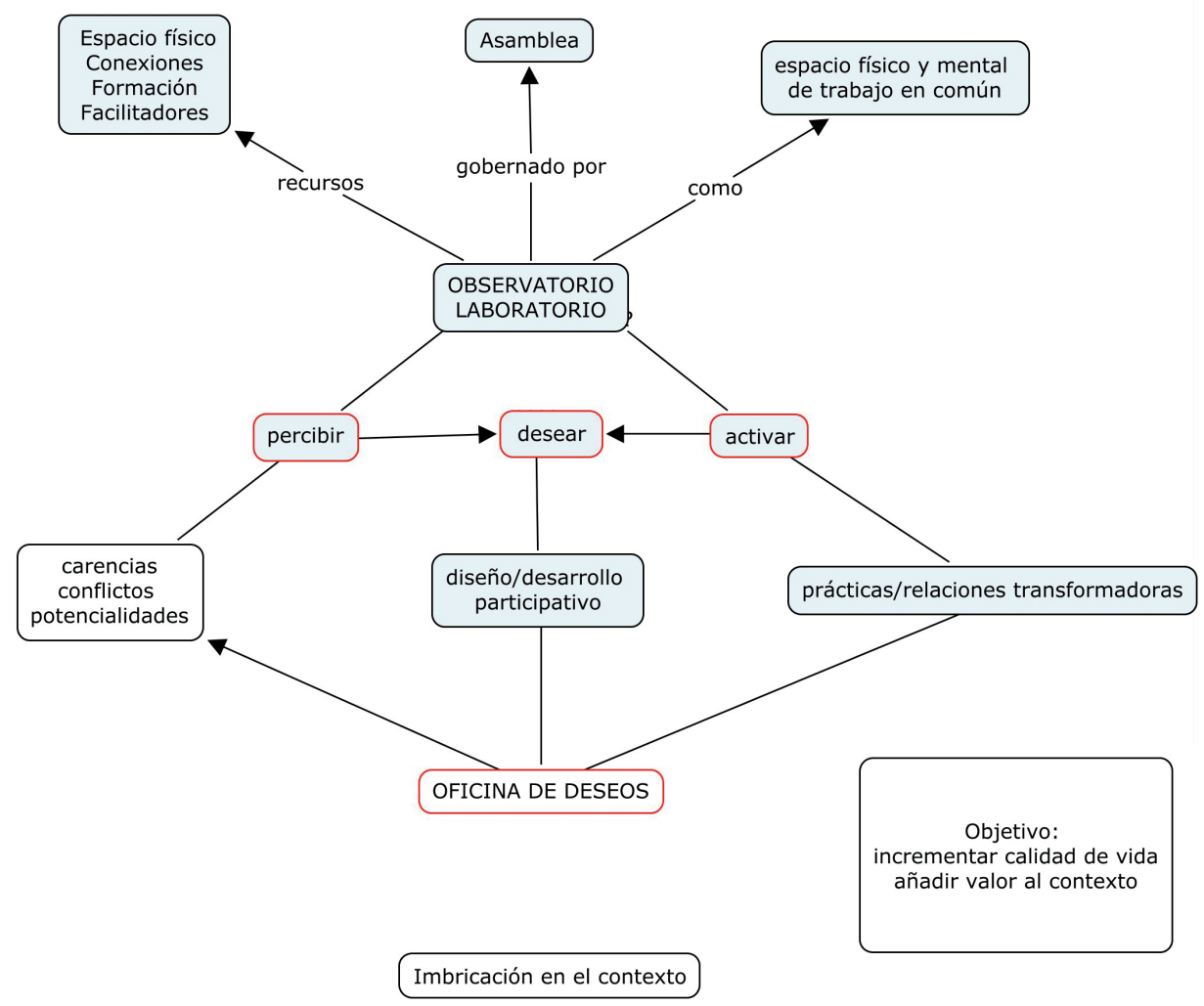

Esta noción de oficina de deseos la recuperaremos bajo variadas formas a lo largo de nuestras prácticas, evidenciando otra de las diferencias respecto a procesos creativos similares del ámbito de las Bellas Artes, la condición copyleft similar en ello a la cultura popular, ya que permite su reutilización y adaptación por cualquiera que quiera llevarlas a la práctica. Incluimos, por tanto, el esquema planteado, incidiendo en su condición activa y en su manifestación diferencial dependiendo del entorno en el que se sitúe. 
6.2.3 Derechos y crisis: welfare, renta básica y política del común-Barcelona, invierno y primavera de 2010 http://www.universidadnomada.net/spip.php?article361

Fig. 14

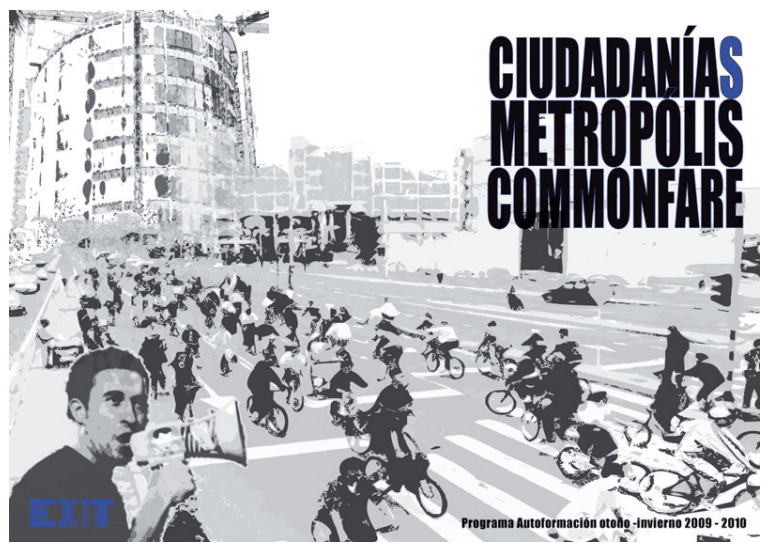

La Universidad Nómada organizó de febrero a junio de 2010 en Barcelona un ciclo a través de distintos seminarios realizados en diferentes centros sociales, mediante discusiones y reflexiones con intelectuales, investigadoras e investigadores militantes, académicos y personas vinculadas a movimientos sociales. El objela plausibilidad de una política efectiva en el marco de la crisis sistémica que, más allá de las lamentaciones, suponga utopías concretas y nociones comunes como formas de distribución de la riqueza producida y por lo tanto una vía de superación de la propia crisis.

Aquí incluimos algunos de los temas tratados, declinación con diferentes variantes que el lector avezado sabrá reconocer como espina vertebral de esta tesis, y fundamento de las prácticas que seguirán a continuación. No hemos asistido a todo el ciclo por lo que nos permitiremos indicar únicamente aquellos seminarios que pudimos disfrutar en directo y que nos han servido para consolidar una base curricular para abordar la realidad. Igualmente, algunas de las entrevistas reseñadas en el anterior bloque fueron grabadas a lo largo de este ciclo, aprovechando la confluencia de investigadores militantes al mismo.

a) «Crisis y derecho a la ciudad: ¿cómo avanzar en una política del común?» Febrero de 2010- Sala Conservas, Barcelona

b) «Metrópolis y renta básica: hacia una ciudad sin fronteras y contra la inclusión diferencial » Abril de 2010 - Ateneu Candela, Terrassa, BCN.

Dentro de la reseña de formación, podemos también citar los diferentes encuentros autoformativos a los que asistimos a lo largo de la primavera-verano de 2010 como parte de nuestra investigación específica para la tesis, intentando identificar modelos diferentes de funcionamiento y análisis en el entorno asambleario y autoformativo. Dentro de ellos, citaremos siguiendo un orden cronológico: 


\subsubsection{Asamblea abierta de la Universitat Lliure La Rimaia (ULL) - La Ri- maia, Barcelona, abril 2010 - http://unilliurelarimaia.org/}

Fig. 15

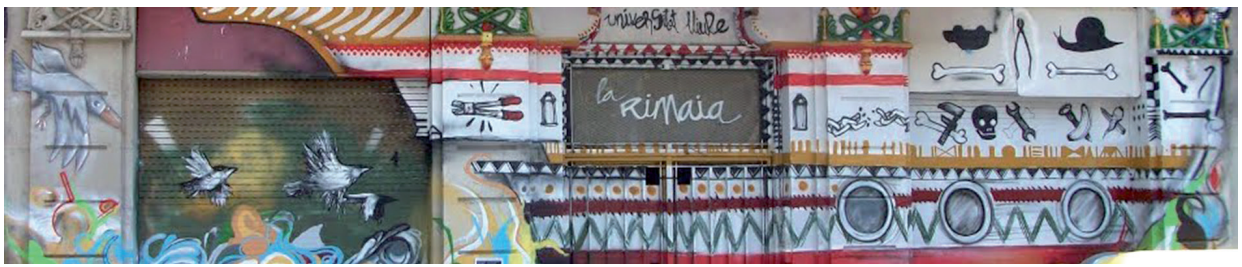

En el 2009, surge esta universidad a partir de la movilización de estudiantes de varias facultades, de donde se perfila la idea de generar un espacio que colmara las insuficiencias de la universidad para paliar el malestar sobre sus carencias. La solución inmediata para intentar colmarlas fue la ocupación de un espacio para encontrarse, generar debate, establecer una relación con los movimientos sociales, etc. De ahí surgió también la idea de crear una universidad libre en donde el conflicto fuera un eje central y dotara de sentido a lo que se quiere aprender integrando a gente de fuera de la universidad, para salir de las temáticas más trilladas que se estaban planteando en las asambleas universitarias.

Fueron integrándose en ella grupos muy diferentes como Tesla, cooperativa alternativa que investiga en torno a la electricidad y que se acabó constituyendo como una cooperativa integral del trabajo, un hackmeetinghackspace como espacio difuso en donde investigar posibilidades de intervención digital, grupos de debate en torno al decrecimiento, la democracia inclusiva; el colectivo de historiadores Praxis dedicado a revisar los últimos 50 años de historia española, colectivos de filosofía que generan un espacio para el pensamiento, etc. Dentro de su planteamiento, les parece esencial conceder un espacio privilegiado a la pedagogía crítica: cómo aprender y de qué aprender; así como a las redes con movimientos sociales, uniéndose a redes ya existentes, como la red de derechos a la vivienda digna, la red de universidades libres, asambleas de parados y sindicatos, y mediante la interacción con los vecinos de barrio intentan generar una asamblea de barrio para abordar los problemas locales.

En abril del 2010, asistimos a una asamblea abierta situada en la tercera sede que tuvieron, en la que participó el colectivo Espai en Blanc con el que nos une una trayectoria conjunta iniciada en 2007 y prolongada a través de colaboraciones con algunos de sus integrantes, que detallaremos en el bloque de producción. En ella, pudimos asistir a una heterogeneidad asamblearia mucho mayor que de costumbre, a la crítica ácida a las instituciones políticas, a un posicionamiento intelectual de gran osadía que rozaba la tabula rasa, y podemos decir que alabamos estas prácticas que intentan volver a pensar no sólo el aprendizaje sino el propio proceso de pensamiento con talante aventurero. 
6.2.5 Sesión de cierre 209-2010, Las lindes - Centro de Arte 2 de Mayo, Madrid, junio de 2010 - http://blip.tv/las-lindes/las-lindes-10-parte-1-3808950

Las Lindes es un grupo de investigación y acción acerca de educación, arte y prácticas culturales que lleva adelante un proyecto de investigación y debate sobre pedagogías críticas. Desde el año 2009, ha ido realizando de forma periódica encuentros abiertos a la participación de docentes, artistas, estudiantes e interesados en la educación, en los que se han trabajado textos indispensables de las pedagogías críticas; se han dado a conocer y analizado distintas prácticas que se están llevando a cabo a nivel nacional e internacional; y se han difundido materiales experimentales susceptibles de ser empleados como recursos didácticos en ámbitos educativos tanto formales como no formales; así como planteado debates y propuestas acerca de las nuevas estrategias para la reformulación de las prácticas educativas de la enseñanza que emplea la comunicación audiovisual.

En junio de 2010, asistimos a la que fue la sesión final del curso 20092010 que sirvió de cierre a la actividad desarrollada durante el curso escolar. En ella, analizaron el trabajo llevado a cabo a lo largo de esos meses y plantearon los objetivos a desarrollar durante el siguiente curso. Fue muy interesante asistir a la sesión de conclusiones con lo que conlleva de análisis de puntos fuertes y débiles. Igualmente interesante fue percibir la indisolubilidad de las teorías con las prácticas, ya que todos los miembros del grupo son docentes en secundaria o en bachiller e intentan llevar al aula las nociones y metodologías debatidas en el proyecto de investigación. Ello supone una implicación con un tramo educativo menos vinculado con la Universidad y en general, más ajeno a las posibilidades transformadoras a nivel político, con lo que ello conlleva de sembrar en fases tempranas, siempre más fértiles.

Su trabajo parte de la propuesta de lecturas sobre modelos pedagógicos de autores como Hooks, Freire o Rancière para generar debate y un cuestionamiento sobre metodologías. De esta manera, a partir de la lectura expansiva y la colectivización de los textos, se elaboran mapas conceptuales interactivos así como propuestas de microexperiencias educativas que luego sirven para contrastar resultados, siguiendo el modelo de guiar en vez de dirigir. Algunas de sus herramientas
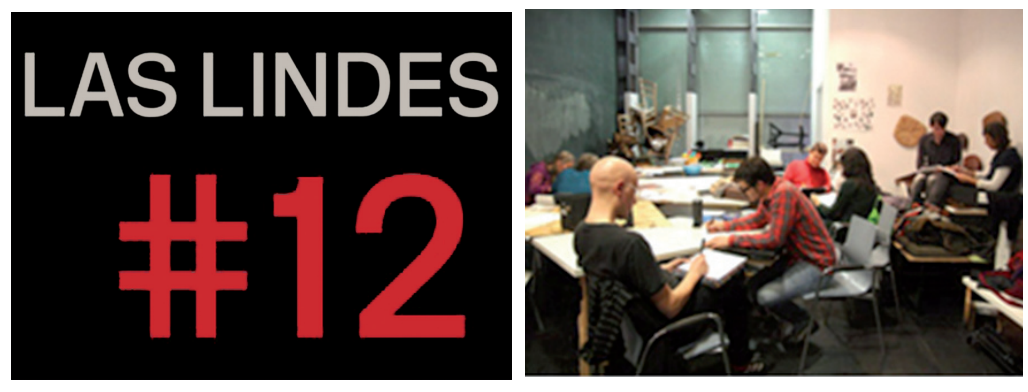

Fig. 16 
prácticas son el envío de cuestionarios y la publicación a través del blog de todos los materiales tanto utilizados para el debate como producidos posteriormente, además del archivo videográfico de las reuniones en sí.

6.2.6 Para los que disfrutamos trabajando - Traficantes de Sueños, Madrid, julio de 2010 - http://paraquienesdisfrutamostrabajando.net

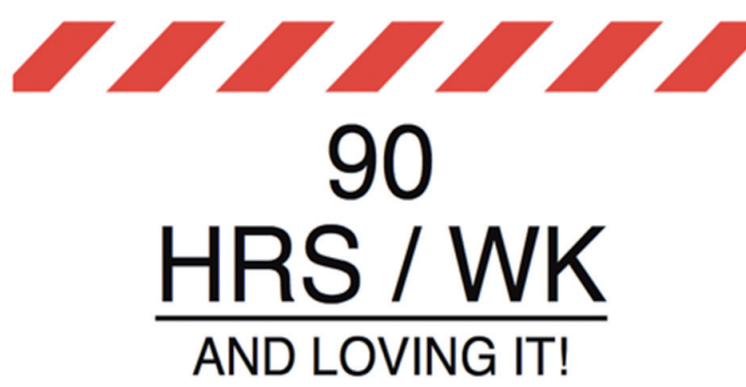

Fig. 17
Al haber sido suficientemente reseñado en el capítulo anterior, nos limitaremos a recordar que este encuentro ha resultado fundamental a la hora de aprender mediante la participación activa, la gestación y dinamización de un proceso de auto-encuesta circunscrito a un ámbito concreto de transformación política.

\subsubsection{Grupo de autoformación La Acera del Frente CSA Patio Maravillas, Ma-} drid, julio de 2010 - http://www.aceradelfrente.blogspot.com.es/

Acera del Frente es un colectivo que surge con el objetivo de luchar por derechos de las personas LTGB integrado en un nuevo espacio de lucha política autogestionado como es el Patio Maravillas. Pretende aunar un trabajo político radical de izquierdas, con una experiencia de transformación propia como individuos, creando un nuevo punto de encuentro LTGB, con una propuesta diferente que converja de modo transversal con el resto de movimientos sociales con carácter independiente y disidente.

En junio de 2010 asistimos en el Patio Maravillas a la cuarta sesión del ciclo de reflexiones teórico-políticas de la Acera del Frente llamada Interseccionalidad, transmaricasbollos, extranjeros y precarios, en la que se abordaron asuntos como el paso de la doble discriminación a la discriminación múltiple,

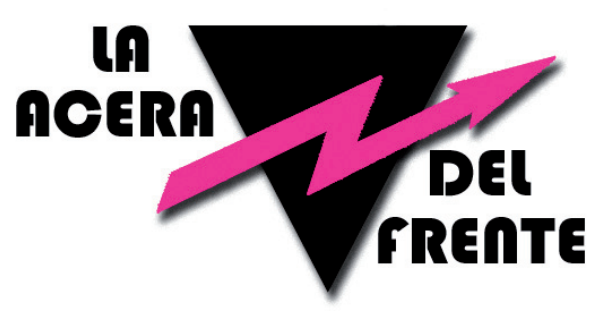
por cuestiones de nacionalidad, género y estatuto laboral que combina el miedo al inmigrante, la homofobia, el exilio político y la precarización. Un taller planteado como espacio transversal en el que llevar a cabo de forma conjunta una revisión autocrítica de las políticas 
del cuerpo y el espacio en los movimientos sociales contrastadas con las vivencias personales de aquellos que estaban participando. Lo que resulta interesante de este grupo es que alejado de todo propósito académico parte de un interés por entender y superar la posición subalterna causada por los motivos anteriormente enunciados.

\subsubsection{Grundtvig Life Learning Programme - Ateliers d'Art Contem- porain, Lieja, (Bélgica), noviembre 2010}

Taller de formación de formadores Active Principles of Art becado por la Comisión Europea dentro del Programa de Aprendizaje Permanente (PAP) de la Unión Europea. El programa Grundtvig atiende a las necesidades de enseñanza y aprendizaje de los participantes en todas las formas de educación de personas adultas, así como de los centros y organizaciones que imparten o facilitan

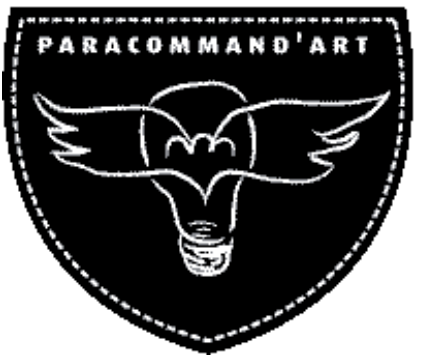
esa educación.

Esta convocatoria, dentro de la estructura de los Ateliers d'Art Contemporain, estaba organizada por los Paracommand'art. Este grupo belga se define como una organización, una oficina de asesoría alternativa y una editorial cuyo punto de partida es la proposición de sus competencias incompletas. Organizan exposiciones, talleres, seminarios de formación y producción, intentando vincular personas, disciplinas e instituciones ajenas entre sí, agrupándolas en torno a preguntas sin respuesta como la cuestión de los flujos migrantes, el medio ambiente, el exceso de población o el amor. En concreto, su filosofía gira en torno a tres cuestiones fundamentales: ¿Quiénes somos nosotros cuando estamos juntos? ¿Cómo podemos activar economías alternativas? y ¿cómo podemos protegernos ante los criterios de censura y autocensura? Conforman un equipo cuyo objetivo es el "despertar político" mediante la aplicación de los principios activos del arte y trabajan con jóvenes parados, migrantes en centros de acogida, jóvenes de barriadas en dificultad, en centros de detención. Mediante el uso de la escritura, la danza, la música, la fotografía y el vídeo, establecen contratos con instituciones públicas para hacer exposiciones de las obras resultantes en centros de prestigio o publicaciones de libros de nivel.

De este taller, resultó especialmente interesante poder aprender metodologías participativas que puedan tener un alcance político, sin caer en lo asistencial, en la medida en que permiten hacer un trabajo de contacto con grupos que coinciden con uno o varios de los perfiles que habíamos considerado como grupos con potencial político de cambio. 


\subsubsection{Commoniversity - Noviembre 2010 -}

http://commoniversity.wordpress.com/

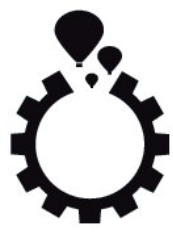

\section{Making Politics with Knowledge \\ 25th - 26th - 27th November 2010 \\ Barcelona}

Fig. 20

Como en el caso de Para quienes disfrutamos trabajando, ya hemos reseñado este encuentro en el capítulo anterior, por lo que nos limitaremos a recordar que ha resultado fundamental a la hora de conocer el funcionamiento de modelos de universidad críticos y comprometidos políticamente así como de plataformas transnacionales en entornos virtuales.

6.2.10 Estética y política, grupo de investigación de la Universidad Politécnica de Valencia 2010-2012, http://cep.webs.upv.es/

Fig. 21

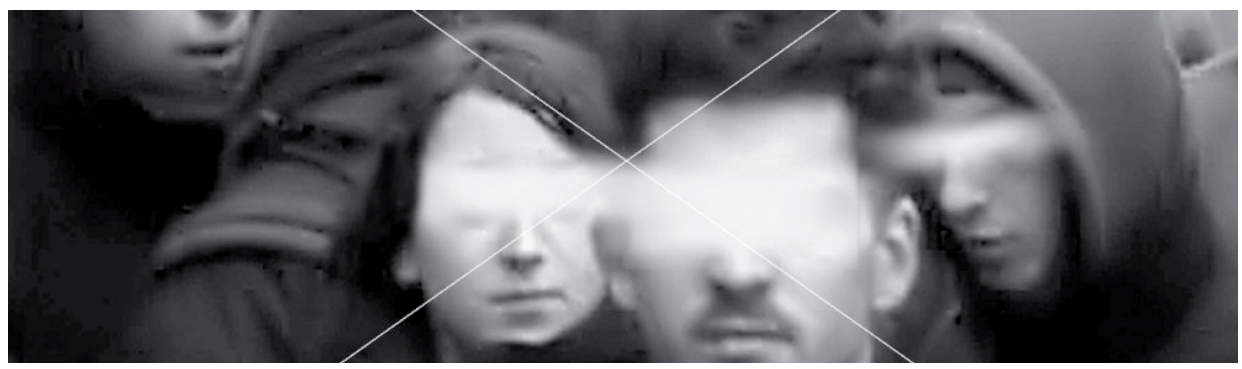

Seminario interdepartamental en el que participamos desde su constitución hace dos años, que versa sobre las relaciones entre arte, política y representación. Si bien es un seminario que se encuadra en un ámbito claramente académico, su estructura orgánica no sometida a ningún modelo preestablecido, surgida porque un grupo de gente teníamos ganas de investigar en un cruce de disciplinas, la sitúa en un espacio intersticial. Hemos trabajado desde la violencia y su representación hasta la condición política del arte a través de una serie de reuniones informales en las que comentábamos textos de autores como Jean-Luc Nancy, Jacques Rancière o Hal Foster o visionábamos conjuntamente obras de Alfred Jaar o películas como la Shoah de Lazmann. Indagamos sobre lo que vemos y lo que podemos decir al respecto, sobre quién tiene la competencia para ver y la 
cualidad para decir, sobre la distribución y redistribución de lugares e identidades, las divisiones y redivisiones de espacios y tiempos que constituyen lo que Rancière llama la distribución de lo sensible. Como fruto de este seminario, podemos nombrar una primera edición del Congreso Internacional de Estética y Política que comentaremos más adelante, así como la preparación en curso de una segunda edición del congreso que versa sobre el pensamiento de Jean-Luc Nancy.

Paralelamente a todo este proceso de formación, podemos decir que en todos los proyectos en los que hemos estado presentes como organizadoras desde Autoformato y desde LaCIV, también nos hemos ido formando en multitud de aspectos, aprovechando los talleres que organizábamos para formarnos previamente y durante los seminarios en sí, en temas que nos parecen fundamentales hoy día. De la misma manera, nos hemos beneficiado de los talleres y seminarios organizados por nuestros compañeros de colectivo que quedaban aún más distantes de nuestras propias disciplinas por lo que aún fueron más enriquecedores, como el taller jurídico en torno a la masovería o tantos otros conceptos y prácticas que hemos aprendido a fuerza de convivir, participar, observar y debatir.

Como podemos ver claramente en la línea de tiempos, hubo un período muy intenso de autoformación asociado a la investigación de la tesis en el que nos desplazamos para asistir a encuentros en los que bajo diferentes formas, seminarios, jornadas, simposios, sesiones de reflexión, etc., en espacios más o menos formalizados, más o menos politizados, se llevaban a cabo actividades de formación conjunta orientada a la transformación social. Para intentar aprehender sus similitudes y diferencias, además de participar en los encuentros, procuramos comprender las líneas estratégicas básicas de cada proyecto a través de sus antecedentes, trayectoria, desarrollo y situación actual. Del mismo modo, intentamos elucidar las hipótesis de trabajo que los diagnósticos propios sobre el contexto hubieran propiciado.

Nos pareció igualmente importante conocer las modalidades posibles de articulación de cada proyecto con propuestas políticas así como con otros movimientos europeos. Como indicamos en las entrevistas, otros aspectos que nos parecieron importantes fueron las estrategias de reapropiación de recursos y la relación con las Administraciones públicas. Por todo ello, en resumen, este aprendizaje nos ha resultado fundamental para poder sistematizar un modelo de autoformación versátil, adaptándolo a cada una de las circunstancias diferentes en las que lo hemos planteado en nuestro ámbito de acción. 


\section{PRODUCCIÓN AUTOFORMATIVA Individual/BD/Autoformato/LaCIV}
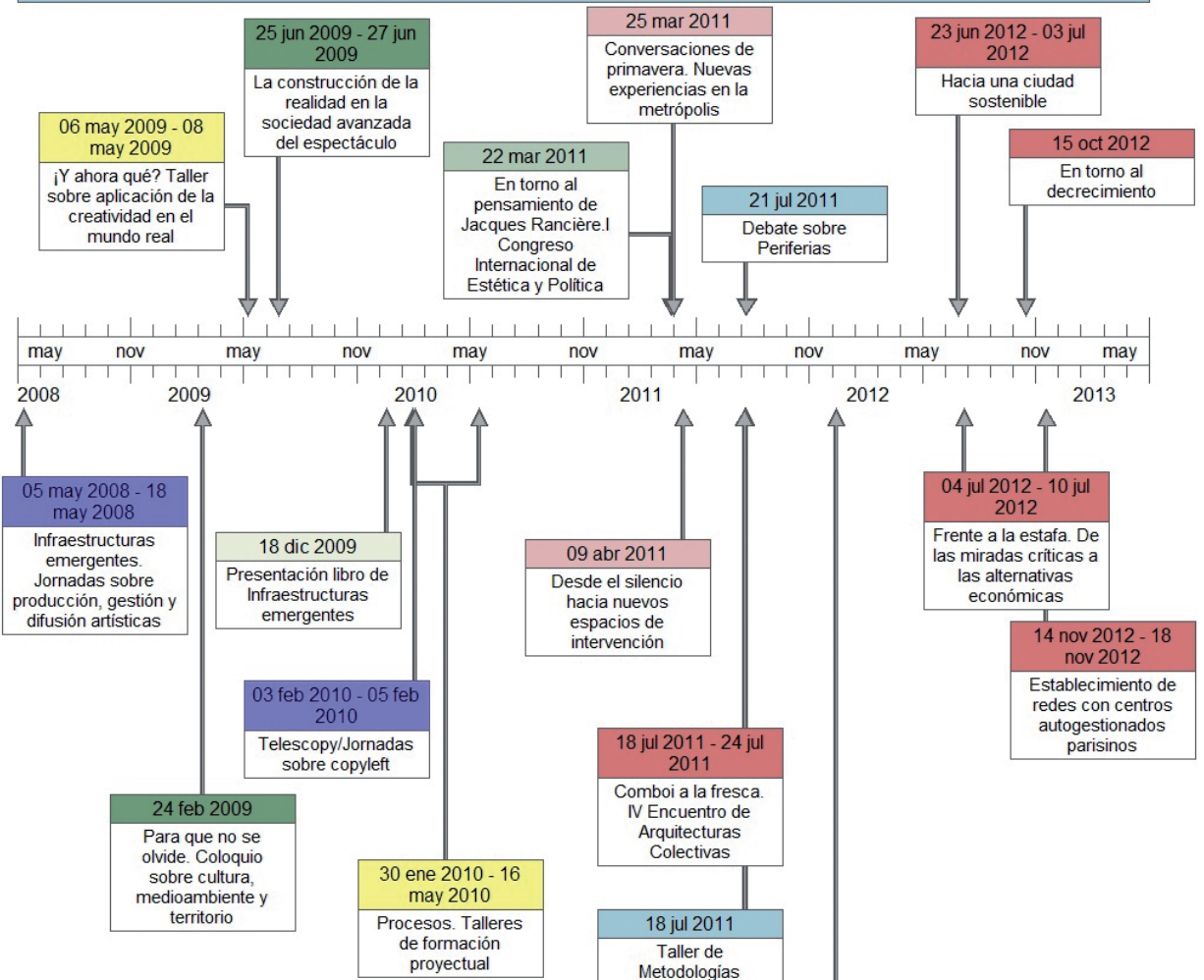

09 abr 2011

Desde el silencio

hacia nuevos

espacios de

intervención

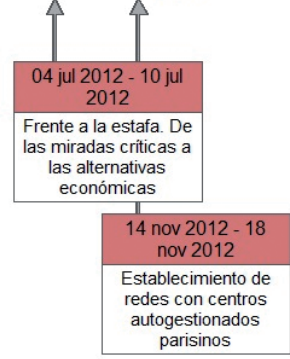

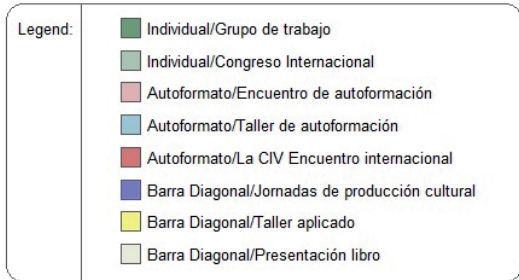

\begin{tabular}{|c|}
\hline 24 feb 2009 \\
\hline Para que no se \\
olvide. Coloquio \\
sobre cultura, \\
medioambiente y \\
territorio \\
\hline
\end{tabular}
obre copyleft

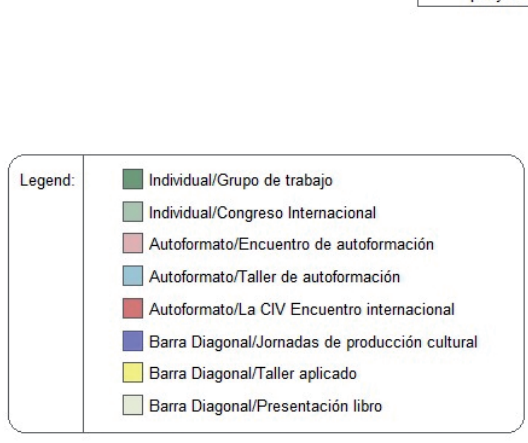

19 jul 2011

Debate sobre agroecología 


\subsection{Producción autoformativa}

Durante el período inicial de 2008 a 2010, se desarrolla la práctica ya declinada del colectivo Barra Diagonal que no repetiremos, orientada fundamentalmente a la producción cultural. Tras la experiencia positiva de trabajo en grupo que fue Para los que disfrutamos trabajando, aún heredera de la producción cultural y realizada en nombre de Barra Diagonal, se trataba de buscar el marco general de operaciones para poder aplicar todo lo que hasta ese momento llevábamos asimilado y que nos había ido situando definitivamente en ese territorio extraño en el que parecía encontrarse cada vez más a menudo tanto el arte como la producción cultural. ¿Cómo trasladar a la ciudad de Valencia unos modos de hacer que correspondían a otros parámetros?

El ámbito de intervención que nos propusimos desde el principio era bastante incierto a la hora de plantear y enraizar alternativas similares a las estudiadas en el proceso de investigación previo por una multitud de factores que pasaremos a enumerar. Por una parte, la ciudad de Valencia había quedado anclada en un modelo de antagonismo crítico propio de los años 90 . Seguía existiendo un movimiento de ocupación y creación de centros sociales posicionados en la marginalidad por una confluencia de voluntad propia y ausencia de sinergias con otros movimientos sociales. Por otra, la enorme distancia que desde las instituciones, se imponía en todos los terrenos, mucho mayor que en otras áreas en donde formaciones políticas menos radicales o menos cronificadas, permitían un trasvase de intereses, medios y espacios.

Uno de los parámetros que elegimos para hacerlo al considerarlo fundamental era trabajar en el propio territorio, aún vinculándose a redes de trabajo de diversa extensión que lo superaran. Un primer movimiento hacia ese objetivo fue la creación del colectivo Autoformato, con su modo propio de operar. Pero antes de pasar a una de las formaciones colectivas clave en nuestras propias prácticas, preferimos repasar brevemente el trabajo de producción en solitario o desde la academia que hemos realizado además de la producción cultural ya nombrada desde Barra Diagonal.

\section{Perifèries 2007, Territori GPS versus Lloc sense ruta, Hotel Chamarel, Denia, junio 2007}

En 2007, iniciamos la colaboración con Rafa Tormo en torno a PERIFèRIES ${ }^{182}$, su encuentro de reflexión y pensamiento en torno a la cultura contemporánea. La primera edición tuvo lugar en Denia y si bien en ella únicamente expusimos una

182. http://www.deja-vou.com/periferies07/PeriferiesValencia.pdf 


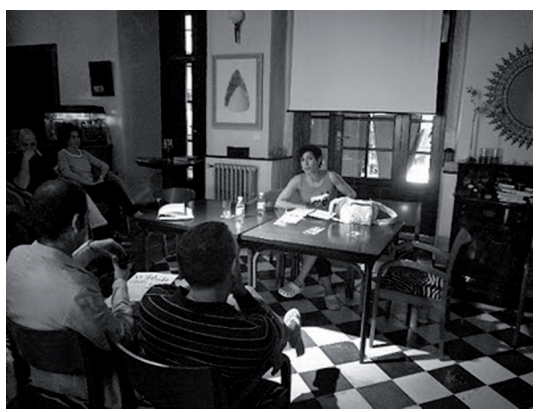

obra (Territoriocupat) y dimos una conferencia sobre nuestro trabajo activista con el colectivo Guerra Mítica ${ }^{183}$, pudimos establecer un vínculo que nos permitió colaborar de forma más estrecha en la siguiente edición de 2009 en Valencia así como conocer a colectivos y artistas que utilizaban prácticas de intervención similares a las nuestras.

Para que no se olvide. Coloquio sobre cultura, medioambiente y territorio, Ubik Café, febrero de 2009

\section{Para que no se olvide}

Coloquio sobre cultura, medioambiente y territorio

a propósito de la reciente presentación de los libros

Terra Crítica 2001-2007 $y$

Arte, cultura e impostura

Participan: José Albelda, Álvaro de los Ángeles, María Diago y Domingo mestre. Modera Mijo Miquel

Aprovechando la presentación de dos libros: Terra crítica 2001-2007, que recoge todos los artículos sobre territorio y medioambiente escritos por el colectivo Terra Crítica compuesto por diferentes profesionales del ámbito de la arquitectura, la sociología y la ecología; así como del libro sobre el panorama cultural valenciano Arte, cultura e impostura, hicimos de moderadoras en un coloquio abierto en el que se evidenció que tanto el tratamiento que se estaba dando en nuestra Comunidad en el ámbito de la cultura como en el del territorio, procedía de una aplicación común de criterios de beneficio y consumo a corto plazo destructora de tanto los ecosistemas naturales como los culturales. Introdujimos en nuestro quehacer como productoras culturales, las nociones de ecología y decrecimiento que ya nunca nos abandonarán ya que pasarán a formar parte del enfoque general en relación al ecosistema que va más allá de su acepción más restringida para abarcar relaciones de producción, criterios de legitimación y demás pautas culturales.

183. Para mayor información, MIQUEL, Mijo. "Guerra Mítica: la escultura como evento mediático", en / Congreso Internacional de Nuevos Procedimientos Escultóricos, editado por la Universidad Politécnica de Valencia, Valencia, 2002. 
Perifèries 2009 - Cercant la realitat amb la veu d'un nosaltres, Octubre CCC, Valencia, junio 2009

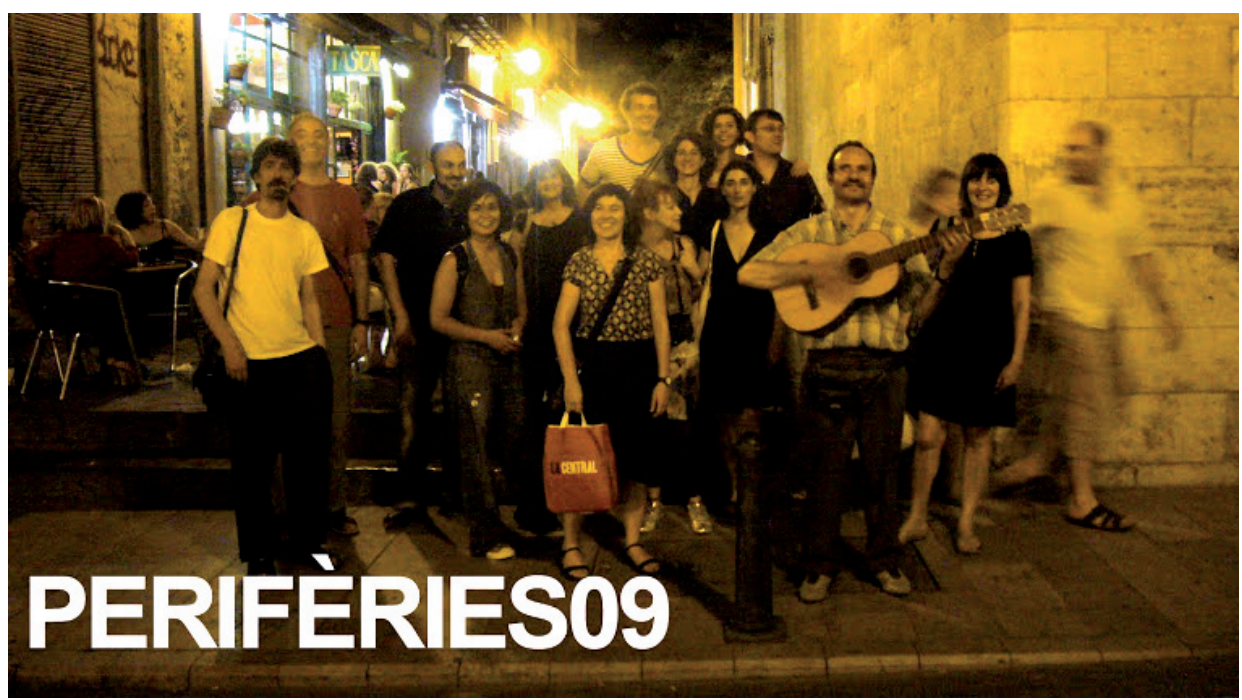

Este encuentro estaba organizado en torno a dos nociones, la construcción de un nosotros posible y la condición real de la realidad. Se estructuró a partir de dos conferencias al respecto de Marina Garcés y Miguel Ángel HernándezNavarro. Paralelamente, se había organizado una muestra de intervenciones por el casco antiguo de Valencia y unos talleres en torno a la creación de comunidad. En este encuentro, actuamos como coordinadoras en la organización general, pero también de forma específica en la planificación de un grupo de trabajo sobre La construcción de la realidad en la sociedad avanzada del espectáculo e invitamos a participar en él a los colectivos La Xarito ${ }^{184}$, Desayuno con viandantes ${ }^{185}$ y la revista Bostezo ${ }^{186}$.

Para comentar este grupo de trabajo, reproducimos parcialmente a continuación el texto que redactamos para la edición del libro de Perifèries09 187:

Un grupo de trabajo como este tiene la esperanza de poder generar dudas a partir de la puesta en común de un estado de cosas en el que las instancias constructoras de esa misma realidad, muchas veces, se encuentran tremendamente distantes de nuestra experiencia cotidiana y sin embargo, se imponen con sorprendente facilidad, a

184. http://www.laxarito.net

185. http://www.desayunoconviandantes.com

186. http://www.revistabostezo.com

187. PERIFÈRIES09. Cercant la realitat amb la veu d'un nosaltres, coordinado por TORMO, Rafael, Ed. UPV, Valencia, 2010. 
contrapelo. Por ello, estamos de acuerdo con la gente de Espai en blanc cuando define los grupos de trabajo como dispositivos capaces de establecer conexiones inéditas entre puntos o nódulos de resistencia, dispuestos a interferir o bloquear el régimen del capital pero aislados entre sí por agujeros estructurales. Pensamos que las periferias, en su marginalidad anónima, pueden servir para trazar con hilo un camino leve entre esos vacíos y ese fue el propósito que nos guió para juntar a tres grupos que funcionan tejiendo realidades más allá del hegemónico parecer de los relatos oficiales.

En un momento en el que la construcción, no de una realidad hegemónicamente compartida, sino de una realidad comunitariamente construida pasa porque se dé el lugar, Desayuno con Viandantes elige la cotidianeidad del café con leche para hacer real el uso compartido del espacio urbano y hacerlo fácil. Articulado o no con otros agentes dinamizadores de la ciudad como Masa Crítica, Portes Obertes o València Escena Oberta, despliega sus manteles en cualquier lugar que considere amenazado de olvido en su uso público, invadido por otros usos, o simplemente agradable de compartir entre croissants y palabras, proponiendo un desayuno comunitario mensual al que cualquiera puede sumarse. La Xarito, por su parte, genera un festival nómada, La Impropia, sobre la relación entre la cultura libre y la cultura popular, que pasa por encima de las pre-ideas del vínculo y la historia, sorteando con acierto los escollos del nacionalismo y las banderas de los parroquianos para conectarlos con las nuevas tecnologías, aprovechando la costumbre instituida del sermón conjunto o de la traca ritualizada. De esta manera, enlaza tradición e innovación permitiendo dar el salto de la cultura popular a la cultura libre sin renunciar a lo propio y menos aún a lo impropio.

Por su parte, Bostezo, la revista crítica que se critica sin provocar somnolencias, intenta reflejar el disenso dentro de lo políticamente correcto, de lo acartonadamente enfilado al bienestar y el progreso, buscando un ejercicio permanente de análisis que no sea deudor de posicionamientos con servidumbres supuestas. Bostezo, según Bostezo, es un proyecto que se ha concretado en una publicación pero que hubiera podido convertirse en un bar o en cualquier otra cosa, y eso ya es indicio de lo inusual de la propuesta. Todos ellos colectivos no ligados a ninguna institución y sin la voluntad de convertirse en tal, desarrollando acciones y prácticas culturales de transmisión directa que no son privativas de nadie y por lo tanto, permiten la pertenencia de cualquiera que así los sienta. Colectivos pues muchas veces anónimos, cambiantes, abiertos... en la época de las multitudes difusas, no está de más escuchar lo que se cuenta sin espacio y lo que se hace sin nombre, no fuera a ser que de ahí acabará por salir un sentido cualquiera.

De esta colaboración surgieron alianzas potentes pues el representante de La Xarito, Lluis Benlloch, se unirá a nosotras para fundar Autoformato y el representante de Desayuno con Viandantes, David Estal, no dejará de colaborar con nosotras desde ese momento en numerosos proyectos hasta el punto de integrarse, junto con el primero y otro pequeño grupo, en el colectivo actual de LaCIV. 
I Congreso Internacional de Estética y Política, En torno al pensamiento de Jacques Rancière - marzo de 2011

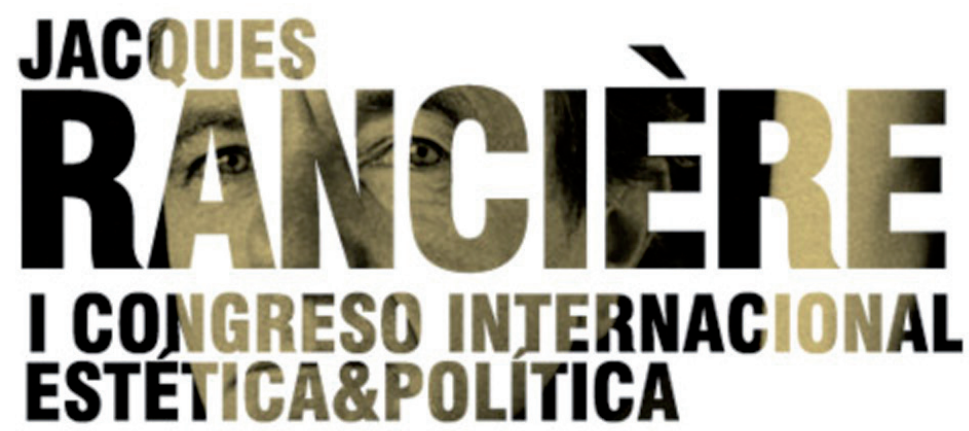

Como hemos dicho, desde el seminario de investigación interdepartamental sobre Estética y política, organizamos un primer congreso en torno al pensamiento de Jacques Rancière, contando con la presencia del filósofo. Este I Congreso de Estética y Política pretendió abordar diversos aspectos de la obra del filósofo francés como la relación entre literatura e historia y la idea de una poética de la historia, la paradójica relación de nuestra sociedad con la representación de lo real, entre el exceso de imágenes y la ausencia de las mismas; las condiciones para pensar el cine políticamente o las formas en que el arte contemporáneo abre espacios para la redistribución del poder.

El programa académico de las jornadas se organizó en dos bloques: por una parte, la ponencia inaugural a cargo de Rancière y la exposición de las ponencias encargadas a algunos de los más importantes especialistas en su obra; por otra, la presentación de las ponencias seleccionadas por el comité científico. Como acto de clausura se organizó una mesa redonda en la que participó Rancière y los ponentes invitados. Como se puede observar, más allá del hecho de formar parte del comité organizador del congreso, o de la inevitable convergencia entre el pensamiento de Jacques Rancière y la temática de nuestra tesis, no consideramos especialmente pertinente para la misma este Congreso puesto que el modelo propuesto de investigación y puesta en común se ajustó a lo que normalmente se viene entendiendo como tal. Habló el maestro ignorante, le siguieron los más importantes especialistas de su obra en un ejercicio de legitimación académica y por último, hablaron los rezagados que intentaban abrirse camino, aplicando al pie de la letra el protocolo esperado.

La única modificación que conseguimos introducir fue la realización del Congreso en el Institut Français de Valencia, situado en pleno centro histórico y que ofrecía mayor accesibilidad y cercanía a aquellos que no estaban directamente implicados en la estructura universitaria, al mismo tiempo que facilitaba una relación 
más continua entre sesiones de trabajo y espacios de socialización (comidas, paseos, celebraciones nocturnas, etc.) ya que, en caso de que se hubiera celebrado en la Universidad Politécnica, hubiera dispersado inmediatamente a los ponentes y asistentes limitando el intercambio en un espacio totalmente formalizado, con sus normas y exclusiones, con sus ritos y sus medallas.

Independientemente de ello, fue un congreso obviamente interesante, con la participación de numerosas cabezas privilegiadas del territorio español, realizando un compendio de intervenciones que enmarcaban y prolongaban el pensamiento de Rancière en la actualidad, pero careció de conexión con metodologías innovadoras y movimientos sociales, situando al propio Rancière en una especie de paradoja filosófica de difícil resolución.

Tras haber comentado el proceso que nos fue llevando, a raíz del trabajo paralelo con movimientos sociales e instituciones académicas, a la constitución de un colectivo centrado en la autoformación, pasaremos a continuación, a enumerar y comentar el trabajo de producción autoformativa realizado desde dicho colectivo denominado Autoformato, que ha centralizado gran parte de las prácticas de producción que hemos realizado durante los tres últimos años y que, en cierto modo, justifica toda la investigación previa al respecto ya que supone su puesta en práctica.

\subsection{Autoformato}

www.autoformato.wordpress.com

Fig. 26
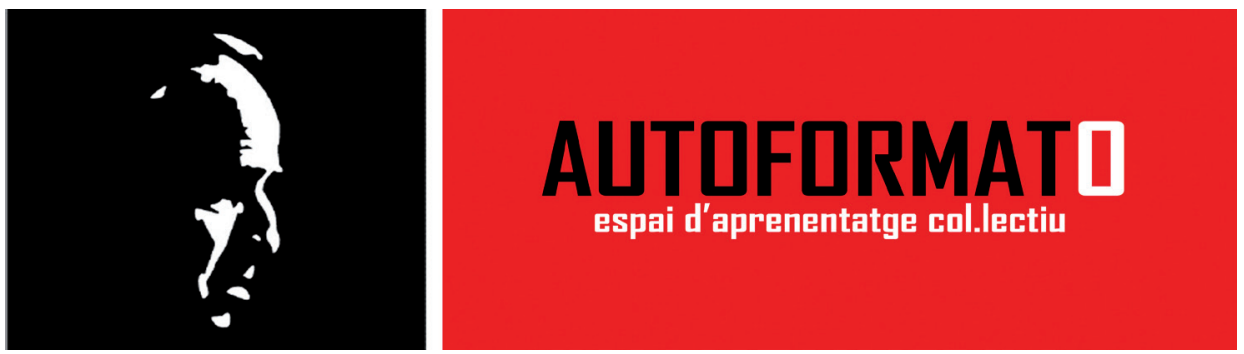

Autoformato (LLuis Benlloch y Mijo Miquel) nace en Valencia en noviembre de 2010 tratando de dar respuesta a las necesidades de autoformación y de aprendizaje colectivo percibidas por diversas personas vinculadas a movimientos y luchas sociales de la ciudad.

Desde entonces, nos configuramos como un espacio de autoformación, esto es, de aprendizaje, producción y divulgación de nuevos saberes anclados en las prácticas políticas de las que participan sus miembros. Por tanto, hemos tratado de configurar y articular momentos de aprendizaje colectivo y producción de 
saberes en las experiencias sociopolíticas de los movimientos de base del territorio, de donde surgimos y por los que nos dejamos impregnar. Para todo ello, hacemos uso de investigaciones, tanto de carácter académico como militantes, con el fin de enriquecer las narraciones e imaginarios de la transformación social.

Un factor clave para entender el nacimiento del colectivo es el análisis compartido de que Valencia se estaba quedando al margen de los nuevos discursos y prácticas políticas de los movimientos sociales. Aquellas nociones que absorbíamos tanto en la teoría como en la práctica en otros lugares y que nos parecían fundamentales para afrontar la coyuntura actual, no las encontrábamos difundidas en ningún espacio de nuestro propio territorio y si lo hacían, era de forma puntual, sin articular un repertorio de saberes militantes que generase nuevos discursos en el seno de las experiencias políticas, como un movimiento fuerte que pretendiera actuar en diferentes frentes de forma conjunta. El contexto valenciano parecía quedar al margen de dichos circuitos de producción de conocimiento, en un marco, además, de desaparición de instituciones culturales y académicas encargadas de la difusión y producción de análisis críticos y narrativas contrahegemónicas.

Desde un primer momento, establecimos una línea de trabajo en torno al análisis metropolitano de Valencia, centrándonos en los principales procesos y experiencias que la configuran. Fijamos la mirada en la extensión de los procesos de gentrificación y conflicto en la ciudad, así como en las políticas neoliberales que los sustentan y animan. Desde Autoformato, intentamos profundizar en nuevas maneras de mirar y vivir el territorio: pensar y repensarse desde otros conceptos para conformar nuestras praxis personales y colectivas. Buscamos llevar a cabo proyectos de autoformación convergente en las siguientes temáticas: migración, gentrificación, procomún, autonomía, prácticas instituyentes, procesos de empoderamiento en las metrópolis, economías críticas, sexualidades disidentes. Mediante la realización de seminarios previos en red con otros grupos de autoformación del resto de España como Traficantes de Sueños, Arquitecturas Colectivas o Tramalloll, preparamos encuentros de puesta en común e intercambio sobre nociones que cubren carencias en nuestras propias prácticas.

Para ello, tratamos de ir perfilando una metodología propia para los seminarios que organizamos, fruto del aprendizaje de los ya realizados, así como de experiencias similares de otros colectivos en las que hemos participado. Nuestra preocupación central es poder integrar los análisis y propuestas de cada invitado en nuestras problemáticas cotidianas, poniéndolos en relación con experiencias prácticas, a la vez que aseguramos un debate posterior a la intervención que siga un modelo lo más horizontal y enriquecedor posible. Apostamos por realizar varias sesiones previas de análisis de textos de los ponentes que vayan a acudir al seminario, para poder aprehender en mayor medida las teorías, conceptos y análisis que proponga cada autor/a. Éste es el momento en que podemos expresarnos y debatir tranquilamente, profundizando 
en nuestras dudas y aplicaciones a nuestra realidad de todo ello y reflexionando sobre en qué medida nos resulta pertinente y/o perturbador, hasta qué punto cuestiona nuestras creencias y nos lleva a transformaciones en nuestras prácticas.

Posteriormente, con la presencia de todos los participantes, se producirá el momento de "carnalización" del diálogo, en el que los cuerpos coinciden en un espacio físico y continúan un diálogo mental ya iniciado en el que todos los participantes intervienen desde una igualdad de capacidades, o porque a través del estudio se hayan igualado conocimientos sino porque el conocimiento aportado desde las prácticas, referente a pragmáticas y emociones así como a abstracciones deductivas es tan necesario y valioso para el teórico como las reflexiones externas lo son para los que nos orientamos a las prácticas transformadoras.

Otra de las preocupaciones que influye en la concepción de los seminarios es poder hacerlos extensibles a las personas que no pueden estar físicamente presentes. De ahí que, como ya ocurrió en el encuentro de "Conversaciones de primavera" (vid Memoria de actividades), se intenta que las sesiones sean retransmitidas vía streaming, con lo que, consecuentemente, se puede garantizar un mayor dinamismo en el debate al contar con la participación del público a través de la red. Nuestra aspiración es que tanto los vídeos como la transcripción de las intervenciones estén alojados en nuestra web, articulando una mayor multiplicación de resultados del seminario. A continuación, incluimos una memoria de actividades que permitirá observar con mayor detalle las metodologías utilizadas, el abanico de asuntos tratados que, efectivamente, se relacionan de forma directa con la metrópolis y sus transformaciones actuales, así como el esfuerzo de dinamización y el nivel de autoexplotación que asumimos ya que partíamos siempre de un presupuesto cero.

\section{MEMORIA DE ACTIVIDADES}

\section{Conversaciones de primavera. Nuevas experiencias en la metrópolis 25 de marzo de 2011 - Octubre CCC}

Conversaciones de Primavera. Nuevas experiencias en las metrópolis establece un espacio de debate en torno a cuestiones que afectan directamente a la metrópolis y las experiencias que en ella tienen lugar. Con esto en mente, a lo largo de este primer seminario, se debatió en torno una serie de enfoques bastante fértiles: desde la noción de "los sin parte" de Jacques Rancière hasta las nuevas formulaciones del anonimato, vinculándolos a las experiencias prácticas que, desde diferentes colectivos, se están llevando a cabo en la actualidad. El proceso se inició con los seminarios de autoformación en torno al pensamiento de Rancière que se llevaron a cabo previamente en el seno de los colectivos de la manera que hemos descrito anteriormente, y culminó en la sesión de intercambio 
de pareceres en directo en el mismo Octubre CCC. En este encuentro, contamos no sólo con la presencia del filósofo francés sino también con la presencia y participación de Marina Garcés, del colectivo Espai en Blanc ${ }^{188}$, así como de Débora Ávila de Ferrocarril Clandestino ${ }^{189}$, que intervinieron planteando el proceso que va de la invisibilidad a la fuerza del anonimato.

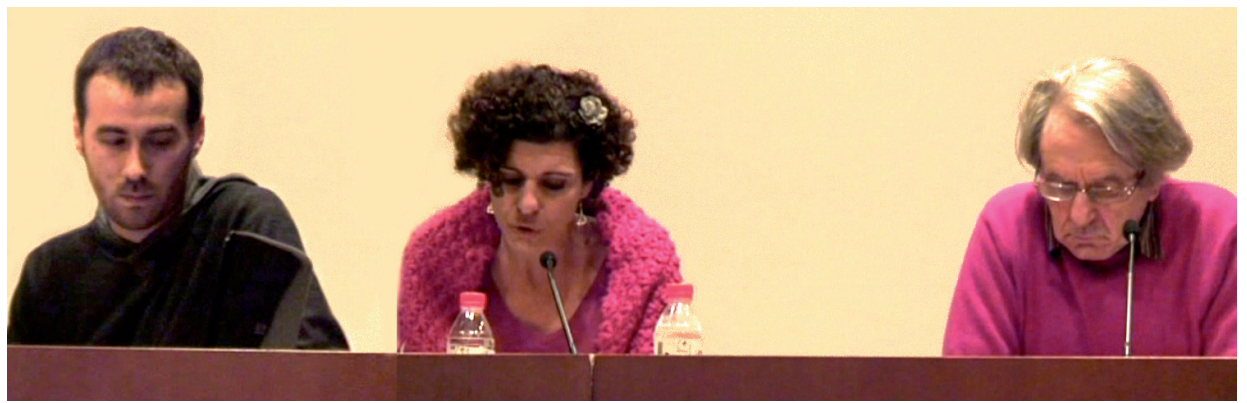

No fue casual que ambas sean mujeres ya que pretendemos desde Autoformato trabajar también en la transformación de un imaginario intelectual que muy a menudo borra la presencia femenina en el momento en que hay que elegir portavoces y que rara vez le concede un protagonismo central en el ámbito de la cultura. Al respecto, debemos reconocer que más de una vez nos hemos sonrojado al comprobar que, en nuestras propias prácticas, venía sucediendo un posicionamiento similar, "casi sin darnos cuenta", y que, cuando pensábamos en personas que pudieran impulsar nuestros procesos de autoformación, nos remitíamos fundamentalmente a miembros del sexo masculino, en un ejercicio claro de reforzamiento bidireccional de visibilidades, y no porque no hubieran mujeres igualmente interesantes sino porque lo que "nos venía a la cabeza" eran hombres.

Por tanto, a partir del momento en que fuimos más conscientes de ello, hemos procurado ser especialmente cuidadosas en este aspecto, no por cuestión de cuotas o mecanismos de representatividad políticamente correctos, sino porque creemos, efectivamente, que el punto de vista femenino en estos momentos de crisis, resulta especialmente pertinente aunque sólo sea porque nos hemos visto relegadas ( $\mathrm{y}$ hemos disfrutado) al territorio de los afectos y los cuidados durante muchos siglos.

Volviendo a la convocatoria en cuestión, el Ferrocarril Clandestino es una red de apoyo y acción en común entre españoles e inmigrantes. Parte de la idea de que la Ley de Extranjería española y, en general, la política migratoria europea, son injustas, porque niegan los derechos fundamentales a quienes migran y les colocan en situaciones de extrema vulnerabilidad. Busca crear un

188. http://www.espaienblanc.net/

189. http://www.ferrocarrilclandestino.net/ 
espacio ciudadano de apoyo entre autóctonos, inmigrantes sin papeles e inmigrantes con papeles para contrarrestar esa vulnerabilidad en el día a día, crear vínculos y entendimiento mutuo y construir alianzas contra las formas de segregación legal, laboral y social que se están creando en nuestras ciudades. Es decir, lleva a la práctica la diferencia fundamental entre ley y moral o, si queremos ponernos más certeros, entre política (como ejercicio de la policía) y ética. Cuestiona la condición moral de una ley injusta que parte de la desigualdad de los seres humanos por razones de nacimiento e intenta mediante la desobediencia civil y otras tantas metodologías activas, recuperar una práctica ética que equilibre un tanto la balanza a favor de los invisibles.

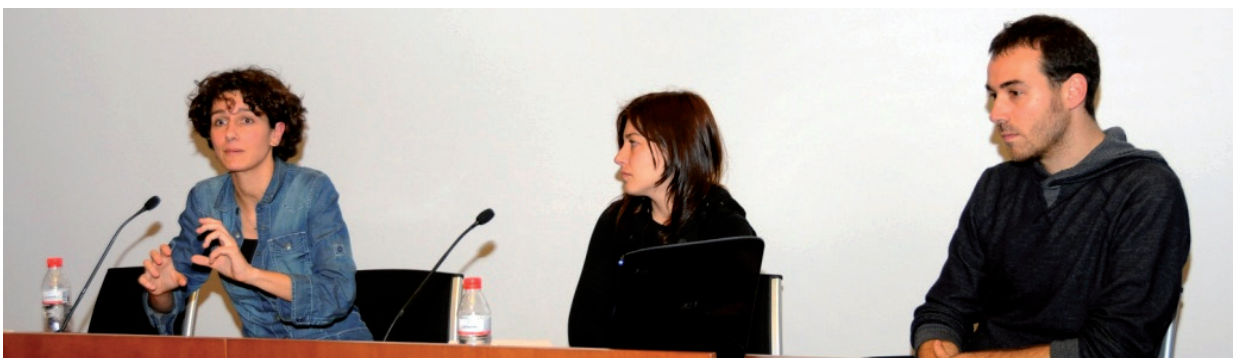

No obstante, este posicionamiento por parte de occidentales con papeles no deja de plantear toda una serie de incomodidades, cuestionamientos y complejidades en el quehacer cotidiano y eso, ese dejar emerger lo problemático de toda práctica, es lo que de verdad, a nuestro parecer, lo convierte, además de una práctica transformadora, en una investigación enriquecedora que no tapa por motivos académicos las zonas de quiebra e incertidumbre. Algunas de estas incomodidades remiten a su posible posición asistencial por lo que FC deja muy claro que se basa en la reciprocidad: no ofrece asistencia, sino una red de intercambio donde quien recibe ayuda un día puede ofrecerla al día siguiente. Aspira a hacer movimiento con todos aquellos, individuos o grupos, que, con independencia de su origen, sienten la urgencia de actuar frente a las formas cada vez más brutales de discriminación y arbitrariedad que está generando el régimen de fronteras externas e internas en nuestras metrópolis. Por todo ello, nos pareció un interlocutor excepcional a la hora de confrontar la visión de los "sin parte" filosófica con unas prácticas más que ancladas en la realidad.

Por su parte Espai en Blanc es "la apuesta colectiva de un grupo de personas que se proponen hacer de nuevo apasionante el pensamiento, es decir, abrir un agujero en la realidad que no se defina por lo que ya sabe sino por lo que no sabe". En sí, esta definición es una declaración de intenciones, sorprendente porque surge de la filosofía con la fuerza de la revolución, pero se justifica por su posicionamiento entre el activismo y la academia, el discurso y la acción, las ideas y la experimen- 
tación. Por eso, es una apuesta a la vez filosófica y política en la que el ejercicio del pensamiento no es una vía de escape ni un planteamiento utópico de la vida que vivimos, sino un reconocimiento de la posición inestable y sin redes en la que nos encontramos todos y un cuestionamiento directo del régimen del saber que exige como punto de partida un dejarse afectar por el mundo, sin el que no hay vínculo ni relación de afecto posible.

Comparte con Ferrocarril Clandestino su voluntad de escarbar justo en lo que nos resulta incómodo, en las paradojas y ocultaciones que todos hacemos con nuestras propias vidas cotidianamente para intentar que se ajusten a determinados ideales referidos a nuestras prácticas, para hacernos la vida posible, sencillamente. Pero lo hace con una intención política, de transformación y para ello utiliza términos como "el combate del pensamiento" para intentar entender la potencia de las nuevas respuestas colectivas. En este caso, aludiendo a su noción de la fuerza del anonimato, la manera que ha encontrado de nombrar esa comunidad basada en el rechazo de la que hablábamos en anteriores capítulos, planteándola como el reverso positivo de la invisibilidad evidenciada por Ferrocarril Clandestino.

Por todo ello, desde la posibilidad de confrontar las prácticas desarrolladas por estos movimientos sociales con las teorías filosóficas de Jacques Rancière, a través tanto de preguntas y cuestionamientos enviados previamente desde los colectivos, como de la interacción en el propio lugar del encuentro con el público presente y el conectado vía streaming, generamos un espacio de diálogo divergente de los cauces habituales de las academias. Este encuentro nos permite realizar una comparación entre el funcionamiento del Congreso de Estética y Política y las Conversaciones de primavera. Consideramos que en este segundo modelo, los grados de hibridación en cuanto a la temática interdisciplinar y el público no necesariamente especializado fueron mucho mayores y nos sumamos a la creencia del Ferrocarril Clandestino ${ }^{190}$ cuando enuncia que no hay acción política transformadora sin construir espacios mestizos.

En el congreso, la parte de los que pueden hablar estaba claramente delimitada: los expertos de la filosofía, desde su conocimiento teórico, enuncian las verdades y los demás las escuchan. Las grandes espadas pueden batirse puntualmente para hacer gala de conocimientos y reflejos, por la belleza del gesto. El público se limita a formular preguntas en torno a lo dicho, o como mucho, probablemente porque ha intervenido en el tercer bloque de aspirantes a, puede realizar alguna matización secundaria admisible. Quizás fuera del espacio de representación se permitan hablar bajándose de la tarima, comentando seriamente entre copa y copa o reconociendo que no hay maestro sin ignorancia pero ni siquiera eso podemos asegurar.

190. Véase Anexo II, El Ferrocarril Clandestino piensa con Jacques Rancière. 
Mientras que, en el segundo modelo de conversación, se propone un diálogo en términos de igualdad entre aquellos que están desarrollando prácticas trasformadoras simultáneamente a la teoría y aquellos que producen principalmente teoría como sería el caso de Rancière. Si acaso, por trabajar a ambos niveles, son los colectivos los que disponen de mayores recursos ya que necesitan contrastar obligatoriamente la teoría y la praxis en su deriva cotidiana. Por ello, nos parece remarcable la frase de Débora Ávila que aparece en su entrevista en relación a la noción de inclusión diferencial, indicando que en el Ferrocarril Clandestino crean los conceptos que necesitan para nombrar la realidad en la que viven y que pretenden transformar.

De hecho, si hay algo simbólico en el orden de intervención de la palabra, en el propio planteamiento del proyecto hemos invertido el sujeto inicial ya que, desde los colectivos, se le hace llegar al filósofo un texto (vid Anexo II) en el que se recogen las dudas surgidas a raíz de la confrontación entre las prácticas y la teoría filosófica, de manera que sean las prácticas las que orienten la conversación y no suceda siguiendo el modelo ilustrado. No vamos a decir, haciendo además una interpretación simplista del término, que el Anexo Il es un magnífico ejemplo de conocimiento vivo frente a un conocimiento académico muerto basado en la acumulación y no en la confrontación, pero si pudiéramos permitírnoslo, lo haríamos con mucho gusto retando a cualquiera que se sonría, a leerlo y opinar al respecto.

Este punto de partida invertido también marca un desarrollo diferencial en cuanto al nivel y variedad de la participación, abriendo la discusión a muchos otros frentes y disciplinas, saliendo del ritual para entrar en un diálogo a cuatro bandas como nuevo modelo ya no de transmisión, sino de intercambio de conocimientos. Eso no impide que se establezca una distancia entre aquellos que abren el turno de palabra y el público asistente ni disuelve de forma automática las inercias en la redistribución de los roles, obviamente, pero por lo menos no refuerza un estado de cosas con el que no pretende comulgar y lanza de forma consciente una propuesta alternativa.

Para terminar, dos apuntes más sobre este encuentro. Por una parte, la gratuidad del mismo frente al pago a tocateja de créditos en el Congreso, como corresponde a todo el montaje de la alta especialización siempre dependiente de la posesión de recursos. Por otra, el hecho de que este encuentro fue posible económicamente hablando (ya que desde Autoformato no poseemos ni fondos propios ni subvenciones), gracias al Congreso utilizando una táctica no de resistencia, sino de crecimiento, ya que vampirizamos en cierto modo la estructura financiera académica (que pagaba viajes y estancias a dos de nuestros participantes) para hacer posible un encuentro autogestionado en todos sus demás aspectos (puesto que nosotros aportábamos la organización, los seminarios previos, la difusión y la 
traducción, que no es poca cosa, pero lo hacíamos, como ya hemos especificado en la primera parte, guiándonos por la economía de los afectos, puro trueque místico entre amigos que se echan un logo, colegas que nos prestan el espacio, por no hablar de la autoexplotación que supone largas horas preparando textos, convocando reuniones, difundiendo resultados, traduciendo a pie de pista...).

\section{Desde el silencio hacia nuevos espacios de intervención -}

Espai de Crítica i Creació Contemporània de Sueca - 9 de abril de 2011 Biblioteca Joan Fuster (Sueca)

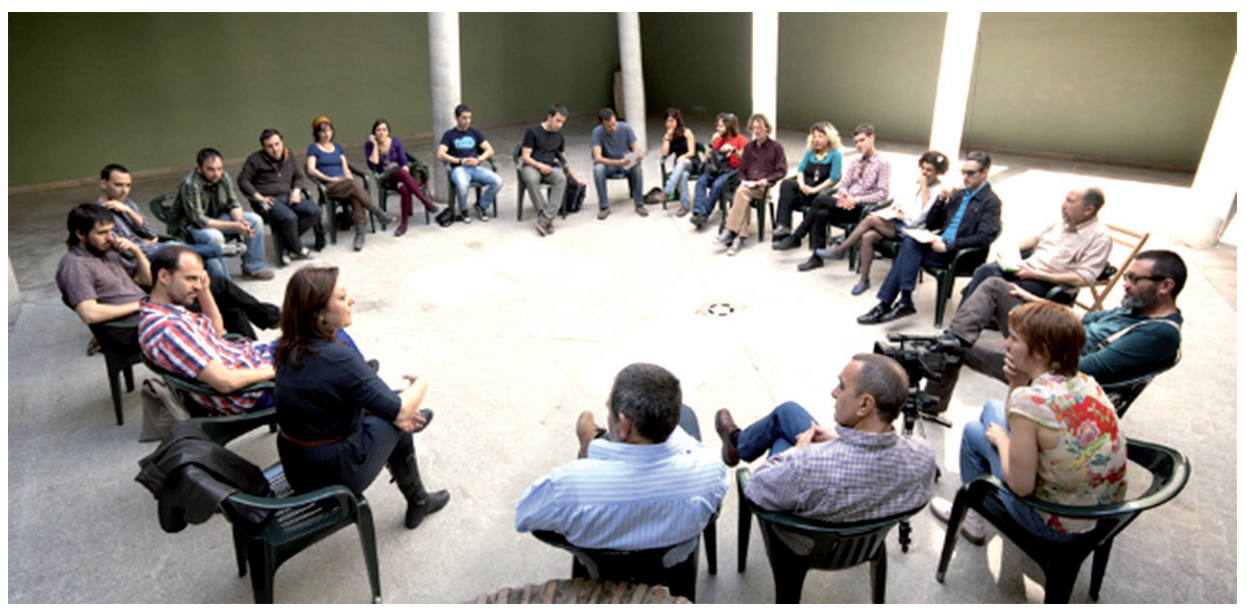

Dentro de las jornadas propuestas por el Espai de Crítica i Creació Contemporània de Sueca, participamos en la organización de una mesa redonda junto con Compartir Dona Gustet, AVCA, De Reull y La Herrería, con la intención de analizar los flujos de conocimiento local para vincularlos a problemáticas globales, uniendo cultura popular y el difuso entramado asociativo existente con el propósito de generar espacios comunes desde donde activar experiencias. Aprovechamos la ocasión para seguir tejiendo redes y conectando con diferentes realidades de nuestro territorio.

Paralelamente, al asistir a la ponencia que Javier Rodrigo de Transductores estaba dando en las mismas jornadas, le propusimos que colaborara con un proyecto que teníamos ya en marcha, Comboi a la fresca, en el que estábamos bloqueados en un punto concreto referente al uso de un solar privado/público en el que queríamos intervenir. Nos remitimos a la anécdota para mostrar de nuevo propuestas de colaboración y procesos de intercambio que van más allá de los colectivos o de los ámbitos de actuación y que superan la dialéctica público-privado tanto en lo referente a procesos de formación como a procesos de intervención. 
En este caso concreto, le ofrecíamos una conferencia remunerada y utilizable para currículum académico en la Escuela de Arquitectura a cambio de un taller interno entre los miembros del Comboi sobre sociogramas y aplicaciones de la teoría del Actor-Red de Bruno Latour al análisis local de espacios urbanos de participación, y que nos sirvió efectivamente, para desbloquear nuestras propuestas de intervención sobre ese solar en concreto, como luego veremos cuando describamos el proceso de transformación del Solar Corona.

\section{Comboi a la fresca - IV Encuentro de Arquitecturas Colectivas 2011 18-24 de julio de 2011 - Ciudad de Valencia}

Fig. 30

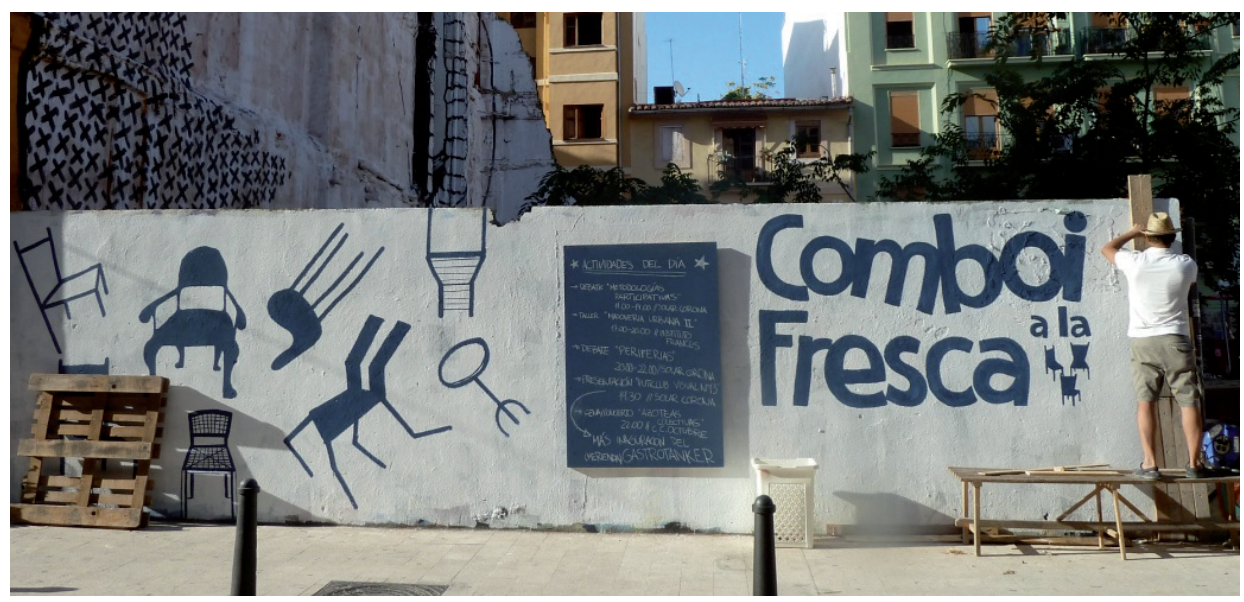

Con el lema Comboi a la fresca, Autoformato participó junto con una extensa red de colectivos de la ciudad en la preparación y realización del cuarto encuentro de Arquitecturas Colectivas, que tuvo lugar en Valencia durante la tercera semana de julio del 2011. Durante estos días, Valencia se convirtió en centro de acción y reflexión sobre la construcción participativa del entorno urbano. Con el objetivo de tejer redes, pensar y activar la ciudad, unos 60 colectivos de Valencia y otras ciudades participaron en este proceso de reflexión, acción, recuperación y gestión participativa del hábitat. Este proceso lo desarrollaremos ampliamente en el próximo apartado ya que aquí nos limitaremos a detallar la aportación concreta de Autoformato como colectivo participante y no la correspondiente a su participación como grupo organizador. En concreto, además de participar en la organización general del encuentro a todos sus efectos, Autoformato se implicó especialmente en la realización de talleres de autoformación, tratando de impulsar este eje en el seno del encuentro. Principalmente, preparó y dinamizó los siguientes talleres: 
a. Taller de Metodologías Participativas I: metodologías asamblearias [ Ana Sánchez Llorca + Autoformato + Asambleas 15M]-Solar Corona

\begin{abstract}
En este taller doble, tratamos de abordar las metodologías asamblearias y participativas en el seno de procesos colaborativos metropolitanos. En una primera fase, queríamos realizar una introducción teórica y puesta en común de metodologías asamblearias vinculadas a las demandas de autoformación de las asambleas de barrio $15 \mathrm{M}$. A raíz de la experiencia del $15 \mathrm{M}$,

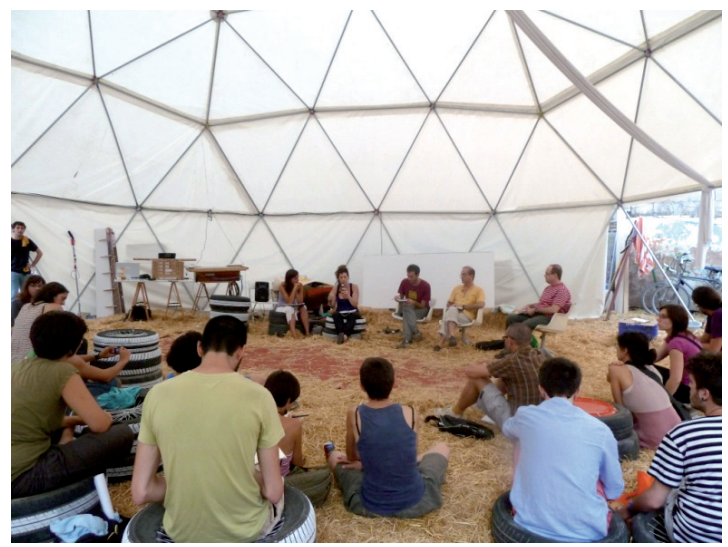
candente en ese momento, se profundizó en la micropolítica de los grupos y las formas de organización horizontales. Cabe tener en cuenta que los problemas acerca de cómo alcanzar consensos en grupos grandes era una necesidad acuciante en las asambleas del 15M por aquel entonces y lo sigue siendo en cualquier grupo de funcionamiento asambleario. Procuramos introducir la primera parte generando un diálogo previo, como en el caso de las Conversaciones de Primavera, con diferentes asambleas 15M, proponiéndoles que hicieran llegar sus necesidades y cuestionamientos a la ponente de forma previa a la realización del taller. A continuación, adjuntamos el correo que les hicimos llegar a través de la red de Asambleas 15M:
\end{abstract}

Desde la asociación de asociaciones y colectivos que se agrupa en el proyecto comboialafresca.arquitecturascolectivas.net, os queremos invitar a participar en un taller de metodologías asamblearias y procesos participativos. Algunos de vosotros ya sabréis quienes somos por la presentación que hicimos en la asamblea 15M y por contactos directos. Estamos organizando un encuentro en Valencia para la semana del 18 al 24 de julio y dentro de las actividades que vamos a realizar, habímos propuesto un taller de metodologías as amblearias y procesos participativos en el que querríamos dar cabida a las diferentes asambleas de barrios y pueblos que han surgido a raíz del 15M, intentando recoger los retos que se nos están planteando a todos en este momento de emergencia. Algunos de vosotros nos habéis hecho llegar ciertas necesidades y carencias a las que nos estamos enfrentando en relación a la conexión de las asambleas con el barrio y su propio potencial de autogestión y empoderamiento. Por todo ello, hemos dispuesto un día en el que pudiéramos tratar estos asuntos con personas que llevan ya mucho tiempo trabajando en esa línea y que quizás puedan ayudarnos a despejar dudas y encontrar caminos. Os invitamos por tanto a hacernos llegar vuestros cuestionamientos al respecto para poder orientar adecuadamente este taller $y$, por supuesto, a invitar a todo aquel que consideréis interesado en el mismo. 
En el taller abierto, se analizó el funcionamiento colectivo como algo que se aprende, que no viene dado. Se trató de explorar cuáles son las herramientas que nos hacen posible funcionar y pensar colectivamente en un mundo tendente a la individualización, los límites y potencias de la participación y el funcionamiento grupal así como algunas claves para su cuidado. Ana Sánchez, activista y socióloga implicada en numerosos procesos de colaboración vecinal, desde los primeros Laboratorios de Lavapiés, hasta la Tabacalera CSA, hizo una revisión de la definición de participación social y de posibles herramientas y metodologías participativas aplicadas a las comunidades autogestionadas. Sánchez introdujo temas y matices totalmente necesarios para poder reflexionar sobre las dinámicas de grupos, desde una cercanía con la práctica y una capacidad de extraer teoría envidiables, sin dejar de lado la dimensión afectiva que tiene cualquier intercambio. En ese sentido, creemos que el campo a desarrollar es inmenso, debido a la carencia generalizada de conocimientos más allá de los intuitivos en lo que respecta a las dinámicas de grupo.

Para ella, promover la participación social haciendo devoluciones creativas y buscando implicar a agentes que no se suelen considerar es en sí un método y un objetivo que parte de la convicción de que el autogobierno y las prácticas horizontales generan mayor calidad de vida sin lugar a dudas, pero que todo ello exige un esfuerzo de aprendizaje y seguimiento. Nociones como la escucha activa o la definición de ideas por adición y no por oposición, la atención contra la toma de decisiones compulsiva (a veces no hay que decidir) o la confusión del consenso con la unanimidad son bases que intentan compensar una mala sino inexistente cultura asamblearia. Como dice ella, la voluntad es una fuerza muy débil para combatir los malos hábitos culturales. Cuestiones fundamentales y muy a menudo obviadas a pesar de su centralidad como la definición del ámbito de decisión (que muy a menudo acaba siendo el bar en el que los que se han quedado tras la reunión cuadran sin quererlo todo lo dicho, o en intercambios de correos entre pequeños grupos, etc. son maneras en que inadvertidamente se modifica este ámbito y se generan malestares o derivas no queridas) o la definición del papel del grupo acaban siendo los mayores lastres que acaban desestabilizando a los colectivos .

Si aplicamos estos conocimientos a nuestro propio proceso como colectivo en este taller, podemos formular una serie de críticas así como una valoración sobre nuestra posible aplicación al colectivo de colectivos que ha sido el grupo organizador del Comboi a la fresca. En relación al taller en sí, no ha habido un trabajo de seguimiento ni de retroalimentación con las diferentes asambleas del $15 \mathrm{M}$ que siguen su camino de una forma bastante improvisada. Igualmente, se hubiera tenido que producir un trabajo previo de acercamiento para el que no se dedicó el tiempo necesario, en este caso, por problemas dentro de la difusión 
del $15 \mathrm{M}$ que no permitieron difundir la convocatoria con el tiempo suficiente como para llevarlo a cabo con aprovechamiento. Por otra parte, tampoco se llegó a integrar al colectivo procedente del $15 \mathrm{M}$ en las diferentes asambleas en marcha en el propio Comboi, como hubiera sido deseable.

Por nuestra parte como colectivo organizador, podemos decir que estamos inmersas en una dinámica de grupo que no hemos analizado con la suficiente distancia y claridad y que quizás debiéramos dedicar a este asunto un poco más de tiempo y dedicación ya que lo que aprendamos en este campo nos puede servir para cualquier otra dinámica de grupo en la que nos podamos ver implicadas. Propondríamos vencer nuestra resistencia a explicitar cómo nos sentimos respecto a los procesos y las personas porque casi siempre hablamos desde los argumentos y las razones y pocas veces hacemos evidente una parte importantísima en cualquier grupo o comunidad de trabajo como son los sentimientos y los afectos. Evitando hacer terapia de grupo, plantearíamos una pequeña revisión de algunos conceptos tratados en este taller de manera que pudiéramos aplicárnoslos a nuestro propio grupo. Por ejemplo, lo que en este tipo de metodologías se llama el punto meterológico, el tomarse el tiempo de decir cómo estamos, cómo nos sentimos respecto a algo, sin necesidad de esperar que llegue el momento en el que ya sea imposible callarlo por malestar y disenso.

Contra esta posibilidad, tenemos una larga tradición generalizada contra la expresión de estos malestares o euforias; acallar, esconder, minimizar han sido las estrategias sistemáticas de afrontamiento de nuestras emociones. No obstante, podemos decir con la distancia que nos da una trayectoria de varios años que en nuestro propio grupo de LaCIV, esta actitud de minimización de enfrentamientos personales, o casi caracteriales podríamos decir, ha bloqueado más de un proceso, ha dificultado la fluidez general de los trabajos y ha acabado por colapsar en un momento determinado nuestro funcionamiento. Por todo ello, decimos con mayúsculas que cuidar la temperatura afectiva de los colectivos no es una broma, ni una debilidad ni pura sensiblería, es tan fundamental como puede serlo en la pareja, en la amistad o incluso en el ámbito laboral más impersonal.

Por todo ello, como decía Ana Sánchez, ralentizar grupos y decisiones pensando en que con ello se sientan bases, no es tiempo perdido. Designar cuál es el espacio de decisión y el modelo de comunicación al resto de integrantes parece esencial en estos momentos para no reproducir algunos fallos de difusión de nuevos proyectos y evitar malentendidos o sentimientos de exclusión. Otra de las ideas que nos ha parecido más interesante es la de no buscar el consenso unánime sino convertir a los grupos disconformes en grupos de observación, ya que trasforma la negatividad en la distancia necesaria para la posición de observador. Por no abundar en las observaciones de género que siguen siendo 
pertinentes en todo colectivo, pues hemos constatado una vez más que en las asambleas y en los momentos de disenso, son muy a menudo los hombres los que copan los turnos de palabra, por lo que incidimos de nuevo en la necesidad de permanecer atentas a desequilibrios similares para intentar compensarlos por ambas partes.

Uno de los casos más acusados cuando se trata de llevar adelante procesos participativos con vecinos, por ejemplo, es prestar especial atención a la participación de mujeres mayores que, por su sexo y edad, rara vez emiten su opinión. Sánchez propone directamente el registro de intervenciones para evitar lo que ya comentamos en algún momento de la tesis, el hecho de que una asamblea resulta relativamente fácil de manipular de forma consciente o inconsciente, que aquellos que tienen mayor soltura de palabra y mayor necesidad de presencia activa pueden acabar orientando un grupo hacia líneas de trabajo no compartidas por la mayoría y que ello redunda siempre en dificultades posteriores, fruto de disensos internos no explicitados. Si hemos aprendido algo en este tiempo, es que los disensos acallados salen caros.

Para terminar, consideramos que este fue uno de los talleres fundamentales de autoformación para cualquier colectivo que desee ponerse en marcha porque lo natural no es la participación en grupo, no basta con la buena voluntad para que una asamblea funcione, mientras que sí somos conscientes de que la inteligencia colectiva es más rica que la individual, que la suma de inteligencias a la hora de enfrentarse a la resolución de conflictos es más eficaz, por lo que estamos decididas a seguir autoformándonos en este asunto y seguir atentas a dinámicas automáticas que resulten perjudiciales.

b. Taller de Metodologías Participativas Il: procesos de participación [ MonoDestudio + Autoformato + Unilab + Sottovuoti + Hiria Kolektiboa + Raons Públiques + Engendro Colectivo] - Institut Français http://monodestudio.wordpress.com/

http://www.sottovuoti.blogspot.com.es/

http://www.hiriakolektiboa.org/blog/

http://raonspubliques.org/

http://engendrocolectivo.blogspot.com.es/

En este taller, se abordó una introducción teórica y puesta en común de procesos de participación de diferentes colectivos que desarrollan su trabajo en este ámbito, desde diversas perspectivas. La incorporación de sociólogos o mediadores sociales en los equipos de urbanismo y arquitectura viene siendo una tónica habitual en muchos países europeos y empieza a abrirse camino tímidamente en el nuestro. En este encuentro, contamos con la presencia de varios grupos de profesionales de este ámbito híbrido que mostraron en el taller diferentes procesos 
e intervenciones realizados mediante el diseño, la gestión y la planificación participativa aplicada con una perspectiva social, de género y de sostenibilidad.

Las metodologías participativas, a diferencia de métodos más convencionales de investigación social, tienen por objeto promover transformaciones sociales mediante el conocimiento de los conflictos plateados y la búsqueda de soluciones entre todas las partes implicadas (administración, técnicos, organizaciones y redes sociales informales). De esto modo, se intenta superar la relación investigador-objeto de estudio sustituyéndola por una relación sujeto-sujeto, que pase del análisis del individuo a las redes de relaciones, intentando realizar devoluciones creativas para posibilitar una construcción colectiva de un espacio común. La investigación con metodologías participativas se ocupa al fin y al cabo de aplicar y sistematizar los procesos sociales de democracia participativa que emanan siempre de procesos colectivos de autoorganización.

Uno de los elementos fundamentales fue la actitud de implicación de los diferentes proyectos como única manera, para ellos, de hacer ciudad así como el análisis de cualquier proceso utilizando un enfoque transdisciplinar. Muchos de estos equipos hacen uso de sociogramas realizados por el grupo motor del cambio así como de otras herramientas sociológicas cualitativas. Por ejemplo, la puesta en marcha de un observatorio del espacio público por parte de diferentes colectivos que impliquen a niños, jóvenes, trabajadores productivos y reproductivos, personas con movilidad reducida, inmigrantes, etc. de manera que se pueda llevar a cabo un análisis lo más completo posible de las dotaciones existentes en un barrio, de sus lugares de encuentro, etc. La exposición de herramientas participativas para incluir a los colectivos más vulnerables, por ejemplo, o las propuestas de mediación en situaciones de enfrentamiento que a menudo se producen entre la esfera técnica y la ciudadana serían algunos ejemplos de esta actitud que parte de la adquisición de un compromiso doble, con la ciudadanía y con la Administración.

\section{c. Debate metodologías participativas \\ [ MonoDestudio + Autoformato + Unilab + Sottovuoti + Hiria Ko- lektiboa + Raons Públiques + Engendro Colectivo] - EASD}

La tercera parte de este taller de metodologías participativas estaba orientada a la aplicación de diferentes enfoques a un caso local en el que la implicación fuera real y por tanto, la necesidad de poner en marcha un proceso de participación partiera de datos concretos. Para ello, se orientó un debate en el que se plantearon diferentes propuestas, a veces contradictorias entre sí, con lo que ello supone de confrontación de metodologías, para iniciar el proceso participativo de diseño y usos del solar de la calle Corona, y permitir la elaboración de conclusiones. En el transcurso del debate, se evidenciaron diferentes maneras de abordar el 


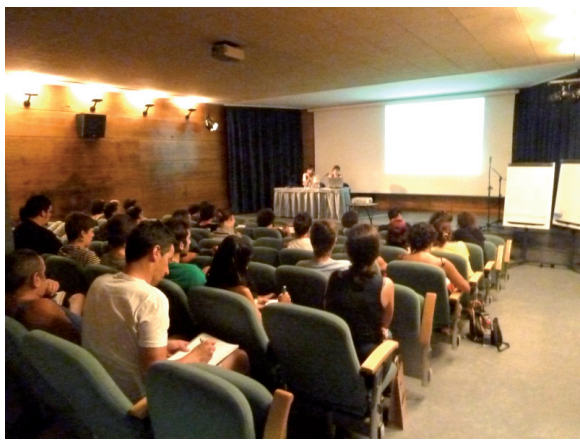

propio proceso participativo en referencia a la centralidad o no de los deseos y necesidades de los vecinos del barrio (que actuarían como multiplicadores de futuras ocupaciones o cesiones de uso) frente a un enfoque que se centrara en las necesidades concretas del espacio en discusión. Se habló también largo y tendido sobre las dinámicas de autogestión del espacio y los diferentes modelos posibles. En el taller, se prestó especial atención a los métodos de inclusión de grupos minorizados que requieren un trabajo específico, como serían la población gentrificada, las mujeres mayores, y las personas de edad avanzada. Todos estos procesos implican abordar antes o después cuestiones como la gestión pública, semipública o privada del espacio, en especial en lo que respecta al propio solar Corona debido a su composición mixta, así como los procesos de autoformación necesarios para llevar a cabo dicha transformación.

En cuanto al desarrollo en sí del debate, hubo una separación bastante evidente entre los colectivos que habían estado presentes desde el principio tanto en los intercambios por correo como en los debates previos, y aquellos que se incorporaron a partir del segundo día. Igualmente hubo problemas a la hora de entender que si bien el debate estaba abierto a todo tipo de propuestas y planificaciones, iban a ser los colectivos y las personas que posteriormente se hicieran cargo del espacio los que debían debatir y planificar los usos a los que deseaban destinarlo. Esto llevó a un conflicto en torno al marco de actuación del taller, lo que causó que se produjeran tensiones entre los partidarios de las metodologías participativas guiadas y los partidarios de la cesión directa a los movimientos sociales.

\section{d. Mesa redonda Periferias}

[ Autoformato + AVV. Sant Marcel-lí + AVV Natzaret + La Matraka +
Espacio elevado al Público ] - Solar Corona
http://www.avnatzaret.com/
http://avsantmarcel-li.blogspot.com.es/
http://lacomadigital.wordpress.com/category/aavv-la-coma/
http://lamatrakacultural.wordpress.com/
http://espacioelevadoalpublico.com/

La mesa redonda "Periferias" pretendía reflexionar sobre las condiciones de los barrios denominados periféricos de Valencia a través de un itinerario por varios de los proyectos de autogestión vecinal, a la vez que se planteaba la visi- 
bilidad de dichas propuestas en la ciudad. Como contrapunto, algunos colectivos provenientes del campo de la gestión cultural y la arquitectura de otras ciudades explicaron cómo han abordado el tema de la periferia en sus diferentes intervenciones. En este caso, pudimos contar con la presencia de diferentes asociaciones de vecinos de zonas desfavorecidas de la ciudad, que han llevado adelante proyectos de autogestión laboral en los que han conseguido implicar a la Administración. Nos parecía esencial poder plantearnos no sólo experiencias de reivindicación de espacios públicos, sino también procesos de empoderamiento desde el punto de vista puro y duro de la supervivencia económica, por lo que la experiencia de asociaciones que han sabido imponerse a las normativas municipales de contratación, por ejemplo, constituye una fuente de autoformación insustituible para colectivos más centrados en procesos de participación con menor carga social. El control sobre los medios de producción, desde siempre, ha sido un mecanismo claro de emancipación y empoderamiento, especialmente en las zonas en las que el porcentaje de habitantes por debajo del umbral de pobreza es mayoritario. Se ha prestado especial atención a todos aquellos aspectos procesuales, más que a los resultados en sí: cómo se consiguieron determinados objetivos: recursos legales, convenios, protocolos, etc.

\section{e. Taller Agroecología [ EcoLab + Engendro Colectivo + Huertos municipales de Godella + Huertos vecinales de Benimaclet + Huerto comunitario de Carolinas + Ecologistes en Acció de la Serranía] - EASD http://ecolab.plataformacero.cc/foro/ http://engendrocolectivo.blogspot.com.es/ http://www.sembraensao.org/ http://www.huertosurbanosbenimaclet.com/ https://sites.google.com/site/huertocomunitariodecarolinas/home http://www.ecologistasenaccion.org/rubrique146.html}

Uno de los procesos que nos parecen fundamentales a la hora de construir procomún es la incorporación del uso de la agroecología en el espacio urbano y su potencial de cohesión social, mediante propuestas participativas de intervención. Cada vez es más patente la realidad de que en el espacio urbano se pueden llevar a cabo experiencias de agricultura que hacen factible la opción de vuelta a la soberanía alimentaria como alternativa socio-económica, al mismo tiempo que son experiencias de encuentro social y de construcción colectiva del espacio público.

Este taller, dinamizado por Engendro Colectivo tuvo como objetivo fundamental la reflexión publica en torno a la agroecología y lo urbano, a la posibilidad de su uso en espacios abandonados que conllevan un gran potencial, 
y en general a las interacciones que provocan. Para responder estas preguntas, convocaron a representantes de diferentes iniciativas, que presentaron sus experiencias enfocadas a las posibilidades que puede presentar el Solar Corona. Se propuso la vía agroecológica, presentándola como una buena manera de fomentar la participación de los vecinos así como la interacción generacional, un factor clave a la hora de actuar en este barrio en el que buena parte de la población afectada por el proceso de gentrificación es de avanzada edad.

Tras la realización del Comboi a la fresca, y la transformación de la plataforma de organizadores en una asociación denominada LaCIV, procesos que detallaremos más adelante, solicitamos una subvención a través del Institut Français de Valencia al Ministerio de Cultura francés. En concreto, se trató de una solicitud dirigida al Fonds d'Alembert (Urbanismo sostenible y pensamiento urbano) en el marco de las ayudas destinadas al desarrollo urbano y la constitución de una ciudad sostenible. Destinamos la subvención obtenida a la realización de una serie de encuentros con sociólogos, arquitectos y urbanistas franceses implicados en la transformación de la metrópolis, así como en una estancia en París para establecer vínculos con centros autogestionados franceses; por último, para la realización de una publicación en relación al proceso del Comboi a la fresca.

Respecto a esta subvención, Autoformato se implicó en las tres actividades principales, tanto en el viaje a París, la planificación de la publicación como en la programación de los diferentes encuentros de autoformación en torno a los procesos de dinamización de la ciudad que se habían activado a raíz de la realización del Comboi. A continuación, detallaremos únicamente aquellos encuentros en los que Autoformato se implicó directamente ya que, como miembro de LaCIV y promotora del proyecto La Calderería, la lista de eventos y colaboraciones sería mucho mayor, pero excedería al cometido de este apartado.

4. Espacios autogenerados y lógicas de los intersticios 12-16 de diciembre de 2011 - La Minúscula, Instituto Francés, UPV

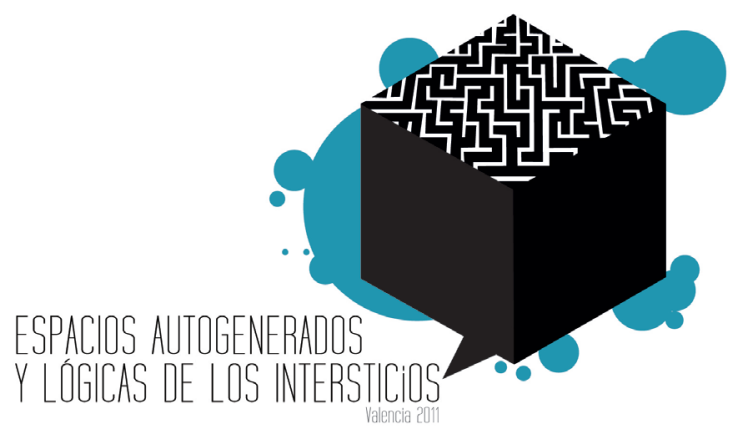

Junto con el espacio La Minúscula, programamos unas jornadas complejas que buscaban generar un espacio de aprendizaje colectivo a raíz del proceso de activación del Solar Corona en el que ambas asociaciones estamos implicadas. 
Una semana de lecturas, talleres y debates que tuvo como objetivo articular e incorporar procesos de autoformación a la práctica del solar en los que se quiso aprehender el marco teórico elaborado por el sociólogo francés Pascal Nicolas Le-Strat alrededor de los espacios intersticiales y la creación de procomún. Este autor concibe este tipo de espacios como fracturas donde la construcción de la ciudad aún resiste a su normalización, caracterizándose por formas de hacer ciudad abiertas y colaborativas que dibujan nuevas formas de antagonismo en la ciudad post-fordista.

Además de las conferencias o presentaciones con un formato más tradicional, propusimos una metodología de trabajo consistente en la realización de un seminario abierto de lectura y discusión previa de textos de estos autores como base para un encuentro horizontal de intercambio y debate. En el marco de las jornadas, Autoformato tradujo textos del sociólogo francés, disponibles hoy en nuestra web. En las fotos, se pueden apreciar los resultados de los talleres en los que se preparó previamente el seminario con Pascal Nicolas-Le Strat mediante la lectura, análisis y comentario de los textos así como las sesiones de debate conjuntas.

En ellas, partimos desde el cuestionamiento de nuestras propias necesidades de autoformación en relación con todo lo tratado en los diferentes textos que Le Strat nos hizo llegar y planteándonos cómo conectarlos con nuestra experiencia cotidiana al respecto. En el trabajo realizado con el sociólogo, aprendimos nociones fundamentales para la valoración del Comboi a la fresca como puede ser la de democracia contributiva. Este concepto se diferencia de la democracia participativa en el hecho de que no se basa en esa teórica participación de la ciudadanía sino en la implicación directa de los agentes. No es lo mismo participar en algo que hacerlo tuyo, como todos bien sabemos. Esta diferencia resulta clave a la hora de poner en marcha procesos inclusivos en los que el objetivo es activar, articular y ceder a una asamblea; pero esto sólo se produce si desde el principio hay una implicación tal en la toma de decisiones que los diferentes agentes entienden que ese proceso es suyo, que tienen el poder de decidir, reactivar o transformar. Como sucede en el aula, toda pretensión de autonomía tiene que ir acompañada de una capacidad de autodeterminación de contenidos, en caso contrario estamos únicamente entrando en el doble vínculo que supone la orden de emanciparse.

Otra noción que nos permitió enlazar los conocimientos adquiridos con Rancière y nuestras prácticas fue la insistencia con la que nos planteó que conseguimos cooperar a partir de nuestras incompetencias, cuando nos situamos en un ámbito que nos fuerza a salirnos de lo que sabemos hacer. Por ello, nuestro trabajo fundamentalmente transdisciplinar nos obliga a ponernos en esta situación permanente de escucha y aprendizaje, de tanteo y descubrimiento en el que ninguno somos expertos y por ello, podemos permitirnos errar y colaborar. 


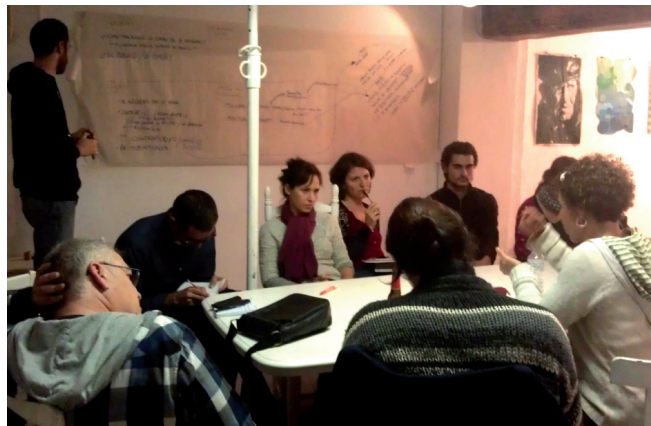

Por otra parte, mediante la presentación de las experiencias de los colectivos L'Âge de la Tortue ${ }^{191}$ y Bazar Urbain ${ }^{192}$ que trabajan en torno a nociones de territorio y espacio público muy similares a las que nosotros estábamos realizando, quisimos estudiar procesos de recuperación de uso y empoderamiento desarrollados en Europa, para activar una reflexión sobre las prácticas y acciones locales. Posteriormente, como se puede ver en la foto, hubo una sesión de análisis conjunta de nuestras propias prácticas, tanto de lo acaecido en el Comboi como de nuestros proyectos futuros orientados hacia el Solar Corona y La Calderería, sesión que nos fue especialmente útil.

Contamos con la visión privilegiada de gente con una trayectoria más larga que nosotros en este tipo de activaciones y con un posicionamiento político claro. No obstante, discrepamos con Le Strat en su creencia de que la fuerza de las multiplicaciones, el hecho de que haya muchísimos nodos similares al nuestro produciéndose en muchos otros lugares, acabará produciendo un punto crítico suficiente para la transformación social y política. No tenemos la suerte de ser tan optimistas y pensamos que nuestra resistencia generalizada al cambio y a un cambio en profundidad que afecta a nociones como el progreso o el trabajo, no va a producirse por simple acumulación, sobre todo cuando esta transformación va contra tantos a los que les conviene el actual estado de cosas.

\section{Jornadas de autoformación de Economía y Urbanismo críticos 26 de junio al 10 de julio 2012 - La Calderería}

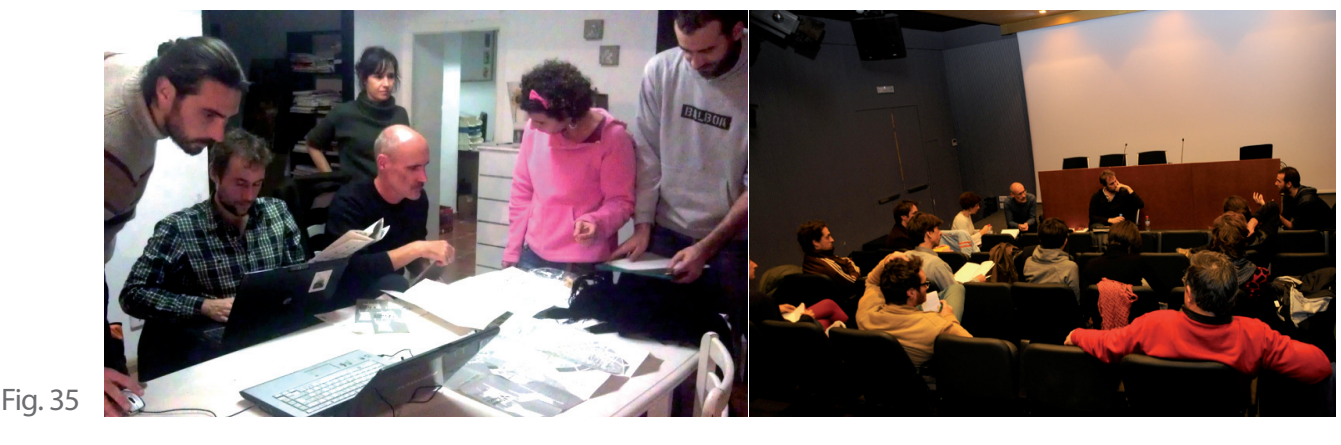

191. http://agedelatortue.org/

192. http://www.bazarurbain.com/ 
Siguiendo con la línea de trabajo que asocia ciudad y ecosistema, dentro de lo que luego describiremos como el proceso de activación de la Calderería, organizamos desde Autoformato un seminario doble que atiende por una parte a la idea de la metrópolis como espacio simultáneo de lucha y de creación en el postfordismo y por otra, a la necesidad imperante de alcanzar una vida sostenible, lo que incluye obviamente conceptos como el hábitat o la economía. Consideramos que era interesante hacerlo doble porque nos permitía enlazar con todo el trabajo que estuvimos haciendo el verano anterior en el Comboi a la fresca, en torno a la noción de tejer redes y crear ciudad.

\section{Hacia una ciudad sostenible}

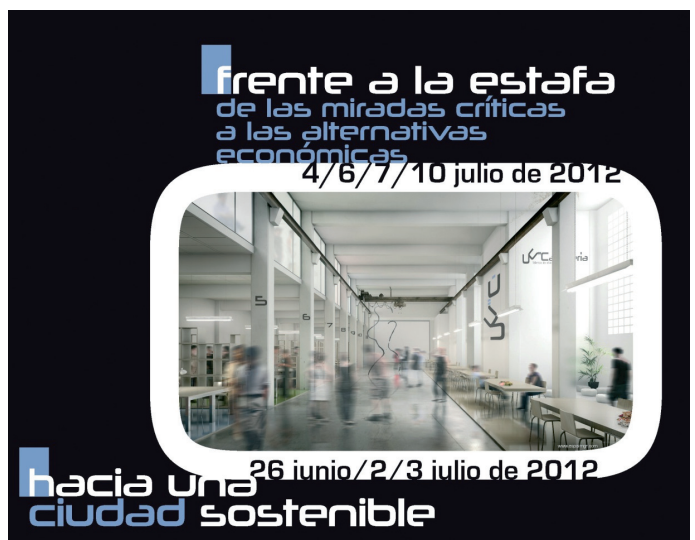

En este primer seminario, nos parecía interesante vincular las posibilidades existentes hoy en día de abordar la idea de ciudad sostenible e intentamos introducirla a través de tres ejes:

1. El urbanismo participativo en la medida en que supone el encuentro entre la arquitectura, el urbanismo, la sociología y la sociedad civil. De hecho, plantea la disolución de fronteras entre disciplinas al emplear un enfoque holístico en su análisis y permite entrar en otro tipo de procesos urbanísticos totalmente diferentes de los aplicados por la Administración española. Para cubrir este frente, hicimos venir a Philippe Verdier que es un especialista francés en este tipo de proyectos, sociólogo y urbanista, y que introdujo nociones y posibilidades concretas de practicar un urbanismo participativo, lo que a nuestro parecer, resulta esencial para poder hablar de sostenibilidad urbana. Igualmente, tuvimos la suerte de poder hacer un análisis conjunto del proyecto que en ese momento nos llevábamos entre manos, La Calderería, en el que hizo especial hincapié en la necesidad de aplicar una planteamiento inclusivo que contara con todos los habitantes del espacio en el que proyectábamos un centro de dinamización vecinal.

2. Por otra parte, como ya hemos comentado en la tesis, nos parece importante valorar el papel que, en la actualidad, pueden jugar los centros culturales o sociales en tanto atractores casi en su sentido físico, como generadores y dinamizadores de procomún. Se ha observado claramente su acción en barrios pauperizados, gentrificados, con la identidad perdida, en procesos prolongados de estancamiento que cambia de signo cuando se introduce un centro de proximidad 
similar que permite articular energías. Para analizar posibles metodologías de acción en relación a nuestro proyecto de La Calderería, invitamos a Maud Le Floch para que nos hiciera una presentación de Le Polau (http://www.polau.org/), laboratorio de proyectos artísticos y urbanos que actúa como interfaz de investigación y de experimentación entre actores artísticos, culturales y urbanos.

Con un planteamiento de vinculación intrínseca de prácticas artísticas y proyectos urbanos, su sede a $250 \mathrm{~km}$ de París en un solar industrial que comparte con una compañía muy importante de artes de la calle, OFF, funciona también como residencia de investigación para artistas y colectivos de urbanistas, con un laboratorio de investigación, con lugares y talleres de creación, asumiendo también su difusión. La ocupación de este espacio es una práctica de economía mixta, ya que recibe financiación pública parcial consistente en ayudas a la creación que se desplazan a proyectos urbanos ya que el acuerdo lo tiene con el Ministerio de Cultura y con fondos regionales. Esta situación responde a una visión estanca que no contempla las lógicas interdisciplinares de la actualidad necesarias para la transformación de la sociedad, ni atiende a las nuevas hibridaciones y registros. Si ese es el caso en Francia, aunque encuentre una salida a través de la desviación reconocida de fondos culturales a proyectos urbanos, mejor que no comentemos la distancia a la que se encuentra el panorama español donde el reconocimiento mismo de grupos interdisciplinares más convencionales plantea problemas.

No obstante, no habría que dejar de cuestionar el trabajo de equipos de arquitectos y artistas que intervienen en la ciudad sin tener en cuenta a sus habitantes, que a veces no piden nada y son usados como un bello pretexto a nivel social, solidario incluso como marco de vida. En estas intervenciones, se produce a menudo una mezcla de tensiones entre generosas y egoístas. Las intervenciones en la ciudad son siempre un lugar de trabajo político en donde chocan inevitablemente múltiples intereses y no solamente económicos por lo que hay que estar especialmente atentas a planteamientos falsamente mesiánicos (en el caso de conflictos exacerbados por la propia intervención) o al contrario, intervenciones que acallan las tensiones sin llegar a resolverlas. Por otra parte, Maud Lefloch nos sugirió al respecto de los funcionamientos asamblearios de diferentes colectivos que comparten la gestión de un centro que, entre la línea vertical y la horizontal, está la línea oblicua que permite acortar los largos plazos asamblearios, mantener operativo el funcionamiento sin renunciar a la cogestión, posibilidad de autogestión que barajaremos posteriormente cuando se trate de concretar el funcionamiento de La Calderería.

3. El tercer eje a través del que intentamos analizar la ciudad sostenible fue el del decrecimiento aplicado al urbanismo, un decrecimiento enfrentado por una parte al crecimiento cero utópico, adoptando una posición radical, y por otra parte a la lógica de la austeridad no como optimización de la inversión sino 
como recorte de lo público. Esta idea de decrecimiento asociada a la ciudad supone cuestionar los modelos urbanísticos asociados a la expansión mediante un posicionamiento a favor de generar calidad, generar trama urbana, lo que supone recuperar espacios en desuso, expandiendo la creación de espacios públicos, es decir, invertir la deriva que se ha mantenido durante los últimos treinta años en nuestro país. Para hablarnos de ello ilustrándonos con ejemplos, hemos invitado al colectivo Etc ${ }^{193}$, compuesto por jóvenes arquitectos que proponen actuar experimentalmente sobre el espacio público de una manera creativa e implicando a los distintos actores de la escena urbana que intervengan a diferentes escalas: construyendo estructuras y objetos, organizando encuentros y talleres o planteando intervenciones más artísticas sobre la ciudad.

Los doce miembros activos del colectivo Etc, once arquitectos y una diseñadora gráfica, han iniciado a partir del mes de octubre de 2011 un recorrido en bicicleta por toda Francia. Le llaman Le Détour de France en una extraña combinación de Tour de France y détournement situacionista. El viaje es flexible en su organización, dura un año y sirve para proponer, documentar y analizar las prácticas de participación en la creación de proyectos urbanos. En muchas ciudades de Francia, están surgiendo iniciativas que implican a los ciudadanos en la gestión y la planificación de sus ciudades. Este fenómeno plantea la necesidad de pensar conjuntamente el futuro de nuestras ciudades, como un medio para la democracia efectiva y el empoderamiento social. Estas iniciativas vienen de personas muy diferentes: los habitantes, asociaciones, comités, artistas, profesionales, instituciones, políticos. El objetivo de Etc es integrar a estos diferentes "actores", participar con ellos en la "construcción urbana ciudadana" y buscar una posible evolución de la arquitectura hacia una práctica más social.

Por último, realizamos un seminario abierto sobre modelos de gestión de centros y proyectos en los que reunimos a nuestros invitados, Maud Lefloch (Le Polau), Kelly Ung y Julien Abitbol (Etc) junto con otros agentes activos en la ciudad. Cuando traemos a gente como Maud Lefloch o a colectivos emergentes de arquitectos que están saliendo ahora de la universidad y
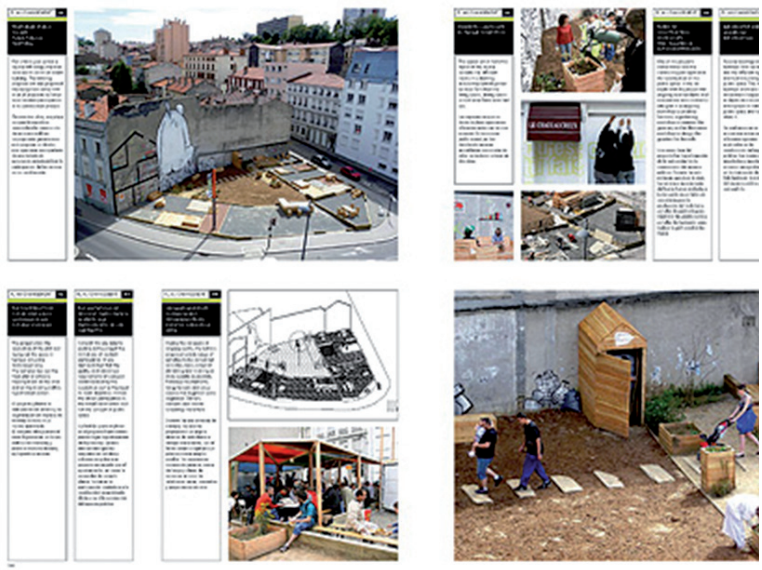
vemos cómo se plantean su

193. http://www.collectifetc.com/ 
profesión, asistimos a la aplicación práctica de ese Outsite ${ }^{194}$, que pertenece a todas las disciplinas y las excede en igual medida. En un momento como el actual ni los arquitectos ni los artistas pueden seguir planteándose su intervención en el mundo bajo las mismas premisas.

Las nociones participativas tiene que integrarse necesariamente en los nuevos modelos de creación de ciudad, de planificación urbana, de la misma manera en que los agentes de la economía social no se limitan a ajustarse a propuestas económicas sino que se inventan nuevos modelos de hibridaciónconciliación que superan los modelos legales impuestos y las categorías típicas de emprendizaje para adaptar a sus vidas la actividad económica, sobre todo cuando se trata de colectivos de mujeres que, inevitablemente, tienen que plantearse conciliaciones laborales y familiares diferenciales. Cuando asistimos a la presentación de los proyectos de estas gentes, observamos que de la misma manera en que nosotros trabajamos durante el Comboi a la fresca en un ámbito híbrido entre la arquitectura, la sociología, el arte y la sociedad civil, hay muchos colectivos que están realizando lo mismo por toda Europa. En nuestro caso podemos citar a Coloco, Bruit du Frigo, Exytz, l'Age de la Tortue, Bazar Urbain, Frères Poussières, entre algunos de los colectivos que hemos invitado, con los que hemos trabajado y seguimos teniendo relación.

Por utilizar una metáfora artística de la evolución de la arquitectura, podríamos aplicarle las dos premisas que caracterizaron la transformación contemporánea de la escultura: su pérdida de pedestal y tras la liberación de ese emplazamiento fijo y autorial, la consecución de su campo expandido, la impregnación mutua hasta la progresiva disolución de disciplinas artísticas, sociales y políticas. Si esta transformación la sumamos a los cambios económicos introducidos por el postfordismo, especialmente en lo referente a la ausencia de distinción entre lo público y lo privado, veremos cómo en la mayoría de casos, estos proyectos o centros emergentes se apoyan en ambos ejes: su economía suele ser mixta con fuentes de financiación tanto públicas como privadas y con situaciones paradójicas como la percepción de ayudas a la creación por parte del Ministerio de Cultura, junto con su reorientación a proyectos de transformación urbana, lo que no hace más que ser un fiel reflejo de las lógicas interdisciplinares que la animan.

194. MIQUEL, Mijo. "De las prácticas transversales a las investigaciones extradisciplinares: la constitución del Outsite", en I Congreso Internacional de Arte y Entorno, Ed. Universidad Politécnica de Valencia, Valencia, 2009. Concepto fundamental a la hora de entender el territorio híbrido en el que suceden estas prácticas y que detallaremos más adelante cuando analicemos el proceso del Comboi a la fresca. 
Frente a la estafa. De las miradas críticas a las alternativas económicas

En los últimos meses, nos hemos cansado de escuchar, leer y debatir los análisis sobre las causas, las consecuencias o las transformaciones de la crisis. Nos hemos familiarizado con conceptos como "financiarización", "sociedad propietaria", represión monetaria, deuda legítima y un largo etc. Desde Autoformato, consideramos que los procesos de autoformación en torno a este ámbito empiezan a presentar signos de agotamiento, dada la abundancia de espacios y sinergias utilizados para este enfoque. Las jornadas sobre "Economías críticas" tratan de explorar y potenciar la elaboración de alternativas económicas en el presente contexto de crisis a la vez que profundizan en los análisis sobre la misma así como en torno a las formas de acumulación del capitalismo contemporáneo.

Por tanto, se trata de combinar dos narrativas diferentes, pero relacionadas entre sí. La primera de ellas, basada en prácticas actuales, gira en torno al campo de la economía solidaria, e indaga en las experiencias, estrategias y nuevos planteamientos que, desde este ámbito, se generan como salidas a la situación económica. Articulado con el anterior, el segundo bloque tiene un carácter más bien analítico y teórico al centrarse en el marco conceptual de los investigadores de la revista Multitudes ${ }^{195}$, referentes en el pensamiento crítico francés. Como siempre, partimos de unas sesiones abiertas preparatorias, en las que trabajamos los textos teóricos confrontándolos con nuestras prácticas para encuadrar dentro de una trayectoria real, los análisis críticos y propuestas prácticas alternativas.

\section{Mesa de experiencias alternativas}

Abrimos esta segunda parte del seminario con una mesa de experiencias alternativas en la que nos centramos en las propuestas prácticas que, desde diferentes puntos de partida, están contribuyendo a crear modelos económicos alternativos, desde la autofinanciación hasta el modelo de gestión único cooperativo, pasando por la imbricación en el contexto, ya sea este rural o urbano. Todos estos ejemplos prácticos demuestran con su quehacer la concreción real de las alternativas así como su plena integración en el territorio.

\section{Mercado de Economía Social (MES) - Madrid} (www.konsumoresponsable.coop/mercado-social-madrid)

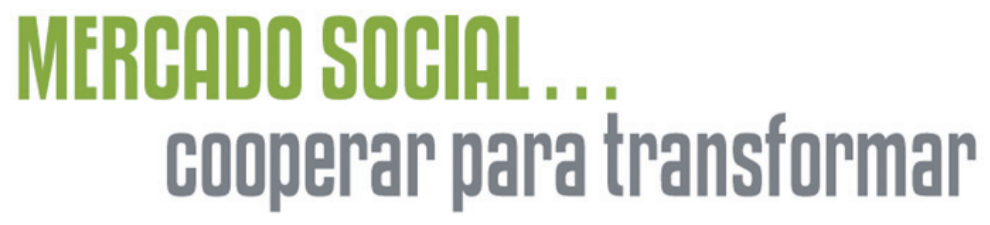

195. http://multitudes.samizdat.net/_Multitudes_ 
El mercado social integra actores muy diferentes y se extiende por todo el territorio español con una plataforma conjunta que permite localizar en cada una de las comunidades los lugares de venta. En este caso, fueron los compañeros de Madrid que llevan más tiempo funcionando los que asistieron a esta mesa abierta para contarnos su experiencia. Nos contaron que el objetivo del mercado social es superar las reglas negativas del mercado convencional para establecer un mercado alternativo que opere bajo criterios y relaciones económicas justas.

También pretende ser un espacio de cooperación que una a las empresas productoras y distribuidoras de la economía social, junto a los colectivos y personas implicadas en el movimiento del consumo responsable. Se trata de construir redes de comercio y consumo con criterios de funcionamiento alternativos como la cooperación, la transparencia, la participación, el compromiso con el entorno y las economías locales, la promoción del empleo y de oportunidades económicas para personas y colectivos excluidos del mercado así como el rechazo a la maximización de beneficios como único fin. Para ello, se intenta crear en un territorio un mercado en el que las entidades y empresas de economía social y solidaria cooperen para subsistir, crecer y ser alternativas económicamente realistas.

\section{Som energia}

\section{http://www.somenergia.coop/}

Fig. 39

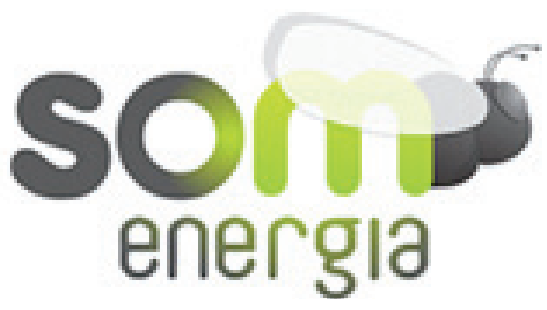

El objetivo de Som Energia es ser una cooperativa sin ánimo de lucro que reúne a miles de personas en torno al deseo de cambiar el modelo energético actual y trabajar de forma conjunta para alcanzar un modelo de consumo energético basado totalmente en las renovables. Este equipo que opera fundamentalmente en Cataluña vinieron a La Calderería a contarnos que es posible superar a Iberdrola y sus subidas retroactivas de tarifas amparadas por el Estado y sus ex presidentes que hallan pronto acomodo como consejeros de la nada. Celebramos ampliamente que haya iniciativas legales constituidas para este tipo de asuntos cuando los monopolios ocultos nos atrapan como clientes cautivos en cuestiones que todos sabemos que no hubieran tenido que dejar nunca de ser públicas. 


\section{Sostre Cívic}

\section{http://www.sostrecivic.org/es}

La vivienda es un tema candente hoy en día, tan candente que es una de las primeras causas de suicidio en nuestro país. Frente a una sociedad que se ha construido

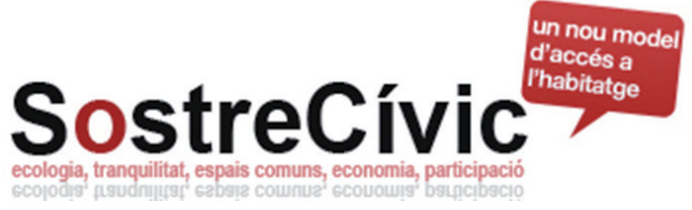
sobre la burbuja inmobiliaria, que se ha endeudado enladrillando, SostreCívic es una asociación sin ánimo de lucro que tiene como objetivo ofrecer propuestas y soluciones aplicables a nuestra sociedad para hacerla más justa y respetuosa con las personas y el entorno a través de valores aplicados a un urbanismo y un acceso a la vivienda no especulativos. Promueve un nuevo camino de acceso al habitat basado en Modelos de Cooperativas de Uso (MCU) según el cual la propiedad de las viviendas siempre reside en manos de la cooperativa y donde sus miembros participan y disfrutan de un uso indefinido de la vivienda a través de un derecho de uso asequible.

\section{Cooperativa Integral Valenciana (Valencia) http://cooperativaintegralvalenciana.es/}

La Cooperativa Integral es un proyecto que busca la emancipación del sistema capitalista mediante la autogestión. Con este propósito trata de crear red entre los proyectos autogestionarios existentes (grupos de consumo, bancos de tiempo, monedas sociales...) así como de facilitar

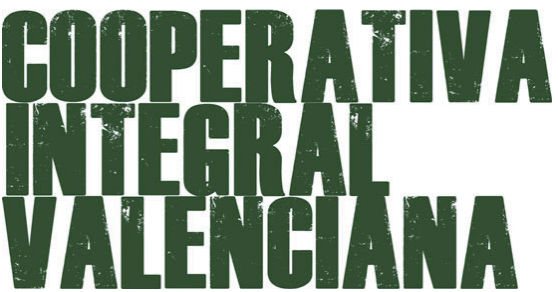

Fig. 41 la formación de nuevos proyectos. Es una propuesta constructiva de desobediencia y autogestión generalizadas para reconstruir la sociedad desde abajo (en todos los ámbitos y de manera integral) y recuperar las relaciones humanas afectivas, de proximidad y basadas en la confianza. Forma parte de una red territorial de cooperativas integrales que surgen como herramientas para formar contrapoder desde la base, partiendo de la autogestión, la autoorganización y la democracia directa y participativa. A raíz de esta invitación, hemos continuado implicándolos en proyectos posteriores como el encuentro sobre el decrecimiento y esperamos, por la cercanía de nuestros intereses y la similitud de nuestros modos, que podamos seguir colaborando en el futuro.

De esta manera, no nos limitamos a teorizar sobre posibles modelos económicos sino que proponemos directamente alternativas prácticas desde el 
ámbito del consumo, la energía, la vivienda y la moneda. No por ello podemos darle la espalda al hecho de que siguen siendo propuestas minoritarias, que asustan por lo novedoso de sus planteamientos, de manera que muchas persona temen dar el paso en elementos tan importantes como estos prefiriendo ajustarse a propuestas menos radicales como mercados de consumo locales 0 acuerdos privados de mancomunidad.

\section{Miradas a la crisis}

Por último, terminamos este seminario doble con unas intervenciones que, desde el ámbito teórico, nos permiten ampliar el horizonte de lo posible y apostar por una radicalidad en la transformación que ya veníamos anunciando desde los diferentes seminarios de autoformación en los que participamos. Empezamos con la intervención de Yann Moulier-Boutang, militante político, ensayista, economista e investigador, en la actualidad es profesor de Economía en la Universidad de Compiégne y en el Institut d'Études Politiques de París. En el marco del Laboratoire Isys-Matisse del CNRS-Université de París I, continúa sus estudios sobre la historia del movimiento obrero, la esclavitud y el trabajo asalariado, las migraciones internacionales, las transformaciones actuales del capitalismo en la globalización y en Europa, los nuevos modelos productivos en la empresa y los territorios a la luz de las nuevas tecnologías de la información y la comunicación y su impacto sobre los derechos de propiedad intelectual.

En su conferencia, Capitalismo cognitivo, polinización y renta básica, nos introdujo el tema fundamental de su último libro ${ }^{196}$ en donde desde sus conocimientos como teórico de la economía, introduce la necesidad fundamental de operar un cambio en el modelo de acumulación y redistribución de nuestras sociedades, modelo que tenga en cuenta todas las externalidades positivas no reconocidas situadas en la base así como la necesidad de fomentar que este tipo de polinizaciones se siga produciendo a través de mecanismos como la renta básica. A continuación, Anne Querrien, de la que ya hemos hablado en relación con los procesos de recuperación en barrios sometidos a una tensión gentrificadora intensa, como fue el caso de Belleville en París, retomó nociones como la Multitud y su posible papel transformador en las metrópolis postfordistas. Finalmente, Madeleine Hersent, que ha colaborado en diferentes proyectos con los coeditores de Multitudes, hizo una presentación de Herramientas y estrategias de difusión de la Economía Social bajo una perspectiva de género, orientadas a grupos invisibilizados y especialmente precarizados como pueden ser las mujeres. En un momento en el que pretendíamos lanzar un centro de Economía Social como La Calderería, resultó fundamental para nosotros empezar a establecer y difundir nociones de base solidas que

196. MOULIER-BOUTANG, Yann. L'abeille et l'économiste. París: Ed. Carnetsnord, 2010. 
permitan este tipo de enfoques de emprendizaje con una perspectiva fundamentalmente social, que enlaza directamente con nociones como control del consumo como modelo paradójico de reactivación económica.

Para terminar con este bloque de economía crítica, disfrutamos de la participación de Paco Álvarez, economista, presidente de ETICA Family Office y ex presidente de la Bolsa de Valencia, con el que seguiremos colaborando vista su clara implicación en el intento de transformación conceptual desde el ámbito económico, piedra angular de todo cambio que podamos pretender en la actualidad, y que nos ofreció una Introducción a la Economía del Bien Común tal y como la viene planteando Christian Felber, aplicando criterios como sostenibilidad, comercio justo, respeto del medio ambiente e integración local.

\section{Seminario sobre el decrecimiento}

\section{5 de octubre de 2012 - La Calderería}

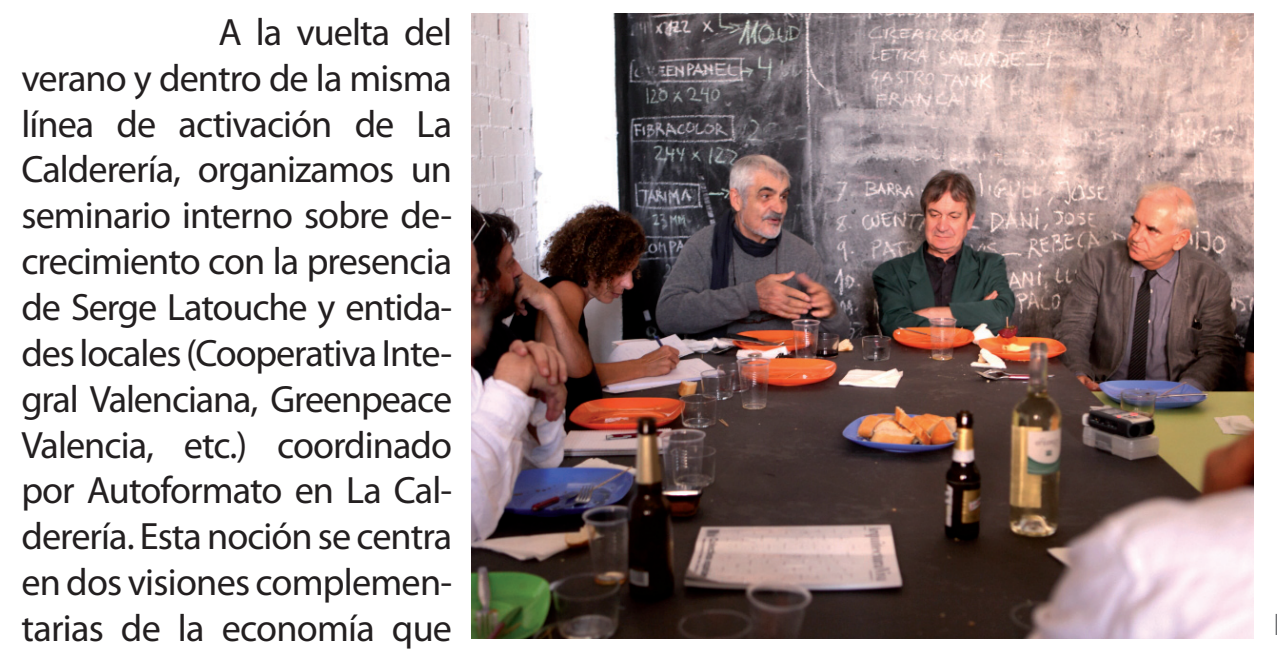
implican la modificación de los parámetros de riqueza, con lo que ello supone de visibilización de otros criterios tanto sociales como económicos a nivel estatal, incluyendo una visión de la economía que abarque no solo la producción sino también el ámbito de la reproducción. Por otra parte, la noción de decrecimiento resulta clave en el siglo XXI y consideramos fundamental incluirla como uno de los ejes de cambio propuestos.

Por todo ello, invitamos a Serge Latouche a una tertulia en La Calderería junto con sociólogos, arquitectos, ecologistas y jóvenes interesados en el modelo del decrecimiento. Tras la comida, el encuentro siguió el modelo de conversación que ya habíamos utilizado previamente, animada por la presencia de especialistas en decrecimiento como Ernest García, sociólogos combatientes 
como José Manuel Rodríguez Victoriano, economistas aterrados como Paco Álvarez, ecologistas plásticos como José Albelda o representantes de propuestas como la Cooperativa Integral Valenciana (que intenta llevar a la práctica el círculo virtuoso propuesto por Latouche como alternativa a la situación actual). Esta crisis que, según los presentes, es una crisis y es una estafa, exige plantearse respuestas revolucionarias y no únicamente posturas reactivas que no asuman la urgencia del momento. Se trataría, por tanto, de elegir entre un decrecimiento organizado o un decrecimiento sin orden ni concierto, como el que, desde las instancias políticas, nos están ofreciendo. El encuentro terminó evaluando las posibles vías para forzar un cambio responsable ante la irracionalidad de las respuestas vigentes.

\section{Investigación sobre centros autogestionados en París}

\section{2-18 de noviembre de 2012}

Por último, hicimos un viaje a París dentro del proyecto subvencionado por el Fonds D'Alembert para hacer una investigación de campo sobre diferentes modelos de gestión y financiación de centros autogestionados con una orientación similar a La Calderería. Dentro de la serie de centros visitados estuvo el célebre 59RueRivoli ${ }^{197}$, centro de producción artística anteriormente ocupado y autodenominado aftersquat, por su condición subvencionada actual (lo que, en este caso, supone que se encuentra desactivado), que nos interesó como proceso de institucionalización derivado en una neutralización de su potencial transformador; el complejo le6d, situado en Saint-Denis, con más de 150 residentes y una orientación clara de centro multidisciplinar autogestionado al mismo tiempo que desarrolla actividades inclusivas con los habitantes de las chabolas situadas al otro lado del canal. Es un centro para nosotros de referencia ya que combina la acción en el territorio con propuestas laborales propias como gabinetes de arquitectos, despachos de abogados, etc., funciona con financiación propia, aplica un sistema de gestión por comités diferenciales, y tiene una orientación general claramente de proximidad. Otro de los centros que visitamos fue Main d'oeuvres, centro de creación con talleres y residencias que inició su camino como espacio autogestionado aunque en la actualidad, disfruta de numerosas subvenciones estatales, hecho que ha transformado indudablemente su carácter; o por último el teatro restaurado del colectivo Frères Poussière que funciona con criterios similares a los de le6d pero en menores dimensiones, y con el que estamos lanzando en la actualidad un proyecto europeo de intervenciones urbanas en colaboración con Encajes Urbanos.

197. http://www.59rivoli.org/, http://www.le6b.org, http://www.mainsdoeuvres.org, http:// www.freres-poussiere.com/. 


\section{Conclusiones AUTOFORMATO}

Con este último seminario sobre decrecimiento y el viaje que realizamos para establecer vínculos a nivel internacional con otros centros, damos por cerrado el apartado dedicado a las actividades del colectivo Autoformato e intentaremos a continuación hacer una especie de resumen de nuestros rasgos diferenciales. Autoformato es un formato de investigación militante que parte de la imposibilidad de establecer una distancia (que no es más que otra manera de blindarse, de no dejarse afectar,) con el objeto de su propia investigación. Actúa más bien como mediador del conocimiento aplicando la siguiente pauta:

1. detecta carencias de conocimiento;

2. propone redes poniendo en relación a diferentes agentes para realizar intercambios de conocimiento bidireccionales;

3. programa un marco de relación en el que efectuarlos;

4. media en el proceso final.

En este proceso, hacemos especial hincapié en dos fases: por una parte, la detección o creación de conceptos en base a necesidades y deseos con una clara intención de investigación militante (en nuestro caso, hasta ahora, nociones como el procomún, la renta básica, las fronteras internas, los procesos participativos urbanos o el decrecimiento). Por otra, la generación de un diálogo en el que desde el primer momento se esté planteando la igualdad de capacidades entre los diferentes interlocutores. Eso implica planificar procesos más largos, de mayor implicación, de ida y vuelta, en los que el momento del encuentro sea simplemente una carnalización de un diálogo previo y de una conversación posterior. Su orientación se caracterizaría por:

1. La puesta en relación de las teorías críticas con las prácticas de los movimientos sociales en la transformación de la metrópolis, priorizando la conexión con la sociedad y respondiendo a las necesidades de autoformación para dotarse de herramientas conceptuales que desde las segundas se planteen como urgentes.

2. La utilización de las nuevas tecnologías para promover la producción y la difusión horizontal de conocimientos a través de archivos, emisiones streaming y vídeos como herramientas básicas para visibilizar y socializar esos procesos.

3. La vinculación con las diferentes instituciones de conocimiento entre las que se encuentra la universidad, buscando su implicación en procesos de construcción conjunta de teoría y devolución de la misma a la sociedad.

Nuestra primera intervención de Conversaciones de Primavera, sería un caso paradigmático de este modus operandi en todas sus facetas. En Comboi 
a la fresca planteamos el mismo sistema aunque luego nos dimos de bruces con la realidad, los problemas de comunicación con las asambleas de barrio, nuestros propios problemas de organización asamblearia, la dificultad de adecuar los tiempos a las necesidades, etc. Intentamos hacer cartografías generales que le den más peso a los encuentros puntuales, que se articulen con otras líneas y proyectos para ir completando carencias, como por ejemplo en el planteamiento del proceso participativo del Solar Corona, pero intentándolo hacer en la misma dirección que en el taller de metodologías participativas: primero atender a las dinámicas internas para pasar después a los procesos participativos. No obstante, el abanico de talleres que generamos durante el Comboi a la fresca es un fiel reflejo de los ejes de acción que nos estructuran:

1. Responder a las necesidades de autoformación en el ámbito político que se plantean como urgentes desde los movimientos sociales: el aprendizaje de metodologías asamblearias y procesos participativos destinados a producir empoderamiento político mediante procesos instituyentes.

2. A partir de una oportunidad táctica, tramar una estrategia. En este caso, plantear un marco de análisis que no se limitara a un espacio determinado (la oportunidad concreta que supone el posible diseño participativo de plaza pública proyectada por el Ayuntamiento en el Solar Corona), sino generar un marco de análisis de carencias y deseos que dinamice las energías hacia un proceso de empoderamiento físico generalizado: no es el solar, son los diferentes espacios por los que se podría optar, inventando herramientas y abordando las realidades jurídicas de ocupación de espacios en desuso.

3. Igualmente importantes consideramos las posibilidades de empoderamiento laboral desde las diferentes modalidades de emprendizaje hasta las alternativas económicas que no utilizan el dinero como moneda de cambio, como fue el caso tanto en el debate de Periferias como en el seminario de economía crítica que desarrollamos posteriormente y el proyecto en sí de La Calderería del que hablaremos más adelante.

4. Por último, las diferentes opciones de soberanía alimentaria propuestas en el debate sobre agroecología urbana así como los diferentes debates sobre decrecimiento, ecología y energías renovables, nos permiten trabajar las posibilidades de empoderamiento ecológico, más que perentorio hoy día.

Desearíamos poder hacer extensibles al máximo estos cuatro ejes. Este último punto indica ya a cuáles son las líneas de sostenibilidad del colectivo en los próximos años. En primer lugar, queremos empezar a trabajar con una serie de archivos o repertorios de textos de cada temática que se aborda, que no sólo incluya las intervenciones de los ponentes, sino que esté orientada hacia la producción de 
reflexión e investigación propia, así como a la facilitación de la misma a través de las traducciones. El formato adecuado sería una edición on-line temática de cada seminario. Avanzar en esta línea, en una mayor profundización, explotación y difusión de los temas que abordamos, es una prioridad que nos marcamos para el 2013. En segundo lugar, el colectivo está empezando a trabajar en red junto a otros colectivos del territorio con inquietudes similares. Igualmente, el trabajo coordinado para la producción de encuentros, tanto en lo concerniente a la invitación de ponentes como en la convocatoria conjunta de su difusión vía streaming, junto con Traficantes de Sueños y la Cooperativa Tramallol, augura nuevas colaboraciones posibles en la línea de la articulación más allá del territorio local.

Por último, hemos presentado un proyecto europeo de formación para adultos (Grundtvig) junto con Encajes Urbanos, un colectivo que ya trabajó con nosotras durante el Comboi a la fresca, en el que aunamos proyectos de difusión del común en entornos desfavorecidos, intervenciones en solares y propuestas ecológicas que trabajan en torno al decrecimiento. Pensamos que la recuperación de espacios en desuso para su colectivización, la implicación de grupos muy diversos en la creación del común y la transformación de la ciudad hacia una propuesta más cercana al slow living con criterios ecológicos son tres elementos fundamentales en las transformaciones que deseamos.

\section{5 Comboi a la fresca}

\section{$4^{a}$ edición del Encuentro Arquitecturas Colectivas}

http://comboialafresca.arquitecturascolectivas.net/
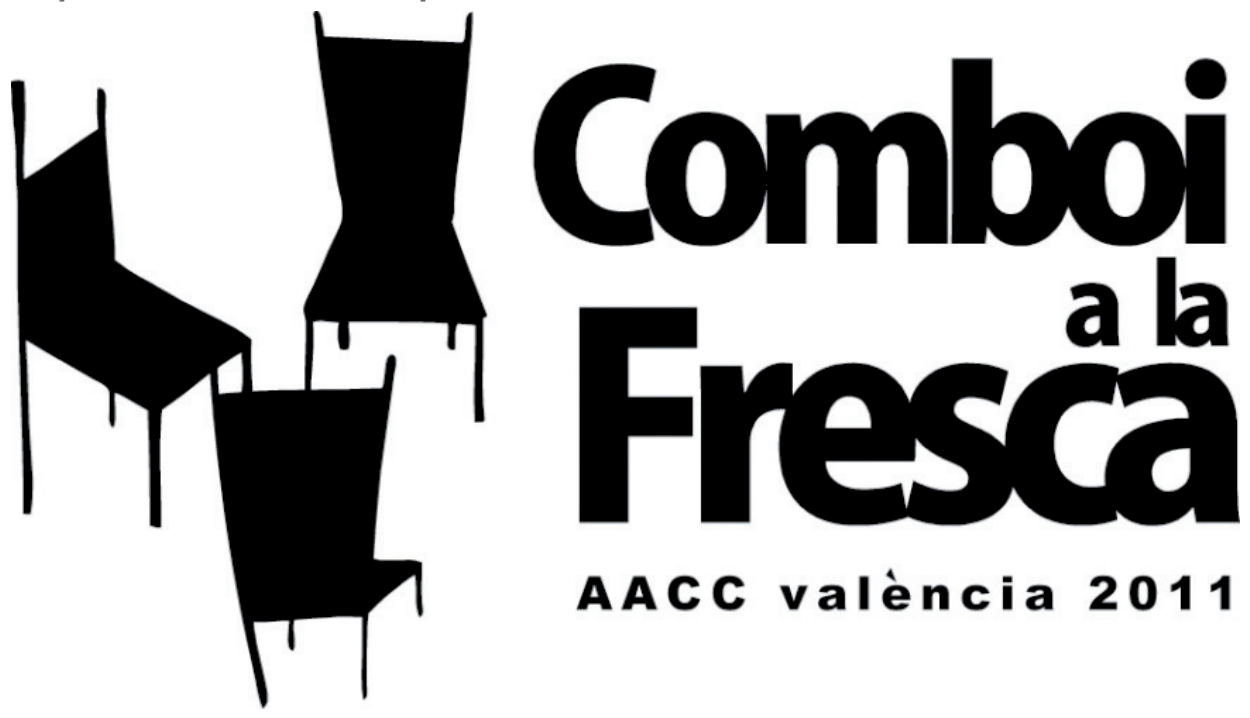

AACC valència 2011 
Retomamos aquí un encuentro del que ya hemos hablado para detallar la intervención específica de Autoformato, pero que nos interesa igualmente como proyecto grupal de transformación a nivel de ciudad. Aunque sería más preciso decir que el Comboi ha funcionado como proceso general de autoformación del grupo en su doble sentido, de una comunidad orientada al empoderamiento ciudadano a diferentes niveles que quizás pueda responder a la definición difusa que anteriormente hicimos de la misma en el capítulo. Este encuentro lo realizamos junto con otra serie de colectivos valencianos en nuestra ciudad del 18 al 24 de julio pero empezamos a trabajar muchos meses antes, en torno a noviembre de 2010, a partir del momento en que propusimos que la próxima convocatoria de Arquitecturas Colectivas se podría realizar en Valencia. Dadas las características de esta ciudad en donde la atomización a todos los niveles es la tónica habitual, resultó un proceso largo y complejo por el trabajo minucioso que supuso de articulación e incorporación de colectivos al núcleo organizador.

Este encuentro nos parece importante porque evidencia el hecho de que la metrópolis es el marco actual en el que suceden los cambios, en donde se juega la posibilidad de implementar una gobernanza real que no se limite a desdibujar actores y responsables sino que constituya el marco real para las instituciones del común. Ese procomún que va más allá de los fenómenos climatológicos y financieros evidenciados de tantas maneras durante esta crisis, con ejemplos tan llamativos como la erupción del volcán Eyjafjallajökull en Islandia en 2010. Los daños económicos, en una época en que la crisis empezaba a mostrar sus dientes, fueron importantes: sólo el turismo español perdió 252 millones de euros y las aerolíneas europeas aseguraban haber perdido 1.264 millones de euros. Independientemente de este detalle que evidenció todo un entramado de dependencias así como de identidades confusas ${ }^{198}$, se hizo patente que las fronteras resultan hoy en día tan imposibles como los procesos de identificación con una idea compartida de Europa, paradoja existencial en la que resulta difícil pensar los espacios comunes.

Pero estos espacios comunes que, nos gusten o no, determinan nuestras dependencias pero también nuestros afectos, no tienen un correlato en la estructura de la ciudad y menos aún en su planificación por lo que, desde ese embrión de colectivo que empezó a caminar allá por noviembre del 2010, nos planteamos cómo crear, fomentar o visibilizar espacios en la ciudad que permitan generar una cultura del procomún. Intentamos hacerlo mediante la creación de una plataforma de colectivos extradisciplinar, orientada a transformar el biopoder

198. Para más información, véase V.V.A.A.Correspondencias desde Eyjafjallajökull. Montaña-isla-glaciar, Ed. Broken Dimanche Press, , Madrid 2011, (libro en el colaboré como traductora), publicación con la que concluyó un proceso abierto de reflexión sobre el malestar inscrito en la idea de Europa generado a raíz de dicha erupción y las implicaciones europeas que supuso. 
en biopolítica que nos permita "poner a trabajar" la ciudad para intereses ajenos al capitalismo. Entraremos ahora en la descripción cronológica del encuentro para intentar explicar lo que entendemos por prácticas de empoderamiento y por espacios del procomún.

De hecho, la primera parte de la tesis actúa como conceptualización previa que permite situar el contexto de intervención de Comboi a la fresca en unas coordenadas específicas que no hacen más que agudizarse cuando se estudia la situación particular de la propia ciudad. En ella, los ciclos de gentrificación y la creación-transformación de barrios mediante intervenciones faraónicas de complejos espectaculares de gran impacto que buscaban la inclusión de la ciudad en las rutas turísticas de alto nivel, han producido una polarización de las posiciones de la Administración y los ciudadanos que, en algunos casos, data de más de quince años de enfrentamiento sobre la forma de la ciudad.

Tal y como Pau Rausell muestra en diferentes artículos, la ciudad ha intentado borrar su pasado huertano mediante un proceso de creación de marca o de imageenering urbano para reposicionarse en esa búsqueda de la etiqueta de la ciudad global propia del siglo XXI. Inicialmente orientada hacia una estrategia cultural en las décadas de los 80-90, a partir del ascenso de la derecha al poder, empieza la apuesta por la cultura rutilante $y$, tras haber fracasado en los intentos de generar alta cultura mediante festivales culturales o encuentros de expertos (Mostra de Cinema, Bienal de Valencia, Valencia III Milenio, etc.), finalmente se decanta por lo rutilante a secas mediante una acumulación de eventos lúdico-deportivos (sector de marketing urbano correspondiente a los grandes cruceros, al turismo de lujo basado en eventos para ricos: ópera, vela, hípica, fórmula uno). En el período 1999-2003, coincidiendo con las operaciones de arquitectura estelar, se desarrolla la expansión de la ciudad en diversos ejes en a partir de una actividad inmobiliaria sin precedentes y sobre los terrenos de la huerta, generando procesos de recalificación y/o expropiación que están teniendo consecuencias desestructurantes a largo plazo. No obstante, citando a Rausell ${ }^{199}$, vemos cómo la planificación urbana de la ciudad (si es que se puede denominar como tal) se ha hecho a golpe de ocurrencia, al margen de toda estrategia planificadora y con unos niveles de gobernanza mínimos:

Una de las primeras carencias parte del hecho de que la planificación no ha sido tal sino que hemos asistido a una secuencia de acontecimientos que responden a lógicas de agentes distintos (poder local, poder autonómico, promotores inmobiliarios, universidades, movimientos ciudadanos) que difícilmente se pueden someter in falsear a la coherencia de una voluntad colectiva de planificación. Ni siquiera hoy, en un momento que sí es posible detectar un discurso de planificación urbana en activo, pensamos que dicho discurso tenga la más mínima influencia en el acontecer de las intervenciones urbanas más que como justificación discursiva posterior. Los procesos de decisión

199. RAUSELL KÖSTER, Pau. Valencia: desde la huerta al ocio. Valencia: Universidad de Valencia, 2010. 
responden a lógicas ocurrenciales que cubre expectativas a muy a corto plazo y muy vinculados a intereses de grupos de presión muy concretos (sean estas facciones de partidos, agentes económicos, clubs deportivos, etc.).

En ese sentido, se evidencia la falta de planificación y la indiferencia con la que se considera la opinión y necesidades de la ciudadanía en la gran profusión de conflictos basados en intervenciones urbanas (o en su ausencia). En la mayoría de los casos, surgen voces disonantes desde las asociaciones de vecinos o desde las plataformas de afectados de nueva creación para intentar generar un diálogo fructífero o por lo menos con fines paliativos, con la Administración. Con ese trasfondo reactivo de las asociaciones de vecinos de primera generación, sumado a los colectivos de segunda generación que empiezan a actuar desde otro punto más cercano al nihilismo de resistencia ${ }^{200}$, nos planteamos desde el principio la necesidad de imbricarnos en estos procesos para poder realizar un encuentro en el que se tuviera en cuenta la ciudad como marco pero también como ecosistema interactivo en el que subsumirse.

En esta ciudad, tenemos la suerte o la desgracia de poder observar en directo y con detalle lo que supone una ciudad cuyo espacio urbano se ve sometido a diferentes tensiones en las que hay una relación directa entre espacio y poder, y cómo esa relación está sustentada en decisiones políticas que son ideológicas, aunque incoherentes. No olvidemos la imagen de la ciudad sometida a tensiones expansivas y la manera que se tiene de resolverlas o complicarlas, cómo está repleta de puntos cegados de expansión que muestran a las claras la vinculación directa entre espacio/poder/política/dinero. Si aplicamos los diferentes niveles de gestión que actúan en la ciudad, como bien explica Rausell ${ }^{201}$ :

La gestión de las urbes es, por tanto, en un complejo ejercicio que trata de fijar en un mundo móvil y acelerado todas las dimensiones que tiene que ver con:

- la circulación de relaciones que se establecen entre la ciudadanía representada y participante. (ciudad vivida)

- la ciudad como espacio de producción y generación de valor añadido (ciudad como unidad de producción)

- Y la ciudad como vórtice de consumo y atracción de flujos. (ciudad como espacio de consumo y distribución)

Y todo ello en un marco donde todos los demás ciudades se mueven también en búsqueda de nuevas especializaciones competitivas (marco dinámico).

En este caso, no resulta extraño que Valencia haya intentado situarse dentro de la dimensión simbólica implícita en el cambio de paradigma que va

200. PASTOR, Marina. Nihilismo de resistencia: pensamiento, interpretación y escultura como tácticas de acción, UPV, Valencia, 2001.

201. RAUSELL KÖSTER, Pau, op. cit., p. 80. 
de la ciudad paleta y huertana a la ciudad espectacular de grandes intervenciones arquitectónicas; lo que ha resultado, a nuestro parecer, claramente dañino (sin entrar en el endeudamiento global e insostenible que nos ha lastrado para las siguientes décadas),es haber aplicado un modelo de gestión centrado únicamente en la dimensión de la ciudad para ser consumida, haciendo caso omiso de su condición de ciudad para ser vivida, lo que se opone radicalmente a la visión que tenemos de una slow city de las que se propusieron en Italia de la mano de Tonucci ${ }^{202}$, cuyo urbanismo integrador, especialmente atento a las necesidades de los niños y los mayores, de aquellos que aún viven las ciudades, al urbanismo depredador de recursos y consumista de Calatrava.

Este contexto de la ciudad como microcosmos en el que se juega la posibilidad de implementar una gobernanza real, basada en un empoderamiento efectivo sobre el territorio que pueda dar pie a la generación más que necesaria de instituciones del procomún, nos enfrentó a la necesidad de reelaborar una cultura del procomún, ignorada u olvidada en muchos casos e inevitablemente necesitada de reinterpretación desde la actualidad. Por otra parte, pasamos a la acción activando una plataforma de puesta en práctica de dicha cultura a nivel de ciudad, habilitando tanto espacios físicos como mentales para llevarlo a cabo, aprovechando la oportunidad que la organización del IV Encuentro de Arquitecturas Colectivas nos ofrecía.

Los encuentros de Arquitecturas Colectivas ${ }^{203}$ se han venido realizando en diferentes ciudades de España desde 2007. La red de Arquitecturas Colectivas es una red de personas y colectivos interesados en la construcción participativa del entorno urbano mediante procesos colaborativos de intercambio de información, de realización conjunta de proyectos y de cita anual para presentar los nuevos proyectos Esta cita anual se concreta en un encuentro entre la ciudadanía, profesionales y agentes sociales de diversa procedencia, en los que conceptos como arte y arquitectura se utilizan como recurso para pensar y debatir sobre la construcción y gestión participativa del entorno urbano. Los colectivos participantes proceden, entre otros, de los campos del asociacionismo urbano, educación, arte, ecología, pensamiento, arquitectura, gestión cultural, cooperativismo, vivienda y nuevas tecnologías.

En esta ocasión, diferentes personas y colectivos de Valencia, con mayor o menor implicación en la red Arquitecturas Colectivas, propusimos que el IV encuentro se celebrara en esta ciudad y, con el objetivo de adaptarlo a las circunstancias anteriormente enunciadas, establecimos un modus operandi nuevo del que surgió la convocatoria Comboi a la Fresca, posteriormente consolidada en una plataforma de intervención urbana con aspiraciones de permanencia y de reincidencia (LaCIV).

202. TONUCCl, Francesco. Cuando Los niños dicen: ¡Basta!, Salamanca: Fundación Germán Sánchez Ruiperez, 2003.

203. www.arquitecturascolectivas.net. 
Las convocatorias anteriores partieron de un pequeño encuentro en Córdoba en 2007 que se tituló AACC en el que participaron 12 colectivos de la ciudad y 4 de fuera, pertenecientes fundamentalmente al ámbito de la arquitectura. Se aprovechó un evento cultural de la ciudad (Eutopía 07) para pedir un espacio institucional, y la coordinación corrió a cargo de Santiago Cirugeda, siendo la metodología la de la presentación mutua entre colectivos. Ya desde el principio, se explicitó un objetivo claro: ante la necesidad de una sociedad civil motivada que intervenga de forma propositiva y creativa en la transformación y acondicionamiento del medio urbano, la idea era conectar en red distintos agentes y ensayar su capacidad para incidir sobre la construcción colectiva del hábitat, entendiendo ese 'hábitat' como una entidad compleja donde se combinan, entre otros, aspectos constructivos, paisajísticos, sociales, culturales y tecnológicos que dan pie a múltiples enfoques disciplinares. Se consideró que la apertura de canales de comunicación, debate y colaboración entre esa diversidad de agentes sólo podía incidir de forma positiva sobre la calidad y adecuación de las propuestas que de ahí puedan emerger.

Posteriormente, con la intención de consolidar este encuentro, se programó el siguiente un año después en Cataluña, y allí se vivió algo completamente distinto, en la montaña, sin dinero ni apoyo institucional, con la participación de mayor número de colectivos y una gran convivencia, pero se mantuvo el formato de presentaciones de colectivos y de sus respectivos trabajos. El tercer año se eligió Donosti como lugar de encuentro, pero esa vez, se aprovechó el hecho de realizarlo en una Comunidad con mayores fondos y que suele destinar dinero a proyectos culturales y se pidió una subvención pública para financiar el viaje de los colectivos (150 euros para cada uno) y rehabilitar el edificio industrial en el que se produjo el encuentro, vinculando ya con ello a colectivos de la ciudad.

En la planificación del encuentro de Valencia, nos planteamos desde el primer momento que, puesto que muchos de los colectivos ya nos conocíamos, nos interesaba más un proceso en el que pudiéramos impregnar e implicar a la ciudadanía, dejando un rastro en la ciudad. Tras múltiples reuniones en locales que posteriormente participaron en la convocatoria de manera más o menos directa (Ca Revolta, Arte-facto, La Minúscula...), decidimos el modo en el que queríamos operar en el encuentro, de manera asamblearia y abiertos a la colaboración de nuevos colectivos que quisieran integrarse en el núcleo de organización. Conectamos para ello en una primera fase con las asociaciones de vecinos de diferentes barrios de Valencia. Como hemos dicho, por un lado, se tuvo la intención de trascender las ediciones pasadas de AACC, teniendo a Pasaia como referente; por otro lado, se pretendió ampliar la base social de AACC: incorporar a todos aquellos colectivos que construyen colectivamente la ciudad, y no han estado ni se les ha tenido en cuenta en las anteriores ediciones. 
Por ello, nos remitimos a las asociaciones de vecinos que han sido fundamentales en la Transición y que, como ya indicamos, han ido perdiendo fuerza conforme sus miembros envejecían y no se producía el esperable relevo generacional. En la reunión que convocamos para presentarles el proyecto, reunión que no auspició especialmente la Federación de asociaciones, temerosa de perder su posición central en esta red de relaciones, pudimos observar en directo la fatiga de los que habían portado el testigo asociativo hasta ese momento y la falta de

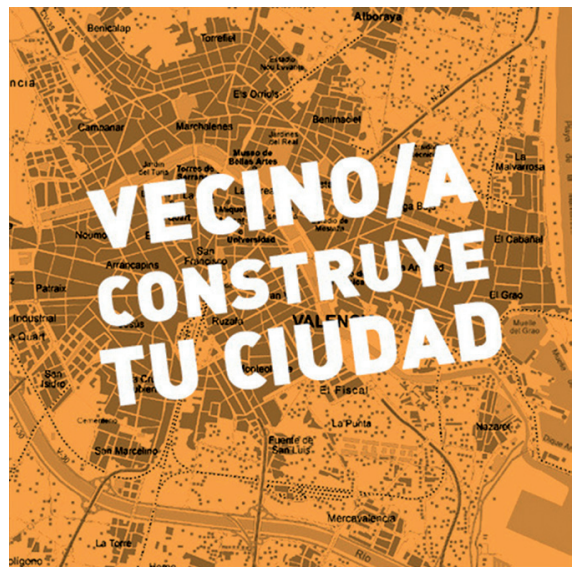
adecuación a las nuevas herramientas digitales de coordinación y difusión, lo que hace que se reduzca su capacidad operativa y movilizadora. No obstante, nuestra sensación primera fue muy gratificante, la mayoría de asociaciones se volcaron en el proyecto iniciando una colaboración que no terminaría con el encuentro, si bien es verdad que las asociaciones que asistieron en su mayoría partían de una insatisfacción o directamente, de la oposición a las intervenciones urbanísticas del Ayuntamiento. Adjuntamos a continuación la carta que enviamos a las asociaciones y colectivos de la ciudad y, ligeramente modificada para adaptarla, a los colectivos del resto de España aunque por red, acabara siendo extensible a colectivos internacionales.

\section{CONVOCATORIA A COLECTIVOS DE VALENCIA.}

\section{qué?}

Los encuentros 'Arquitecturas Colectivas' se han venido celebrando desde 2007. Se trata de encuentros entre la ciudadanía, profesionales y agentes sociales de diversa procedencia, en los que conceptos como arte y arquitectura se utilizan como recurso para pensar y debatir sobre la construcción y gestión participativa del entorno urbano. Durante las jornadas se celebran presentaciones, talleres prácticos, exposición de proyectos, intercambio de referencias, etc. Otra característica de estos eventos es que se aprovecha la oportunidad para construir y ensayar prototipos de equipamiento de espacio público o de nuevas tipologías de vivienda, o como en este caso, para reciclar un espacio en desuso.

\section{quién?}

Arquitecturas Colectivas es una red de personas y colectivos interesados en la construcción participativa del entorno urbano. Esta red proporciona un marco instrumental para la colaboración en diferentes tipos de proyectos e iniciativas. Esto se manifiesta principalmente en tres formas: mediante sistemas de 
comunicación (on-line, audiovisual o impresa), mediante proyectos colaborativos (diseño y construcción de prototipos, cooperación internacional, apoyo a procesos participativos) y mediante encuentros presenciales (intercambio de experiencias, talleres, testeo de prototipos).

Esta red está en permanente crecimiento, con presencia de colectivos provenientes del Estado Español, Europa y Latinoamérica y a día de hoy la componen, entre otros, Recetas Urbanas, Straddle3, La Fundició, Proyecta, Proyecto ASILO, Mytaki, Todo por la Praxis, Democracia, Patio Maravillas, Estaesunaplaza, Hackitectura, AulaAbierta, Nautarquía, M-etxea, Lur Paisajistak, Hiria Kolektiboa, La Matraka, vi-bok, Caldodecultivo, Alg-a, ColoCo, Sostre Cívic, VdeVivienda, Re-farm the City, Tv Negra, Semillero de Proyectos, Faro de Oriente, Nodo, Axial, Ecocultura TV, Global Nature, Apartados, Radiópolis, Unidad Permanente de Vivienda.

\section{por qué?}

Desde muchos ámbitos se siente la necesidad de una sociedad civil motivada que intervenga de forma propositiva y creativa en la transformación y acondicionamiento del medio urbano. La idea es conectar en forma de red distintos agentes y ensayar su capacidad para incidir sobre la construcción colectiva del hábitat, entendiendo ese 'hábitat' como una entidad compleja donde se combinan, entre otros, aspectos constructivos, paisajísticos, sociales, culturales y tecnológicos que dan pie a múltiples enfoques disciplinares.

\section{ARQUITECTURAS COLECTIVAS 2011: COMBOI A LA FRESCA}

En esta ocasión, estamos organizando un encuentro en Valencia, previsto para el verano 2011 durante la segunda y tercera semanas de Julio con el objetivo de:

1. Crear redes entre personas y colectivos de Valencia y entre éstos y AACC.

2. Canalizar dinámicas urbanas mediante nuevos discursos y prácticas transformadoras tratando de ampliar el círculo de A.A.C.C. para llegar a la ciudadanía.

3. Difundir el potencial político real de la ciudadanía.

\section{Proponemos:}

Un formato que consiste en la colaboración a distancia entre colectivos (locales y foráneos, local-local o foráneo-foráneo) durante los meses previos a la convocatoria. Las propuestas, acciones o talleres desarrollados se presentarán durante la semana del encuentro. El trabajo realizado quedará materializado en un catálogo de propuestas colaborativas y participativas.

\section{Para ello:}

Los colectivos locales y foráneos rellenarán sus datos (Origen/Fuerza/ Experiencia/Localización geográfica/Logo del colectivo) en la Baraja de cartas de presentación con el objetivo de iniciar la partida. En ellas, los colectivos resumen 
su trayectoria así como los asuntos centrales de los que se ocupan. De esta manera, todos los colectivos participantes podrán visualizar una serie de convergencias y posibilidades de combinación, dependiendo de las afinidades en problemáticas o rango de intereses entre ellos. El objetivo de esta baraja es facilitar la conexión entre colectivos para iniciar propuestas colaborativas que investiguen y desarrollen una acción, intervención o propuesta de transformación que se llevará a cabo y/o presentará durante el mes de julio.

\section{Convocamos:}

A todas las personas o colectivos que, desde distintos ámbitos, miradas y dimensiones, colaboren en la construcción y gestión participativa del hábitat:

- A participar en el encuentro.

- A proponer un proyecto o continuar con un proyecto ya empezado en el ámbito de la metrópolis.

- A trabajar en colaboración con otras personas o colectivos de Valencia o de fuera, conociendo otras herramientas y recursos y conformando equipos transdisciplinares.

- A visibilizar el trabajo realizado durante el encuentro y difundirlo posteriormente mediante la edición de un catálogo.

- A conformar una red propia de colectivos locales en Valencia y pertenecer a la red de AACC.

Os invitamos a una presentación previa al encuentro con el fin de explicaros más extensamente el proyecto y animaros a participar. ¡Nos vemos el próximo 4 de Febrero en Ca Revolta (Calle Sta Teresa no 10) a las 19h30!

En dicha presentación del Comboi a la fresca, realizada en febrero (aunque llevábamos desde noviembre de 2010 realizando reuniones semanales desde el grupo motor) en Ca Revolta, presentamos los antecedentes del encuentro (Isabel Pastor), hablamos del contexto social y de los referentes (Lluis Benlloch), comentamos la metodología y el formato de la convocatoria (Mijo Miquel) y finalmente, abrimos un debate entre las asociaciones asistentes y los colectivos organizadores durante una merienda reparadora. El listado inicial de asociaciones convocadas fue el siguiente:

AAVV Sant Marcel.lí/AAW Patraix/AAVV Orriols/AAVVTorrefiel/AAWV Velluters /AAVV Nou Moles/Amics del Carme/AAVV El Carme/Plataforma per Russafa/ AAVV Benimaclet/Benimaclet Viu/AAVV Campanar/AAVV Natzaret/AAVV Cabanyal/ Amics de la Malva/AAVVVilanova del Grau/AAVV Patacona/Koordinadora de collectius del Parque Alcosa/Federació AAVV /Salvem el Cabanyal/Salvem el Botànic/Per l'Horta/ CIES no/Mujeres grandes/València en Bici/Acció Ecologista Agró/Ecologistes en acció/ Conciència crítica/Universitat d'Estiu de l'Horta/Muixeranga de València

Igualmente, con fines testimoniales, enumeramos a continuación los colectivos que formamos parte de la organización general del encuentro: 
Encajes Urbanos, Sostre, Desayuno con Viandantes, La Minúscula, Autoformato, Recetas Urbanas, StreamingLab, Crearqció, United Artists from the Museum, y Makea así como algunas personas que, a título individual, quisieron incorporarse al proyecto.

http://encajesurbanos.com/

http://www.sostre.org/

http://www.desayunoconviandantes.com/

http://laminuscula.es/

http://autoformato.wordpress.com/

http://www.recetasurbanas.net/

http://www.unartists.org/

http://crearqcio.blogspot.com.es/

http://www.makeatuvida.net/

Nuestra propuesta de base fue provocar un proceso generalizado metropolitano de apropiaciones ciudadanas: apropiación del hacer ciudad, intentando paliar la sordera participativa de los políticos y de aquellos quienes les diseñan la agenda; apropiación de los saberes, y los conocimientos, que no tienen porque residir en los técnicos, sino en alianzas y redes de colectivos, colectivos y técnicos, como ya comentamos; apropiación como reverso de expropiación, dándole la vuelta a un término bastante generalizado durante las últimas décadas de urbanismo salvaje a golpe de decreto (recordemos casos aún no cicatrizados de expropiaciones en la huerta que circunda la ciudad, en el Cabanyal, en el Carme y el papel fundamental que ejercieron los diferentes Salvem que fueron surgiendo como plataformas reactivas de resistencia).

Con el objetivo de tejer redes y hacer ciudad, Comboi a la fresca fue simultáneamente un proyecto que reunió a diversos colectivos multidisciplinares en un espacio de reflexión sobre los fenómenos de transformación que caracterizan hoy a las metrópolis contemporáneas partiendo del análisis de estos procesos de cambio, y una plataforma de construcción de un espacio de comunicación entre ciudadanos, técnicos y movimientos sociales bajo el concepto de cuidadanía, concretado en pequeños proyectos de investigación-acción que se daban ya en la ciudad y en los movimientos sociales, pero que podrían alcanzar mayor dimensión y continuidad a través de la colaboración entre los diferentes agentes implicados.

Para esta convocatoria, propusimos pues un formato que consistió en la colaboración a distancia entre colectivos (locales y foráneos, local-local o foráneo-foráneo) durante los meses previos a la convocatoria de manera que las propuestas, acciones o talleres se desarrollaran y/o presentaran durante la semana del encuentro. Para iniciar estas múltiples colaboraciones, los colectivos locales y foráneos rellenaron sus datos (Destreza-Fuerza-Debilidad-Contacto-Logo del colectivo) en la baraja de cartas de presentación (toda la información sobre los diferentes colectivos y proyectos está en la página web del encuentro) con el 
objetivo de iniciar la partida, dándole un aire lúdico a toda la propuesta ya que el juego es una herramienta privilegiada en todos los procesos colaborativos. En dichas cartas, los colectivos resumieron su trayectoria así como sus intereses prioritarios de manera que todos los participantes pudieron visualizar una serie de convergencias y posibilidades de combinación, dependiendo de las afinidades en problemáticas o rango de intereses entre ellos. El objetivo de esta baraja fue facilitar la conexión entre colectivos para iniciar propuestas colaborativas que investigaran y desarrollaran una acción, intervención o propuesta de transformación conjunta.

\section{Ejemplo 1: cartas de colectivos (anverso y reverso)}
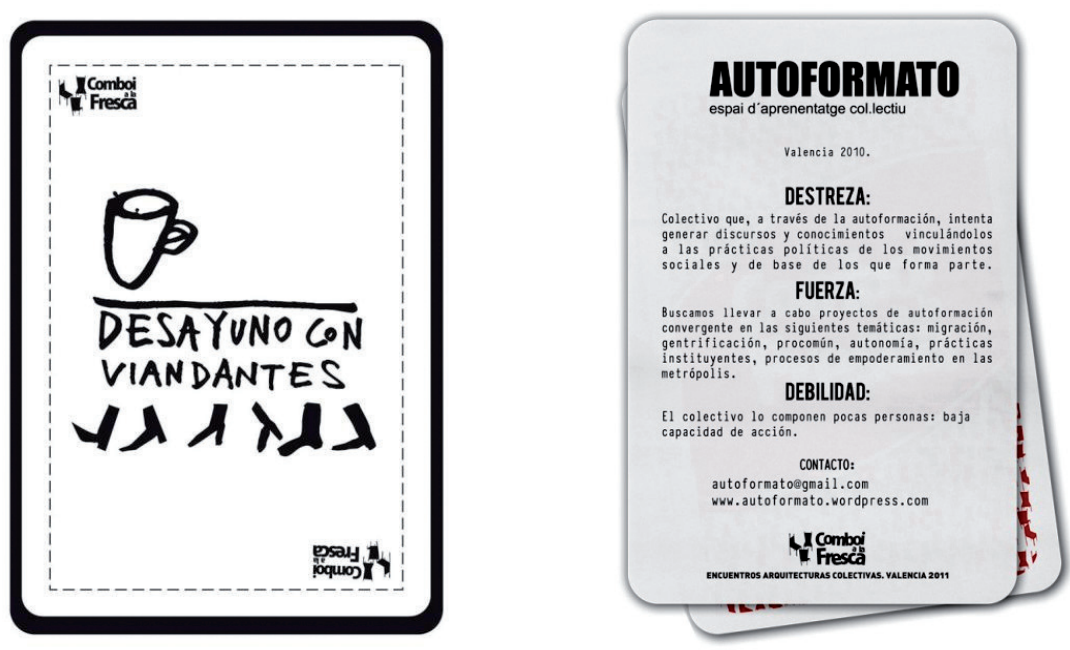

Ejemplo 2: formación de una red

a) determinado colectivo >> propone una temática como la gentrificación, el proceso de desalojo de vecinos de un barrio

b) una vez colgada la propuesta en la web, se incorporan colectivos con la misma temática e intercambian correos para ir perfilando una posible intervención conjunta:

REPENSAR BON PASTOR (Barcelona)

ARRABAL DE SAN BERNARDO (Sevilla)

Ejemplos de Valencia...

c) Propuesta específica para el Comboi a la fresca.

Consideramos que el enfoque lúdico que le aportaron las cartas fue un acierto como modo de presentación alternativo que pudiera motivar a la colaboración entre colectivos. Igualmente, la página web con un aparato de búsqueda muy sencillo y un blog de la ciudad de Valencia en el que se iban colgando todas las noticias que pudieran aportar información sobre el contexto 
y sobre las actividades y problemáticas de los grupos participantes fue un elemento importante para fomentar el conocimiento de lo que sucedía en la ciudad y las posibilidades de colaboración coherentes con el territorio.
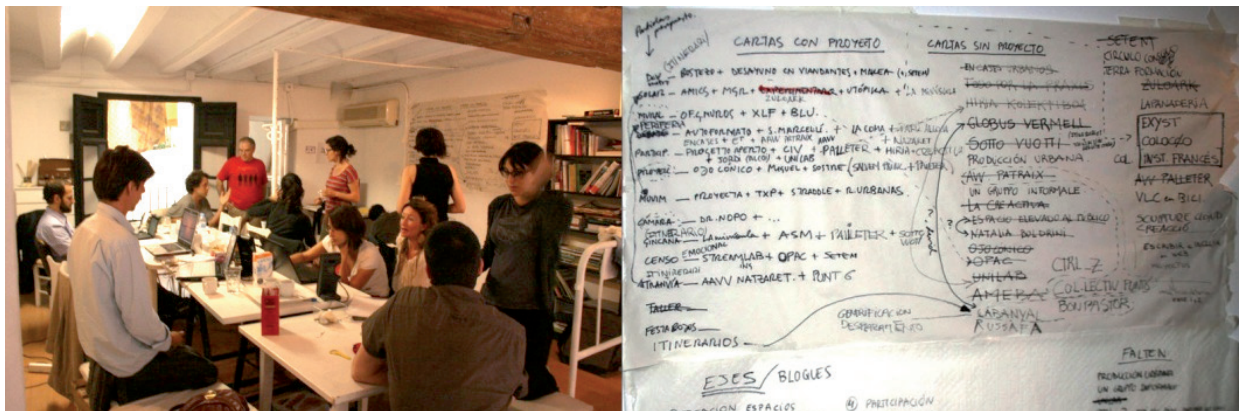

En algunos casos, hubo que intervenir en el desarrollo de los proyectos conjuntos, actuando como dinamizadores: realizamos un análisis de las diferentes cartas e intentamos hacer una primera agrupación guiada por la convergencia de intereses, aprovechando las líneas de trabajo ya presentes y buscando su complementariedad. Tuvimos que aprender a gestionar la tensión entre no erigirnos en portavoces de luchas que no nos concernían directamente y la tarea de organizadores que nos obligaba a hacer equilibrios entre la ausencia de injerencia y la necesidad de concretar para establecer un programa y buscar la financiación que fuera pertinente. Si bien mantuvimos largas discusiones al respecto, al final decidimos que no tenía ningún interés demonizar la intervención nuestra en el proceso, idealizando una idea de articulación orgánica y espontánea, sino que se trataba de hacerlo con el mayor respeto y transparencia posibles. Al final, resultó ser una opción interesante que permitió agrupar intervenciones, aunando esfuerzos y favoreciendo la articulación con los colectivos y asociaciones locales.

Paralelamente, desde la organización, seguimos llevando adelante las numerosas tareas que supone la planificación de un encuentro tan masivo y con tanta ambición. El seguimiento de las diferentes colaboraciones, la habilitación de espacios, la búsqueda de financiación o el proceso abierto de reactivación del Solar Corona, fueron todas ellas tareas muy exigentes que afrontamos con la dedicación que nuestra vida cotidiana nos permitía ya que tuvimos, lógicamente, que simultanear nuestras ocupaciones habituales y condicionamientos personales (familia, trabajo, etc.) con un encuentro que exigía más y más horas de trabajo cuanto más nos acercábamos a las fechas de su celebración.

A continuación, podemos observar el diagrama de distribución de tareas que realizamos, que muestra claramente la complejidad del proyecto y la enormidad de nuestros empeños no retribuidos. Esa fue una piedra de toque que 
nos angustió hasta el final ya que no obtuvimos financiación de prácticamente nadie. Sin duda alguna, el encuentro se pudo realizar gracias a la generosa contribución de muchísimos ciudadanos, asociaciones y espacios que nos ofrecieron su tiempo, infraestructuras, materiales o espacio de forma altruista ya que la aportación en dinero líquido se redujo a la ridícula suma de 2.300 euros, suma que nos permite en cierto modo alardear de haber hecho posible lo imposible. Tendremos un gobierno endeudado hasta las cejas, unas instituciones que ignoran a sus ciudadanos pero una capacidad colectiva de multiplicar panes y peces que podría considerarse del orden de lo milagroso.

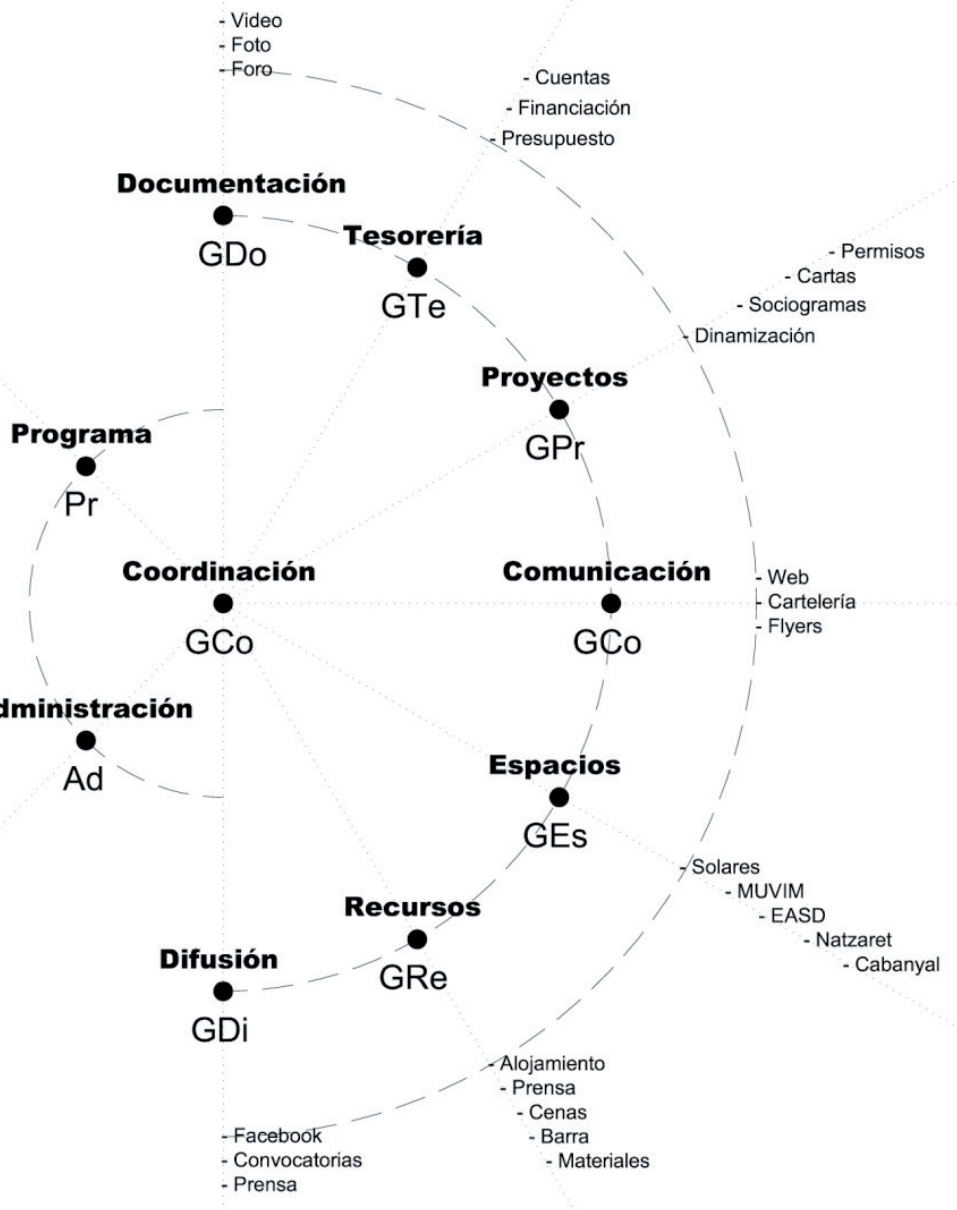

Fig. 47

Este adjetivo no se queda corto si pensamos que, finalmente, participaron unos 60 colectivos tanto nacionales como internacionales (a los que alojamos, dimos de comer y acompañamos) en este proceso de reflexión, acción, recuperación y gestión participativa del hábitat, implicando igualmente a muchas 
personas y empresas locales que colaboraron cediendo sus espacios, imprimiendo gratis los materiales de difusión o contribuyendo con materiales de construcción necesarios, por no hablar de los bares que cedieron su espacio, de los grupos de música que tocaron gratis y un sinfín de otros colaboradores de todo tipo y condición. En total, veintitrés emplazamientos ubicados en distintos barrios de Valencia, tanto espacios públicos como privados del centro y la periferia (solares, medianeras, explanadas, azoteas y locales), fueron los escenarios que se utilizaron para desarrollar el programa de actividades divididas en convocatorias de acción participativa por la mañana (Comboi) y sesiones de reflexión conjunta por la tarde (A la fresca) más un plus nocturno compuesto de cena, concierto u otra actividad lúdica como proyecciones en la calle, etc. Siete días de locura.

A continuación, incluimos con valor testimonial una de las numerosas actas que redactamos tras las reuniones colectivas en las que siempre faltaba alguien, comprobando hasta qué punto es importante dejar constancia escrita de las decisiones que se van tomando de manera que las reuniones no se conviertan en permanentes vaivenes en los que, dependiendo de la composición de la reunión, las opciones vayan en una dirección o en otra. Hicimos mucho trabajo de ida y vuelta inevitablemente, como por ejemplo el estudio de la posibilidad de lanzamiento de un crowdfunding, opción que tomamos a la desesperada viendo que las instituciones no nos iban a financiar y que no deseábamos contar con el mecenazgo de ninguna gran empresa que pudiera beneficiarse y ensombrecer en cierto modo el trabajo de tanta gente que estaba, entre otras cosas, deseando escapar a la lógica mercantil que se cierne sobre tantos procesos urbanos.

Lugar: La Minuscula

Fecha y Hora: 27 de Mayo 2011 a las 16:45

Asisten: Adrián, David, Boris, Nacho, Miguel Ángel, Paula, Mijo, Anaïs, Mario, Michael, Inés, Tania, Domingo, Laura, Carol, Santiago, Makea, Lluis, Mariví, Adriá, Julia, Alberto, Hugo.

Se redacta el orden del día con las cuestiones a tratar.

\section{ORDEN DEL DÍA.}

\section{DIFUSIÓN}

1.1. Difusión y gestión de medios,

1.2. Fecha Fnac,

1.3. Intervención coordinación $15 \mathrm{M}$,

\section{DOCUMENTACIÓN.}

2.1. Crowdfunding,

2.2. Acción conexión $15 \mathrm{M}$,

2.3. Recopilación de material,

\section{TESORERÍA}


3.1. Listado de entidades (sponsors),

3.2. Fiesta Comboi a la fresca II,

\section{PROYECTOS}

4.1. Muros (escif)

4.2. Presentación lista, blog etc,

4.3. Participación instituto francés,

4.4. Cuestionar programación,

4.5. Taller participación,

4.6. Post. Iting (intervenciones de quita y pon),

\section{COMUNICACIÓN,}

5.1. Imagen,

5.2. Aplicaciones,

\section{ESPACIOS}

6.1. Enunciado para equipos que intervienen,

6.2. Seguros de responsabilidad civil,

6.3. Qué con los otros solares,

\section{RECURSOS}

7.1. Conciertos,

7.2. Alojamiento,

Se acuerda dar 5 minutos a cada tema. Los temas que requieran más opinión y discusión serán tratados en los diferentes foros. Cada cuestión tratada en el foro tendrá fechas límite para participar.

\section{DIFUSIÓN.}

1.1. Difusión y gestión de medios (Mariví)

1.1.1. Mariví es la responsable de comunicación del VEO, David, que ha localizado una carencia en esta faceta de gestión la invita a participar en AACC y a darnos una visión de su trabajo.

1.1.2. Mariví plantea que debemos hacer una reflexión sobre qué visibilidad queremos que tenga el evento. Esto obliga a una reflexión ética ya que los medios son manipuladores y el discurso en los medios es pervertido.

1.1.3. En lo que respecta a medios de comunicación tradicional (prensa, radio tele) lo más práctico es trabajar con un gabinete de prensa profesional que prioriza, dosifica y cualifica. Este gabinete construye una estrategia de comunicación y visibilidad.

1.1.4. Si se pretende una comunicación amplia y "tradicional" el gabinete de prensa es inevitable... Frente a esta forma de trabajar "inevitable" sería posible intentar sacarle partido y organizar en paralelo un observatorio sobre el estado de los medios.

1.1.5. S. Cirugeda comenta que es importante plantearse para qué se 
usa la prensa, ¿para atraer? ¿para validar contenidos? En el caso del encuentro de Valencia donde hay tantas asociaciones locales y dado que los proyectos van a tener continuidad temporal sí sería bueno utilizar/ colaborar con la prensa.

1.1.6. Laura sugiere que elijamos con qué medios y/o periodistas queremos trabajar. Se comenta que parece difícil hacer esto aunque siempre es bueno conocer gente de la profesión de confianza que puedan transmitir de forma exacta nuestro discurso.

1.1.7. Mijo comenta que el planteamiento tácito seguido hasta ahora es no buscar la difusión previa (sólo se ha hecho a través de las redes sociales) pero que sí se busca difusión (desde el punto de vista propositivo creativo) durante el encuentro.

1.1.8. Mariví piensa que el observatorio pueden realizarlo como colaboración estudiantes de periodismo y de post grado de la Universidad de Valencia). Mariví puede sondear a ver si este grupo quiere participar. Ella solo podrá colaborar de forma puntual.

1.1.9. Luis propone coordinarse con el equipo de comunicación $15 \mathrm{M}$ en la medida de lo posible.

1.2. Fecha FNAC

1.2.1. Se propone como fecha el 12 de julio. Realizarán la presentación Tania, David y Adrian.

\begin{tabular}{|l|l|l|l|l|}
\hline No & PTO & ACCIÓN Quién & Cuando \\
\hline 01 & 1.1 .4 & $\begin{array}{l}\text { Orientar conceptualmente el } \\
\text { observatorio sobre la } \\
\text { comunicación }\end{array}$ & Mariví & 03.06.2011 \\
\hline 02 & 1.1 .8 & $\begin{array}{l}\text { Confirmar interés del grupo de } \\
\text { postgrado en dirigir el } \\
\text { Observatorio de comunicación }\end{array}$ & Mariví & 03.06 .2011 \\
\hline 03 & 1.1 .2 & $\begin{array}{l}\text { Reflexión global sobre la manera } \\
\text { de comunicar el evento y tratar } \\
\text { con la prensa. ¿Quid con } \\
\text { gabinete de prensa? }\end{array}$ & Comboi & 03.06 .2011 \\
\hline 04 & 1.2 .1 & $\begin{array}{l}\text { Presentación encuentro AACC en } \\
\text { la FNAC }\end{array}$ & $\begin{array}{l}\text { Tania, David, } \\
\text { Adrian }\end{array}$ & 12.06 .2011 \\
\hline
\end{tabular}

1.3. Coordinación $15 \mathrm{M}$

1.3.1. (Adriá Solves, comisión comunicación 15M). El papel de la comisión de comunicación del $15 \mathrm{M}$ es saber que se hace en los barrios (comisiones) y viceversa.

1.3.2. $15 \mathrm{M}$ y AACC pretenden sumar aunque no se puede estar en 
todas partes. Las puertas de las dos asociaciones de asociaciones están abiertas.

1.3.3. Lo importante seria tener una buena comunicación, por lo que ambas partes están abiertas a recibir delegados.

1.3.4. Se discute la posibilidad de organizar (desde AACC y los equipos que van a participar en el encuentro) un Workshop sobre metodología y técnicas participativas / asamblearios que son un punto débil de los participantes en el 15M.

1.3.5. Se deberían dar herramientas asamblearias. El formato sería de charlas (se debe acotar muy bien ya que son procesos largos) y un pequeño workshop.

1.3.6. Sería una actividad añadida al programa. La coordinarían Lluis y Mijo. 1.3.7. El movimiento $15 \mathrm{M}$ tiene un listado para mailings donde se informe de la posibilidad de inscribirse a este workshop.

\begin{tabular}{|c|c|c|c|c|}
\hline № & PTO & ACCIÓN & Quién & Cuando \\
\hline 04 & 1.3 .4 & $\begin{array}{l}\text { Orientar conceptualmente el } \\
\text { workshop de herramientas } \\
\text { asamblearias }\end{array}$ & Lluis y Mijo & 03.06 .2011 \\
\hline 05 & 1.3 .7 & $\begin{array}{l}\text { Contactar con los posibles } \\
\text { ponentes al workshop }\end{array}$ & Mijo & 03.06 .2011 \\
\hline 05 & 1.3 .7 & $\begin{array}{l}\text { Una vez organizado el workshop } \\
\text { mandar mailing }\end{array}$ & $15 \mathrm{M}$ & ¿'????? \\
\hline
\end{tabular}

\section{DOCUMENTACIÓN.}

\subsection{Crowdfunding}

2.1.1. Todo el mundo vota a favor de organizar el crowdfunding.

2.1.2. El equipo responsable colgará en el foro los precios propuestos y se dará opinión hasta el martes 9:00 am. Una vez pasado el plazo recogerán los comentarios y aplicarán la política de precios.

2.1.3. El crowdfunding debería generar un beneficio de entre $1500 €$ a $3000 €$.

2.1.4. Para ejecutar el crowdfunding correctamente es fundamental que todo el mundo cuelgue la info de la que disponga en el google docs.

\subsection{Acción de AACC en plaza $15 \mathrm{M}$}

2.2.1. Mañana se realizará una acción en la plaza $15 \mathrm{M}$. Todo el mundo es bienvenido. La acción durará de las 11:00am a las 02:00 am.

2.3. Recopilación de material.

2.3.1. Se está reflexionando en que hacer con el material una vez terminado el evento. Publicación, que tipo etc. El grupo comunicación trae un disco duro a cada reunión para recoger el material a acumular. 


\begin{tabular}{|l|l|l|l|l|}
\hline № & PTO & ACCIÓN & Quién & Cuando \\
\hline 06 & 2.1 .2 & Hacer comentarios en el foro & Comboi & $\begin{array}{l}31.06 .2011 \\
\text { a 9:00 }\end{array}$ \\
\hline 07 & 2.1 .4 & $\begin{array}{l}\text { Organizar y estructurar el crowd } \\
\text { funding }\end{array}$ & $\begin{array}{l}\text { Equipo } \\
\text { recursos }\end{array}$ & 03.06 .2011 \\
\hline 08 & 2.3 & Aportar toda la documentación & Comboi & 01.06 .2011 \\
\hline
\end{tabular}

\section{TESORERÍA.}

3.1. Contactos y listado de sponsors.

3.1.1. Se ha realizado un primer listado de posibles sponsors y responsables. Nadie ha aportado nuevos sponsors.

3.1.2. La esponsorización es fundamental para la realizabilización del encuentro por lo que todo el mundo debe implicarse. Se propone que para la semana que viene, todo el mundo aporte un nuevo posible esponsor y lo gestione.

3.1.3. La esponsorización puede ser en $€$ o en material, ayuda para organización etc.

3.1.4. Hay que generar un documento de patrocinio invitando a colaborar en la financiación del encuentro y explicando donde se van a ver los sponsors y qué jerarquía de tamaños etc. se les va a dar. Se encarga de esto el grupo de tesorería.

3.1.5. El Poli financia proyectos culturales de alumnos. Sería una pena no optar a esta fuente de financiación. Crearqció (julia) en coordinación con Adrián solicitarán un proyecto y Mijo con un alumno suyo otro de arte efímero. Los requisitos son mínimos alumno + tutor + entidad asociación.

3.1.6. Mijo ha conseguido fondos de la escuela de Bellas Artes, el departamento de escultura y papelería. Hay que ir comunicando estos montantes al grupo de financiación.

3.2. Fiesta Comboi a la fresca ll.

3.2.1. Como lugar se propone "la UCE" lo mira Laura. Aquí nos dejan el bar. Magatzen, lo mira Carol y Magazine lo mira Tania.

3.2.2. La fecha estaría entre fin de junio y principios de julio a confirmar en función de la sala.

3.2.3. Actividad sería concierto del grupo "Ortxata" + DJ de Ortxata. (cote gratis??) coordina Lluis. 


\begin{tabular}{|l|l|l|l|l|}
\hline No & PTO & ACCIÓN & Quién & Cuando \\
\hline 09 & 3.1 .4 & $\begin{array}{l}\text { Generar documento de } \\
\text { solicitud de esponsorización }\end{array}$ & $\begin{array}{l}\text { g. financiación + } \\
\text { g. comunicacion }\end{array}$ & $\begin{array}{l}03.06 .2011 \\
\text { a 9:00 }\end{array}$ \\
\hline 10 & 3.1 .2 & $\begin{array}{l}\text { Todo el mundo aporta al } \\
\text { menos un sponsor }\end{array}$ & Comboi & 30.06 .2011 \\
\hline 11 & 3.1 .5 & $\begin{array}{l}\text { Coordinación de proyectos } \\
\text { culturales Poli }\end{array}$ & Adrian & 03.06 .2011 \\
\hline 12 & 3.2 .1 & $\begin{array}{l}\text { Mirar sala donde se pueda } \\
\text { hacer la fiesta fechas de }\end{array}$ & $\begin{array}{l}\text { Laura, Carol, } \\
\text { Tania }\end{array}$ & Lluis \\
\hline 13 & 3.2 .3 & $\begin{array}{l}\text { Confirmar fech.2011 } \\
\text { disponibilidad de Ortxata }\end{array}$ & 03.06 .2011 \\
\hline
\end{tabular}

\subsubsection{Alberto:}

3.2.5. Los conciertos y cena en el Muvim son solo hasta la 1.00.

3.2.6. Hay que pasarle la programación y organizarse con él para el mobiliario, material, etc.

\begin{tabular}{|l|l|l|l|l|}
\hline 14 & 3.2 .4 & Coordinarse con Alberto & $\begin{array}{l}\text { No sé quien se } \\
\text { encarga de } \\
\text { esto... }\end{array}$ & 03.06.2011 \\
\hline
\end{tabular}

\section{PROYECTOS.}

4.1. Muros (Escif).

4.1.1. Blu \&CO no podrán pintar durante el periodo del encuentro, lo harán la semana antes. Nacho irá confirmando el planning a medida que lo sepa.

4.1.2. El presupuesto aun es variable (600 a 1.200) porque aun hay muchas incógnitas.

4.1.3. La pintura tiene esponsor y por tanto es gratis. Se están negociando más solares.

4.1.4. Hay que enviar por buzoneo los avisos a vecinos y firmar autorizaciones con propietarios etc. Ya existe un modelo que hay que adaptar. 4.1.5. El seguro RC para los pintores está comprendido en el precio de la"plataforma elevadora telescópica"

4.1.6. En cuanto a otros trabajos de muros (tags, intervenciones efímeras etc.) sería mejor conquistar nuevos muros que no estén ya utilizados.

4.1.7. Necesitan un buen acondicionamiento de la zona de maniobra de la máquina telescópica. 


\begin{tabular}{|c|c|c|c|c|}
\hline № & PTO & ACCIÓN & Quién & Cuando \\
\hline 14 & 4.1 .4 & $\begin{array}{l}\text { Buzoneo de información a } \\
\text { vecinos }\end{array}$ & ¿???????? & ¿?????? \\
\hline 15 & 4.1 .4 & $\begin{array}{l}\text { Firma de aprobación por parte } \\
\text { de los propietarios de los } \\
\text { solares }\end{array}$ & ¿'???????? & ¿'?????? \\
\hline 16 & 4.1 .7 & $\begin{array}{l}\text { Acondicionamiento de la zona } \\
\text { de trabajo }\end{array}$ & g. Solar & 01.07 .2011 \\
\hline
\end{tabular}

4.2. Presentación lista, blog etc,

4.2.1. Se ha emparejado ya con proyectos a la mayoría de colectivos. Se colgará esta tabla del foro y se enviará a todos los participantes para que confirmen, se organicen y aquellos que no tienen "pareja" que encuentren un proyecto con otra asociación.

4.2.2. Para explicar cómo funcionan estos emparejamiento se ha generado un documento que explica cómo funciona en 4 pasos.

4.2.3. Se ha nombrado un colectivo "coordinador" del proyecto. Su función es asegurarse de que todo va según previsto y que el proyecto llegue a buen puerto. Este colectivo coordinador debe igualmente coordinar las necesidades, la agenda etc del proyecto.

4.2.4. Si en el proyecto existe una asociación que se encuentre en la organización será el coordinador. Este caso es mayoría.

4.2.5. Se está diseñando una plantilla por proyecto para rellenarlo según un "protocolo". Esto debe incitar a los que no tienen proyecto que lo busquen.

4.2.6. Los colectivos que no tienen proyectos se les propondrá una conexión y/o un proyecto.

\begin{tabular}{|l|l|l|l|l|}
\hline № & PTO & ACCIóN & Quién & Cuando \\
\hline 17 & 4.2 .1 & $\begin{array}{l}\text { Generar liks de proyectos y } \\
\text { sugerir proyectos a los que } \\
\text { no tengan }\end{array}$ & g. programa & $\begin{array}{l}03.06 .2011 \\
\text { a 9:00 }\end{array}$ \\
\hline
\end{tabular}

\subsection{Instituto Francés,}

4.3.1. Adrian debe confirmar la participación de Coloco y Exyst así como su modalidad de participación.

4.3.2. El IF pagará el viaje de todos + alojamiento de dos personas.

4.3.3. Además el IF con el responsable de relaciones internacionales de la UPV quieren traer a 2 colectivos más. AACC colaborará como intermediarios a través de Mijo. Queda por definir el formato de 
trabajo de estos otros dos grupos fuera del encuentro de AACC (fin Septiembre y Noviembre Diciembre- Mijo).

4.3.4. Ver como se materializa la propuesta del belga Louis Louis con su coro de viento etc. Lluis hablará con la banda del Puig para ver si les interesa participar.

\begin{tabular}{|l|l|l|l|l|}
\hline No & PTO & ACCIÓN Quién & Cuando \\
\hline 18 & 4.2 .1 & $\begin{array}{l}\text { Generar y hacer público } \\
\text { listado de proyectos y } \\
\text { formato de proyecto }\end{array}$ & $\begin{array}{l}\text { g. financiación + } \\
\text { g. comunicación }\end{array}$ & $\begin{array}{l}03.06 .2011 \\
\text { a 9:00 }\end{array}$ \\
\hline 19 & 4.3 .1 & $\begin{array}{l}\text { Confirmar participación de } \\
\text { Coloco y Exyst y como }\end{array}$ & Adrian & 03.06 .2011 \\
\hline 20 & 4.3 .3 & $\begin{array}{l}\text { Coordinación IF + UPV para } \\
\text { actividades post encuentro } \\
\text { AACC }\end{array}$ & Mijo & 03.06 .2011 \\
\hline 21 & 4.3 .4 & Banda de El Puig & Lluis & 03.06 .2011 \\
\hline
\end{tabular}

4.4. Cuestionar programación,

4.4.1. A partir del nuevo listado de proyectos por asociación de colectivos hay que ir adaptando la programación.

4.4.2. Una vez aceptados los proyectos, las asociaciones deben confirmar su planificación y fechas de realización etc. Una vez confirmadas estas fechas se integrarán en la programación detallada.

\section{COMUNICACIÓN.}

5.1. Imagen.

5.1.1. El grupo de comunicación está trabajando sobre la imagen global del evento en sus diferentes formatos. Cartelería colectiva, camisetas, flyer etc.

5.1.2. Proponen realizar un macro cartel con el logo de Comboi dibujado a varias manos colectivamente.

5.1.3. Proponen generar un plano de la ciudad con los lugares de actividades y transportes etc etc.

5.1.4. Proponen generar pegatinas tipo congreso "my name is:"

5.1.5. Proponen que la baraja no sea un objeto en sí pero que participe en un "juego proyecto" por lo que se le confeccionaría un tablero.

5.1.6. Se propone estudiar la posibilidad de unificar formatos y que por ej el mapa sea el tablero y el programa etc. También se plantea la posibilidad de imprimir bajo el formato "cuaderno" con toda la info. Inés se informará de precios y David enviará plano de Valencia en formato free hand. 
5.1.7. Se plantea la pregunta de si la info que contiene la carta no es un poco de carácter privado como para imprimirla en y distribuirla.

5.1.8. Con el fin de conseguir esponsorización de impresiones enviarán un listado con el $n^{\circ}$ de copias y de formatos para poder preguntar a las copisterías.

5.1.9. Se colocará un capítulo "sponsors" en el blog y en la cartelería.

5.1.10. Se plantea la cuestión financiera de cómo hacer las camisetas. Auto producción o subcontratación.

5.1.11.Van a consultar a la"pegatineria" si pueden esponsorizar algo.

5.2. Aplicaciones

\section{SOLARES.}

6.1. Intervenciones en el solar.

6.1.1. El Comboi tiene hasta el martes para hacer sus sugerencias sobre el texto de "enunciado" a enviar a los participantes que quieran intervenir en el solar.

6.1.2. Cada grupo que intervenga en el solar debe "autofinanciar" su intervención.

6.2. Seguro de responsabilidad Civil.

6.2.1. Se asegurará solo a los organizadores y el evento en sí. Cada participante es responsable de sí mismo.

6.3. Obras en el solar.

6.3.1. Poner en marcha lo antes posible el acondicionamiento del terreno.

6.3.2. Gestionar cuanto antes las licencias necesarias.

Redacta: Hugo Prades

Revisa: David Estal

Valencia a 30.05.2011

Los barrios implicados directamente en la convocatoria (Patraix, Velluters, El Carmen, Russafa, Natzaret y Cabanyal) respondían todos ellos a un patrón de conflicto previo con la Administración, con asociaciones reactivas o creadas específicamente para enfrentarse a dichos conflictos. Estas asociaciones se interesaron en poder colaborar con grupos ajenos a su problemática y que aportaran un punto de vista o conocimientos prácticos que les permitieran abordar los conflictos desde enfoques diversos, o bien contribuir a su visibilización en el ámbito ciudadano echando mano de otras herramientas. Su mera presencia dificultó de antemano la participación de ciertas instituciones ya que, en el caso de Valencia, la ciudad se ha venido entendiendo como territorio de lucha política en donde medir la potencia de cada una de las partes, permaneciendo en muchos casos ajena a criterios urbanísticos, por lo que mantener la neutralidad en las intervenciones resulta poco menos que imposible. Este hecho no hizo más que reforzar la argumentación previa de 
que la metrópolis es hoy en día el territorio de apropiación pero también el de resistencia, ya sea esta de carácter reactivo, ya sea de forma creativa, constructiva, como se ha pretendido poner en práctica en la convocatoria.

Todos los proyectos desarrollados entre colectivos de dentro y de fuera de la ciudad se organizaron en torno a tres ejes:

1. Participación (taller jurídico, taller de metodologías participativas y taller de masovería urbana, más debates y mesas redondas).

2. Itinerarios Sensibles por distintos barrios de la ciudad.

3. Creación de Espacios (Solar Corona, Solar Princesa, Azoteas Colectivas, etc.).

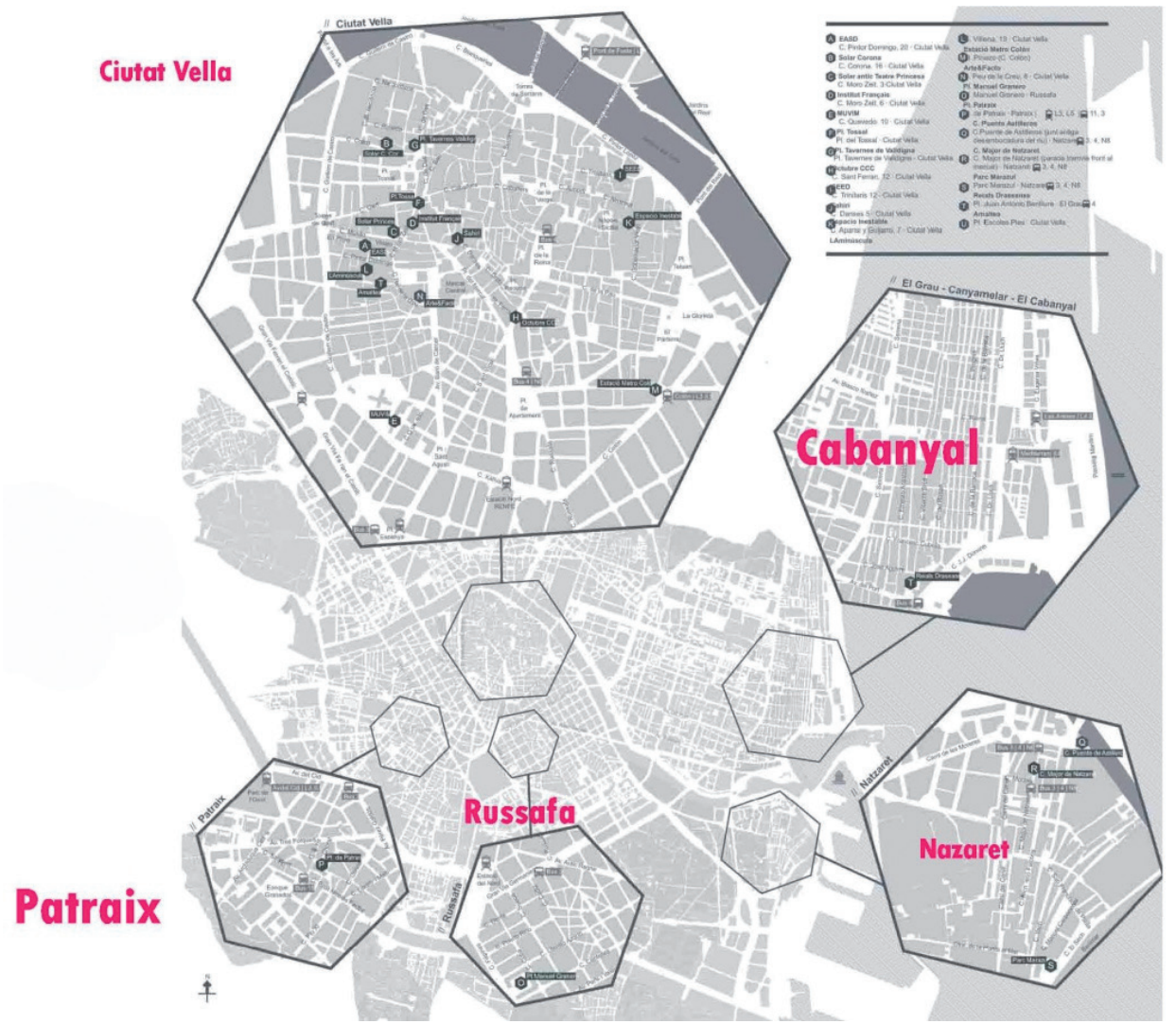

La intención del eje de Participación era la de socializar y seguir desarrollando conocimientos que nos permitieran afrontar de forma creativa los retos a los que nos estamos teniendo que enfrentar de forma aún más acusada desde el inicio de la crisis: la falta de vivienda, la expropiación de los espacios, la negación de toda capacidad igualitaria en el diseño del territorio, la invisibilización de conflictos e intereses, la deshumanización de la polis. Por ello, tanto el taller 
jurídico, centrado en la gestión y protocolo de espacios en desuso, como el de masovería urbana, en torno a las estrategias alternativas de acceso a la vivienda, se centraron en vías legales de transformación del territorio, aportando los conocimientos técnicos y los instrumentos jurídicos legales que requiere ampliar las posibilidades de acción en el planeamiento urbanístico tanto en el espacio como en el tiempo. La implementación del contrato de masovería urbana, por ejemplo, fomenta la rehabilitación y cuidado de viviendas en desuso a cambio de poder usarlas, reinterpretando la noción de trueque, y la guía jurídica incluye en el panorama de espacios en los que se puede dar un posible empoderamiento elementos que rara vez se consideran, como es el caso de espacios subterráneos, aéreos o desregulados (azoteas, refugios, solares). Todos los conocimientos y contactos acumulados al respecto durante el encuentro se han concretado en una serie de recursos: grupos de trabajo, archivos compartidos, el inicio de elaboración de cinco guías jurídicas de las cuales dos han llegado a buen puerto y la continuación de algunos de los proyectos iniciados. En este sentido, cabe destacar el proyecto de recuperación y reactivación para usos temporales del solar en la calle Corona, del que posteriormente hablaremos en mayor detalle.

Además, como consecuencia y resultado de los talleres jurídicos, financiación y visibilidad de la red, se crearon tres grupos de trabajo. Con respecto a temas jurídicos, se propuso trabajar en cinco guías a modo de recursos sencillos que permitieran a cualquier persona que no estuviera familiarizada con temas jurídicos tener una información básica sobre los pasos a seguir en función del tipo de proyecto que quisiera desarrollar: una guía que se ocupe de protocolos de activación de solares, edificios y azoteas; otra guía que trabaje sobre formas jurídicas para colectivos y agrupaciones de colectivos; otra guía que se ocupe de formas de cesión de poderes o bienes públicos y privados; otra guía que trate la legalidad básica (licencias, permisos, seguros); Y por último otra guía que desarrolle una ficha-tipo para subir información de proyectos de uso de la vía pública.

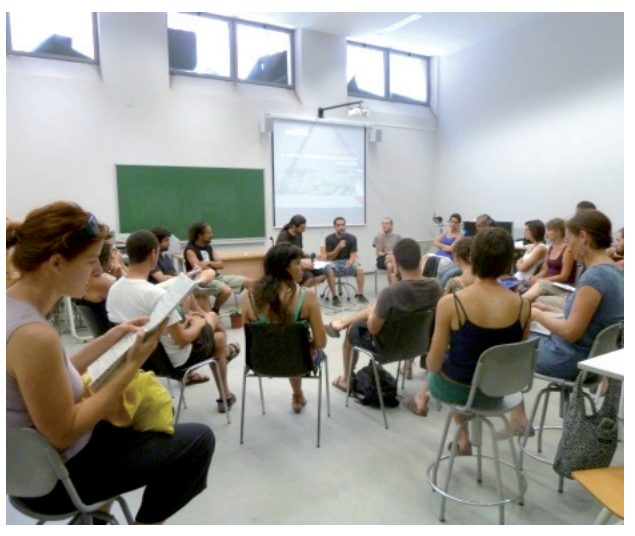

En cuanto al taller de metodologías participativas, ya lo hemos comentado extensamente pero recordamos que la primera parte se centró en la introducción teórica y puesta en común de metodologías asamblearias vinculadas a las demandas de autoformación emanadas desde las diferentes asambleas 15M, percibidas también como necesarias desde el interior de la plataforma. La segunda parte del taller consistió en la puesta en común de procesos de 
participación así como un debate sobre diferentes propuestas para iniciar el proceso participativo de diseño y usos del solar, temporalmente cedido por su propietario, situado en la calle Corona. Como vemos, todos los talleres se propusieron ya con la intención de dotarse de continuidad y sostenibilidad tanto en lo que se refiere a las acciones en sí, como a la redacción y publicación de documentos que sirvan para generar una biblioteca básica del procomún urbano. Paralelamente se realizaron las dos mesas redondas ya comentadas, la de agroecología urbana y la de Periferias, en torno a la visibilización de proyectos de autogestión laboral en la periferia de la ciudad de Valencia. Como podemos ver, ambas propuestas completan procesos de autoformación muy complejos respecto a nociones como la soberanía alimentaria, la interacción generacional o la solidaridad barrial, articulados junto a dos cuestiones básicas de sustento: el trabajo y la comida.

Por último, tanto los itinerarios como la creación de espacios se orientaron a la potenciación de los derechos de uso del espacio mediante construcciones colectivas en el espacio social, visibilizando procesos de gentrificación y exclusión, problemáticas de fronteras internas relacionadas con la inmigración, modelos de transporte urbano centralizados, etc. Dentro del primer grupo, se propuso un primer itinerario en Russafa (De la Russafa histórico social a la intercultural) en el que habitantes del barrio realizaron un recorrido guiado a través de la Ruzafa contando con diferentes voces y a pie de calle, su transformación a partir de su fundación como municipio que se integra en la ciudad, hasta la situación actual de carencia de dotaciones sociales y como centro de los diferentes procesos migratorios. El segundo recorrido (Patrimonio industrial y memoria obrera) se realizó en el barrio de Patraix. En él, se llevaron a cabo una serie de intervenciones que fueron desde un recorrido guiado por el patrimonio industrial hasta talleres sobre los modelos de preservación y puesta en valor de dicho patrimonio y de la memoria obrera vinculada al mismo, a partir de diferentes experiencias llevadas a cabo tanto en Valencia como en Barcelona.

El tercer itinerario (Gincana popular) era lúdico y dirigido a los más jóvenes: una gincana en la que se buscó la prolongación de lo doméstico en el espacio público mediante juegos intergeneracionales que intentaban visibilizar la problemática y oportunidades que supone la proliferación de solares en desuso que jalonan el barrio. El cuarto itinerario (Un deseo llamado tranvía) se definía como un recorrido urbano lúdico, creativo y reflexivo por las lindes del barrio de Natzaret, como estrategia de visibilización del aislamiento físico y la poca accesibilidad a la que está sometido. Fue una deriva guiada que pretendía fomentar el debate urbanístico y mostrar las debilidades internas que permiten pensar soluciones posibles. El recorrido finalizó en la calle Mayor en donde se realizó la inauguración ficticia de la línea 2 de metro que debería llegar hasta Natzaret, prometida desde hace ya tiempo y nunca realizada. 

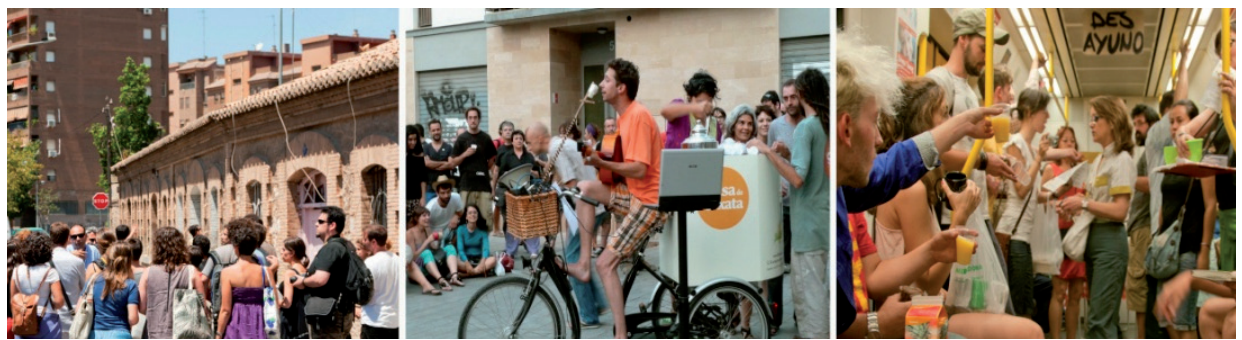

El quinto itinerario (Comboi al convoy) consistía en la ocupación durante 3 horas de las líneas 3 y 5 del metro de Valencia por parte de convocatoria de un desayuno colectivo en el que se invitaba a todos los que compartían vagón, como continuación de la actividad mensual del colectivo "Desayuno con Viandantes". El sexto (Música en el espacio) ponía en práctica la idea de la ocupación sonora de los espacios desde la tradición musical valenciana proponiendo intervenciones sonoras experimentales, sumadas a castillos de personas e implosiones de petardos en la plaza Viriato de Velluters. El último itinerario (Vamos al Cabanyal) proponía un recorrido guiado por el Cabanyal para conocer de cerca su historia, su peculiar parcelación, el modernismo popular y la propuesta de prolongación de una avenida, explicando la problemática de la situación actual del barrio y las posibilidades de transformación que tiene para integrarse en la Valencia del siglo XXI. Paralelamente Repensar Bon Pastor comentó el proceso similar que se ha vivido en el barrio de Sants de Barcelona. Este itinerario finalizó en el antiguo matadero del Cabanyal en donde uno de los colectivos había realizado un equipamiento de sombra, por lo que se pudo realizar un concurso de paellas final con fiesta de despedida.

La Creación de espacios, por último, se concreto en la autoconstrucción de un espacio para un proyecto de co-working con dos contenedores cedidos por Santiago Cirugeda (aunque esta actividad se suspendió al comprobar el mal estado en el que se encontraban los contenedores que llevaban almacenados 3 años sin uso); las intervenciones en el Solar Corona acondicionado como sede del encuentro mediante la construcción de una cúpula geodésica y su acondicionamiento; las intervenciones en medianeras realizadas por diferentes artistas internacionales (Escif, Ericailcane y Blu); la proyección de películas en el solar que ocupaba el antiguo Teatro Princesa, reivindicado para la construcción de equipamientos culturales por el barrio; así como la ocupación de azoteas colectivas como espacios en desuso en los que rara vez se piensa.

En resumen, tras el encuentro, todas estas iniciativas colaborativas han supuesto la catalización y dinamización de corrientes subterráneas de reapropiación urbana, planteadas desde los principios de continuidad y sostenibilidad, la fructífera colaboración entre ciudadanos, técnicos y asociaciones, la superación de 
divergencias para implementar nuevos modelos de hacer ciudad y nuevas prácticas para conseguirlo. Igualmente, la conexión con la red nacional de Arquitecturas Colectivas así como con otras redes a nivel europeo, nos ha dado un horizonte mucho mayor de aprendizaje y expectativas de intercambio. Seguimos adelante con proyectos de cesión temporal de solares y elaboración de publicaciones posibles tanto escritas como audiovisuales, con grupos de trabajo orientados a las metodologías participativas, con encuentros a pequeña escala con colectivos similares de Francia y con teóricos especializados en asuntos como el procomún. Seguiremos pues, intentando habitar y rehabilitar este entorno metropolitano con todas las herramientas que nuestra precariedad postfordista nos permita.

\section{CONCLUSIONES del COMBOI A LA FRESCA}

Intentaremos realizar a continuación una especie de sumario de la convocatoria, este proceso de transformación de un encuentro cerrado en unas jornadas inmersas/hibridadas en la ciudad y en sus dinámicas de cambio en las que se pretendió debatir, generar cuestionamientos y encontrar respuestas para necesidades específicas (o por lo menos intentarlo). Cerrado por fin el encuentro, continuamos con el proceso que no termina cuando se van los últimos invitados ni cuando se limpia el último espacio sino que se prolonga de forma esencial en el posterior proceso de análisis y evaluación conjunta que será el verdadero cierre, sino de un devenir, por lo menos de una fase inicial que se inició hace ya muchos meses.

En cualquier proceso de autoformación, se toman miles de decisiones de forma asamblearia y, a menudo, intuitiva ya que en gran medida se está trabajando en terra ignota. La confianza en que se están tomando decisiones correctas resulta básica para seguir funcionando durante el proceso, pero ello no quita para que sea fundamental llevar a cabo un seguimiento y evaluación posteriores que permitan afinar las herramientas, valorar las orientaciones y reforzar los aprendizajes. En este caso, hubo una primera asamblea general de conclusiones en la que se compartieron aciertos e inquietudes entre todos los participantes de la red de Arquitecturas Colectivas, intentando superar la falta de comunicación que se pudo haber producido durante la primera fase con el grupo inicial de los encuentros, situado a distancia y repartido por la geografía española. Si bien es verdad que se quedó corto el tiempo dedicado a ello, unas tres horas de evaluación conjunta, podemos decir que fue bastante fructífero el intercambio de pareceres.

Para ello, se prepararon previamente junto con los otros miembros de AACC una serie de parámetros que pudieran servirnos de orientación para llevar a cabo el análisis con un mínimo de profundidad, parámetros que sirvieron igualmente para explicitar los criterios que acabaron modelando el encuentro: 
1. Mapa de relaciones institucionales: ¿con cuántas hemos hablado y con cuántas ha sido positiva la interlocución?

2. Vías de financiación.

3. Relación con la prensa, ¿cuál ha sido la relación con los medios?: evaluación del Observatorio de Comunicación.

4. Colaboración entre asociaciones locales: enganche a la red de nuevos colectivos.

5. Relación con colectivos de otros países así como relaciones con la red de Arquitecturas Colectivas.

6. Modelo de encuentro: ventajas y desventajas de las diferencias de modelo aplicadas en este encuentro.

7. La continuidad y la sostenibilidad como criterios de base: ¿cuántos proyectos se mantienen en el tiempo?

8. Herramientas que se han generado para seguir construyendo la red.

Respecto a todas estas preguntas, intentaremos hacer a continuación una evaluación de base bastante general. Sobre financiación y relación con las instituciones, resulta evidente que no nos ayudó el hecho de encontrarnos en periodo electoral pero también es verdad que dejamos la cuestión de la financiación para un segundo momento. Arrancamos trabajando el encuentro desde el punto de vista del concepto, luego abordamos la metodología, y para cuando empezamos a pensar en el dinero, ya estábamos en la campaña electoral, lo que resultó desafortunado. También es verdad que hay una profunda relación de desconfianza entre nosotros y las instituciones, sólo porque en el programa aparezcan determinados nombres como "Cabanyal", ya es motivo de lejanía de las instituciones, por lo que nuestra relación con el ámbito municipal fue de mutua ignorancia aunque sorprendentemente, a raíz de la repercusión mediática del encuentro, contactaron con nosotros para iniciar una colaboración. Contamos puntualmente con el respaldo de la Universidad Politécnica, la Escuela de Arquitectura así como de la Facultad de Bellas Artes, ya que algunos de nosotros trabajamos en ellas y nos resultaba más fácil explicar el proyecto y conseguir apoyos pero, como ya hemos dicho, la financiación fue ridícula comparada con el alcance de la empresa. Sigue siendo increíble cómo se consiguió llegar a tanto y hacer tanto, casi sin parar y con tanta gente implicada, por lo que no nos cansaremos de remarcar la importancia del factor humano.

En lo que respecta al ámbito de la comunicación, creemos haber aportado un punto de partida diferencial reflejado en el gabinete de prensa que se proponía no sólo enviar fotos y textos para conseguir visibilidad, sino también generar un contra-gabinete que recogiera y reflexionara sobre la tergiversación de la información en los propios medios de comunicación. Esta actividad funcionó regulando las informaciones y los medios en los que quisimos salir, rechazando aquellas que nos parecían de antemano tergiversadoras, proporcionando 
contenidos e imágenes y observando cómo, en determinados casos, a pesar de este empeño, la información acababa transformándose, no tanto en los medios escritos como la prensa, pero sí, de forma mucho más lábil, en los soportes digitales. Este gabinete concluyó su trabajo en el mismo sentido con el que se plantearon las conclusiones de todos los talleres, permitiendo una reflexión posterior y acumulación de conocimientos.

Valoramos también la relación con el resto de colectivos de la red AACC. Hubo inicialmente poco diálogo, porque muchos colectivos no conocíamos la red, no sabíamos cómo funcionaba, así que esta tarea de conexión recayó en las personas que ya habían trabajado en anteriores ediciones. Quizá esta circunstancia nos ha permitido tener más frescura, por no conocer bien otros modelos, pero también reconocemos que la falta de experiencia, el partir de cero, ha dejado fuera la experiencia que otros tuvieron antes. No obstante, como ya hemos dicho, se ha mantenido el contacto con colectivos italianos, franceses y del territorio español tanto a través de la red AACC como de forma independiente, lo que ha seguido ampliando nuestras interacciones.

En cuanto a los objetivos y modelo del encuentro, nuestros objetivos principales eran tejer redes y hacer ciudad y creemos que hemos cumplido ambos objetivos. Esto no sucede de un día para otro y la temporalidad del encuentro fue muy breve, pero pensamos que hemos encaminado un poco nuestras acciones en esa línea. El objetivo prioritario fue incluir a toda la ciudad y dejarnos manchar por ella, sus modos y maneras, y pensamos humildemente que algo de esto sí que hubo. Continuamos generando dinámicas de funcionamiento de forma bidireccional que han seguido asentándose de forma específica. El formato por el que optamos fue, en lugar de centralizar, vincular a diferentes barrios, algunos de las periferias. Frente a la focalización en nuestras propias redes, nos propusimos la impregnación de muchos de los agentes que ya están en funcionamiento en la ciudad. En este modelo ha estado muy bien de cambiar de sitio, conocer realidades, implicar a gente de diferentes barrios, etc. Las desventajas han sido respecto a otras ediciones la dificultad de estar todos juntos mucho tiempo, ya que la gran cantidad de actividades, algunas de ellas simultáneas y realizadas en barrios diferentes, lo imposibilitaba. No obstante, la construcción de la cúpula geodésica en el solar Corona y la implicación del colectivo La Matraka en un servicio mínimo de comidas permitieron que hubiera un espacio de relación común en las horas de ocio que compensó parcialmente la dispersión.

Respecto a la continuidad, hemos visto que han surgido nuevos proyectos y nuevos colectivos que dos años después, siguen funcionando de manera autónoma como es el caso, por ejemplo, del Solar Corona o de LaCIV, por lo que valoramos positivamente la activación de redes a nivel local. Muchos colectivos siguen trabajando juntos, algunos de ellos creados para el propio encuentro 
como StreamingLab, funcionando entre ellos como redes de amistad en la acción. En cuanto al tema de la implicación de las asociaciones y colectivos locales, de la ciudadanía, es el trabajo más duro, el que requiere más tiempo y esfuerzo. No obstante, la prueba de que algo ha funcionado es que las colaboraciones no se han quedado únicamente en el evento, por mucha repercusión mediática que haya tenido. Respecto a estos colectivos de Valencia, ha resultado fundamental la articulación de una red que pueda actuar de forma conjunta y el mejor ejemplo de ellos ha sido el barrio del Carmen donde se ha consolidado una red de agentes sociales (L'escoleta del Carme, Collectiu de Mares i Pares de CiutatVella, Assemblea 15M de Ciutat Vella, Endavant, Racó de la Corbella, AV. Àmics del Carme, Ca Revolta, El Micalet, Assemblea del solar Corona, Falles Populars i Combatives, Amaltea, Acció Ecologista Agró, Els Cucs de Velluters, Ateneu al Margen, la Mandràgora, Arran-Ciutat Vella, la Minúscula) denominada Ciutat Vella Batega, poniendo en acto esta idea de sumar la afectación y la afección como ejes fundamentales de acción. Valoramos muy positivamente los vínculos con los movimientos de base de la ciudad, el activismo vecinal, de barrio, aquellos que llevan muchos años funcionando. La importancia de la relación entre técnicos y movimiento vecinales (no sólo entre movimientos asociativos de primera y segunda generación) es fundamental para darle nuevo impulso a los procesos de recuperación de la ciudad.

Además de los vínculos locales, el Comboi ha supuesto que 10 o 12 colectivos de aquí se activen también en la red estatal de AACC, convirtiéndonos en un nodo importante a nivel nacional. La red de AACC supone un trabajo más a medio plazo, no sólo como un evento para unos días. Tiene ese potencial y, sin dejar de lado las problemáticas de colectivos trabaja a distintas velocidades, acelerándose en los encuentros y haciendo un trabajo más reflexivo a largo plazo. De algunos talleres y de varias actividades, se han hecho valoraciones separadas y se han colgado en la web del Comboi a la fresca para que se puedan consultar allí ${ }^{204}$.

Por otra parte, se ha seguido trabajando en red de forma conjunta desde el taller jurídico y de masovería para ampliar su radio de acción, creando una red estatal para un banco de experiencias en el tema de cesión de usos de viviendas, herramientas jurídicas y técnicas, cuyo resultado más directo ha sido la publicación y difusión de tres Guías Prácticas para la Activación de Espacios ${ }^{205}$, a disposición de los colectivos de la Red y de cualquiera que esté interesado. Estas guías plantean protocolos legales que permiten la gestión pactada de espacios entre colectivos por un lado y la administración o particulares por el otro. Agrupan consejos legales y prácticos basados en legislaciones, ordenanzas, convenios urbanísticos y experiencias realizadas por todo el territorio del Estado:

204. http://comboialafresca.arquitecturascolectivas.net/?page_id=1315).

205. http://arquitecturascolectivas.net/herramientas/grupos/grupo-juridico/guias-practicas-para-la-activacion-de-espacios 
1. Activar una azotea: Estrategias de uso de azoteas [Recetas Urbanas]

2. Activar un solar en desuso: Guía para la activación de Vacíos Urbanos Autogestionados [Todo por la praxis]

3. Activar un edificio en desuso: Aspectos jurídicos a tener en cuenta a la hora de formalizar un Convenio de cesión temporal y gratuita con un Ayuntamiento (Paco Pallardó, LaCIV, Valencia).

El taller de metodologías también se planteó constituirse en grupo de trabajo dentro de AACC, para seguir trabajando en conjunto profundizando en el número y uso de herramientas de transformación:

- A nivel de red: a través de la prolongación de los talleres, punto de proyección y sostenibilidad con herramientas digitales para seguir compartiendo.

- A nivel de Comboi: a través de la creación de una coordinadora de iniciativas vecinales (LaCIV) para vehicular proyectos que nacen del encuentro.

Desde la humildad y el escepticismo sobre su rango de acción, nuestras prácticas locales intentan introducir estos cambios y modos de pensar autónomos erigiéndose en interlocutoras válidas ante las instancias públicas, generando procesos de agenciamiento de espacios en desuso que posteriormente cedemos a asambleas constituyentes que los llevan adelante mediante prácticas autónomas. El Comboi en relación a la descripción del régimen del procomún y los procesos de reutilización de espacios en desuso ha propiciado:

1. Generación de sinergias a nivel de ciudad

2. Creación de procomún - ideas, metodologías, fórmulas (masovería, procesos participativos, etc.)

3. Incremento de valor en barrios

4. Trabajo desde una base no mercantilista y colaborativa (no hablar con vecinos sino construir con ellos)

5. Horizontalidad en las propuestas que supone el establecimiento de negociaciones en términos de igualdad con instituciones públicas (capacidades igualitarias e instituyentes)

Desde Autoformato, evaluamos el potencial político del encuentro, trabajando desde un eje separado que pudiera coordinar a aquellos colectivos que intervinieran en ese sentido, conscientes de que de nada vale producir una deriva forzada si no hay detrás una necesidad de empoderamiento real. De ahí que el planteamiento de activar un eje y dejar fluir el resto funcionara de forma eficaz, ya que se trataba de montar una arquitectura de partida y dejar que lo que se desarrollara surgiera de la vinculación entre colectivos de fuera de Valencia y los de la ciudad. Independientemente de ello, consideramos que sólo la organización en sí, un montón de colectivos juntos pensando el territorio y planificando intervenciones, activando redes, previendo ocupaciones alegales de solares, etc. 
es de por sí una posición activa y política en la medida en la que la pasividad es la tónica general, sin que haga falta circunscribir lo político a un estallido que conlleve un cambio profundo.

Una primera fase de acercamiento a esa propuesta de autoformación instituyente se realizó en las jornadas paralelas de Rancière (Conversaciones de primavera), en donde la charla de Débora Ávila de Ferrocarril Clandestino y Marina Garcés introdujo las nociones de procomún, ciudad y anonimato. De este modo, podemos vincular la noción general de procomún en el ámbito de la ciudad de manera que se pueda hablar por una parte de procesos de empoderamiento que serían su aplicación práctica, y por otra, dibujar una realidad de fronteras internas que tampoco se llegan a percibir, desde el punto de vista del trabajo práctico del Ferrocarril Clandestino y la campaña de Ciudades sin fronteras. Si eso lo combinamos con los encuentros en julio, se va creando una especie de plataforma extraña desde la que introducir ciertos conceptos en diferentes dinámicas de los colectivos. Es una apuesta arriesgada e interesante que se continúa en dos ámbitos directos: la autogestión del Solar Corona y su transformación en centro atractor de sinergias transformadoras a nivel de barrio, y la constitución de la Coordinadora de Iniciativas Vecinales con sus proyectos directos del Centro de Proximidad de Velluters y el proceso de activación de La Calderería que analizaremos a continuación.

\subsection{El Solar Corona}

http://solarcorona.wordpress.com/

Fig. 51

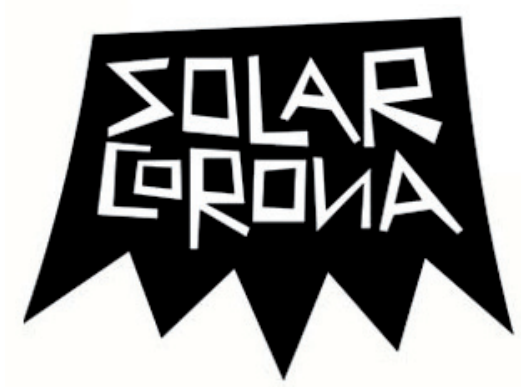

El Solar Corona inició su andadura a principios de 2011 cuando empezamos a poner en marcha el programa del Comboi a la fresca. En concreto, se trata del solar situado en la calle Corona $\mathrm{n}^{\circ}$ 12-14 dentro de lo que se denominaba popularmente el Arrabal dels Tints, debido a la presencia de talleres del gremio de los tintoreros que usaban la acequia de Rovella como desagüe. Nos encontramos un solar abandonado durante más de una década con una parte privada, $472 \mathrm{~m}^{2}$, y una parte pública de $162 \mathrm{~m}^{2}$ que, junto al estrecho solar situado al otro lado de la calle, conformaría la futura plaza que se abrirá a modo de esponjamiento en una trama carente de los mismos. La parte privada consta de una ruina donde antiguamente se realizaban labores relacionadas con los tintes, que sólo conserva la cimentación. Hoy, emergen desde los cimientos excavados varios árboles frutales y palmeras, de los que podemos disfrutar tras haber limpiado toda la maleza y deshechos que los rodeaban. Su condición mixta, privada y pública, ha supuesto una complicación permanente a la hora 
de proponer su gestión, por una parte porque supone duplicar todos los trámites para permitir su uso y, en segundo lugar, porque la parte publica está dividida a su vez por un muro y un callejón lo que hace que, en términos prácticos, tan sólo una pequeña parte, la que cedió en su momento el propietario privado al Ayuntamiento, se haya podido utilizar para usos comunes.

La ocupación del solar podemos dividirla en dos fases: una primera que atañe a la ocupación temporal durante el Comboi, con todo lo que ello supuso, y una segunda fase en la que el encuentro pasa a ser únicamente el momento de transición de usos del solar hacia un espacio autogestionado por una asamblea constituida con ese propósito. El Solar Corona se definía en el proyecto del encuentro de A.A.CC. como el espacio de visibilización del mismo en toda la ciudad de Valencia, único emplazamiento espacio que permanecía estable durante toda la semana, de manera que actúo como centro social y espacio de descanso tanto para organizadores como para participantes.

Desde la organización del encuentro, se realizó el acondicionamiento del espacio con un presupuesto prácticamente inexistente ya que el proceso de limpieza fue principalmente manual. Los colectivos del Comboi junto con algunos vecinos procedimos al desbrozado de la superficie plana colindante a la ruina, y a la extracción de basura y residuos del interior de la misma, así como la poda de la vegetación existente. Una retroexcavadora niveló y acabó de extraer los residuos de la parcela. La intervención llevada a cabo supuso también la instalación de una cúpula geodésica de $14 \mathrm{~m}$ de diámetro, que permaneció únicamente durante el evento ya que pertenecía a uno de los colectivos participantes de fuera de Valencia, así como el acondicionamiento y acceso de la ruina sin rebajar el nivel existente. Se realizó una escalera de acceso al jardín en ruinas, así como el amueblamiento de las estancias interiores y una valla provisional de protección para evitar accidentes en el desnivel. Otra escalera efectuada con ayuda de los vecinos da acceso a la parte posterior de la ruina donde emergen tres palmeras. Se efectuó también un aterrazamiento vegetal para proteger del desmorone de parte del terreno. El jardín se completó con una plantación de aromáticas y especies autóctonas.

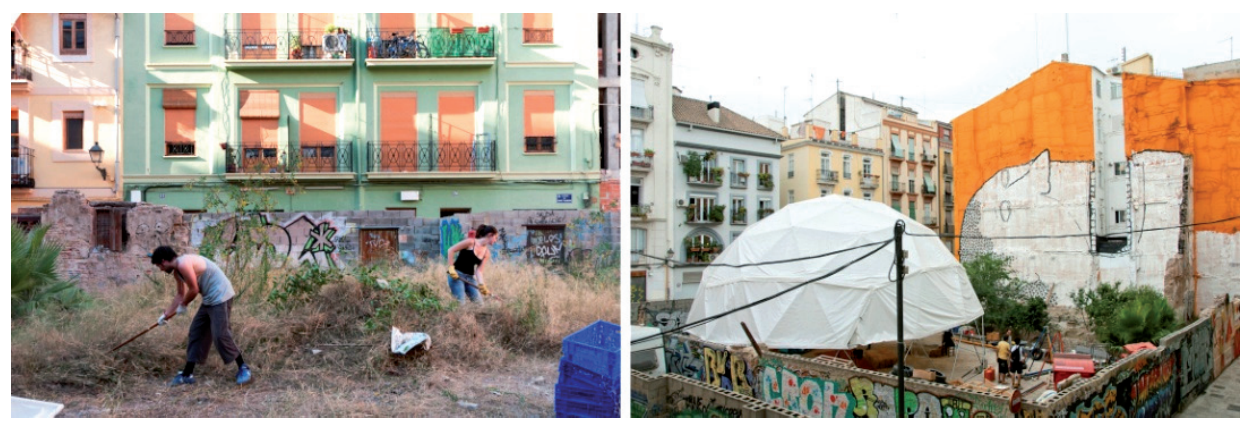

Fig. 52 
Desde el Comboi, nos hicimos cargo de la solicitud de permisos, el desbroce, la intervención en la zona perteneciente al Ayuntamiento, la negociación con el propietario Vicent Donat definiendo los usos que se le iban a dar al solar mediante un protocolo específico, redactando las condiciones de ocupación, los usos previstos, los materiales disponibles, las fases de ocupación y el post-mortem del encuentro. Igualmente, hubo que contratar un seguro de responsabilidad civil, abordar el problema de las excavaciones arqueológicas, dar de alta el agua y realizar un plano detallado del espacio, sin dejar de atender por ello a los posibles usos futuros.

En esta fase, resultó esencial el taller impartido por Javier Rodrigo en relación al uso del solar según las teorías de Bruno Latour, la teoría del actor-red (TAR) según la cual la capacidad de agenciamiento de un espacio es importante pero también lo son las emociones, los objetos, las distancias, los elementos arquitectónicos, etc. Se intenta relacionar lo macro y lo micro, estudiando los contextos, las problemáticas, los recursos y los potenciales que vehicula poniéndolos en relación con los dispositivos o herramientas, los actores o agentes sociales y las instituciones implicadas. En este caso, se trataba de generar un espacio micro a través de una serie de fases que fueran llevando al objetivo final: la cesión a una asamblea del diseño y uso de ese espacio. Javier Rodrigo no cesó de recordarnos que las transformaciones políticas se ganan por negociaciones y gradientes, según él, no se puede entrar de lleno en una dinámica de oposición que imposibilite cambios en la disposición de los actores. A través de esta fase, se va consiguiendo un proceso de vinculación y trabajo en común que va en la línea de la conciencia del espacio, de la generación de deseos respecto a ese espacio, etc. El desarrollo de un principio de corresponsabilidad es importante en la medida en que sirve para generar trama y apoyo aunque no se consiga el objetivo original, lo que permite seguir avanzando en otros contextos. En una primera fase, se trata de una relación vivida, real, basada en la experiencia de ese espacio y no en una relación ideológica. Según Rodrigo, las fases a establecer serían:

1. Focalizar el problema

2. Generar el deseo

3. Imaginar conjuntamente

En este caso, nos habíamos quedado bloqueados por la separación del espacio mediante un muro, dudando entre su derribo y ocupación u otras alternativas similares. Más de una vez, estuvimos tentados de renunciar al proyecto y llevar adelante el Comboi sin intervención alguna en el solar por la gran cantidad de problemas asociados que conllevaba. Pero tras realizar el taller, decidimos que no podíamos tomar decisiones y mucho menos aquellas que pudieran poner en peligro el proyecto (como era el derribo del muro), sino que atenderíamos a los tiempos que exige un proyecto participativo: que la emergencia del deseo y la imaginación conjunta del espacio debía correr por cuenta de aquellos que asumieran 
su gestión tras el Comboi. Tras los talleres de metodologías participativas del encuentro, nos ratificamos en esta postura que implicaba no generar expectativas de huertos, talleres, etc., a pesar de nuestro deseo de continuar trabajando en esa dirección, sino respetar tiempos y procesos hasta que se constituyera la nueva asamblea gestora.

Por ello, nos limitamos a activar un contrato de cesión de usos con el propietario y con el Ayuntamiento, dejando que fueran los implicados directamente los que tomaran estas decisiones, marcando con ello de nuevo la diferencia entre democracia participativa y democracia contributiva. La combinación entre el taller de masovería y el de procesos participativos fue el marco para detectar necesidades y deseos a nivel de barrio, abriendo el proceso a todos los espacios del barrio, a negociaciones prolongadas en el tiempo que supusieran constantes incorporaciones de agentes variopintos. En ese sentido, nos resultó de gran ayuda la presencia de Sostre, una asociación en Barcelona que trabaja en la cesión por parte de los Ayuntamientos de espacios temporales, con un planteamiento de ocupación temporal que contempla el "mientras tanto", qué pasa con esos espacios, carreteras, solares, etc. hasta que las instancias públicas hagan uso de ellos.

Finalmente, se trató de usar el solar Corona para ir más allá de la propuesta puntual de diseño de la plaza planificada en ese espacio, contemplando otros espacios y usos posibles. De hecho, supone llevar a cabo un proceso de empoderamiento generalizado en el que los vecinos empiezan a considerar "posible" el hecho de pensar y decidir sobre su barrio. La naturalización de la idea de autogestión de los espacios públicos es la que produce la transformación social así como la experiencia directa de auto-organización, si bien en este caso, no se produce la coincidencia absoluta entre los promotores del cambio y los usuarios del espacio.

En el mes de septiembre de 2011, el equipo del Comboi retoma la actividad para generar todo el material de conclusiones y documentación del encuentro y comienza a gestar lo que será el actual proyecto del Solar Corona. El propietario, encantado con la repercusión y el estado del espacio después de nuestra intervención, ofreció la renovación del convenio de manera indefinida. Aparecerá así el equipo del Solar Corona. En su asamblea gestora, se encuentran algunos miembros de diferentes asociaciones vinculadas al Comboi (en nuestro caso en concreto, Lluis Benlloch, de Autoformato, forma parte de ella), pero no solamente ya que se han incorporado otros colectivos y vecinos. Este primer período se caracteriza por la poca actividad del espacio. Con el mal tiempo y la poca duración de la luz del día cesaron las reuniones de reactivación pero se siguió proyectando conjuntamente. Esta etapa fue importante porque supuso la reafirmación del grupo en la voluntad de continuar con el proyecto del espacio. Con la llegada del buen tiempo el Solar sufre un proceso de revitalización casi automático. La formación de REC (red de espacios culturales de Carme, Velluters y Botànic) vincula el Solar a otros 
espacios activos de Ciutat Vella y motiva de nuevo al equipo del Solar Corona, que recoge las inquietudes hacia el espacio por parte de las asociaciones del barrio y reactiva el proceso que comenzó en septiembre de 2011.

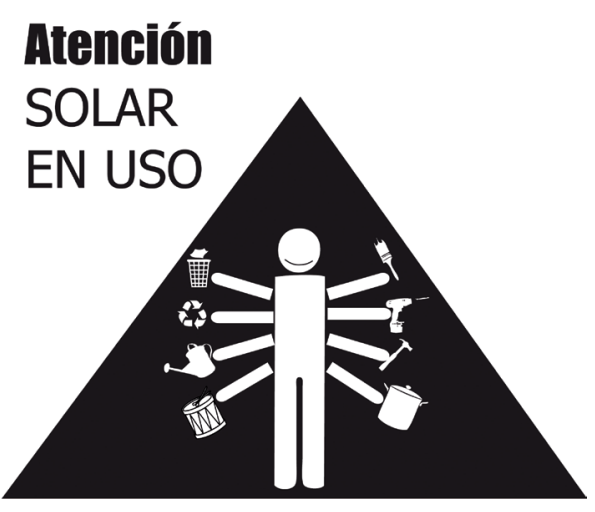

Sábado 28 de Enero a las 12:00h Jornada de trabajo en el Solar Corona.

En la actualidad el Solar Corona es un espacio gestionado y dinamizado por vecinos/as y diferentes asociaciones del barrio del Carmen. Se ha consolidado como un espacio al aire libre, de carácter comunitario, para la realización de actividades sociales y culturales, tanto por parte del colectivo que gestiona el espacio, como por las diferentes entidades y vecinos que desean hacerlo y lo solicitan a través de la asamblea. Al mismo tiempo, el solar también cumple la función de ser un pequeño parque comunitario en un centro histórico caracterizado por la falta de espacios públicos, de manera que varios días a la semana el solar abre sus puertas para uso y disfrute de los más pequeños. La fórmula de uso del espacio sigue estando regida por un contrato de cesión de uso por parte del propietario dónde se fijan las condiciones para ello, y que es renovado año a año entre ambas partes. Los objetivos prioritarios que se plantearon al constituirse fueron los siguientes:

1. La autoconstrucción colectiva del espacio a partir de la reutilización y del reciclaje de materiales. Esta autoconstrucción se basa en el diseño colaborativo por parte de todos los vecinos y colectivos que utilizan y dan vida al espacio, y se realiza a través de metodologías participativas

2. La conciencia de que se está ante la generación de un nuevo tipo de recursos culturales basados en la articulación de espacios de lo común, lugares que no pertenecen al ámbito privado ni propiamente a lo público, sino que se basan en la lógica de sus usuarios, de las comunidades activadas en torno a ellos, que pueden activar necesidades y deseos a través de los mismos.

3. Una concepción flexible y nómada sobre el solar, que hace que se perciba el recurso como temporal y limitado, de manera que se apuesta por la continua apertura de nuevos espacios y recursos autogenerados en el territorio, dando lugar a redes, que mutan continuamente, de espacios comunes.

La asamblea trabaja con reuniones quincenales para la toma de decisiones así como a través de jornadas extraordinarias para el mantenimiento y 
mejora del espacio. Se estructura en subgrupos para agilizar las diferentes vías de actuación: Legalidad, Acondicionamiento, Difusión, etc. Además, se ha creado un protocolo de uso para facilitar la propuesta de actividades por parte de colectivos locales. El equipo del Corona entiende que este ha de ser un espacio por y para los vecinos, un espacio de actividad y aprendizaje social abierto a todas las posibilidades de transformación que se deseen.

Como ya hemos comentado, se ha integrado en la red Ciutat Vella Batega que agrupa a colectivos con intenciones de transformación política como la Asamblea 15M, Endavant, Ca Revolta o AlMargen, así como otras asociaciones (Falles Populars i Combatives, Amaltea, el Col.lectiu de Pares i Mares de Ciutat Vella, o L'Escoleta) con los que se reúne una vez al mes y con los que ha realizado un diagnóstico colectivo de los principales problemas y necesidades del barrio, priorizando tres puntos: la rehabilitación del barrio (de las viviendas y de los equipamientos), la participación de los vecinos y la lucha contra la exclusión social. A raíz de estas reuniones, se han consolidado 4 grupos de trabajo mixtos (Espacios, Prostitución, Economía Social y Participación) con la intención de redactar un plan de gestión comunitaria de recursos públicos y presentarlo a la Administración, negociando para ello tanto con propietarios particulares como con el Ayuntamiento.

En resumen, consideramos que el Solar Corona ha funcionado como activador de la transformación que supone considerar posible la autodeterminación de espacios públicos convirtiéndolos en comunes, como atractor de diferentes agentes de transformación social, espacio donde realizar actividades pero sobre todo, donde tejer relaciones y debatir usos, y finalmente como catalizador de energías, con una intención clara de expandirse replicando el modelo de gestión de usos a otros solares como el de la Botja, ocupado temporalmente por la asamblea $15 \mathrm{M}$ y a la espera de nuevos usos tras la firma de un nuevo protocolo de usos.

\subsection{La Coordinadora de Iniciativas Vecinales (LaCIV)}

http://www.laciv.org/

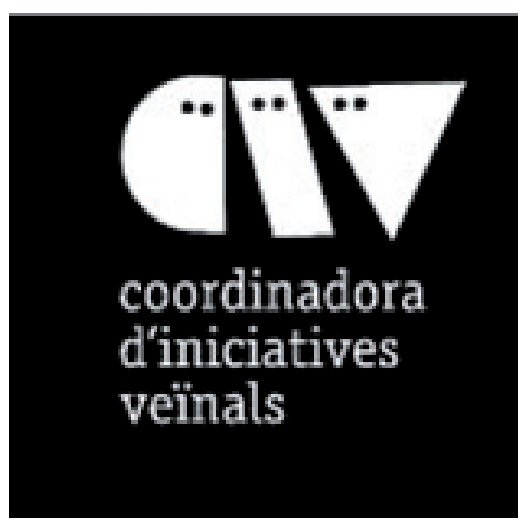

Tras la experiencia de haber organizado el encuentro de Arquitecturas Colectivas en Valencia en julio de 2011 y con el objetivo de dar continuidad al trabajo realizado en este y otros encuentros, para seguir trabajando y alimentando los recursos iniciados en Valencia y así, seguir avanzando conjuntamente en este proyecto colectivo que sin duda supone nuevos caminos y alternativas hacia la construcción participativa del hábitat, nos hemos constituido como Coordinadora de Iniciativas Vecinales. 
Como ya se apuntó durante el encuentro, se debería empezar a pensar la manera de catalizar estas alternativas y formalizarlas, con el objetivo de que además, puedan suponer alternativas profesionales para muchas de nosotras.

Por ello, optamos por consolidar un equipo profesional multidisciplinar: la Coordinadora de Iniciativas Vecinales (CIV) cuyos objetivos son cartografiar necesidades, generar posibilidades e impulsar prácticas de intercambio y colaboración con la participación ciudadana como motor del proceso. Sus integrantes y colaboradores son los siguientes:

Daniel Atienzar Gómez. Arquitecto.

Miguel Ángel Baixauli. Cineasta y antropólogo.

Tania Magro Huertas. Arquitecta.

David Estal Herrero. Arquitecto.

Domingo Mestre. Artista visual y comisario de exposiciones.

Inés García Clariana. Arquitecta e Ingeniera de la Edificación.

Lluís Benlloch i Calvo. Sociólogo y gestor cultural.

Adrián Torres Astaburuaga. Arquitecto.

Mijo Miquel.Traductora, profesora de la UPV y gestora cultural independiente. Paula Roselló Borcha. Arquitecta y estudiante de Antropología.

Francisco Javier Pallardó López. Abogado.

Alberto Flores. Diseñador e Ingeniero Técnico Industrial.

\section{Colaboradores habituales}

Anáïs Florin Langlois

Javier Mestre Jorda

Rebeca Manteiga Delgado

\section{Colaboradores puntuales}

Espai MGR

Mariela Apollonio

Crearqció

El trabajo de la CIV está orientado a la producción de modelos culturales emergentes, operando como núcleo dinamizador y de gestión. Su metodología de trabajo se adapta al contexto sobre el que interviene, actuando como catalizador e intensificador de las dinámicas preexistentes en el territorio y potenciando la transferencia de recursos y conocimientos entre actores sociales múltiples. El modelo de CIV pone en práctica este tipo de cuestiones constituyéndose como asociación que propicia un cambio en las relaciones de poder, iniciando, a través de una institucionalización, la creación de un modelo de gestión en el que se pueda propiciar esta relación en la que el empoderamiento de los ciudadanos funcione como eje fundamental. ¿Qué pretende ser? Bisagra entre vecinos, Universidad y Administración 
Pública que incluya la redistribución a la ciudadanía, desarrollando propuestas legales de mediación urbana. Su metodología de trabajo es la MAP (MediaciónActivación-Participación), metodología de proximidad basada en la IAP/TAR, que podemos detallar de la siguiente manera:

\section{Activación}

- Activación de espacios en desuso (masovería, reciclaje de recursos y autoconstrucción).

- Generación de contenidos / programa para espacios en desuso.

- Emprendizajes colaborativos y procesos colectivos de autoconstrucción.

- Gestión de centros culturales, centros cívicos o centros juveniles.

- Desarrollo (participativo) de contenidos para centros culturales, cívicos o juveniles.

- Dinámicas participativas para la gestión de centros culturales, cívicos o juveniles.

- Gestión cultural en contextos de conflicto o precariedad.

- Optimización de recursos culturales.

\section{Mediación}

- Interlocución entre vecinos/instituciones en procesos participativos de desarrollo comunitario.

- Vínculos de investigación-acción-participativa entre las instituciones académicas y la ciudadanía.

- Coordinación de procesos socio-artísticos y proyectos de cultura emergente.

- Ecosistemas de aprendizaje para procesos ciudadanos de innovación social. - Educación expandida y comunidades de aprendizaje para grupos sociales minorizados y/o marginalizados.

- Coordinación de procesos culturales colaborativos entre Poblaciones/ Instituciones/Barrios/Comunidades/Vecinos

- Pedagogías colectivas y políticas espaciales.

\section{Participación}

- Planes comunitarios o de necesidades. Globales o temáticos: salud, integración, educación, cultura...

- Planes estratégicos participativos.

- Audiovisuales participativos de procesos colectivos.

- Construcción multimedia de narrativas comunitarias.

- Acontecimientos culturales de inclusión social.

- Historia de vida y memoria oral (patrimonio inmaterial).

- Estrategias y procesos colectivos de conversión de la "participación" en implicación y en trabajo colaborativo.

- Pedagogías colectivas para prácticas culturales emergentes y colaborativas. 
Como primer proyecto, recién constituidos y aún envueltos en la organización del Comboi a la fresca, recibimos un encargo del Ayuntamiento para la redacción del proyecto básico que desarrollara la museología y los correspondientes soportes fijos y audiovisuales museográficos del equipamiento socio-cultural que se tendría que ubicarse en la calle Guillem de Castro $n^{\circ} 38$, una vez construido el pasaje de conexión de la Plaza del Pilar con la primera ronda de circunvalación. Por ello, aceleramos el proceso de constitución legal de la LaCIV, lo que producirá muchos desplazamientos en nuestras relaciones y funcionamiento, ya que pasamos de estar implicados desde un voluntariado absoluto y con intenciones políticas, a formar parte de un equipo profesional retribuido que debe cubrir sus propósitos, adaptándolos en este caso al lenguaje de la Administración.

Más allá de la propuesta museográfica que nos interesaba relativamente, negociamos la transformación de este espacio en un centro de proximidad que pudiera llevar a cabo las tareas de mediación entre ciudadanos y Ayuntamiento que nos habíamos propuesto. Propusimos una institución polivalente de proximidad, puesta al servicio del desarrollo cultural del barrio de Velluters $y$, por extensión, del conjunto de la ciudad de Valencia. La misión del centro sería la dinamización cultural de barrio a partir de la transferencia bidireccional del saber y del conocimiento sobre el contexto, al tiempo que se fomentara la puesta en valor, como recurso, de todas las potencialidades del lugar.

El concepto de centro que aplicamos era el de un espacio transdisciplinar con cabida para diversas iniciativas culturales sin olvidar su contexto más inmediato, abriendo puertas a la historia de Velluters, tanto en su vertiente vinculada al patrimonio artístico y cultural del entorno, como en aquella que se relaciona con la memoria, la historia oral y las identidades del territorio. Un espacio expositivo, lúdico y de formación desde el que diseñar actividades cuyo objetivo fuera fomentar el aprendizaje y la relación entre los vecinos. Un centro donde se pudieran encontrar diferentes ventanas de acceso a la información, es decir, distintos niveles de recursos que dieran cabida a las iniciativas vecinales. Este nuevo equipamiento cultural podría ser percibido como un punto de partida, como el inicio de un recorrido que afectara al barrio mediante la intervención en el entorno, contribuyendo a la integración del mismo en la ciudad, su puesta en valor y la creación de beneficios tanto materiales como intangibles

Para llevarlo a cabo, desarrollamos cada uno de estos cuatro puntos:
a) Estudios previos estadísticos del barrio de Velluters
b) Metodología de trabajo a utilizar.
c) Memoria básica de gestión
d) Valoración económica 

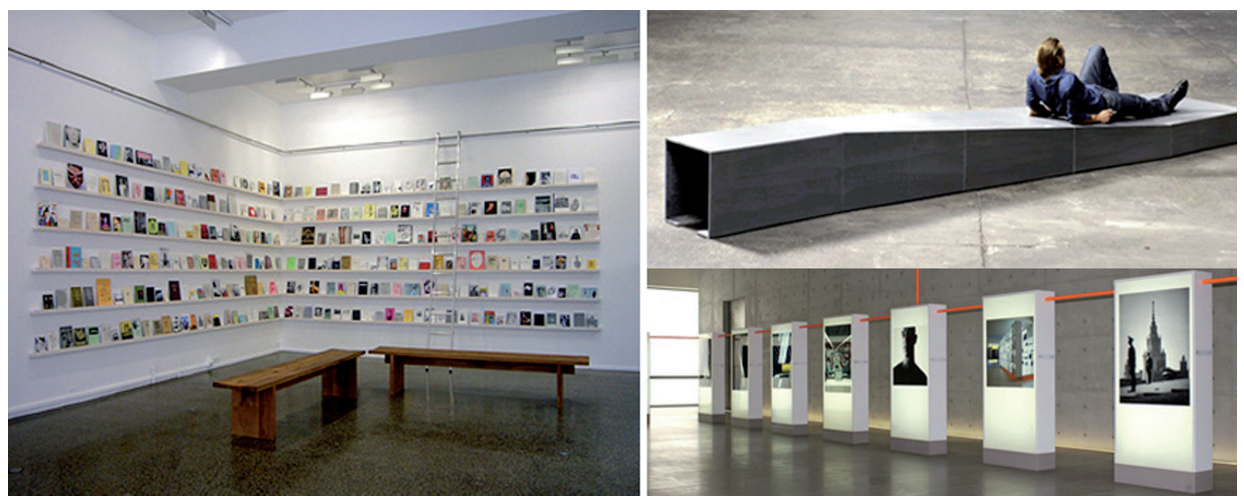

Socialmente, Velluters es, ahora mismo, un barrio con una importante diversidad, donde vecinos de clase alta conviven con colectivos marginales e inmigrantes de diversas procedencias. De ahí que la principal premisa debiera ser la de promover las relaciones entre unos y otros para alentar una transformación orientada de sus hábitos, dado que existe una necesidad de interacción - de compatibilidad, en definitiva- que resulta vital para solucionar los problemas de convivencia. Son estos problemas específicos del barrio los que se pretendía abordar desde la concepción de un Centro de Iniciativas Vecinales para Velluters. Un proyecto sociocultural orientado a los vecinos y usuarios en proximidad, que los haga promotores de su programación y coautores de sus logros. Así, un espacio de estas características podría servir para impulsar la participación ciudadana, entendida como vehículo para la interacción entre el vecindario y la administración con el fin de impulsar la transferencia bidireccional del conocimiento, revitalizando el empleo a través del emprendizaje (emprendimiento - aprendizaje) y creando nuevas redes de proximidad.

Lamentablemente, a pesar de haber entregado este proyecto al Ayuntamiento y negociado la puesta en marcha del centro, dudamos mucho de que, vista su situación económica, se lance a construir un nuevo centro cuando los que ya lanzó permanecen vacíos en gran parte, carentes de contenidos y de financiación. Por ello, damos por cerrada esta etapa, contentas de haber experimentado en carne propia lo desagradable que supone tener que maquillar con eufemismos las intenciones y hasta qué punto resulta negativo este tipo de trabajo porque absorbe toda la energía y transforma paulatinamente el punto de vista, limitando cualquier autonomía de pensamiento posible.

Para seguir avanzando, diremos que desde LaCIV se han presentado numerosos proyectos a convocatorias y concursos pudiendo realizar intervenciones en IDENSITAT Cabanyal 2012, asistiendo a mesas redondas y de debate, más alguna intervención puntual en convocatorias ajenas. No obstante, nos gustaría entrar a describir el proyecto que nos ha definido en el último año, que ha ocupado nuestro tiempo y energías de forma central, que ha acabado también con nosotras como colectivo que inició el proyecto y con el que cerraremos la parte práctica. 


\subsection{La Calderería}

\section{http://www.lacaldereria.org/}

De forma simultánea al encargo del Ayuntamiento, recibimos una propuesta de una empresa inmobiliaria de Valencia que había sabido de nosotras por las noticias editadas en diferentes periódicos. Dada la delicada situación por la que pasa el sector inmobiliario, la promotora Invergi2 SL propuso a LaCIV el encargo profesional para la elaboración y gestión de un plan de activación y renovación de usos de una nave vacía de su propiedad local situada en los no 88,90 y 92 de la C/ Jerónimo de Monsoriu de Valencia en el barrio de Ayora, junto a la estación de metro Marítim-Serrería.

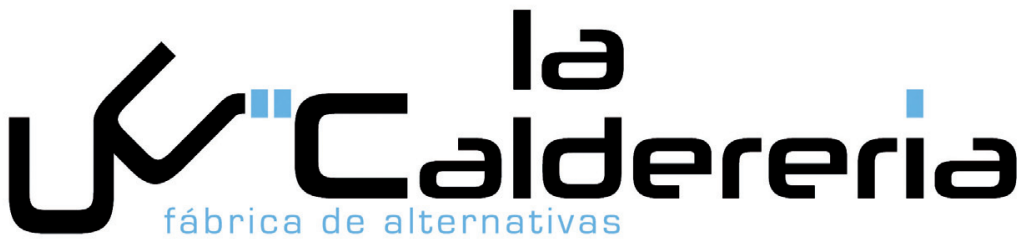

El edificio fue construido a mediados del siglo pasado y estaba dedicado en origen a la fabricación de calderas, silos y demás tipos de contenedores metálicos. La edificación se compone de una nave, diáfana en planta baja y con altillo, cuya superficie total es de cerca de $1.000 \mathrm{~m} 2$, y sobre ella, se encuentran situadas las viviendas de los antiguos trabajadores de la empresa. Con este proyecto de activación se buscó facilitar, de esta forma, la consolidación de un innovador clúster de proyectos sociales y colectivos, basados en la cultura de la creatividad y la solidaridad, que posibilitara el establecimiento de nuevas conexiones entre agentes locales múltiples que fueran capaces de generar sinergias y oportunidades de colaboración.

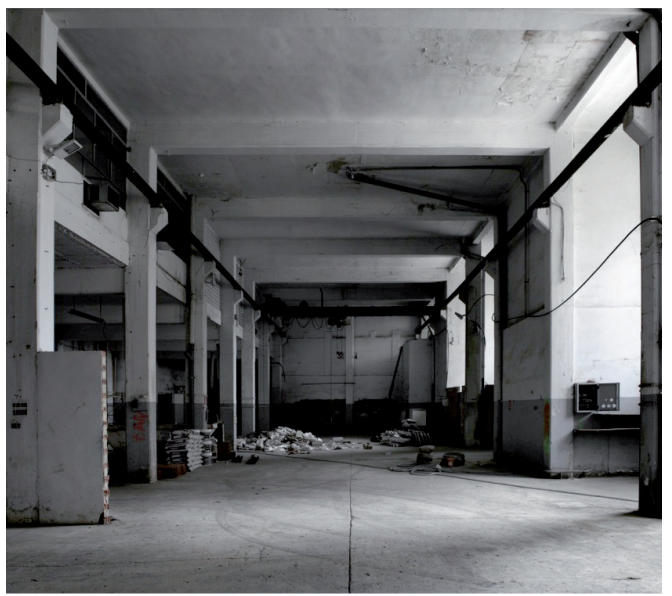

La Calderería pretendió ser un laboratorio de cultura emergente y de economía social. Para conseguir estos objetivos, la Coordinadora de Iniciativas Vecinales (LaCIV) diseñó una estrategia de activación y de cogestión colectiva en base a una convocatoria de proyectos de usos y aprovechamientos temporales del espacio, dirigida a creadores y colectivos relacionados con la cultura emergente y la economía social. A partir de esta convocatoria, se propuso la 


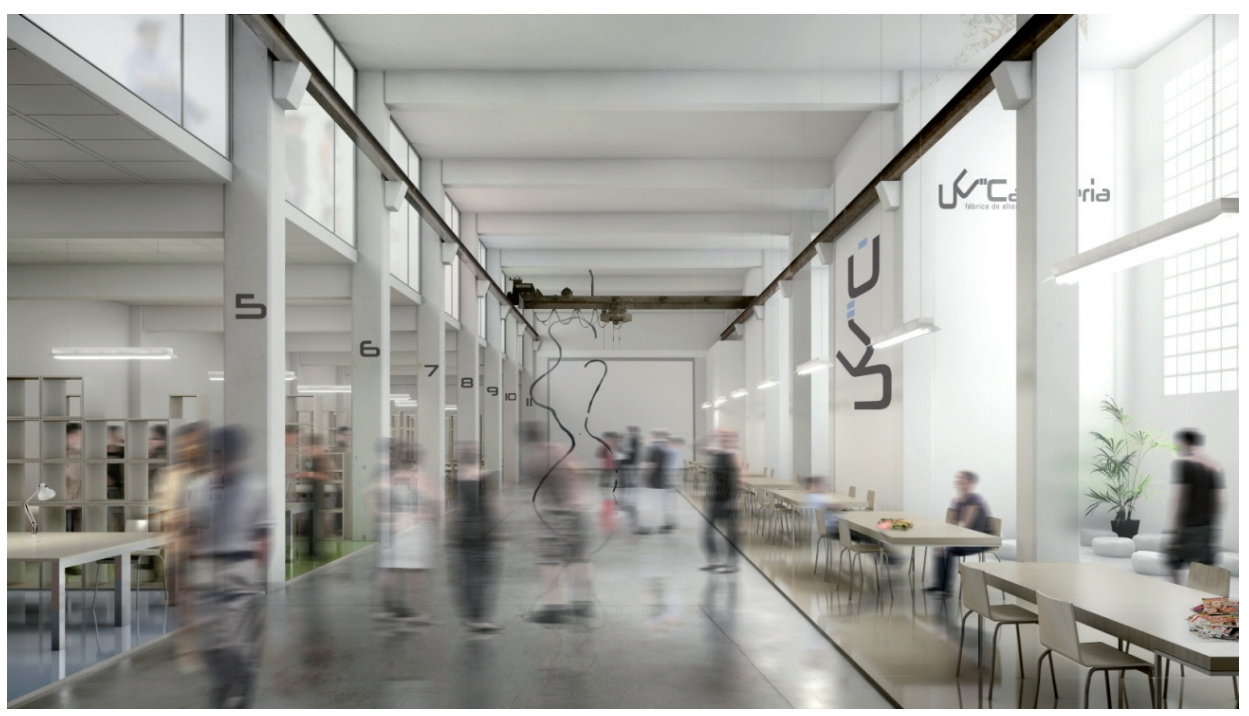

cesión a los proyectos seleccionados de una serie de espacios ubicados en esta antigua nave. Así nos imaginamos este espacio que iba más allá del co-working, pretendiendo generar en otro barrio de Valencia un polo atractor de transformación social.

La convocatoria tuvo como objeto seleccionar una serie de proyectos cuyo carácter creativo y cuya voluntad de implicación colectiva facilitaran la creación de nuevas redes de colaboración entre agentes sociales y culturales relacionados con la economía social. Para ello, se ofertaron diferentes espacios de producción ocupables, de forma temporal o permanente, en régimen de masovería urbana. Establecimos la condición de que pudieran participar en la convocatoria todas aquellas propuestas que mantuvieran algún tipo de relación con la economía social y las diversas formas de producción cultural emergente para orientar el centro en convergencia con nuestros planteamientos de manera que fuera más allá de un espacio compartido de trabajo y pudiera consolidar una creación de común. Para ser más precisos en nuestras intenciones, habría que especificar que entendemos por economía social el conjunto de actividades de las diversas entidades de trabajo en las que se prima el interés general sobre el particular, y en las que la toma de decisiones se realiza de modo democrático y participativo, prevaleciendo siempre el valor del trabajo sobre el del capital.

En cuanto a la propuesta de participación de otros colectivos, la masovería urbana se propuso como un mecanismo de trueque no económico entre propietarios y personas con necesidad de utilizar un espacio. El concepto de masovería urbana define una estrategia que resuelve dos objetivos: por una parte, reducir el número de viviendas o espacios que, debido a su mal estado de conservación o la necesidad de realizar obras con el objetivo de dotarles de las condicio- 


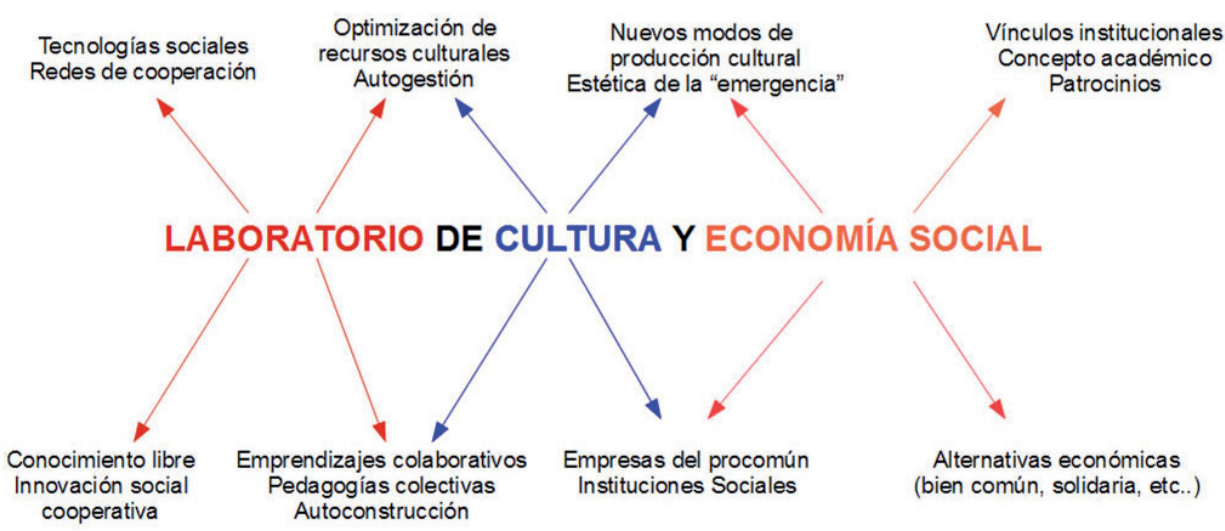

nes mínimas de habitabilidad, quedan desocupados, y por otra parte, dar respuesta a las necesidades de vivienda/espacios de una parte de la población por medio de regímenes alternativos de tenencia. La masovería urbana se propone como un mecanismo para animar a los propietarios de viviendas o espacios desocupados a realizar una rehabilitación o reactivación y mantenimiento sin tener que intervenir en el proceso de construcción. Por medio de un contrato de masovería urbana, el propietario de una vivienda o espacio cede el uso, por un tiempo acordado y a cambio de que los masoveros o cesionarios asuman las obras de rehabilitación y mantenimiento.

En nuestro caso se trata de un espacio que se nos cedió a cambio de un proyecto de rehabilitación y gestión para una rehabilitación y activación del espacio mismo. Si entendemos el futuro uso de la planta baja como un catalizador de sinergias del entorno urbano, a largo plazo la reactivación de este espacio en desuso también supondría una reactivación y una plusvalía económica y social, tanto del espacio cedido como del barrio. En este caso, el propietario nos cedía el espacio a cambio de la mejora y reactivación del mismo y nosotros pretendíamos extender este tipo de relación a los nuevos agentes implicados así como a todos aquellos que nos propusieron actividades puntuales de uso del espacio. Por aportación al espacio, consideramos dos modalidades posibles:

\section{Capital Económico}

- Reformas directas en el espacio

- Conservación y mantenimiento de la propiedad

- Intercambio dinerario: cuando haya beneficios, se compartirán con los propietarios

\section{Capital Simbólico}

- Visibilidad pública y revalorización del espacio

- Publicidad indirecta para todos nuestros apoyos

- Contribución al cumplimiento de la responsabilidad social de las empresas 
Por último, entendemos como cultura emergente las prácticas colectivas vinculadas a procesos sociales de transformación y a nuevas formas culturales colaborativas e inclusivas, que configuran un paradigma de cooperación cultural múltiple y emergente. El concepto emergente explica la totalidad cualitativa de los cambios que son generados espontáneamente por un sistema. Las propiedades de este comportamiento se deben a las interacciones entre las diferentes partes del sistema.

Paralelamente a la convocatoria, hicimos un estudio sociológico del barrio en el que nos estábamos insertando para identificar los diferentes agentes que pudieran hacer de nuestra presencia un elemento integrado e integrador. Como se puede ver en el dossier más extenso de La Calderería, investigamos el contexto del barrio en varias direcciones: la historia del barrio de Aiora, su marco urbanístico y social así como un análisis estadístico de la población. Igualmente, hicimos un mapa del tejido asociativo que nos pudiera orientar también en lo referente a las necesidades de los actores.

Para conseguir el objetivo final de activación del espacio, se establecieron las condiciones de cesión temporal y se llevo a cabo parte de la rehabilitación y el acondicionamiento del espacio. Para la visibilización del espacio el equipo de la CIV programó el encuentro Caldeando. Comboi al Marítim, que se celebró en junio y julio de 2012 y del que hablamos ya en el apartado de Autoformato pero que especificaremos aquí en toda su extensión. El modelo de activación se inició con una jornada de puertas abiertas en la que los interesados en los espacios de La Calderería tuvieron la oportunidad de visitar el espacio. En él, hicimos la presentación

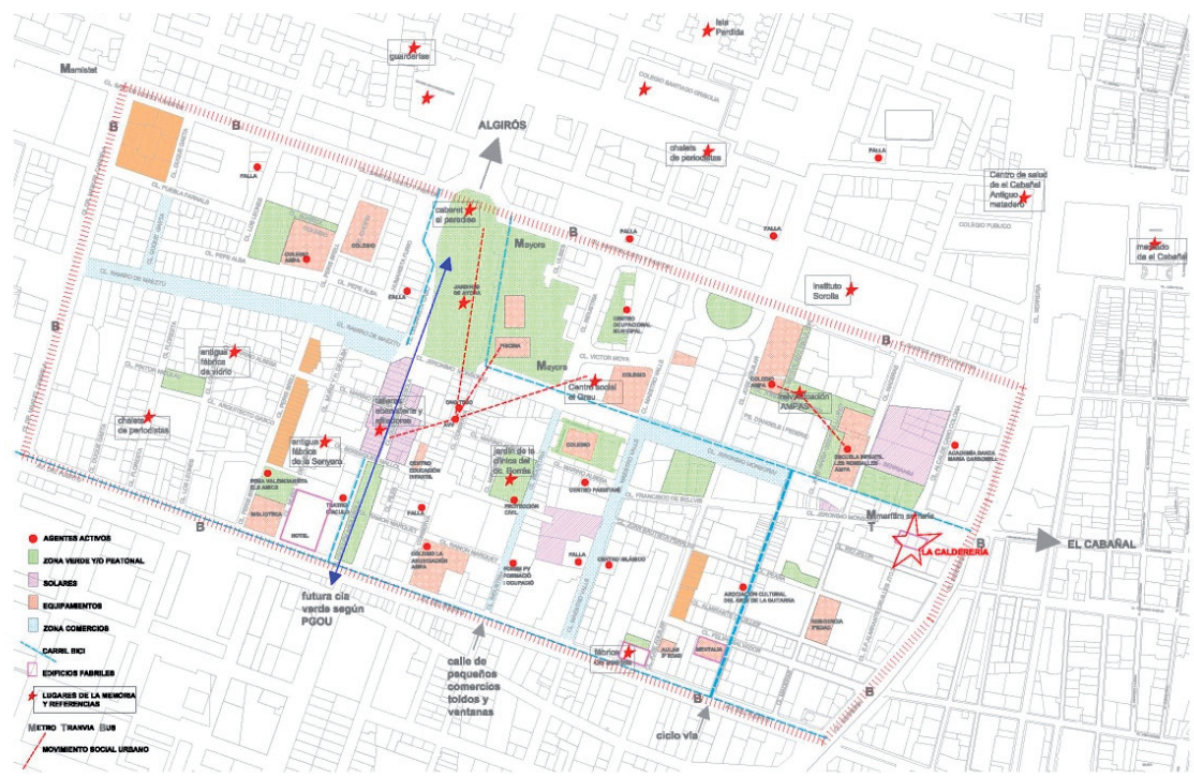


del proyecto general de La Calderería aclarando dudas y contestando preguntas, así como diferentes actividades lúdicas que nos permitieron disfrutar de día en común. A continuación, lanzamos las diferentes actividades del encuentro en sí con el que empezamos nuestra andadura. Siguiendo los pasos de Comboi a la fresca el encuentro programó varias actividades durante dos semanas. A continuación, tenemos el detalle de las actividades.

\section{Inauguración Fiesta de San Juan}

Inauguramos La Calderería "caldeando el ambiente" y que mejor día que el día más largo del año. El día en que la ciudad arde por los cuatro costados y la playa se enciende, por lo menos en nuestras tierras. Empezamos temprano para disfrutar de un día en familia con refrigerio, actividades para niños, música, buen ambiente y alguna sorpresa. Fue una manera agradable y lúdica de presentarnos en el barrio abriendo el espacio a todos los vecinos que sintieran curiosidad por saber quiénes éramos y lo que planeábamos hacer en ese espacio sin que hiciera falta ningún protocolo, ya que hicimos actividades tanto dentro como fuera del espacio de manera que resultara cómodo establecer el primer contacto. Igualmente, hicimos extensa nuestra invitación a cualquier colectivo o interesado que quisiera acercarse a celebrar con nosotros de manera que la presentación fuera también a nivel de ciudad.

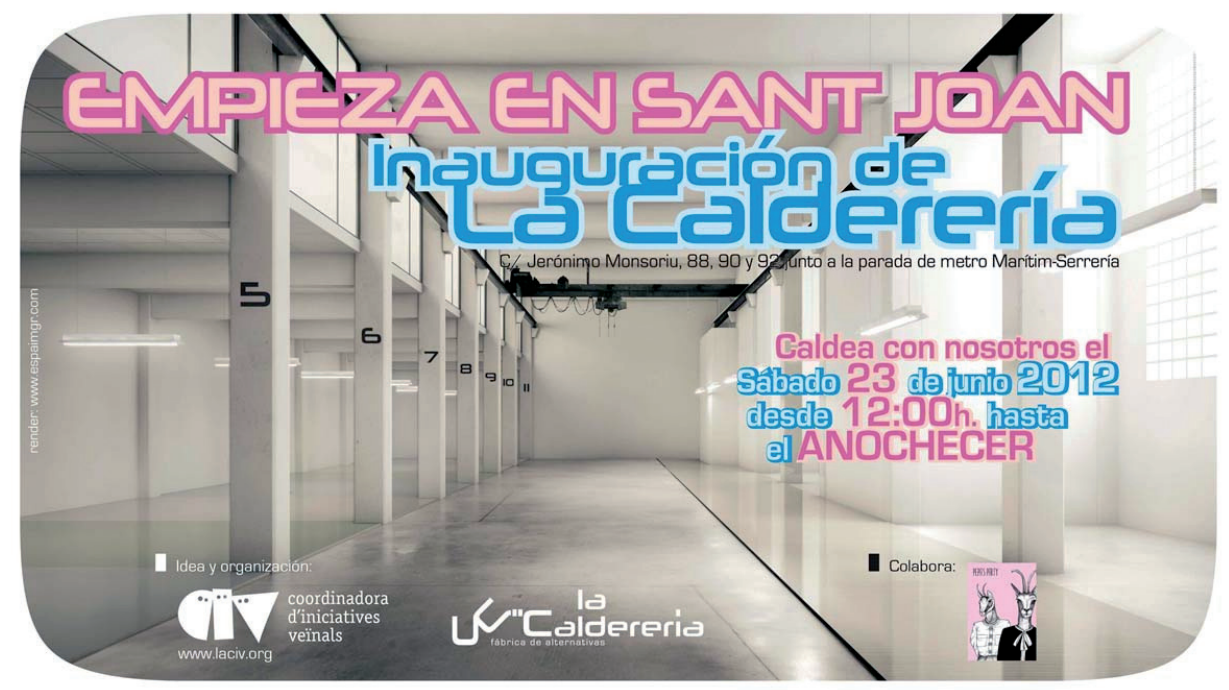

Fig. 61

\section{Taller de autoconstrucción con madera}

Del lunes 25 de junio al viernes 29 de junio de 2012, organizamos un taller de autoconstrucción con madera cuyo objetivo era adquirir conocimientos prácticos en 
el empleo del tablero de madera como material constructivo ensamblado en seco a la vez que experimentar en la construcción a escala 1:1 las posibilidades de este material en la construcción de espacios y elementos multiuso para La Calderería. Con ello, continuábamos la línea de autoconstrucción que habíamos iniciado en el Solar Corona a la vez que intentábamos paliar las carencias de mobiliario cara a las siguientes activi-

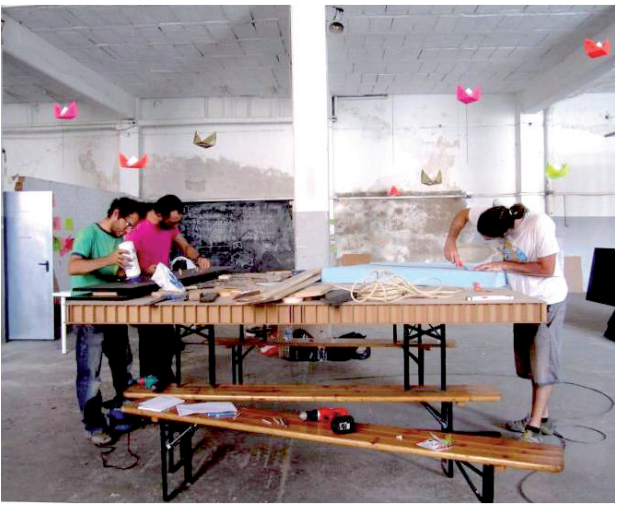
dades que habíamos programado en el espacio.

Seminario Frente a la estafa. De las miradas críticas a las alternativas económicas

De estas jornadas ya hemos hablado extensamente en el apartado del colectivo Autoformato pero, tras haber realizado la presentación del tipo de centro que queríamos poner en pie, se entiende mucho mejor la pertinencia de los temas abordados: una introducción a la construcción de modelos económicos alternativos al dominante aplicables al presente más inmediato, profundizando en el debate que permitiera perfilar y detallar alternativas. Con estas jornadas, terminamos la segunda fase de activación de La Calderería y pasamos a abrir el centro a actividades puntuales propuestas desde el exterior. Al mismo tiempo, intentamos

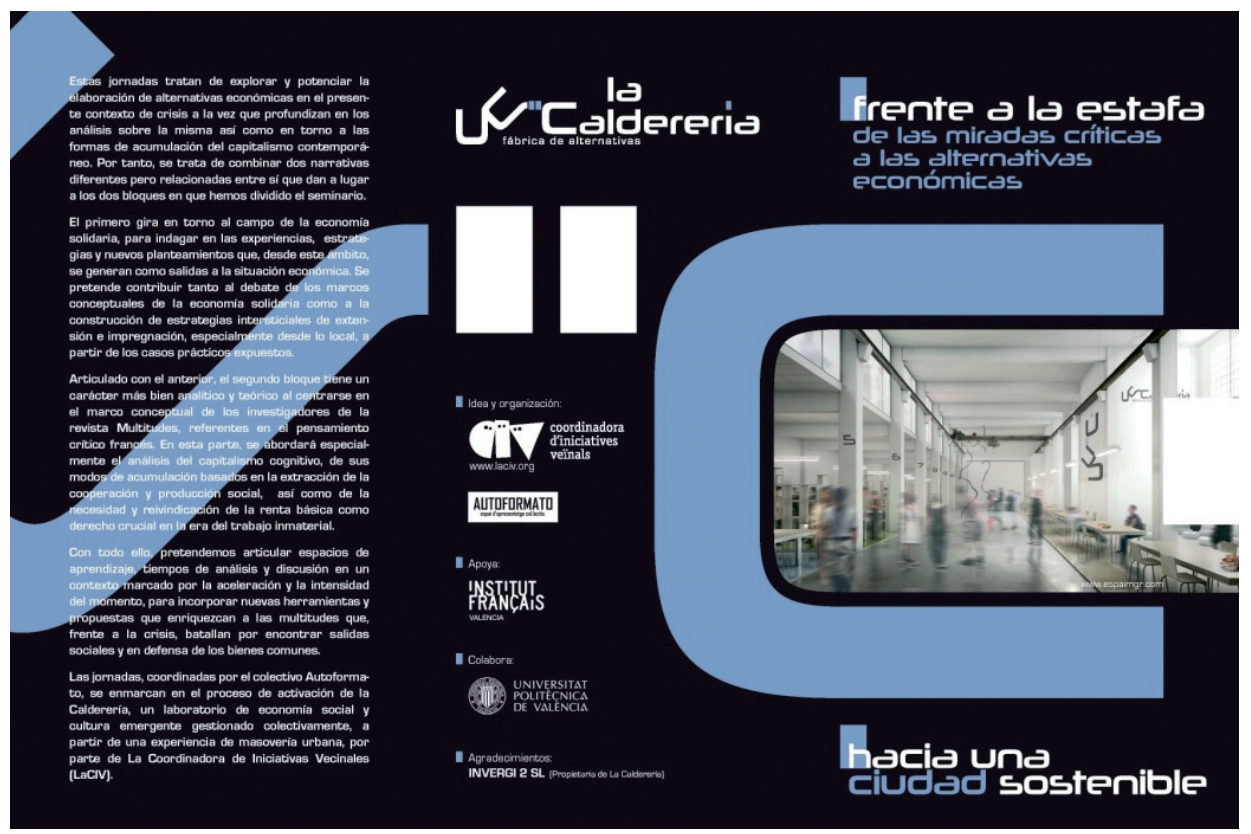


cerrar el modelo de gobernanza que proponíamos al propietario, redactando un contrato tipo que nos permitiera abrir la gestión a las diferentes propuestas presentadas de manera que pudiéramos funcionar con una gestión horizontal e independiente. Esto nos llevó a mantener numerosas negociaciones con todas las partes implicadas al mismo tiempo que seguíamos aceptando actividades puntuales que fueran, poco a poco, mejorando el espacio.

El cronograma de nuestra relación de actividades en relación con La Calderería quedaría como sigue:

- Septiembre 2011: INVERGI 2SL se reúne con LaCIV para mostrarle La Calderería y hacer la primera propuesta de usos.

- Noviembre 2011: INVERGI 2SL contrata a LaCIV para realizar un estudio básico de activación de La Calderería.

- Enero 2012: reuniones con entidades vecinales del barrio para redactar el primer mapa de relaciones.

- Febrero 2012: entrega al propietario del estudio básico de activación de La Calderería.

Fin de la primera fase de activación.

- Marzo 2012: nuevas incorporaciones a LaCIV.

Formación de grupos de Comunicación, uso, viabilidad, acondicionamiento y coordinación.

- Mayo 2012: reforma previa de patologías.

- Junio 2012: Jornada de Puertas Abiertas.

Caldeando. Comboi al Maritim.

Lanzamiento de la convocatoria de uso.

Fin de la segunda fase de activación.

- Septiembre 2012: primeras actividades puntuales.

Conferencia ¿Crisis en la Movilidad Sostenible? Ideas y soluciones en el contexto de la Semana Europea de la Movilidad Sostenible, a cargo de Ole Thorson, presidente de la Asociación Internacional de Viandantes.

Presentación del Taller 3 de Proyectos Arquitectónicos de la ETSAV-UPV.

- Octubre 2012: Tertulia sobre decrecimiento con Serge Latouche, ya reseñada en el apartado de Autoformato.

Exposición (En)Cuadre, Espacialidad Ciudadana, organizada por el Máster de Fotografía de la Universidad Politécnica de Valencia.

Taller de elaboración de pan.

- Noviembre 2012: TEDxValenciaWomen. Hacia la soberanía alimentaria.

- Diciembre 2012: III encuentro creación escénica contemporánea:

¿A quéestamos jugando?

Punt a part. Taller de punto para principiantes.

LaBarracaFleaMarket, mercadillo de trueque. 
Como podemos ver, pronto se hizo obvio que la ciudad de Valencia estaba más que necesitada de contar con un espacio similar en el que poder realizar actividades autogestionadas de todo tipo. Se multiplicaban las propuestas de actividades puntuales más o menos en la línea del centro, como se puede ver en el cronograma, pero la situación empezaba a convertirse en insostenible. Nos veíamos obligadas a gestionar continuamente un espacio que aún no contaba con las condiciones mínimas de ocupación. Pudimos poner en marcha un baño gracias a la persona que realizó el taller de pan, teníamos la luz pinchada a la escalera de la finca porque habían robado todo el cableado del espacio y la arqueta no estaba dada de alta. El seguro llegaba a su fin y nos veíamos incapaces de gestionar el flujo continuo de demandas. Por otra parte, las negociaciones con el propietario no iban por buen camino ya que este se negaba a firmar un contrato horizontal con los 7 colectivos que iban a continuar la gestión del espacio y nosotros nos negábamos a seguir realizando estas tareas de administración general no retribuida que nos impedían realizar nuestros propios proyectos. Los demás colectivos estaban impacientes por lanzar sus propios proyectos y ocupar los diferentes espacios. El contrato temporal de un año que habíamos firmado con el propietario llegaba a su fin.

El 31 de diciembre de 2012, La Calderería cerró sus puertas un año después de haberlas abierto a la ciudad y a las iniciativas de sus ciudadanos, colectivos, asociaciones y demás agrupaciones. Sí, cerramos puertas con tristeza, dejamos atrás esta etapa en la que creímos posible poner en marcha un centro de estas características en una zona periférica de la ciudad, sin recursos pero con ganas. Nos despedimos del espacio pero no del proyecto. No obstante, a raíz de los últimos acontecimientos, quisimos cerrar este proceso de la mejor manera posible informando de los motivos de cese del espacio, del proceso que seguimos y el desenlace final que ha tenido, por si a alguien le puede servir esta experiencia acumulada para su propio caminar.

Una cuestión fundamental fue el hecho de que el propietario se mostró reticente a firmar un contrato de alquiler en "masovería urbana" individualizado con los proyectos presentados a la convocatoria, así como, en segundo término, también al ofrecimiento de una gestión horizontal de la cesión de uso temporal en la que se hallaba desde el inicio. Ante esta continua negativa desestabilizadora, intentamos negociar recordándole la motivación de nuestras propuestas que se basaba en las firmas de varias asociaciones que se hacían responsables de un espacio tan grande y con tantos condicionantes. En la misma medida, sabemos que, detrás de esa negativa a la horizontalidad, se encuentra la oferta de una empresa interesada en ocupar el espacio mediante un contrato de alquiler al uso. Sinceramente, nos sentimos un tanto defraudadas en nuestro esfuerzo durante todo este año por adecentar y activar un espacio con la promesa de un acuerdo de masovería prolongado durante tres años que hiciera sostenible la gran inversión, ya iniciada, en tiempo, dinero y esfuerzo que exigía el espacio. 
No ha podido ser. Por una parte, nos queda la satisfacción de haber sabido visibilizar y activar un espacio tal y como nos comprometimos y en un tiempo récord. Por otra, la decepción de ver cómo el funcionamiento mercantilizado clásico se impone a cualquier beneficio social en unos tiempos en que éste debiera ser una prioridad en muchos frentes. Hemos aprendido muchas cosas por el camino, pero nos queda la añoranza de lo que hubiera podido llegar a ser ese espacio con el potencial que pudimos percibir, la necesidad que pudimos constatar y la calidad de las respuestas que por parte de tantos hemos recibido. Por eso, pensamos que sería maravilloso que este proyecto o muchos otros similares se multiplicaran por la ciudad y ocuparan activándolos la miríada de espacios en desuso que alberga. 


\section{Finales y principios}

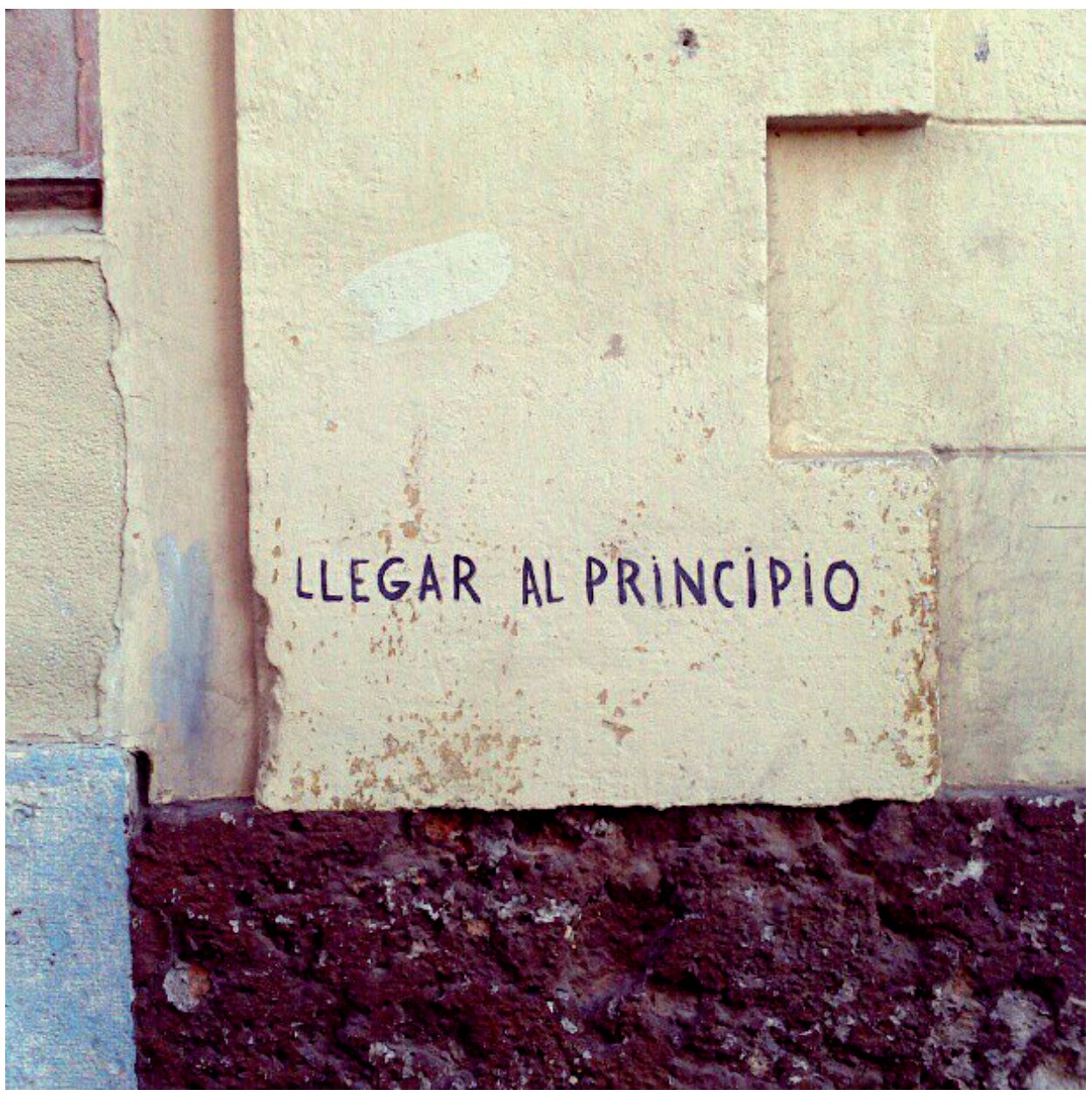

Fig. 64 
Finalmente, para concluir como se espera que hagamos, recordaremos nuestro propósito inicial de comprobar si, en el contexto de las metrópolis postfordistas, determinados procesos de autoformación pueden llevar a transformaciones sociales en el ámbito político cuando van asociados a prácticas instituyentes. Mediante el análisis de nuestras prácticas, podemos decir, como ya hemos especificado en los diferentes apartados dedicados a ello, que la autoformación constituye efectivamente un cuestionamiento de los lugares asignados en la redistribución de los saberes, ya que se plantea desde la autonomía del conocimiento y emana de la necesidad de formarnos en cuestiones a las que no responden las instituciones del saber, pero a las que consideramos urgente atender.

En las conclusiones de Autoformato, detallamos cómo hemos intentado localizar y desarrollar las herramientas necesarias para producir sucesivos empoderamientos y constituirnos en institución: empoderamiento físico a través de la generación de espacios del procomún, económico a través de las diferentes propuestas de protocolos jurídicos y alternativas laborales, y empoderamiento político a través de las herramientas asamblearias y participativas para llevar a cabo diferentes procesos de autogestión; todo ello estando vinculadas necesariamente a procesos de cooperación social y resistencia protagonizados por los diferentes movimientos sociales presentes en el territorio.

Consideramos pues que se ha producido en diferentes ámbitos esa conversión en institución que nos ha situado en una posición de interlocución legitimada desde la que dialogar con los poderes constituidos y poder provocar cambios de orden político: en el Solar Corona, en los procesos de LaCIV y en La Calderería; aunque también hemos comprobado que instituirse conlleva grandes riesgos de estructuralización y pérdida de porosidad. La experiencia nos lleva a reconocer que nuestras aspiraciones iniciales de constituirnos como mediadoras urbanas que respondieran a la necesidad de intervenciones transversales a nivel de ciudad a través de LaCIV, fue cooptada por un proceso de diseño de un Centro de Proximidad en Velluters que, además de obligarnos a renunciar a nuestro contenido más político, generaba una ilusión de profesionalización inexistente como inexistentes son los dineros del Ayuntamiento. Este conflicto entre la necesaria retribución laboral y los espacios y los tiempos para la producción militante se repite frecuentemente entre los colectivos, al no haber métodos de retribución alternativos a este trabajo de creación de valor social. 
Por otra parte, el segundo error que podemos detectar fue dejarnos arrastrar por un proyecto cuyas dimensiones y estado nos superaba (La Calderería,) que prácticamente eliminó cualquier otro proyecto posible que se planteara LaCIV al canalizar todas nuestras energías. De esta manera, el propietario se benefició de las externalidades positivas que generamos en torno a su centro al visibilizarlo y permitirle así relanzar el espacio revalorizado en el mercado. La teoría de Richard Florida llevada a la práctica de la peor de las maneras posibles, como el propio autor ha reconocido últimamente en una declaración pública de retractación. A cambio, tenemos muchos elementos positivos que contraponer, nuestra apertura a nuevos agentes, la continuidad y multiplicación de nuestros procesos de empoderamiento que hemos conseguido dinamizar en muchos ámbitos y que seguimos proyectando. Pero antes de ponernos sentimentales y empezar a hacer proyecciones de futuro esperanzadoras para terminar la tesis con buen sabor de boca, nos gustaría recalar momentáneamente en algunos términos y conceptos, por esto de seguir a pie de pista hasta el último momento y gastar los últimos palomos del sombrero.

En primer lugar, nos gustaría partir del hecho de que nuestras prácticas se han desarrollado en el territorio del Outsite ${ }^{206}$, concepto al que ya hemos aludido en páginas anteriores y que queremos desarrollar aquí con mayor amplitud, para dibujar un espacio de trabajo que no corresponde ni al urbanismo ni a la arquitectura ni al arte ni a la sociología ni al trabajo social, sino que excede a todos y nos deja en la situación del ignorante que se arremanga las ideas y aborda el territorio con las manos, dejando de lado los marcos de conocimiento que se ha construido y que le permiten parapetarse en su ámbito. Con estas hibridaciones, por nuestra parte intentamos romper con el modelo autorreferente del arte, trabajando en el campo expandido de la cultura que también podemos llamar vida - colectivos ejerciendo como ciudadanos de esta cosa que llamamos Valencia para salir de territorio inerme de la queja, sin renunciar a la ocupación física y haciéndolo como celebración.

Ahondando en su definición, el Outsite es ese lugar que se define por su permanente ajenidad, por su condición de outsider encarnado en un Site, específico del lugar y ajeno a cualquier disciplina. A pesar de ello, es un espacio plenamente local aunque no pertenezca a una categoría concreta, ni a una disciplina determinada ni una práctica localizable, ni siquiera a una autoría única. En nuestro caso, como se nos ha hecho saber desde los colectivos franceses con los que hemos colaborado, la intervención a nivel local, el trabajo sobre el territorio propio, resulta un modus operandi diferencial respecto a otros colectivos similares que funcionan más bien con la lógica del encargo ya que viven y trabajan en espacios distintos, con lo que ello implica de distancia operativa.

206. MIQUEL, Mijo. “De las prácticas transversales a las investigaciones extradisciplinares: la constitución del Outsite". En: Ciudades (im)propias: la tensión entre lo global y lo local. Valencia: Universidad Politécnica de Valencia, 2011 
Al quedar la autoría disuelta, es fundamental darse cuenta de que el anonimato supone un reconocimiento de lo colectivo, ya que cualquiera puede ser parte integrante de ese proceso y todos podemos reclamarnos partícipes del mismo, manifestando una puesta en acto de la capacidad igualitaria en los procesos de intervención. Igualmente, su condición extraterritorial hace que su valoración sea problemática ya que los criterios de análisis también se encuentran "fuera de". Este tipo de hibridaciones se ve en la necesidad de generar todos los mecanismos tanto de legitimación como de transmisión que implica su condición híbrida de autoría disuelta, en la necesidad de autoproclamarse como práctica instituyente, lo que le asegura a su vez el cuestionamiento del régimen de saber.

Al analizar nuestras propias prácticas, vemos cómo, frente a un modelo convencional de conocimiento compartido, hemos lanzado un proceso colectivo de investigación, en el que todos los participantes hemos salido del inevitable posicionamiento previo, (por nuestra condición particular de investigadores, activadores sociales, vecinos o simpatizantes), y nos hemos expuesto a modificarlo. Al partir de nuestras ignorancias respectivas, unos hemos renunciado a las seguridades institucionales, mientras que otros hemos realizado el proceso inverso, al generar esferas autónomas de reconocimiento, trabajando todos a partir de lo que denominamos el mínimo común dinamizador. Nuestras incompetencias, nuestro caos también son nuestra potencia al evitar la rigidez, la consolidación de estructuras.

Por tanto, la condición que, a nuestro parecer, resulta clave a la hora de analizar nuestros procesos es ese estado difuso que nos sitúa en términos de igualdad. No es el saber lo que nos iguala, es la constitución de una comunidad en la ignorancia, la indefinición, la fase embrionaria de nuestras nuevas instituciones. Si bien anteriormente hablamos de la comunidad en el rechazo como primera condición para la constitución de un vínculo, es la aceptación del valor positivo de nuestra ignorancia la que nos permite pasar a los actos. El momento de la contaminación mutua, el de la pérdida de referentes propios y la construcción de referentes comunes podría ser aquel en que se pusiera en obra realmente una capacidad igualitaria entre pares. Por ello, nuestra gran baza es que no sabemos hacia dónde vamos, la carencia de objetivo definido que supone una renuncia a la estrategia, pero también una apertura a los posibles, una desconfiguración primera. De esta manera, no trabajamos para demostrar teorías sino que creamos los conceptos que se necesitan para explicar eso innominado que sucede, en un ir y venir incesante de los modos a los nombres y viceversa. Consideramos este concepto clave para entender el proceso del Comboi así como las derivas posteriores de nuestros colectivos.

En resumen, frente al planteamiento interdisciplinar, proponemos un Outsite en el que se confunden, diluyen, contaminan y desaparecen las disciplinas, para provocar un empoderamiento que genere un espacio político, ese que en un capítulo anterior llamamos comunidad, que otras han denominado un nosotros, y 
que hace alusión ni más ni menos a eso que somos cuando nos juntamos desde una composición diversa, procedentes de experiencias muy diferentes y lenguajes distantes, lo que nos obliga a buscar un lugar común desde donde operar así como un vocabulario básico para entendernos. Desde ahí, hemos intentado recuperar un espacio común a través del hacer, interpretando la resistencia en positivo como biopoder transformado en biopolítica, es decir, a través de la ruptura de la tenaza entre lo público y lo privado que abre una ventana a la generación de lo común.

Las metodologías de trabajo utilizadas nos permiten evaluar el Comboi, el Solar y La Calderería como hechos diferenciales respecto a otros eventos. Consideramos que ha habido un proceso contributivo en la medida en que hemos constituido una comunidad efímera que se instituye en sujeto político de derecho y que gobierna su propio territorio mediante la autogestión y la autonomía, dotándose de las normas necesarias para hacerlo. Este proceso de auto-organización presupone la producción constante de lazo social, que favorece la constitución, el mantenimiento y la renovación de esta comunidad. De hecho, podríamos interpretar nuestras prácticas como el proceso de autoformación de una comunidad que surge de un malestar social más o menos generalizado, en la que la afectación y la afección van de la mano y son igualmente necesarias. Sólo nos falta por añadir el hecho de que es el mundo entero el que nos está afectando y no nuestra vinculación personal con el territorio.

La necesidad de replantearnos una cierta filosofía política orientada al gobierno es una línea argumental que planea a lo largo de toda la tesis, poniendo numerosos ejemplos de la emergencia de ese disenso cada vez más palpable y generalizado, malestar que evidencia el fracaso de la política tal cual está planteada, en la medida en que se ha revelado como un espacio de representación que tiende a reducir la noción de libertad y a blindar a las élites que lo constituyen así como su funcionamiento, por lo que resulta cada vez más evidente el hecho de que necesita ser reformulada. Enlazando con el final del capítulo 4 donde planteamos que el sujeto de cambio quizás sea la comunidad entendida inicialmente como una comunidad anónima en el rechazo, retomando los planteamientos de Marina Garcés, recalaremos brevemente en la teoría política sobre la comunidad y, de forma derivada, sobre la democracia. Si bien es verdad que nuestras disquisiciones abarcan el aspecto macro del asunto, no dejamos de observar que resulta esencial poner en acto los mismos cuestionamientos a nivel micro, en nuestras propias ciudades, en los intersticios que quedan para poder proyectar deseos, imaginar usos y transformar las fronteras de lo posible.

Los propios procesos de dinamización territorial que hemos puesto en marcha acaban legitimándonos cara a la Administración y a los ciudadanos. En Valencia, por su proceso de expansión y especulación, existe una cantidad inaudita de solares y de naves en desuso que podrían representar el intersticio posible. 
Estos espacios abandonados son un símbolo perfecto para un proceso de creación de comunidades precarias y mutantes, siempre al borde de la extinción. Son espacios donde proyectar deseos, donde generar sinergias que se expandan y desborden el propio espacio delimitado, evidenciando que la teoría de los atractores es útil. Permiten operar la transformación de la idea de que el espacio público, al ser de todos, no pertenece a nadie, en la idea de un espacio en blanco sobre el que se puede proyectar y transformar. Tan sólo el hecho de permitirse imaginar ya desplaza la frontera de lo posible, al transformar la posición pasiva generalizada en una activa mediante diferentes direcciones de implicación: de los colectivos al vecindario en general, de los vecinos que reivindican a los colectivos que median y del aislamiento antagonista al establecimiento de redes de solidaridad y producción.

Esos intersticios se alzan pues como símbolo y como literalidad - al ir más allá de lo que se considera posible, permiten atravesar los límites en tanto lugares temporales de abrigo precario y sostenibilidad fugaz, albergando instituciones nómadas que se desplazan a otros territorios tras fisurar el marco de realidad. Esa definición tan literaria no hace sino describir el proceso que se planificó en el Solar Corona o en La Calderería, espacios abandonados y en desuso, residuos de planes y proyectos, magníicos símbolos y encarnaciones territoriales de comunidades en permanente transformación, que no consolidan formas aparentemente democráticas de gobierno, sino que, a tenor de cada proyecto, van reconstituyéndose. Este fue el proceso llevado a cabo en el Solar Corona y que hubiera debido cumplirse en La Calderería: la cesión del gobierno a otra comunidad reconstituida de manera que se pudiera renovar el vínculo en permanencia y optar a esa temporalidad limitada que supone la transformación social. Resulta igualmente importante tanto la generación de la comunidad como su interrupción, la admisión de la necesidad permanente de reconstituirse, renovar vínculos y abrirse a la disolución.

De manera más detallada, diríamos que la diferencia entre la deriva del Solar Corona y La Calderería residiría en que, en el primer caso, hubo una interrupción de la comunidad (programada de antemano), una cesión y reconstitución de una nueva comunidad de implicados agrupados en una Asamblea constituyente, que decidieron mantenerse abiertos en todo momento a la incorporación de nuevos actores. En la actualidad, al haberse sumado a la red Ciutat Vella Batega, esta comunidad empieza a plantearse de nuevo su disolución y readaptación a un marco de mayor alcance, a través del que se está negociando un plan general de gestión comunitaria de recursos públicos de ese barrio junto con otros colectivos.

En La Calderería, este proceso quedó en suspenso, se prolongó una comunidad que perdía afectos y que no estaba territorial ni afectivamente implicada en el espacio. Hubiera debido producirse la cesión a una nueva agrupación horizontal de implicados, funcionando como el centro de proximidad que se suponía que iba a ser y actuando como bisagra de articulación entre dos barrios: Cabanyal y 
Ayora. La interrupción se produjo por motivos ajenos (la imposibilidad de cerrar un acuerdo horizontal con el propietario), pero también por la disolución progresiva de los vínculos. Pensamos que fue igualmente un efecto secundario del cambio de estatuto interno de nuestro colectivo, puesto que pasamos de ser una plataforma puntual reunida en torno a un encuentro (Comboi a la fresca), realizado sin retribución alguna y con una temporalidad cerrada, a la constitución de una entidad jurídica con propósitos profesionales. Nos enredamos en burocratizaciones varias, en propuestas unificadas, en orientaciones generales, y la comunidad se fue deshaciendo: empezaron a funcionar los términos diferenciales, la inclusión matizada y los raseros, los conflictos por las posiciones de poder y el agotamiento que se produce cuando no hay aportaciones ni afectivas ni económicas que compensen la balanza.

Esta deriva, que cualquier colectivo ha experimentado en algún momento, plantea la incógnita de si estas comunidades sólo pueden existir en los intersticios, en ese espacio entre lo singular y lo plural, que elude la unidad, o si cabe plantearse opciones alternativas, mediante herramientas como la renta básica, que liberarían tiempos no mercantilizados para dedicarlos a la generación del procomún. En cualquiera de los casos, no podríamos hablar de comunidades desobradas, aunque nuestro vínculo sea lo que Jean-Luc Nancy ${ }^{207}$ definiría como ese ser-en-común que nos es dado, porque nos orientamos desde la base hacia una transformación social, y para ello, hay que pasar del "como si" de la política al "haciendo asi" del obrar. Nuestra experiencia supone inevitablemente un hacer y es a través de ese mismo quehacer que la comunidad se constituye, pero evitamos el cierre identitario de la comunidad, consiguiendo cierto "desobramiento", al conjurar la consolidación y estructuralización mediante la limitación temporal. Se trabaja para un futuro en el que no se estará presente, eludiendo de esta manera por ausencia de estrategia en el tiempo, el grave peligro de la comunidad de intereses, el lobby autogestionado que puede acabar siendo una comunidad que medie entre los ciudadanos y los Estados, ese pequeño Monsanto que todas llevamos dentro y que nos hace correr el riesgo de convertirnos en gated communities mediante procesos de inmunización, de inclusión diferencial, ejercitando el poder que nos concedería el número para modificar a nuestro favor los pactos sociales de cohabitación.

Esa urgencia en la necesidad de transformación, ese mínimo común dinamizador insoslayable, hace que haya verdaderamente una implicación común y por tanto, un encuentro incómodo donde se producen enfrentamientos e incomprensiones, pero también lazos y construcciones de vínculo. Esta implicación no significa sin embargo una relación de apropiación, lo común también es lo

207. NANCY, Jean-Luc, La comunidad afrontada, Postfacio a la edición española de La comunidad inconfesable, Ed. 2003. 
impropio, en el sentido de que no se puede realizar la separación entre sujeto de acción/objeto de transformación, no es una relación de pertenencia o de exclusión, sino precisamente, lo que es inapropiable porque es de todos y a todos nos afecta. Por ello, Pascal Nicolas Le-Strat, cuando nos visitó en Valencia, hablaba de que el Comboi había sido un bello ejercicio de democracia contributiva, que supone en relación a la democracia participativa la misma diferencia que hay entre implicación y participación: la gran distancia que va de participar en algo a formar parte de ello.

Si basamos nuestra noción de comunidad no en una identidad que suponga pertenencia y por tanto, lógicamente, exclusiones, sino en una relación, inevitablemente ponemos el acento en la comunicación, en ese pensar-con, y no tenemos más herramientas para hacerlo que las comunes, esa lengua y ese sensus communis kantiano al que ya hemos aludido anteriormente. Por otra parte, recordando nuestra corporalidad, nuestra presencia inmediata en el mundo, nos gusta hacer referencia al término intercorporalidad usado por Garcés, relacionado por una parte con la imposibilidad de no interactuar enunciada por Merleau-Ponty, así como de la idea de hombre spinoziana como ser imaginativo, que sólo percibe los cuerpos externos a través de su propio cuerpo, no siendo para él los afectos más que las ideas de nuestras afecciones corporales.

Esta presencia corporal y esa imposibilidad de pensar solas no nos remiten automáticamente a una posición utópica de concordia comunitaria sino que nos siguen poniendo en lo que Miguel Cereceda ha denominado Incomunidad ${ }^{208}$, esa comunidad incómoda de la cesión mutua, de la comunicación defectuosa y del verdadero fondo común de todo hombre: el horizonte de la muerte, según coinciden en decir Georges Bataille y Blanchot.

Hemos querido expresar no sólo la incomodidad que la comunidad produce y las patologías derivadas de su propia realización, sino también lo incomunicable mismo que la comunidad contiene, el fondo mortal que se revela en su interior (p. 19).

Pero nosotras creemos que hay algo más que la muerte en la construcción de una comunidad posible. Si bien es importante mantener presente la clausura que toda comunidad lleva implícita en su posible cierre identitario, también lo es reconocer que hay maneras de conjurar ese fondo mortal mediante la práctica de su constante apertura a la alteridad, insistiendo en la composición nómada y mutante de lo inapropiable. Todas estas experiencias prácticas de autoformación y gestión, que no son otra cosa que la extensión de las fronteras del gobierno hacia una emancipación, no constituyen una comunidad cerrada sino una porosa, no consolidan una institución de muerte, en el sentido de acabamiento del horizonte, sino una comunidad anónima, abierta, inapropiable y nómada. Una comunidad

208. CERECEDA, Miguel y VELASCO, Gonzalo (eds.): Incomunidad. El pensamiento político de la comunidad, a partir de Roberto Esposito, Madrid, Arena Libros/UAM, 2011. 
basada en la precariedad de sus vínculos, en la condición efímera de su existencia y por tanto, menos preocupada en perdurar que en transformar, implicar y ceder. De esta manera, se hace visible la doble acepción que según Roberto Espósito tiene el étimo munus, presente en la palabra communitas, como acto mismo de donación, aunque este étimo también pueda entenderse en el sentido de ley. Para él, pensar la comunidad implica desplazar el foco del cum a ese elemento de donación, mientras que Nancy se centraría en el primer término, en la relación, que excluye por tanto la obra comunitaria. Siguiendo la lógica del don implícita en el munus, que no es un objeto que se dé o se pueda compartir, sino el acto mismo de la donación, y combinándola con la potencia de ley que tiene la autogestión en relación a su capacidad instituyente, intentamos entender nuestras prácticas puntuales que serían, en cierto modo, una donación a un bien común, a un futuro tan anónimo como colectivo.

Esposito relaciona esa condición de inapropiado y de inapropiable con tres características que suponen el reverso de lo común: lo propio, lo privado y lo inmune como tres ejes de constitución de la ley y simultáneamente, como tres modos de disolución de lo social. A ellos, contraponemos lo inapropiable, lo anónimo y lo expuesto de nuestras prácticas. Sólo disponemos de estas incertidumbres políticas como herramientas de choque pero no tenemos más tiempo, va llegando la hora de poner en común nuestras ignorancias y poner en común nuestro rechazo a este gobierno de lo económico que domina nuestras vidas, que lleva a la privatización, la apropiación y la inmunización de lo público frente a la vulnerabilidad porosa de lo común. Como dice Esposito ${ }^{209}$ :

Se trata, porsupuesto, de una batalla difíil-incluso porqueno hacefalta cometerelerror estratégico de abandonar el espacio público a favor del común, arriesgándose mientras tanto a favorecer el proceso de privatización. Pero en ningún caso se debe confundir el bien común con aquello que pertenece a la soberanía del Estado o de la Administración regional reguladas por la subdivisión jurídica preliminar entre público y privado.

Retomando las diferentes preguntas abiertas en esta tesis, diremos que seguimos sin tener respuestas para las grandes cuestiones, que, evidentemente, no podemos ofrecer una alternativa clara a este sistema de gobierno basado en la democracia representativa y la filiación nacional. No obstante, nos gustaría hacer un repaso de las propuesta utópicas que hemos recogido y dibujado a grandes rasgos: la transformación de la retribución en redistribución mediante mecanismos como la renta básica; la aplicación de criterios de la globalización desde abajo y la aceptación de que vivimos en un mundo común en el que no tiene sentido seguir defendiendo fronteras, ni externas ni internas, porque estamos implicados todos en ello de manera superlativa; la implementación del decrecimiento frente al progreso, de la calidad de vida en las urbes frente a la especulación y el tránsito, la necesidad

209. ESPOSITO, Roberto, Comunidad, inmunidad, biopolítica, en Las Torres de Lucca nº 0 (Enero-Junio 2012), Istituto Italiano di Scienze Umane, pp.101-114 
de reactivación de los vínculos comunitarios y la revisión de ese contrato social en el que se basa cualquier funcionamiento posible. Todas ellas sometidas a un cada vez más necesario proceso destituyente que permita la emergencia de todo tipo de propuestas, el debate público y la reconstitución de una comunidad en permanente transformación. Recordamos lo que dijimos en su momento: proponemos la continuación de un proceso que lleva implícito el aprendizaje de su objetivo: mediante la participación, queremos aprender a participar, mediante la autogestión, a gobernarnos. Este aprendizaje no pretende un estallido y recambio del poder, no queremos oponer una globalización a otra globalización, lo que proponemos es la paulatina incorporación de actores sociales al ejercicio del poder: la administración de los recursos, la toma de decisiones y el establecimiento de leyes mediante redes horizontales de cooperación entre colectivos e individuos, ya que por el momento, no parece posible llevar a cabo un proceso destituyente generalizado. 


\section{Bibliografía}

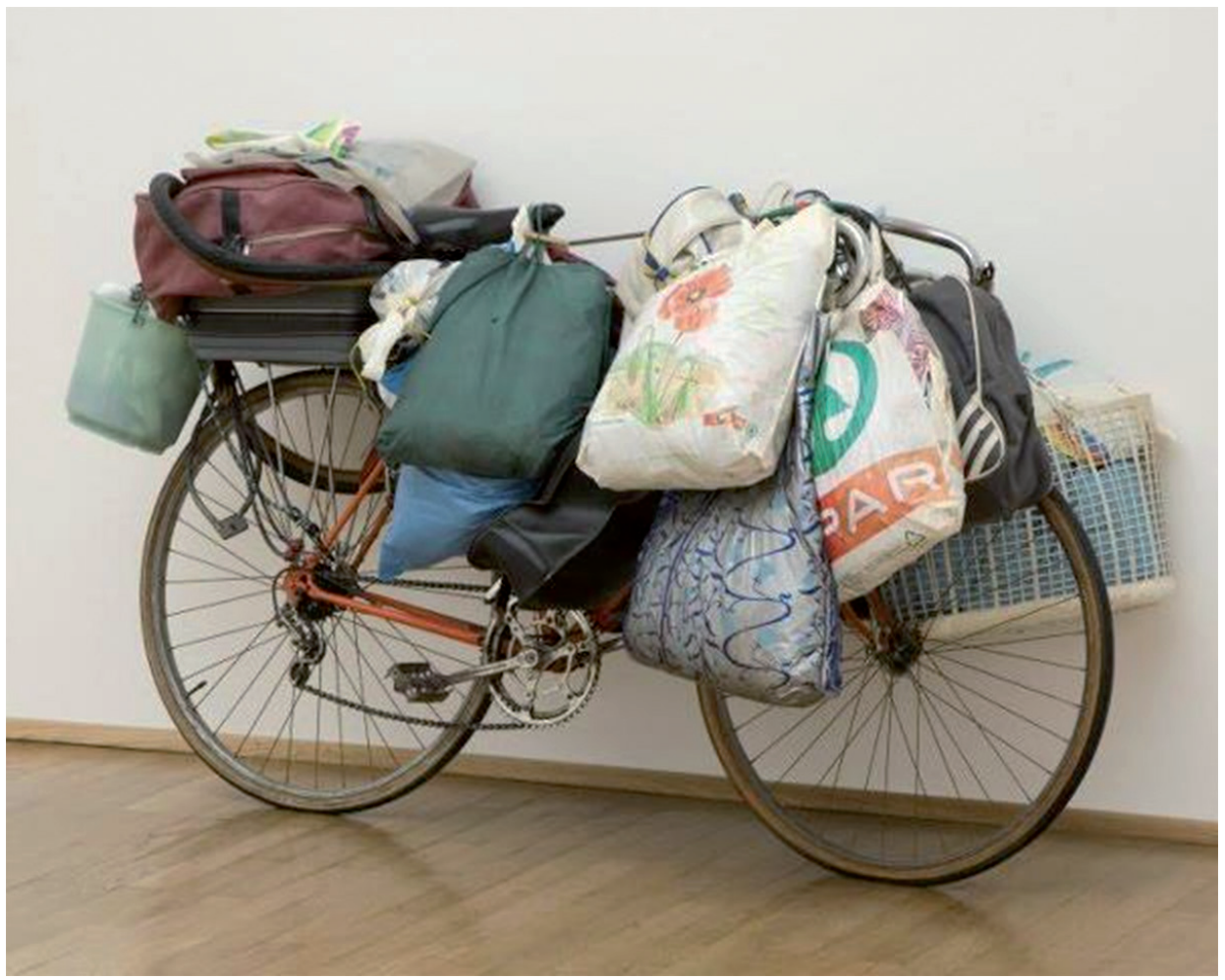

Fig. 65 


\section{MONOGRAFIAS Y ARTÍCULOS}

ACHACHE, Gilles. "El marketing político". En: El nuevo espacio público. Buenos Aires: Gedisa, 1992.

ARENDT, Hannah. Sobre la revolución. Madrid: Revista de Occidente, 1967.

"AUTONOMIA y Metrópolis". En: Del Movimiento okupa a los Centros Sociales de Segunda Generación. Málaga : La Invisible, 2008.

BADIOU, Alain. "Que signifie changer le monde?: séminaire 2010-2011". Entretemps. Disponible en: http://www.entretemps.asso.fr/Badiou/10-11.htm\#_ftnref21. [Consulta: 10 de enero de 2012]

BALIBAR, Etienne. Europe, Constitution, Frontière. París: Les Éditions du passant, 2004.

BARRA DIAGONAL. Infraestructuras Emergentes, Valencia: Universidad Politécnica de Valencia, 2009.

BERARDI AKA BIFO,Franco. "Patologías de la hiperexpresividad". Eipcp [en línea]. Disponible en web :<http://transform.eipcp.net/transversal/1007/bifo/es>. [Consulta: 12 Mayo de 2.011]

BLANCHOT, Maurice. Escritos políticos. Madrid: Acuarela libros, 2010.

BLANCHOT, Maurice. La comunidad inconfesable. Madrid: Arena Libros, 2007.

BUITRAGO, Ana (ed.), Arquitecturas de la mirada. Barcelona: CuerpodeLetra, 2009.

BUTLER, Judith. "Pero ¿qué reivindican? Y ¿adónde van ahora?". Scribd: The world's digital library.[En línea]. Disponible en: <http://es.scribd.com/epidermicus/d/86333441Butler-Judith-So-What-Are-the-Demands-Occupy-Wall-Street $>$. [Consulta: 3 de Febrero 2.1013]

CAPITALISMO cognitivo, propiedad intelectual y creación colectiva. Madrid:Traficantes de Sueños, 2004.

CASTELLS, Manuel.La era de la información. Madrid, Alianza Editorial, 2006. 3 vols. 
CAMUS, Albert. L'homme révolté. París: Gallimard, 1951.

CERECEDA, Miguel y VELASCO, Gonzalo (eds.). Incomunidad. El pensamiento político de la comunidad, a partir de Roberto Esposito. Madrid: Arena Libros/UAM, 2011.

COMITÉ INVISIBLE. L'insurrection qui vient. Paris : La Fabrique, 2007.

CORRESPONDENCIAS desde Eyjafjallajökull . Montaña-isla-glaciar. Madrid: Broken Dimanche Press, 2011.

CORSANI, Antonella y LAZZARATO, Maurizio. "Intermitencia: reapropiación de la movilidad, producción de lo común". En: Contrapoder: 2005, n’ 9.

CREACIÓN e inteligencia colectiva. Sevilla: Zemos98, 2005.

CURCIO, Anna y ROMERO, Gigi. Hacia una gramática del conocimiento vivo.[En línea]. Disponible en <http://commoniversity.wordpress.com/ >. [Consulta: 7 de febrero de 2011]

DELEUZE, Gilles. «Instincts et institutions ». En: Lîle déserte et d'autres textes. París: Minuit, 2002.

DE SOUZA SANTOS, Boaventura. La universidad popular en el siglo XXI, Lima: Fondo Editorial de la Facultad de Ciencias Sociales, 2006.

DEWEY, John. Democracia y educación. Madrid: Morata (Col. Raíces de la memoria). Madrid, 1995.

DI NICOLA, Alberto. VERCELLONE, Carlo. ROGGERO,Giggi. "la clase creativa ". Eipcp [en línea]. Disponible en web: <http://transform.eipcp.net/transversal/0207/denicolaetal/es>. [Consulta: 12 de Agosto 2.012]

ESPAI EN BLANC (coord), El combate del pensamiento. Barcelona: Bellaterra, 2010.

ESPAI EN BLANC (coord), El impasse de lo político. Barcelona: Bellaterra, 2011.

ESPAI EN BLANC (coord.), La sociedad terapéutica. Materiales para la subversión de la vida. Barcelona: Bellaterra, 2008.

ESPAI EN BLANC (coord.), La fuerza del anonimato. Barcelona: Bellaterra, 2009.

ESPAI EN BLANC (coord.), Luchas autónomas en los años setenta. Del antagonismo obrero al malestar social. Madrid: Traficantes de sueños, 2008.

ESPAI EN BLANC (coord.), Vida y política. Barcelona: Bellaterra, 2006.

EXPÓSITO, Marcelo."Entrar y salir de la institución: autovalorización y montaje en el arte contemporáneo ". Eipcp[en línea]. Disponible en web: <http://transform.eipcp. net/transversal/0407/exposito/es>. [Consulta: 24 de Abril de 2.013]

ESPOSITO, Roberto, Comunidad, inmunidad y biopolítica. Barcelona: Herder, 2009.

ESPOSITO, Roberto. "Inmunidad, comunidad". Las Torres de Lucca, 2012, nº 0. 
FELBER, Christian, L'Economie citoyenne ou quand l'intérêt général sinvite dans le bilan des entreprises. París: Actes Sud, 2011.

FERRERIRO BAAMONDE, Xulio."Mercantilización y precarización del conocimiento: el proceso de Bolonia". En: La universidad en conflicto: capturas y fugas en el mercado global del saber. Madrid: Traficantes de sueños, 2010.

FLORIDA, Richard. La clase creativa. La transformación de la cultura del trabajo y el ocio en el siglo XXI. Barcelona: Paidós, 2010.

FOUCAULT, Michel. Dits et écrits, IV. Paris : Gallimard, 1984.

FOUCAULT, Michel, El nacimiento de la biopolítica, Curso en el Collège de France 19781979, Buenos Aires: Fondo de Cultura Económica, 2007.

FOUCAULT, Michel,. "El sujeto y el poder". En: Más allá del estructuralismo y la hermenéutica. Buenos Aires: Nueva Visión, 2001.

FOUCAULT, Michel. Vigilary castigar, México: Siglo XXI, 1976.

FREIRE, Paulo. Pedagogía del oprimido. Madrid: Siglo XXI, 1975.

FUMAGALLI, Andrea, Doce tesis sobre el capitalismo cognitivo. [En línea]. Disponible en: $\quad$ http://www.grupomartesweb.com.ar/index.php?view=article\&catid=45> [Consulta: 12 de Febrero 2.012]

GALCERÁN, Monserrat. Deseo (y) libertad, una investigación sobre los presupuestos de la acción colectiva. Madrid:Traficantes de sueños, 2009.

GALCERÁN, Montserrat. "El discurso oficial sobre la Universidad". En: Logos Anales del Seminario de Metafísica, 2.003 no 36.

GALCERÁN, Montserrat. La educación universitaria en el centro del conflicto. En: La universidad en conflicto: capturas y fugas en el mercado global del saber. Madrid: Traficantes de sueños, 2010.

GARCÉS, Marina, "Dar que pensar. Sobre la necesidad política de nuevos espacios de aprendizaje". En: El combate del pensamiento. Barcelona: Bellaterra, Barcelona, 2010.

GARZÓN ESPINOSA, Alberto. "Economía Crítica y Crítica de la Economía". En: Número 5, Mayo-Junio 2009.

GUATTARI, Félix. "Máquina y estructura”. En Psicoanálisis y transversalidad. Buenos Aires: Siglo XXI, 1976.

HAACKE, Hans. "Museos, gestores de la conciencia". Brumaria. [En línea].Disponible en web: $<$ http://www.brumaria.net/textos/hanshaacke.htm> [Consulta: 4 de Enero 2.013] HARDT, Michael y NEGRI, Antonio. Imperio. Buenos Aires: Paidós, 2002.

HARDT, Michael y NEGRI, Antonio. Multitud. Guerra y democracia en la era del Imperio. Madrid: Debate, 2004. 
HEGEL, G.W.F., Fenomenología del espíritu. México: Fondo de Cultura Económica, 1966.

HERNÁNDEZ CATALÁN, Rosario, Pero este trabajo yo para qué lo hago. Estudio sociológico sobre los malestares ocultos de algunas precarias conscientes. Madrid: Federación Mujeres Jóvenes, 2010.

HERREROS, Tomás. "Laboratorios de autoformación, universidades anómalas, nuevas universidades". En: La universidad en conflicto:capturas y fugas en el mercado global del saber. Madrid: Traficantes de sueños, 2010.

HERSENT, Madeleine, (editora), Femmes, économie et développement. De la résistance à la justice sociale. Toulouse: Erès, 2011.

HOBBES, Thomas. Leviatán ola materia, forma y poder de un estado eclesiástico y civil. Madrid: Alianza Editorial, 2006.

HOLMES, Brian."El dispositivo artístico o la articulación de enunciaciones colectivas". Brumaria. [En línea].Disponible en web:

$<$ http://www.brumaria.net/textos/Brumaria7/12brianholmes.htm>. [Consulta: 2 de Mayo 2.012]

HOLMES, Brian."La personalidad flexible. Por una nueva crítica cultural". Brumaria. [En línea]. Disponible en web: <http://www.brumaria.net/textos/ Brumaria7/09brianholmes.htm >. [Consulta : 24 enero 2012]

IMPASSE: dilemas políticos del presente. Buenos Aires: Tinta Limón, 2009.

JENKINS, Henri. Convergence Culture, Where Old and New Media Collide. Nueva York: New York University Press, 2006.

KpD.'La precarización de los productores y productoras culturales y la ausente vida buena". Eipcp [en línea]. Disponible en web:<http://eipcp.net/transversal/0406/ kpd/es/>. [Consulta: 4 de Mayo de 2.012]

KOJÈVE, Alexander. Comentarios a La dialéctica del amo y del esclavo, por Hegel. Publicaciones mínimas [En línea]. Disponible en: $<$ http://www.sindominio.net/etcetera/PUBLICACIONES/minimas/62_Kojeve.pdf.>. [Consulta: 14 de Mayo 2.010] Laser Posse Sapienza Pirata. “El cognitariado se alza en Europa: fuerza de trabajo intermitente, trabajo cognitario y la cara oculta del capital humano estilo UE ". Brumaria. [En línea].Disponible en web:

$<$ http://www.brumaria.net/textos/Brumaria7/22laserpossesapienzapirata.htm>. [Consulta: 23 de Enero de 2.010]

LATOUCHE, Serge. En defensa del decreixement. Valencia: TresiQuatre, 2011.

LAUTER Paul. Contenido, cultura, carácter. [En línea]. Disponible en http://www.worksanddays.net/2003/File05.Lauter_File05.Lauter.pdf. [Consulta: 24 de Febrero de 2011] 
LAVILLE, Jean-Louis, GARCÍA JANÉ, Jordi. Crisis capitalista y economía solidaria. Barcelona: Icaria, 2009.

LAZZARATO, Maurizio. “Del biopoder a la biopolítica”. Multitudes, Marzo de 2.000 [en línea]. Disponible en <http://www.sindominio.net/arkitzean/otrascosas/lazzarato. htm > y consultado el 17 de junio de 2011.

LAZZARATO, Maurizio. "El ciclo de la producción inmaterial ". Brumaria. [En línea]. Disponible en web:

$<$ http://www.brumaria.net/textos/Brumaria7/04mauriziolazzarato.htm>. [Consulta: 7 de Noviembre de 2.012]

LAZZARATO, Maurizio. “Del conocimiento a la creencia, de la crítica a la producción de subjetividad". Eipcp.[En línea]. Disponible en web: <http://eipcp.net/transversal/0808/lazzarato/es $>$. [Consulta: 12 de Mayo 2.012]

LAZZARATO, Maurizio. "Las desdichas de la "crítica artista" y del empleo cultural". Eipcp [en línea].Disponible en web: http://eipcp.net/transversal/0207/lazzarato/ es>. [Consulta: 12 de Mayo de 2.012]

LAZZARATO, Maurizio," La forma política de la coordinación". Eipcp [en línea]. Disponible en web: < http://transform.eipcp.net/transversal/0707/lazzarato/es>. [Consulta: 12 de Mayo de 2.012 ]

LAZZARATO, Maurizio."Logic and Theory of Inquiry". Eipcp [en línea].Disponible en web: $<$ http://eipcp.net/transversal/0406/negri/en>. [Consulta: 12 de Mayo de 2.012]

LAZZARATO, Maurizio. "Multitud y clase obrera”. En Contrapoder, 2003, nº 7.

LAZZARATO, Maurizio. "Trabajo autónomo, producción por medio del lenguaje y general intellect" . Brumaria. [En línea].Disponible en web: <http://www.brumaria. net/textos/Brumaria7/02mauriziolazzarato.htm>. [Consulta: 12 de Mayo de 2.012]

LAZZARATO, Maurizio, NEGRI, Antonio. "Trabajo inmaterial y subjetividad". Brumaria. [En línea].Disponible en web: <http://www.brumaria.net/textos/ Brumaria7/03mauriziolazzarato.htm >. [Consulta: 12 de Mayo 2.012]

LEFEBVRE, Henri. La revolución urbana. Madrid: Alianza Editorial, 1970.

LOPEZ CUENCA, Alberto. “El traje del emperador. Sobre la mercantilización del arte en la España de los años 80". Revista de Occidente. [En línea]. Disponible en web: $<$ http://www.ortegaygasset.edu/revistadeoccidente/articulos/(273)Alberto_Lopez.pdf $>$ [Consulta: 17 de enero 2.010]

LÓPEZ PETIT, Santiago. El infinito y la nada. El querer vivir como desafío. Barcelona: Bellaterra, 2003.

LÓPEZ PETIT, Santiago. La movilización global. Breve tratado para acatar la crisis. Madrid:Traficantes de sueños, 2009. 
LÓPEZ PETIT, Santiago. "¿Qué es hoy una vida política?". En: Impasse: dilemas políticos del presente. Buenos Aires:Tinta Limón, 2009.

LORENZO VILA, Ana y MARTÍNEZ LÓPEZ, Miguel. Metodologías de autorganización. Madrid:Traficantes de Sueños, 2005.

LOREY, Isabel. "Gubernamentalidad y precarización de sí. Sobre la normalización de los productores y las productoras culturales". Eipcp. [En línea]. Disponible en web: $<$ http://transform.eipcp.net/transversal/1106/lorey/es >. [Consulta: 4 de Noviembre 2.012] LOREY, Isabelle. "Tentativa de pensar lo plebeyo. Éxodo y constitución como crítica”. Eipcp[en línea]. Disponible en web: <http://transform.eipcp.net/transversal/0808/ lorey/es>. [Consulta: 4 de Noviembre 2.012 ]

MALO, Marta y ÁVILA, Débora. "El gobierno de la diferencia: gestión y gradaciones de derechos sociales". En: Repensando la metrópolis. Prácticas experimentales en torno a la construcción de nuevos derechos urbanos. Málaga: Centro de Estudios Andaluces, 2010.

MALO de MOLINA, Marta. Globalización desde abajo. Esquema del proyecto de investigación [en línea].Disponible en: <http://marceloexposito.net/pdf/1969_martamalo_globalizaciondesdeabajo.pdf>[Consulta: 7 de Julio de 2.012]

MALO de MOLINA, Marta (Editora), Nociones Comunes. Experiencias y ensayos entre investigación y militancia. Madrid:Traficantes de sueños, 2004.

MARX, Karl. El Capital. Madrid: Alianza, 2010.

MERLEAU-PONTY, Maurice. Las aventuras de la dialéctica. Buenos Aires: Leviatán, 1957.

MESTRE, Domingo. Arte, cultura e impostura. Valencia: Comissariat Associació, 2008 .

MIQUEL, Mijo. "Comboi a la fresca: una experiencia valenciana de arquitectura colectiva". En "Vínculos del frío. Latitud Norte: ética y estética del habitar. Valencia: Universidad Politécnica de Valencia, 2012.

MIQUEL, Mijo.“De las prácticas transversales a las investigaciones extradisciplinares: la constitución del Outsite". En: Ciudades (im)propias: la tensión entre lo global y lo local. Valencia: Universidad Politécnica de Valencia, 2011

MIQUEL, Mijo. "Guerra Mítica: la escultura como evento mediático". En: Actas del I Congreso Internacional de Nuevos Procedimientos Escultóricos. Valencia: Universidad Politécnica de Valencia, 2002.

MOLINA, Miguel. (2002). "Crónica de las intervenciones y disentimientos de las últimas décadas en Valencia". Papers d'Art n 81, Girona.

MONCUSÍ FERRÉ, Albert. Nuevos y viejos vecinos en dos barrios de Valencia (Orriols y Russafa), Valencia: Ayuntamiento. Regidoria de Benestar Social i Integració, 2009. 
MONTMANN, Nina. "La empresa de la institución artística en el capitalismo tardío". Eipcp. [En línea]. Disponible en web: <http://transform.eipcp.net/transversal/0106/ moentmann/es>. [Consulta: 23 de febrero 2.012]

MORINI, Cristina. "El trabajo de cuidado como arquetipo del biocapitalismo". Webjournal. [En línea].Disponible en web: <http://swarm-webjournal.info/articulo/ el-trabajo-de-cuidado-como-arquetipo-del-biocapitalismo > MOULIER BOUTANG, Yann. L'abeille et l'économiste. París: Carnets Nord, 2010. MOULIER BOUTANG, Yann. "Riqueza, propiedad, libertad y renta en el capitalismo cognitivo". En: Capitalismo cognitivo, propiedad intelectual y creación colectiva. Madrid: Traficantes de sueños, 2004.

NANCY, Jean-Luc. "La comunidad afrontada": [Postfacio a la edición española]. En: La comunidad inconfesable, Arena, Madrid, 1999.

NANCY, Jean-Luc. La comunidad desobrada. Madrid: Arena, 1999.

NAVARRO, Vicent. “Los súper ricos y la Banca” [En línea]. Disponible en: $<$ http://www. vnavarro.org/? $\mathrm{p}=7354>$. [Consulta 12 de Abril 2.012]

NEGRI, Antonio. Lametrópolisy la multitud.DDOOSS [en línea] disponible en $<$ http:// ddooss.org/articulos/otros/Antonio_Negri.htm > [Consulta 12 de Febrero 2.012]

NICOLAS-LE STRAT, Pascal. Fabrique de sociologie. Montepellier : Fulenn, 2011.

NICOLAS-LE STRAT, Pascal. «La constitution intermittente de l'activité ». En: Multitudes. $2004, n^{\circ} 17$.

NUNES, Rodrigo. "¿Pesimismo del intelecto, optimismo del General Intellect?". Eipcp [en línea]. Disponible en web: <http://transform.eipcp.net/transversal/0707/nunes/ es>.[Consulta : 4 agosto 2.010 ]

OBSERVATORIO METROPOLITANO. Fin de ciclo: Financiarización, territorio y sociedad de propietarios en la onda larga del capitalismo hispano (1959-2010). Madrid: Traficantes de Sueños, 2011.

PASTOR, José Manuel y PÉREZ, Francisco. La contribución socioeconómica de las Universidades públicas valencianas. Valencia: Universidad de Valencia, 2009.

PASTOR AGUILAR, Marina. Nihilismo de resistencia: pensamiento, interpretación y escultura como tácticas de acción. Valencia: Universidad Politécnica de Valencia, 2001. Los PIRATAS son los padres: Historias en los albores de la era digital. Barcelona: eXgae \& Conservas, 2008.

PRECIADO, Beatriz. Museo, basura urbana y pornografía. [En línea]. Disponible en: $<$ http://lasdisidentes.wordpress.com/2012/08/12/museo-basura-urbana-y-pornografia-por-beatriz-preciado/> [Consulta: 4 de Mayo 2.112] 
PRIETO del CAMPO, Carlos. Apuntes preliminares sobre la economía política de lo común en la era del poder constituyente de la intelectualidad de masas antagonista. [En línea]. Disponible en: < www.universidadnomada.net $>$ [Consulta: 05 de diciembre de 2010] PRIETO del CAMPO, Carlos. “Lo público y lo común: Estado, derecho, Administración pública/poder constituyente, capitalismo, movimientos antisistémicos". En: Revista Trasversales, 2009, número 14.

"El PROCOMÚN o la reapropiación pública de lo público". En: Revista Archipiélago, 2004, no 77-78.

PRODUCCIÓN cultural y prácticas instituyentes. Líneas de ruptura en la crítica institucional. Madrid:Traficantes de Sueños, 2008.

RABHI, Pierre. Manifeste pour la terre et l'humanisme. Paris : Actes Sud, Paris, 2008.

RANCIÊRE, Jacques. El desacuerdo. Política y filosofía. Bueno Aires: Nueva Visión, 1996.

RANCIÈRE, Jacques. El espectador emancipado. Pontevedra: Ellago, 2010.

RANCIÈRE, Jacques. El maestro ignorante .Barcelona: Laertes, 2002.

RANCIÈRE, Jacques. La división de lo sensible, Centro de Arte de Salamanca, 2000.

RANCIÈRE, Jacques. Moments politiques. Interventions 1977-2009. París: La Fabrique, 2009.

RAUNING, Gerald. "La industria creativa como engaño de masas". Eipcp [en línea]. Disponible en web: <http://eipcp.net/transversal/0207/raunig/es>. [Consulta: 17 de Mayo de 2012].

RAUING, Gerald. "Prácticas instituyentes. Fugarse, instituir, transformar". Eipcp. [En línea]. Disponible en <http://eipcp.net/transversal/0106/raunig/es > [Consulta: el 17 de mayo de 2012.]

RAUNIG, Gerald. "Prácticas instituyentes, no 2.La crítica institucional, el poder constituyente y el largo aliento del proceso instituyente ". Eipcp. [En línea]. Disponible en web: <http://transform.eipcp.net/transversal/0507/raunig/es >. [Consulta: 12 de Junio 2.012]

RAUSELL KÖSTER, Pau. Valencia: desde la huerta al ocio. Valencia: Universidad de Valencia, 2010.

RECIO, A. “Empresa red, distribución de la renta y relaciones laborales". En VII Jornadas Economía Crítica. Albacete: Universidad Castilla la Mancha, (2000).

RIFKIN, Jeremy. La era del acceso. Barcelona: Paidós Ibérica, 2000.

ROSS, Andrew. "La emergencia de la Universidad Global". En: La universidad en conflicto: capturas y fugas en el mercado global del saber. Madrid: Traficantes de sueños, 2010. 
SAFÓN CANO, Vicente. "¿Del fordismo al postfordismo?": El advenimiento de los nuevos modelos de organización industrial". En: Actas del I Congreso de Ciencia Regional de Andalucía: Andalucía en el umbral del s.XXI. [En línea]. Disponible en< http://www.uca.es/escuela/emp_je/investigacion/congreso/mbc011.pdf > [Consulta: 23 de Agosto de 2.011]

SANCHEZ CEDILLO, Raul. “Hacia nuevas creaciones políticas. Movimientos, instituciones, nueva militancia ".Eipcp[en línea]. Disponible en web:

$<$ http://transform.eipcp.net/transversal/0707/sanchez/es $>$. [Consulta: 12 Junio de 2.012]

SANZ FERNÁNDEZ, Fernando. "La mercantilización de la educación como escenario mundial del espacio europeo de educación superior". En: Educación XX1, 2.006, núm. 9.

SGUIGLIA, Nicolás. Libertad, autonomía y procomún. Movimientos urbanos en la era de la precariedad. Málaga: Universidad Libre Experimental, 2010.

SLOTERDIJK, Peter. "El arte se repliega en sí mismo. Presentación de una exposición singular". Brumaria[en línea]. Disponible en web:

$<$ http://www.brumaria.net/textos/petersloterdijk.htm>. [Consulta: 4 mayo 2.010 ]

SHIVA, Vandana. Manifiesto para una democracia de la Tierra. Barcelona: Paidós, 2005.

SOJA, Edward. Postmetrópolis. Estudios críticos sobre las ciudades y las regiones. Madrid:Traficantes de Sueños, 2008.

SPINOZA, Baruch. Ética demostrada según el orden geométrico. Madrid: Trotta, 2009. SPINOZA, Baruch.Tratado político. Madrid: Alianza, 1986.

TERRA CRITICA. Terra crítica 2001-2007, País, Ciutat, Ciutadania, Planeta. Vañencia: UPV, 2008.

THOMAS, W. I. The child in America: Behavior problems and programs, New York: Knopf, 1932.

TONUCCl, Francesco. Cuando Los niños dicen: ¡Basta! Salamanca: Fundación Germán Sánchez Ruiperez, 2003.

TORET, Javier. Producción de subjetividad en tiempos de la crisis. [En línea]. Disponible en:<https://n-1.cc/pg/file/read/2535/produccin-de-subjetividad-en-tiempos-dela-crisis-notas-para-el-encuentro-crisis-sistmica-nuevos-derechos-mquinas-creativas-de-lucha-y-contrapoder> . [Consulta 9 enero de 2010]

TORMO, Rafael(coord..), PERIFÈRIES09. Cercant la realitat amb la veu d'un nosaltres. Valencia: Universidad Politécnica de Valencia, 2010.

TORRES, F. "Las dinámicas de la convivencia en un barrio multicultural. El caso de Russafa en Valencia". En Papeles del CEIC, 2006, vol. 2006/1, n 23.

TRANSDUCTORES: Pedagogías en red y prácticas instituyentes. [Editores Antonio Collados y Javier Rodrigo]. Granada: Centro de Arte José Guerrero, 2012. 
TRANSDUCTORES: Pedagogías colectivas y políticas espaciales. [Editores Antonio Collados y Javier Rodrigo]. Granada: Diputación Provincial de Granada, 2010.

La UNIVERSIDAD en conflicto: capturas y fugas en el mercado global del saber. Madrid: Traficantes de sueños, 2010.

UNIVERSIDAD NÓMADA. Prototipos mentales e instituciones monstruo. Algunas notas a modo de introducción. Eipcp [en línea].Disponible en web: < http://eipcp.net/ transversal/0508 .>: [Consulta: 2 de Mayo 2.012]

VERCAUTEREN, David, CRABBÉ, Olivier "Mouss", y MÜLLER, Thierry, Micropolíticas de los grupos. Para una ecología de las prácticas colectivas. Madrid:Traficantes de Sueños, 2010.

VIRNO; Paul. "Antropología y teoría de las instituciones". Eipcp[en línea]. Disponible en web: <http://transform.eipcp.net/transversal/0407/virno/es >. [ Consulta : 24 de Febrero 2.012]

VIRNO, Paolo, Multitud y principio de individuación, disponible en http://www.sindominio.net/arkitzean/multitudes/virno_multitud.html> [Consulta: el 14 de julio de 2012]

VIRNO, Paolo. Gramática de la multitud. Para un análisis de las formas de vida contemporáneas. Madrid: Traficantes de Sueños, 2003.

VON OSTEN, Marion. "Salidas incalculables". Eipcp [en línea].Disponible en web: http://transform.eipcp.net/transversal/0207/vonosten/es>. [Consulta: 12 de Mayo de 2012]

WALLERSTEIN, Inmanuel y BALIBAR, Etienne. Raza, nación y clase. Madrid: lepala, 1991.

WEINGÄRTNER, Julia y MONASTERIO, Marta."Poner la vida en el centro: respuestas del ecofeminismo y del decrecimiento a la UE". En: Menos para vivirmejor, 2010, no 64.

YUDICE,George. El recurso de la cultura: Usos de la cultura en la era global. Barcelona: Gedisa, 2002.

\section{PÁGINAS WEB DE REFERENCIA}

http://www.59rivoli.org/

http://www.aceradelfrente.blogspot.com.es/

http://agedelatortue.org/

http://arquitecturascolectivas.net/

http://ateneucandela.info/

http://atravesadasporlacultura.wordpress.com/

http://autoformato.wordpress.com

http://www.autonomiaobrera.net/pages/

http://barradiagonal.wordpress.com/

http://www.bazarurbain.com/ 
http://bookcamping.cc/

http://cep.webs.upv.es/

http://www.collectifetc.com/

$\mathrm{http} / / /$ comboialafresca.arquitecturascolectivas.net/

http://commoniversity.wordpress.com/

http://conservas.tk/

http://crearqcio.blogspot.com.es/

http://www.cs-seco.org/

http://www.deja-vou.com/periferies07/PeriferiesValencia.pdf

http://www.desayunoconviandantes.com

http://www.eacc.es/

http://www.edu-factory.org/

http://eipcp.net/transversal/

http://encajesurbanos.com/

http://www.espaienblanc.net/

http://estrecho.indymedia.org/

http://es.wikipedia.org/wiki/Anarquismo_en_España/

http://www.ferrocarrilclandestino.net/

http://www.freres-poussiere.com/.

http://iconoclasistas.com.ar.

www.konsumoresponsable.coop/mercado-social-madrid

http://kulturometer.org/

http://lacaldereria.org/

http://www.laciv.org/

http://www.lainvisible.net/

http://laminuscula.es/

http://www.laslindes.es/

http://latabacalera.net/

http://www.laxarito.net/

http://www.le6b.org/

http://www.mainsdoeuvres.org,/

http://www.makeatuvida.net/

http://medialab-prado.es/laboratorio_del_procomun

http://www.modifi.es/

http://multitudes.samizdat.net/

http://www.museoreinasofia.es/redes/presentacion/nueva-institucionalidad/2011.html

http://patiomaravillas.net/

http://paraquienesdisfrutamostrabajando.net/

http://www.recetasurbanas.net/

http://www.reu08.org

http://www.revistabostezo.com 
http://www.situaciones.org http://solarcorona.wordpress.com/ http://www.somenergia.coop/ http://www.sostre.org/ http://www.sostrecivic.org/ http://swarm-webjournal.net/ http://www.traficantes.net/ http://transductores.net/ http://www.ulexmalaga.org/ http://www.unartists.org/ http://unilliurelarimaia.org/ http://www.universidadnomada.net./ http://www.youcoop.org/

http://ypsite.net/ http://zemos98.org/ 


\section{Listado de imágenes}

Figura 1: Fotografía tomada por la autora en el centro autogestionado de la Tabacalera de Madrid.

Figura 2: Fotografía procedente de RuralContemporanea, acción realizada por Andrés Montes en Villanueva de los Infantes, http://www.ruralc.com/2012/08/ residencia-de-andres-montes-en-la-sede.html.

Figura 3: Fotografía publicada en Internet por diferentes medios de comunicación a raíz de las primeras manifestaciones del 15M en Madrid.

Figura 4: Fotografía no identificada, publicada en Internet .

Figura 5: Imagen encontrada en la página web de Blackburn College, acompañando una noticia de Blackburn students go edupunk http://www.blackburn.ac.uk/college-news/blackburn-students-go-edupunk/

Figura 6: Gráfico publicado en http://latrampadelaselecciones.wordpress.com/

Figura 7: Imágenes recogidas en la web de Madrilonia http://madrilonia.org/wp-content/uploads/2012/08/ocupa-congreso4.png

Figura 8: Imagen aparecida en todos los medios a raíz de las manifestaciones de la "primavera valenciana" el 21 del 02 del 2012, provocadas por la represión policial de jóvenes del Instituto Luis Vives que protestaban contra los recortes.

Figura 9: Logotipo de Barra Diagonal

Figura 10: Cabecera de la página web de la convocatoria de Para quienes disfrutamos trabajando, en http://paraquienesdisfrutamostrabajando.net/

Figura 11: Mural pintado por Escif para el Institut Français de Valencia.

Figura 12: Logotipo de la Universidad Nómada Expandida.

Figura 13: Portada de la 11 edición del Festival Internacional ZEMOS98.

Figura 14: Imagen creada por la Universidad Nómada para el ciclo del mismo nombre.

Figura 15: Fotografía de la fachada de La Rimaia publicada en su página web, http:// unilliurelarimaia.org/.

Figura 16: Fotografía procedente de la web de las lindes en la convocatoria citada, http://www.laslindes.es/

Figura 17: Imagen publicada en el informe redactado sobre la convocatoria Para quienes disfrutamos trabajando.

Figura 18: Logotipo del colectivo La Acera del Frente, http://www.aceradelfrente. blogspot.com.es/ 
Figura 19: Logotipo de Paracommand'art.

Figura 20: Cabecera de la página web http://www.edu-factory.org/ para la convocatoria de Commoniversity en http://commoniversity.wordpress.com/

Figura 21: fotografía utilizada para el cartel del I Congreso Internacional de Estética y Política de Valencia.

Figura 22: Fotografía de la organización en la primera convocatoria de Perifèries 2007, http://www.deja-vou.com/periferies07/PeriferiesValencia.pdf

Figura 23: Flyer de la presentación del libro.

Figura 24: Fotografía de la organización en la segunda convocatoria de Perifèries2009.

Figura 25: cabecera de la web del I Congreso Internacional de Estética y Política, En torno al pensamiento de Jacques Rancière.

Figura 26: Cabecera original del blog de Autoformato.

Figura 27: LLuis Benlloch, Mijo Miquel y Jacques Rancière, fotografía del encuentro "Conversaciones de primavera", autor OCCC.

Figura 28: Marina Garcés, Débora Ávila y Lluis Benlloch, fotografía del encuentro "Conversaciones de primavera", autor OCCC.

Figura 29: Sesión de debate del Espai de Crítica i Creació Contemporània de Sueca, fotografía de la organización.

Figura 30:IVEncuentro de Arquitecturas Colectivas, julio de 2011. Fotografía de la autora.

Figura 31: Taller de Metodologías Participativas, IV Encuentro de Arquitecturas Colectivas, julio de 2011. Fotografía de la autora.

Figura 32: Debate de Metodologías Participativas, IV Encuentro de Arquitecturas Colectivas, julio de 2011. Fotografía de la autora.

Figura 33: Cartel del Encuentro Espacios autogenerados y lógicas de los intersticios, diseño: flouFlou

Figura 34: Seminario interno del Encuentro Espacios autogenerados y lógicas de los intersticios.

Figura 35: Encuentro en La Minúscula y en el Instituto Francés del Encuentro Espacios autogenerados y lógicas de los intersticios.

Figura 36: Cartel de las Jornadas de autoformación de Economía y Urbanismo críticos, diseño: FlouFlou

Figura 37: Proyectos desarrollados por el Colectivo ETC.

Figura 38: Logotipo del Mercado de Economía Social.

Figura 39: Logotipo de Som Energia. 
Figura 40: Logotipo de Sostre Civic.

Figura 41: Logotipo de la Cooperativa Integral Valenciana.

Figura 42: Fotografía del Seminario sobre el decrecimiento con Serge Latouche, Paco Álvarez y Pascal Letellier.

Figura 43: Logotipo del Comboi a la fresca.

Figura 44: Imagen incluida en la carta a las asociaciones. Diseño: FlouFlou

Figura 45: Anverso y reverso del modelo de cartas usadas en el Comboi a la fresca.

Figura 46: Imágenes tomadasdurantelas reuniones de preparación del Comboi a la fresca.

Figura 47: Diagrama de organización del Comboi a la fresca.

Figura 48: Mapa de localización en el folleto disponible durante el Comboi a la fresca.

Figura 49: Fotografía de diferentes talleres realizados durante el Comboi a la frescarealizadas por la autora.

Figura 50: Fotografía de diferentes itinerarios realizados durante el Comboi a la fresca realizadas por la autora.

Figura 51: Logotipo del Solar Corona.

Figura 52: Limpiando el Solar Corona antes del Comboi a la fresca y cúpula geodésica montada durante el encuentro.

Figura 53: Cartel de la jornada de trabajo del Solar Corona.

Figura 54: Logotipo de la Coordinadora de Iniciativas Vecinales (LaCIV)

Figura 55: Imágenes del proyecto de Centro de Iniciativas Vecinales de Velluters.

Figura 56: Logotipo de La Calderería.

Figura 57: Fotografía de La Calderería en su estado original.

Figura 58: Render de La Calderería.

Figura 59: Diagrama de funcionamiento de La Calderería.

Figura 60: Plano sociológico del barrio de Ayora.

Figura 61: Flyer de inauguración de La Calderería.

Figura 62: Fotografía del taller de autoconstrucción de madera.

Figura 63: Tríptico del seminario de economía crítica.

Figura 64: Fotografía de un muro intervenido por Escif, Valencia

Figura 65: Fotografía de autor desconocido disponible en Internet.

Figura 66: Equipo del Comboi a la fresca. Fotógrafo: David Poliakoff. 


\section{ANEXO I}

Informe Para los que disfrutamos trabajando 


\section{RESULTADOS Y ANÁLISIS DE LAS JORNADAS \\ "PARA QUIENES DISFRUTAMOS TRABAJANDO" \\ LÍNEAS DE FUTURO PARA LAS Y LOS TRABAJADORES CREATIVOS \\ www.paraquienesdisfrutamostrabajando.net}

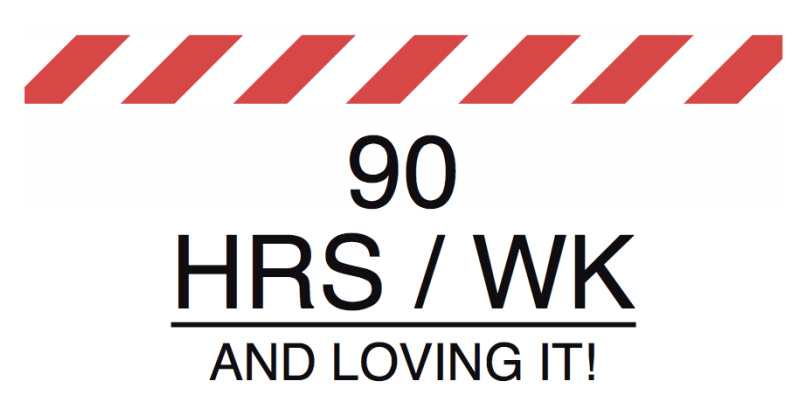

Proyecto coordinado por

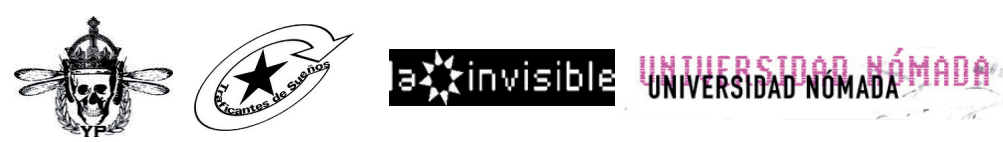

En colaboración con

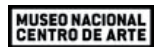

REINASOFIA 


\section{Acerca de este informe}

Este informe ha sido elaborado a varias manos por algunas de las personas que coordinamos las primeras jornadas de «Para quienes disfrutamos trabajando. Jornadas sobre precariedad y autoorganización del trabajo creativo», celebradas en el local de Traficantes de Sueños en los primeros días del mes de julio de 2010. Estos encuentros fueron organizados por un pequeño consorcio de entidades políticas y culturales formado por Traficantes de sueños, YProductions, la Universidad Nómada y La Invisible de Málaga. Para su organización se contó con una pequeña dotación del Museo Nacional y Centro de Arte Reina Sofía, a través del Departamento de Actividades Públicas. La financiación sirvió para cubrir los costes de desplazamiento de las personas que participaron en el encuentro, el alojamiento de algunos de ellos, la publicidad y la web del evento (http://paraquienesdisfrutamostrabajando.net/), así como dos seminarios previos realizados en Madrid y Málaga respectivamente. El acuerdo para producir estas jornadas fue el producto de la colaboración de estos grupos, así como de las ideas que se elaboraron con motivo del programa de talleres públicos organizado por atravesad *s por la cultura durante el año 2009. El objetivo de estos talleres, y otros encuentros semejantes en otras ciudades, consistió en ensayar una crítica a las condiciones actuales de la llamada «producción cultural», así como un pensamiento original sobre el papel y la forma de la institución cultural.

El documento que aquí se presenta es fruto del compromiso de los organizadores por dejar constancia de algunos de los resultados de la Jornadas. Para ello se ha trabajado con los vídeos, actas y papelógrafos producidos durante el evento. En un principio, la «postproducción» de las Jornadas se iba a acompañar, además de este documento, de otro conjunto de artículos y reflexiones dirigidos a analizar algunos de los elementos considerados como más significativos de los encuentros, como puedan ser: la discusión acerca de un posible marco teórico sobre la economía cultural, la percepción subjetiva del trabajador cultural sobre sus propias condiciones materiales, la reciente explosión de las candidaturas urbanas a capital cultural, etc. La elaboración de estos materiales concluiría con un segundo encuentro destinado a «devolver» los materiales producidos. Tanto el propósito del encuentro como de los documentos reunidos radicaba en animar futuras discusiones. Desgraciadamente, y como sucede en tantos otros casos, la financiación comprometida por parte del Museo para la realización de la «postproducción» (el encuentro y los documentos) ha sido recientemente descartada por recortes presupuestarios de orden general. Lamentamos la fragilidad de estos proyectos y su dependencia institucional que sin duda confirma uno de los problemas que se recogieron en las jornadas. Valga, en cualquier caso, las notas que aquí se recogen como resumen y síntesis para futuras aproximaciones a estos problemas.

Antes de dar paso al documento propiamente dicho, es preciso también hacer algunas aclaraciones en relación con sus objetivos. Este informe pretende ofrecer una visión de lo que 
consideramos los puntos fuertes, pero también débiles, de las sesiones, sin tratar por ello de hacer pasar estas páginas por un diagnóstico objetivo. Por eso, si bien hay partes en las que se desgrana el funcionamiento de los encuentros y la información generada de manera meramente descriptiva, estaríamos muy satisfechos/as si este documento sirviese para generar una hoja de ruta que incluyese algunos de los temas y problemas que pueden ser considerados (evidentemente por alguien más que los abajo firmantes) como de «urgente discusión colectiva» en un futuro inmediato. Algunas de las reflexiones y provocaciones lanzadas en este texto tratan pues, antes que nada, de levantar aquellos «lugares comunes» que no por obvios dejan de requerir un trabajo colectivo dentro del «sector».

Por otra parte, quizás una de las pocas maneras en la que resulta posible analizar críticamente un contexto del que a su vez nos percibimos como parte y caso de estudio consiste en tomar distancia y observar desde fuera nuestro propio funcionamiento. Es por eso que en muchos casos pudiera pensarse que adaptamos la posición del «observador objetivo». Más allá sin embargo de este «estilo», lo que aquí se quiere es sacudir nuestras propias inercias, intentar animar la constitución de dispositivos analíticos y subjetivos capaces de operar bajo una lógica diferente dentro del campo de la producción cultural. En este sentido, este informe puede ser calificado como un auto-análisis, un ejercicio critico acerca de lo que consideramos nuestras potencias, pero sobre todo nuestras debilidades

Este texto no tiene, en definitiva, un valor de análisis sociológico o antropológico acerca de los discursos que circulan en el llamado sector de la producción cultural, siempre tan difícil de definir. Su propósito, como el de las Jornadas, consiste en construir un mínimo vocabulario compartido entre las y los trabajadores que se pueden considerar a sí mismos como vocacionales de la producción o la creación de bienes y servicios culturales, a fin de afrontar unas situaciones de precariedad, explotación, desposesión y banalización del sentido de su actividad cada vez más acuciantes. En último término, se trata de explorar las posibilidades políticas de la autoorganización del sector. En relación con este propósito, el resultado de las Jornadas, tal y como se analiza en las conclusiones, es más bien ambivalente. No obstante, esperamos que lo que aquí se recoge genere coaliciones, vínculos y líneas de debate, que sirvan para profundizar la discusión sobre las condiciones del trabajo «creativo» y la dimensión real de aquellos malestares y problemáticas que si bien generalizados, son todavía percibidos como simples «anomalías del funcionamiento normal del sector».

Al final del texto, se recogen también los textos y las ideas, siempre útiles, que ya se han lanzado en la red por otros participantes con el link a las páginas en las que están disponibles. Por último y no menos importante, agradecemos enormemente la buena respuesta a la convocatoria de las Jornadas y la energía desplegada durante las sesiones, así como la confianza depositada en los colectivos organizadores.

Traficantes de Sueños, YProductions, La Casa Invisible y Universidad Nómada

Marzo de 2011 


\section{Introducción. Las jornadas}

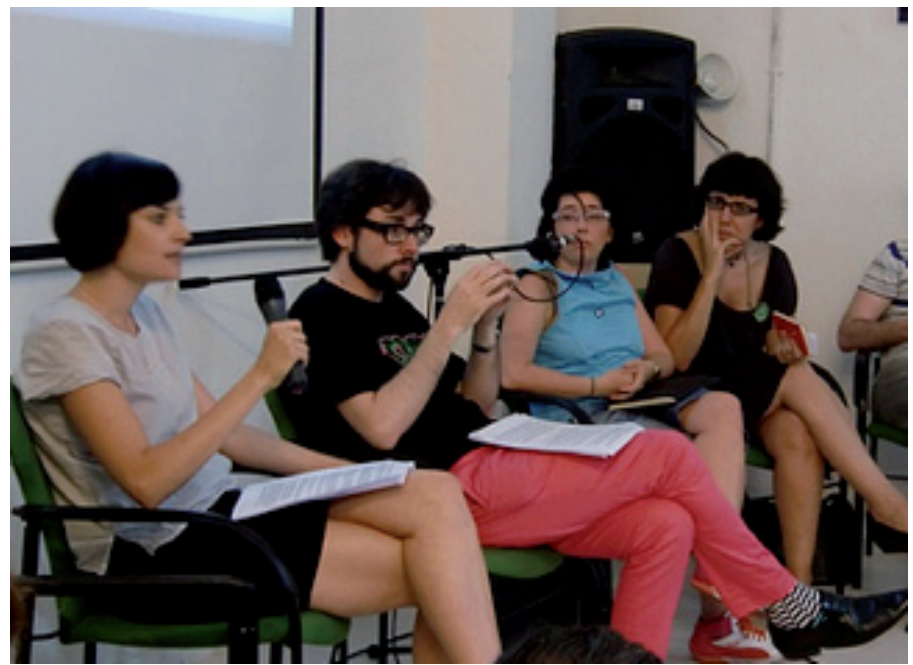

Clara, Jaron (YP), Zoe Romano (Serpica Naro) y Ana Méndez (Traficantes de Sueños)

Bajo la rúbrica «Para quienes disfrutamos trabajando. Jornadas sobre precariedad y autoorganización del trabajo creativo», los días 2 y 3 de julio de 2010 tuvo lugar en Madrid un encuentro de «trabajadores culturales» de muy distinto tipo. El día 2 se dieron dos conferencias públicas a cargo de Clara Piazuelo y Jaron Rowan de YProductions y Zoe Romano de Serpica Naro (Milán), respectivamente. El día 3 se dedicó exclusivamente al desarrollo de un conjunto de talleres entre los invitados y asistentes. Su propósito inicial era detectar los «malestares» y las posibles «soluciones» que existían entre los trabajadores del sector.

Aquí es preciso, sin embargo, hacer una precisión. El llamado «sector del trabajo cultural y/o creativo» no tiene límites precisos, ninguna tipo de sindicación clara, a excepción de asociaciones profesionales de diversa índole, así como tampoco parece existir una idea precisa, más o menos compartida, de todas las actividades que entrarían dentro del mismo. Baste decir, que a estas Jornadas fueron invitados artistas que exponían en galerías pero que también trabajaban regularmente con museos y centros de arte; un buen número de empresas y asociaciones de creadores cuyos clientes principales eran instituciones públicas, pero igualmente asociaciones y empresas culturales más enfocadas al mercado privado; empresas y proyectos políticos relacionados de una forma u otra con la producción de bienes culturales; colectivos de creadores de centros sociales okupados o no: empresas de desarrollo de software libre y diseño gráfico y algunos funcionarios y responsables de museos e instituciones culturales. Esta 
diversidad de situaciones «de mercado», de estatutos de contratación y de categorías profesionales coincidía también con una fuerte diversidad de trayectorias biográficas, percepciones subjetivas de la propia actividad y también tipologías de producción que iban desde ámbitos técnicos, como el software, hasta la edición y producción de música y libros; desde la organización de eventos hasta la consultoría experta; desde la producción de obras de arte hasta la gestión de instituciones culturales. Consideramos que esta multitud de situaciones es a la vez representativa de las realidades laborales y productivas de la cultura, y al mismo tiempo es muestra de la ficción de un «sector cultural» siempre demasiado poroso y difuso como para ser asimilado a categorías de clasificación que provienen de las economías industriales. Podemos decir que esta diversidad se convirtió tanto en el principal factor de riqueza del encuentro, como en su principal debilidad a la hora de compartir un lenguaje o algún posible objetivo común.

El diseño de las jornadas arrancó de un presupuesto que podía reunir a casi todos los presentes: la existencia de una cierta identificación con un trabajo que podríamos llamar «creativo» y de un conjunto de situaciones subjetivas y laborales más o menos compartidas, en las que se podían vislumbrar un cierto campo de malestares comunes. La dinámica, que se propuso, tenía en este sentido un cierta vocación de autoencuesta. El método partió de tres sesiones o talleres:

1.1 «Señalamiento de los principales problemas del sector». Se propuso a los participantes que se dividiesen en 5 ó 6 grupos de 6 a 10 personas. A la vez se les invitó a que discutiesen los problemas que consideraban más acuciantes en el sector y en su propia realidad laboral. Estos problemas debían ser organizados en tres columnas o niveles: personal, coyuntural y estructural. Se trataba, en primer lugar, de observar el grado de auto-responsabilización con el que se manifestaba la precariedad y el malestar laboral, y qué tipo de tensiones subjetivas eran las más destacadas. En segundo lugar, se intentó descubrir si la crisis era un elemento relevante en la lectura de la coyuntura. Por último, resultaba interesante certificar también si todos coincidíamos en señalar los mismos problemas estructurales, lo que indicaría que ciertamente eran problemas de todo el sector.

1.2. «A la búsqueda de soluciones». Tras la puesta en común de los grupos singulares, se listaron en un papelógrafo todos los problemas recogidos en los grupos. Se trataba de componer una tabla con todos los «problemas» detectados y colaborativamente agrupar las aportaciones consideradas homólogas. Los más citados fueron elegidos como los «principales problemas del sector». El taller partió de esta lista con los diez problemas más acuciantes. Seguidamente se formaron cinco nuevos grupos de trabajo específicos dirigidos a imaginar/construir posibles soluciones. 
1.3. «Selección de propuestas y creación de grupos de trabajo». Después de la lluvia de ideas de propuestas, se volvió a convocar una reunión general de puesta en común. De nuevo con un papelógrafo se trató de volver a elegir colaborativamente las «soluciones» más interesantes. El objetivo era agrupar las líneas de trabajo e intervención que se habían repetido más y que parecían más viables. La propuesta era formar grupos de trabajo desde los que partir para desarrollar estas líneas de trabajo durante los siguientes meses. El propósito era preparar una nueva discusión.

Lo que sigue son los resultados recogidos en las actas y en los papelógrafos del día 3 de julio, acompañados por un pequeño análisis de los mismos realizados por los organizadores de las Jornadas.

\section{Taller 1/ Principales problemas del sector}
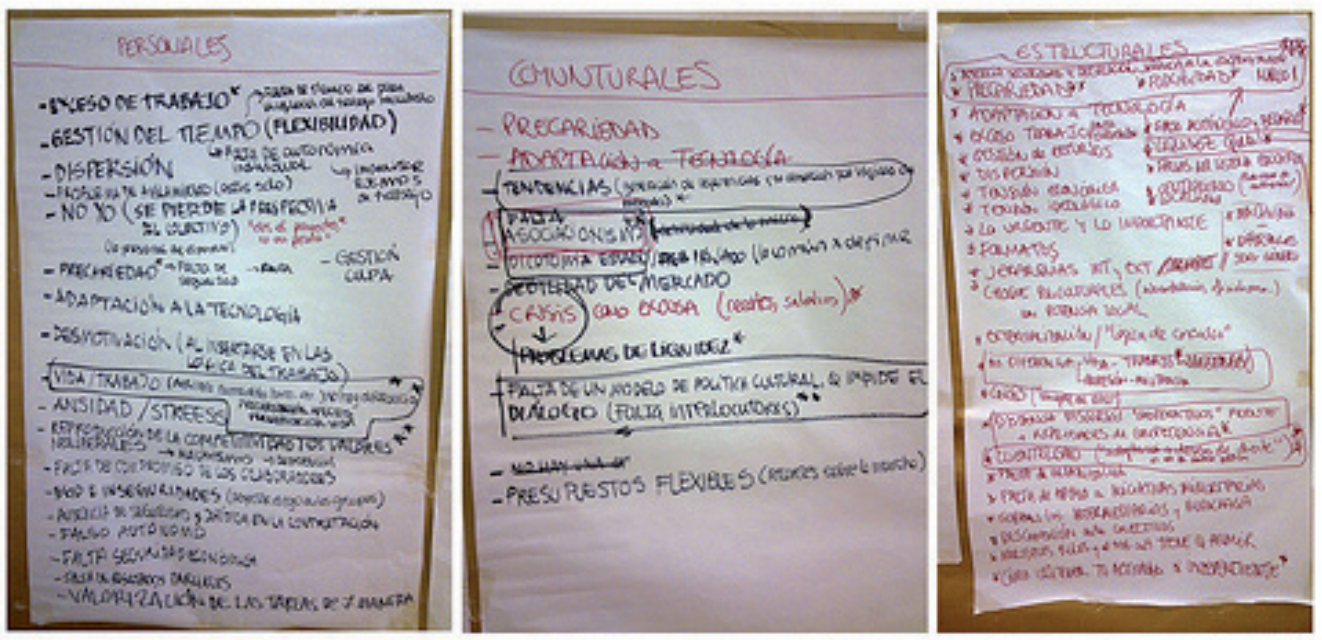

Papelógrafos de las dinámicas colectivas

\subsection{Resultados}

Transcribimos las aportaciones de los grupos de trabajo, tal y como quedaron expuestas en el papelógrafo de la puesta en común. 


\begin{tabular}{|c|c|}
\hline Personales & Coyun \\
\hline $\begin{array}{ll}\text { - } & \text { Flexibilidad } \\
\text { - } & \text { Fusión vida / trabajo } \\
\text { - } & \text { Ansiedad y estrés } \\
\text { Interiorización de dinámicas } \\
\text { competitivas } \\
\text { - } \quad \text { Subjetividad versus retórica } \\
\text { - } \quad \text { Dificultad para planificar y gestionar } \\
\text { - } \quad \text { tiempo. Dispersión } \\
\text { - } \quad \text { Plienación / autoexplotación } \\
\text { - } \quad \text { Desarrollo de trabajos que no gustan } \\
\text { - } \quad \text { Infravaloración por parte de los } \\
\text { - } \quad \text { Pompañeros de tu propio trabajo } \\
\text { Presión creciente para sacar adelante } \\
\text { la propia vida } \\
\text { Desmotivación ante las condiciones } \\
\text { materiales de trabajo } \\
\text { Falta de compromiso de los } \\
\text { colaboradores } \\
\text { Patologías del «ego» e inseguridad } \\
\text { - Gestión de la culpa y la } \\
\text { responsabilidad } \\
\text { Soledad y aislamiento }\end{array}$ & $\begin{array}{ll}\text { - } & \text { Precariedad } \\
\text { - } & \text { Flexibidad como imperativo } \\
\text { - } & \text { Tendencias (generación de } \\
& \text { referencias y su absorción por } \\
& \text { lógicas de mercado; compromisos } \\
\text { - } & \text { Fdquiridos) } \\
\text { - } & \text { Dicotta asociacionismo } \\
\text { - } & \text { Debilidad del mercado } \\
\text { - } & \text { La crisis como excusa: recortes, } \\
\text { - } & \text { menos salario } \\
\text { - } \quad \text { Caroblemas de liquidez } \\
\text { cultural, lo que impide el diálogo } \\
\text { (faltan interlocutores) } \\
\text { Presupuestos flexibles que se } \\
\text { recortan sobre la marcha } \\
\text { Falta de welfare }\end{array}$ \\
\hline
\end{tabular}

\section{Estructurales}

- Ausencia seguridad y regulación jurídica en la contratación

- Flexibilidad

- Precariedad

- Falsos autónomos

- Falsos becarios

- Falta de liquidez

- Fallas del sistema educativo

- Centralismo y localismo (chovinismo y estrechez de miras de las autonomías)

- Machismo 
- Diferencias sexo / género

- Adaptación a la tecnología

- Exceso de trabajo / autoexplotación

- Gestión de recursos

- Dispersión

- Tensión económica

- Tensión ideológica

- Primacía de lo urgente y lo importante

- Jerarquías internas (reparto de capital simbólico, social, afectivo) y externas

- Choque políticas culturales con potencia social (subcontratación, oficialismo)

- Externalización / lógica del concurso

- Indiferencia entre vida y trabajo (o profesión y militancia)

- Crisis («siempre en crisis»)

- Distancia de los «discursos cooperativos» frente a una realidad competitiva

- Clientelismo («adaptación a deseos del cliente» en vez de cambiar políticas)

- Falta de organización

- Falta de apoyo a iniciativas minoritarias

- Sobran intermediarios y burocracia

- Desconexión entre colectivos

- Los múltiples roles que el trabajador cultural tiene que asumir. Contradicción entre las tareas de gestión/burocracia frente a las creativas

- Dificultad de legitimar tu propia iniciativa, aun siendo independiente

- Poca cohesión del sector

- Poca solvencia empresarial y de las estructuras económicas

- Problemas organización: ubicación / dinero

- Verticalidad de las decisiones

- Dificultad de gestionar lo colectivo: la implicación, los deseos, las singularidades; falta de socialización de cada trabajador singular, de organización de «lo afectivo»

- Falta visión general del sector y la ciudad

- Falta cartografías de conflictos, no de recursos

- Falta espacio físico de encuentro

- Subsunción de la vida en el capital

- Diferencias de implicación respecto al trabajo en función de la formación propia

- Dificultad de gestión del capital de los grupos; formas de contratación

- Exceso de trabajo

- El artista como banco, obligado a adelantar el dinero por los retrasos en el pago de las instituciones 
- Las listas negras de las instituciones

- Dificultad de elegir el camino / lugar para rentabilizar tus proyectos

- Dificultad de valorar otros inputs no económicos para rentabilizar tus proyectos

- Exceso de trabajo

- $\quad$ Ausencia de espacios de politización

- $\quad$ Pregunta: estos problemas, ¿son sólo de nuestro sector?

\subsection{Propuesta de análisis}

A partir de enunciados de carácter tan sintético, a veces una o dos palabras, resulta difícil sacar conclusiones generales. Una lectura algo más detenida permite, no obstante, obtener algunos elementos comunes, que parece se repiten de forma incesante, y que nos remiten a grandes líneas de un posible discurso sobre el malestar en el sector. Así, si mantenemos la división en los tres ejes propuestos, podríamos organizar esta heterogeneidad de líneas discursivas en torno a tres campos semánticos: el «discurso personal», la «crisis / siempre en crisis» y los «problemas del sector»

1. «El discurso personal». Hablamos aquí de un discurso, porque curiosamente es en este espacio de lo «subjetivo» que se vuelve sobre sí mismo, donde los enunciados encuentran una coherencia interna más alta. Domina en este campo semántico la permanente tensión entre lo vocacional y un tiempo de trabajo que se confunde con la vida; una fuerte precariedad emocional que deriva de la identificación con la actividad laboral, o de la «puesta en juego de la subjetividad» en la actividad laboral; y por último una suerte de amargura, de frustración de las expectativas primeras. Efectivamente se trata de tres grandes líneas de tensión:

a) Continuum vida-trabajo. Los participantes denunciamos las características del trabajo creativo y de los proyectos auto-empresariales. Si consideramos, por un lado, que el trabajo creativo se alimenta de los input de la actividad cotidiana de las personas y, por otro, que la contratación de proyectos surge de contactos personales; que las decisiones (y buena parte del trabajo) se toman más allá de todo horario y que el orden de los trabajos es siempre automoludable; no es extraño que los participantes sintamos una fuerte superposición / integración de los tiempos de trabajo y vida. Esta integración no permite una planificación de los «antiguos» tiempos de ocio y transmite una sensación de «estar todo el tiempo trabajando», de no «tener la vida en tus propias manos». Enunciados que van precisamente en sentido contrario de lo que se esperaba del «trabajo por cuenta 
propia». Se produce así una fuerte sensación de auto-explotación, que viene determinada porque lo que se pone a trabajar es la vida, las ideas, los contactos, los afectos... La autoexplotación percibida en la autoempresarialidad coincide con un forma de autoexplotación más profunda, la de la subjetividad de cada cual.

b) Precariedad emocional. La fuerte identificación con el trabajo (en tanto apuesta personal), la responsabilidad vivida en solitario (generalmente en el seno de microempresas de dos o tres trabajadores) y el contexto incierto (proyectos temporalesflexibilidad), conducen casi siempre a una sensación casi constante de alta ansiedad y fuerte estrés. El desarrollo de habilidades muy ligadas a las «formas de ser», esto es, la simpatía o la oratoria pueden ser determinantes a la hora de conseguir un contrato («cada proyecto implica mucho de cada uno»). En paralelo, el éxito o el fracaso de un proyecto, o del conjunto de la empresa, se percibe como el resultado de las capacidades y el trabajo del sí: el resultado es la autorresponsabilización, la culpabilización o distintas formas de interiorización del éxito y el fracaso, que refuerzan el fuerte componente «egotista» del trabajador cultural, y que al fin y al cabo se vuelcan en una personalidad frágil, permanentemente dependiente del registro de la valoración externa.

Por otra parte, muchas competencias necesarias para el desempeño de la actividad, como la contabilidad o el marketing, no coinciden normalmente con el perfil de trabajador creativo. Esta carencia se convierte en factor de estrés. La forma micro-empresarial conlleva un alto grado de soledad y aislamiento, se trabaja de forma intensiva con pocas personas, lo que en el caso de relaciones malavenidas puede convertirse en una tortura emocional. La falta de control sobre el propio tiempo de trabajo, la continuidad entre trabajo y tiempo libre genera una suerte de atmósfera de inmersión total, en la que el estrés o las patologías laborales no encuentran respiro.

c) Incumplimiento de expectativas. Las expectativas sobre los auto-proyectos creativos y las expectativas sobre la cooperación en el sector son quizás los dos elementos que aparecen siempre en las vocaciones culturales, a la vez que son también dos fuentes principales de frustración. Del auto-empleo «creativo» se espera poder desarrollar proyectos interesantes, un campo de proyectos en el que plasmar la intuiciones propias, al tiempo que un espacio de permanente aprendizaje y exploración. Y sin embargo, buena parte del trabajo efectivo se reduce a buscar financiación, redactar proyectos, presupuestos adaptados a los clientes, comprar/conseguir materiales, llevar la contabilidad... En muchas ocasiones, y sólo a fin de «mantener la empresa», se ve necesario aceptar trabajos que ni por los contenidos, ni por las formas, ni por los tiempos, ni por su escasa continuidad, eran lo que en un principio se estaba en disposición de desarrollar. Estas condiciones materiales del trabajo producen una fuerte desmotivación, que sumada a la sensación de exposición subjetiva continua y de «trabajar todo el tiempo», pueden hacer emerger una fuerte disonancia entre lo que se esperaba y la realidad. 
De otra parte, se presupone que dentro del sector creativo prima cierto espíritu de colaboración. La percepción subjetiva del trabajo en el sector es sin embargo la de una cruel competencia entre agentes y empresas por la captación de recursos y el desarrollo de ideas. Cualquier reflexión puede convertirse en un taller, cualquier jornada en una marca, cualquier línea de trabajo en un proyecto anual. Se establece así un medio ambiente de «tonto el último» a la hora de valorizar económicamente la producción colectiva y la agenda de contactos. Una denuncia repetida es la de la distancia entre una retórica de cooperación dentro del sector, frente a una realidad generalizada de secretismo. Esta tensión entre la cooptación y la cooperación viene motivada en parte por el siempre difícil equilibrio entre la subsistencia de la propia estructura y la «filosofía de compartir» inherente a muchos agentes que conformamos la dilatada esfera cultural.

2 «La crisis / siempre en crisis». La propuesta de ordenar los problemas en el campo de «la coyuntura», y por lo tanto en el terreno de lo que considerábamos como especial de este tiempo, lo que es específicamente singular de un momento que tarde o temprano pasaría, trataba de apuntar sobre los impactos y transformaciones que había producido la crisis económica en el sector. En este sentido, se podían intuir dos líneas narrativas: un discurso propiamente sobre la crisis, que señalaba las dificultades asociadas a los recortes presupuestarios o la escasez de financiación; y otro discurso sobre un sector «siempre en crisis» y que coincidía con lo que podríamos llamar problemas estructurales.

a) La crisis en la producción cultural. En muchos grupos de trabajo apareció una fuerte ansiedad ante la coyuntura de crisis. Se observaba una caída de las ventas, el deterioro de los presupuestos públicos, los recortes en cultura, la creciente competencia dentro del sector por captar estos recursos menguantes. Pero al mismo tiempo, también, se acusaba a la «crisis como pretexto», como una operación injustificada para introducir recortes, rebajas salariales o de las tarifas, etc.

b) «Siempre en crisis». En esta línea, quizás mayoritaria en los grupos de trabajo, la crisis no había producido ninguna discontinuidad, las condiciones de trabajo y contratación eran antes, y son ahora mayoritariamente precarias, los problemas de las políticas culturales eran básicamente los mismos: la falta de cooperación, la debilidad del asociacionismo, las relaciones institucionales. En este campo, los problemas coyunturales no son distintos de los problemas estructurales.

3 Los problemas del sector. La mayoría de los grupos, al igual que la mayor parte de los participantes e invitados, señalamos el trabajo en cultura como una actividad problemática, sujeta a una serie de déficit y contradicciones estructurales, que son constitutivas del trabajo en el 
sector. Sin embargo, el diagnóstico de estos problemas sólo puede ser múltiple y contradictorio. Lejos de poder señalar un «discurso personal» relativamente unificado respecto a una serie de percepciones y enunciaciones, más o menos compartidas, aquí las narraciones se cruzan, ponen acentos distintos, a veces contradictorios y opuestos según las líneas de intervención y las posiciones políticas. Intentamos agrupar, los problemas en campos o territorios, para señalar problemas «laborales», «institucionales», «internos al sector» o a las vías de «realización económica».

a) Los «problemas laborales», casi unanimente compartidos, tienen que ver con la precariedad y la siempre creciente exigencia de flexibilidad. Se apunta desde luego a figuras laborales bien conocidas en algunos ámbitos específicos como los falsos autónomos, o los falsos becarios. También a la inseguridad jurídica, tanto en los contratos colectivos, como en los individuales: esto es, contratos abusivos o leoninos por parte de la parte contratante, y que muchas veces son rotos sin mayor pretexto. Subyace todo un conjunto de problemas propios de la contratación por proyectos: la temporalidad, la falta de continuidad, el trabajo «que tenía que estar para ayer», etc. Dentro del terreno de la precariedad, aparece también, si bien quizás sólo apuntado, la propia velocidad tecnológica del sector: la obsolescencia de competencias que sólo poco antes eran punteras. Lo mismo ocurre con la obsolescencia semántica y topológica marcada por los trends y tendencias de la moda cultural, que exigen en muchos casos una permanente innovación de métodos, campos de trabajo, materiales, conceptos, etc., poco justificada en relación con la eficacia y el sentido de la producción.

b) Los déficit institucionales. Aquí se pierde la unidad de referencias, los señalamientos son múltiples y no tienen coherencia interna. Se apunta por un lado al sistema educativo, que por ejemplo no da valor a la «cultura», o que no contribuye a la formación en competencias específicas, pero que tampoco contribuye a formar un «espíritu empresarial». Las instituciones y las políticas culturales son acusadas de burocratismo, de depender de los políticos de turno, de moverse en el arco que va del centralismo al chovinismo estrecho de las Comunidades Autónomas, y sobre todo de clientelismo, que hace que la contratación se apoye sobre redes informales y poco transparentes. También aparece en la mira todo otro tipo de críticas, que señalan la desresponsabilización de las administraciones públicas respecto del viejo «derecho a la cultura», de practicar políticas de externalización y subcontratación que fomentan la precarización del sector cultural, y de no apoyar a las iniciativas minoritarias más interesantes. Una ausencia notable en este campo, fue la «propiedad intelectual», especialmente para una gran cantidad de proyectos que de una forma u otra se sienten interpelados por este problema, y participan de proyectos de producción y difusión con licencias no restrictivas. 
c) Los problemas del sector. El diagnóstico interno es también complejo y contradictorio. De un lado, aparece toda una crítica dirigida conra la estrechez de miras de los agentes y empresas culturales, la falta de espacios de encuentro, la incapacidad de superar la retórica de la cooperación sobre una realidad que empuja a la competitividad. O también la ausencia o renuncia a una dimensión conflictiva del trabajo cultural, la necesidad de abrir experimentos de politización, etc. Pero al mismo tiempo aparecen problemas relativos a la falta de cultura empresarial, la escasa capacidad para dotarse de instrumentos empresariales eficaces, etc. Por último habría que mencionar todo un terreno de crítica «micropolítica» que apunta a las relaciones entre los trabajadores culturales y a formas de jerarquía no siempre explícitas: principalmente el machismo y los problemas de género, pero también la poca horizontalidad de muchas decisiones, la primacía de las dinámicas competitivas, la capitalización individual de proyectos y relaciones, etc.; todo ello en contradicción con algunas de los elementos definitorios o de marca del trabajo cultural: la participación, la cooperación, etc.

d) La rentabilidad. Se trata de una dimensión transversal a todas las demás, pero que aparece bajo la pregunta de «¿cómo valorizar económicamente la actividad que realizamos?», siempre en un contexto en el que la propia actividad cultural no tiene a veces mercado objetivo posible (si bien puede tener públicos amplios) o formas claras de obtención de retorno económico. Los problemas de valorización económica son propios de cualquier actividad empresarial, y normalmente remiten, casi de forma automática, a las fórmulas típicas del diagnóstico empresarial: problemas de estructuración interna de la actividad empresarial, definición del plan negocio, diseño estratégico de las líneas de trabajo más rentables, fomento de la cultura empresarial y de la corresponsabilización, etc. Sin embargo, al lado de esta pregunta, en algunos grupos del taller apareció otra, que se puede formular casi como el negativo fotográfico de la primera: «¿Cómo valorizar y visibilizar los elementos singulares y la riqueza que la prioridad de la capitalización y de las urgencias de comercialización dejan de lado?». Como se puede ver, de nuevo, las respuestas y los diagnósticos, casi siempre incipientes, basculan entre la identificación y el rechazo con los modelos empresariales, y en realidad con las formas hegemónicas de estructuración del sector de la llamada producción cultural. Se repite de nuevo la tensión, por la que si bien se intentan producir nuevas fórmulas de estabilidad económica, así como formas de relación y funcionamiento más coherentes con los procesos de cooperación, se acaban también reproduciendo roles y soluciones propias del modelo que se busca torpedear. Se trata de una tensión que atraviesa a casi todos los proyectos. 


\section{Taller 2/ "A la búsqueda de soluciones"}

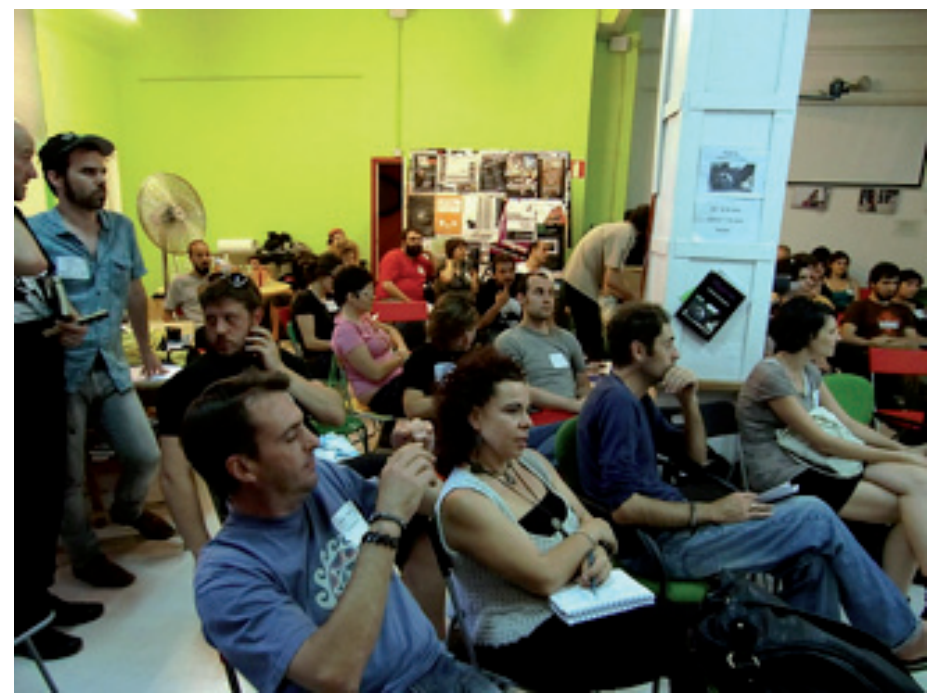

Sesión $2^{\circ}$ día de taller

Reunidos de nuevo a primera hora de la tarde del sábado 3 julio, delante del papelógrafo, recogimos aquellos «problemas» en los que parecía había más coincidencias o mayor consenso. Se elaboró así la lista de los «problemas comunes» al sector, que quedó como sigue:

1. Falta de espacios de politización / asociacionismo

2. Carencia de una visión general del sector / ciudad

3. Relaciones internas

4. Relación con instituciones

5. Contratación / precariedad

6. Vida-trabajo / profesión-militancia

7. Crisis

8. Clientelismo

9. Cooperación / competencia

10. Liquidez $/$ artista $=$ banco

El encuentro se definió sobre la base de la elaboración de un diagnóstico compartido, no como un programa de investigación con su secuencia de hipótesis-entrevistas-análisis. Por eso las categorías no son homogéneas, y en muchos casos se superponen o podrían ser englobadas unas 
dentro de otras. Quizás la estructura futura de un encuentro de características y propósitos similares, podría tomar en consideración una metodología más política y eficaz, pero también más cercana a un particular proceso de auto-investigación.

Siguiendo el guión propuesto, nos volvimos a dividir en grupos. En esta ocasión cada grupo trabajaría sobre distintas líneas de acción / solución en relación con cada problema específico. En un espacio de cerca de hora y media, los grupos discutimos sobre cada uno de los diez temas. Estos son los resultados:

\subsection{Resultados}

\section{Falta de espacios de politización / asociacionismo}

- $\quad$ Crear una red de proyectos que funcione como punto de partida y se construya a partir del trabajo cotidiano

- Aprovechar las condiciones micro para construir alternativas desde las realidades concretas

- Compartir el código fuente (modos de hacer, transparencia, con quién se trabaja, presupuestos, salarios, etc..) como punto de partida para construir esa red

- Acción directa, propuestas concretas para reclamar derechos

- Crear soportes para generar soluciones prácticas (hacer más transparentes los procesos y compartir problemas y herramientas)

- Visibilizar las dimensiones negativas, evitar imagen de éxito

- Hacer un manifiesto o texto común

- Carecemos de modelos de remuneración dentro de la cultura libre: organizar espacios de reflexión en torno a esta cuestión

- $\quad$ La relación con las instituciones no debe ser clientelar. Hay que denunciar los conflictos concretos

- Crear micro-residencias para que los proyectos puedan aprender unos de otros 


\section{Carencia de una visión general del sector/ciudad}

- Cartografiar la ciudad; otros grupos como AVAM o MapeaMadrid hacen mapas de recursos; en su lugar debemos hacer una cartografía de conflictos, que aborde dimensiones más complejas y planes de estrategia y futuro

- Encuentros periódicos (como los hackmeeting): encuentros auto-organizados, auto-financiados para narrar lo que hacemos, para reforzar conocimientos y redes locales

- Repensar el modelo de archivo (buscar referencias): ¿cómo se elige quién sale y quién no? ¿cómo se ordena?

- Pensar en una economía para la producción cultural más allá de las instituciones, sus espacios y equipamientos; tenemos que pensar una forma de remuneración de la cultura libre

\section{Relaciones internas}

- Trabajar la diferencia y la pluralidad

- Desarrollar la capacidad de reconocer los conflictos internos

- Buscar otros modelos de trabajo y relación

- Poner en común afectos: las relaciones internas son tan importantes como la dimensión productiva

- No negar sino explicitar roles y su relación con cuestiones de género; ser capaces de cuestionarlos

- Desarrollar dinámicas de autoformación: talleres, banco de conocimiento, teatro, humor, esquizoanálisis, dinámicas de grupo

- Capacidad de escucha

- Corregir la «asambleitis»

- Pedir ayuda a profesionales

- Obligarse a encontrar tiempo

- Cuidar los espacios informales

- Asumir que el conflicto es algo normal en los grupos

- Metodologías para la formación del artista como trabajador 


\section{Relación con instituciones}

- $\quad$ Estudio de la trayectoria de las políticas culturales

- Analizar otros referentes (se mencionana: la alta inversión de Austria, Artistas Visuales de Escocia, Arts Council, Tabacalera). Se trata de desarrollar formas de apropiación de riqueza a través de formas de cogestión con las instituciones

- Crítica del proceso de individualización de los artistas. Se apunta a la idea de metabrand y a un trabajo de crítica sobre el concepto de obra de arte

- $\quad$ La universidad fomenta la subjetividad neoliberal; son necesarios otros modelos de educación que no entiendan la cultura como un mercado

- Crear una nueva concepción de la institución: pensar las relaciones con las instituciones como algo complejo y ambiguo

- La crítica al gran evento se ha generalizado pero ésta no ha dado lugar a herramientas concretas o discursos específicos.

- Generar herramientas mestizas

\section{Contratación/ precariedad}

- $\quad$ Falta una figura jurídica y/o estatuto de los trabajadores culturales

- Hay que agruparse para ser más fuertes

- $\quad$ Hay que inventar fórmulas específicas adecuadas a los trabajadores culturales

- $\quad$ Sindicato de trabajadores culturales

- $\quad$ Sindicato biopolítico: que apueste por nuevos derechos

- «Pequeños sindicatos»: grupos para defender y presionar (aunque son gremiales y corporativos, tienen su eficacia)

- Denunciar activamente las formas de explotación

- Denunciar la pacificación que existe de cara a la relación con la institución

- ¿Cómo ponemos en marcha un conflicto? ¿Cómo se crea un grupo? 


\section{Vida-trabajo/ profesión-militancia}

- ¿Cómo se devuelve el capital social que extraemos de los movimientos sociales?

- Renta básica: reparto del dinero

- Incluir valores intangibles en los presupuestos

- $\quad$ Introducir el requisito de que la actividad aporte al común y que éste sea visibilizado

- Hay que ser conscientes de dónde nos colocan y mantener una actitud responsable respecto a las prácticas y al capital social que manejamos

- En la medida en que el sistema de contratación, no es claro y se entremezclan los afectos y contactos, se producen relaciones ambiguas

- Trabajas en un lugar ene el que conoces a la gente: esto genera problemas de dependencia económica, política, etc. Hay que diversificar las formas de obtener renta.

- Tenemos que «aprender» a trabajar y militar, aprender de los mayores

- $\quad$ Exigir retribución del trabajo, ubicar los favores

- Todos estamos en multiplicidad de posiciones, según el lugar desde el que se considere. Parece preciso poner límites

\section{Crisis}

- La crisis como excusa

- $\quad$ Crisis de valores

- Falta de cohesión social

- Incrementar la autonomía respecto de las instituciones

- Generar autoempleo

- Proyectos de menor inversión y más imaginación

- Des-especialización: visión más abierta

- Acabar con un concepto de trabajo sólo como elemento económico 


\section{Clientelismo}

- Causa: excesiva dependencia del sector público o un cliente, dependencia económica y política

- Hay que romper el aislamiento

- Crear plataformas

- Unir colectivos pero con una continua crítica para no perder singularidades

- Diversificar fuentes de renta

- $\quad$ Plantear conflictos

\section{Cooperación / competencia}

- $\quad$ Honestidad respecto a nuestras actividades, posibilidades y carencias

- Ética

- Análisis de casos

- Crear una plataforma para potenciar el trabajo colaborativo, para poner en común trabajos e iniciativas, para visibilizar los presupuestos, los casos de éxitos, los clientes para los que se trabaja, etc.

- Pensar cuánto necesitamos para vivir y para funcionar; no hay mentalidad empresarial

- Analizar los presupuestos públicos y que recaigan en lo común

- Generar un frente común para obtener lo que necesitamos: ¿derechos económicos y laborales?

- Analizar la producción de valor del sector cultural y la posición que ocupan los trabajadores en este sistema

- Webs donde se discutan colectivamente los salarios mínimos 


\section{Liquidez $/$ artista $=$ banco}

- Visibilización de los problemas económicos

- Visibilización de las empresas que no pagan: escraches

- Hacer uso de los sindicatos para los impagos

- Webs y blogs para informar a fin de mantener el anonimato y evitar represalias

- Fomentar la «previsión de fondos»

- $\quad$ No dejarse llevar por relaciones personales en dinero, tiempos, garantías...

- Asegurar la asunción colectiva de impagos en cadena («resolución solidaria»)

- $\quad$ Finanzas solidarias

\subsection{Propuesta de análisis}

Los enunciados recogidos en las actas de cada grupo y en los papelógrafos logran resumir (pero no acaban de reflejar de manera rigurosa) las complejidad de las discusiones presentes. Con una propuesta tan apretada, con «diez problemas» a tratar en poco más de una hora, el debate tuvo necesariamente un carácter rápido y poco elaborado. La metodología propuesta implicaba la recogida de todas las «soluciones» que fueron presentadas en cada grupo, sin necesidad de que hubiera una elaboración profunda acerca de las mismas, o que el grupo en su conjunto se sintiera reconocido en todos y cada uno de los items de su lista. Sobra decir que los pequeños equipos de trabajo que se constituyeron ad hoc para proponer y discutir «soluciones» no funcionaron de acuerdo con la metodología de «grupos de discusión» propia de las ciencias sociales: no se dejó ni el tiempo suficiente para hablar, ni se llegaron a definir consensos, o al menos posiciones coherentes que como mínimo nos permitiesen reconocer líneas de sentido que propiamente pudiesen ser consideradas como el discurso (o los discursos) del sector.

A pesar de estas «deficiencias», hay, sin embargo, algunos rasgos y elementos comunes que pueden servirnos como hipótesis de lectura de las posiciones narrativas de algunos segmentos del trabajo cultural-creativo. En un primer vistazo aparecen, sin duda, gran cantidad de enunciados que parecen referidos al campo semántico de la política: llamamientos a la solidaridad, la reivindicación del asociacionismo, propuestas de acción, etc.. Por otro lado, hay otro conjunto de enunciados que aunque «solidarios» con «lo político», o con lo que propiamente se define como una posición de «izquierdas», entrarían en otro campo semántico, y cuyo tono es más bien ético. Éste se manifiesta en declaraciones de intenciones («deberíamos hacer», «sería mejor»), y sobre todo en una enunciación de valores: honestidad, ética profesional, autonomía, solidaridad. Las fronteras no son sin embargo claras. El «discurso político» muta muchas veces 
en posiciones de corte ético, cuando se refiere al «buen comportamiento», y al «deber ser» de la contratación o el funcionamiento del sector (por ejemplo, en relación con las instituciones). Se trata, en estos casos, de una suerte de «deontología profesional» antes que de una política de organización y conflicto. Estas diferentes formas de acercarse a «la política» o, de manera más concreta, estas diferentes enunciados de reivindicación, señalan de nuevo la heterogeneidad de los agentes presentes, así como sus diferentes prioridades. Efectivamente, a las jornadas asistieron sujetos muy distintos: algunos más ligados a prácticas de corte «profesional» en el ámbito cultural, otros que pivotaban entre el espacio galerístico y las prácticas colectivas, asociaciones culturales cuya prioridad es encontrar sostenibilidad económica, y grupos y proyectos empresariales que se definen a sí mismo como colectivos políticos. Se trata de imaginarios muy diferentes que describen una realidad compleja y sin perímetros claros que llamamos «sector cultural». En cualquier caso, si bien de acuerdo con la información aquí registrada, queda patente que hay muchos preceptos que no se comparten, muchas estrategias que se perciben de manera diferente y una agenda poco afín, todavía pensamos que es posible construir un lenguaje común que nos permita percibir los conflictos compartidos.

En este sentido, cabe destacar otro conjunto de elementos discursivos fuertemente divergentes con los elementos de carácter político o ético. En varios momentos aparece, se repite, y en algunos casos es dominante, una línea discursiva que propiamente podríamos llamar como el «discurso de la racionalización empresarial». Éste aparece en las «soluciones» más técnicas que remiten a la asesoría, las mejoras profesionales, las estrategias de negocio, las alianzas empresariales. En el fondo, aunque acomplejado e ilegítimo, en una dinámica de discusión cuya «invitación a pensarse políticamente» era generosamente manifiesta, lo que aparece aquí es de nuevo la «figura del profesional», que ofrece la perspectiva de que si «el negocio no va sobre ruedas es porque no lo hacemos suficientemente bien» o porque las distorsiones al funcionamiento del mercado han sido políticamente impuestas (como por ejemplo el clientelismo de las instituciones). En este terreno, la aparente radicalidad «ética» encaja, mejor que mal, con el «discurso de la racionalización empresarial», antes que con las propuestas más típicamente sindicales o conflictuales. Esto nos hace sospechar, que el discurso del «emprendedor» y del «empresario de sí mismo» ha calado fuerte, interiorizado como ethos particular de una parte importante del sector.

El mapa de intersecciones, coherencias y desacuerdos, entre estas líneas de discurso (profesional/empresarial; ético y sindical/conflictual) se puede reconocer en casi cada uno de los problemas que se propusieron como motivo de discusión. Así, por ejemplo, en relación al «asociacionismo» se presentaron una gran cantidad de propuestas de carácter «sindical» y «conflictual», se propusieron estrategias de conflicto, reclamación de derechos, declaraciones conjuntas y se apostó por formas de «contratación colectiva». Pero muchas veces, este discurso proto-sindical parecía recogerse en una suerte de mutualismo productivista, dirigido a compartir recursos y conocimientos, sobre la base de una solidaridad algo ambigua, antes que a organizarse 
sobre estrategias políticas definidas. En relación con el problema de la «cooperación / competencia» las posiciones de nuevo bascularon entre propuestas que apuntaban a las posiciones laborales y al análisis económico, y llamamientos de carácter ético sobre la base de la solidaridad, la colaboración, la transparencia y la honestidad, siempre acompañados con soluciones técnicas (webs, plataformas).

Quizás se pueda confirmar esta misma intuición en lo que se refiere a las «soluciones»a la «carencia de una visión general del sector». Ante este problema se repite, de nuevo, la urgencia por compartir recursos y promover los intercambios en forma de encuentros, archivos, residencias, etc. En pocos casos, sin embargo, salta lo que en principio podría sugerirse con tal pregunta: la necesidad de diagnósticos amplios sobre la realidad del sector, concentrados en las formas de contratación, los modelos de explotación del trabajo y la propia circulación monetaria en la producción cultural.

Los dos problemas que aparecen más orientados por una invitación política «contratación / precariedad» y «vida / trabajo» aparecen igualmente debilitados y contradictorios. Cuando los grupos discutimos sobre «contratación / precariedad» surgieron por ejemplo propuestas de carácter sindical basadas en distintas formas de asociacionismo, entre las que aparecían con fuerza las clásicas asociaciones corporativas, que son ya características de distintas ramas del trabajo artístico.

En relación al complejo problema de «vida / trabajo» y que remite a una de las más importantes condiciones del trabajo creativo y relacional en nuestra época, la creciente indistinción entre tiempo de vida y tiempo de trabajo, y entre relación laboral y relación a secas, se observan también las mismas contradicciones. De una parte, aparecen propuestas de renta básica, justificadas por la necesidad de remunerar de forma universal una vida que se ha vuelto productiva. De otra, se señalaron otras mucho más próximas al discurso de la racionalización empresarial basadas, sobre todo, en una política de límites y fronteras entre el tiempo de trabajo y el de ocio, y entre las redes laborales y las sociales, muchas veces acompañadas, de nuevo, por sucesivos llamamientos «éticos».

En relación con el problema «crisis» nuestras respuestas mostraron también las mismas contradicciones. Aparte de elementos de diagnóstico que presentaban la coyuntura, de nuevo, como una excusa para recortar derechos y salarios, así como la falta de cohesión social y de valores, casi todas las respuestas recogidas apuntaban al estrecho marco del sector cultural. En este caso se trataba de «generar autoempleo», de «diversificar» las líneas de negocio y de obtener una mayor autonomía respecto a las instituciones. Como se sabe, en la relación con las instituciones públicas se juegan buena parte de los problemas y las frustraciones del sector. En la medida, en que una parte significativa de las empresas y proyectos trabajamos prioritariamente con instituciones públicas, y nuestra propia condición de posibilidad se encuentra en la creciente 
externalización y subcontratación de actividades recogidas en el capítulo de las políticas culturales, la relación con las instituciones cobra una centralidad desconocida en otros sectores laborales más orientados hacia los mercados privados.

Es por eso que quizás en este aspecto es donde se manifieste realmente un campo de demandas compartidas por casi todos los asistentes: la crítica del clientelismo, la falta de transparencia, la tardanza en los pagos, las cargas de la dependencia respecto de las instituciones que gestionan los presupuestos culturales. Y es aquí también donde la reflexión y las demandas explícitas muestran de forma más clara los límites antes mencionados. Por ejemplo, en lo que se refiere al problema «de la relación con las instituciones», aparecen críticas a la Universidad, al eventismo, así como propuestas de otros modelos institucionales y la generación de marcos de colaboración entre instituciones y trabajadores. Las referencias, sin embargo, a los marcos que orientan las políticas culturales, los modelos contratación o la propia tendencia a la externalización están relativamente ausentes. Dicho de otro modo, todavía no somos capaces de elaborar una crítica tanto de la generalización de la externalización y la subcontratación, como de algunas reglas poco claras, consideradas injustas o arbitrarias. Esta crítica se dirige concretamente contra el clientelismo y los problemas de pago (retraso, plazos largos). En este terreno, se proponen tanto acciones colectivas y conflictuales (que pasan por la denuncia, las plataformas reivindicativas), como soluciones más orientadas al mercado («diversificar») y a la empresa («previsión», líneas de crédito, etc). Sobrevuela sobre todas estas «desviaciones» una paradoja esencial sobre la que es preciso alguna reflexión. El calificativo de «sector» se señaló durante las jornadas como un significante vacío y amorfo, incapaz de describir el tipo de tareas que se comprenden dentro de este termino así como la cadena de valor que efectivamente produce. Paradójicamente, las reivindicaciones son eminentemente de orden sectorial y las soluciones vienen regidas, sobre todo, por una mejora de las condiciones laborales de los agentes del sector.

Un último indicador, que puede ser útil a la hora de corroborar, el grado o la capacidad de autorreflexividad de las empresas culturales, proviene de las respuestas al problema de «las relaciones internas». A fin de dar cuenta de este problema se señalaron toda una serie de técnicas de trabajo que pasaban por visibilizar los conflictos, organizar talleres, recurrir a asesorías externas, el cuidado de los espacios informales, etc. Cabe señalar, de manera general, la fragilidad del cuestionamiento de los orígenes de los malestares (jerarquías implícitas, falta de democracia, machismo y problemas de género), que entre otras muchas causas podrían localizarse también en un modelo laboral y empresarial que lleva implícito tales contradicciones. 


\section{La formación de grupos de trabajo}

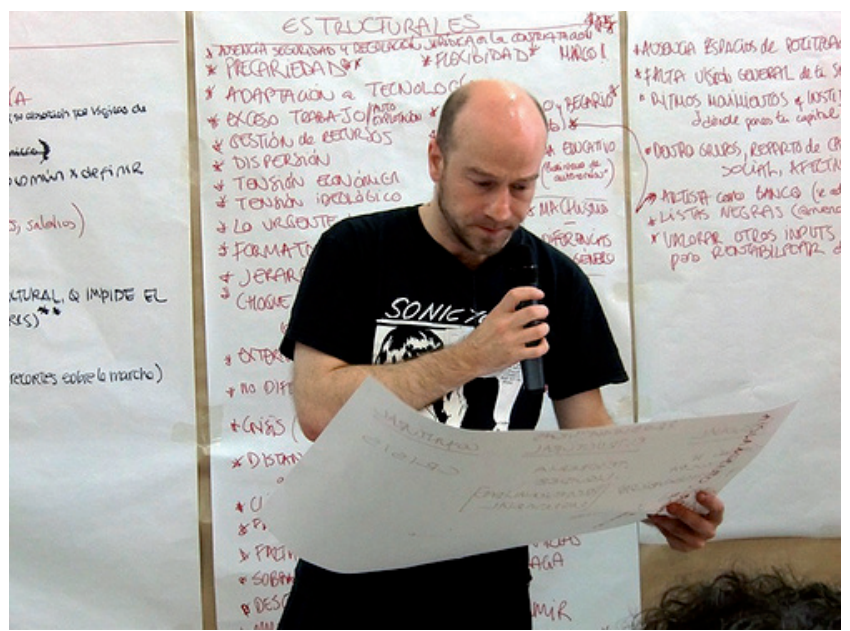

Kamen Nedev durante sesión de puesta en común

La última dinámica del día 3 de julio, tras recoger en el papelógrafo todas las soluciones a los «diez problemas del sector», consistió en proponer una serie de grupos de trabajo. Con estos equipos, nos teníamos que encargar de elaborar distintas herramientas que pudieran ser útiles para la organización del sector durante los siguientes meses. Los grupos que nos parecieron más pertinentes fueron:

- Cartografías: un grupo dirigido a elaborar mapas de trabajadores, empresas y recursos en el sector.

- Cultural-meeting: encargado de una posible reedición del encuentro.

- Asociación / denuncia / sindicato: este grupo debería estar destinado a ensayar alguna posible estrategia de organización y conflicto.

- Herramientas web

- Talleres y dinámicas de grupos: en este caso organizados sobre problemas específicos como finanzas, políticas públicas, relaciones producción, cultural/comunes y responsabilidad profesional.

Estos grupos no quedaron formalmente constituidos en el encuentro, sólo se llegaron a hacer listas con los mails. Durante los meses posteriores no fue activado ninguno de ellos. A excepción de otra nueva iniciativa que en el invierno de 2010-2011 ha trabajado por la organización de un nuevo cultural meeting, el resto de grupos no se han llegado a constituir. 


\section{A modo de conclusión: ¿Es posible la auto-organización política de los trabajadores culturales?}

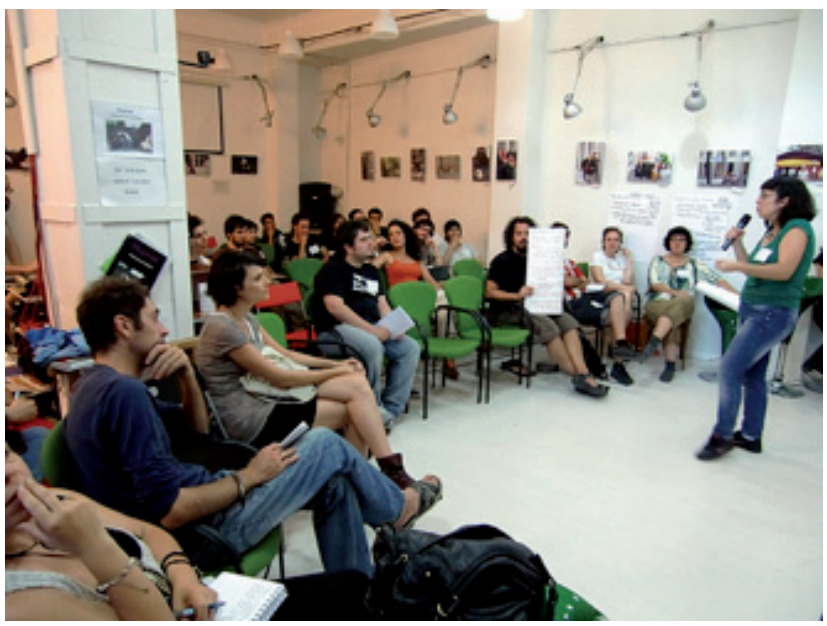

¿Es posible que en las condiciones actuales se genere un espacio expansivo de autoorganización política de los malestares y las demandas de las y los trabajadores culturales? ¿Seremos testigos, o incluso sujetos, de la constitución de algo parecido a un sindicato del «cognitariado creativo»? El espacio para la sorpresa y la innovación está siempre abierto en política. De todos modos, y a la espera de futuras constituciones políticas, parece preciso detectar los malestares comunes, afinar nuestras herramientas de intervención sobre los mismos y tal vez pensar que bajo formas tan individualizadas como las que actualmente operan entre los productores culturales, estos malestares pueden tener asegurada una larga vida.

En este sentido, los talleres de «Para quienes disfrutamos trabajando» nos ofrecen algunas aproximaciones provechosas a las dificultades que ahora mismo parecen encallar la capacidad de autoorganización y autorreflexión del trabajo creativo-cultural. Si bien no existe todavía un trabajo colectivo eficaz sobre estos problemas, es evidente que existen malestares relativamente compartidos. Por ejemplo, lo que hemos llamado el «discurso personal» se sitúa en una percepción de unos niveles de frustración y explotación elevados. La indistinción entre vida y trabajo lleva al agotamiento, a una incapacidad de organizar los tiempos de una forma saludable, a contaminar toda relación social y afectiva con proyectos y cooperaciones de carácter laboral. La puesta en juego permanente de la subjetividad, de las redes sociales, de las capacidades relacionales y afectivas en el trabajo creativo-cultural deriva en esa «precariedad emocional» que se señala continuamente. La frustración es en este terreno manifiesta: «La promesa de trabajar en cultura era otra», la realidad está hecha de competencia, agotamiento, autoexplotación, etc. 
Pero, ¿por qué tenemos que elaborar este discurso de manera tan «personal»? ¿Por qué no somos capaces de declinarlo colectivamente, cuando los problemas parecen tan generalizados y ocupan, efectivamente, tantas y tantas conversaciones dentro del «sector»? Hay, y siempre está presente en este tipo de encuentros, un «protagonista invisible» que subyace al discurso de los trabajadores culturales. Sospechamos que se trata de algo intocable, que no podemos socializar y compartir: se trata de la singularidad, de lo propio, de la individualidad del creador o del proyecto empresarial. Tal vez lo que frustra la capacidad de socializar, de colectivizar, o sencillamente de generar alianzas políticas sólidas (que siempre tienen un punto impersonal y no-productivo) es este escollo que llama a preservar nuestra propia marca y su capital (relacional, económico, etc.), y que parece remitirse a algo no compartible o siquiera expresable. Eso puede explicar la dualidad entre cooperación y competencia propia de las relaciones en el sector, en las que se comparte algo al tiempo que se preserva mucho (contactos, relaciones, capitales de todo tipo), y en las que la apertura viene a veces mediada y medida por una estricta contabilidad de la reciprocidad «favor / contrafavor». Nos encontramos aquí de nuevo con la tensión entre el deseo de cambiar, colaborar, poner en crisis, etc. frente a la regularidad, la estabilidad y la preponderancia de diferentes tareas manageriales que nos exige la condición de «profesionales» dentro del ámbito cultural.

Como bien sabemos, en la producción cultural, el capital no es sólo material y monetario, es sobre todo relacional y social. Por eso la colaboración, y la participación se sitúan en un marco ambivalente. Por un lado, se trata de aspectos que son irrenunciables desde un punto de vista «profesional»: el reconocimiento es igual a más capital (contactos, proyectos, marketing), y el reconocimiento siempre parte de otros. Por eso también, la competencia es el propio modo de distribución de estos capitales: yo te reconozco a cambio de «otros reconocimientos», pero también compito contigo por tu mismo reconocimiento. Por otro lado, la colaboración y la participación pueden hacer disolver los procesos de individualización y fomentar otro tipo de economías basadas en la reciprocidad y el equilibrio. Y sin embargo, parece que la balanza se decanta en favor del objetivo inmediato de cualquier empresa situada dentro del modo capitalista de producción, esto es, la producción / reproducción del capital (sea el tipo de capital que sea). Este objetivo viene impuesto por el contexto general «de mercado», que es desde luego mucho más fuerte que los deseos particulares de los sujetos. Se trata de una prescripción que opera sobre cualquier empresa, incluidas las empresas culturales (si es que de esa particular especialización se deriva realmente algún carácter excepcional).

La paradoja que aquí se expresa proviene del hecho de que la producción culturalcreativa es siempre colectiva y social, arranca de comunidades, formas de vida, espacios y cuencas de cooperación difusos en los tejidos urbanos. Nada es propiamente el producto de una singularidad, de una empresa o de un punto privilegiado. Debemos entonces asumir que «la gente del sector», en tanto apoderados de la coolness de los tendencias creativas de una sociedad, capitalizamos una cierta cantidad de esa riqueza generada socialmente. Desde esta perspectiva, los procesos de devolución, de continuo enriquecimiento del contexto del que nos nutrimos es más una obligación que una decisión. Evidentemente se trata una (auto)exigencia compleja y problemática, que exige una capacidad de imaginación y organización que todavía dista mucho de haberse alcanzado. Evidentemente, cuando se asume que la naturaleza de nuestra producción 
es social y colectiva, se pone en tensión todo un modelo de organización empresarial basado en la producción de marca y en la capitalización individual.

A estos elementos habría que añadir, por supuesto, la dimensión institucional que define el marco y también en buena medida el funcionamiento del sector. Las políticas culturales operan conscientemente sobre las presiones que experimentamos los trabajadores culturales. En buena medida, son responsables de la actual situación por medio de la promoción del «emprendizaje» y del fomento del autoempleo en cultura, así como de la generalización de las prácticas de externalización y subcontratación. Desde el lado de los trabajadores, la asunción del discurso del emprendedor y de la autoempresarialización señala no sólo el último éxito de estas políticas, sino que también simboliza la última trampilla que los trabajadores del sector cierran sobre sí: la individualización como marca y el sujeto productor como singularidad irreductible. La ausencia de conflictos y luchas contribuye también a ocultar la «verdad» colectiva de los trabajadores culturales como sujetos explotados, aunque sea a su propio cargo y por su propia responsabilidad. La pereza en el diagnóstico colectivo y la incapacidad para pensarse «objetivamente» en una larga cadena productiva es otra de las consecuencias de este fenómeno.

Un último escollo a la organización política del sector, que en muchos relatos aparece como el «primer y principal problema», es la propia inadecuación de la organización sindical a la estructura laboral del sector. Los sindicatos están organizados por «empresa» a partir de grandes colectivos laborales que comparten algunas características comunes, ya sea en relación al tipo de trabajo, la condición laboral o las formas de contratación. A partir de ahí, la organización sindical se escala en ramas y sindicatos de industria. ¿Puede un conjunto laboral segmentado en una multitud de categorías, tipos de actividad, estructurado fundamentalmente en microempresas y trabajo por proyectos, organizarse en nada parecido a lo que fuera un sindicato clásico? Es de nuevo una pregunta que sólo se puede responder a partir de la práctica política.

Hay, no obstante, otro punto de partida de las posibles relaciones entre política y cultura, que no pasa por los «profesionales», esto es, por aquéllos y aquéllas que han convertido alguna habilidad o recurso «creativo» en su profesión. Se trata de la producción amateur y underground, en la que la diferencia entre la comunidad social y los «creativos» todavía no se ha producido, y en la que las urgencias de «comer»y de «mantener la empresa» se resuelven desde otros lugares. La enorme ventaja de esta otra perspectiva es que aquí lo que se pone en el centro es la creación y su sentido. En un marco, en el que la producción cultural se vuelve cada vez más banal, y en el que la producción sustantiva se disuelve en los trends de una innovación vacía, las reivindicaciones y demandas que surgen de las comunidades creativas, por ejemplo las alojadas en centros sociales okupados o no, se convierte en una lucha directa por una «producción» cultural directamente empotrada en dinámicas sociales y políticas. Se convierte en una lucha por recursos colectivos para la creación colectiva: en una lucha por un emergente procomún cultural. 


\section{6. ¿Nuevos pasos?}

De las ideas recogidas en este informe, sugerimos algunos posibles pasos para el futuro próximo:

- $\quad$ Si bien los encuentros de este tipo son tan positivos como escasos, es tal vez pertinente centrar mejor algunas cuestiones que pueden ayudar a provocar un análisis más ajustado sobre la situación del sector. Como ya hemos señalado, es preciso desarrollar diagnósticos amplios sobre la realidad del sector que comprendan las formas de contratación, los modelos de explotación del trabajo y la propia circulación monetaria en la producción cultural. Del mismo modo, se podrían proponer modificaciones concretas de las políticas culturales, los modelos contratación o mecanismos paliativos de la externalización laboral.

- Este primer encuentro se definió sobre la base de la elaboración de un diagnóstico compartido, y no como un programa de investigación. Una estructura futura para un encuentro de características y propósitos similares, podría tomar, en paralelo a las dinámicas de discusión colectiva, consideraciones metodológicas más cercanas al proceso de investigación. La utilización herramientas para recabar información, como encuestas y entrevistas entre los participantes pero, de manera más amplia, entre otros agentes y trabajadores de las instituciones culturales, puede dotarnos de un cuerpo empírico mucho más potente a la hora de ilustrar y reconocer los problemas generales del sector.

- Por lo general, en los diagnósticos sobre la situación del sector cultural subyace una lógica «gremialista» que apunta más sobre problemas corporativos que sobre un discurso crítico más amplio. La incorporación de miradas externas, provistas por agentes que provienen de otros ámbitos, puede servir para romper la excesiva endogamia que padecen nuestras reivindicaciones, así como para generar alianzas políticas y sindicales con colectivos laborales que sufren situaciones precariedad y explotación similares a las nuestras.

- Igualmente, es urgente la producción de textos que sirvan de base para la discusión colectiva respecto a temas tan acucientes como la precariedad en el sector, las nuevas formas de empresarialidad, la cultura como derecho, etc. La recopilación y la generación de estos textos es otra de las asignaturas pendientes sobre la que los coordinadores de estas primeras jornadas querríamos trabajar en un futuro próximo.

- Por último, y con una fuerte transversalidad respecto a los puntos anteriores, parece necesario subvertir el imaginario colectivo que naturaliza modelos embarrados en intereses individuales. Se trata de presupuestos subjetivos nada fáciles de dinamitar y que aparecen casi de forma automática. Sin embargo, cuando se introducen dinámicas de reconocimiento colectivo y prácticas cooperativas que provienen de otras tradiciones (economía social, economía solidaria, movimientos sociales) aparecen puntos de vista más sugerentes y políticamente productivos. 


\section{Otros informes y opiniones}

- Felipe G. Gil/ ZEMOS98 http://equipo.zemos98.org/Vivir-asi-es-morir-de-amor

- María Ptqk http://ptqkblogzine.blogspot.com/2010/08/informe-sobre-empresasculturales.html

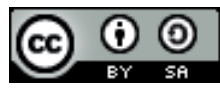

Reconocimiento-Compartir bajo la misma licencia 3.0 España www.paraquienesdisfrutamostrabajando.net 


\section{ANEXO II}

El Ferrocarril Clandestino piensa con Jacques Rancière 


\section{EL FERROCARRIL CLANDESTINO \\ PIENSA CON JACQUES RANCIÈRE}

\section{Presentación breve del Ferrocarril Clandestino}

\section{Qué pensamos}

En el siglo XIX en Estados Unidos se organizó una red clandestina de personas para facilitar la huída de sus compañeros, amigos o vecinos esclavizados desde el sur a las "zonas libres" del norte. Trabajaban juntos blancos y negros, esclavos, ex-esclavos y blancos "libres", con un objetivo común. No se trataba solo de apoyar a los esclavos, sino de luchar por una sociedad mejor para todos, una sociedad sin esclavitud. Sabían que, aunque se les llamara "esclavos", desde siempre habían sido libres y que su situación de esclavitud suponía una violencia intolerable. Esta organización se llamaba Ferrocarril Clandestino/Subterráneo (en inglés: Underground Railroad)

Hoy vivimos otro tiempo. La esclavitud y el trato desigualitario toman formas diferentes a las de antaño. Pero hoy también sigue siendo imprescindible defender contra viento y marea la misma idea: somos libres e iguales en nuestra dignidad y capacidades, cualquiera que sea nuestro origen. Se trata además de una evidencia palpable en nuestra experiencia cotidiana. Ahora, cuando esta idea evidente es atacada, nos organizamos para mantenerla viva, porque no queremos que dependa de las decisiones más o menos generosas de otros. Vivimos y queremos vivir en común de acuerdo a esta idea, asumiendo sus consecuencias: las oportunidades, y también las dificultades y contradicciones.

Por eso hoy, en deuda con el modo de hacer del Underground Railroad, afirmamos que:

1.- Vivimos juntos, trabajamos juntos, sufrimos la(s) crisis juntos,... y nos organizamos juntos. Con papeles y sin papeles, extranjeros y autóctonos.

2.- Además del apoyo mutuo en nuestra vida cotidiana, buscamos una transformación social y política para todos. No se trata de trabajar para "ellos" sino de construir un "nosotros", una vida en común.

3.- Somos iguales. Quien vive aquí tiene los mismos derechos básicos que quien nace aquí. Ninguna ley, práctica institucional, medida administrativa o penal orientada a regular la residencia y el acceso a derechos básicos puede vulnerar este principio básico indiscutible. 


\section{Quiénes somos}

Desde 2005, personas de aquí y de allá, con o sin experiencia política anterior, nos hemos juntado y coordinado a partir de diferentes dispositivos locales en nuestros barrios (Oficinas de Derechos Sociales, Asesorías, Asociación de Sin Papeles, grupos de vecinos,...). Lo que nos une son nuestras ideas y formas de hacer, más que una estructura sólida o una identidad organizativa cerrada y definida. Por eso funcionamos como una red con diferentes nodos que funcionan con autonomía. Estamos organizados pero no somos un partido político, un sindicato, o una ONG.

\section{Qué hacemos}

Buscamos crear un espacio ciudadano de apoyo entre autóctonos, inmigrantes sin papeles e inmigrantes con papeles para enfrentar las dificultades del día a día, crear vínculos y entendimiento mutuo y, construir alianzas que nos permitan actuar juntos, en batallas grandes y pequeñas, contra las formas de apartheid legal, laboral y social que se están estableciendo en nuestras ciudades. Aspiramos a hacer movimiento con todos aquellos, individuos o grupos, que, con independencia de su origen, consideran necesario actuar frente a las formas de discriminación y arbitrariedad que está generando el régimen de fronteras impulsado por nuestros Estados y apoyado con/en nuestra complicidad y silencio ciudadano.

Nos preocupa la continua invención de trabas burocráticas y administrativas inverosímiles para normalizar nuestra residencia; las redadas indiscriminadas para cazar y amedrentar a personas sin y con papeles; la existencia de centros de internamiento para extranjeros y los abusos que allí se cometen; conseguir y mantener trabajos dignos; la criminalización y estigmatización de los inmigrantes... $\mathrm{y}$, en general, la deriva securitaria, el miedo y la guerra al otro que nos lleva a nuestro empobrecimiento como sociedad.

En cada barrio nos organizamos en grupos de apoyo mutuo en donde inventamos y ponemos en práctica estrategias y mecanismos de autodefensa para sortear las dificultades cotidianas, crear alianzas y ganar apoyos para luchar juntos por cambiar lo que vivimos juntos. Tenemos clases de castellano, asesorías legales y talleres de autoformación. Cuando es necesario, nos organizamos en comisiones de trabajo que funcionan de modo transversal a todos los nodos de la red que formamos.

En esta web puedes ver lo que hemos hecho y lo que nos traemos entre manos: www.ferrocarrilclandestino.net 


\section{Algunas ideas inspiradoras para el Ferrocarril Clandestino más o menos afines a las aportaciones de Jacques Rancière}

\section{a) La actualidad de la política y la igualdad: lo que podemos conseguir hoy, no hay que esperar a mañana.}

En nuestro día a día tratamos de pensar/hacer política desde lo que podemos vivir y sostener ya hoy: ¿qué modo de vida? ¿qué tipo de vínculos? ¿qué formas prácticas de organización en común para salir adelante? Por ejemplo, nos organizamos en pequeños grupos mixtos (personas con papeles, autóctonas o extranjeras, personas sin papeles) para elaborar y poner en práctica mecanismos para sortear las dificultades de la vida cotidiana legales, laborales, judiciales... etc. Así, nos acompañamos en las detenciones (para mediar con la policía en comisaría, con los abogados de oficio,...) en los juicios, en la realización de los innumerables trámites administrativos, pensar posibles opciones laborales...

Nuestra práctica política, pone el acento en lo que podemos vivir ya hoy como iguales y no tanto en la elaboración de un programa o una estrategia para alcanzar un horizonte por venir. No quiere decir que no nos impliquemos o propongamos pequeñas, o grandes, batallas tácticas (la despenalización de la venta ambulante de cds y dvds, modificaciones en las leyes de extranjería, negociaciones con las instituciones... ) pero nuestro modo de actuación pasa por priorizar la construcción de un modo de convivencia más igualitario ya hoy (con sus contradicciones, dificultades, y retos por enfrentar a partir de la constatación de las diferencias que nos atraviesan).

\section{b) La mirada política al "todo" desde "la parte sin parte"}

Hacemos nuestra una cierta lectura "sintomática-estructural" de la noción "de parte sin parte" para evitar una mirada particularista, que sería finalmente mantenedora del orden establecido. Es decir, consideramos que la situación particular de los sin papeles encarna el modo de funcionamiento del todo, y no es por tanto, el resultado de un mal funcionamiento contingente que puede ser corregido dentro la propia lógica de la situación dominante.

Esto lo tratamos de decir en nuestros comunicados y panfletos destacando que lo que está en juego no es la situación particular de un colectivo de personas sino lo que somos y queremos ser todos, el modo de convivencia que somos capaces de construir para todos y cualquiera.

c) La parte sin parte como una creación política, como el resultado, por hacer, de un proceso de subjetivación

Entendemos que no hay nada en nuestra posición en la "estructura social" que suponga una garantía o un privilegio para aparecer como actores políticos, que un actor 
político es el resultado de un trabajo, de una práctica, y no la expresión de algún destino estructural que nos estuviera esperando. Así, aparecer como un actor político es uno de nuestros objetivos principales (un actor capaz, no reducido a la pasividad de sostener un lugar -económico, social, mediático...- que no queremos y no hemos elegido).

Este nuevo lugar que no tiene lugar en lo que hay lo tenemos que construir en el día a día, en nuestras discusiones, asambleas, preparación de nuestras iniciativas concretas... y en nuestro modo de aparición pública. Así, por ejemplo, hemos formado una compañía de teatro con personas sin papeles que representa públicamente en diferentes espacios (teatros, centros culturales, centros sociales, locales de otras asociaciones...). Los que sólo son escuchados como víctimas toman la palabra como artistas. Igualmente en los momentos de aparición en los medios de comunicación (para presentar una iniciativa, defender una propuesta, convocar a una manifestación... ) nos enfrentamos a la demanda explícita para que la persona sin papeles aparezca como una víctima humanitaria, mostrando mediante testimonios personales la dureza de sus condiciones de vida, para que después, periodistas, expertos, analistas, tertulianos puedan realizar su análisis y mostrar la "verdadera" interpretación de la situación. Intentamos, por el contrario, que la persona sin papeles aparezca, no como un sujeto sufriente individual, sino como un analista político de la situación, como portavoz de una batalla política y de iniciativas de cambio, y con un mensaje político que trasladar con voz propia

\section{Nuestros dilemas...}

\section{No hay acción política transformadora sin construir espacios mestizos.}

Apostamos decididamente por el trabajo mestizo, pues entendemos que la verdadera política, aquélla que desafía los órdenes impuestos y da voz a palabras y sujetos silenciados, debe partir de la transformación de nuestras subjetividades de partida.

Sólo desde el contagio mutuo, podremos romper con una visión estática de la política que cree contar con explicaciones para todo porque hay muchas cosas que no ve, e incorporar así nuevas maneras, nuevos códigos, nuevos lenguajes de lo político; podremos ver reflejada la imagen de la posición social que se nos atribuye y, desde ahí, imaginar lo que queremos transformar; podremos, en definitiva, construirnos como sujetos políticos desde un lugar nuevo, propio, compartido. Al dejarse afectar por el otro desdibujamos nuestras posiciones estructurales y nos abrimos a experimentar un nuevo común desde donde entender el presente y pelearse con/contra él.

Sin embargo, en este caminar mestizo, nos encontramos con varias dificultades:

a) Escapar de la idealización de migrantes y autóctonos: a veces, los autóctonos, pensamos a los migrantes como sujetos que, debido a su condición (de 
extranjeros, desarraigo, movilidad, precariedad), serían en sí mismos portadores de una potencia política. Idealizamos al otro extranjero como punta de lanza de la revolución por venir (al que los autóctonos debemos seguir por su valentía, energía y la bondad inherente de sus propósitos vitales). Pero ese movimiento no siempre se da. A veces, el migrante lo que espera del otro que le ayude y de algún modo sirva de puente para logran un cierto bienestar ¿Cómo enfrentar esa doble instumentalización para transformarla en igualdad? Por ejemplo:

- Compañeros migrantes que se acercan a las oficinas de derechos sociales y cuando consiguen lo que necesitaban (cierta información, asesoramiento, clases de castellano) se marchan sin más compromiso. - Ideamos y abanderamos luchas desde las situaciones que los migrantes enuncian como injustas (controles racistas de identidad, centros de internamiento para migrantes) y sin embargo son minoría los que luego se unen a ellas.

b) ¿Cuál es el papel de los blancos, con papeles en esta lucha mestiza? ¿Señalar a quienes no tienen parte y esperar a que lideren la lucha? ¿Tomar postura a favor de una parte y desidentificarte con la parte que te toca...? A veces, se sitúa al blanco autóctono como poseedor de un saber privilegiado sobre la situación que debe guiar a los inmigrantes "extraviados" ante su nueva vida en occidente. Otras veces, por no querer manipular ni decidir por el otro en un debate, nos exasperamos y no entendemos (los autóctonos) por qué "ellos" no participan en debates que consideramos muy importantes para "ellos".

A veces, desde la posición migrante se espera a que los autóctonos marquen el ritmo de la protesta, la campaña o la movilización porque los autóctonos conocerían mejor lo que se puede y lo que no se puede hacer y conseguir. A veces, desde la posición autóctona se espera que los migrantes empujen las luchas porque se considera que deben ser los protagonistas principales mientras que los autóctonos jugarían un papel de apoyo.

c) Hablamos de mestizaje, pero a veces para lograr ciertos objetivos tendemos a usar estratégicamente posiciones estructurales, como las que tenemos como autóctonos: se nos plantea la pregunta sobre todo en luchas concretas como experiencias de brigadas de vecinos que denuncian públicamente a la policía cuando está realizando identificaciones y redadas racistas, intentando que el juego simbólico de vecinos blancos que denuncian a la policía llamen la atención sobre el resto de vecinos. ¿Tiene sentido jugar desde ahí?

d) Partimos de la idea de que las identidades cerradas pueden ser limitantes y excluyentes; compartimos la idea de la política como desidentificación. Sin embargo, en determinados momentos ciertas identidades pueden servir como un primer punto de anclaje, de afirmación de igualdad en un camino 
que luego tienda a la reconstrucción de dichas identidades. Por ejemplo, apoyamos en su día la formación de una asociación de bangladeshíes en Madrid que buscaban apoyar a sus compatriotas en su proyecto migratorio, como un primer paso en su politización que podría llevar luego, en un segundo momento, a la integración de esta asociación dentro de una Asociación de Sin Papeles de Madrid mucho más mestiza. El experimento no funcionó...

e) Las desigualdades de partida: Afirmamos la igualdad de inteligencias como un a priori, pero nos damos cuenta en el camino que muchas veces no nos entendemos (en nuestras prioridades, en nuestros modos de hacer, en nuestra manera de entender un problema,...) aunque estamos seguros de que queremos entendernos. ¿Existe mayor potencialidad política en explicitar esas diferencias, aunque ello suponga ralentizar un proceso de lucha o, al contrario, es mejor seguir adelante en la ilusión de que estamos en lo mismo?

f) Las desigualdades sobrevenidas en la lucha: en un momento de la experiencia, coinciden gentes que apuestan por construir nuevos imaginarios de convivencia y cooperación en pie de igualdad, pero durante el proceso, algunas posiciones empiezan a distanciarse, surgen diferencias y competencias internas (no siempre por una cuestión de criterio, sino también de motivaciones personales: intereses particulares que chocan con lógicas más universales) ¿Cómo trabajar con ellas? ¿se pierde entonces la dimensión política del proceso?

\section{Arenas movedizas: entre los problemas particulares y los desafíos universales.}

En nuestro trabajo cotidiano fijamos tres líneas de trabajo que nos parecen imprescindibles: (1) la solución de problemas particulares en la vida cotidiana, (2) la politización y la producción de conflicto en el ámbito público y (3) el desarrollo de meras experiencias de convivencia, incluso de ocio, que significan la construcción "desde abajo" de una vida en común. Entendemos que ninguna de ellas tiene sentido en sí misma si no es acompañada por las demás, y, sin embargo, en nuestro día a día, lograr entrelazar estas líneas de trabajo se torna una misión harto complicada:

a) En el intento de solucionar dificultades de la vida cotidiana, tememos caer del lado de la victimización y el asistencialismo; no saber o no poder salirnos del humanitarismo e, incluso, en su nombre, legitimar el orden establecido (como, por ejemplo, cuando utilizamos los mismos argumentos que la policía de forma estratégica para lograr que dejen libre a un compañero detenido por no tener papeles; o cuando legitimamos un código penal a cambio de conseguir ciertas reformas que hagan más fácil la vida de los vendedores ambulantes) 
b) En el intento de organizarnos para cambiar la situación social-política tememos caer en una política vacía, que pone voz a la injusticia pero no la desafia, que derive en un activismo político ajeno a la vida concreta y sus dificultades en el día a día.

c) Vivir y estar juntos con nuestros afectos, amistades, divertimentos tampoco está vacío de riesgos: podemos acabar por convertirnos en un grupo de amigos, que disfrutan fiestas, comidas y conciertos juntos pero con dificultades para un compromiso político de vaya más allá.

Así pues, nos preocupa cómo compaginar estas prácticas, que sentimos necesarias, sin caer en extremos que entendemos nos alejan de la política. Pero no es sólo la conjunción de nuestros objetivos (enunciados como blancos, autóctonos) lo que nos tensiona: muchas veces, la tensión viene también del lado de los objetivos del «otro», lo que nos lleva a un nuevo dilema...

- En el momento de la lucha, se enuncia un desafío al orden establecido (adquieren voz propia los que no la tienen, para reclamar derechos que le son negados), pero descubrimos que este desafío busca, a veces, lograr su parte en el orden establecido (por ejemplo, lograr papeles para ganar mucho dinero e invertirlo en una casa o en un consumo que nosotros criticamos). ¿Cómo manejar la tensión entre una mera lucha particular por tener un lugar legítimo en la distribución de partes que ya hay (una práctica que no cuestione el todo, una mera práctica de acomodación -legítima- en la distribución policial) y el objetivo político de subvertir la distribución de partes?

\section{Los mensajes que transmitimos...}

- En este sentido nos preguntamos acerca del papel debe o no debe tener la estrategia en la política... Con frecuencia nos sorprendemos calculando continuamente los efectos que tiene o puede tener lo que decimos/hacemos/su intensidad: midiendo palabras, sopesando los efectos de aquello que decimos, pues sentimos que nuestros desafíos deben llegar más allá de nosotros mismos, ¿pierde o gana potencialidad política la lucha? ¿Cómo orientar nuestros pasos sin estrategia?

- Pese a nuestras reflexiones, no podemos dejar de preguntarnos por la viabilidad discursiva-pública del término igualdad, ya que sentimos que su reiterado uso (manido en los discursos institucionales) ha acabado por vaciarlo de sentido ¿Cómo dotarlo de contenido en nuestros días? ¿Cómo hacer de la igualdad una afirmación movilizadora? 


\section{ANEXO III}

\section{Dossier La Calderería}




\section{LA CALDERERÍA FÁBRICA DE ALTERNATIVAS}

PROPUESTA PARA ACTIVAR Y RENOVAR LA ANTIGUA CALDERERÍA UBICADA EN LOS BAJOS DE LA C/ JERÓNIMO DE MONSORIU NN 88, 90 Y 92, EN EL BARRIO DE AYORA, COMO LABORATORIO DE CULTURA Y ECONOMÍA SOCIAL

Un proyecto de:

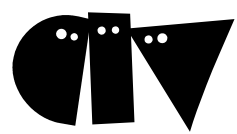

WWW.LACIV.ORG

Cliente:

Hermanos Giner (Invergi 2 SL)

Propuesta realizada por:

Equipo CIV, Coordinadora de Iniciativas Vecinales

Daniel Atienzar

Miguel Angel Bauxauli

Lluis Benlloch

David Estal

Alberto Flores

Inés García

Tania Magro

Domingo Mestre

Mijo Miquel

Francisco Pallardó

Paula Roselló

Adrián Torres

Valencia, 16 de febrero de 2012 


\section{ÍNDICE}

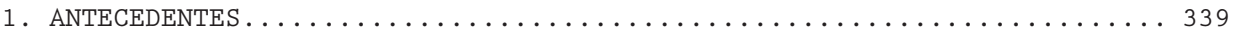

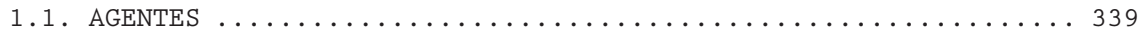

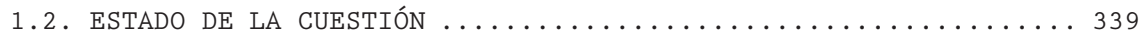

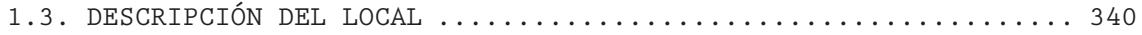

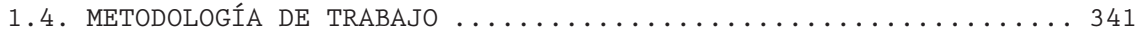

2. ARTICULACIÓN CON EL BARRIO ....................... 342

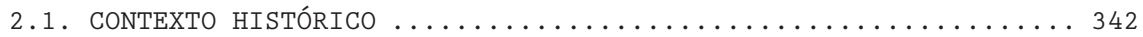

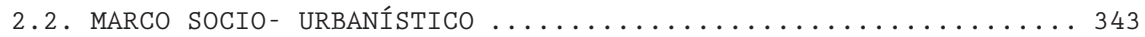

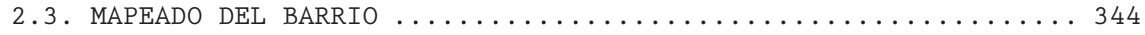

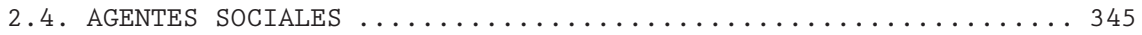

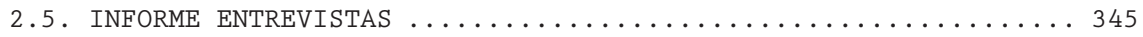

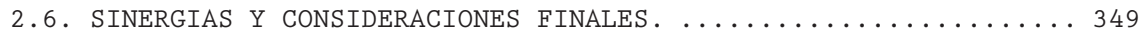

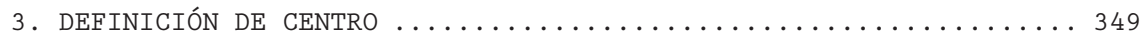

3.1. ORIENTACIONES ESTRATÉGICAS. ESCALA Y GRADUALIDAD ........... 349

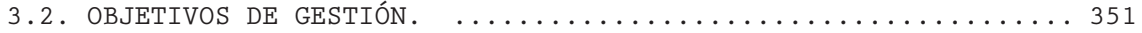

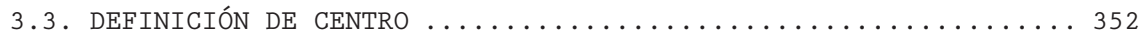

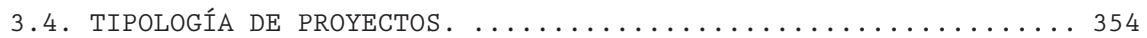

3.5. AVANCE DE LÍNEAS DE PROGRAMACIÓN BÁSICAS $\ldots \ldots \ldots \ldots \ldots \ldots \ldots . \ldots \ldots$

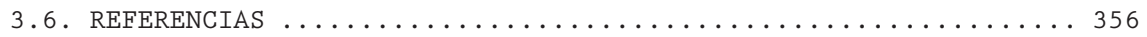

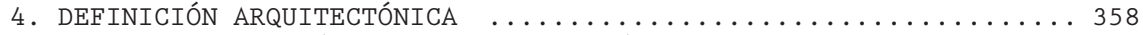

4.1. CONTEXTO URBANÍSTICO. FICHA URBANÍSTICA $\ldots \ldots \ldots \ldots \ldots \ldots \ldots . \ldots \ldots$

4.2. DESCRIPCIÓN DEL LOCAL Y DEL EDIFICIO. ................ 359

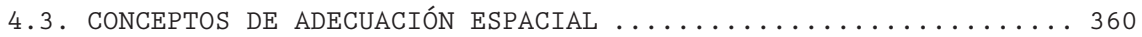

4.4. NECESIDADES PROGRAMÁTICAS. USOS Y DIVISIONES ............. 361

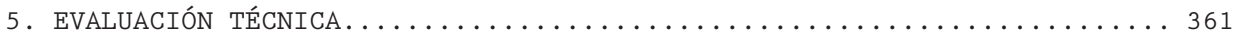

5.1. INFORME DEL ESTADO ACTUAL, PATOLOGÍAS Y PRIORIDAD DE INTERVENCIÓN....... 362

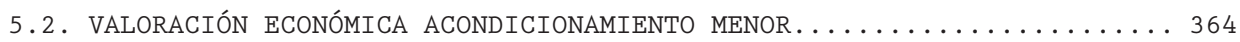

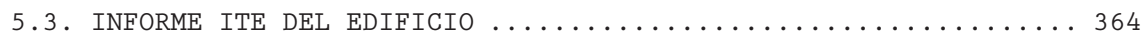

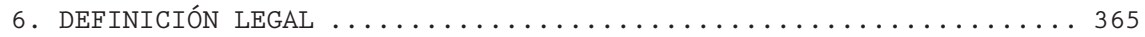

6.1. PLAN DE ACTIVACIÓN .............................. 365

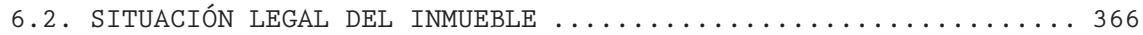

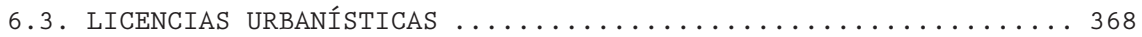

6.4. CONVENIO DE CESIÓN DE USO. COMODATO (FASE 2) ........... 369

6.5. EL CONTRATO DE ARRENDAMIENTO “AD MELIORANDUM"O DE

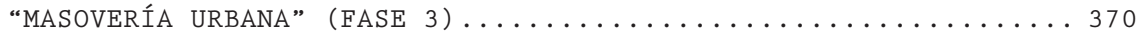

6.6. IMPUESTOS, SEGUROS Y OTRAS DILIGENCIAS. ................ 376

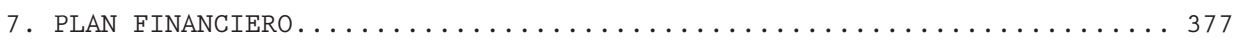

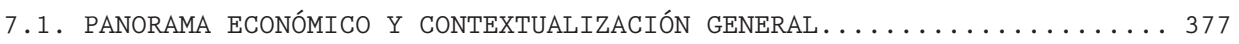

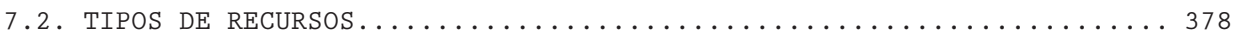

7.3. ANÁLISIS DAFO (DEBILIDADES, AMENAZAS, FORTALEZAS, OPORTUNIDADES) $\ldots \ldots 378$

7.4. LÍNEAS ESTRATÉGICAS DE FINANCIACIÓN PARA LA CALDERERÍA . . . . 380

8. ACCIÓN DE VISIBILIZACIÓN Y ENCUENTRO .................. 381

8.1. ACCIONES SOCIOARTÍSTICAS A CORTO PLAZO DE VISIBILIZACIÓN.

DINÁMICAS PARTICIPATIVAS ......................... 381

8.2. PLANTEAMIENTO CONCRETO DEL ENCUENTRO CIV-CALDERERÍA . . . . . . 381

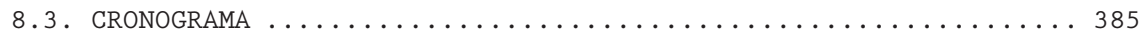

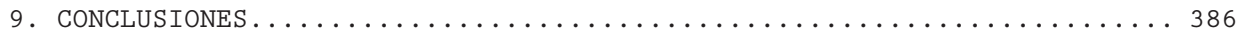

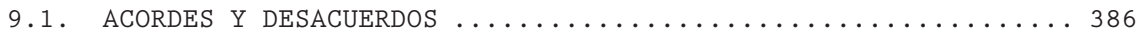

9.2. CRONOGRAMA APROXIMADO DE ACTIVACIÓN ................ 388 


\section{ANTECEDENTES}

\subsection{AGENTES}

\subsection{ESTADO DE LA CUESTIÓN}

1.3 DESCRIPCIÓN DEL LOCAL

\subsection{METODOLOGÍA DE TRABAJO}

\section{ANTECEDENTES}

\subsection{AGENTES}

- Promotor: Nacho Giner, representante de INVERGI 2, S.L.

- Activador: CIV, equipo multidisciplinar (arquitectura, gestión cultural, sociología y antropología).

\subsection{ESTADO DE LA CUESTIÓN}

Dada la delicada situación por la que pasa el sector inmobiliario, el propietario (promotor) propone la cesión del presente local para activarlo de forma contextualizada al equipo (CIV) organizador de 'Comboi a la Fresca', el encuentro realizado en julio en Valencia, dentro de la Red de Arquitecturas Colectivas, en el cual, técnicos, vecinos y agentes sociales propusieron nuevas vías de construcción y regeneración de la ciudad basadas en la gestión participativa del hábitat.

En septiembre de 2011 se aprueba redactar la presente propuesta de colaboración profesional al propietario.

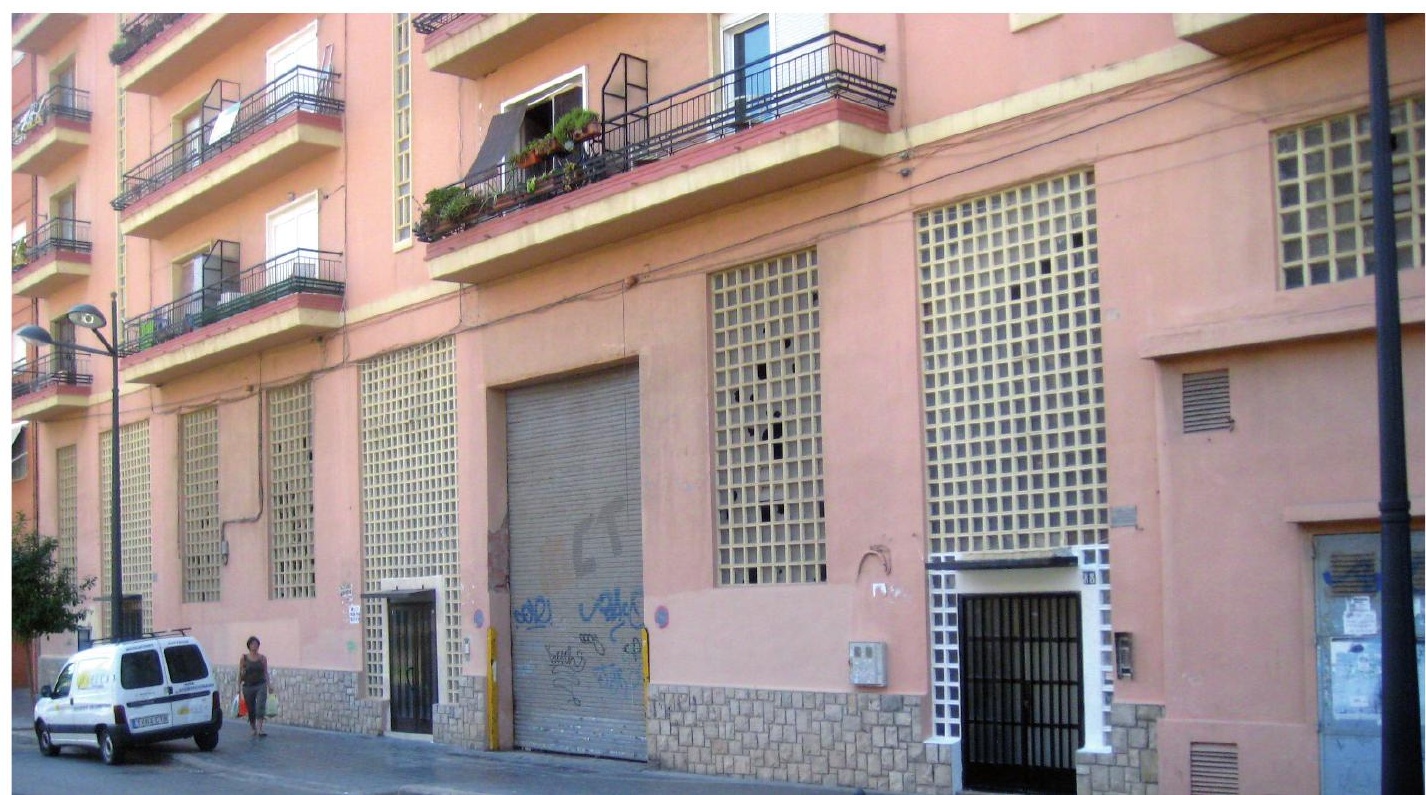




\subsection{DESCRIPCIÓN DEL LOCAL}

\section{- Emplazamiento:}

Calle Jerónimo de Monsoriu, 88, 90 y 92, bajos. Local en planta baja de un edificio de viviendas ubicado estratégicamente a la salida del metro de Serrería, en conexión con el Marítimo y el Centro de Valencia. Además, se encuentra tangente al bulevar de Serrería y cerca del puerto 0 las naves de Juan Verdeguer. Actualmente, se trata de un barrio residencial poco identificado socialmente, bien conectado con el resto de la ciudad, que combina algunos comercios y pequeñas oficinas con talleres herederos de una actividad industrial casi obsoleta en la zona.

\section{- Evolución histórica:}

El edificio donde se ubicaba la calderería se construyó, según ficha catastral, en 1960, acogido a los beneficios de la Ley de julio de 1954 del Instituto Nacional de la Vivienda. Se caracteriza por ser una tipología de bloque aislado, actualmente abrazado en una manzana, como consecuencia de la evolución morfológica del tejido industrial alrededor de las vías de ferrocarril a tejido residencial.

\section{- Descripción:}

Con una superficie de aproximadamente $1000 \mathrm{~m}^{2}$ de planta rectangular y estructura ordenada de hormigón de grandes luces, se trata de un espacio típico a doble altura, donde las oficinas en altillo, a las que se accede por un corredor ventilado por el patio interior de manzana, miran a un espacio tangente de 7,3 m de alto que a su vez vuelca a la calle por su lado mayor a través de diversos ventanales verticales de pavés no practicables, y dos accesos, uno mediante puerta industrial.

\section{- Estado de conservación:}

Aunque la estructura está en buenas condiciones, el espacio presenta patologías visibles de humedad, grietas, cristales rotos, lucernarios caídos y mal estado de la red de evacuación de aguas. Además, carece de la ventilación (natural y forzada) adecuada para la normativa actual.

\section{Vistas del interior de la Calderería}

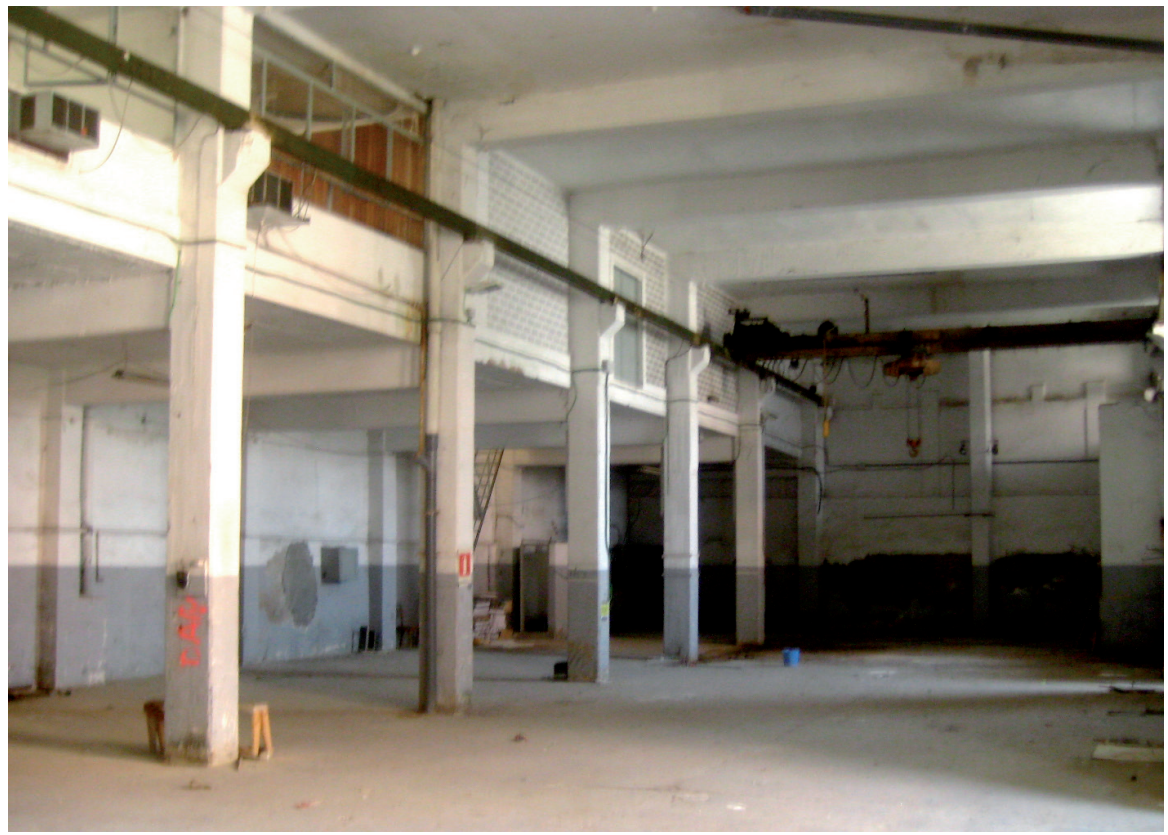




\subsection{METOdOLOGía DE TRABAJO}

Para conseguir el objetivo final de activación del espacio, bajo las condiciones que se establecerán de cesión, masovería y arrendamiento, es necesario conseguir desde el inicio los recursos para la rehabilitación y acondicionamiento del espacio. Ello conllevará una renovación del lugar que, junto con la visibilización del proceso podrá repercutir en el entorno vecinal a la vez que recuperar la inversión realizada con beneficios.

Una vez acondicionado y visibilizado el lugar mediante la realización de un encuentro, la colaboración de socios y la incentivación de la participación ciudadana en el barrio, se consigue potenciar la necesidad de uso del espacio con un contenido adecuado al continente, al barrio y a la situación económica actual. Asi pues, con este proceso, se transformaría 'mientras tanto' la Caldedería en un centro de referencia con carácter polivalente que desarrolle alternativas profesionales, culturales y sociales.

Para llevar a cabo este estudio previo se han desarrollado las siguientes tareas y objetivos parciales que se plantean en la tabla adjunta.

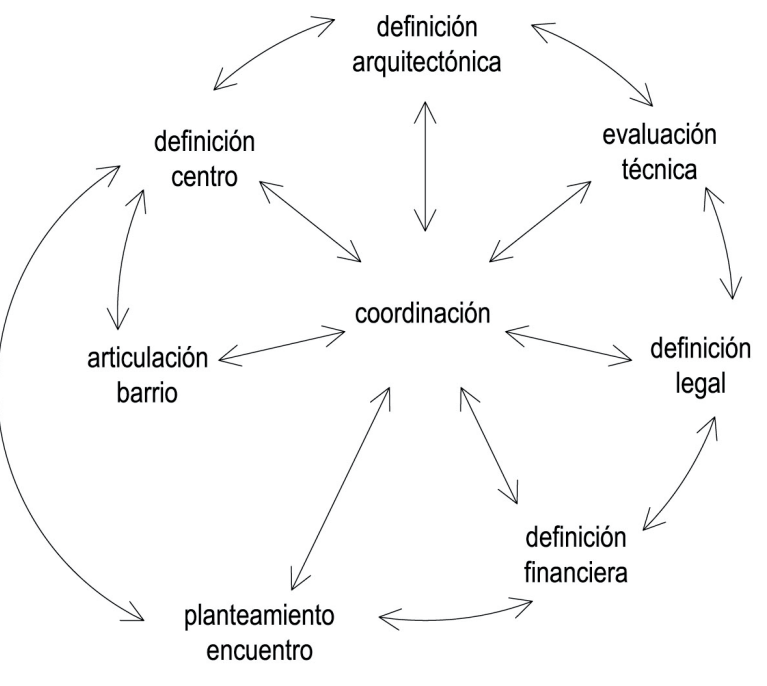

Plano de la Calderería

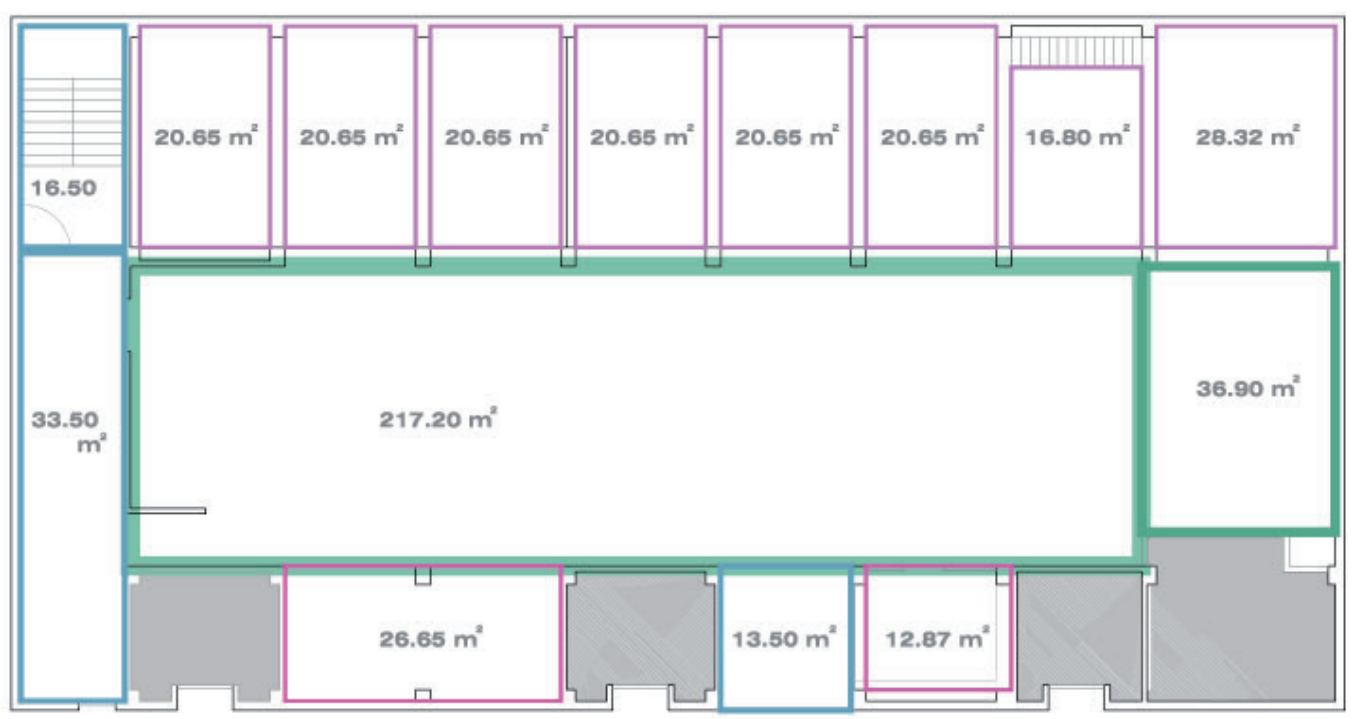




\section{ARTICULACIÓN CON EL BARRIO}

2.1. CONTEXTO HISTÓRICO

2.2. MARCO SOCIO-URBANISTICO

2.3 MAPEADO DEL BARRIO

2.4. ANÁLISIS ESTADÍSTICO

2.5 INFORME ENTREVISTAS

2.6 SINERGIAS Y CONSIDERACIONES FINALES

\section{ARTICULACIÓN CON EL BARRIO}

\subsection{CONTEXTO HISTÓRICO}

El barrio de Ayora está ubicado al Noreste de la ciudad, pertenece al distrito XII llamado Camins al Grao, junto con los barrios de Albors, La creu de Grau, Camí Fondo y Penya Roja.

Hasta el siglo XIX, la huerta de Ayora fue un paisaje apenas poblado, tan sólo vivían algunos habitantes en conjuntos salpicados de casas de campo dispersas, mayoritariamente labradores. Con la construcción de la vía Camí Vell del Grau (actual Avd. del Puerto), el barrio creció rápidamente mediante la construcción de una serie de almacenes, talleres y factorías, alrededor de esta arteria, que se convertiría en el eje principal entre la ciudad y el puerto. El vell Camí del Grau fue proyectado en 1788 por el arquitecto Vicente Gascó e inaugurado por Carlos IV en 1802 para canalizar el tráfico de los caminos Fondo y Viejo del Grao y revitalizar el puerto. A finales del siglo XIX, El Cami al Grau era una de las vías más transitadas de la ciudad, especialmente durante el verano, cuando la gente se dirigía a la Villanueva del Grao o al Pueblo Nuevo del Mar, como lugares de ocio.

La edificación se fue extendiendo hacia las vías del ferrocarril de Barcelona (1862), actual calle de Serrería, pero no es hasta las décadas de los 60', 70' y 80' cuando en el barrio aparecen dos terceras partes de todas sus edificaciones, en las que se ve el dominio que tuvo la especulación. Los criterios desarrollistas crearon amplias zonas para actividades industriales y barriadas, para acoger a los inmigrantes que llegaban a la ciudad con el objetivo de cubrir los puestos de trabajo ofertados.

Actualmente quedan en el barrio vestigios de la Valencia Burguesa en algunas viviendas cercanas a la Avd del Puerto y otras como en el Palacete y Jardín de Ayora (1900). Los jardines de Ayora y el palacete modernista acompañan la evolución urbanística del barrio desde los planos de 1920 hasta la actualidad, así como las trazas de las calles Conserva e Industria y las paralelas a éstas hasta Serrería. Es de destacar también la traza diagonal de la calle Francisco de Bellvis, que a modo de enganche entre dos barrios, empieza en Ayora, traspasa la calle Serrería y atraviesa transversalmente el barrio del Cabañal hasta llegar al mar. La estructura de calles se ha conformado siguiendo las direcciones de las calles Berenguer Mallol y Conserva, y obviando la dirección diagonal de la calle Francisco de Bellvis, que a su vez era paralela a la carretera local de Algirós.
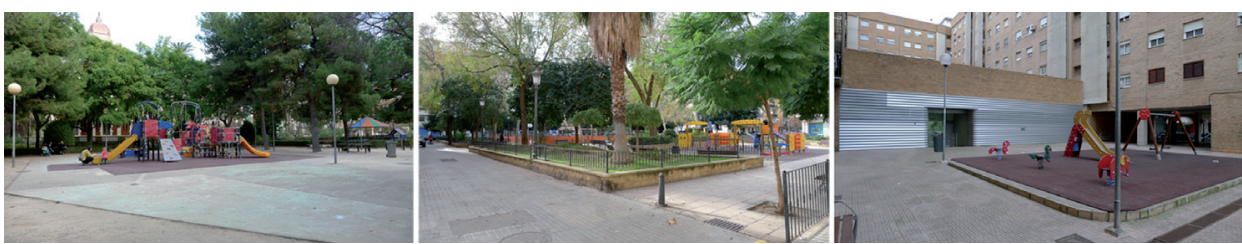
El pasado industrial del barrio permanece en la memoria y también en el plano físico. Algunas calles llevan el nombre de las industrias que antes se encontraban en ellas, como la calle Hierros, la calle Maderas, la calle Serrería o la misma calle Industria. En el barrio se conservan numerosos edificios de antiguas fábricas, algunos rehabilitados para otros usos. Es el caso de la antigua Fábrica de Aceites en la Avd, del Puerto, que actualmente es un edificio de oficinas, o el centro Mentalia. Además, existen numerosas plantas bajas diáfanas y amplias, utilizadas actualmente sobre todo para aparcamientos, talleres de coches y grandes superficies comerciales.

\subsection{MARCO SOCIO-URBANÍSTICO}

Actualmente Ayora es un barrio residencial, con servicios terciarios, sobre todo pequeño comercio, transporte y servicios públicos. Se trata de una zona bien comunicada con el resto de la ciudad mediante autobús, tranvía y metro. Además el carril bici atraviesa el barrio por la calle Jerónimo de Monsoriu y lo rodea por la Avd. del puerto y la calle Serrería. Una estación del servicio Valenbisi está ubicado enfrente de la estación de metro Marítim- Serrería.

El barrio dispone de numerosos equipamientos como colegios, centro de la tercera edad, guarderias, biblioteca, piscina, zonas verdes, jardines y parques infantiles. El centro de salud, el polideportivo y el mercado se encuentran fuera de los límites estrictos del barrio. En cuanto a los centros docentes, son numerosos: escuelas infantiles y primarias, una guardería pública y una guardería concertada. A pesar de la numerosa cantidad de centros docentes siguen faltando plazas para toda la demanda que existe en el barrio pues en cada curso hay pocas plazas y en el barrio hay gran cantidad de niños/as. Una gran parte de la población de Ayora son parejas jóvenes con hijos/as. El Instituto Serpis y el Instituto Sorolla están cerca, pero no estrictamente en los límites del barrio.

Nos encontramos con una gran heterogeneidad en la edificación: vivienda social y vivienda de promoción privada, edificios de diversas alturas y tipologías y edificios de distintas épocas. Son características en la calle Peris Brell las tipologías de vivienda unifamiliar con jardín delantero. Antiguamente en la calle Floresta se encontraban los llamados popularmente "chaletitos de los periodistas", ya desaparecidos y también con la misma tipología. Otra tipología que nos encontramos por el barrio es la de casa patio-taller de principios de siglo XX. Es el caso de las viviendas en la calle José Aguilar, en la calle Conserva y las ya desaparecidas en la calle Guillém Anglesola. De los años 60' aproximadamente, nos encontramos con algunos edificios de vivienda colectiva con espacios intermedios a los que se puede acceder desde la calle y que constituyen un espacio comunitario público muy interesante. Son ejemplos de ello, el edificio de la calle Marino Albesa, cerca de la calle Conserva y el edificio situado entre Victor Moya y Calle Industria. De los años 90' nos encontramos con algunas tipologías de vivienda colectiva con espacios intermedios semi-privados, de acceso restringido a la comunidad y cerrados al exterior. Se trata de las edificaciones más modernas cercanas a la calle Serrería, entre Jerónimo de Monsoriu y la Avd. Del Puerto.
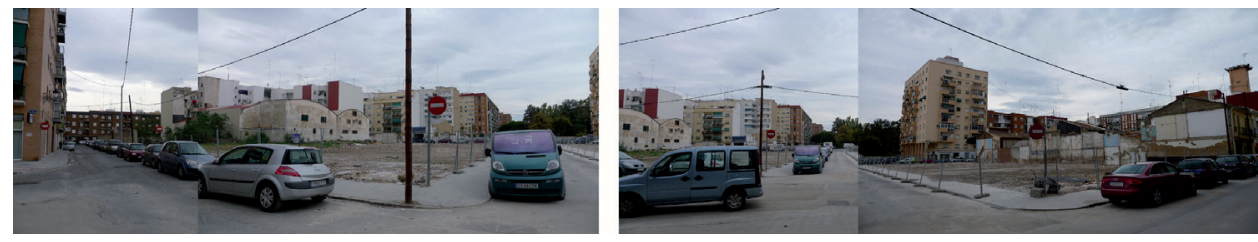


\subsection{MAPEADO DEL BARRIO}

"Hacer mapas sirve para agilizar el trabajo y la reflexión colectiva a la hora de pensar nuestro territorio. Un mapa nos brinda la posibilidad de tomar distancia, de imaginar un vuelo de pájaro que nos facilite descifrar las conexiones entre las diversas problemáticas a fin de cuestionarlas y elaborar alternativas de resistencia, organización y cambio. La cartografía es un proceso en permanente mutación, un punto de partida disponible a ser retomado por otros, una plataforma desde la cual idear otras actividades". Mapeo Colectivo. Iconoclasistas

El mapeo se ha ido desarrollando y completando después de cuatro derivas por el barrio. Estas visitas al territorio analizado se aprovecharon también para realizar las entrevistas con algunas asociaciones y agentes activos. El mapeado ha supuesto una herramienta gráfica que nos ha permitido visibilizar parte de la información que se ha ido recopilando en las distintas derivas, asi como algunos datos extraídos de las entrevistas.

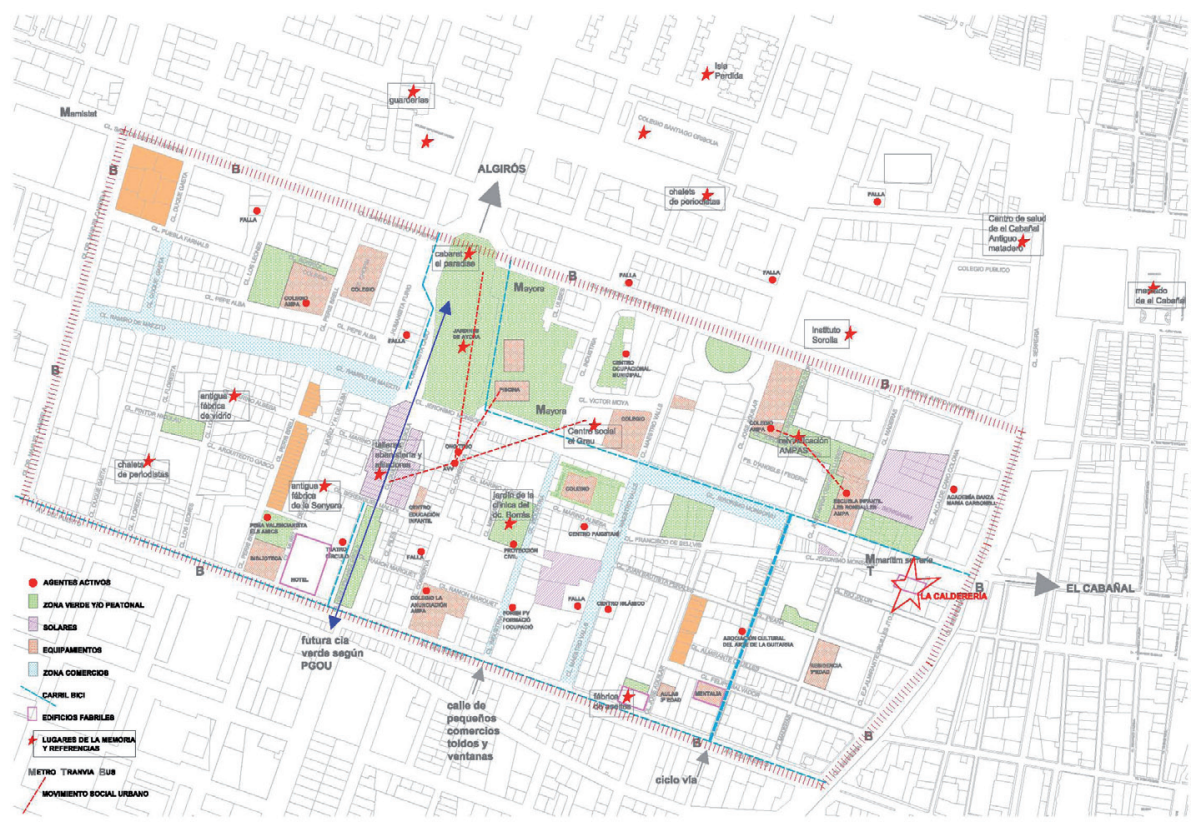




\section{ESTRUCTURA D'EDAT I SEXE.}

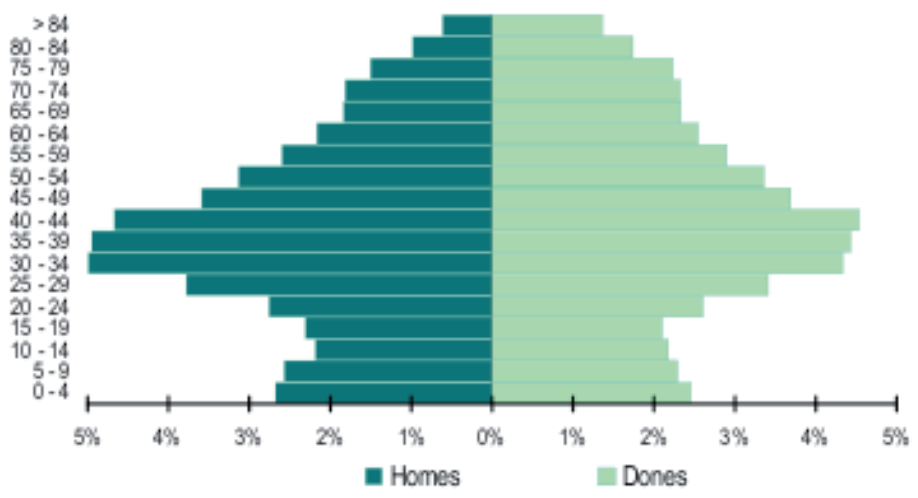

\subsection{AGENTES SOCIALES}

L'ánálisi dels agents socials al barri es pot resumir amb la següent taula.

\begin{tabular}{|l|l|l|l|}
\hline Tipus & Àmbit barrial & Tipus & Àmbit contextual \\
\hline Veïnals & AV. Veïns Aiora & Educatives & $\begin{array}{l}\text { AMPA Aiora } \\
\text { AMPA Rondalles } \\
\text { AMPA Miquel Adlert }\end{array}$ \\
\hline Comercials & -- & Falles & $\begin{array}{l}\text { Mestre Valls } \\
\text { Conservas } \\
\text { Humanista Furió }\end{array}$ \\
\hline Esportives & Club Futbol Algirós & Ètniques & $\begin{array}{l}\text { Centre Islàmic } \\
\text { Centre Paquistaní } \\
\text { Àmigos de la Guitarra }\end{array}$ \\
\hline
\end{tabular}

\subsection{INFORMES ENTREVISTAS}

Documento realizado a partir de las entrevistas a las AMPA's del CEIP Ayora y la Escuela Infantil Les Rondaless, la AV. Ayora-Marítim, la ONG TESO, y las fallas Maestro Valls y Conservas

\section{-NOTAS SOBRE LA HISTORIA}

Según se desprende del análisi de las entrevistas, el barrio era en esa transición de los años 60 a 70 como un "pequeño pueblecito", donde las casas tenian "las puertas abiertas" todo el día, y contaban con animales en casa, como gallinas, pollos, etc... El balance que se hace de aquella época es en cierta manera contradictorio, ya que al mismo tiempo que se recuerda positivamente y con calidez, se califica de "tercer-mundista".

El barrio es definido como un antiguo barrio industrial caracterizado por las fábricas que poblaban la zona. En Ayora estaba la fábrica de aceite, que daba a la Avenida del Puerto; había una importante fábrica de clavos; en Serrería estaba el Matadero (hoy centro de salud). Cerca de la Calderería, había una fábrica de reparación de campanas. Por la zona de la calle conservas, había una de gaseosa. Una de las má grandes era la Fábrica de Águila, ya en el marítimo, y hoy polideportivo del Cabanyal.

La zona de industria y talleres que a partir de los primeros 80 empezaría su traslado hacia los polígonos de fuera de la ciudad, a causa de la modernización de las normas sobre ruido, higiene, medio ambiente, etc... 
Justo en esos años, empieza el desarrollo urbanístico del barrio, en la zona más cercana a Blasco Ibáñez. Es entonces cuando se formó el eje vertebrador hoy de la zona: la calle Ramiro de Maetzu. La zona de Humanista Furió fue habitada por población emigrante proveniente especialmente de Castilla la Mancha, mientras que el ámbito de las calles Conserva, Hierro, etc... fue de oriundos de la ciudad y su entorno, con cierta población valenciano hablante.

Carmen Vila, presidenta de la AV. Ayora-Marítim, destaca como la población trabajadora del barrio ha ido mejorando sus condiciones de vida, de manera que ha abandonado progresivamente las primeras viviendas que construyeron/habitaron en el barrio hacia pisos más acomodados en el mismo barrio.

Ayora destaca por su trayectoria de lucha vecinal en el conjunto de la ciudad. En su seno, nació una de las primeras asociaciones de vecinos de la ciudad, la AV. Ayora-Marítim, que llegó a acoger a más de 100 activistas vecinalews, pero que se fue desgranando poco a poco en diferentes asociaciones que intervenian en diferentes zonas del ámbito Camins al Grau-Marítim. Por tanto, de ahi salieron "AV. la Isla", "AV. La Amistad", "AV. Baleares". Por tanto, estamos ante uno de los barrios embrionarios del asociacionismo vecinal de la ciudad, que además contó en su local con auténtico centro de barrio con escuela de música, de baile, etc... Entre estas iniciativas, destacó en los años 80 la escuela de mediación para casos de violencia de género en el barrio,

\section{- LAS LUCHAS VECINALES}

Desde la Asociación de Vecinos, se recuerdan las principales luchas que ha vivido el barrio en aras de una mejora de las condiciones de vida y los equipamientos de la zona. Una de las más recordadas es la batalla por la mejora de los centros educativos. En concreto, se recuerda como el colegio primogénito de la zona, el Jaume I, se situaba en diferentes plazas interiores, caracteristicas del barrio, en el interior de manzanas de edificios. Las condiciones eran fatales. Como resultado de las protestas, se consiguió que se hicieran varios colegios que acogieran a los alumnos del mismo (Miquel Adlert, Grabador Planes, Centro social del Grao...).

Pero entre todas las reivindicaciones de los vecino del barrio la que más sobresale es la que gira entorno el Palacete de Ayora, probablementre uno de los pocos referentes del barrio. A finales de los 70, el palacete fue adquirido por un empreario del ocio nocturno que lo convirtió en "Cabaret Le Paradis", convirtiéndose en un conocido local de la noche valenciana en medio de la huerta valenciana, incluso punto de referencia de la primera movida de la ruta destroy. Los vecinos ante la juergas, fiestas y problemas que de ello se derivaban iniciaron una serie de protestas encaminadas a conseguir su cierre. Carmen Vila recuerda las procesiones nocturnas con velas que cortaban el tránisto en mitad de las huertas de Ayora.

Ricard Pérez Casado facilitó la titularidad pública del palacete, pasando a ser entonces "L'escoleta", una guardería para las familias más desfavorecidas del entorno. El presidente de la AV era el presidente del patronato de la guardería, por lo que ésta guardaba una fuerte implicación con la comunidad al atender principalmente a aquellas madres de clase trabajadora que iban a trabajar. En los años 90, y con el cambio de color en el consistorio municipal, se privatizó el servicio, que pasó a atender a familias de clase media-alta de la ciudad, tornándose una guardería de moda entre las clases acomodadas. Hoy el centro está cerrado y reclaman para él una ludoteca infantil en sintonia con el parque que lo rodea.

Los años 90 vienen marcados por el intento de mejorar la zona con el resto de la ciudad. Fruto de estas presiones, se consigue una línea de metro que comunica el barrio con el centro de la ciudad, 
y que según todas las entrevistas, y pese a lo que tardó en construirse, ha cambiado mucho la zona. En ese proceso, se consiguió además la piscina cubierta. Estos hechos son ya inseparables del desembarco de Carmen Vila como presidenta de la Federación de Asociaciones de Vecinos de Valencia, y sus coqueteos con los poderes públicos, que ella misma mostró en la entrevista.

\section{- LOS EQUIPAMIENTOS HOY}

En casi todas las entrevistas, la percepción que se tiene hoy de los equipamientos del barrio es muy favorable, destacándose que abarcan muchas áreas. En el barrio y su entorno está la piscina a la que ya se ha hecho referencia, un buen numero de colegios e instituto, una guarderia, una biblioteca (aunque no es conocida por parte del vecindario), un polideportivo cercano (Cabanyal), una universidad popular (Algirós) así como un centro de juventud (Algirós).

El caso de los colegios es bien curioso, ya que en la zona se llegan a contar cuatro colegios públicos. Desde las AMPA's, comentan que a pesar de ello, las plazas en el barrio van muy justas, ya que todos los colegios solo tienen dos grupos por año (Ayora, Miquel Adlert...), eso es, 60 alumnos, e incluso una (Jaume I). Compaginan una en valenciano, y otra en castellano. Esta situación provoca que no puedan absorber totalmente una demanda proveniente de unos vecinos jóvenes con hijos que se han ido a vivir en los últimos años a la zona, especialmente a las nuevas viviendas de las zonas que colindan con Serrería.

Además, hay que tener en cuenta que hay un buen número de centros privados que complementan la oferta existente en la zona. Entre los mismos, se destacan una academia de inglés, una sala de teatro, una academia de danza, una escuela de música y un centro de rehabilitación.

Las AMPAS además reclaman que hay que tener en cuenta todas las actividades que las mismas organizan, de carácter educativo la mayor parte. Son especialmente importantes para los padres y madres para poder comaginar los horarios laborales con los niños/as. En este sentido, en el CEIP Ayora tienen una escuela de verano, una "escola matinera", clases de inglés, de baile... asi como otras más pensada para los padres como, evidentemente, la "escuela de padres", clases de valenciano o capoeira.

Sea como sea, el debate sobre estos temas está presidido por las referencias al desaparecido Centro Social del Grau.

\section{- EL CENTRO SOCIAL DEL GRAU}

Este centro se situaba al lado del Jardín de Ayora, cara a la calle Jerónima de Monsoriu. Era el auténtico dinamizador de la vida del barrio, acogiendo gran parte de las actividades que otrora realizara la asociación de vecinos en su propio local. Es definido como "un aglutinante para el barrio". Alli habian clases de pintura, cerámica, escultura, todo tipo de bailes, música... Era el sitio donde uno podía montar la actividad que quisiese. Tenía también una de las guarderías del barrio y salas grandes que eran aprovechadas por las fallas para sus actividades festivas.

Desde la Asociación de Vecinos, en cambio, se veia con recelo, ya que aducen que las actividades no estaban reguladas, que alli alguien quería montar unas clases, las cobraba y todo el dinero iba para él, se percibía como "un reino de taifas". Esta actítud dañaba el barrio, refiriéndose a los comercios de la zona, a parte de que el centro cada vez estaba cada vez más deteriorado (el ascensor se rompió y cayó dos veces)

En este punto, el discurso de la asociación de vecinos contrasta con el resto de entrevistas a vecinos, a quien supuestamente representa. Ya que mientras unos lo ven como el auténtico referente del barrio, desde la asociación se deseaba la regulación o cierre del mismo. 
Hacia el año 2004, se detectó aluminosis en el edificio teniendo que ser cerrado. Desde entonces, han habido periodos intermitentes en los que ha habido obras y otros en los que no. A día de hoy, y a pesar de las promesas del ayuntamiento, el edificio sigue cerrado.

Más allá de todas las actividades que acogía y de ser el pulmón asociativo de la zona, desde las AMPA's se repite la idea de que actuaba como referente en un barrio que carece de los mismos...

\section{- REFERENTES E IDENTIDADES}

Efectivamente, en las diferentes entrevistas al tejido asociativo del barrio, no solo se comprueba este hecho sinó que además se percibe nitidamente las identiades múltiples que conjugan los vecinos de la zona delimitada administrativamente como Ayora. Y es que este entorno parece sufrir fuerzas centripetas en lo que concierne a la identidad, que lleva a los vecinos a definirse por zonas externas al barrio. Así pues, aquellos que habitan en la parte más arrimada a Algirós, hablan de éste como si fuese su barrio. Igual ocurre con la parte más cercana al Marítimo, que se reclaman de alli, y además, dicen tener una fuerte identidad de ese lugar. Pero otro tanto ocurre con la Avenida del Puerto, que actua como referente para los que viven cerca de ella. La falta de una identidad en el interior de la zona, hace que los vecinos acudan al entorno a buscarla. Ayora se diluye en pos de potenciar los barrios limitrofes.

Este hecho se refuerza con otros elementos, por ejemplo, con el hecho de que no haya fiestas de barrio ni apenas asociaciones que cubran el ámbito del barrio, una vez constatada la decadencia, sino cierre de la tiempo atrás poderosa asociación de vecinos. Mari Carmen, presidenta del AMPA del CEIP Ayora aporta otro argumento interesante. Para ella, se nota mucho que una gran mayoría de vecinos de la zona son emigrantes de regiones del interior de la Comunidad Valenciana o de otras Comunidades Autónomas, de manera que los fines de semana, puentes y vacaciones se marchan allí. Entraría en juego, pues, también las dobles identidades de las poblaciones migrantes, que en el caso del éxodo rural español, aún mantienen lealtades y pertenenencias muy fuerte hacia sus pueblos de origen.

Para Mónica, presidenta de la AMPA de les Rondalles, serán "nuestros hijos" los que cambiarán esta dinámica, ya que ellos harán vida en el barrio. Partes de Ayora "se están haciendo ahora", y necesitan un elemento aglutinador en ese hacerse contemporáneo.

\section{-DEL EQUIPAMIENTO A LA INSEGURIDAD}

Preguntados por las necesidades del barrio hoy, y una vez resuelto el tema de los equipamientos, los discursos de los vecinos se dirigen al tema de la seguridad, necesidad constante en los discursos sobre la ciudad hoy en día.

El eje temporal que los vecinos dibujan en este sentido tiene un antés y un después en la demolición de las casas bajas de Guillem Anglesola, las cuales, una vez expropiadas, se habian convertido para los vecinos en un foco de "trapicheo de drogas", insalubridad e insegruidad al estar ocupado por población gitana y migrante.

Una vez "solucionado" este aspecto, los vecinos describen la seguridad del barrio como bastante buena, "no hay muchas noticias de robos y tirones". Según Concha, presidenta de la Falla Maestro Valls, "ahora hay más inmigración extranjera, no nos juntamos con ellos ni ellos con nosotros. Viven en el barrio sin más. No ha habido ningún problema entre nosotros. Se convive bien" al mismo tiempo se declara expectante de como reaccionará el centro islámico que hay delante del casal de su falla cuando lleguen las fiestas, ya que este año erá el primero de convivencia de los dos locales. 
Hay zonas del barrio donde la inmigración es mucho más visible que en otras, como se desprende de las escasas referencias que se hace al tema por parte de las asocaciones de padres y madres de la zona nueva cercana a Santos Justo y Pastor, que llegan a afirmar que apenas hay niños de población migrante en sus colegios.

\subsection{SINERGIAS Y CONSIDERACIONES FINALES}

\subsubsection{SITUACIÓN}

La Calderería está situada frente a una de las vías principales de acceso al barrio, la Calle Jerónimo de Monsoriu, eje comercial y dinámico, de tráfico controlado. La parada de metro y tranvía se sitúa justo enfrente del edificio, por lo tanto, la Calderería está directamente comunicada con el resto de la ciudad, a 10 minutos del centro urbano. La buena comunicación del espacio amplía el abanico de posibilidades en cuanto a su uso y su proyección e incidencia. Por otro lado, el futuro uso del gran solar que se encuentra enfrente, podría estar relacionado con el uso de La Calderería potenciando así su funcionalidad, visibilidad y posibilidades.

\section{DEFINICIÓN DE CENTRO}

\subsection{ORIENTACIONES ESTRATÉGICAS. ESCALAY GRADUALIDAD 3.2 OBJETIVOS DE GESTIÓN 3.3 DEFINICIÓN DE CENTRO 3.4 TIPOLOGÍA DE PROYECTOS 3.5 AVANCE DE LÍNEAS DE PROGRAMACIÓN BÁSICAS 3.6 REFERENCIAS}

\section{DEFINICIÓN DE CENTRO}

\subsection{ORIENTACIONES ESTRATÉGICAS. ESCALA Y GRADUALIDAD}

La dinamización y uso de La Calderería se establece a partir de una estrategia gradual que debe abordar en el tiempo:

- el arreglo paulatino del espacio.

- la integración progresiva de proyectos diversos en unas líneas de actuación comunes .

- la producción desde dentro de proyectos propios acordes con dichas líneas.

Todo ello en función del objetivo de generar un Centro definido como Laboratorio de Cultura y Economía Social.

CIV plantea a través de esta propuesta de centro un programa de activación para este espacio, en base al ensayo y la experimentación de nuevas formas de organización y uso, dinamizando un vivero de proyectos colaborativos, una especie de caldero de ideas y experiencias alternativas que sirvan para afrontar la salvaje crisis económica en la que estamos inmersos a partir de una trama 
de colaboraciones y alianzas de coproducción. Se plantea para ello la organización continua de charlas informativas y workshops sobre alternativas económicas viables, presentaciones de proyectos innovadores de producción cultural, autoorganización y autogestión, residencias de organizaciones, asociaciones y colectivos con proyectos programáticos viables y adaptados a la modificación de las condiciones económicas, así como iniciativas de capacitación o coordinación del barrio para generar resultados articuladores, autosuficientes y transformadores.

Con la definición del centro como Laboratorio de Cultura y Economía Social se pretende no solamente orientar la dinamización y los usos del espacio hacia unas líneas comunes de actuación, sino generar valor añadido en las propias actividades y usos al integrarse en un proyecto común innovador y con rasgos diferenciadores capaces de hacer de La Calderería una propuesta de centro única y completamente novedosa, un centro de referencia en tanto que Laboratorio vivo de nuevos modos de producción de cultura.

Pero esa sería en todo caso la definición conceptual. El nombre del centro (provisional) podría ser :

LA CALDERERÍA. Fábrica de Alternativas.

Las líneas estratégicas del propio centro se definen entonces como indicadores conceptuales que permitirán aglutinar proyectos e integrarlos en una propuesta común de colaboración en el seno de este Laboratorio colectivo.

Dichos indicadores conceptuales son:

- Economía Social y Economías Alternativas: principalmente Economía Social como concepto generalizado, pero también deben incluirse otras "alternativas económicas" como la economía del bien común, economía solidaria, economías del procomún, democracia económica, acción social comunitaria, etc. Es decir proyectos que favorecen el desarrollo de una economía social, cooperativa y solidaria en la que no se persigue el beneficio privado sino el desarrollo comunitario y del procomún, y a partir de los cuales sectores de la población marginalizados y/o con escasos recursos pueden desarrollar nuevas actividades económicas autónomas.

- Emprendizajes Colectivos. Emprendizaje $=$ aprendizaje colectivo emprendedor de nuevos proyectos económicamente viables. Los Emprendizajes Colectivos son por tanto, en nuestro ámbito, proyectos pedagógicos orientados a la auto-ocupación colectiva en función de los modos de actuación de las Economías Alternativas.

- La Producción Cultural Colaborativa se concibe entonces, a partir de estas premisas, como todas aquellas iniciativas de producción de cultura en las que se privilegian los fines sociales, la cooperación, el trabajo sobre la exclusión (género, migración, etc), la autoconstrucción, el fomento de la autonomía a partir de grupos productivos y redes de consumo, la soberanía alimentaria, la autogestión, el trueque de servicios comunitarios, el arte directamente implicado en procesos sociales de transformación (estética de la emergencia), etc.

Se plantea como punto de partida para este Laboratorio de La Calderería una escala mixta de actuación: barrial y metropolitana. Ahora bien, al tratarse de un proyecto concebido a partir de una estrategia gradual que lo vaya dimensionando en el tiempo, según la dimensión de las actividades que pueda ir promoviendo realmente el centro se accederá probablemente a una escala estatal, en tanto que centro de referencia de determinadas actividades en el ámbito territorial del Estado español. 
Dicha estrategia gradual para dimensionar el centro en el tiempo pasa, en principio, por tres fases fundamentales:

1.El desarrollo de un encuentro (en varias fases) en el cual se procederá a concebir y construir el equipamiento básico del espacio, se dará el primer paso para la visibilización del mismo como un Laboratorio de uso multidisciplinar y se seleccionarán los proyectos susceptibles de integrarse en dicho Laboratorio.

2. A partir de esta integración de proyectos, se plantea entonces, en principio, un modelo pasivo de centro: un lugar de acogida de proyectos e iniciativas que desarrolla una función de mediación y gestión (vivero de proyectos y emprendizajes) para empezar a trabajar desde dentro en la puesta a punto del espacio y en las formas reales de funcionamiento del Laboratorio colectivo.

3. Se plantea una última fase como horizonte de actuación: la conversión progresiva del centro en lugar de producción propia, un modelo activo que pasaria a ser emprendedor de proyectos, es decir a convertirse realmente en un Laboratorio que aglutina y produce propuestas innovadoras en torno a las Economías Alternativas, el Emprendizaje Colectivo y la Producción Cultural Colaborativa.

\subsection{OBJETIVOS DE GESTIÓN}

La CIV será la mediadora con los propietarios del espacio y la responsable de los contratos y de su debido cumplimiento. Ahora bien, a partir del encuentro planteado, y en función de las propuestas alli desarrolladas, es posible que se establezca una entidad jurídica específica de coordinación del Centro y de contratación con los propietarios para el período de masovería. Por lo tanto a partir de ahora hablaremos en este documento de la entidad de gestión como LaCIV (o entidad gestora posterior).

Se plantea en cualquier caso un modelo de gestión desde una perspectiva cotidiana, concepto básico de la gestión cultural que se refiere al planteamiento de la coordinación de las actividades del centro (desde su inicio de actividad y en cada una de sus fases) en términos de operatividad práctica, unos términos cotidianos y funcionales que vayan resolviendo las cuestiones organizativas de manera gradual y según las estrategias previstas.

La CIV (o entidad gestora posterior) se plantea operar como gestora de mediación y coordinación de este Laboratorio colectivo o Fábrica de Alternativas. Su labor debe ser la de coordinación de los procesos colectivos orientados a la organización y el funcionamiento del centro, ejerciendo como mediadora en las diversas fases de la autoconstrucción del espacio y la dinamización de sus actividades en el periodo estipulado de masoveria, hasta alcanzar la autonomía económica y funcional del Laboratorio y su previsible fase final de autogestión colectiva con arrendamiento del espacio.

Las responsabilidades de CIV (o entidad gestora posterior) incluyen entonces, desde esta perspectiva, todo lo referente a la coordinación de los proyectos y a la inclusión del vecindario y de las asociaciones de barrio en la dinámica del Laboratorio, pero también a todos los pormenores de funcionamiento del espacio (arreglo y mantenimiento del espacio, apertura y cierre de puertas, cumplimiento de horarios de las diversas actividades programadas, limpieza y seguridad, etc). 
Durante todo el proceso gradual de habilitación progresiva del espacio y de dinamización de actividades, CIV (o entidad gestora posterior) buscará también todos los apoyos institucionales posibles y los patrocinios viables para ir incorporando alianzas económicas y de financiación capaces de apoyar e impulsar la viabilidad del Laboratorio manteniendo su autonomía de gestión. En función de los frutos obtenidos en dichas posibilidades de financiación, se irán diseñando fórmulas hibridas de colaboración público-privada o de patrocinio, pero en relación de no dependencia.

El desarrollo de una estrategia permanente de búsqueda de patrocinios, tanto para actividades concretas (encuentros, workshops, etc) como para aportaciones más globales a la viabilidad del Laboratorio, debe basarse en que una parte muy importante de la rentabilidad que se puede obtener por parte de los hipotéticos inversores es de tipo simbólico, en forma de visibilidad mediática y de mejora de su imagen corporativa o responsabilidad social, es decir: en forma de publicidad indirecta de las empresas implicadas.

Paralelamente, se plantean una serie de líneas de actuación propias que progresivamente se irán incorporando a la dinámica del centro y que deben permitir hacer viable la labor de coordinación de CIV (o entidad gestora posterior) y las amortizaciones del contrato de masovería, tanto en su carácter de mediadora y dinamizadora de sinergias y de proyectos como en sus responsabilidades operativas de funcionamiento.

Estas líneas están desarrolladas en el punto 3.5.

\subsection{DEFINICIÓN DE CENTRO}

La Calderería se define (tal como hemos expuesto en el punto 3.1.) como un Laboratorio de Cultura y Economía Social. Esa sería la definición conceptual del centro, tal como se ha dicho con anterioridad, que cubre de modo sintético las líneas estratégicas más amplias del propio centro: las Economías Alternativas, el Emprendizaje Colectivo y la Producción Cultural Colaborativa.

El nombre provisional del centro y su definición específica podrian ser:

LA CALDERERÍA. Fábrica de Alternativas

"Esta fábrica es un laboratorio de proyectos y emprendizajes colaborativos en el que apostamos por lo social como principio articulador de la trama urbana y de las relaciones económicas. Pretendemos hacer de este espacio un "caldero" colectivo de ideas e iniciativas prácticas que participe activamente en un modo emergente de producción cultural que está implicado en una economía social efectiva. En La Calderería trabajamos para poder hacer ciudad desde la ciudadanía, impulsando la participación en el tejido de redes de cooperación y de libre intercambio de conocimientos, y experimentando con nuevas formas culturales y económicas a partir de un trabajo colaborativo de producción de alternativas."

Este Laboratorio colectivo, promovido y coordinado por CIV (o entidad gestora posterior), persigue el desarrollo autónomo de nuevas estrategias de colaboración que permitan la producción colaborativa de cultura y que estén vinculadas a formas económicas alternativas (con fines sociales, comunitarios, cooperativos y solidarios) y que impulsen la creación de proyectos viables de emprendizaje colectivo y una reflexión abierta sobre la crisis global de la institución social en su conjunto. 
La Fábrica de Alternativas de La Calderería está abierto a todas aquellas personas fisicas 0 jurídicas sin ánimo de lucro -creadores, agentes culturales y sociales- con capacidad de obrar en colaboración y de impulsar redes productivas y discursivas relacionadas con la implantación de alternativas viables a los modelos culturales y económicos hegemónicos desde cualquier ámbito de actuación (social, creativo o cultural).

El Laboratorio de La Calderería es por tanto un espacio de reflexión abierta y acción productiva colaborativa, receptor/dinamizador de iniciativas sociales y culturales creativas, que se autoconstruye y se organiza de forma orgánica y horizontal. La Calderería quiere aglutinar en su espacio tanto el trabajo de personas físicas como de asociaciones, ONG's, colectivos, equipos de trabajo, artistas, creadores, empresas del procomún, asociaciones o personas cuyo trabajo fomente los valores solidarios, inclusivos, etc... para que compartan una apuesta por el emprendizaje colectivo y el trabajo cooperativo. Compartir o coexistir en un espacio común, un vivero donde desarrollar proyectos propios y/o colectivos con la finalidad de ofrecer y recibir conocimientos y recursos. Laboratorios, talleres, aulas, sedes, espacios colectivos... se ponen a disposición de gente con iniciativa y con necesidad de espacio para desarrollar un proyecto profesional y/o cultural, con la finalidad de generar una oportunidad de trabajo y formación colectiva.

La Fábrica de Alternativas de La Calderería apuesta por lo social como articulador de la trama urbana, en sus dimensiones reales y simbólicas, como un espacio de intercambios equitativos impulsores de un procomún autoconstruido y de una realidad social, económica y cultural alternativa a los actuales modelos hegemónicos. En este sentido, el propio barrio en que se ubica La Calderería (Ayora) es un barrio estratégico tanto por su propia ubicación en la metrópoli como por su caracteristica de ser "un barrio que está por hacer" (sin aglutinantes identitarios sólidos), lo cual nos permite tener como horizonte inmediato de integración en el entorno la producción de las coordenadas alternativas para nuevas articulaciones de dicho barrio.

El Laboratorio de La Calderería, finalmente, se ubica en ese espacio de emergencia de propuestas alternativas a los modelos hegemónicos e impulsa desde una perspectiva multidisciplinar la puesta en marcha de proyectos culturales y sociales con incidencia transformadora en el contexto social. Por este motivo, la estancia y permanencia en el espacio así como las formas posibles de colaboración con el Laboratorio debe ser algo flexible, que se adapte a las necesidades de la gente, desde cesión de espacio para actuaciones puntuales, como la residencia de proyectos por un periodo de tiempo corto o más extenso, en función de los requerimientos de desarrollo de los proyectos y la disponibilidad de las instalaciones.

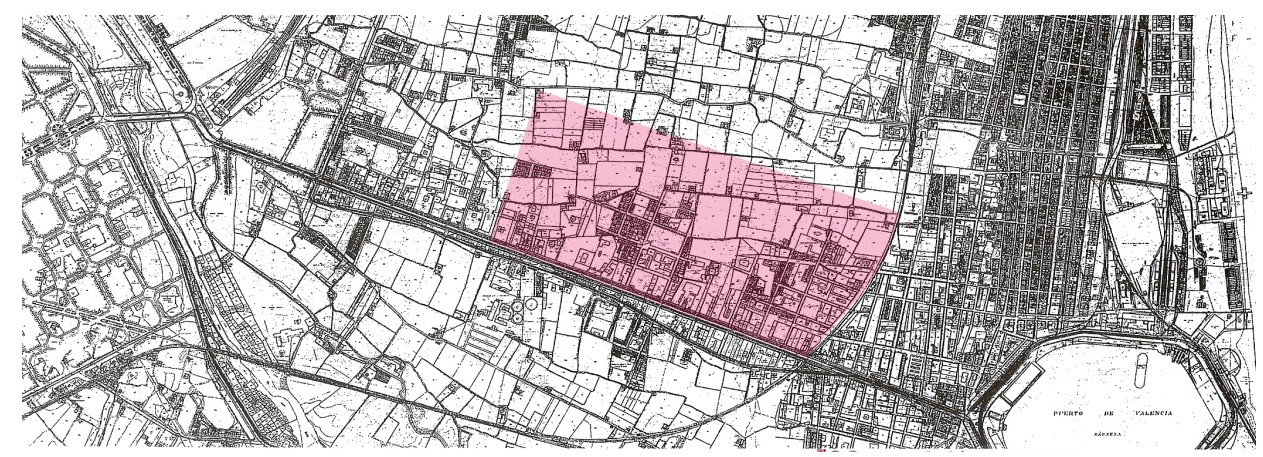




\subsection{TIPOLOGÍA DE PROYECTOS}

La CIV pondrá en marcha en La Caldereria, como venimos diciendo, un Laboratorio de proyectos basados en las Economías Alternativas, el Emprendizaje Colectivo y la Producción Cultural Colaborativa, es decir un Laboratorio de Cultura y Economía Social denominado sintéticamente Fábrica de Alternativas.

Todo lo dicho anteriormente constituye un principio de elaboración de un discurso integrador de todas las dimensiones que se abarcan en este Laboratorio, discurso que debe ir ampliándose y matizándose en función de los desarrollos procesuales previstos. Dentro de esa dinámica integradora, se está realizando un trabajo por parte de CIV, en tanto que proyecto propio inicial, para poner en valor el "simbolismo" del espacio real de La Calderería en relación al mundo del trabajo y visibilizar la genealogía histórica del lugar, configurando con ello una imagen atractiva, responsable y coherente con las líneas conceptuales elaboradas.

Según esas líneas conceptuales que determinan las prácticas del Laboratorio, se genera una integración operativa o una especie de clúster o espacio de coworking que articula alternativas económicas y emprendizajes en cultura y que define la tipología de proyectos integrables, las actividades del centro y sus potenciales alianzas académicas e institucionales. Se pondrá siempre el acento en la noción de integración a todos los niveles: vecinal, laboral, cultural, generacional, genérica, económica, etc, y se implementará en lo posible las pedagogías colectivas como motor de este Espacio de Emprendizaje Colectivo que debe establecer alianzas permanentes con las instituciones académicas (Aula Ciudad).

Se desarrollarán por tanto estrategias que fomenten prácticas efectivas para el emprendizaje mixto academia-ciudadanía. A partir de la colaboración permanente con las instituciones académicas, se potenciará la producción de ecosistemas de aprendizaje, la economía social y la autonomía ciudadana. Ampliando el espectro académico de investigación e intervención social, se generarán proyectos específicos capaces de integrar investigaciones académicas con procesos sociales de transformación (por ejemplo: un proyecto posible de oficios colaborativos que integraría oficios tradicionales con un laboratorio ciudadano multimedia de nuevos oficios).

Parte de la labor de coordinación de proyectos de CIV (o entidad gestora posterior) consistirá en acoger proyectos de movimientos sociales y vecinales y generar "relatos" sobre ello. Se dedicará toda una línea de actuación a la visibilización de problemáticas y la articulación de intervenciones, construyendo permanentemente el relato de la temporalidad del centro y de los procesos que se instituyen. Con ello se pretende integrar en lo posible a los vecinos pero también configurar un espacio novedoso en el ámbito de la ciudad, orientado hacia un lugar de acontecimientos relacionados con el conocimiento libre y que sumen propuestas novedosas al procomún y alternativas económicas viables.

Se privilegiarán en los proyectos, además, los conceptos de transmisión, producción y uso común del conocimiento y las prácticas de talleres de empleo, masovería, nichos de proyectos ciudadanos, seminarios abiertos, open innovation, workshops de autoconstrucción y usos novedosos de los espacios, etc. En esta misma línea se promoverá el desarrollo de procesos socio-artísticos y acontecimientos culturales y pedagógicos para el empoderamiento ciudadano como parte de la estrategia de mediación del centro. Se promoverá asimismo el desarrollo de proyectos de reciclaje y transformación de elementos del barrio.

Para la coordinación de los proyectos del Laboratorio y la dinamización de las sinergias se diseñará un Banco de Tiempo capaz de gestionar las posibilidades de trueque e inversión de 
colaboraciones para la sustentabilidad del espacio y sus tareas de mantenimiento.

Tipología de proyectos que el centro quiere acoger:

- Proyectos de visibilización de la diversidad social y de reconocimiento de las diferencias como base de la convivencia y del desarrollo común de la trama social del barrio, la ciudad y/o el territorio.

- Trabajo con grupos sociales minorizados y/o marginalizados (por ejemplo por su origen étnico o tendencia sexual, género, etc).

- Proyectos de construcción de narrativas de la ciudadanía y los movimientos sociales.

- Proyectos de desarrollo sostenible de la comunidad o territorio con componentes de "economía social".

- Proyectos que implementen las prácticas colaborativas y las pedagogías colectivas como base de los procesos de innovación social realmente creativos e inclusivos.

- Prácticas socio-artísticas, acontecimientos culturales de inclusión colectiva y procesos educativos colaborativos.

- Proyectos de Tecnologías sociales: conjunto de organizaciones, tecnologías, proyectos y prácticas que permiten el desarrollo autónomo de proyectos colectivos y colaborativos.

Tipología de proyectos que el centro quiere producir:

- Desarrollo de proyectos colaborativos en que se favorezcan los flujos relacionales, las nuevas prácticas espaciales y la construcción de un conocimiento común.

- Proyectos con un componente pedagógico, ya sea formal o informal, capaces de desarrollar ecosistemas de aprendizaje para el empoderamiento ciudadano.

- Proyectos de mediación social entre la ciudadanía y las instituciones, especialmente en labores pedagógicas de transmisión bidireccional del conocimiento y el impulso de las hibridaciones de acción.

- Proyectos que fomenten el emprendizaje mixto academia-ciudadanía en nuevos espacios de innovación social y pedagógica.

- Proyectos que fomenten la "economía social" y la innovación en formas de financiación y gestión.

- Proyectos desarrollados bajo la lógica del "código abierto" en lo que se refiere a la documentación, acceso y uso de la información.

- Proyectos y prácticas transdisciplinares que fomenten la "auto-formación" y el emprendizaje colectivo.

- Proyectos colaborativos con instituciones (académicas u otras) que fomenten la autonomía (y no la funcionarización) tanto de los grupos de investigación como de la ciudadanía implicada.

- Proyectos de "educación expandida" y comunidades de aprendizaje: aprender haciendo, aprendizaje basado en problemas y retos específicos (proyectos viables), experimentación en la resolución de problemas próximos y reales.

- Procesos socio-artísticos, diagnósticos participativos, prácticas colaborativas, pedagogías colectivas, prácticas instituyentes, políticas espaciales, culturas emergentes, etc. 


\subsection{AVANCE DE LAS LÍNEAS DE PROGRAMACIÓN BÁSICAS}

Las líneas de programación y actividades del Centro responden de momento a las líneas de actuación propias del punto 3.2.

Estas líneas son:

- Apertura de una cafetería y de un comedor popular (en régimen de Asociación Cultural) e inclusión de máquinas de vending para los espacios comunes.

- Actividades semanales en el Espacio Común para propuestas pedagógicas, seminarios y workshops, talleres populares (danza, yoga, tai-chi, etc), actuaciones puntuales de artes escénicas o música (en horarios compatibles con el vecindario) y funcionamiento como Salón de Actos para asociaciones del barrio.

- Actividades continuas en los espacios de trabajo, donde se desarrollan proyectos concretos en diversas modalidades de implicación en la gestión del Laboratorio.

- Elaboración de un programa de actividades mensual que permita la difusión de las mismas con suficiente antelación y asegure su capacidad de convocatoria.

- Creación de eventos culturales y encuentros pedagógicos y de autoconstrucción susceptibles de recibir patrocinios específicos y financiación institucional puntual.

- Fiestas mensuales o trimestrales de captación de fondos para la autogestión del centro.

\subsection{REFERENCIAS}

\subsubsection{Centros de referencia:}

MediaLab Prado: http://medialab-prado.es/

MediaLab Prado sería la institución de referencia más clara para La Calderería, ya que constituye un centro de producción cultural colaborativa y multidisciplinar que ha singularizado su propuesta con la creación del Ilamado Laboratorio del Procomún. Este Laboratorio tiene como objetivo articular un discurso y una serie de acciones y actividades en torno a este concepto, procomún, una comunidad de recursos que debe ser activamente protegida y gestionada y que busca producir prácticas transformadoras de la realidad económica y cultural, surgido de un espacio orientado a la producción, la investigación y difusión de la cultura digital y del ámbito de confluencia entre arte, ciencia, tecnología y sociedad. La alusión al MediaLab Prado y su Laboratorio del Procomún es pues fundamental en tanto que se ha constituido como una institución que ha logrado integrar una singularidad de proyectos en un centro que es de referencia en el ámbito estatal. Además es un centro con alianzas institucionales muy fuertes como son la Comunidad de Madrid, el Centro de Arte Reina Sofía o el Grupo de Investigación en Cultura Urbana del Departamento de Antropología Social de la UNED (Madrid). Este grupo posee el Proyecto Prácticas culturales emergentes en el Nuevo Madrid (Ministerio de Ciencia e Innovación, CS02009-10780)

http://medialab-prado.es/article/intimidades_metropolitanas

CSA. La Tabacalera Madrid:

http://latabacalera.net/

Matadero Madrid: 
http://www.mataderomadrid.org/

La Fundició (Barcelona):

http://workingimages.org/contenido/la-fundicio-barcelona

LaCasalnvisible(Malaga):

http://www.lainvisible.net/?q=node/17426

CCCB Lab:

http://www.cccb.org/lab/es

PensarT:

http://www.pensart.org/index.php/statement

\subsubsection{Referentes Teóricos (economía social)}

La Federació de Cooperatives del País Valencià; la Red de Economia Alternativa i Solidaria; la Coordinadora Valenciana d'ONG's, etc....

REAS:

http://www.economiasolidaria.org/

Especial Diagonal "Semillas de otra economía":

http://www.diagonalperiodico.net/La-apuesta-delascooperativas.html

CIDEC-UV:

http://www.uv.es/cidec/c/eventos.shtml

Economia Social (wikipedia):

http://es.wikipedia.org/wiki/Econom\%C3\%ADa_social_en_Espa\%C3\%B1a

Jornades cooperativisme Castelló:

http://wiki.casalpopularcs.org/JornadesCooperativisme/JornadesCooperativisme

El VII Congreso de la Red Rulescoop 'Economía social: identidad, desafíos y estrategias' organizado por el Institut Universitari d'Economia Social i Cooperativa de la Universitat de València: http://vlcsocial.es/index.php/es/component/content/article/96-prima-pagina/505-uncongreso-identificara-los-rasgos-y-valores-de-la-economia-social

Colaboratorio Platoniq:

http://youcoop.org/

ZZZINC:

http://zzzinc.net/

Disonancias:

http://www.disonancias.com/es/

Laboratorio del procomún:

http://medialab-prado.es/article/ciudad_y_procomun 


\section{DEFINICIÓN ARQUITECTÓNICA}

\subsection{CONTEXTO URBANISTICO \\ 4.2 DESCRIPCIÓN DEL LOCAL Y DEL EDIFICIO \\ 4.3 PLANOS DEL ESTADO ACTUAL Y SUPERFICIES \\ 4.4 CONCEPTOS DE ADECUACIÓN ESPACIAL \\ 4.5 NECESIDADES PROGRAMÁTICAS. USOS Y DIVISIONES 4.6 PLANOS}

\section{DEFINICIÓN ARQUITECTÓNICA}

\subsection{CONTEXTO URBANÍSTICO}

\subsubsection{DATOS DEL EMPLAZAMIENTO}

UBICACIÓN: Calle Jerónimo de Monsoriu, 88, 90 y 92, bajos.

TIPOLOGÍA EDIFICATORIA: Bloque aislado en configuración de manzana. (PB: Comercial + Vivienda Social)

ESPACIO/LOCAL: Planta baja de edificio de viviendas ubicado en el Bo de Ayora .

\subsubsection{ENTORNO FÍSICO}

El espacio que ocupa la antigua Calderería se encuentra ubicado en el Barrio de Camins al Grau de Valencia. Se trata de una de las zonas que más sufrieron el desarrollismo de los años 60 y 70 en la ciudad de Valencia, tejida a partir de edificios residenciales desarrollados en altura que absorbieron y en algún caso, como es el de la Calderería, albergaron pequeñas estructuras de carácter industrial.

La estructura de sistema de barrio combina vías muy secundarias de escasa sección y heredadas de trazados anteriores, con grandes vías, como es el caso de Serrería o la Av. Del Puerto, que conectan el barrio con el resto de la ciudad y contienen un importante flujo de tráfico rodado

Con respecto al entorno más inmediato al edificio, la calle Jerónimo Monsoriu cuenta con una importante sección, por lo que se garantiza un acceso adecuado a la obra.

Por otra parte, la calle en la que se ubica el edificio cuenta con todos los servicios necesarios de suministro de electricidad, agua y de saneamiento.

\subsubsection{NORMATIVA URBANISTICA. FICHA URBANISTICA}

El suelo en el que se ubica el edificio objeto el presente proyecto de activación, dentro de Clases de suelo, s e clasifica como Suelo Urbano (S.U.), y dentro de la Zonas de clasificación urbanistica como Zona de Ensanche (ENS-1) en el PGOU de Valencia (aprobación definitiva el 28 de Diciembre de 1988). El uso global o dominante de esta Zona es el de Residencial plurifamiliar (Rpf) 


\subsection{DESCRIPCIÓN DEL LOCAL Y DEL EDIFICIO}

Como ya se ha comentado con anterioridad el local que es objeto de este proyecto se encuentra en el bajo de un edificio de viviendas. A pesar de esta ubicación, la importante altura y su estructura en planta hacen que el espacio que se genera cuente con las caracteristicas propias de los edificios de tipología puramente industrial.

La disposición de los diferentes elementos que configuran el local, generan unas unidades espaciales de partida. A continuación se describen las más importantes (ver plano A-01).

\section{UNIDAD ESPACIAL GENERADA 1}

Se trata de la gran sala central. Sus dimensiones en planta son de $32 \times 8 \mathrm{~m}$. y la altura libre es de 7,30 m. Esta gran superficie en planta, libre de compartimentación, genera un espacio de gran riqueza espacial y con múltiples posibilidades no sólo para ser intervenido, sino para ser entendido.

\section{UNIDAD ESPACIAL GENERADA 2}

La posición longitudinal y adosada a la medianera del altillo genera, bajo él, un espacio que recorre toda la longitud de la gran sala central pero con una altura menor, de 4,50 m. Esta diferencia de altura hace que se pueda entender como un espacio de prolongación de la sala central pero con un carácter propio.

\section{UNIDAD ESPACIAL GENERADA 3}

La planta de la calderería se encuentra invadida por los cuerpos que albergan los zaguanes que sirven de entrada a los edificios de viviendas. Estos volúmenes generan una secuencia de entrantes y salientes que hacen entender los espacios entre zaguanes como unidades espaciales propias, aunque su altura es la misma que la de la sala central.

\section{UNIDAD ESPACIAL GENERADA A.1}

Se trata del espacio propio del altillo que, a pesar de su extensa longitud en planta (recorre toda la planta de la calderería en su lado más largo), su compartimentación y una altura libre de $4,30 \mathrm{~m}$., hacen que se generen espacios con una escala más doméstica. También hay que destacar su posición elevada con respecto a la sala central, lo que produce una serie de visuales a tener en cuenta.

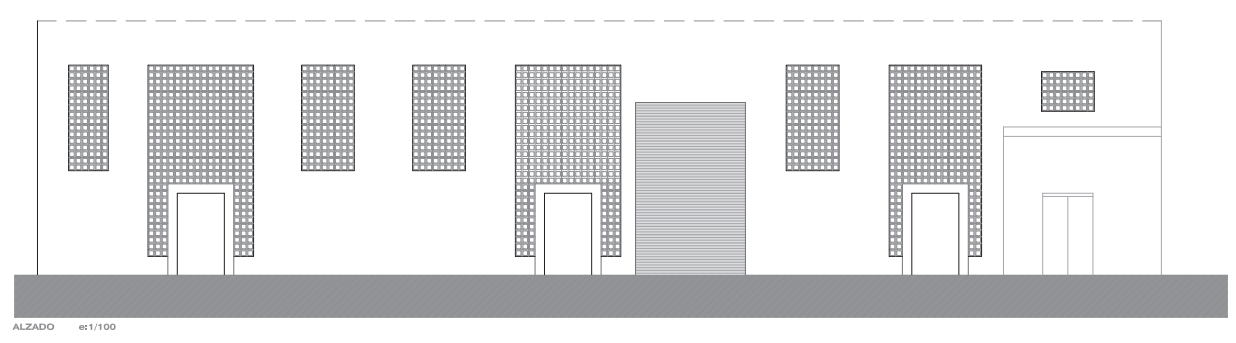


Además de la riqueza espacial con la que cuenta este local también hay que incidir en la gran escala que alcanza la puerta de acceso. Es punto importante a tratar a la hora de abordar los procesos de activación pues las características de este hueco abren un gran abanico de posibilidades en cuanto a los sistemas de acceso y al diálogo con el entorno urbano.

\subsection{CONCEPTOS DE ADECUACIÓN ESPACIAL}

\subsubsection{CUESTION DE ACTITUD HACIA EL ESPACIO}

Por qué?.

Surge la necesidad de generar una concepción amplia de la palabra espacio, "más allá del espacio" y una nueva dimensión no explorada del espacio: lo in-visible

Se plantea la deconstrucción del concepto de espacio desde la construcción del mismo, entendido siempre como algo "por generar".

Enfoque: (de) generación del espacio existente y (re)generación desde un trabajo de percepción.

\section{CONCEPTOS.}

1.-FLEXIBILIDAD trabajándola con el objeto de romper la sensación de compartimentación (que actualmente así se percibe) .

2.-ELIMINAR PARTICIONES FIJAS (las justas e imprescindibles) e incorporar la movilidad a través de elementos-objetos ajenos al espacio percibido

Metodologías de Integración de los conceptos planteados:

- Generando controversias entre la materialidad

- Puntos opuestos: LUZ natural-exceso de artificialidad -sombras

- Objetos travestidos en arquitectura (doble identidad)

Para ello, se trabajará el espacio desde lo Global, desde el enorme marco que supone la Calderería en todasu dimensión con libertad de ordenación, entendiendo esta libertad como lo flexible, sin espacios (pre)definidos y compartimentados.

Trabajar la atmósfera entendida según Zumthor, como una actitud ante el espacio. Será la atmósfera la que describirá la realidad arquitectónica en la medida del grado de seducción inducido desde los objetos y el trabajo de la pequeña escala.

Ausencia de codigos arquitectonicos que aparecerán simplemente como concepto del espacio: espacios intermedios, espacio de transición de espacios, espacios de uso específico, espacios de distancia de otros espacios, espacios de conexión

No al PROGRAMA ARQUITECTONICO y sí a los espacio de provocación.

\subsubsection{ESTRATEGIAS ESPACIALES. JUEGO DE PROVOCACIÓN Y PERCEPCIONES}

A.Elementos de movilidad.

- Puente grua existente. Fijarlo en posición (una o dos posiones dentro de la sala)

- TELON. Como concepto. Tejido, controversia material. (Terciopelo como confort acustico). MOVILIDAD: VERTICAL Y HORIZONTAL. La flexibilidad como libertad en la configuración

- Objetos multi-trans, potenciando el juego de configuracion. 
- RE-VESTIR el espacio generando posibilidades. Uso de Redes-Mallas-Lonas

- Extrapolar ejemplos de apropiación del espacio. HILO CONDUCTOR como delimitador del espacio. Como prolongación de la seducción en el espacio.

B. Texturas espaciales / ESPECIALES:

Jugar con las pre-existentes (naturales) y las nuevas (artificialidad). Provocar la controversia espacial.

C. LUZ. Contrastes natural -artificial desde la provocación espacial.

D. Intrusos en el Espacio. Organización de Uso.

E. Opciones de Reciclaje.

F. Integración de pequeñas opciones.

Fachada. Interior-Exterior. Noche-día. Control de Luz. Nuevo lenguaje de las pequñas cosas. La doble altura como percepción e integración de nuevos puntos de vista y generadoras de nuevas situaciones.

\subsection{NECESIDADES PROGRAMÁTICAS. USOS Y DIVISIONES.}

Se describen a nivel gráfico dos modos de apropiación del espacio:

- Mediante la inserción de tres módulos ocupacionales (p.e.:contenedor), con aperturas diversas e inclusión de funciones. Mediante su ubicación entratégica en el espacio terminará de configurar y prolongar usos diversos apropiándose de sus superficies más inmediatas.

- Mediante el concepto de "reparcelación", por la cuál a través de un módulo mínimo o unidad se plantean "espacies de espacios" a ocupar.

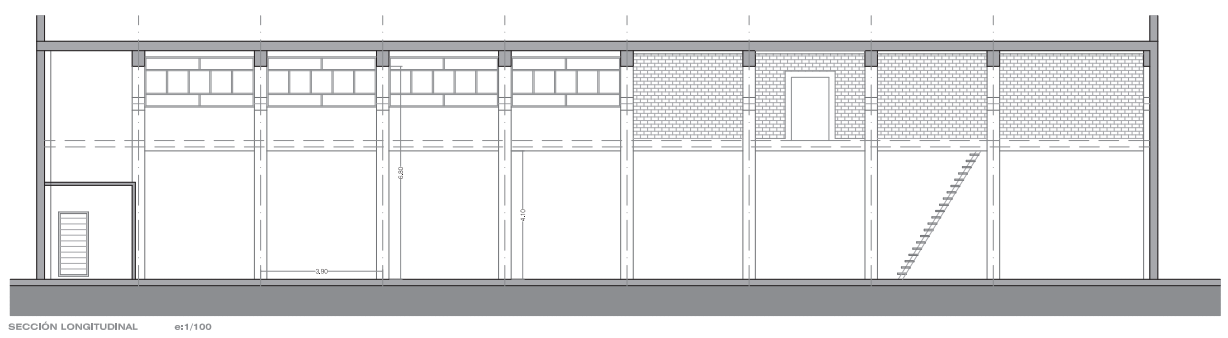

\section{EVALUACIÓN TÉCNICA}

5.1 INFORME DEL ESTADO ACTUAL, PATOLOGÍAS Y PRIORIDAD DE INTERVENCIÓN.

\subsection{VALORACIÓN ECONÓMICA, ACONDICIONAMIENTO MENOR.}

5.3 INFORME ITE DEL EDIFICIO 


\section{EVALUACIÓN TÉCNICA}

\subsection{INFORME DEL ESTADO ACTUAL, PATOLOGÍAS Y PRIORIDAD DE INTERVENCIÓN.}

Tras la inspección técnica se aprecian diferentes patologías, ninguna de ellas es considerada grave, si bien, el estado de conservación es el habitual para locales que no han sido utilizados durante los últimos años, conviene que sean reparadas para prolongar la vida útil del local.

Se ha procedido a clasificar las patologías según a los elementos a los que afecten, a su vez el nivel de importancia ALTA / MEDIA / BAJA se corresponde con la prioridad a la hora de realizar las reparaciones. - DESCRIPCIÓN DE LOS DAÑOS APRECIADOS.

Perdida de sección de armaduras en pilar estructural de Hormigón Armado. Por procesos de corrosión de las armaduras del pilar de hormigón armado se ha producido una pérdida de sección en pilar de planta baja.
CATEGORIA:
ESTRUCTURAL
IMPORTANCIA:
ALTA
REPARACION:
COMUNIDAD PROPIETARIOS.

Humedades en 2 bajantes. Se observan restos de manchas de humedad en el encuentro de la junta de las instalaciones con el tabique, lo que provoca la aparición de manchas de humedad.

CATEGORIA:

INSTALACIONES

IMPORTANCIA:

MEDIA

REPARACION:

COMUNIDAD PROPIETARIOS.

Filtraciones del patio de luces del n90 y n92 de Jerónimo Monsoriu. A causa de estas filtraciones se ha producido el desprendimiento del falso techo de escayola en las oficinas del altillo.
CATEGORIA:
CUBIERTA - IMPERMEABILIZACION
IMPORTANCIA:
MEDIA
A REALIZAR POR:
COMUNIDAD PROPIETARIOS

Último tramo de bajantes del edificio. Realizadas en plomo, por lo que están fuera de normativa y en mal estado con pies y/o cabeza, oxidadas.
CATEGORIA:
INSTALACIONES
IMPORTANCIA:
MEDIA
A REALIZAR POR:
COMUNIDAD PROPIETARIOS

Puerta de acceso al local. Mal estado de conservación, la parte inferior tiene un estado de oxidación avanzado.
CATEGORIA: INSTALACIONES
IMPORTANCIA:
MEDIA
A REALIZAR POR:
PROPIETARIO 
Vidrios en Lucernarios. Existencia de vidrios en lucernario rotos, tanto en fachada delantera como trasera.

$\begin{array}{ll}\text { CATEGORIA: } & \text { ESTETICO } \\ \text { IMPORTANCIA: } & \text { BAJA } \\ \text { A REALIZAR POR: } & \text { PROPIETARIO }\end{array}$

Grietas, fisuras, desconchados de menor entidad. Son fisuras o grietas provocadas por el asiento de la estructura a lo largo del tiempo, o por carga puntuales Para valorar el estado de estas fisuras sería necesario ver su evolución en el tiempo mediante testigos, existen bastantes, pero en principio parece estable por lo que la reparación es sencilla.

$\begin{array}{ll}\text { CATEGORIA: } & \text { ESTETICA } \\ \text { IMPORTANCIA: } & \text { BAJA } \\ \text { A REALIZAR POR: } & \text { CIV }\end{array}$

\section{DESCRIPCIÓN DEL ESTADO DE LAS INSTALACIONES.}

El estado de conservación de las instalaciones es malo o inexistente, las instalaciones interiores de electricidad y fontaneria deben ser revisadas y actualizadas conforme a normativa vigente y a los usos que se estimen. Existen altas previas de electricidad, agua y Teléfono.

La red de saneamiento no consta como conectada a la red general de alcantarillado, su evacuación se realiza por una acequia que discurre longitudinalmente en la parte trasera del bajo. La existencia de malos olores esta generada por la casi total inexistencia de tapas de registro, y las inexistencia de sellado en las arquetas, si bien sería recomendable una limpieza de lodos de la canalización de saneamiento, si bien actualmente cumple con su cometido.

\section{CONCLUSIONES}

A nivel estructural el local se encuentra en buenas condiciones, si bien presenta una patología puntual en unos de los pilares,

Existen patologias debidas a fugas de agua, que provocan humedades, y entradas de agua en el local, con la consiguiente sensación de humedad.

El resto de patologías son consideradas estéticas y de baja importancia.

ayer...

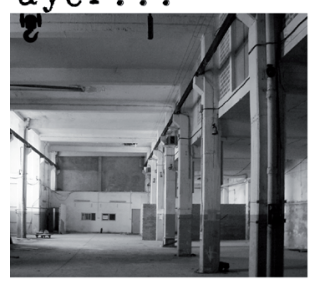

man̄ana

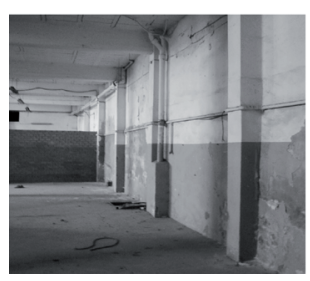

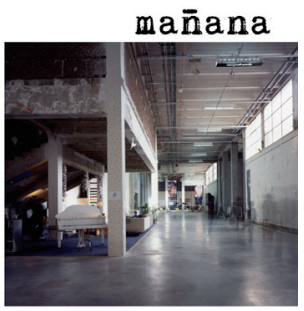

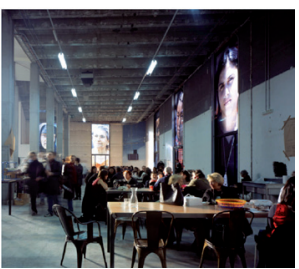




\subsection{VALORACIÓN ECONÓMICA, ACONDICIONAMIENTO MENOR}

Los trabajos mínimos para habilitar el espacio para un uso genérico son:

Por parte de LaCIV.

- Limpieza y eliminación de cableado obsoleto.

- Demolición de tabiques y retirada de escombros.

- Reposición y sellado de tapas de las arquetas de saneamiento.

- Reparaciones de grietas y desconchados de menor entidad.

- Limpieza y pulido de suelo de hormigón.

PRESUPUESTO ORIENTATIVO: 7.000

Por parte de la Comunidad de propietarios.

- Reparación de pilar de hormigón armado.

- Reparación de filtraciones de patio de luces y reponer falsos techos.

- Reparación de bajantes.

Por parte del propietario:

- Reparación de los vidrios rotos en fachada.

- Reparación de puerta de entrada principal.

\subsection{INFORME ITE DEL EDIFICIO}

La ITE (Inspección Técnica del edificio) es una inspección visual realizada por un técnico competente para conocer el estado general de un edificio. Se formaliza en un documento que consta de un INFORME de la inspección realizada y un DICTAMEN final, visado por el correspondiente colegio profesional, con la opinión sonre las condiciones del edificio y los criterios de intervención, el cual deberá entregarse a la propiedad y al Ayuntamiento.

El objetivo es identificar los deterioros producidos por causas exteriores o interiores, vicios, fallos o falta de mantenimiento.

Este trámite obligatorio para edificios de mas de 50 años debe realizarse al menos cada 5 años. La necesidad de llevar a cabo una Inspección Técnica del Edificio es una obligación legal impuesta sobre los propietarios de los edificios y que viene reflejada en la Ley 16/2005 Ley Urbanistica Valenciana.

Según el Artículo. 207, "Inspección periódica de construcciones" de la citada Ley.

1. Los propietarios de toda edificación catalogada o de antigüedad superior 550 años deberán promover, al menos cada cinco años, una inspección, a cargo de facultativo competente, para supervisar su estado de conservación.

2. Dicho facultativo consignará los resultados de su inspección expidiendo un certificado que describa los desperfectos apreciados en el inmueble, sus posibles causas y las medidas prioritarias recomendables para asegurar su estabilidad, seguridad, estanqueidad y 
consolidación estructurales o para mantener o rehabilitar sus dependencias en condiciones de habitabilidad o uso efectivo según el destino propio de ellas. Asimismo dejará constancia del grado de realización de las recomendaciones expresadas con motivo de la anterior inspección periódica. La eficacia del certificado exige remitir copia de él al Ayuntamiento y al Colegio Profesional correspondiente.

3. El Ayuntamiento podrá exigir de los propietarios la exhibición de los certificados actualizados de inspección periódica de construcciones y, si descubriera que éstas no se han efectuado, podrá realizarlas de oficio a costa de los obligados."

En la actualidad el Ayuntamiento no está exigiendo ITE de edificios de más de 50 años para la concesión de licencias administrativas, si bien, es un requisito indispensable para optar a las ayudas de Conselleria de rehabilitación de edificios.

El plan Autonómico de Vivienda 3009-3012 establece ayudas a las comunidades de propietarios para la rehabilitación de los elementos comunes de edificio que pueden alcanzar el 20\% del presupuesto protegido con un límite de 3500 euros por vivienda.

\title{
6. DEFINICIÓN LEGAL
}

\author{
6.1 PLAN DE ACTIVACIÓN \\ 6.2 SITUACIÓN LEGAL DEL INMUEBLE \\ 6.3 LICENCIAS Y PERMISOS NECESARIOS \\ 6.4 CONVENIO DE CESIÓN DE USO COMODATO (FASE 2) \\ 6.5 CONTRATO DE ATTENDAMIENTO "AD MELIORANDUM" \\ 0 DE "MASOVNERÍA URBANA" (FASE 3) \\ 6.6 IMPUESTOS, SEGUROS Y OTRAS DILIGENCIAS
}

\section{DEFINICIÓN LEGAL}

\subsection{PLAN DE ACTIVACIÓN}

La activación y renovación del local propuesta parte de la autonomía de la voluntad existente en el ámbito civil y se fundamenta y configura en la libertad de pactos de la contratación del Derecho Privado con las únicas limitaciones establecidas en las leyes.

El Desarrollo del Plan de Activación en su conjunto tiene por objetivo la realización en un plazo determinado de una serie de acciones que faciliten la activación social y económica del espacio, así como la visibilización y difusión del centro y del proceso. 
El contexto social y económico en el que nace el proyecto conlleva desarrollarlo bajo las premisas básicas y principios orientadores de mínima inversión, bajo coste, reutilización, recuperando y reinterpretando el concepto de trueque en las contraprestaciones no dinerarias o en especie y qué el proyecto sea, a su vez, coherente con el objetivo de una acción responsable sobre el local y de la huella económica y social que deje su nuevo uso.

El Plan de Activación se compone de tres fases:

1a fase

Estudio Básico de Activación y de primera convocatoria y difusión del Encuentro. Fechas noviembre 2011- marzo 201

- Redacción del Estudio Básico de Activación: Definición de centro, Definición arquitectónica, Evaluación técnica, Definición legal del modelo, Articulación con el Barrio y Plan financiero y de viabilidad.

- Planificación y Gestión previa a la organización de un Encuentro colectivo de activación de espacios en desuso que sea motor para el fin indicado.

$2^{\text {a }}$ fase.

Convenio de cesión de uso entre la propiedad del inmueble, como cedente, y la COORDINADORA DE INICIATIVAS VECINALES (CIV), como cesionaria del uso temporal del espacio para el acondicionamiento básico previo del espacio y la preparación y difusión del Encuentro.

Fechas marzo/abril 2012 hasta septiembre/octubre 2012.

$3^{\text {a }}$ fase.

Una vez realizado un primer acondicionamiento previo y visibilizado el espacio mediante la realización del Encuentro previsto, se propone la puesta en disposición del Proyecto de las obras y acondicionamiento y proyecto de Actividades previstas, del acondicionamiento previo básico realizado en la $2^{\text {a }}$ fase, así como el compromiso en la mediación y el asesoramiento de CIV en la firma de un contrato de arrendamiento (o de "masovería urbana") entre la propiedad y la entidad jurídica qué, como consecuencia del Encuentro y su difusión, se constituya para la gestión de "La Calderería" como Centro o bien entidad que siendo preexistente asuma el Proyecto.

Ese contrato de arrendamiento propuesto para la $3^{\text {a }}$ fase tendrá por objeto la realización de obras y acondicionamiento para la mejora del estado del inmueble, qué, al concluir el plazo pactado, quedarán en beneficio del propietario, a cambio de la cesión del goce y uso pacifico del inmueble a la entidad signataria por tiempo determinado.

Fechas septiembre/octubre 2012- septiembre/octubre 2015. Tres años (posibilidad de prorroga).

\subsection{SITUACIÓN LEGAL DEL INMUEBLE}

\subsection{1 ÁMBITO JURÍDICO-CIVIL}

Registro de la Propiedad:

Descripción: FINCA URBANA. Planta baja sin distribución interior, destinada a fines comerciales y con acceso directo desde la calle, del edificio sito en Valencia, calle Jerónimo Monsoriu, números 88,90 y 92 . Tiene una superficie de seiscientos cuarenta y cuatro metros noventa decímetros cuadrados (644,90 m2), una cuota del 16,60 por ciento. 
Titularidad: Pertenece a INVERGI 2, S.L., en cuanto a la totalidad del PLENO DOMINIO adquirida por compraventa según escritura pública otorgada en Valencia, de fecha 23 de marzo de 2004.

Inscripción: Consta inscrita en el Registro de la propiedad no 18 de Valencia, al tomo 2804, libro 627, folio 58, Finca nº 3/ 43540, Inscripción 1a.

Cargas: Libre de cargas.

\subsection{2. ÁMBITO JURÍDICO-ADMINISTRATIVO}

\section{En el Catastro:}

Tres fincas catastrales, una por cada uno de los números de los edificios de los que forman parte. Datos según consulta descriptiva y gráfica de los de los bienes inmuebles de naturaleza urbana: Uso principal: Uso comercial. Año construcción: 1960.

- Ref. 9118203YJ2791G / 0002 / FZ.

Datos del inmueble: CL Jerónimo Monsoriu, n 88. CP. 46022 VALENCIA.

Coeficiente participación: 22,5.

Superficie construida: $344 \mathrm{~m} 2$

Tipo finca al que pertenece el inmueble: división horizontal. Suelo: 252m2.

- Ref. 9118204YJ2791G / 0001 / XB.

Datos del inmueble: CL Jerónimo Monsoriu, n 90. CP. 46022 VALENCIA.

Coeficiente participación: 22,5.

Superficie construida: $342 \mathrm{~m} 2$.

Tipo finca al que pertenece el inmueble: división horizontal. Suelo: 237m2.

- Ref. 9118205YJ2791G / 0001 / IB.

Datos del inmueble: CL Jerónimo Monsoriu, no 92. CP. 46022 VALENCIA.

Coeficiente participación: 22,5.

Superficie construida: $292 \mathrm{~m} 2$.

Tipo finca al que pertenece el inmueble: división horizontal. Suelo: $207 \mathrm{~m} 2$.

\section{CIRCUNSTANCIAS URBANISTICAS:}

De acuerdo con el Plan General de Ordenación Urbana (PGOU) de Valencia (BOE 14/01/1989 DOGV 03/05/1993):

Clasificación: Suelo urbano.

Calificado como Ensanche (ENS).

Uso global: Residencial plurifamiliar (Rpf.)

Usos permitidos y prohibidos: Los establecidos en el Art. 6.17 de las Normas Urbanisticas del PGOU de Valencia.

A continuación, y a expensas del pertinente informe de compatibilidad urbanistica del Ayuntamiento, se señalan aquellos Usos compatibles que destacan por resultar acordes a las características del inmueble y en subrayado los propios del inmueble: 
a) Almacenes compatibles con la vivienda (Alm.1).

b) Locales industriales compatibles con la vivienda (Ind.1).

c) Aparcamientos de uso público o privado (Par.1).

d) Aparcamientos expresamente vinculados a vehículos destinados al transporte colectivo de viajeros y/o al transporte de mercancías (Par.2).

g) Uso Comercial compatible con la vivienda (Tco.1).

i) Locales de oficina (Tof.2).

j) Actividades recreativas. (Tre.)

k) Dotacionales. (D.)

Respecto a la calificación de protección oficial subvencionada que aparece en la inscripción registral del inmueble, no precisa solicitud de descalificación al ser de fecha anterior al Real Decreto Ley 31/1978, de 31 de octubre, sobre política de vivienda, y tienen el precio de venta libre (Art. 1 del Real Decreto 727/1993, de 14 de mayo (BOE no 130, de 1/6/1993).

\subsection{LICENCIAS URBANÍSTICAS}

La cesionaria del uso promotora de obras y acondicionamiento que mejoren el estado actual del local en las fases previstas, y promotora de las actividades o servicios a desarrollar en el mismo, solicitará por si misma 0 a través de tercera/s personas o entidades que la sustituyan las licencias urbanísticas que sean necesarias, tanto para las actividades o servicios a desarrollar en el local arrendado como para la ejecución de la obras de mejora que se convengan.

La validez del convenio de cesión de uso, así como contrato de arrendamiento que pueda iniciar la $3^{\text {a }}$ fase del Plan se supeditará, mediante cláusula específica, a la pertinente obtención de la compatibilidad urbanística y de las licencias urbanisticas necesarias para las obras y actividad/ es o servicios a desarrollar en el inmueble.

\subsubsection{USOS, ACTIVIDADES Y/O SERVICIOS:}

Respecto a los Usos, Actividades o Servicios que configuren y den contenido a la cesión de uso del local en cuestión, se prevé la realización de ACTIVIDADES INOCUAS o no calificadas de acuerdo con la Ordenanza Municipal de Usos y Actividades (BOP 28 abril 1981) y PGOU de Valencia (1988) y que se ajustarán a lo establecido en el Decreto 54/1990, de 26 marzo, del Consell de la Generalitat Valenciana, por el que se aprueba el Nomenclátor de actividades molestas, insalubres, nocivas y peligrosas 0 a aquella normativa que la reemplazara.

Las actividades inocuas precisan, de acuerdo con la normativa y ordenanzas vigentes hasta la fecha de este escrito, de la obtención de un certificado de compatibilidad urbanística y de la comunicación ambiental con una antelación previa de un mes a la fecha prevista para su comienzo.

La compatibilidad urbanística certificará que el proyecto es acorde con el planeamiento urbanístico y con las Ordenanzas municipales en base a la documentación presentada y requerida para tal trámite. 


\subsubsection{OBRAS Y ACONDICIONAMIENTO:}

La obligación administrativa de solicitar las licencias y/o permisos pertinentes recaerá sobre la parte cesionaria y promotora titular de las obras y acondicionamiento que soporta los gastos 0 el coste que comporta su realización por sí o por tercero.

De acuerdo con lo expuesto y a expensas de lo que se determina en el Proyecto o Memoria técnica de las obras que finalmente se prevean o se pacten en cada fase, dado el carácter de obras de acondicionamiento y mejora del local, sin modificación de usos compatibles ni modificaciones sustanciales de volumen o elementos arquitectónicos, se requiere la tramitación de Licencia municipal de Obras Menores en Locales.

El principio de mínima inversión, así como de unidad espacial y arquitectónica del espacio aconsejan no triplicar costes de proyecto, obra y tiempo, proporcionando al inmueble desde el inicio de un carácter unitario, tanto a efectos de obra, en su caso, como de sus correspondientes licencias de obra y actividad, salvo las pertinentes y necesarias por su adaptación a las fases previstas en el Plan, como a su prolongación en el tiempo que es connatural a su objetivo.

\subsection{CONVENIO DE CESIÓN DE USO. COMODATO (2 ${ }^{\mathrm{a}}$ FASE)}

Es Comodato el contrato en virtud del cual se cede gratuitamente a la otra parte un bien (nofungible) para que lo use durante cierto tiempo o para determinada finalidad $y$, transcurrido el plazo o alcanzada la finalidad, lo devuelva a su propietaria (art. 1740 Código civil).

El comodato viene a ser una variante de la figura jurídica del precario, de la que se diferencia en el que el primero no puede ser resuelto a menos que el propietario necesitare urgentemente el bien, mientras que en el precario puede ser resuelto en cualquier momento.

\subsubsection{RÉGIMEN JURÍDICO Y CONTENIDO DEL CONVENIO.}

Las condiciones que se pacten en el Convenio de Cesión de uso parten de la libertad de pactos existentes en la contratación privada y por tanto se regirá por lo pactado y supletoriamente por lo establecido en para la figura del Comodato en el Código civil (Art. 1.741 y ss. y concordantes). El propietario/comodante entregará el bien al comodatario (CIV), que recibirá el uso del mismo para la realización de sus actividades acorde a sus fines, y especialmente para la preparación y acondicionamiento previo básico del espacio que permita la difusión y visibilización del mismo y del proceso qué culminará en la realización de un encuentro colectivo en el mes de Julio de 2012, más un periodo de interlocución y gestión para posibilitar la continuidad del plan en su $3^{\text {a }}$ fase.

La cesión de uso será por tiempo determinado, desde el mes de marzo/abril hasta el mes de septiembre/ octubre de 2012. Una vez celebrado el encuentro en el mes de Julio continuando la difusión del Centro y del Proyecto bajo idénticas premisas a las iniciales se facilita, mediante la interlocución, asesoramiento y gestión pertinente de la cesionaria, se realizará la puesta en disposición de los

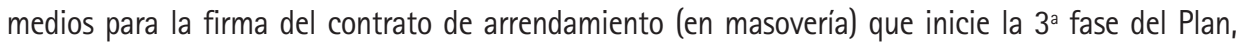
entre la propiedad cedente y la entidad signataria como parte arrendataria qué, o bien se constituya expresamente para la gestión del centro, o bien siendo preexistente asuma la misma.

En cualquier caso, e independientemente del resultado de aquella actividad el convenio de cesión que da forma a la $2^{\text {a }}$ fase del Plan finalizará en fecha de 31 de octubre de 2012 salvo nuevo pacto en contrario. 
Se especificará en el convenio de cesión, y será cláusula esencial del mismo, el estado en el que se encuentra el inmueble en el momento de la formalización, mediante la definición y catalogación detallada, así como de las patologías detectadas en la evaluación técnica efectuada.

El comodatario para el fin propuesto tendrá autorización del propietario comodante para la realización de las obras y acondicionamiento previo básico que se definen para la $2^{\text {a }}$ fase, quedando en todo caso las expensas invertidas en beneficio del bien inmueble.

Las altas de los suministros y tributos correspondientes a la propiedad del bien cedido, serán atendidos por el propietario comodante. Los gastos derivados del uso, como de las actividades serán atendidos por la parte cesionaria.

El comodatario se obligará a conservar correctamente el bien cedido, pudiendo el comodante inspeccionar el bien cuando lo estime oportuno, a fin de constatar su estado.

En caso de necesidad urgente, recuperará el comodante el bien cedido, a cuyo efecto ambas partes convendrán que será suficiente dirigir al comodatario comunicación escrita fehaciente con una antelación mínima de un mes, especificando la causa de necesidad y el plazo en que debe ser reintegrado el bien a su propietario. La desatención de dicho requerimiento, podrá dar lugar a favor del comodante de indemnización. La inexistencia de causa justificada podrá dar lugar a indemnización de la parte cesionaria.

\subsection{EL CONTRATO DE ARRENDAMIENTO "AD MELIORANDUM" 0 DE "MASOVNERÍA URBANA" (3a FASE)}

Para dar continuidad al Plan de Activación en la tercera fase prevista se propone la formalización de un contrato de arrendamiento, y por tanto no gratuito, de bien inmueble para uso distinto del de vivienda, clasificado como "atípico" y "complejo" por la doctrina jurídica y por la jurisprudencia y que como tal se encuentra excluido del ámbito de aplicación de la Ley 29/1994, de 24 de noviembre, de Arrendamientos Urbanos (LAU).

La reciente denominación de "masovería urbana" a este tipo de contratos proviene de trasladar al ámbito urbano actual, simbólicamente y por analogía, la tradicional figura de la "masovería" rústica catalana, como modalidad del tradicional contrato de aparecería rústica o agrícola, donde la propiedad de una finca rústica cede total o parcialmente el uso de la misma junto al de la casa de labora aneja a los masoveros o aparceros por un periodo de tiempo determinado a cambio del mantenimiento de la finca, de la casa aneja y de la entrega de una parte de los frutos a la propiedad de acuerdo con un porcentaje establecido en virtud de la inversión previa y de las determinaciones establecidas de común acuerdo.

El contrato de arrendamiento propuesto tendrá por objeto la realización de obras y acondicionamiento para la mejora del estado actual del inmueble (que posibiliten un uso acorde a las actividades o servicios a desarrollar), qué, al concluir el plazo pactado, quedarán en beneficio del propietario, a cambio de la cesión del goce y uso pacifico del inmueble a la entidad signataria por tiempo determinado.

Se prevé igualmente la reserva en la administración y gestión económica posterior del Centro resultante acorde a sus fines, proporcionando continuidad a las actividades o servicios ofertados en el mismo mediante un derecho de renegociación y renovación preferente de las personas 0 entidades subarrendadas. 


\subsubsection{RÉGIMEN JURÍDICO Y CONTENIDO DEL CONTRATO.}

El arrendamiento de bien inmueble donde el arrendatario asume como obligación principal la realización de prestaciones que consisten en la realización de obras y acondicionamiento para mejorar el estado del inmueble cedido (que no son las propias y especificas que definen un arrendamiento urbano dado que el precio se sustituye total o parcialmente por esa obligación), es un contrato atípico y "complejo" qué, como tal, se encuentra excluido, según extensa jurisprudencia de la aplicación del régimen especial de la LAU.

Por tanto nos encontramos ante un contrato civil atípico que se regirá por lo pactado y supletoriamente por lo establecido en para el contrato de arrendamiento en el Código civil (Art. 1542 y ss. y concordantes).

La "locatio ad meliorandum" o "para mejora", en sus diferentes variantes ya fue tratado por en el Derecho romano, donde tuvo gran implantación en su bajo imperio y recuperado por el Derecho común medieval, especialmente en las épocas de repoblación en la península ibérica.

Al igual que el Contrato de comodato, la libertad de pactos existente en la contratación Derecho Privado adquiere vital importancia la negociación de las cláusulas o estipulaciones del contrato de arrendamiento por el que se regulará.

A continuación se señalan las caracteristicas y condiciones que se proponen y se prevén en aquellas cláusulas que se consideran esenciales para el contenido del contrato:

\subsubsection{OBJETO.}

El objeto, carácter principal y factor económico decisivo de la relación contractual propuesta es la realización de una serie de obras y acondicionamiento para mejorar el estado actual del inmueble por parte de la cesionaria de uso (arrendataria) a cambio que el cedente permita su goce y uso pacifico durante un plazo determinado.

Desde el mismo momento de la firma del contrato se entenderá fehaciente y suficientemente autorizadas por el propietario arrendador las obras de mejora y acondicionamiento acordadas en el procedimiento que se convenga, pero no de aquellas obras que puedan provocar una disminución de la estabilidad o seguridad del inmueble y que necesitarán de autorización expresa del propietario.

\subsubsection{ESTADO DEL INMUEBLE.}

Se especificará en el contrato de arrendamiento, y será cláusula esencial del mismo, el estado en el que se encuentra el inmueble en el momento de la formalización, mediante la definición y catalogación detallada, asi como de las patologías detectadas en la evaluación técnica efectuada. Se adjuntará como Anexo Informe de evaluación técnica.

\subsubsection{DURACIÓN.}

Caracteristica intrínseca de cualquier contrato de arrendamiento es la obligación de establecerse para una duración determinada. Se propone por la partes una duración de TRES AÑOS, asi como la posibilidad de prorroga por dos años más, si asi se pactase, en atención al objeto del contrato. 


\subsubsection{LAS PARTES DEL CONTRATO.}

- La mercantil INVERGI, S.L. propietaria titular del pleno dominio del inmueble actuará en el contrato de arrendamiento en calidad de parte arrendadora y como tal, cedente temporal del uso del mismo.

- La entidad signataria (preexistente o, preferiblemente,

- constituida para la gestión del Centro), actuará en el contrato arrendamiento en calidad de parte arrendataria y como tal, cesionaria del uso.

La parte arrendataria es, en el contrato propuesto, a su vez, Promotora de las obras y acondicionamiento para mejorar el estado actual del inmueble que se obliga a realizar, así como promotora y gestora de la activación económica y social del local.

Una vez formalizado el contrato, se prevé la actuación de una serie de terceras personas (físicas y/o jurídicas) mediante relaciones contractuales (formales) o de colaboración (formales y/o informales) qué se encuentran vinculados al mismo y tienen incidencia, e mayor o en menor medida, sobre el objeto del contrato:

\section{- Subarrendatarias ("en especie" o "en metálico"):}

El propietario arrendador prestará en el contrato su consentimiento y autoriza a la realización de subarrendamientos parciales, con la obligación de ser notificado fehacientemente en el plazo máximo de 1 mes desde que se concertó, sin que ello de derecho a modificación alguna de las condiciones del arrendamiento. El subarriendo supone la subsistencia sin desvinculación del arrendatario y la introducción de una tercera persona en parte del objeto del contrato.

La parte subarrendataria se comprometerá a realizar (en especie) o a sufragar (en metálico) un $\%$ de las obras de mejora y acondicionamiento del inmueble que se establezcan. Debe tenerse en cuenta, que el subarriendo sigue al arrendamiento, de forma que extinguido éste, se resuelve inmediatamente el subarriendo.

La parte subarrendataria se comprometerá a realizar (en especie) o a sufragar (en metálico) un $\%$ de las obras de mejora y acondicionamiento del inmueble que se establezcan en el Proyecto básico de las obras (si fuera del 100\% sería una cesión o subrogación). Si opta por la obligación de sufragar en metálico un \% del valor de mercado del total de las obras y acondicionamiento a realizar podrá hacerlo en un solo pago o mediante su prorrateo anual o mensual que se determinará en la negociación de cada contrato de subarriendo. A cambio obtendrá la cesión de uso de un espacio concreto, o de un \% del espacio siempre por tiempo determinado en función al \% aportado sobre el valor de las obras y acondicionamientos totales pactadas en el arrendamiento original.

La parte subarrendataria se comprometerá adicionalmente a respetar en todo momento el Proyecto básico realizado o encargado por la parte arrendataria y la licencia de obras obtenida por la parte arrendataria, en su caso, el Reglamento de funcionamiento interior del centro que se redacte, a satisfacer los GASTOS mensuales corrientes y gastos mensuales por gestión y coordinación que se determinen (todo ello deberá ir como Anexo en cada contrato de Subarrendamiento), así cómo a suscribir seguros pertinentes.

Resumen Obligaciones y compromisos de la parte subarrendataria: \% de las obras y acondicionamiento totales (en especie o en metálico) y de respetar el proyecto de obras $+\%$ 
Gastos de gestión y coordinación Centro y de respetar el Reglamento de funcionamiento interior del mismo + \% gastos de suministros (luz y agua, más Internet en su caso)+ suscripción seguros pertinentes, + impuestos que correspondiesen en su caso.

\section{Contratista de obra.}

Régimen ordinario entre parte promotora de obra (en este caso arrendataria) y contratista de obra, salvo que se facilita el Proyecto básico de obra y la licencia, en su caso, a la que ha de sujetarse, e incluso la posibilidad de la entrega de materiales. Se le encarga un \% o la totalidad de las obras a realizar a cambio de su contraprestación en metálico.

\section{Colaboradoras, donantes y/o patrocinadoras:}

A través de contactos formales (contratos o convenios) o informales (verbales o de hecho) la parte arrendataria como promotora de las obras y acondicionamiento del inmueble podrá recabar colaboración activa, gratuita u onerosa, para el objetivo del Plan de Activación. Así tanto en obra y acondicionamiento en especie (obra, materiales, muebles) como en metálico que pueda repercutir en el valor de la obras y acondicionamiento, como en las actividades y/o servicios a desarrollar en el inmueble.

Las colaboraciones formales podrán realizarse mediante la celebración de los respectivos contratos de Donación, Patrocinio publicitario y/o convenios de acuerdo con su respectivo régimen jurídico y contractual.

El valor económico de estas colaboraciones, donaciones y/o patrocinios si fueren en metálico, material de obra o en muebles (mejora útil) se podrá tener en cuenta tanto en la evaluación anual y final del pago de la renta (valor de las obras y acondicionamiento), como en la propia renta si el compromiso fuera previo a la firma del contrato.

\subsubsection{PRECIO/RENTA.}

La cláusula relativa a la fijación del precio y la renta en este tipo de contrato de arrendamiento complejo constituye un elemento esencial del mismo.

La normativa no exige la fijación de la renta o precio sea en dinero o en metálico necesariamente (aunque sea lo habitual) y queda a la libre disposición de las partes, sin que exista un límite legal.

El precio en el contrato propuesto será la contraprestación en especie de obra y acondicionamiento por el uso cedido durante el plazo pactado, por tanto:

Precio $=$ Obras y acondicionamiento que mejoren el estado actual del inmueble cedido en uso, por un valor de mercado de $\mathrm{X}$ a realizar durante el plazo pactado de TRES años.

El precio incluye la totalidad de los costes que lleven asociadas las obras y acondicionamiento, como son los gastos, tasas e impuestos en su caso que se devenguen por la realización, tramitación y obtención de Proyecto de obras y de la correspondientes licencias, certificados o permisos.

Las OBRAS Y ACONDICIONAMIENTO que configuran la renta se delimitarán y desglosarán en el contrato y/o en Anexo que las detalle y cuantifique. En cualquier caso, se ajustarán_a la mejora del estado actual de la zonas privativas del inmueble que permitan su uso acorde a las actividades o servicios a desarrollar. 
A titulo orientativo en este estudio y a expensas de lo que se finalmente se determine, y en todo caso con sujeción a lo dispuesto en el informe evaluación técnica y la definición arquitectónica del espacio, se prevén la realización de obras y acondicionamiento consistentes en:
A. Trabajos de electricidad.
B. Trabajos de conservación de zona privativa interior (grietas, goteras, pintura).
C. Trabajos de fontanería y saneamientos.
D. Trabajos de carpintería metálica (accesos).
E. Trabajos de "compartimentación".
F. Trabajos de desescombro y limpieza.
G. Trabajos de rotulación y cartelería funcional interior y exterior.
H. Trabajos de realización y acondicionamiento in situ de mobiliario.
I. Trabajos de instalación calefacción/refrigeración (en su caso).

Las labores de rotulación, cartelería y pintura en fachada (elemento común), serán sufragadas por la parte arrendataria, previa tramitación de la autorización pertinente en las respectivas comunidades de propietarios.

La parte arrendataria se comprometerá a presentar en el Ayuntamiento de Valencia el Proyecto de obras y de actividad, en el plazo máximo de tres meses desde la firma del contrato.

De igual modo se prevé la fehaciente notificación al propietario de la obtención de las licencias pertinentes, y a adjuntándose desde ese momento los proyectos autorizados al contrato.

Por tanto, en el contrato de arrendamiento que se suscriba se fijará, en el modo se ha expuesto, el total del valor económico de mercado del total de las obras y acondicionamiento a efectuar en las fases de ejecución que se determinen.

\section{Pago.-}

Pago en especie mediante la realización de las obras y acondicionamiento del inmueble que se establezcan en el contrato se entenderá realizado en el lugar mismo de la ejecución de las obras, esto es, donde la cosa arrendada existe en el momento de constituirse la obligación.

Las obras y acondicionamiento se pueden conceptuar como pago anticipado en especie desde el mismo momento de su materialización en el inmueble objeto de arrendamiento, comprometiéndose el propietario a proporcionar anualmente a la parte arrendataria un recibo de la renta anual como pago anticipado.

\section{Evaluación anual del pago.-}

La parte arrendadora podrá realizar una evaluación anual de las obras de mejora efectuadas, valorización económica de la misma, así como de la posible compensación o prorrateo anual por el valor del total de las obras comprometidas.

No habrá retraso del pago anual, cuando como resultado del visado y certificado que se establezca en el contrato, quepa la compensación y/o prorrateo en el total de la renta/obras pactadas. 


\subsubsection{DERECHO DE RESERVA EN LA ADMINISTRACIÓN Y GESTIÓN POSTERIOR DEL CENTRO RESULTANTE.}

Se propone la estipulación en el contrato de un derecho de reserva en la administración y gestión económica posterior del Centro resultante que sea acorde a los fines de la entidad signataria, que proporcione a su vez continuidad a las actividades o servicios ofertados mediante un derecho de renegociación y renovación preferente de las personas o entidades subarrendadas.

\subsubsection{OTRAS ESTIPULACIONES PARTICULARES:}

Comisión mixta de seguimiento.-

Con el fin de facilitar la coordinación y seguimiento del contrato de arrendamiento cabe la posibilidad de estipular la constitución de una Comisión mixta, que estará formada por representantes personas físicas de cada una de las dos entidades firmantes. La parte arrendataria designará a sus representantes para esta comisión para cada reunión. La propia Comisión mixta una vez constituida decidirá su régimen de reuniones (al menos una anual) y adopción y validez de sus acuerdos. Serán funciones de esta comisión:

- Velar por el cumplimiento del contrato.

- Seguimiento de las contraprestaciones: realización de las obras/uso y goce pacifico.

- Evaluación del Plan de Activación en su conjunto.

- Evaluación anual de pago (compensación/prorrateo).

- Resolución de controversias.

Resolución de controversias.-

Las partes se comprometerán a resolver de mutuo acuerdo en el seno de la Comisión mixta de seguimiento las incidencias que se pudieran plantear sobre la interpretación, cumplimiento, extinción, resolución y efectos del contrato.

\section{Cesión y subrogación.-}

La arrendataria podrá ceder el total los derechos inherentes al contrato, subrogándose en la posición de aquella, una tercera entidad (cesionaria) que determine. La cesión implica la desvinculación del titular arrendatario original y su sustitución por otra persona.

No se reputará cesión el cambio producido en la persona del arrendatario por consecuencia de la fusión, transformación o escisión de la sociedad arrendataria. Tanto la cesión o fusión, transformación o escisión de la entidad arrendataria deberá ser notificada fehacientemente al propietario sin que ello sea motivo de elevación de la renta o de condición prevista.

No actualización de la renta.-

Dado el carácter no dinerario de la renta, se pacta la no actualización de la renta o de la valoración económica de las obras que la configuran, ya fuere al alza o a la baja. Por tanto no se aplicará variación porcentual alguna experimentada por el Índice de Precios al Consumo (IPC) en todo el período de duración del contrato. 


\section{No Fianza.-}

Dada las características no dinerarias de la renta, no cabrá exigibilidad de fianza en la formalización del contrato propuesto, ya fuere en especie o dineraria.

Gastos de comunidad, Impuesto Bienes Inmuebles (IBI), servicios y suministros.-

Serán de cuenta del propietario arrendador:

- Los gastos ordinarios y extraordinarios de las Comunidades de propietarios respectivas.

- El Impuesto Bienes Inmuebles (IBI) de cada una de las tres fincas catastrales cuyo uso se cede en arrendamiento.

- Los servicios y suministros que no cuenten con contador individualizado y que se correspondan a los bajos que componen el inmueble arrendado.

Resolución del contrato.-

La resolución del contrato de arrendamiento se producirá en aplicación del principio general, previo estudio en la Comisión mixta de seguimiento, de mutuo a acuerdo o en caso de incumplimiento de lo pactado (se podrá exigir cumplimiento, o resolver).

\subsection{IMPUESTOS, SEGUROS Y OTRAS DILIGENCIAS}

Todos los impuestos, contribuciones, permisos, arbitrios y cuotas correspondientes a la propiedad del inmueble serán sufragados por el propietario del mismo. No así aquellos que se impongan sobre la actividad o servicios a los se destine el local cedido en uso, especialmente los Impuestos sobre las actividades económicas que desarrollen en el centro, que serán a cargo y cuenta exclusivamente de la parte cesionaria, arrendataria y respectivas subarrendatarias sucesivamente, quienes se obligan a tener asegurado el riesgo del local y de la actividad o servicio a desarrollar. La parte cesionaria liberará de toda responsabilidad a la propietaria, por los daños a las cosas 0 a las personas que se produzcan o sean consecuencia directa e indirecta de las actividades 0 servicios que se realice en el local, y se hace responsable de los que se ocasionen.

Por ello, la parte cesionaria suscribirá un seguro de Responsabilidad civil general que garantice las responsabilidades que puedan derivarse de daños materiales y a personas ocasionados por el uso de los espacios asignados y siempre dentro de estos espacios, sin perjuicio de las obligaciones y de las pertinentes responsabilidades que se establezcan en los contratos de subarrendamiento. 


\section{PLAN FINANCIERO}

\subsection{PANORAMA ECONÓMICO Y CONTEXTUALIZACIÓN GENERAL}

7.2 TIPOS DE RECURSOS

7.3 ANÁLISIS DAFO

7.4 LÍNEAS ESTRATÉGICAS DE FINANCIACIÓN

7.5 VIABILIDAD ECONÓMICA POR FASES, COSTES, INGRESOS, BENEFICIOS

7.6 ACUERDOS ECONÓMICOS

\section{PLAN FINANCIERO}

\subsection{PANORAMA ECONÓMICO Y CONTEXTUALIZACIÓN GENERAL}

La situación de grave crisis económica que estamos viviendo en España se ve notablemente empeorada en la Comunidad Valenciana por algunos indicadores, entre los que cabe destacar los casi 3 puntos más de desempleo en $2011(24,12 \%)$ sobre la media nacional $(21,34 \%)$ y su importante nivel de endeudamiento. En relación con este último aspecto, cabe destacar que, según los últimos datos disponibles en diciembre de 2011, nuestra Comunidad se sitúa como la segunda más endeudada del Estado, con 20.469 millones de euros, solo por detrás de Cataluña, que alcanza los 39.268 millones de euros, y por delante de Madrid, cuya deuda se mantiene en 15.191 millones de euros (pese a que cuenta con algo más de 6 millones de habitantes frente a los poco más de 5 millones de la Comunidad Valenciana). Una segunda posición que se convierte en la primera si nos centramos en la deuda relativa o en la ratio con el Producto Interior Bruto (PIB), tal como se puede observar en el gráfico que describe la evolución de la deuda autonómica desde el año 1995, momento en que la Comunidad Valenciana ocupaba un lógico tercer puesto en el ranking autonómico, hasta este año 2011, en el que mantiene el puesto de cabeza que ostenta desde finales del siglo pasado.

A escala municipal, la situación tan solo es ligeramente mejor puesto que el Ayuntamiento de Valencia se sitúa en la actualidad, con 860 millones de euros de deuda, como la tercera ciudad en el ranking de endeudamiento, por delante de ciudades como Sevilla que la superan en población.

Ante esta situación, agravada por el fracaso de la emisión de bonos patrióticos y la reducción de la deuda de la Generalitat Valenciana a la categoría de bono basura, junto con las oscuras perspectivas de recesión en todo el contexto europeo, la obtención de recursos económicos provenientes de las instituciones públicas valencianas para la activación de un Centro Vecinal Polivalente en la ciudad de Valencia se presenta hoy como una legítima aspiración *, pero de muy difícil materialización. 


\subsection{TIPOS DE RECURSOS}

\subsubsection{DINERARIOS}

- Aportaciones económicas de todos los posibles financistas que pudieron participar en el Comboi a la Fresca, aunque finalmente no lo hicieran (excluyendo a los que dijeron que no les interesaba con claridad).

- Aportaciones, por adelantado, de pequeñas cantidades por parte de quienes puedan estar interesados en continuar un proceso de aparcería en ese espacio.

- Recurso a la microfinanciación para aspectos específicos de los encuentros (por ejemplo, realización de un documental de carácter etnográfico sobre la historia obrera y/o la evolución urbana de la zona.

- Aportación económica de instituciones culturales como la Sala Parpalló, el MUVIM o el Museo de Etnología.

- Fiestas de presentación del proyecto, tanto en La Calderería como en otros espacios afines.

- Organización de conciertos, exposiciones y otras actividades de asistencia masiva que permitan recaudar fondos mediante el cobro de entradas o a través del servicio de bar.

\subsubsection{EN ESPECIE}

- Proveedores y empresas de la zona que serán quienes nos faciliten herramientas y materiales necesarios para la rehabilitación a cambio de visibilidad y/o publicidad en los eventos que alli se realicen.

- Otras empresas interesadas en apoyar el proceso aportando materiales (pintura, impresiones, etc.) a cambio de la obtención de visibilidad pública.

\subsubsection{LABORALES Y OTROS RECURSOS HUMANOS}

- Trabajo de reforma arquitectónica a cargo de los alumnos de la escuela taller

- Trabajo propio de quienes puedan estar interesados en continuar el proceso de apacería en ese espacio.

- Decoración de las paredes por alumnos de BBAA a través de la asignatura de pintura mural, tanto para exteriores como en interiores

- Compartimentación del local y otras mejoras a través de la convocatoria de un concurso de proyectos de intervención en el espacio interior y exterior de la Calderería, dirigido a alumnos de grado y máster de arquitectura y producción artística.

\subsection{ANÁLISIS DAFO (DEBILIDADES, AMENAZAS, FORTALEZAS, OPPORTUNIDADES)}

A continuación enumeramos una relación de las Debilidades, Amenazas, Fortalezas y Oportunidades que presenta la activación de un Centro Vecinal Polivalente con unidades de producción en la antigua Calderería. 


\section{DEBILIDADES:}

- El espacio se localiza fuera de lo que se considera el "centro de la ciudad", sin llegar a tratarse totalmente de la periferia de la ciudad, que en esta zona la constituyen los poblados marítimos.

- El local se encuentra en malas condiciones físicas y necesita una importante inversión para su acondicionamiento y rehabilitación.

- Su ubicación colinda con importantes barreras físicas como la Calle Serrería, cuya amplitud se percibe como una barrera

- simbólica (que históricamente remite a la antigua valla que protegía las vías del tren antes de ser soterradas) y la Estación de Metro que resta visibilidad a su fachada. En menor medida, por estar más alejadas, también se perciben como lindes o limitaciones del barrio la Avenida del Puerto y la Avenida Blasco Ibáñez.

- El nivel medio de estudios del barrio es relativamente bajo.

- Falta de identidad propia del barrio y de redes activas de movilización social.

\section{AMENAZAS:}

- La bajada de rentas y el declive del nivel de vida provocado por la depresión económica

- La posible "competencia" (incluso desleal) de los relativamente próximos Centro de Recursos Culturales de Juan Verdaguer y el Centro Cultural de Las Atarazanas, ambos de titularidad municipal.

- La acelerada degradación de la situación económica en el conjunto del Estado, que en nuestra Comunidad autónoma es mucho más perceptible por los motivos ya expuestos (mientras redactamos este informe una de nuestras posibles fuentes de financiación, la Sala Parpalló, ha desaparecido), hacen que todas las previsiones financieras que estamos haciendo sean provisionales y dependientes, para su viabilidad, de una mínima estabilización del panorama económico.

\section{FORTALEZAS:}

- El carácter innovador y experimental de nuestra propuesta.

- El amplio equipo de recursos humanos que la CIV es capaz de activar.

- Proximidad de los principales campus de las dos universidades públicas valenciana.

- Todas las barreras urbanas que acotan la zona de influencia de La Calderería (grandes avenidas, estación de metro, tranvía) son, también, importantes vías de comunicación que cabe poner al servicio del proyecto.

- Inexistencia de un laboratorio colaborativo de Economía Social.

OPORTUNIDADES:

- La propia situación de crisis que permite cambios que sin ella no serían posibles, por ejemplo la creación de centros vecinales no institucionales

- La necesidad de autoformación que el continuo reciclaje profesional exige al conjunto de la sociedad 
- La firma, por el conjunto de las cinco universidades públicas valencianas, de un convenio que orienta sus políticas hacia la interacción social con las ciudades que les acogen.

- La posibilidad de generar sinergias positivas mediante colaboración con los centros municipales de Las Atarazanas y de las Naves de Juan Verdaguer, configurando un triángulo formativo y cultural en la zona de influencia del Puerto de Valencia.

- Agilización de los trámites necesarios para la constitución de empresas y apertura de negocios.

- Ayudas institucionales a la contratación de desempleados y al emprendizaje.

\subsection{LÍNEAS ESTRATÉGICAS DE FINANCIACIÓN PARA LA CALDERERÍA}

Ateniéndonos a todo lo anterior, hemos apostado por diversificar nuestros objetivos, centrándonos, por un lado, en la captación de recursos y materiales provenientes de las empresas y comercios ubicadas en la zona, que tendrían el carácter de entidades colaboradoras en el proyecto, así como de de los futuros usuarios del Laboratorio de Economía Social que deberán ser socios del mismo para poder usar las instalaciones; socios y usuarios que, lógicamente, deberán se $r$ los primeros interesados en invertir tiempo y dinero en reformar el espacio para, así, adelantar en el tiempo tanto su habitabilidad como su usabilidad. Algunos de estos usuarios podrán optar por el subarrendamiento de espacios de trabajo o de coworking para el desarrollo de microempresas 0 negocios autónomos que se potencien entre sí.

Por otro lado, consideramos que dado el carácter innovador y experimental de la iniciativa es factible, una vez superada la parte más aguda de esta crisis, conseguir recursos por parte de las universidades valencianas, de instituciones culturales como la Sala Parpalló o el Museo de Etnología, de las instituciones relacionadas con el fomento del empleo y de las diferentes organizaciones valencianas relacionadas con la economía social, conformándose ésta como la segunda línea estratégica a la que recurriremos para la obtención de financiación.

Una tercera línea de financiación podría estar ligada a alguna iniciativa de crowdfunding (microfinanciación en masa) que obtuviera recursos económicos a través de la promoción de los aspectos emocionales ligados a la recuperación de la memoria obrera del barrio. Alternativa que podría vertebrarse alrededor de la puesta en valor de la historia del edificio a través de un documental que enfatizara las peculiaridades de un proyecto industrial -caracterizado por la atípica construcción de viviendas para los propios obreros en las plantas altas de la fábricaque intenta ser reactivado socialmente como espacio postindustrial, puesto al servicio de la ciudadanía como Centro Polivalente con unidades de producción.

Para la tercera fase, una vez puesto en marcha el centro, cabria contar con la posibilidad de obtener ayudas económicas de la UE para proyectos internacionales que, según se contempla en el Programa Cultura (2007-2013), cumplan con uno o varios de estos objetivos :

- facilitar la movilidad transnacional de los profesionales del sector cultural;

- fomentar la circulación de las obras de arte y de los productos artísticos y culturales al otro lado de las fronteras nacionales;

- promover el diálogo intercultural. 


\section{ACCIÓN DE VISIBILIZACIÓN Y ENCUENTRO \\ 8.1 ACCIONES SOCIOARTISTICAS A CORTO PLAZO DE VISIBILIZACIÓN \\ 8.2 PLANTEAMIENTO DEL ENCUENTRO CIV-CALDERERÍA \\ 8.3 CRONOGRAMA}

\section{ACCIÓN DE VISIBILIZACIÓN Y ENCUENTRO}

\subsection{ACCIONES SOCIOARTÍSTICAS A CORTO PLAZO DE VISIBILIZACIÓN}

Con la finalidad de dar a conocer el espacio y comenzar a tender vínculos con los agentes sociales del barrio se pretende realizar una serie de acciones socioartisticas. Que van desde el reconocimiento del barrio por los agentes implicados, a las intervenciones in-situ del espacio Calderería.

Como primeras acciones se plantean:

TALLER DE CONTEXTO.

Escala Ciudad/Barrio/Calderería.

Urbanismo participativo con la finalidad de analizar los condicionantes, conocimientos y recursos del barrio para extraer una relación de necesidades para el centro.

Realizado a través de la ETSAV urbanismo.

Dirigido por: HIRIA KOLECTIBOA, RAONS PÚBLIQUES o la propia ETSAV Urbanismo...

Participantes: Alumnos de la ETSAV.

Colaboradores: AAW Ayora.

Duración: 3 dias.

INTERVENCIONES GRÁFICAS.

Pintura mural de la persiana de la puerta y cristales paves de la fachada.

A través de una convocatoria a artistas gráficos e ilustradores locales.

Realizado a través de la Escuela de Bellas Artes.

Colaboradores: Montana Colors.

Duración: 3 días.

\subsection{PLANTEAMIENTO DEL ENCUENTRO CIV-CALDERERÍA}

\subsubsection{OBJETIVOS}

Convocar usuari@s para el espacio.

- Concebir y conceptualizar de forma colectiva la organización del espacio.

- Construir el equipamiento básico de las zonas comunes del espacio.

- Lanzamiento del espacio de uso multidisciplinar en el barrio de Ayora y en la ciudad de Valencia. 


\subsubsection{PLANTEAMIENTO CONCRETO DEL ENCUENTRO CIV-CALDERERÍA.}

El encuentro para activar La Calderería, tiene como objeto servir de punto de inicio y activación de uso del espacio por parte de los usuari@s, mediante un formato atractivo y dinámico. El encuentro estará abierto a la participación de los futuros usuari@s del espacio, como a las personas interesadas en participar en las diferentes actividades del programa planteadas para el encuentro. Para el programa del encuentro se plantean diferentes tipologias de actividades, como:

- Fiesta de Bienvenida.

- Presentaciones de casos afines.

- Mesas redondas.

- Talleres metodológicos y dinámicas de organización.

- Talleres de construcción de equipamiento.

- Comidas y cenas colectivas.

- Conciertos y actividades culturales.

- Celebración de "Activación iniciada".

El encuentro tendrá una duración de 10 días durante el verano de 2012, en el que acontecerán dos fases secuenciadas:

- 1. Fase. Conceptualización y dinámica de centro. (3 días)

- 2. Fase. Acondicionamiento y Autoconstrucción. (7 días)

El grueso de las actividades del encuentro se realizarán en las instalaciones de La Calderería, contando con la realización

de actividades complementarias en otras localizaciones de la ciudad de Valencia, con el objetivo de focalizar la atención durante esos días sobre el espacio de La Calderería.

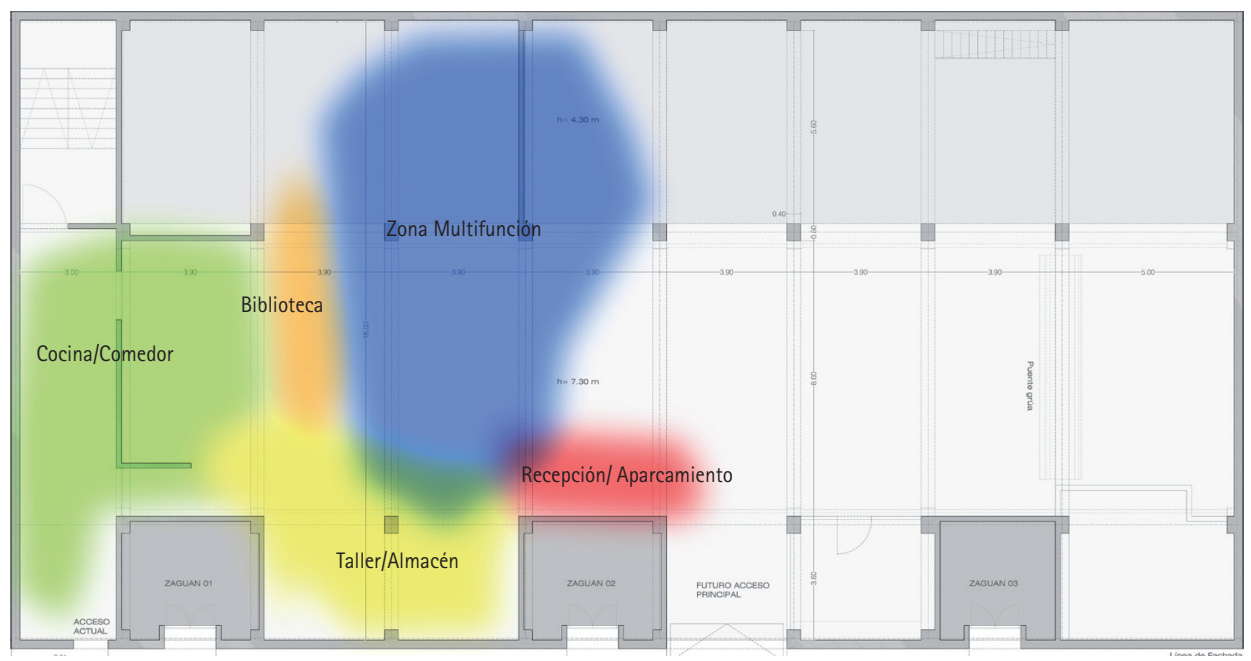




\subsubsection{CONVOCATORIA}

Se plantea lanzar una convocatoria pública a asociaciones, ONG's, creadores, artistas, diseñadores, arquitectos, profesionales 0 a cualquier tipo de personas o colectivos con necesidad de espacio para desarrollar sus actividades o proyectos, del ámbito de la ciudad de Valencia o alrededores.

A través de la convocatoria se pretende producir el establecimiento de conexiones con agentes locales múltiples como instrumentos para activar el tejido social y artístico del barrio y la ciudad.

En este contexto, la presente convocatoria tiene como objetivo facilitar la creación de redes de colaboración y la disposición de espacios de trabajo a bajo coste. La convocatoria de proyectos es la herramienta de CIV para atraer la atención de los futuros usuari@s y plantear las condiciones de explotación de los módulos espaciales.

La dotación de dicha convocatoria es el uso de las diferentes tipologias de módulos (oficina, bajo altillo y doble altura) para los que tendrán que presentar sus propuestas.

Los participantes en la convocatoria tendrán que presentar la siguiente documentación:

- Ficha para la convocatoria debidamente cumplimentada.

- Descripción del proyecto (mínimo 500 palabras, máximo1000 palabras).

- Propuesta de colaboración (mínimo 500 palabras, máximo1000 palabras).

- Justificación de su adecuación a las líneas de trabajo de La Calderería (máximo 250 palabras).

- Resumen biográfico o societario del agente local o artista: 500 palabras.

- De 1 a 3 ilustraciones relacionadas con el proyecto que pueden ser imágenes 0 textos (éstos, de un máximo de hasta 500 palabras cada uno). En caso de proyectos escénicos, se aconseja la presentación de un máximo de 3 vídeos.

Los proyectos presentados serán examinados por la comisión de valoración para verificar su adecuación material y técnica, así como para evaluar la calidad y oportunidad de desarrollo social o artística de conformidad con los criterios de la propuesta de La Calderería, entre los que destaca:

- Calidad y coherencia del proyecto.

- Adecuación a las líneas de trabajo de La Calderería.

- Vinculación, en su caso, con otros creadores y/o agentes locales.

- Viabilidad de su realización.

- Repercusión social, artística, conceptual o técnica.

- Originalidad y grado de innovación.

La comisión de valoración estará constituida por un comité científico-técnico formado por un grupo de especialistas de la Universidad, la AAW y la CIV.

Los seleccionados deberán participar en los talleres que se realizarán durante el encuentro. La convocatoria debería estar resuelta un mes antes de la fecha de realización del encuentro. 


\subsubsection{TALLERES DE FORMACIÓN Y AUTOEMPLEO .}

Para la correcta proyección, adecuación del espacio y el proceso de construcción colectiva del mismo, se realizará mediante talleres participativos y colectivos bajo la dirección de equipos de trabajo o colectivos con reputación y cualificación destacada.

Dependiendo de la escala que en cada momento se trabaje se adoptará un determinado formato de taller.

\section{TALLER DE CONCEPTUALIZACIÓN}

- Escala Caldereria/Zonas Comunes.

- El taller es una herramienta de trabajo para activar proyectos en el contexto de Ayora y la ciudad de Valencia; por ello, responde a un doble objetivo:

Ser un punto de encuentro con diversos agentes, iniciativas y redes locales, de tal forma que se muestren sus trabajos en un proceso de diálogo con los casos de estudio presentados en Transductores.

Presentar e intercambiar recursos y metodologías prácticas que posibiliten una discusión sobre estrategias y metodologías potenciales de trabajo en red en el territorio. Generar un briefing de usos para el espacio Calderería.

- Dirigido por: Transductores

- Participantes: Usuari@s Calde, personas interesadas en el trabajo en red y sus posibilidades.

- Duración: 3 dias.

TALLER DE AUTOCONSTRUCCIÓN

- Zonas Comunes/Módulos.

- Construcción del equipamiento básico de las zonas comunes del espacio Calderería, a través de la optimización de recursos.

- Reciclaje de material encontrado en el espacio junto con residuos industriales cedidos por las empresas portuarias.

- Generación de prototipos para el equipamiento de los módulos.

- Capacitación de los asistentes en el uso de herramientas y autoconstrucción.

- Creación de manuales de montaje de las diferentes soluciones generadas.

- Dirigido por: Colectivos Red AACC, EXYZT, Coloco, Tuprima... Participantes: Usuari@s

Calde, personas interesadas en la autoconstrucción y aprovechamiento de recursos.

- Duración: 7 dias.

\subsubsection{PRESENTACIONES}

Para generar una visión y evolución de la idea del centro, se proponen presentaciones de grupos o colectivos que hayan realizado proyectos similares en la activación de espacios en desuso de formacolectiva en el ámbito del Estado español o en experiencias en el extranjero.

Adoptando el formato de presentaciones y mesas redondas, dónde de pie a los ponentes, invitados y usuari@s a la reflexión sobre los problemas a nivel organizacional/ gestión y beneficios sociales que provocan este tipo de centros e instalaciones colectivas. 
Se toman como referentes los siguientes casos, que sería deseable que compartiesen sus experiencias en el marco de la primera fase del encuentro (conceptualización).

- La Tabacalera. Madrid.

- La Casa Invisible. Málaga.

- La Fábrica de toda la vida. Santos de Maimona, Badajoz.

\subsubsection{ZONAS COMUNES}

Una de las finalidades del encuentro es proyectar y construir las

zonas de uso común del espacio para que la estancia y disfrute por parte de usuari@sy visitantes, sea agradable y confortable.

Se plantea el espacio a ocupar y las zonas a desarrollar en el encuentro:

- Taller

- Cocina/ Comedor

- Biblioteca

- Sala de exposiciones-multifunción

- Escenario-grada

- Aparcamiento bicicletas

- Espacios de trabajo

- Almacén

\subsection{CRONOGRAMA}

La secuencia de acciones pre-encuentro deben ir coordinadas y enfocadas por un lado para obtener la visibilización del espacio, y por otra, a extraer información "valiosa" y recursos para las distintas fases de trabajo que se desarrollarán durante el encuentro.

$\begin{array}{lllll}\text { MARZO } & \text { ABRIL } & \text { MAYO } & \text { UNIO } & \text { ULO } \\ \text { - Visibilización. } & \text { - Visibilización. } & \text { - Visibilización. } & & \text { - Visibilización. } \\ \text { - Lanzar } & \text { - Taller Contexto } & \text { - Jornada de } & & \text { - Fecha límite entre- } \\ \text { convocatoria } & \text { Urbanístico. } & \text { puertas abiertas. } & \text { ga de propuestas. } \\ \text { usuari@s del } & \text { - Jornada de } & & \text { - Resolución de la } \\ \text { espacio. } & \text { puertas abiertas. } & & \text { convocatoria. } \\ \text { - Lanzar } & \text { - Fiesta } & & \text { - Fiesta usuari@s } \\ \text { convocatoria } & \text { presentación } & \text { seleccionados. } \\ \text { para red AACC } & \text { encuentroy } & & \\ & \text { espacio. } & & \end{array}$




\section{CONCLUSIONES}

\subsection{ACORDES Y DESACUERDOS \\ 9.2 CRONOGRAMA APROXIMADO DE ACTIVACIÓN}

\section{CONCLUSIONES}

\subsection{ACORDES Y DESACUERDOS}

\section{Barrio}

Carácter:

Heterogéneo, indefinido, inesperado pero cómodo y familiar.

Carencias:

Centro social identitario con el barrio.

Lugar de intercambio de asociaciones.

Perspectiva:

Articular el barrio desde lo social después de las sucesivas transformaciones urbanas.

Contenidos:

Inmigración, vivienda social, pasado industrial. Sinergias:

AMPAS, AAW, ONG Teso, Club de Fútbol Algirós, Falla Maestro Valls, escuelas de danza y teatro.

Propósitos:

¿Para qué te interesaría la Calderería?

¿Qué recursos podrías aportar para su recuperación?

\section{Concepto}

Presente:

Pertinencia al estado de crisis actual que favorece el intercambio y la re-agrupación.

Discursos:

Establecer como valor añadido el diálogo con el entorno y los referentes, sirviéndose de la

red generada a nivel institucional en base a la economía solidaria.

Modelo:

Progresivo, de pasivo a activo de producción propia.

Gestión:

Asociación de asociaciones.

Definición del gestor, curador y cuidador.

Marca:

Calderería de cultura y economía social (laboratorio de ideas, conocimientos y experiencias colectivas).

Fábrica de alternativas.

Proyecto

Cualidades:

Doble altura, altillo, puente grúa, recovecos y fachada a la calle.

Condiciones:

Evacuación vertical y acceso. Ventilación e iluminación natural.

Sistema:

Capas funcionales formadas por unidades (periféricos y/o específicos) y divisores (lineales) que se adaptan al programa creando especies de espacios.

Derribos:

Tabiques de planta baja. 
Materiales:

FINSA.

Intercambio:

Concretar la superficie que se ofrece a cambio de trabajo.

Inversión:

Compensar los gastos variables con la disponibilidad de recursos existentes, posibles y talleres.

\section{Acondicionamiento}

Comunidad de vecinos:

Reparación pilar, filtración del patio, bajantes y paveses de la fachada.

Propietario:

Acometidas.

Masovero:

Limpieza (chorro de agua/arena), grietas, baños, instalación eléctrica y fontanería, baños.

Valoración:

Oferta económica constructores.

Negociar responsabilidades y cargas.

Oportunidad:

Aprovechar los paveses rotos de fachada para situar el logo del Centro.

\section{Trámites}

\section{Contrato:}

Masovería urbana por contraprestación de obra, basado en la buena fe y el código civil.

Anexos:

Informe valorado de patologías y posibilidad de vicios ocultos.

Responsabilidad propietario:

$|\mathrm{B}|$, gastos de comunidad y de suministro.

Agentes:

Propietario, masovero, subarrendista.
Promotor, contratista, oficios.

Vigilar:

IVA y retenciones.

Licencias:

Acondicionamiento menor y actividad compatible con local de asociación.

Conveniencia:

Un solo inmueble extendido a los tres.

Revisar:

Grado de protección oficial y vado garaje.

Costes:

Restar la bonificación de tasas por acción social comunitaria y asistencial.

Seguro contenido y uso.

Reto:

Sacar beneficio de los costes de la obra.

\section{Viabilidad}

Gastos:

Acondicionamiento (fijo) + proyecto (variable) + tasas + actividades (acción y encuentro) + mantenimiento.

Ingresos:

Propietario + inventario + recursos + patrocinadores + créditos + ayudas + mecenazgo (donaciones) + talleres + red + crowdfunding + trueques + fiesta de recaudación + socios colaboradores.

Remuneración:

Honorarios $=$ ingresos - gastos

Viabilidad económica:

Previsión financiera, vínculos y amortización.

Fiscalidad:

Asociación sin ánimo de lucro con fin social.

Búsqueda de asesor fiscal.

Beneficio:

Obra de acondicionamiento, mejora + visibilidad, comparado con el precio de 
mercado actual por el alquiler del local.

Dinamización

Presentación y difusión pública:

Patrocinadores, agentes sociales, cooperativas, medios de comunicación.

Expectativa:

Visibilizar trabajo de campo, cartel en fachada, web, vídeo y acciones.

Activación:

Taller de barrio de construcción de los contenidos.

Taller de formación de autoconstrucción de las unidades.

Convocatoria:

Arreglo zonas comunes y creación prototipo usuarios.
Selección:

Tu proyecto, ¿a qué otra gente involucra y qué soporte financiero tiene?

Créditos:

Promotor, organizadores, patrocinio y colaboradores.

Presupuesto:

Incluido en la valoración de masovería como activación necesaria para la obra y servicio del local.

Referencias:

La Otra, La Fábrica de toda la vida y el Ranchito.

\subsection{CRONOGRAMA APROXIMADO DE ACTIVACIÓN}

\begin{tabular}{|l|l|l|l|l|l|}
\hline Febrero & Marzo & Abril & Mayo & Junio & $\begin{array}{l}\text { Julio } \\
\text { Septiembre }\end{array}$ \\
\hline $\begin{array}{l}\text { Entrega Plan } \\
\text { de Activación. }\end{array}$ & $\begin{array}{l}\text { Convenio de } \\
\text { cesión. } \\
\text { Visibilización. } \\
\text { Presentación. } \\
\text { Convocatoria. }\end{array}$ & $\begin{array}{l}\text { Taller de } \\
\text { barrio. }\end{array}$ & $\begin{array}{l}\text { Acondicionami } \\
\text { ento. }\end{array}$ & $\begin{array}{l}\text { Jornada de } \\
\text { puertas } \\
\text { abiertas. }\end{array}$ & $\begin{array}{l}\text { Talleres de } \\
\text { autoconstrucci } \\
\text { ón. } \\
\text { Encuentro. } \\
\end{array}$ \\
& & & & $\begin{array}{l}\text { Recepción de } \\
\text { propuestas. }\end{array}$ & $\begin{array}{l}\text { Contrato de } \\
\text { masovería. }\end{array}$ \\
\hline
\end{tabular}




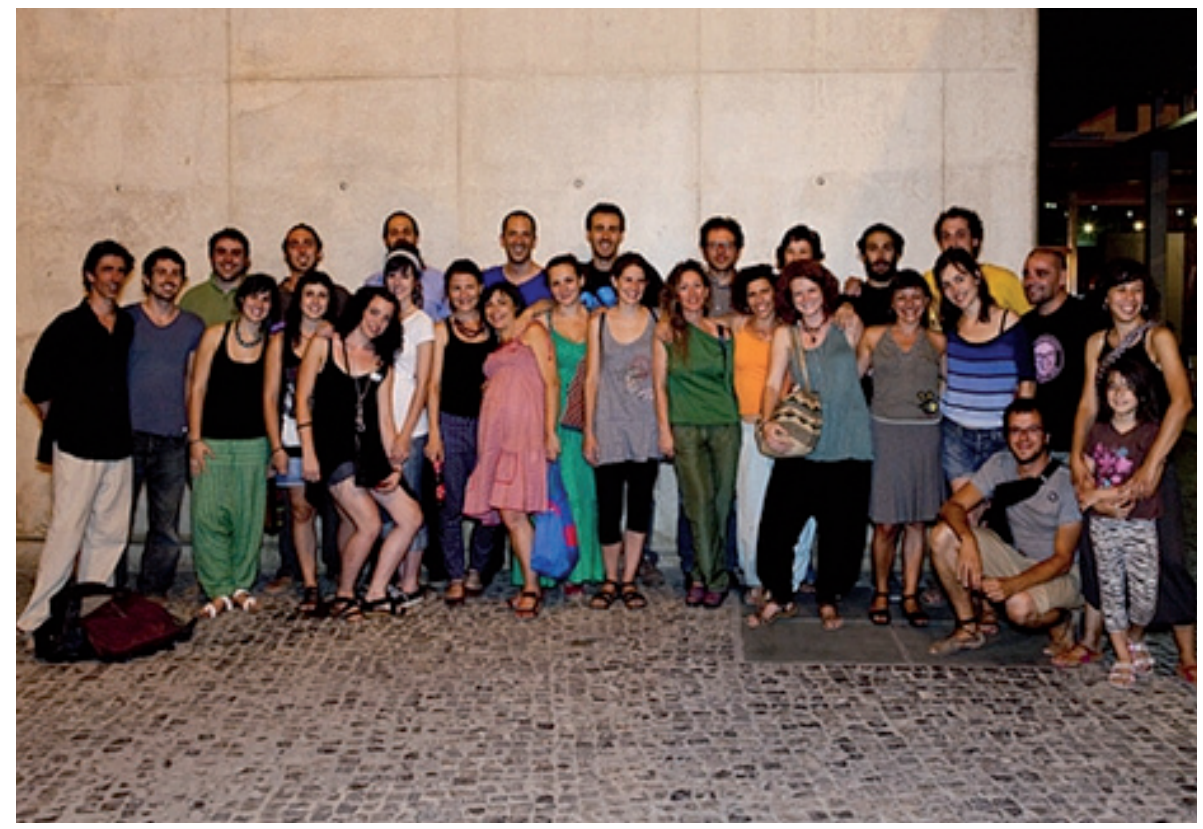

Fig. 66 


\section{ANEXO IV}

\section{Listado de materiales audiovisuales}




\section{Listado de materiales audiovisuales}

Edición general del DVD: Pau Mik

1. Entrevistas CENTROS SOCIALES - UNIVERSIDADES LIBRES - OFICINAS DE DERECHOS SOCIALES - realizadas por Mijo Miquel, editadas por Pau Miquel:

1. Nico Sguiglia - La Invisible - ULEX (Universidad Libre Experimental)

2. Javier Rodrigo - Transductores

3. Emmanuel Rodríguez - Traficantes de Sueños

4. Débora Ávila - Ferrocarril Clandestino

5. Raul Sánchez - Universidad Nómada

6. Xavi Martínez - Ateneu Candela, ODS

7. Arnau Monterde - Ateneu Candela

8. Pablo Molano - Universitat LLiure La Rimaia

2. Entrevistas PARA QUIENES DISFRUTAMOS TRABAJANDO realizadas de forma conjunta por Adrián Rodríguez (entrevistador, miembro de Exit-Raval, editor), Chinowski Garachana (sonido, miembro de la ULEX Málaga) y Mijo Miquel (miembro de Autoformato).

1. Emmanuel Rodríguez - Traficantes de Sueños

2. Pablo de Soto - Hackitectura

3. Simona Levi - Exgae/Conservas

4. Jara Rocha - Medialab

5. Felipe G. Gil - Zemos98

6. Carlos Sanjuán-Creador@s Invisibles

7. Maria ptqk - productora cultural

3. Solar Corona, proceso de activación previo al Comboi a la fresca, junio-julio 2011 realizado por Blai Mesa dentro del Taller de acciones visibles e invisibles en el Comboi a la fresca.

4. Fragmentos de la Asamblea de conclusiones del Comboi a la fresca en julio 2011 realizada por Miguel Angel Baixauli.

5. Teaserde LaCaderería, paralaConvocatoriaderenovación deusosyacondicionamiento de espacios - realizada por Javier Mestre. 
